\title{
ALL-WOMEN INITIATIVES \\ IN ART AND TECHNOLOGY 1986-2020. \\ ATENEA: MENTORING AND NETWORKING \\ PROJECT IN STEAM
}

\author{
Elena Robles Mateo \\ Dissertation submitted for the degree of Doctor of Philosophy \\ at Universitat Politècnica de València \\ Doctorate Art Programme, Facultad de Bellas Artes de San Carlos
}

Supervisor: Prof. Nuria Lloret Romero

Valencia, October 2020

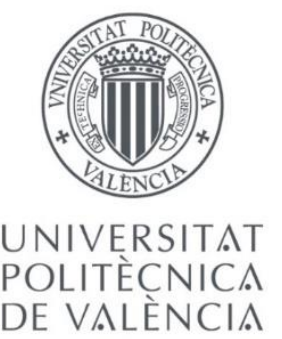


(C) 2020

Elena Robles Mateo

ALL RIGHTS RESERVED

Programmea Operativo del Fondo Social Europeo 2014-2020 de la Comunitat Valenciana para la promoción de la investigación científica, el desarrollo tecnológico y la innovación en la Comunitat Valenciana: Subvenciones para la contratación de personal investigador de carácter predoctoral 2016-2019.
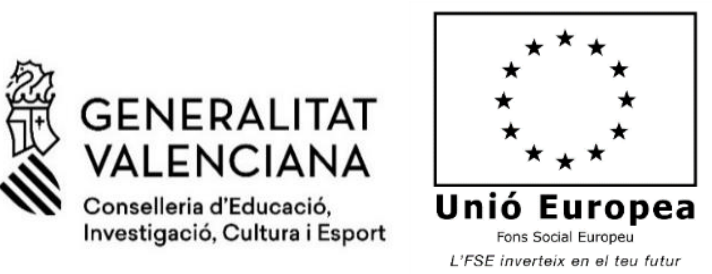


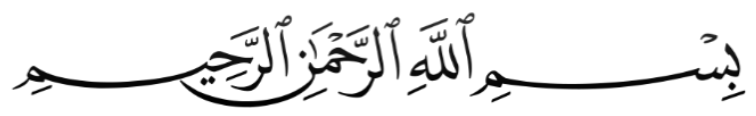





\section{ACKNOWLEDGMENTS}

My heartfelt appreciation goes to my supervisor and colleague Prof. Nuria Lloret, without her this doctorate dissertation and my research work had not been possible, neither I had reached the place I am now.

I would like to express the deepest appreciation to Kathy Rae Huffman for her generous and altruist help to my research, for supporting me and for being an inspirational referent to my professional career. I am particularly grateful to Anna Couey and Lucia Grossberger for their interest, their fruitful contribution and kind support to this dissertation.

Endless gratitude to my parents and my husband for having blind faith in me, as to my friends for always being present as my therapist, my pillow and my source of motivation.

Lastly, I owe a very important debt to Prof. Christa Sommerer and Prof. Roger Dannenberg, together with the related assistants of the Interface Cultures Department in Kunstuniversität Linz and the Computer Science Department at Carnegie Mellon University, both for enabling me to perform my stays abroad to develop this research. 
Especially, to Noelia

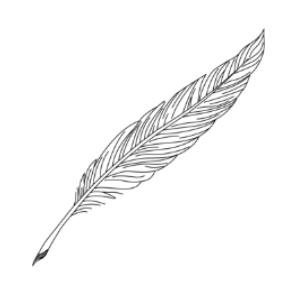




\section{TABLE OF CONTENTS}

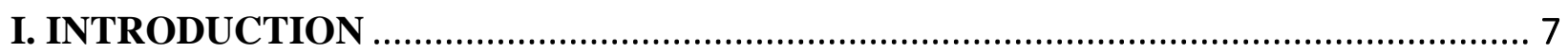

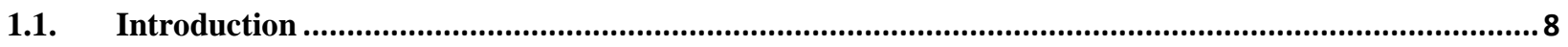

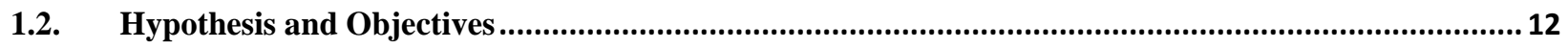

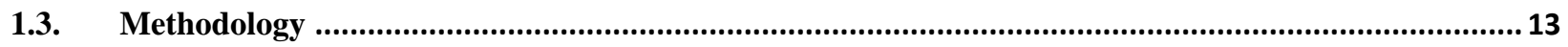

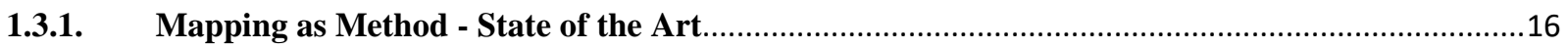

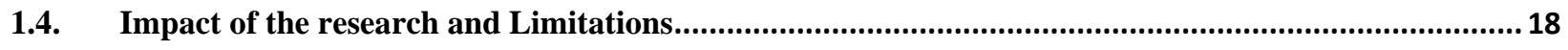

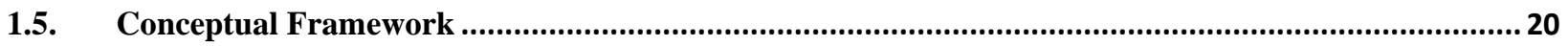

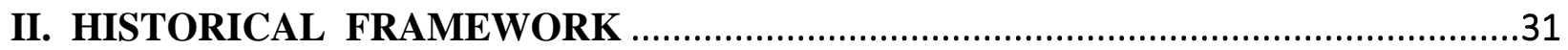

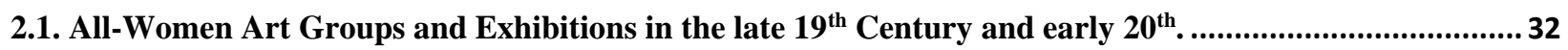

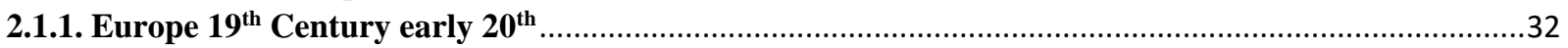

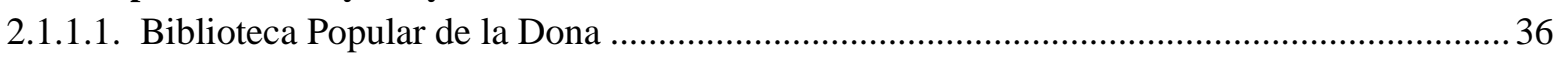

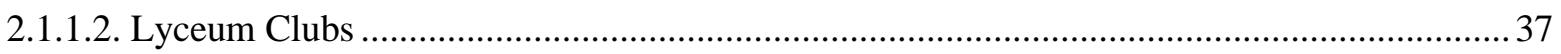

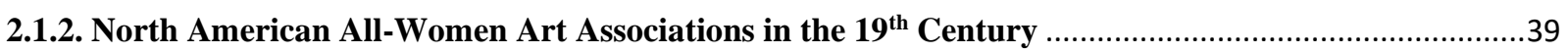

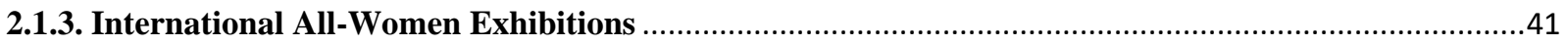

2.2. Women's Spaces and The women's Movement along the 1960s and 1970s .............................................4 44

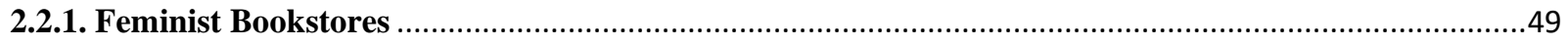

2.2.2. Feminist Art and All-Women Art Spaces in United States..........................................................

2.2.3. 1970s- All-women Art Groups in Europe

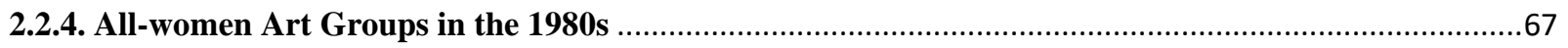

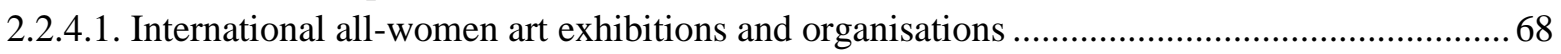

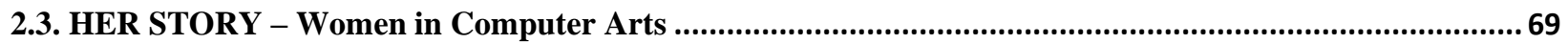

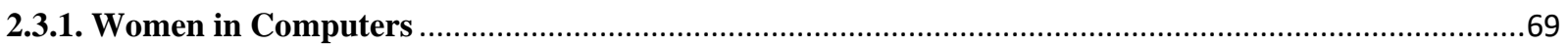

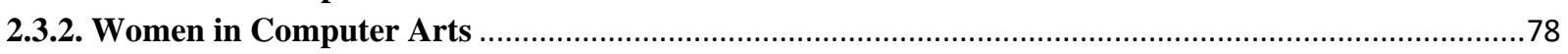

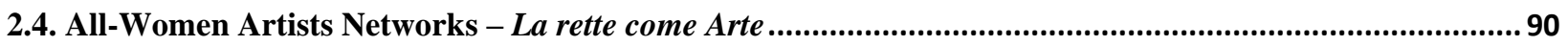

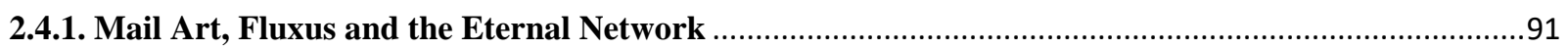

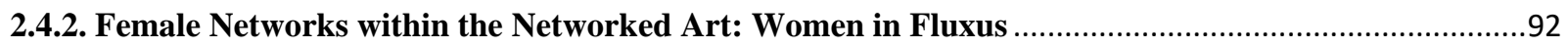

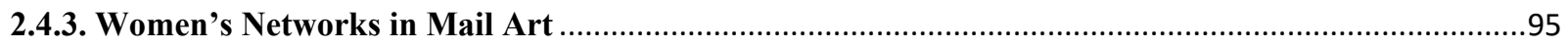

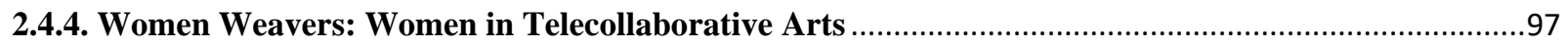

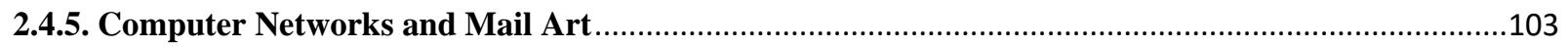

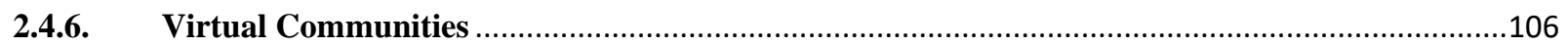

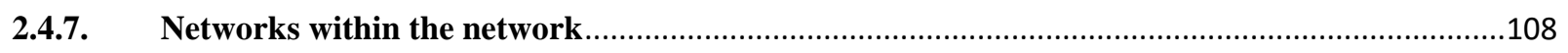

2.4.8. Women in early Net Art: Networked art works in the formative years of the Internet .............113 
3.1. Early all-women curatorial projects in the United States ....................................................................... 120

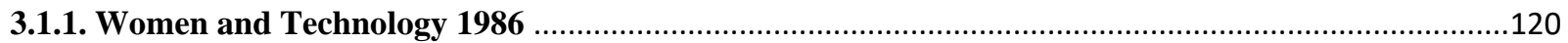

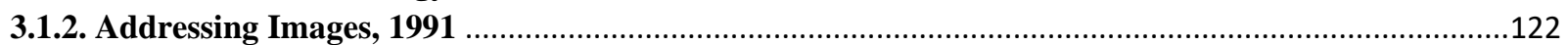

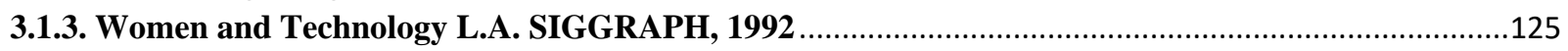

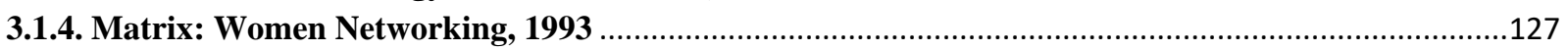

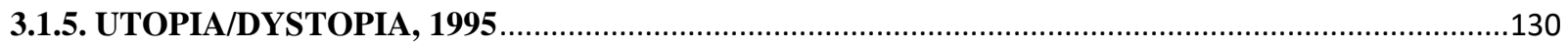

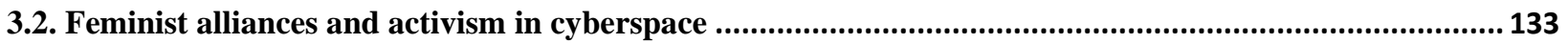

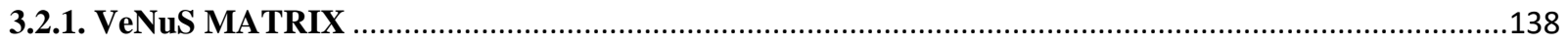

3.2.2. Social Cyberfeminism: The cyberspace and all-women activist groups..........................................141

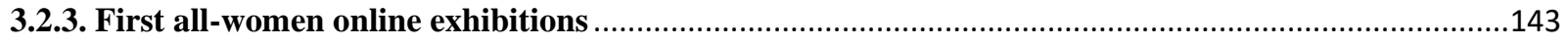

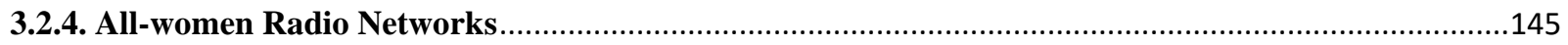

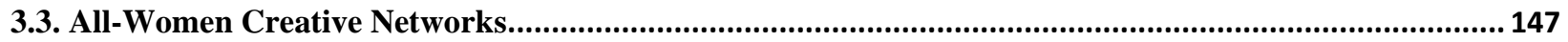

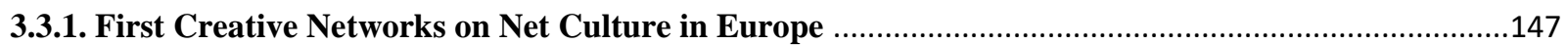

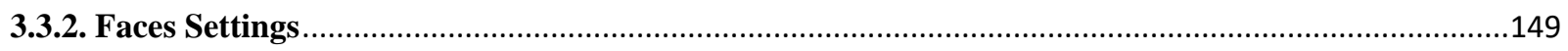

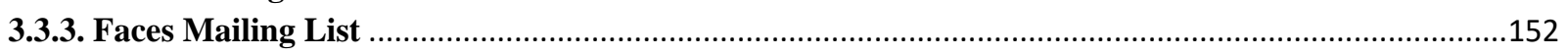

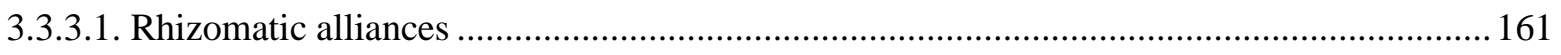

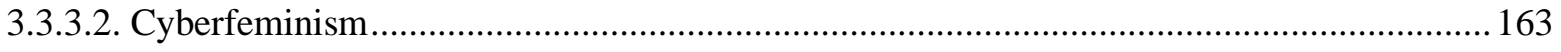

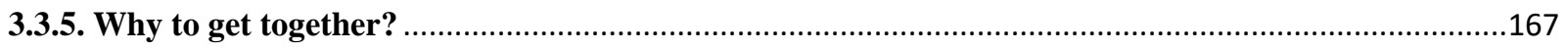

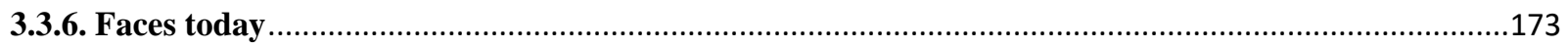

3.4. Mapping: All-Women Initiatives in Art and Technology ........................................................................ 179

3.4.1. Interactive Visualization Map: All-Women Initiatives in Art and Technology ...............................179

3.4.1.2. All-Women self-organised initiatives in Art and Technology .......................................... 180

3.4.3. Mapping all-women initiatives conceived within an institutional framework ...................................189

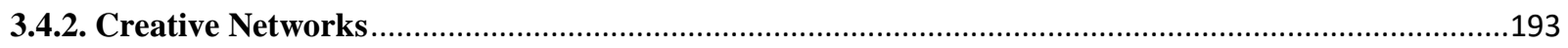

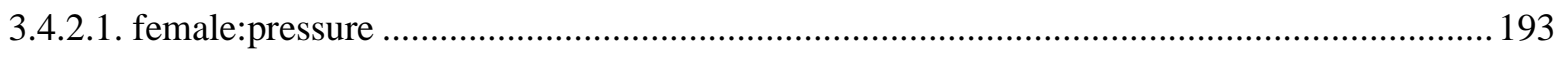

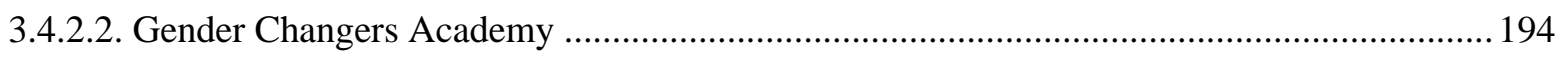

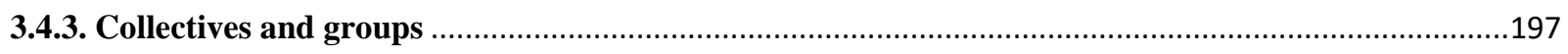

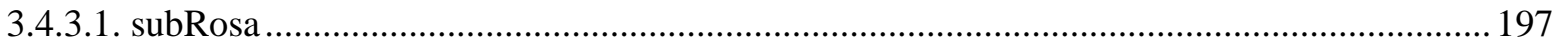

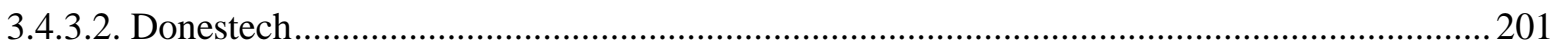

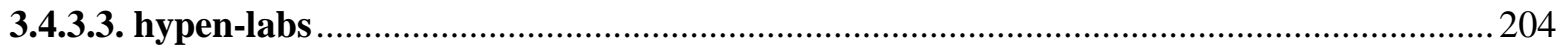

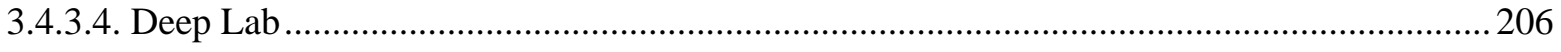

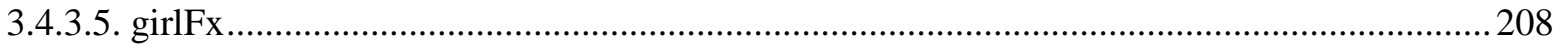

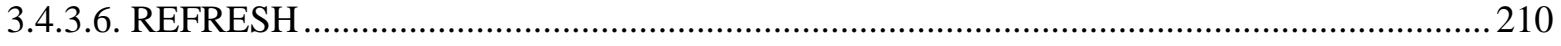

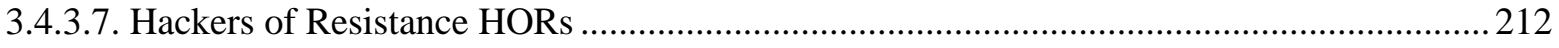

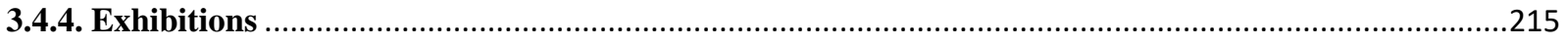

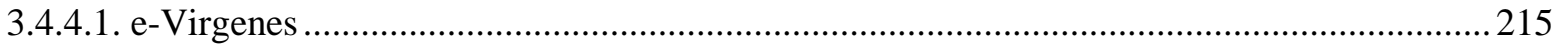

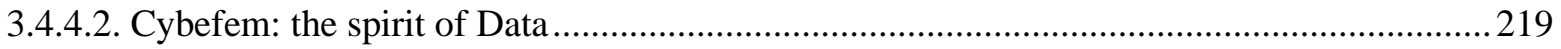




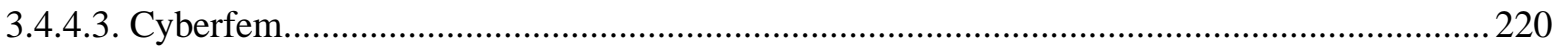

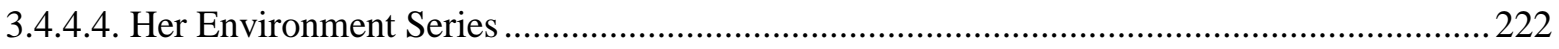

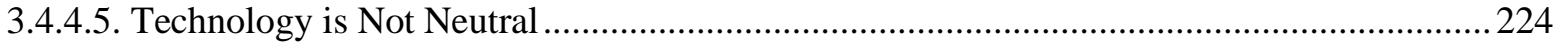

3.4.4.6. Making/Breaking The Binary: Women, Art and Technology 1968-1985 …......................225

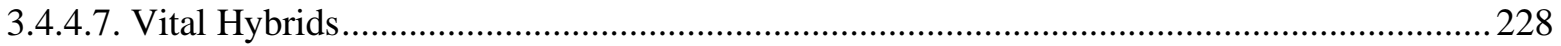

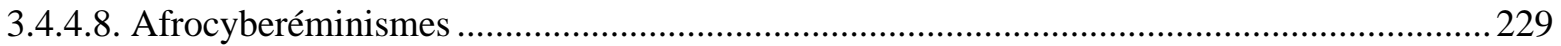

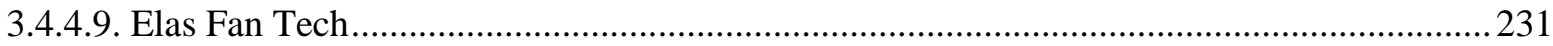

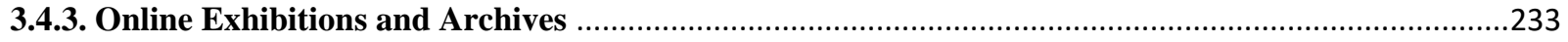

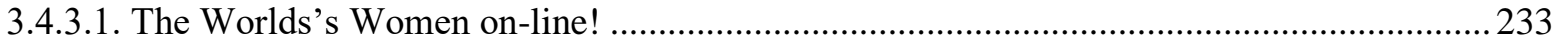

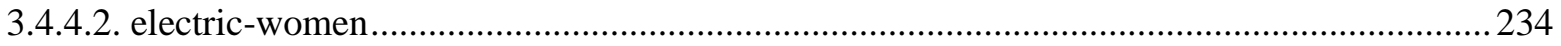

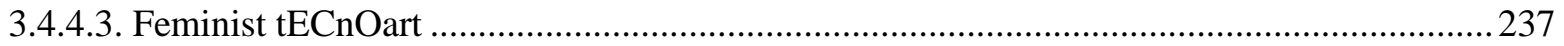

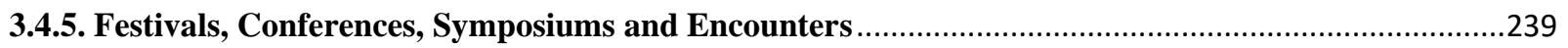

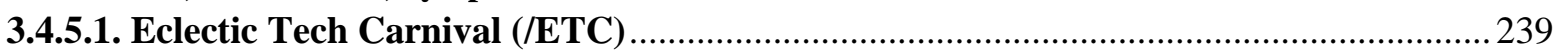

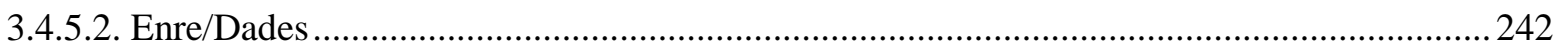

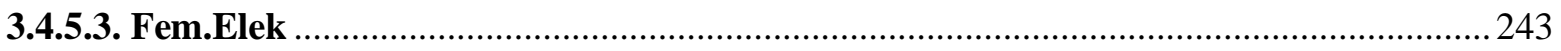

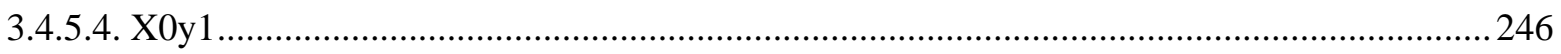

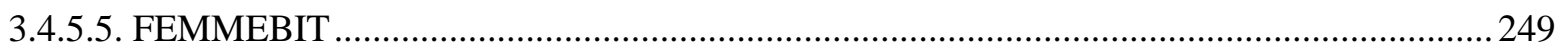

3.4.5.6. CURRENT: Feminist Electronic Art Symposium ...................................................... 251

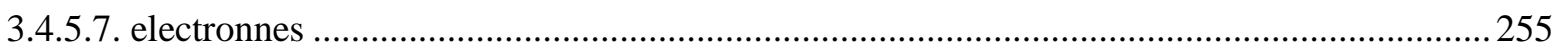

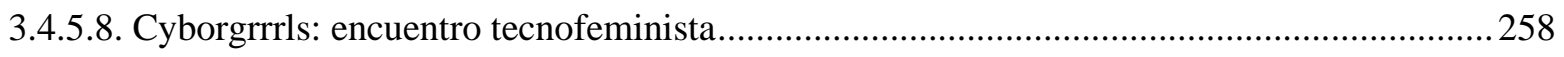

3.4.5.9. Alliance of Women in Media Arts and Science (AWMAS) ..............................................2. 261

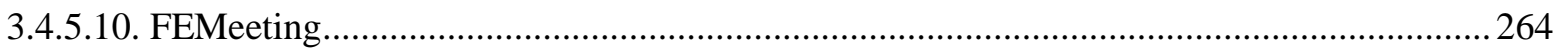

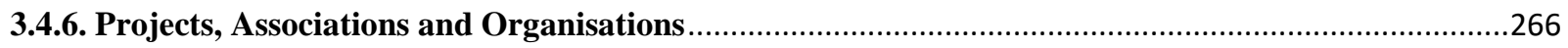

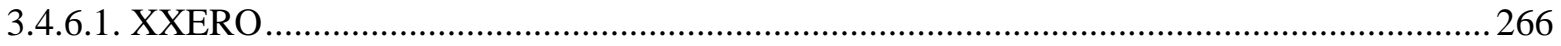

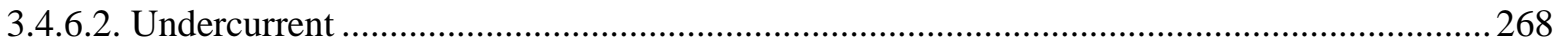

3.4.6.3. IMA Series: Hidden Alliances. IMAfictions and Machine Divas ....................................2270

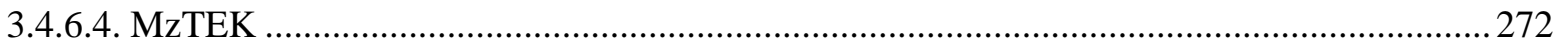

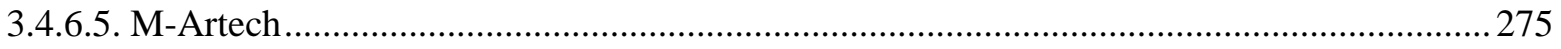

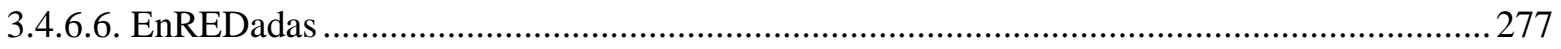

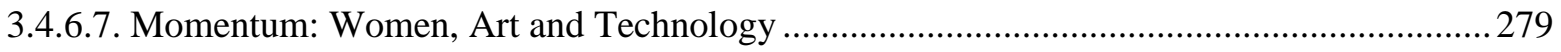

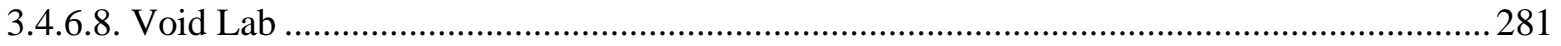

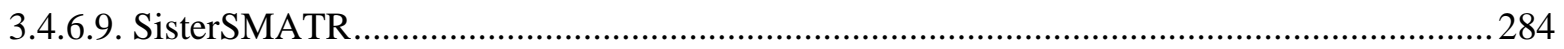

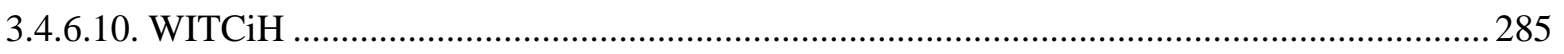

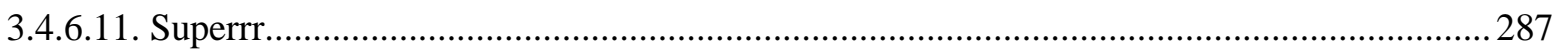




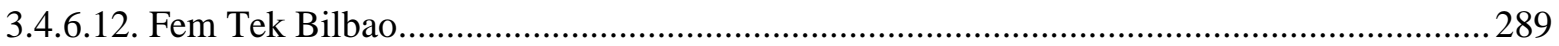

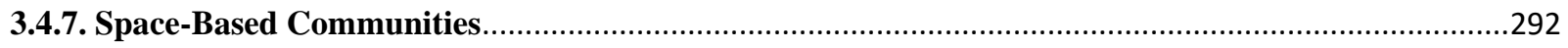

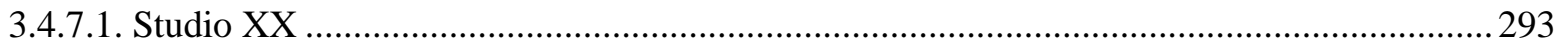

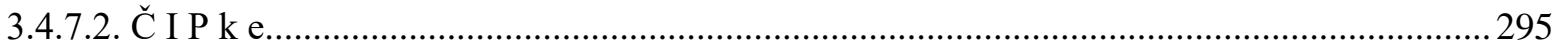

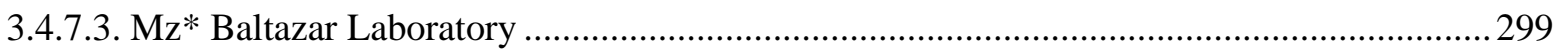

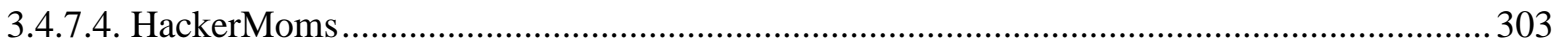

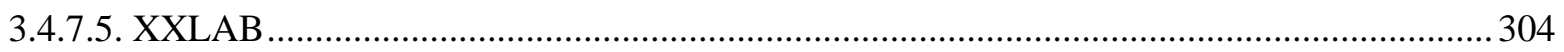

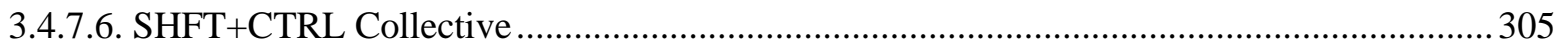

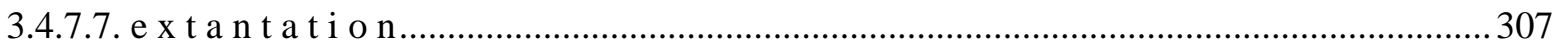

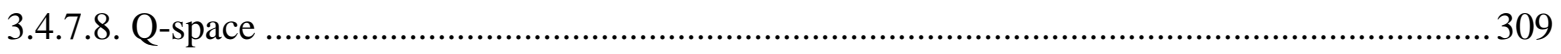

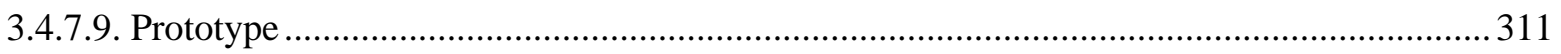

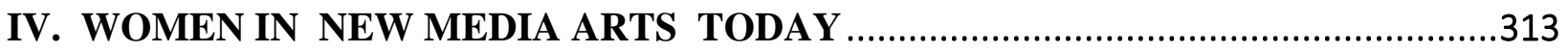

4.1. Questionnaire: "Women's Networks and Feminist Organisations in Arts and Technology" ................. 314

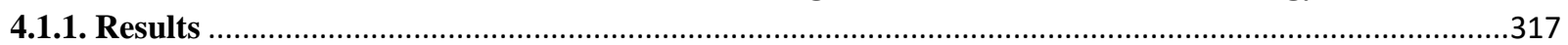

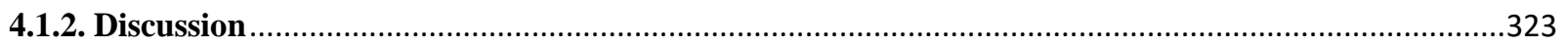

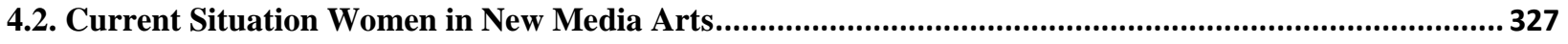

4.2.1. Institutional awareness on Women in Creative Industries and New Media Arts ...............................330

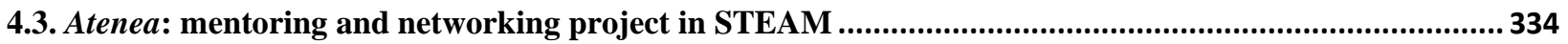

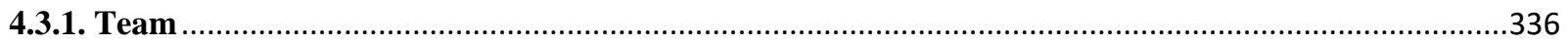

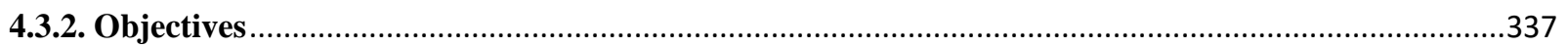

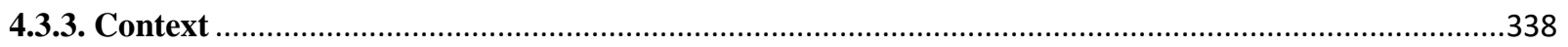

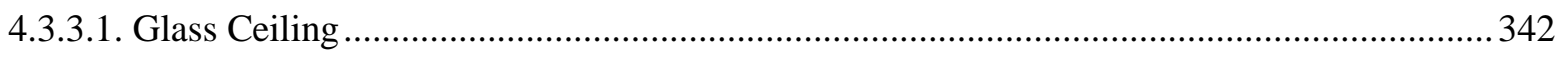

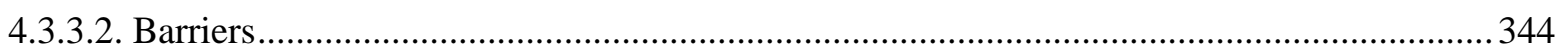

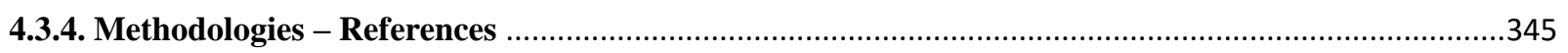

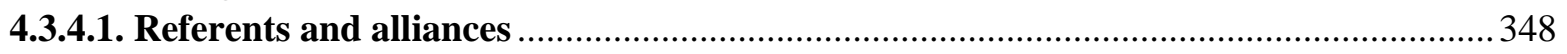

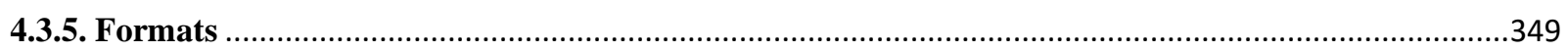

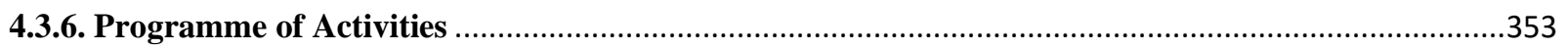

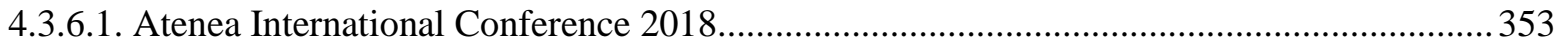

4.3.6.2. Atenea Exhibition 2018: Women in Art and Tech............................................................ 356

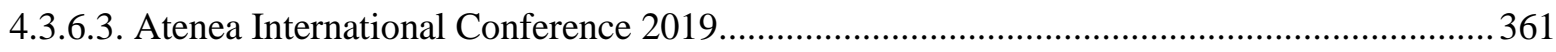

4.3.6.4. Atenea Exhibition 2019: Women in New Media Arts ......................................................... 366

4.3.6.5. Programmea Mentoras/Mentorship Programme ................................................................... 368

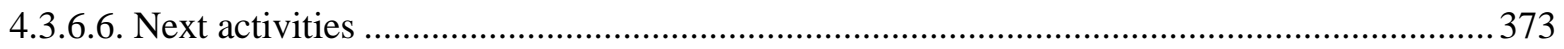


V. DISCUSSION

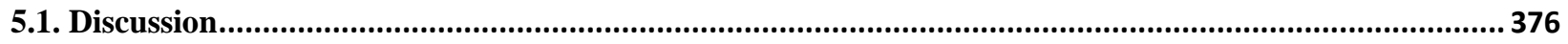

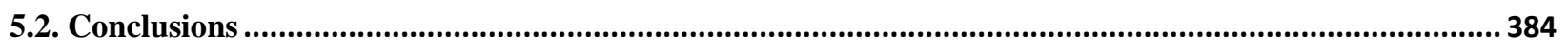

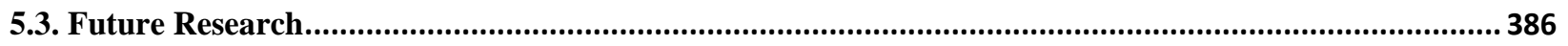

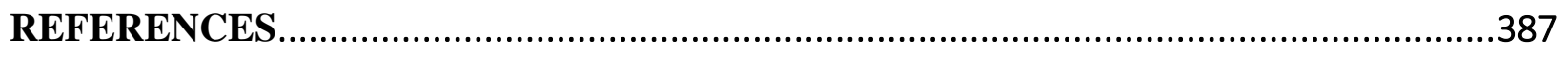

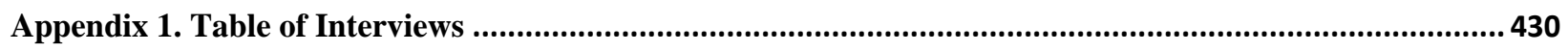

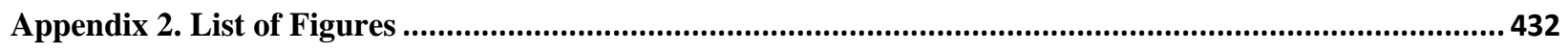

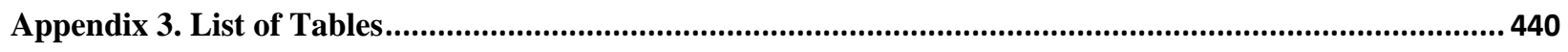

Appendix 4. Partial list of other all-women initiatives in technology and arts.............................................. 441

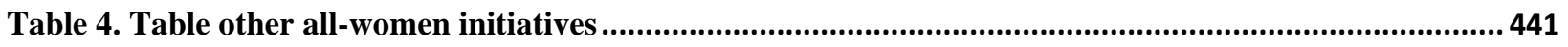

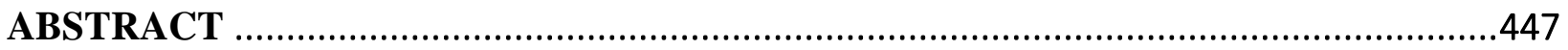

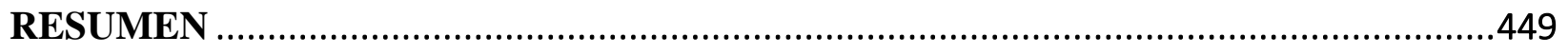

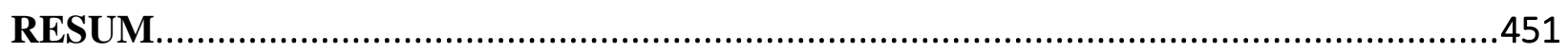


[This page intentionally left blank] 


\section{I. INTRODUCTION}




\subsection{Introduction}

Along this dissertation, I explore a series of all-women's and feminist initiatives that have emerged at the intersection of art and technology internationally since the middle 1980s. This research work aims to map this techno-social and artistic phenomenonregarding women's associationism and segregation in new media arts since its earliest practices. The majority of these cases have appeared in the grassroots of a general panorama in new media arts, and they are apparently scattered from each other in time and location, differing in formats of collaboration and methodologies. Therefore, my main objective is to identify on the one hand the earliest practices and on the other hand the highest number possible of initiatives at an international level, in order to describe them, to visualise their correlation and to categorise them in terms of format, extension and structure. At a first glance, I can presume that the white and male-dominant environment in the art and tech fields seems to be the main source of motivation for the emergence of such initiatives. However, I also aim to comprehend the main purpose that each of these initiatives seeks to achieve regarding the situation of women in art and technology and the praxis-theory positions they adopt to address it: what do they expect to change and how. Within this mapping process, I want to establish an attempt of categorisation to be able to identify general self-organised patterns of segregation, activism and collaboration that persist in time and which responds to techno-cultural positions. Collaboration and support by institutions will also be considered along the mapping.

Additionally, while identifying the earliest practices, I make a historical retrospective to compare their context with those contemporaries, to understand the reason why this phenomenoncontinues to exist over time. There is a repeating question that comes up over and over along my research, that points at the question what has not changed for women in new media arts for these initiatives to keep appearing. I want to study the reason why some have lasted more than others over time and the possible 
correlation between them and their members, also the influence of feminism and other theories to understand the repetition of formats and strategies. Finally, I want to investigate the impact that the situation of women in new media arts has in institutional bodies nowadays.

Although there is a notable historiography on feminist art and an increasing research interest on feminist curatorial projects, only a few references can be found regarding women in new media arts. Moreover, there is a worrying absence of bibliography on all-women curatorial projects and organisational forms in new media arts. The scarce works that exist on the topic are in majority focused on women, gender, art and technology from a feminist poststructuralist perspective, far from my research interest. These works generally and repeatedly point digital subcultures such as cyberfeminism along the 1990s as the first collective practices developed by women in new media from an activist or feminist position. Position which I argue. Additionally, in the last decades, there is an increasing academic interest for studies on feminist hackerspaces, seen as alternative places for knowledge and community building, which methods are inherited from the hacker and DIY culture. However, along this dissertation I show earlier practices of segregation and space appropriation by women in arts in order to challenge general feminist scholarship. I will also talk about collective art practices by women on communication cross-border before the 1990s and the expansion of the Web. Thus, in this dissertation I seek to contextualize this techno-social and artistic phenomenonwithin the historical and cultural panorama of new media arts, punctually considering feminist theories regarding segregation, also those on women, art and technology. Mainly, I aim to investigate the linkage of such initiatives to the history of all-women art groups and art spaces, to the history of women in computerbased arts and to network cultures.

I have addressed the study of this series of all-women self-organised initiatives from three cotemporary theoretical approaches, which have encouraged me to approach the initiatives as: creative 
networks, spaces of cultural resistance or community-based spaces. Additionally, I am also interested in studying the way in which Information and Communication Technologies (ICTs) have enabled new forms of alliances, connectivity and communication cross-borders, and in which manner they have impacted analog forms of real encounters. Thus, I analyse the way in which these initiatives perform a combination of local and transnational activism that has been extended by ICT, seeking to understand if analog formats such as face-to-face activities are still essential for the establishment of a community. Along the mapping process, I describe which initiatives and formats are intrinsic to digital age and network cultures, while others maintain analog formats.

To be able to deeply understand this techno-social and artistic phenomenon, I have conducted a series of interviews ${ }^{1}$, virtual and face-to-face, together with a digital survey, which results have been combined with historical and theoretical ethnographic research methods. Through this dissertation I aim to contribute to the historiography on women's studies, cultural management and history of new media arts, by providing a source of references that can be useful for these and other different disciplines.

Besides the introductory and discussion section, this dissertation is divided in three main blocks:

Second block is a historical framework regarding women's associationism and women's networks in arts and technology, which I divided in two subparts. The first subpart situates the lineage of segregated all-women groups and spaces in arts since the early $19^{\text {th }}$ Century to the 1980 s in Europe and North America, while presenting early international exhibitions and projects at the intersection of Arts, Science and Humanities. This subpart if followed by an argument on the retrieval of such

\footnotetext{
${ }^{1}$ See Appendix 1.
} 
strategies of segregation and space appropriation by the so-called second wave of feminism along the 1970s, also in North America and Europe, considering the main feminist theories that influenced this period. The second subpart situates the contribution of women within the framework of early computer and networked arts history, contrasting the work environment from the early experimental laboratories and festivals, and pointing the parallelism of uses between analog and electronic networks by women artists.

Third block presents the mapping of the initiatives. It is subdivided in two parts as well. The first subpart contextualizes the emergence of all-women collective formats in the new media arts panorama. The first subpart keeps on the line about women in early computer and networked arts and presents the early all-women curatorial projects in new media arts and computer networks. In this part, the general scenario of new media arts in the national and international events in United States and Europe is presented, exposing their differences regarding the women artists representation and institutional support, despite the male-dominant environment in both locations. In this point I will describe the impact of the domestication of Internet networks and the web browser in the art world combined with the shift that feminist theories had on technology, exploring how these influenced the emergence of new all-women initiatives to emerge in cyberspace. The second subpart presents the ultimate mapping: a list of all the all-women self-organised initiatives that I have identified, a listing by categories, year and location. I will describe most of them through a theoretical contextualization. In this whole chapter I expose my qualitative research data collected through interviews. This subpart is complemented by a further list of other all-women projects in new media from different nature (selforganised, institutional) and other mixed initiatives where women or diversity play an important role, which I provide in Appendix 4. 
Fourth block is also divided in two subparts and it is based on practice research. First subpart are the results of the questionnaire I designed to identify further case studies outside my geographical and linguistic network, in addition to gather qualitative information regarding contemporary women in new media arts, some of them members of my case studies. Second subpart is the presentation of my curatorial and organisational practice: Atenea. Atenea is a project that provides an online and offline networking platform for women in Arts and STEM to collaborate. The design of the project combines the results gathered through this research work combined with further research on the positive results of combining STEM and Arts, addressing the contemporary problem in Spain regarding the lack of women in Science and Technology. Here I describe the objectives and methodologies of the platform, explaining the theoretical background that supports the programme of activities already performed and the coming ones.

\subsection{Hypothesis and Objectives}

There has been a notable establishment of a series of all-women self-organised initiatives at the intersection of art and technology in the last three decades, mainly in Western countries but also beyond. Despite the differences, these initiatives share some strategies of segregation and space appropriation from analog formats, while some base their formats and networks in the digital age tools.

The main objective of this research is to map such initiatives at an international level within its techno-social and artistic framework.

The subobjectives are:

1. To identify and locate these initiatives, focusing in finding the earliest practices. 
2. To describe them and draw a general categorisation of the whole; to study the possible correlation between them and feminist theories regarding segregation and collective activism.

3. To address the current situation of women in media arts and creative industries, to understand and contextualize the objectives of such initiatives in this regard.

4. To analyze the influence of the information and communication technologies in the formats of activism, associationism and community-building.

5. To develop my own initiative, theory-praxis based, which combines the results of the present research with secondary sources on women and girls in Arts and STEM fields.

\subsection{Methodology}

The present work is based on qualitative and quantitative research methods, both focused on an international social phenomenonthat intersects with the artistic, technological and cultural sphere. Case studies analysis and mapping research have been mainly used at an international level. The case studies have been selected based on a thematic criterion, that is to be a self-organised initiative by women in new media arts following a collective and collaborative approach. They have been analysed in more or less intensity depending on the availability of resources and accessibility of the members. Due to the diverse variety of formats that these initiatives embrace in relation to ICT and the complex techno-social landscape, the theoretical references that I have used for the present work belong to different fields. Within the topic of new media arts, the main fields I rely on, are: network cultures, space-based communities in technology and history of all-women art groups. Despite the artistic component, my approach attempts to rely on social science positions, leaving humanistic considerations regarding the work of the artists presented out of this research scope.

The following are three contemporary works that have especially influenced the present dissertation in regarding terminology, analytical categories and empirical research: in referring to all- 
women and feminist groups, exhibitions and initiatives in arts, the compilation of essays on all-women art spaces in Europe in the long 1970s edited by Deepwell and Jakubowska's (2018); on creative networks and artists virtual communities, Rasa Smite's (2012) work based on her PhD dissertation on creative network communities and the work by Tatiana Bazzichelli (2008) where she develops the notion of networking as art in a historical framework from a techno-artistic perspective. The field of network cultures is relevant in my work, enabling me to study new forms of socio-technical systems that have emerged with digital ICTs. Concepts like organised networks by Ned Rossiter (2006) have enabled me to describe some of my case studies that have emerged after the web 2.0. I have also referred to theories on virtual communities that point the relevance of combining virtual and real-life encounters, such as Reinghold (1997) and Marx and Virnoche (1997). Theories that study the relation between new information technologies, social movements and community building cross-borders connecting local and global sphere that have influenced me are: Global Communication and Transnational Publich Spheres by Angela Crack (2008), Castells trilogy Information Age -and his rhizomatic concept of network society- and the work by Aristea Fotopolou (2016), which argues the influence of networked feminism in local feminist activism. Works that I have consulted regarding women's alliances in new media and feminisms considering the impact of ICTs are: the essays by Faith Wilding, Judy Wajcman and Montserrat Boix. Within Social Media Archeology, in referring to women artists in early computer networks and telecollaborative arts, the essays by Anna Couey and Judy Malloy have been a main reference to my research.

I have also adopted some postmodern sociological positions towards practice research like Pierre Bourdieu notion of reflexive sociology (1990), and in the legacy of the rhizoma concept developed by Guattari and Deleuze in Capitalism and Schizophrenia (1972-1980). I have applied the method of Actor Network Theory (ANT) to map the relationships between all the elements of the networks at a material and semiotic level, that is between concepts, things and humans, that form a 
whole that exists by the constant activity of the parts (Latour, 2005). ATN implies a network analysis and a mapping methodology, as its approach explores social effects towards answering questions regarding the structure, power and organisation.

Due to the simultaneous online and real-life activity of my case studies, I have followed mixed methods of real-life (Bhattacherjee, 2012) and virtual ethnography (Galasso, 2011) in order to identify, contextualize and describe them. Additionally, I have combined qualitative and quantitative data from primary and secondary sources (Ritchie et al., 2013) to develop a further study and description. The primary sources I have developed have been empirical observation together with interviews with the members of the case studies in addition to an online questionnaire ${ }^{2}$. Due to the ethnographic nature of my research, a notable part of the references comes from interviews and personal communications. These interviews have been loosely structured and have been performed virtually (Crichton \& Kinash, 2003) through telephone, online calls, emails and chats, and in real encounters, providing data that has been combined with quantitative and qualitative data from the same and other sources. Secondary sources employed have been bibliography on the topic from academic libraries, online academic archives and open content online. Another important method for my research has been the analysis of documents that have not been published or archived digitally, for example, several catalogues, essays and invitation letters regarding the early case studies in the middle 1980s that have been provided by courtesy of the artists participants of the research. I have also accessed to specialized archives such as the Ryerson \& Burnham Library at the Art Institute of Chicago and the National Museum of Women in the Arts in Washington D.C, among others.

As for the primary as for secondary sources, I have followed a feminist intersectional approach in the overall of the methods, taking into consideration the age, ethnicity, language and sex (Lykke,

\footnotetext{
${ }^{2}$ Presented in chapter 4.1 .
} 
2010) of the subjects and referents that have provided data to the research. Moreover, I have also applied a transnational feminist perspective considering the different socio-cultural and economic contexts (Grewal \& Kaplan, 1994), acknowledging neither new media arts field exists in equal manner and in equal access globally, nor women share the same issue of representation in technological fields or the same feminist approach, if so. I have taken into consideration in my research the predominance of the English language and the Anglo-American and Western Europe culture in the academic discourse as a barrier of access and an element of global influence.

Finally, I have applied PAR (Participatory Action Research) (Chevalier \& Buckles, 2013) in the last part of this work when designing, developing and implementing Atenea. Atenea is a researchbased project at the intersection of arts, science, technology. It addressed the situation of lack of visibility of women in new media arts in Spain and the low numbers of girls interested in STEM fields. It has been partially developed collaboratively and collectively, with a flexible contribution and participation of members of the network/project and partners depending on the activity. For the design of the conferences, exhibitions and mentorship workshops, I have followed cultural management methods for the organisation of academic and practice formats and curatorial methodologies based on cross-institutional collaboration.

\subsubsection{Mapping as Method - State of the Art}

There is an increasing contemporary work on mapping and visualizing women professionals and all-women and feminist associations, concretely in music, since the first archive of female:pressure ${ }^{3}$. All-women mapping projects that have served as reference to my work are GenderArtNet by Bettina Knaup and Maria Ptqk together with Constant vzw, the essay Network

\footnotetext{
${ }^{3}$ See <www.femalepressure.net $>$ described in chapter 3.4.2.1.

${ }^{4}$ See $<$ http://genderartnet.constantvzw.be/emerge>
} 
Analysis and Feminist Artists (2017) by Michelle Moravec, the mapping on Latin-American cyberfeminist iniatitives developed by enREDadas ${ }^{5}$ and Geochicas, a female collective of feminist mappers also from latinoamerica ${ }^{6}$. Also, the research work developed by Dr. Liz Dobson on All-Women and Feminist Sound/music Tech collectives ${ }^{7}$ and the grassroot data base of music industry organisations with women and non-binary people by Rene $\mathrm{Kladzyk}^{8}$. In terms of format the Observatorio de Nuevos $\operatorname{Medios}^{9}$ and the archive and visualization map of Women in Media Arts archive of Ars Electronica Center ${ }^{10}$ started in 2016. The largest mapping work on women worldwide is probably Joni Seager's series Women's Atlas (1997-2019). Other mapping works are the international open and collaborative Feminist Network Project ${ }^{11}$, the Angelena Atlas $^{12}$ by the Mapping Feminist LA (MFLA), FEMArtNet ${ }^{13}$ mapping in Medellin, Red Ciberfeminismo in Mexico ${ }^{14}$ by Patricia Fernanda Briones Medina (2016), HarassMap ${ }^{15}$ started in 2009, WikiFemia $^{16}$, between other feminist mapping. Other mapping projects we want to outline: LibViz ${ }^{17}$, What is Missing ${ }^{18}$ and Walk along the Kang Dukkyung's life journey ${ }^{19}$. One referent interactive visualization map on women in STEM and Arts is the one developed by the lecturer at my university Salome Cuesta called Mujeres STEAM ${ }^{20}$. Finally, to note that the field is currently spot of interest, I have found some similar mapping projects on all-

\footnotetext{
${ }^{5}$ Available at <https://enredadas.org/2018/08/08/mapeo-de-iniciativas-ciberfeministas-latinoamericanas >

${ }^{6}$ See <https://geochicas.org >

${ }^{7}$ See $<$ https://bit.ly/2xQutb4>

${ }^{8}$ See $<$ https://bit.ly/2kqDODv>

${ }^{9}$ See <http://www.nuevosmedios.es>

${ }^{10}$ See <http://archive.aec.at/womeninmediaarts>, also discussed in chapter 4.2.

${ }^{11}$ See <https://feministnetworkproject.wordpress.com>

${ }^{12}$ See <https://linktr.ee/angelenaatlas >

${ }^{13}$ See <http://platohedro.org/femartnet $>$

${ }^{14}$ Available at $\langle$ https://bit.ly/2xNFpqb $>$

${ }^{15}$ Available at $<$ https://harassmap.org/en $>$

${ }^{16}$ Available at <http://wikifemia.org/>

${ }^{17}$ Available at <http://libviz.artlabo.org/free_openSource_lib>

${ }^{18}$ Available at <http://whatismissing.net>

${ }^{19}$ Available at <http://tiny.cc/66osiz>

${ }^{20}$ Available at <https://goo.gl/YxYpBu)>
} 
women collectives in music: Women in Music Networks ${ }^{21}$ and the work by Dr Liz Dobson on more than fifty all-women and feminist sound/music tech collectives, co-ops and non-profits ${ }^{22}$.

Theoretical work in this line which I have consulted during my research and has served as reference is the guide and directory by Cynthia Navarreta (1982) on Women's Art Organisations in United States of America. I have taken also as reference of contemporary qualitative research works on self-organised collectives such as Sonia Núñez Puente (2008) and Maria Fernandez Sanchez (2011) on investigations on Spanish cyberfeminist collectives and all-women activist platforms on the Net, Nuria Verges on the feminist collective on ICT, Donestech, the study on the transnational feminist network female:pressure by Rosa Reitsamer (2012) and on music subcultures groups by Teresa López Castilla (2015).

\subsection{Impact of the research and Limitations}

With the results of my research I expect to provide a referent point of resources on women's groups and associations in new media arts that fills up the existing historiographic gap of references for students and general audience at an international level. I also expect to contribute to the general historiography of all-women and feminist associations and groups in visual arts, creative technology and culture.

I acknowledge that this study was an attempt to map as many initiatives as possible, yet the invisible barriers of language would prevent me from accessing the overall of initiatives and references in the topic. Therefore, this thesis is a result of an open mapping-process which I expect to enlarge and extend in future research phases. Other important limitations have been the lack of bibliography on the

\footnotetext{
${ }^{21}$ Available at $\langle$ https://bit.ly/2OcJPSz $>$
}

${ }^{22}$ Available at <https://bit.ly/2xQutb4> 
topic of all-women groups and initiatives not only in new media arts but also in general visual arts, specially outside the scope of feminist art within the north American framework. There is an enormous bibliography in referring to cyberfeminism, but this refers to collective artivist practices on the net from a feminist and postmodern approach, rather than studies on women artists' alliances and collaborations cross-borders in new media practices. The fact is that I have faced a lack of historiography or inexistence of bibliography on women's associations in new media arts, in an informal or formal way. There is however, bibliography on women's associations in digital platforms, regarding information technologies and related issues on gender and the Internet, specially cyberfeminists. There is also a humble but increasing bibliography on feminist hackerspaces and makerspaces. The most important limitation that I have faced when seeking references, has been that as per cyberfeminism or feminist hackerspaces or general works on women in new media: the assumption and understanding of feminism from a unique theoretical position, for example, addressing solely topics on gender identity, sexuality and related, fact that has eclipsed the content of the major body of work on the topic. The influence of the global feminist agenda on the general feminist art works is very notable and therefore in the theoretical content and approach, as I have also noted the change of terms from women to gender in some of my case studies.

The extensive bibliography on cyberfeminism and general feminist art has been a negative input rather than positive. The fact that most of the contemporary bibliography refers to the 1990s as the historical moment when women artists started to perform feminist issues through new media creates misunderstandings about the real circumstances of the previous works. I argue that feminism has not escape from the historiographical narratives, leaving outside of the narration previous and parallel practices that were intended by the authors as feminists, as I will discuss when talking about the early computer networks pieces. Another important limitation that I have faced is that some of the initiatives I have studied do not exist anymore and they have left little recorded about their activity. Additionally, 
the contact to these and other cases has been impossible to establish, due to the invisible barriers of the Internet and sometimes lack of interest by the members.

Finally, due to time and topic limitations, other new media art practices related to video games production, animation or electronic music have not been addressed completely in this dissertation-

\subsection{Conceptual Framework}

"The appropriation and use of space are political acts".

Pratibha Parmar

The initiatives that have been studied in the present work embrace a complex variety of formats and methods. However, there are three structural notions that I have identified in all of them which embrace techno-social and artistic aspects: spaces of creative cultural resistance, creative networks and community-based spaces. These three notions are related to the concepts of associationism-activism, segregation, and appropriation of space as politic act. In the case of these initiatives, segregation is based in mutual affinity: that is biological sex [women] or ideology [feminism(s)], and new media arts practices.

Segregation in groups can take place due to spiritual or social norms (i.e. sex segregation by religion, culture), voluntarily (by a common identity or affinity) or by discrimination. When both of those last reasons come together, it is called spaces of resistance and adopts a political aspect (Hooks, 1989), which formats can vary depending on the methodologies, purposes and communication technologies. When the purposes are creative and cultural, such as artists groups, they are addressed as creative tactics to create spaces of cultural resistance (Bloch, 2012) that I summarize in creative spaces of resistance. These spaces of resistance commonly happen in the margins, in the grassroots of 
bigger social and cultural contexts, they are self-organised, self-run and generally their structure is collective, collaborative and horizontal. They tend to appear as a reaction to a general situation of discrimination or discomfort, and they establish by themselves a community. Therefore, creative spaces are also considered social networks, as personal relations and nodes of connectivity are established between the people involved (Bazzichelli, 2008, p.94). Hence, they can also be defined as creative networks (Smite, 2012) or space-based communities (Wuschitz, 2014).

Separatism and space appropriation in the margins of a general panorama for subverting the use of such spaces is an ancient tactic in subcultures and young people (Smith, 1997, p.292). Segregation based on biological sex can take place socially by different reasons: for religious and cultural belief systems, by discrimination or voluntarily based on mutual affinity (Ember \& Ember, 2003). Today, in a global society where virtual and real-space function simultaneously, connecting local with global, notions of space, time and connectivity are challenged (Castells, 2001; Crack, 2008). Artist and activist Faith Wilding (1998) makes a perspective on women's separatism from the feminist history timeline to understand the coming challenges of women alliances after the Internet. She explains that separatism has been applied voluntarily and collectively by women in history for useful tactics as for pedagogical situations, using any private or public space to organize, from kitchens to churches, sewing circles to streets (Wilding, 1998). Leila Rupp (1997) describes how already by the end of the $19^{\text {th }}$ Century in the first transnational alliances by women's organisations, segregated groups that seek to organize were criticized by some contemporaries as exclusionary. Second-wave feminism is commonly characterized by the enormous number of segregated groups and women's centers for health, conscious raising, alternative art spaces, community building, networking, common support, and essentially to rediscover the experience of the feminine sex, in addition to new forms of organisation (Spain, 1992; Mitchell, 2016). Virginia Wolf’s essay “A Room for one's own” published in 1929 has been the main referent for women to claim the right for separatism in women's activism. 
Despite the strong rejection to first and second-wave feminism strategies, Faith Wilding (1998) would defend separatism still in the digital era as a positive strategy for minority groups, in fact productive towards building own spaces of learning and creativity. In the contemporary digital era, electronic networks have extended social relations capabilities, enabling the establishment of segregated virtual communities and emphasizing existing ties in the virtual sphere, giving rise to what Angela Crack (2008) calls transnational networks of mutual affinity, referring to civil society groups that make use of the ICT to "communicate and engage in political activism across state borders" (p.20). I will refer to this term when talking on creative networks which combine local and global activism due to ICT and which membership and activity have multilocation.

This phenomenon exists within the artistic world, as digital arts are a refection of the economic, political and technological dimensions of human history (Paul, 2016). Although transnational alliances in artistic and all-women groups existed since the early $19^{\text {th }}$ Century $^{23}$, in network culture studies, the networked nature of communities is addressed according with a new techno social panorama, which contemporarily is called the Internet Age or Network Society (Castells, 2001). This socio technical situation is based on interconnectedness, openness and decentralized access (Castells, 2001). According to Rasa Smite (2012), who discusses creative networks, these principles make the "process of self-organisation in digital network environments possible as a result of which new socio-technical formations such as network communities are created":

Digital networks do not only provide new possibilities on a translocal level, but they also hold a potential for developing and strengthening local community networking as well as

\footnotetext{
${ }^{23}$ See chapter 2.1
} 
possibilities to extend the field of local communication or social activism on local, translocal and global levels (Smite, 2012, p.52).

Smite (2012) studies the rise of creative network communities along the early 1990s on the Net Art Culture as social dynamics born in digital networks, noninstitutionalized contexts and with translocal qualities, comparing them with the cotemporary social networks born in the Web 2.0. One of these creative networks is one of the main case studies analysed in this work: Faces mailing list ${ }^{24}$. Additionally, the present work is based on the term coined by Tatiana Bazzichelli (2008) "the art of networking [...] as a metaphor of art as a network: art that creates network" when studying the phenomenon that my case studies represent from a social and artistic perspective. Bazzichelli (2008) explains that to network means to "create relationship networks, to share experiences and ideas" (p.37), therefore my focus of interest relies in the networking process of such initiatives members and of women artists through networked systems.

Although the topic of women in the radio waves is out of my research scope, I want to present a similarity that has served to my research in regarding methodologies of resistance that women perform in free and community radios with those of my case studies. The scholar that has served me as main reference about women and radio is Caroline Mitchell (2016), concretely her approach to women's community radio as places for “individual empowerment, representation, creativity, as well as spaces of resistance - including collective and transnational feminist campaigning and activism" (p.5). I consider her analysis of feminist and women-only radio programmes and stations and its relation theory-praxis very close to my approach to my case studies. Mitchell (1998) develops a concept of a "women's or feminist public sphere in relation to women's community radio" based on the Habermas' concept of public sphere when talking about virtual communities. Mitchell talks about

\footnotetext{
${ }^{24}$ See section 3.3.3.
} 
the community radios as a participatory media, where women and minority groups encounter (based on ethnicity, sexual orientation, etc.) (Mitchell \& Lewis in Föllmer \& Badenoch, 2018). Alternative spaces of media practices promote feminist ideas like symbolic annihilation, that for women and minorities enables them a media to produce and represent themselves challenging mainstream media (Mitchell, 1998). As I will present when talking about virtuality and cyberspace, Mitchell describes the process of disembodiment of women in the radio. In this case, it is in vocal format where women in the waves produce their symbolic representation, discourses, and position themselves. Radios would give space to speak to women, to tell the silenced stories, understanding that feminism was about allowing women "to find their voices". (Mitchell, 2016, pp.15-9). In the relation with the process of practice (PAR: participatory action research) that feminist radio and women's community radio developed through offline workshops, for example, I find the parallelism in methodologies with my case of studies (women-only workshops and safe spaces: next paragraph). Mitchell marks in the nature of women's and feminist community radio space and praxis three points which I also apply to my research case of study: gendered representation on and off line through community media, the participatory medium critical capacity and the women friendly methodologies, and the approaches taken by women as "agents of resistance against a range of traditional representations of themselves in radio" (Mitchell, 2016, p.7).

Continuing with the offline activities, real-face encounters are essential for the community building of my case studies. The strategy of community building through a common real space is a strategy retrieved by some feminists that seek to escape from individualistic cultures such as capitalist society. The movement that illustrates this are the feminist hackerspaces, which was partly formed by female artists (Wuschitz, 2014, p.137), and relies on the "circulation of knowledge and availability of hardware" within a male-dominated maker space (Wuschitz \& Savic, 2019). Stefanie Wuschitz 
(2014), founder of the feminist hackerspace Mz*Baltazar Laboratory ${ }^{25}$, relates the concept of shared usage of space with the design of feminist hackerspaces and the fundaments o women-centered spaces and collectives in open cultures for "legitimizing belonging" and to remain inclusive (p.13):

A space-based community is defined by its site-specific, collaborative practices, copying the supportive conditions and the anticipation of aimless and playful exploration that a hacker space can offer to its members, yet applying it in a new way: based on the need to carve out time for all potential agents. A space-based community adapts its visual culture to 'newcomers' by giving ownership over space to weak elements in the community. In this way it conveys the option to bridge the spaces that divides: workspace, living space, playing space (p.163)

Wuschitz opens the door for a future research on the subversive potential and the networked character of the space-based community to position against institutions through creative strategies (p.215). She suggests that this networked character could develop in local and translocal ties for political action and the creation of more space-based communities. I will discuss in further chapters how these ties are invisibly being netted by the members of such spaces and their translocal and transnational activity. Most of the space-based communities that I will present are based in radical openness in terms of technology (free and open source) and learning structures (anti hierarchical).

The notion of cultural resistance as strategy is also as "old as history". However, notable forms to describe the use culture as resistance to a dominant power can be found in the $19^{\text {th }}$ Century in the British work Culture and Anarchy from 1869, and later in Antonio Gramsci works along the 1920s, describing, as part of the revolutionary project, a strategy of cultural resistance and "how to create counterhegemonic culture behind enemy lies" (Duncombe, 2007). French difference feminist Lucy

\footnotetext{
${ }^{25}$ See point 3.4.7.3.
} 
Irigaray in 1985 would claim the reappropiation by women of their own figures in order to face the Western excessive constructions of women, as "tactics of opposition available at the borders of discourse" (in Paasonen, 2005, p.195). In the same line of language as political position, one year later, in 1986 American Bell Hooks published Choosing the Margin as Space for Radical Openness, probably one of the most influencing books in the context of my case studies, together with the following theories of intersectionality, accounting an intersection of cultural factors (sex, sexuality, age, ethnicity, etc.) to be "victim of oppression" (Collins, 2000). Hooks (1989) described the difference between the space of marginality created by oppressive structures and the space voluntary appropriated by the marginalized as a site of resistance, segregated culture and opposition to domination: "a location of radical openness and possibility" (p.23). Based on her experience as a black woman in United States, she combined terms referring location and space with the words "struggle, marginality and resistance". Hooks (1989) would shift the conception of marginalization to a new political position for the minorities oppressed, exploited and colonized by others (p.21). following her work and Paulo Freire's Pedagogy for the Oppressed from 1970, many artists and theoreticians, such as Sandoval (1994), would describe a list of tactics as methodology of the oppressed, technologies of resistance for the survival of subaltern groups that are oppressed. She describes differential movement as the "reappropriation of space and boundaries to impress dominant powers" (p.89). The notion of cultural resistance can be found in works on communities in arts and science (Aviva Rahmani, 2014) and art and technology (Tuer, 2005). Nadine Bloch (2012) describes creative cultural resistance as the extension of cultural resistance with a "very dramatic high-risk acts" through activism and art practices simultaneously performed while investing in community.

Some feminist hackerspaces and other initiatives which formats are workshops follow the concept of space-based community and the pedagogy of the oppressed proposed by Paulo Freire in 1970s, he challenged the hierarchy of student-teacher comparing it with the oppressor and the 
oppressed. These space-based projects seek to create horizontal learning environments where there are no hierarchies but rather an environment of sharing and exchange knowledge. Creative tools and methods based called Do it Yourself (DIY) and Do It With Others (DIWO) are pillar in the feminist hackerspaces and most of my case studies that work on workshop formats. DIY or DIWO comes from the legacy of hands-on and self-made methods from non-institutionalized tasks such as sewing, knitting or tinkering: it is since the knowledge is generated while the action is being performed (Schuswitz, 2014, p.219). In the art and activist world that is related to electronic networks, Tatiana Bazzichelli (2008) explains how the inheritance of the avant-garde art movements escaped from close structuredness towards interactivity with the public, merging along the 1970 s with the punk culture in the digital networks (cyberpunk) and the hacker movement that raised from it (p.21). A new network of artists, activists and collectives would emerge around electronic networks, working based on selfmanagement (DIY) self-organizing and self-producing communication media and artistic content outside the commercial sphere with low-cost and collaborative tools: fanzines, posters, music, etc. The Riot $\mathrm{Grrl}^{26}$ would be the female-face of this period, and as Virginia Wolf was the theme for secondwave feminism, the Riot Grrrls would be for the so-called third wave and its "nomadic, plural" (Braidotti, 2014), "personal and rebel” understanding of feminism (Chidgey, 2012). Today, some scholars (Chidgey, 2013) point to this low-cost young women's zines movement as the inheritance of DIY media content with low-cost resources in the grassroots, DIY feminism or DIY feminist networks (2012, p.87). However, I argue that the self-organised collective artistic production has a deeper root previous to the DIY movement in the 1980s, for example in the forms of media production self-founded and collaboratively produced in the early stages of the women's movement: self-produced journals, papers, meetings, collectives, self-funded meetings, etc. (Rupp, 1997), or in the pirate and community

\footnotetext{
${ }^{26}$ The Riot Grrrls legacy is so notable that still emerging feminist initiatives in art and technology, such as Suprrr in Berlin or Cyborgrrrls in Nicaragua, keep on the legacy of its name. See table 3.4.1.1
} 
radios developed by women after the IIWW until the feminist free radios along the 1990s, sites of resistance based on participation (Mitchell, 2016).

Bazzichelli (2008) recognises that the influence of the DIY movement in the Italian hacker and cyberpunk scene was clue for the following emergence of network cultures and creative networks. She describes the Italian hacker scene in the 1980s and 1990s as one step further that the international, applying a social and artistic approach to the use of free technology and the importance of sharing knowledge beyond exploring the technology limits:

The scene of Italian cyberpunk and the hacker movement show that, starting with a conscious use of technology and the instruments of language, it is possible to conceive of a type of art in which it is possible to personally intervene activating an open process of creation. (p.21)

This whole Italian scene would be the direct reference for my case studies described as creative networks. The concept of social hacking by taking the hacker culture to social positions would be also taken by cyberfeminists such as Montserrat Boix when talking about feminism hacktivism (Boix, 2006) and social cyberfeminism (de Miguel \& Boix, 2005). The concept of hacking technology would be extrapolated to society, and then gender (transhackfeminism) by radical artists and activist in computer art practices. The hacker and maker culture are situated against capitalist and consumerism, promoting low-cost, collaborative and recycling methods (Bazzichelli, 2008, p.124), like the DIY feminism constitutes a "grassroot, micro-political feminist response to consumer capitalism and state authority" (Chidgey, 2009). The hacker culture was based on electronic networks as a format of work, however space-based and real-face encounters were based to establish and reinforce the community ties in addition to the virtual sphere. Hacklabs (hackerlaboratories), independent magazines, hackmeetings (meetings focused on self-teaching and knowledge exchange), etc. Not surprisingly, women were 
scarce in the hack world which would be accused by many of biases and sexism like the general tech environments (Sollfrank, 1999), giving rise to feminist hackerspaces.

Lastly, I want to present another term in regarding contemporary interdisciplinary forms of horizontal collaboration that network cultures researcher Ned Rossiter (2006) calls organised networks, socio technical dynamics, different from networked organisations, co-emergent with digital communication media. I will apply this terminology to the self-organised all-women initiatives and networks that are rise and work partially within an institutional framework, so far with some type of support by local cultural centers, university departments, local art galleries, etc. 
[This page intentionally left blank] 


\section{II. \\ HISTORICAL \\ FRAMEWORK}




\title{
2.1. All-Women Art Groups and Exhibitions in the late $19^{\text {th }}$ Century and early $20^{\text {th }}$.
}

\author{
"The only way for a woman, as for a man, to find herself, \\ to know herself as a person, is by creative work of her own." \\ Betty Friedan in The Feminine Mystique, 1963
}

\subsubsection{Europe $1^{\text {th }}$ Century early $20^{\text {th }}$}

The academic interest on women's associations and collective exhibitions in arts that took place during the end of the $19^{\text {th }}$ century and early $20^{\text {th }}$ is increasing, compare to the absence of academic documentation on the topic until a few years ago. In December 2017 the research laboratory Artl@s (from l'Ecole Normale Superieure, PSL, Label Transfer) and AWARE (Archive of Women Artists Research and Exhibitions) with the collaboration of Jeu de Paume, organised a symposium in Paris called WAS (Women artists Shows-Salons-Societies): expositions collectives d'artistes femmes 18761976. Researchers from different countries such as Spain, Greece, Italy, Argentina, Russia, Chile, Poland, among others, presented a series of all-women women artists associations that have existed from two centuries ago in different locations, from which little is preserved in the general art history books. These authors exposed in the conference how many women created a space on their own to promote their artwork and create community. For example, Georgina Gluzman retrieves the first women-only art exhibitions held in Buenos Aires by the Club Argentino de Mujeres during the 1930s and 1940s, Gloria Cortes Aliaga in Chile from 1916-1939, Natalia Bodanova the first ones in Russia in 1914, the first Association of Greek Women by Glafki Gotsi in the 1050s, and in Eva Bobrowska on the first female exhibition in Poland at the beginning of the $20^{\text {th }}$ Century and Agatha Jakubowska presented the project Wystawy sztuki kobiet ${ }^{27}$, a platform that gathers a complete archival on all-

\footnotetext{
${ }^{27}$ Available at http://wystawykobiet.amu.edu.pl
} 
women exhibitions from the $19^{\text {th }}$ Century until today, between others ${ }^{28}$ (AWARE, 2017). Another publication on the topic is Women in International and Universal Exhibitions 1876-1937edited by Myriam Boussahba-Bravard and Rebecca Rogers published in 2018, which compilates essays from different art historians on the international contribution of women to art, exhibitions and collecting since the last quart of $19^{\text {th }}$ Century to middle $20^{\text {th }}$, in different parts of the world.

Among others, these contemporary researchers have demonstrated that the all-women collections and curatorial projects are not a new thing born with the feminist art in the 1970s. For instance, in Europe in the $17^{\text {th }}$ Century there were important female art collectors such as the Dutch Mennonite Agnes Block who was also horticulturalist and who is considered the first person to gather an art collection of art pieces made exclusively by women. Agnes Block commissioned seventeen female artists to paint hundred watercolors of her most prized botanical specimens from her exquisite garden (Kemp et al., 2018). By the beginning of $19^{\text {th }}$ Century in cities like Paris, there were private academies only for women which existed due to the prohibition to female students to attend official Academies and Universities. These female private academies, however, were ruled by male artists, like the one of the painter Robert-Fleury named Academie Julian in Paris, attended by international female students like the Russian diarist, painter and sculptor Marie Bashkirtseff (Reynolds, 2000, pp.327-44). Marie Bashkirtseff was also part of L'Union des femmes peintres et sculpteurs (UFPS), the first allwomen organisation of artists in France, founded by the female sculptor Hélène Bertaux in Paris in 1881, which surprisingly, was active until 1994. The main objective of the UFPS was to offer space and material for an egalitarian art education to women of any social class and economical level, as many women could not afford the private women-only academies in Paris in that time. Some of the women artists that were part of the UFPS were not merely artists but activists, for

\footnotetext{
${ }^{28}$ More information and the archival of the conferences available at $\langle$ https://bit.ly/2NIA91S $>$
} 
example, both Bertaux, and Bashkirtseff were involved in the feminist journals of the time (Gonnard \& Lebovici, 2007, p.479). Thanks to the demands made by Bertaux and the women in her academy, women could attend the Ecole des Beaux-Arts in Paris for first time in 1897, and in 1903 women were allowed for first time to compete for the Prix de Rome (Birnbaum, 2019).

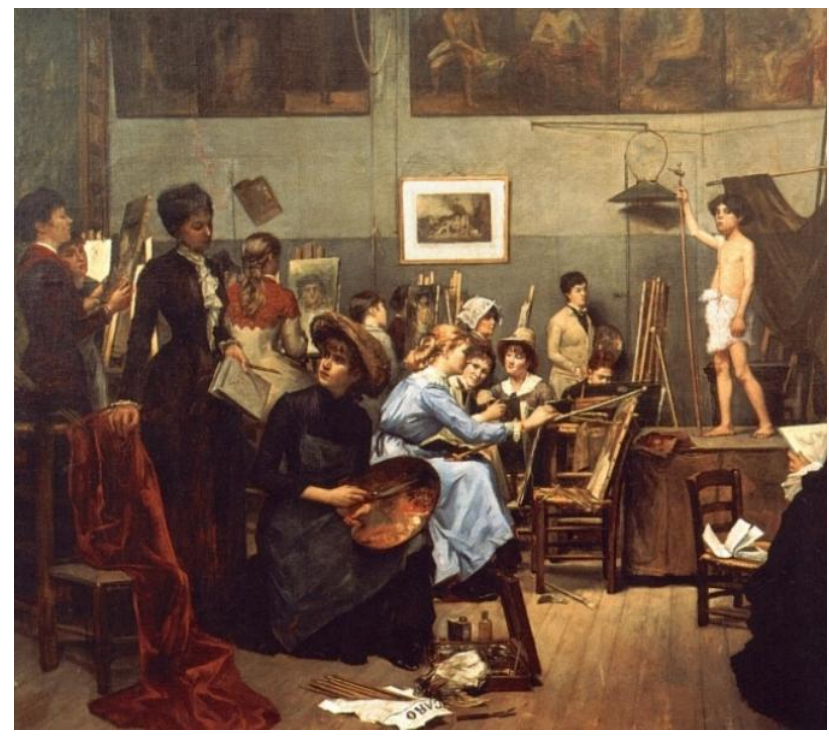

Figure 1 Picture: Dans l'atelier (1881); Marie Bashkirtseff. Piece currently exhibited in the Dnipropetrovsk State Art Museum

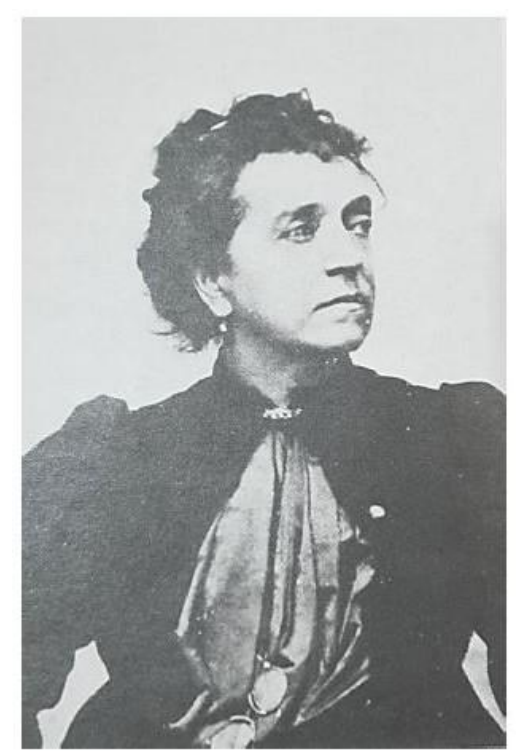

Figure 2 Anonyme-1889-Madame Léon Bertaux (18251909)

By that time France was the main international artistic destination and the claims made by women artists to make visible the work of their female counterparts were notable. In 1905, Maria Lamers de Vits published Sculpteurs, Graverus et Leurs Ouvres, an homage to Hélène Bertaux, the arguable first compilation of women sculptors published, being an antecessor of the feminist compilations of 21st century. According to Birnbaum (2019), in 1904, artist Marie Thelike RideauPaulet founded an alternative all-women artists group besides the UFPS, it was called the Syndicat des femmes artistes peintres et sculpteurs. One of the artists involved, Marie-Anne Camax-Zoegger, founded in 1930 by her own all-women artists group, the Société des Femmes Artistes Modernes 
(FAM), which organised several all-women exhibitions, three of them international and in collaboration with other international women artists' groups. For its eight years of existence, FAM featured the work of more than two hundred female artists from different generations, backgrounds and artistic styles, most of them were immigrants based in Paris. FAM provided support to artists whose work challenged gender stereotypes, race, class and nation (Birnbaum, 2019).

Since the publishing of the influential feminist essay by Linda Nochlin in 1971 "Why there have been no great women artists?", feminist and humanistic researchers are retrieving through investigations, archives, platforms and exhibitions the historically ignored work made by female artists who were part of a culturally established art groups and movements, but who unfortunately, remained in the shadow. For example, in regarding to European avant-garde groups, Katy Deepwell published an article in 2015 called "Narratives of Women Artists in/out of Vorticism" on Women Futurists and Women artists influenced by futurism, inspired by Lucia Re's influential essay Futurism and Feminism (1989). Both authors retrieved the female figures of Futurism and its notable contribution to the movement, such as Valentine de Saint-Point, Enif Robert, Maria Ginanni, Irma Valeria, Rosa Rosà, Benedetta and Marinetti Mina Loy. This last one wrote in 1914 a Feminist Manifesto, described as a "feminist-futurist-woman", and "one of the greatest and most influential among the experimental writers of the twentieth century" (Re, 2009). There are publications like Ulrike Müller's Bauhaus Women (2009) that exposed the situation of women in the Bauhaus schools. In other cases, like Spain, the group of women artists, poets, actresses, sculptors and writers within the Generacion del 27 that was not recorded in literature books until recently, has been named Las Sinsombrero ${ }^{29}$.

\footnotetext{
${ }^{29}$ See the project Las Sinsombrero available at <https://leer.es/proyectos/las-sinsombrero >
} 


\subsubsection{Biblioteca Popular de la Dona}

Due to socio-political reasons, Spain remained outside the international women's movement and the transnational women's organisations until late in the $20^{\text {th }}$ Century (Rupp, 1997). However, one can find numerous examples of all-women initiatives that promoted culture, art and education for women with a strong social commitment. That is the case of the first library dedicated to women in Europe and one of the first worldwide, founded in 1909 by Francesca Bonnemaison in Barcelona, the Biblioteca Popular de la Dona, today called Centre de Cultura de Dones Francesca Bonnemaison. (Llinàs Carmona, 2008, p.19). The library was in fact a self-organised institute, founded and managed by and for women, addressing specially working-class students, its objective was the inclusion of women to the job market in old and new emerging types of profession, in order to enable them to achieve economic independence. To do so, they promoted artistic, technical and scientific knowledge to women, with a wide range of specialties from music, art, business, photography, dressmaking, technical graphics, gymnastics, among others. The institute organised both theoretical and practical activities including workshops on artistic industries skills, inspired by the Arts and Crafts formats in Europe, providing job scholarships (Ajuntament de Barcelona, 2014).

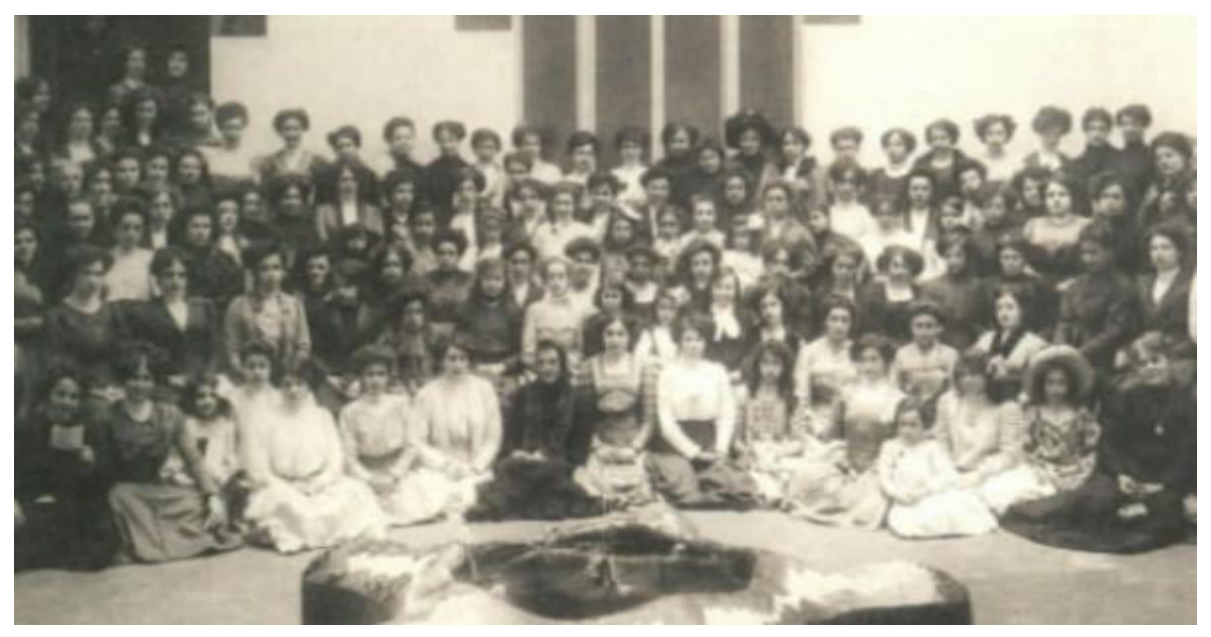

Figure 3 Image of the students of Biblioteca Popular de la Dona circa 1914. Source: Beteve.cat 
Bonnemaison, a conservative bourgeois woman, created a space which became "un espacio de sociabilidad femenina interclasista [...] enclave emotivo, como espacio simbólico para diversas generaciones de mujeres" (Plana \& Vergés, 2015):

El movimiento promovido por las mujeres conservadoras se constituyó en un agente educador y dinamizador de la cultura femenina. Y se convirtió también, desde estas premisas, en un instrumento de emancipación femenina, ya que supuesto la ruptura con los presupuestos pedagógicos de las primeras décadas del siglo XX, que limitaban el acceso a la educación de las mujeres en congruencia con el discurso de la domesticidad / esposas, madres y amas de casa/ y facilitó su formación profesionalizadora (p.133).

To my understanding, this is an early predecessor of my contemporary case studies community basedspaces $^{30}$, and associations ${ }^{31}$. Contrary to most of our case studies members ideology and like other initiatives by the end of $19^{\text {th }}$ Century and beginning of $20^{\text {th }}$, conservative and bourgeois female personalities founded la Biblioteca Popular de la Dona.

\subsubsection{Lyceum Clubs}

Along the first two decades of $20^{\text {th }}$ Century, a model of artistic and cultural space appropriation spread along Europe: The Lyceum Clubs. Intellectual and artistic women of the contemporary societies formed these spaces: poets, actresses, activists, scientists, educators, artists, writers, etc. The Lyceums provided spaces in the European capitals for cultural encounters, exhibitions, conferences, courses and others. The first one in London, was founded in 1904 by Constance Smedley. Later, others were founded in cities like Berlin, Paris, Brussels, Roma, Stockholm, Milano, Florence, The Hague, Innsbruck, La Havana, Madrid and Barcelona (González, 2011). The one in Madrid was opened in 1926 by Carmen Baroja and directed by María de Maetzu during the dictatorship of Primo de Rivera

\footnotetext{
${ }^{30}$ See section 3.4 .7

${ }^{31}$ See section 3.4.6.
} 
and was very controversial in the society of that time. Detested and criticized by the conservative side of their societies, these lyceums flourished in their cities as all-women spaces of creative resistance at the intersection of arts, science and culture, were intellectual men took part actively in their program.
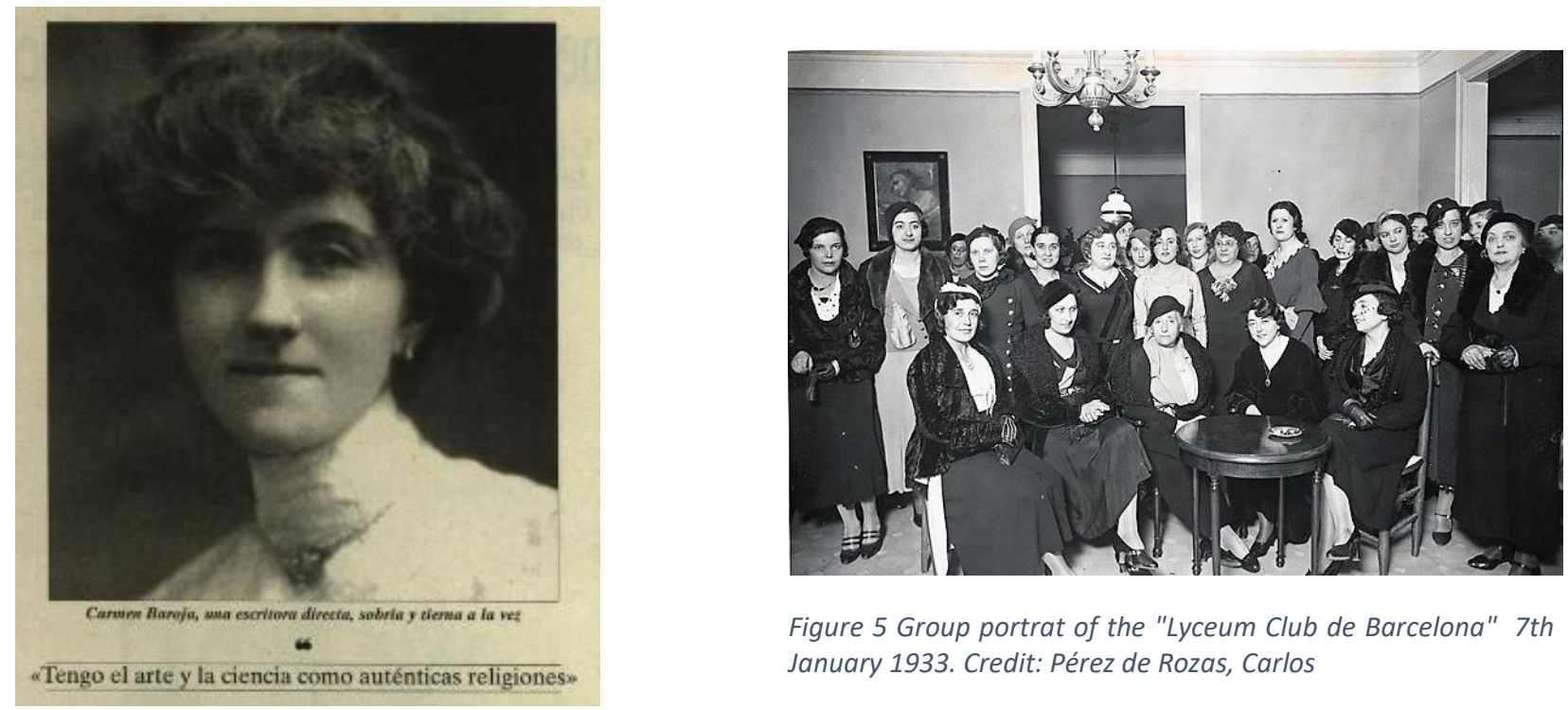

Figure 5 Group portrat of the "Lyceum Club de Barcelona" 7th January 1933. Credit: Pérez de Rozas, Carlos

Figure 4 Carmen Baroja in Revista Pergola (Bilbao) VII: "Art and Science are authentic religions for me". Retrieved from www.kachumbambeteatro.com

It is important to note, the outstanding contribution that women activist made regarding women's rights in Spain during La Segunda República (1931-1939), the numerous projects, associations and initiatives that were dedicated to women's education ${ }^{32}$, achieving egalitarian and democratic rights that many Western countries would not experience until decades later (Perez Galan, 2000, p.317). The first year of the República, the Lyceum Club Barcelona opened in 1931 but like the one in Madrid, it closed with the end of The Spanish República in 1939 and the beginning of The Spanish Civil War.

\footnotetext{
${ }^{32}$ For example, the Asociación Femenina de Educación Cívica
} 


\subsubsection{North American All-Women Art Associations in the $19^{\text {th }}$ Century}

During the $19^{\text {th }}$ Century, in different cities of United States there were numerous women's clubs and associations founded by philanthropist women, born from the critic panorama of women's exclusion from the art world, but also as an attempt for alliance, for local and international women's support, and a way to remain together through the years towards a construction of women's art discourse (NAWA, 2019). Philanthropist and wealthy women like the American Elizabeth Mills Reid founded in 1885 women's art clubs like the American Woman's Art Association Paris ${ }^{33}$. Its purpose was to host an annual show for Paris resident artists, who some of them took part of The Woman's Building exhibition -as I will discuss in the following point- such as Mary Cassatt, Mary Fairchild MacMonnies Low and other prominent women artists who helped preside over the club, serving as jurors and officers. Parisian artists and teachers attended the exhibitions, providing valuable critical perspectives and praise (The American Women's Group, 2019). Unlike the French panorama, by the end of the $19^{\text {th }}$ Century many venerable art institutions in United States would allow women to exhibit individually and in groups, however they were neither allowed to request membership neither to be part of the jurying or committees in places such as the Boston Art Club (Vose Frey, 2012, p.2). In this context the still active National Association of Women Artists (NAWA) also named National Association of Women Painters and Sculptors, was founded in 1889 by five innovative north American women who realized that only combining their forces could create an association to confront the discrimination to women artists and erase the stereotype of female artists only related to crafts and decorative arts (Briggs, 1932, p.33).

In this line, I would also like to refer two modern compilations of North American women artists, one of those is the listing of female North American artists from 1867 to 1930 by Julie Graham (1980) American Women Artists' Groups. Another is the one by Karen J. Blair (1994), who in her book

\footnotetext{
${ }^{33}$ See $<$ https://www.awgparis.org $>$
} 
The Torchbearers that was dedicated to female amateur arts associations in America from 1890 to 1930 she stated: "no group of art lovers met more resistance in proving the worth of their work and justifying their cause than the advocates for the visual arts" (p.178). The anachronism of the statement is notorious. In her book she describes how before First World War many women's club were already created as spaces for women and girls as meeting places: for students of arts, cliniques, libraries, summer camps and industrial homes and numerous for welfare purposes (Blair, 1994, p.178). Historian Daphne Spain (2016) has published several works on the influence of women's associations in the urbanistic and spatial development of the North American cities, reflecting how "numerous historians have revealed the role of women as city builders during the late nineteenth century, while others have focused on women's participation in the public sphere" (p.12). In the United States of America women associationism was strongly manifested through the social movement called The Woman's Club Movement, focused on women's responsibility towards public policy -the second phase of this movement was started by African-American women (Appleby et al., 2015, p.455).

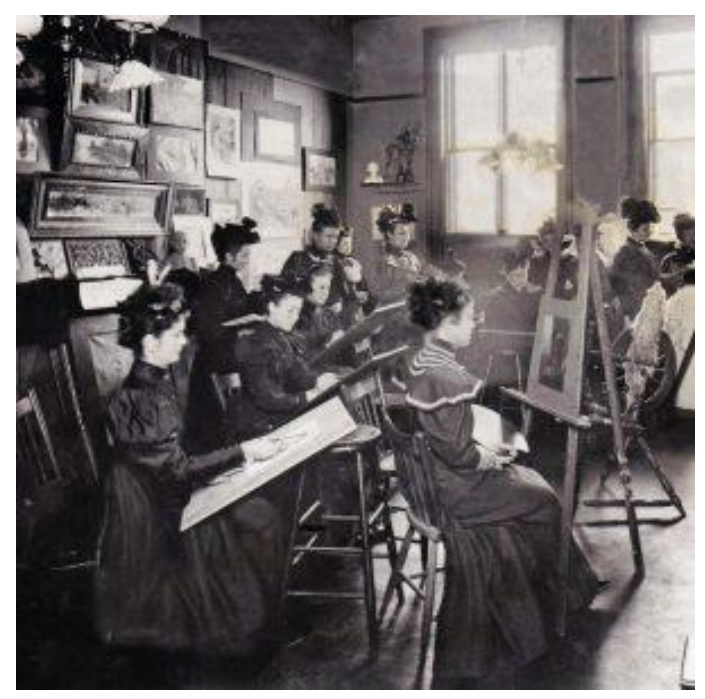

Figure 6 An early studio session of The Women's Art Association of Canada, circa 1887.

Continuing with segregated spaces, the city that exemplifies this is Chicago, known since the end beginning of $19^{\text {th }} \mathrm{C}$. by its numerous women's associations related to arts, humanities, welfare, women's health, etc., many of them still on going. Other women art groups and associations were The 
Woman's Art Club of Cincinnati ${ }^{34}$ founded in 1892 by nineteen women artists in response to the discrimination suffered by the Art Club of the city and which is active until today; The Women's Art Association of Canada ${ }^{35}$, founded in 1887, which in 1893 affiliated with the National Council of Women.

\subsubsection{International All-Women Exhibitions}

The first international exhibition of Art and Science (and technology, if we consider the techniques implied for arts and crafts) by women, with multiplicity of disciplines gathered, was The Woman's Building, organised within the framework of the outstanding international cultural fair on the celebration of the assumed Columbus arrival to America in 1492, named The World's Columbia Exposition, that took place in 1893 in Chicago. The exhibition run for six months and was visited for more than twenty-five million people from international origins (Navarreta, 1982). Within the complexity of neoclassic buildings that were designed and built for the event, one was dedicated to women: The Woman's Building, conceived by Susan B. Anthony as a reaction to the absence of women from the Fair's planning board. The plan was inspired by the previous prototype at Philadelphia the Centennial Exposition Woman's Pavilion in 1876 (Navarreta, 1982). It was organised and managed by a group of north American women, the Lady Managers, members of philanthropy groups, the suffrage movement, education and arts. The building plan was designed by the first woman to graduate in architecture in the Massachusetts Institute of Technology, Miss Sophia Hayden of Boston (Elliot, 1893, p.37). This building and its assemblage signified a women's accomplishments worldwide and helped to galvanize women nationally and internationally (Cox et al., 2018, p.3).

The compilation of articles collected the catalogue by different authors reflect the main bases of the Pavilion programme, claiming the equality between women and men and encouraging and

\footnotetext{
${ }^{34}$ See <http://womansartclub.com>

${ }^{35}$ See <https://www.womensartofcanada.ca $>$
} 
supporting women in liberal and fine arts as in science, by extoling the artistic and scientific values of the international women involved in the fair, retrieving the list of women artists in History (Elliot et al, 1893). The exhibition held pieces from international women artist from different countries, including Spain, England, Russia, Italy, Greece and Japan, Turkey and Algeria, between others, from a wide variety of fields: fine art, illustration, literature, music, science, applied arts, photography, handcrafts, education, etc. Topics like women in American History and a special space for child-rearing and education (Elliot et al., 1893). As I will discuss in the chapter about the transnational women's alliances, the Woman's Building reflected a clear intention of union cross-borders through the organisation of international events that women celebrated in the $19^{\text {th }}$ Century, with an impact in their contemporary culture and economy (Webster 2004 in Cox et al., 2018, p.45). This curatorial project is considered like the first time that women from different activist associations communicated and organised themselves to build up such a fair dedicated to women in arts and sciences internationally. The Woman's Building would be the referent for the name and establishment of the Woman's Building in California in 1973 (Cox et al., 2018). On the other side of the stage, within the general fair, a group of female sculptors was hired during the last construction phase, due to the lack of male sculptors and the quantity of work still required. A group of ten female students of the acclaimed sculptor and professor at the Art Institute of Chicago, Lorado Taft, were accepted to help with the last construction of decoration fair. They were named The White Rabbits (Pohlad, 2018). 


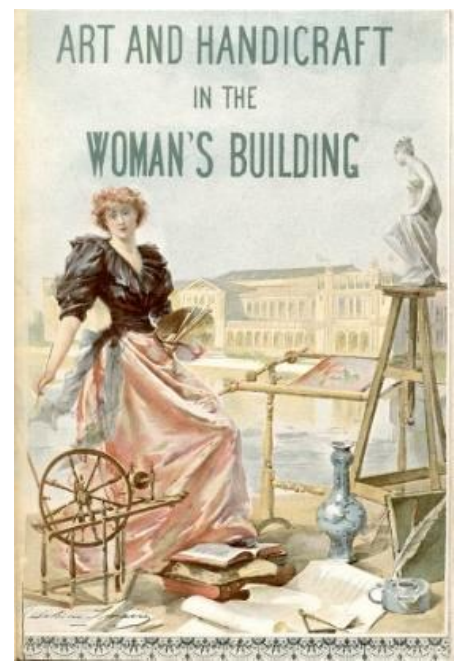

Figure 7 Picture Madeleine Lemaire's poster for poster for The Art \& Handicraft in the Woman's Building

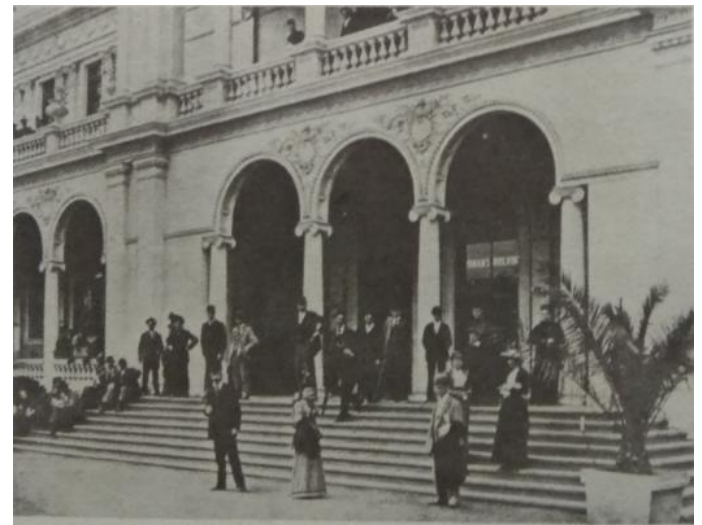

Figure 8 The Woman's Building. World's Columbian Exposition, Chicago, 1893. Retrieved from Navarreta, 1982.

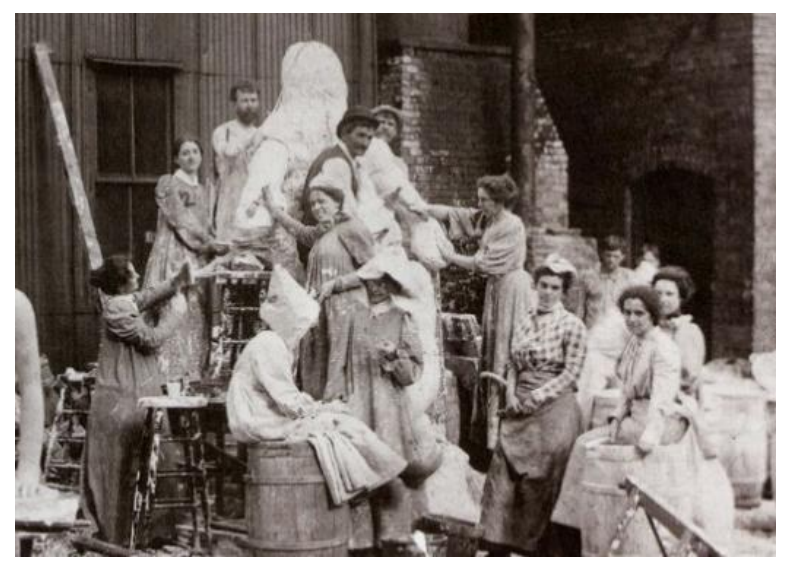

Figure 9 Lorado Taft and several of his female students at work, known as The White Rabbits, circa 1899.

Along the end of $19^{\text {th }}$ century and beginning of $20^{\text {th }}$, exists documentation of all-women exhibitions in North America, such as the Exhibition of Women Printmakers in 1887 in Boston or the Exhibition of Sculpture by Women in New York in 1910. Before starting the following chapter ubicated in the 1960s, I refer to Cynthia Navarreta's (1982) words to clarify that the gap between this period and the following "does not mean that there were no exhibitions in between" following an initial phase of elitist group's shows, “women's organisations did continue to mount 'annuals' and other smaller shows - mostly in their own quarters and attended by their friends, relatives and colleagues. Not until the sixties did the spate of exhibitions in museums begin" (p.23). 


\title{
2.2. Women's Spaces and The women's Movement along the 1960s and 1970s
}

\author{
"As a woman, I have no country. As a woman, \\ I want no country. As a woman, my country is my world." \\ "A woman must have money and a room of her own \\ if she is to write fiction." \\ Virginia Woolf (1929)
}

The women's movement is described as the series of historical phases in western culture when women started to bring their voices collectively in public (Mitchell, 1998), and started to invade in forms of activism the public urban sphere (Spain, 1992). Contemporary scholars like Daphne Spain have demonstrated the way in which the construction of public and private spaces can influence the access to knowledge by men and women (Dear \& Wolch, 1989; Spain, 2016): Massey \& Allen (1984) explain that it is not just that the spatial is socially constructed; the social is spatially constructed too. For example, Daphne Spain investigations show the influence in urbanistic structures in north American cities by the women's movement and activism in the $19^{\text {th }}$ Century and then in the 1960 s and 1970s. The called second wave of feminism during the 1960s and 1970s, is also known as the period where the foundation of feminist art and feminist alternative art spaces took place, together with the spreading of women-only spaces in different cities of Western countries. Some decades earlier, in 1929 Virginia Wolf published an essay titled A room of one's own, expressing the need for a woman writer (and artist) to have a (literal and symbolic) "own space, where the room is the metaphor for the conditions that tallow women to give full expression to their creativity and imagination" (Hajek, 2018, p.82). This statement would become like a manifesto for the second wave feminism to claim sex segregated spaces as spaces of their own to face the historical and cultural women's individual and collective exclusion from the public sphere and private spheres of knowledge in Western societies (Spain, 1992). With the premise of the need of a room for one's own in order to be able to create 
fiction, Wolf's statement would become a cliché, spread around in feminist books, women spaces names, college courses titles, etc. (Wolf, 2013). Since then, feminist literature concerning the space segregation would be based on the sex/gender difference criteria.

One of the most influencing works in feminist history is the work by Simone de Beauvoir, published two decades after, Le Deuxième Sexe (1949), where her final thesis was that any cultural and scientific attempt in history of describing what a woman is or means, has been always done from an androcentric perspective where men is the subject and women is the Other. Inspired by her, after the 1960s the second wave feminists mainly attempted to define what means to be a woman as a political subject from an existentialist perspective. The work by de Beauvoir would be revolutionary, opening the gender studies field based on the distinction between sex and gender and influencing the continuity of the branches of feminism(s), like the ones in regarding the gendered spaces -which spaces are assigned to one gender based on social and cultural roles (Spain, 1992)-, and the one regarding gender, technology and $\operatorname{art}^{36}$.

Talking about feminism in this period means talking about the theoretical and political work of feminists in Western Countries. As the vote and equal civil rights were achieved in most of these countries (in Spain like in Portugal it happened after the dictatorships were over by 1970s), the main groups of radical and difference feminist politics would base woman's liberation in terms of defining themselves from men and creating solidarity and alliance between women (Rendell, 1999). Following de Beauvoir position, the intellectual work by the French feminist Lucy Irigaray in 1977, would continue with this position, arguing from a critical psychoanalytical perspective that the sex differences are not based on equation male/female, being female the non-male, and would encourage women to develop a deeper understanding of their sexuality, proposing "an alternative female symbolism based

\footnotetext{
${ }^{36}$ As I will discuss in the following chapter.
} 
metaphorically on the female genitals, a vaginal symbolism, with a different syntax of meaning" (Rendell, 1999, p.18). These theories would strongly influence the first manifestations of feminist art, the called cunt $\mathrm{rrt}^{37}$ which the third-wave feminist art practices would inheritance, like cyberfeminism and the gynepunks. Moreover, the notions of feminine and masculine started to be deeply discussed since then by many feminist scholars: from historical materialism or psychoanalytic perspectives (Hélène Cixious, Luce Irigaray and Julia Kristeva), the sex differences would be understood depending on the author as the reason for women's oppression due to structures of patriarchy (Shulamith Firestone, Germaine Greer and Mary Daly and radical lesbian feminists), because of capitalism (British feminists), class and race supremacy (Black Feminism) (Rendell, 1999, p.17). The historical context after the IIWW and the spread of new media (TV) was very influential: women were no more needed as labor force in the countries that had been involved in the war, and media propaganda started to encourage the stereotypes of ideal house wives $^{38}$. This situation created a female collective feeling that Betty Friedman effectively described as "the problem with no name" in her book The Femenine Mystique in 1963. This work gave the language to identity the issues in relating the limitation of women to spaces, to claim again the access to the workplace, and it would extremely influence women in the United States in the 1960s and then in Europe (Stephanie Coontz in Spain, 1992, p.33). Later, another outstanding referent for feminist activism and art was the Fluxus member Kate Millet, with her statement "the personal is political" she argued that differences between sexes creates forms of sexual politics and asymmetrical power relations which "resulted in the control of women through indoctrination and violence" (Rendell, 1999, p.17). In addition, black feminists and lesbian feminists would emphasize concepts of sexuality, social class and race (p.17).

\footnotetext{
${ }^{37}$ Concept explained when discussing feminist art and the Woman's House

${ }^{38}$ See chapter 2.2 .
} 
The second wave feminism coexists with and within the hippie movement, where universal concepts of fraternity were spreading in society through art and music along the 1960s and 1970s. For feminists, the concept of sisterhood was again retrieved -like it was in the so-called first wave-, thanks to relevant works like Robin Morgan's Sisterhood is Powerful from 1970. The concept of sisterhood for Morgan's would encourage a universal alliance of women based on the sex identity, as women in the first transnational alliances aimed to achieve (Rupp, 1997). This, together with the claim for a room for one's own and the theoretical and political framework of women's liberation (sex differences, women and gender representation in media, history and culture, patriarchy, etc.) gave rise to an increasing number of alliances by women in different formats of activism and associations (Spain 1992; 2016; Kroløkke \& Sørensen, 2006). Jo Freeman, leader of the Chicago Women's Liberation Union (CWLU) would be a referent for feminist activism, organisations for strategic structures. She believed that natural structures such as the ghetto, the church, the campus or the factory, are key for any social movement to achieve success (in Spain, 1992, p.16). In works like The Women's Liberation Movement published in 1971, she points the negative loss that the country suffered with the $19^{\text {th }}$ Century women's club, which served as communication networks and political structures for educating women. She believed that women-only groups and consciousness-raising workshops as material critiques that started to be established towards finding the differences of women from men, at the physical and emotional level (Rendell, 1999, p.15), were the equivalent of those that took place in the first wave (Spain, 1992, p.16). The above quoted work by Daphne Spain describes the influence of women's movement and civic independence through women and feminist spaces in the urbanistic shaping of metropolis (p.11). Specifically focused in North America, Spain (2016) states:

By 1986 about one-half of women and men believed that wives should care for the home while men earned a living outside it. Such significant social change required feminists to create places where women could learn to demand it. A long line of social movements set the example. The 
abolition, suffrage, temperance, settlement house, and civil rights movements all changed the use of urban space. The Second Wave was next in line (p.26).

Spain (1992) explains that besides the women's clubs or the segregated colleges, until 1970s women had a few places outside the home to gather separately from men in United States (p.12), as happened similarly in Western Europe. Due to the theoretical influence of the abovementioned feminists, the different emerging branches of feminists would combine their strategies and methodologies to produce spaces for their daily life, as best example of Henri Lefebvre's theory about spaces and society: “space is an abstract concept lacking materiality or meaning. Lefebvre states that space becomes a place only when it is filled with people, cultural practices, objects, representations, and interpretations. Place can be described as space that is politicized, culturally relevant, and historically specific" (in Spain 2016, p.14).

Spain (2016) explains that some contemporary sociologists distinct the new forms of social alliances to the old as the new are based through sharing a common identity, while the old were based on ideology. She states that second wave feminism would incorporate both (p.25). Thanks to the two major feminist groups, reformers and radical feminists, feminist places would be created in response to gender discrimination and segregation towards forming their own identities (p.13). All-female groups started to meet in feminist spaces, women's homes, places considered free spaces, a concept that I will discuss in the chapter on feminist hackerspaces, meaning a place where women can learn and interact in environments of cooperation on a group identity working on nonhierarchical, collective spirit and responsibility, non-competitiveness and democratic values. As Spain (2016) explains:

Feminist places included features of natural structures, free spaces, and radical democratic spaces: they were spaces in which women mobilized for political action to claim their rights through democratic cooperation. They also combined elements of both exclusion and care (pp.13-52). 
Feminist places, as Spain calls them, were all-women bookstores, clinics, domestic violence shelters, centers, alternative art spaces, ... From all of them, the most important were the women's centers for women together with the movement itself. These spaces provided women a safe environment to explore their sexuality, taking into consideration their economic, marital and job status, by expressing solidarity, getting support and resources, their negative feelings and emotions against men through alternative exercises, contributing to their own autonomy (Spain, 2016, pp.13-52).

\subsubsection{Feminist Bookstores}

Sisterist : sister- ist, adj.: To be sisterist is to recognise and celebrate diversity among women, to work towards a common goal regardless of race, creed, nationality, or sexual preference, to disregard social structures which place women in groups that separate them from each other.

Jane Evershed

If there is an exemplification of space-based community in the feminist activism, those were the feminist bookstore. In North America as in Europe, during the 1970s and 1980s the feminist space that would be crucial for the establishment of a feminist ideology, a feminist vocabulary and the dissemination of ideas cross-borders would be the feminist bookstore, often part of the women's centers libraries (Spain, 1992, p.84). Within it, lesbians and women of color (in United States) played an important leadership (Hogan, 2016). Considered transnational, the feminist bookstore movement "affected the ways feminist literature was distributed outside mainstream and border-constructed pathways" (Hogan, 2016). The collections of the bookstores commonly gathered conferences papers, publications, books, articles, newsletters, and they would generally hold cultural and artistic activities. More than one hundred feminist bookstores created a translocal and transnational network by using the Feminist Bookstore News (FBN) to connect locally and transnationally for thirty years (1976-2000). They were, moreover, the theoretical support for the emerging Women's Studies (Hogan, 2016). The most relevant factor is that they cultivated a strong sense of community for the women locally, while 
a sense of connectivity cross-borders between the different bookstores, universities and organisations. Some feminist qualified this period networking through feminist bookstores "the glory days of feminist community-building [...] Feminist bookstores transformed women's lives, and like women's centers, they created oases for women in vast urban landscapes" (Spain, 1992, pp.93-110). This phenomenon of simultaneous activism between the local and the global would be repeated with the emergence of cyberspace of the Internet (Hawthrone \& Klein, 1999, p.7). Some of the most notable feminist bookstores were: Sisterhood in Los Angeles and New Words in Boston, Toronto Women's Bookstore opened in 1973, Milano Libreria delle Donne in 1974, Librairie Des femmes founded in 1974 in Paris, Librería Mujeres in Madrid and Zaragoza and laSal in Barcelona in 1978, Vrouwenboekhandel Xanthippe Unlimited, in Amterdam in 1976, The Feminist Bookstore founded in Sydney in 1974 and The Feminist Library in Lambeth founded in 1975 (Ventepakamchatka, 2015). Most of the time they were cooperatives, self-organised and self-funded, holding a wide range of activities, since own publications to art exhibitions and live music.

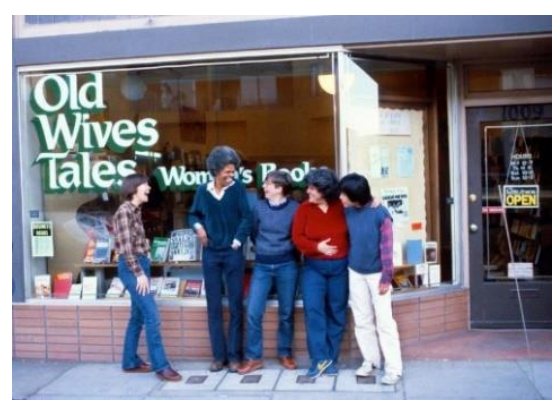

Figure 10 Old Wives' Tales in Valencia 16 Calle San Francisco founder Carol Seajav's. Opened from 1976 to 1995. Source: www.foundsf.org

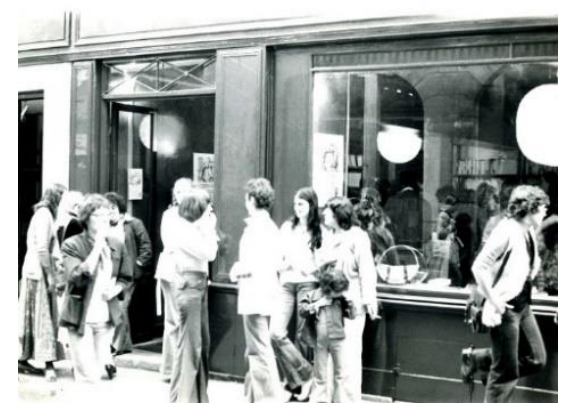

Figure 11 Librairie Des femmes founded in 1974 in Paris. Source: www.librairie-des-femmes.fr

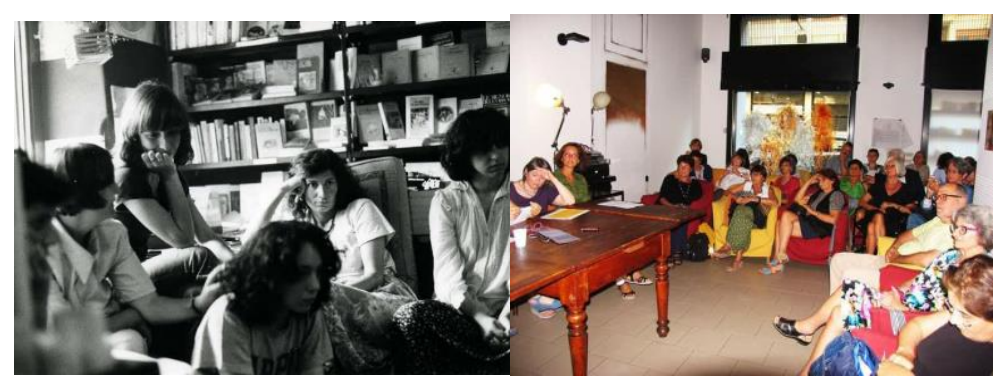

Figure 12 Librerie delle Done in Milan, active with platform, providing resources, creating meetings, social networks, blog, art. Left: circa 1974, Right: photo from 2017. Source: www.libreriadelledonne.it 


\title{
2.2.2. Feminist Art and All-Women Art Spaces in United States
}

\author{
"In the current political climate, feminist art collectives prove a model \\ for collective, activist work that may be the only way forward. \\ As Mary Beth Edelson once said to me years ago: \\ $<$ If you want to get anything done, form a group>"
}

Kathleen Wentrack, 2019

In Western countries the coalition of the women's liberation theories in the art world gave rise to the called feminist art. All the issues that were a topic of concern of the contemporary feminist theoreticians would start to be conceptual investigations, reflections through artistic practices by women artists: sexuality, body, femininity, gender roles, etc. Feminists artists challenged the institutions and the art scene by opening new education programmes for women, alternative exhibitions with lecture and debate activities, women art collectives to support each other's work (Lippard, 1995; Wentrack, 2019), although many of the early founders of these spaces were still in the process of acknowledging what really meant to practice feminism, as the same Lippard stated (2002, pp.100-1). The feminist art was characterized not only by the topics they addressed, but for the new creative methodologies based on environments of collaborative working and alliances that were against the romantic stereotype of male artist-genius so prevalent still by then -and now (Wentrack, 2019). Despite the little historiography regarding women's networks in arts, the fact is that the emergence of a wide range of self-organised and artists-run all-women initiatives such as exhibitions, collectives, associations and galleries in the 1970s helped to shape the women's art movement, and the understanding of feminism in visual arts nowadays (Deepwell \& Jakubowska, 2018).

Although the bibliography on feminist art is notorious, the lack of historical studies of the women's and feminist art collectives generally points as unique referents the North American art groups (Deepwell \& Jabukowska, 2018), which methodologies and strategies have arguably influenced 
other feminist and non-feminist artists groups (Wentrack, 2019). Just to have an overview of the numerous Women's organisations in arts that existed by 1970s in United States, one can consult The Guide to Women's Art Organisations and Directory for the Arts by Cynthia Navarreta, originally published in 1979 a reedited in 1982. It is an excellent documentation of the work of hundreds of women artists' groups (in Visual Arts, Dance, Music, Theatre, Architecture\&Design, Crafts, Film\&Electronic Print Media, Writing) and their proliferation across United States during the 1970s. In curatorial formats, some recent curatorial work represents the influence of this period in all-women art groups, that was the exhibition curated by Carey Lovelace at the Bronx Museum of the Arts in 2008 called Making it Together" 39 Women's collaborative Art+Community: "the exhibition explores an important chapter in recent history when women artists, inspired by the 1970s Feminist Movement, worked collectively in new ways to engage communities and address social issues" (Lovelace, 2008). Other attempts to map an international view of feminism with notes on international alliances have been Cornelia Butler's WACK! Art and Revolution (MOCA 2007 and MoMA 2008), Marua Reilly's Global Feminisms (NYC and London, 2007, Paris 2009-10), elles@centrepompidou in Paris 20092011, and the one curated by Gabriel Schor Feminist Avantgarde: Art of the 1970s (Munich, 2015).

Due to the male dominance in the art world and the exclusion of women in the art galleries and exhibitions, many feminist and women-only art studios and spaces were opened, also many associations were established during the 1970s and 1980s (Lippard, 2002, p.95-7). One of the most influential feminist art text was "Why there have been no great women artists?" by Linda Nochlin published in 1971, which title was a response to the classical art professor statement: "There are no great women artists and never will be" (Lippard, 1973). Nochlin "exposed the idea that greatness had been defined since antiquity as white, Western, privileged and male, and she wondered how to redefine it to include non-white and non-Western artists, the unprivileged and women" (Diaz Ramos, 2016,

\footnotetext{
${ }^{39}$ Available at <https://www.careylovelace.com/CLWomenCollaborative.htm>
} 
p.17). From this essay, Nochlin started to retrieve the work by women artists hidden in art history through all-women exhibitions, the first international showcase of art in these terms was in 1976, cocurated with Ann Sutherland Harris, with eighty-three artists exhibited from twelve different countries within the timeline 1550-1950 under the title Women Artists ${ }^{40}$. Another branch of research and activism empathized in the contemporary female artists and one of the key feminist scholars in art Lucy Lippard stated in her article in defense of separate women's art published in 1973: "the most obvious manifestation of discrimination in the art world has been the absence of women's work from major galleries and museums." The article pointed out the absence of female referents, providing data from 1973 in US: $75 \%$ of the undergraduate students in American art schools were female, and approximately $98 \%$ were male instructors. "While the women are tolerated in the housekeeping positions (curator, critic, dealer), the primary function of artmaking is reserved largely for men" (Lippard, 1973). To the critics against segregated spaces and exhibitions which stayed that "art has no sex, art has no color", Lippard (1973) claimed: "Art has no sex and color, but artists [sic] do", therefore segregated spaces and women art magazines were and will be necessary. Feminist historians Rozsika Parker and Griselda Pollock (2013) would define this women's tactical as a "collective effort to provide their own supportive network as immensely important, widening the possibilities of work for many women" (pp.134-35) ${ }^{41}$. Lippard was one of the founding members of the Ad Hoc Committee of Women Artists, founded in 1970 and she focused on addressing the under-representation of women in the Whitney Museum' Biennial. Other members like her were part of Women Artists in Revolution (WAR), the Art Workers Coalition (AWC) and Women Students and Artists for Black Art Liberation (WSABAL), these organised groups by women artists made public art museums a visible target for

\footnotetext{
${ }^{40}$ Available at <https://www.brooklynmuseum.org/opencollection/exhibitions/950>

${ }^{41}$ This strategy, however, has been criticized by many feminist and non-feminist scholars as risky to remain the work in isolation, at the periphery of the cultural scene, far from a larger dialog of transformative change (Cox et al., 2018). This is the controversy or the women-only or segregated spaces even today in virtual communities or emerging organised networks (as we will see in future chapters).
} 
their demands, by gathering in front of museums like MOMA and Whitney in New York (Diaz Ramos, 2016, p.17). WAR was the first women's group to get mad at the AWC's mostly male leadership. Alternative art spaces were creating new ways to make the artwork visible to curators and artists beyond the galleries, one of the first women's alternative space and workshop was in the Women's Interact Center, emerged from WAR, in New York. (Lippard, 2002, p.100) The registry idea caught on and is still used across the country in various contexts as a way for unaffiliated artists to make their work visible to curators and critics (to no longer depend solely on galleries that excluded women, artists started showing their art in alternative spaces). The first women's alternative space and workshop center in New York, the Women's Interact Center, began to emerge from WAR in July 1971. That same year, Lippard organised the first women's museum exhibition from the second wave of feminism at the Aldrich Museum of Contemporary Art in Ridgefield, called Twenty Six Contemporary Women Artists. Together with Judy Chicago and Miriam Shapiro, Lippard started WEB (West East Bag), an international network of east and west north American women artists, "encouraging the creation of slide registries and protests against institutions in other cities”. (Lippard, 2002, p.101). Other collective forms were organisations, exhibitions, magazines, and alternative spaces such as Women in the Arts, the Feminist Art Journal, and Women Artists' News. Other exhibition spaces and women's co-op galleries were Las Damas de Arte (1971 to present), the oldest women's art collective in USA (Wentrack, 2019). Lippard (2002) also supported the publications made by artists were and "still are important not only for their content and educational information but also for he networking they generate." (p.101) 


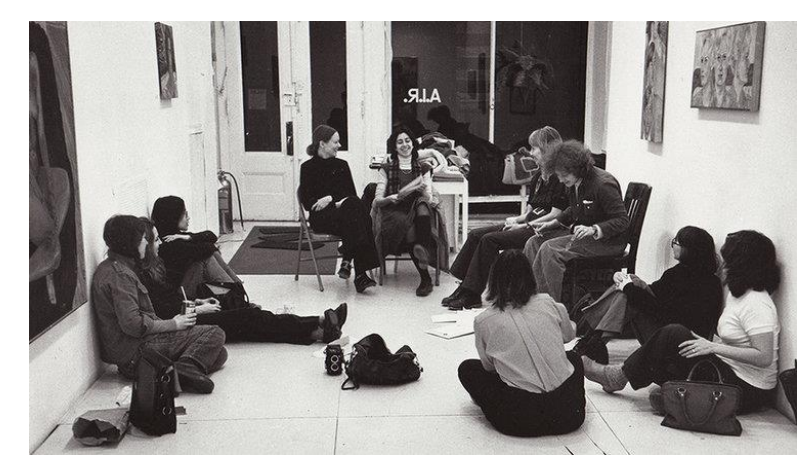

Figure 13 A.I.R's first gallery on 97 Wooster Street, 1974. Pictured from left to right: Rachel bas-Cohain, Joan Snitzer, Kazuko Miyamoto, Blythe Bohnen, unidentified, Daria Dorosh, Laurace James, unidentified, Dotty Attie, Anne Healy. Retrieved from www.airgallery.com

Some of the first exhibition spaces for and by women in the USA were the A.I.R. Gallery ${ }^{42}$, founded in 1972 as a non-profit women's cooperative gallery in New York, in 1973 supported by its same artists network, that has been relevant in the career of women artists such as Ana Mendieta (A.I.R, 2017). SOHO2O was a feminist alternative art space founded by twenty women artists in New York that today continues to provide opportunities to artists through exhibitions and public activities, and Artemisa in Chicago (1973-2003), city with a notable background in alternative art spaces and women centers (Wentrack, 2019). Also, Women Art Registry, a slide collection founded in response to the statement "there are no women working in kinetics, or light, or conceptual art" (Lippard, 2002, p.101). Other all-women art spaces in USA were ARC Gallery (1973-present), Sapphire and Crystals (1986present), and Woman Made Gallery (1992-present), in the legacy of the $19^{\text {th }}$ Palette Club (1880-2003) and the Century Women Artists' Salon (1937-1953) (Gardner-Hugget, 2018).

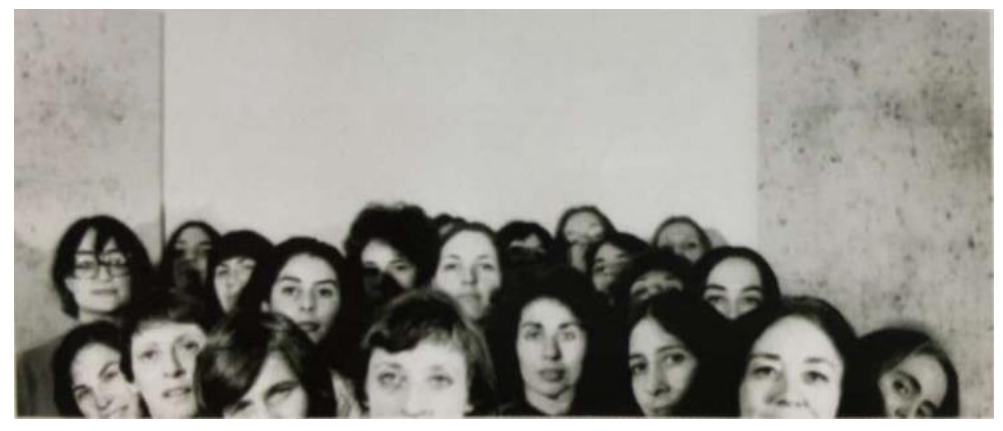

Figure 14 SOHO2O members in 1976, photo credit: John Waggaman / SOHO2O archive

42 See <https://www.airgallery.org> 
The first feminist art education programme focused in establishing a new feminist art pedagogy and methodology bases took place at Fresno State College in 1970 in California's San Joaquin Valley, under the direction of the feminist artist Judy Chicago. Fifteen female students had their own space to create feminist artwork through experimental practices without male interference, claiming an intellectual, emotional and creative space for them:

By taking ownership of the studio we demonstrated in real life Virginia Woolf's dictum that in order to be artists, women need to claim a space in which to think and work, locking the door against the domestic demands of the home and the patriarchal precepts of the university (Meyer \& Wilding, 2010, pp.40-1).

Meyer and Wilding (2010) described that through group discussions, based on the feminist consciousnessraising, the students produced and conceptualized artwork collectively, developing "female imagery and production techniques to communicate female content through conceptualizing and producing artwork collectively, and developing”.

The main pedagogical strategies developed with gender as central concept, was the representation of female body and sex, called cunt art $^{43}$, and a search for new media like video and film-making for performance art. Judy Chicago would promote the use of new media like video, as for her it didn't carry the same cultural baggage as more traditional art forms as female media, or the use of experimental female media, “Women's Work, from dress-making to film-making” (Meyer \& Wilding, 2010, pp,44-7).

\footnotetext{
${ }^{43} \mathrm{We}$ will see the influence of this in the early cyberfeminist art groups in chapter 3.2.
} 


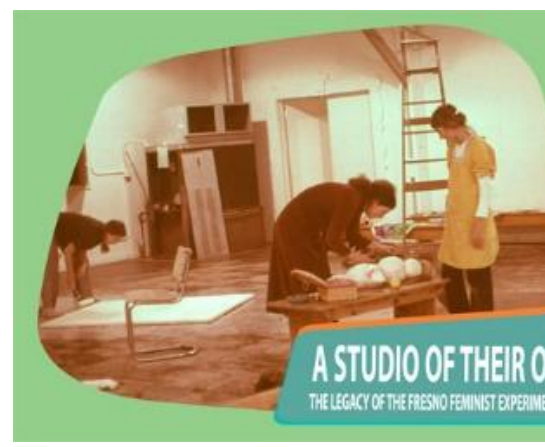

Figure 15 Photo Credit: Detail from Members of the Fresno Feminist Art Programme at work in the feminist studio, 1970. Photograph by Dori Atlantis.

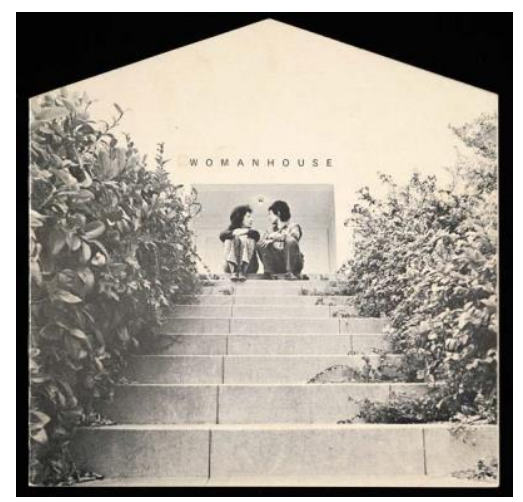

Figure 16 Womanhouse catalogue, Feminist Art Programme at CalArts, 1972. Designed by Sheila Levrant de Bretteville. The Getty Research

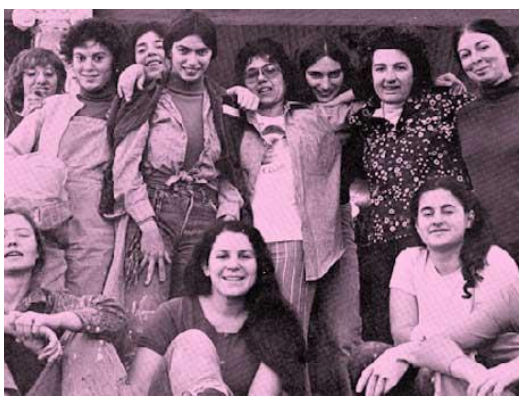

Figure 17 Woman House students 1972, available at

http://home.refugia.net/portfolio/wo manhouse

The pedagogical principles of Fresno on experimental and collective exercises influenced the new feminist art programme CalArts that Chicago co-founded by the end of that year with the artist Miriam Schapiro, in which where most of the Fresno students were accepted, bringing the techniques and methodologies from Fresno with them (Meyer \& Wilding, 2010). The artistic projects were exhibited in the month-long exhibition the Woman's House in the Womanspace gallery (1973-1974), that was part of the programme of activities in the Woman's Building. The Woman's Building was founded in 1973 by different feminist artists of the country in honor to the Woman's Building ${ }^{44}$ in Chicago in 1893.

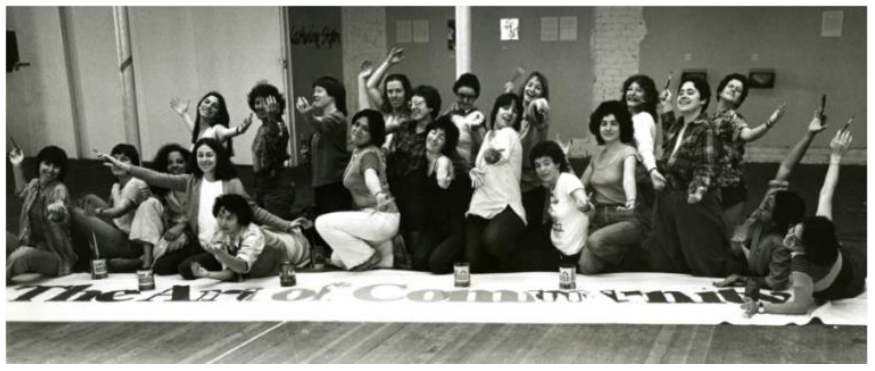

Figure 18 The Art of Community, The Woman's Building Class, Copyright (c) the Woman's Building, 2016

\footnotetext{
${ }^{44}$ The building was active until 1991 and until today its online open archive. See $<$ https://thewomansbuilding.org>
} 
The building, dedicated to serve as a public center for women's culture, was a reaction to the Los Angeles Country Museum of Art's (LACMA) that in 1970 held an exhibition called Art and Technology, which included sixty male artists and no woman (Spain, 1992, p.9). Additionally, , in ten years period, from eighty-one single showcases in the LACMA, only one was from a woman (Wolverton, 2002, p.xv). Chicago, Shapiro, Arlene Raven and Sheila Levrant de Bettreville founded the Woman's Building, offering a public center for formation in creative writing, graphic design, printing arts, performance art, video and visual arts (Wolverton, 2002, xv). The group of artists women formed from the LACMA was the LACWA, the ad. Hoc L.A. Council of Women Artists, that issued a manifesto/report protesting for the absence of women and the sexism in the art institutions, exposing the quoted data and further. They set a precedent of the women artists activism in the $20^{\text {th }}$ century. The building housed galleries, print shop, a branch of Sisterhood, Bookstore, offices, a restaurant, and the most important: The Feminist Studio (Spain, 1992, p.9).

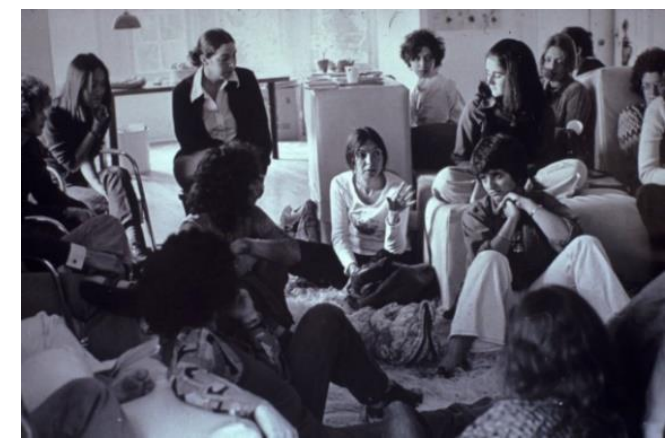

Figure 19 Feminist Studio Workshop in 1973, from "!Women Art Revolution". Credit: Sheila Levrant de Bretteville / Zeitgeist Films

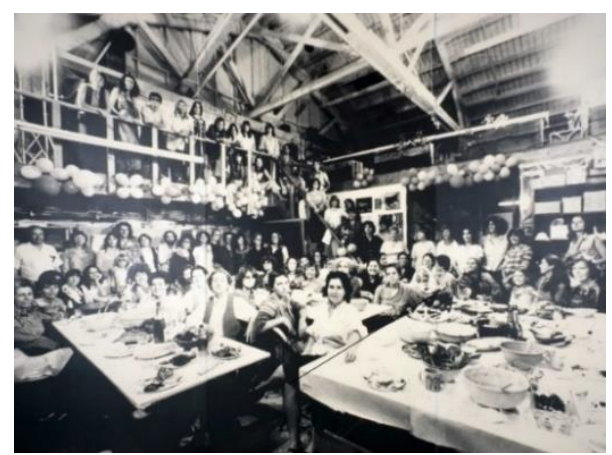

Figure 20 Judy Chicago's 39th birthday dinner in The Dinner Party Studio. Source: https://judychicagocollaboration.org

Community building activities happened daily in the Women's House, for instance as reading and debate groups, one to note regarding my case studies are the weekly group dinners held every Wednesday, called The Dinner Party Studio, where Chicago was preparing her 
influencing artwork The Dinner Party (1974-1979). Faith Wilding related the coming third-wave feminist alliances and groups practices to this period, she described these memories ${ }^{45}$ :

We organised the big kitchen for studio dinners, and to sustain ourselves during the long days we spent in the studio. Iloved the kitchen with its large central wooden table where our Wednesday nightdinners were held. There was a wooden keg of wine we would take to a local winery for periodic refills, and always coffee and tea - there were always small groups of us hanging in the kitchen talking nineteen to the dozen. We took turns cooking dinner on a $\$ 10$-dollar budget limit for feeding about seventeen people. Wednesday night dinners became a $\mathrm{n}$ immediate tradition welcomed by some and feared by others. (Wilding \& Meyer, 2010, p.26)

Also in California, in 1979 was founded The Women's Building in the Bay Area in San Francisco (Navarreta, 1982, p.5), a colorful non-profit space that gathers artistic and other events still ongoing today.

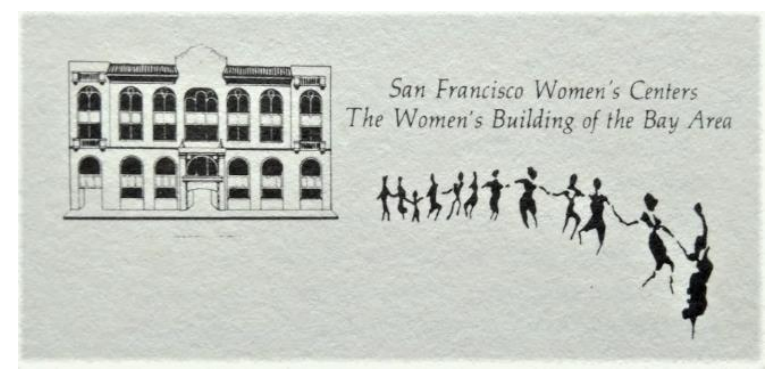

Figure 21 Initial logo Image of San Francisco Womens Center. The Womens Building of the Bay Area. Retrieved from Navarreta, 1982

\footnotetext{
45 This point is related to 3.3.5 and the legacy of all-women dinners for networking and community building.
} 


\title{
2.2.3. 1970s- All-women Art Groups in Europe
}

\author{
"One of the most interesting events of recent years seems to me \\ to be the advent of a movement that is gradually spreading in \\ France in the form of more or less large groups of women \\ artists who are determined to come out of their double world: \\ isolation as women and as artists."
}

Aline Dallier-Popper, Le Mouvement des femmes dans l'art, in Opus International, n66-67, Paris

Despite the contemporary postmodern theories that attempt to escape from a lineal dominant and hegemonic perspective for the description of history, "feminist art history does not appear to have fully escaped the historiography of modernist art history that today is challenged by more horizontal approaches to cultural expression" (Öhrner, 2018, pp.47-8). Due to a combination of socio-political and economic reasons that have contextualized the position of the art production in the United States after the Second World War, a disparity of bibliography regarding feminist art and all-women groups from East and West coast of US eclipses the initiatives that existed in Europe and other parts of the world. There is a notable scholarship in print available made in and about the US art groups due to the proliferation of English print publications, compared to other feminist works made in other languages, and it became the principal point of reference for research on feminist art in other parts of the world: "one would get the impression that the all-women exhibitions that occurred during the 1970 s took place almost solely in the US, and nothing else existed, because no one thought it significant enough to write about" (Deepwell \& Jakubowska, 2018, p.2). A recent publication edited by two historians, British Katy Deepwell and Polish Agata Jakubowska (2018) compiles a list of essays that explores a series of all-women self-organised initiatives in art that occurred in different parts of Europe during the long 
1970s and the turn into the 1980s, its relation between them and the different approaches to feminism they held, considering its diversity and the complex socio-political and economic context. Both authors outline the problematic of travelling feminism ${ }^{46}$ when analyzing transnational feminism intersections with local and global concepts regarding modernism and globalization theories in academia, in addition to the dominant place of the English language in these discourses. With the compilations of essays by different European historians, Deepwell and Jakubowska (2018) have questioned the common assumption that "feminism was initiated or innovative solely in the USA and was exported to Europe" (pp.1-2). Some of the all-women exhibitions described were born from and against the UN International year of Women in 1975. Additionally, there was a general feminist political movement that was part of the counter-cultural movement after 1968 (Deepwell, 2018, p.73). The compilation of all-women initiatives exposes the wide range of formats that emerged in that period: from art spaces to festivals, ephemeral events, exhibitions, art projects, conferences, etc. The contributions in the book reflect the two main networks of exchange by women artists and writers in Europe: one across the north-western part of Europe, and the second in the south of Europe between Portugal, Spain, France and Italy, and communist countries like Poland and Russia in addition.

The Mediterranean network of all-women initiatives had strong ties and developed a deep theoretical and artistic work on feminism, and despite some consideration to the publications by the members of the Libreria delle Donne in Milan, little is recognised by historians from the scene in EuroMediterranean countries. Katia Almerini (2018) has retrieved the cases of two artistic cooperatives that worked as heterotopias (following the concept described by Sauzeau), one in Barcelona, BarBiblioteca laSal, and the cooperative Beato Angelico in Rome. Both were run by women in the middle 1970s, and both were pioneers in experimenting "new forms of creativity developed through empowering women" (Almerini, 2018, p.189). Almerini outlines specially the women's experience on

\footnotetext{
${ }^{46}$ See a recent discussion regarding ‘travelling feminism’ by Margara Milan in The Travelling Gender.
} 
their agency, the strategies of resistance, and the forms they adopted towards a spatial empowerment in both cities. Nowadays, this network of Mediterranean connection has been lost, and most of the bibliography and referents in gender studies and feminist art are from United States, creating a historical disconnection between contemporary feminist activism and its precedents, that in some cases existed before the emergence of feminism.

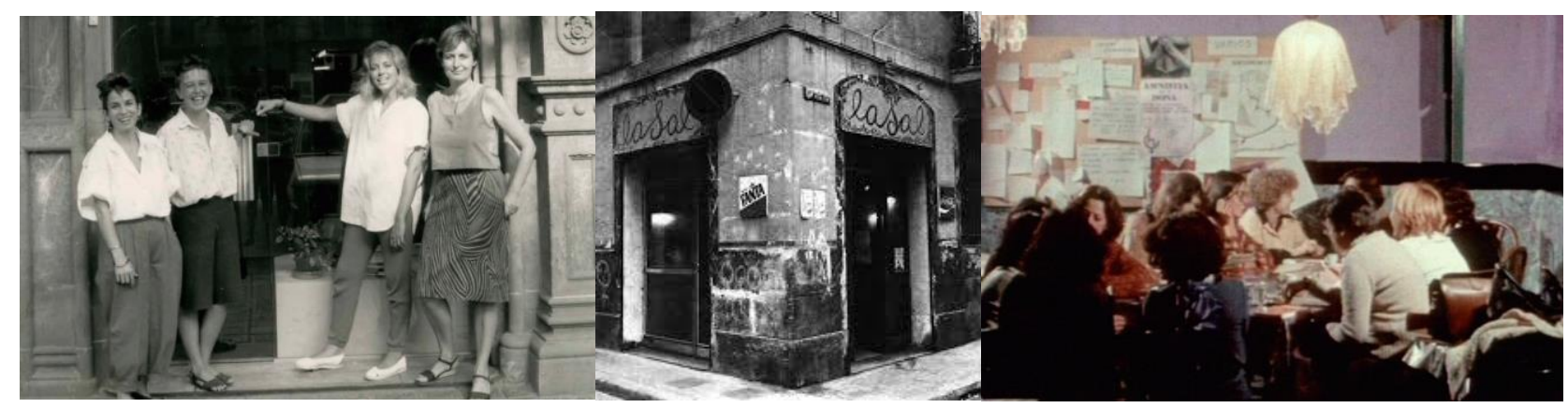

Figure 22 laSal was a women's space for art, Reading circles, meetings, and founded a press editorial itself. Photos circa 1976. Retrieved from http://tiny.cc/eb64iz

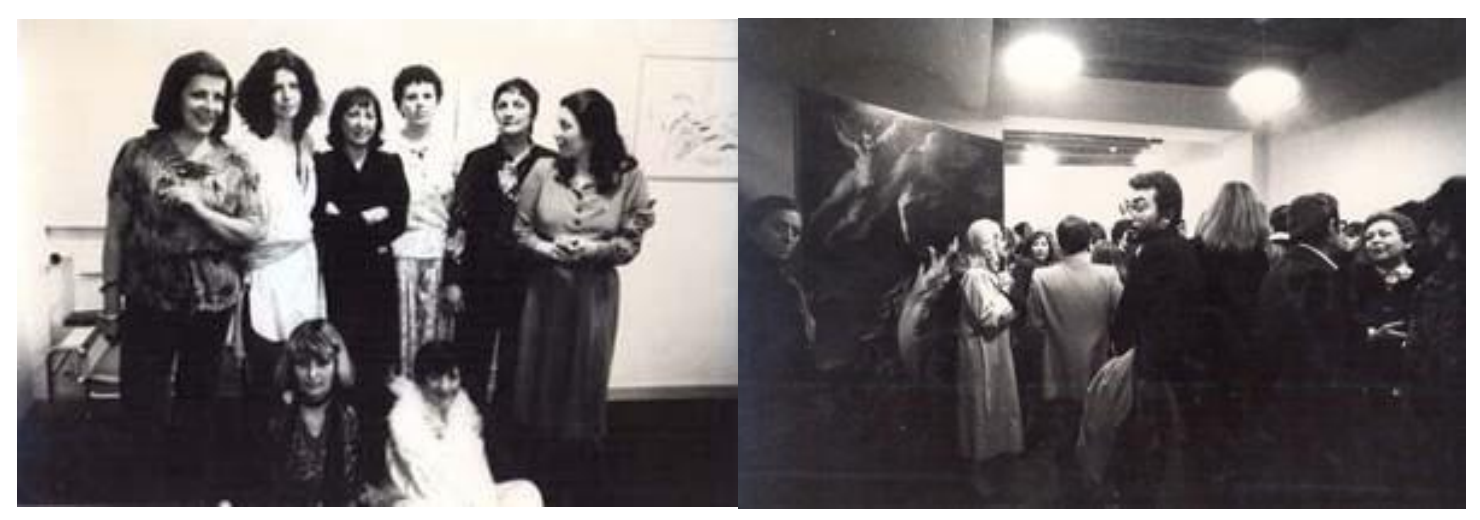

Figure 23 Members from the Cooperativa Beato Angelico opening party at Eva Menzio;s place. Aprile 1976. Retrieved from www.herstory.it

Fabienne Dumont is an historian expert in female artists groups in France. Dumont (2018) talks exposes how a feminist art movement "truly existed in France", in parallel to the social movement, and it was "heterogeneous and dynamic". From the abovementioned UFPS, that was still active, in 1975 the artist Christiane de Castéras founded Feminie-Dialogue, a non-profit organisation with a very active production in the three decades of existence (twelve exhibitions in France and abroad). There were also Femmes en lutte (founded in the UN Woman's Year 1975), Collective Femmes/Art (in 1976), 
and the groups exhibition Utopie et Femisnisme, La Spirale. The group La Vision des femmes (founded in 1978) was the only one that established a space for encounters, workshops, debates, etc. (Dumont, 2018, pp.46-9). Some were more conservative than others, but all of them faced the underrepresentation of women in art institutions: "No longer recognizing themselves in the images forget for them, women artist took their destiny into their own hands and while criticizing women's assignment o particular roles, proposed new images to represent them" (Dumont, 2018, p.49). It is interesting to note, that like in the Californian feminist art scene, textile art was retrieved also in Femenie-Dialogue thanks to Aline Dallier. By then in France there were also ecomuseums, dedicated to exhibit work by social and ethnic groups and its cultural and community traditions (DeRoo, 2004, p.196 in Dumont, 2018, p.49).

Annika Öhrner (2018) denounces the inexistence of the five feminist all-women art exhibitions in the international research and timeline, that happened in Sweden in the 1970s: from Livegen-EGET LIV [Serf-OWN LIFE] presented in 1973 to Vi Arbetar for livet [We are Working for Life] in 1980. Collectively organised by women, with the support of a network of Swedish museums, they demonstrated different approaches as women artists related to the women's movement. Textile art was also present in the art practices in these exhibitions (Öhrner, 2018, pp.47-8). Elke Krasny (2018) studies the feminist Austrian groups such as $\operatorname{InAkt^{47}}$ (International Action Community for Women Artists) that developed $a$ "feminist labor of cultural policy activism, of self-organisation and of maintaining an autonomous self-defined and free all-women art space" (p.97), and the VBKÖ's Archive (p.119). The International Exhibitions Kvindeudstillingen XX på Charlottenborg in Denmark held in 1975 for the UN Women's Year, and the collaboration between the two feminist art groups The Store Group and the Rejsnin group (Kaiser, 2018, p.174).

\footnotetext{
${ }^{47}$ www.intakt-kuenstlerinnen.com
} 


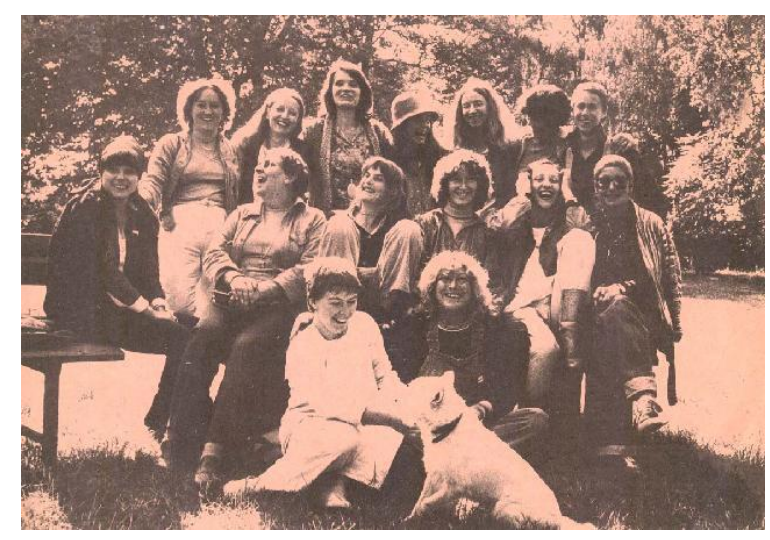

Figure 24 Image of InAkt [Internationale Aktionsgemeinschaft Bildender Künstlerinnen] Vienna, 1983.

A notable amount of feminist collaborative projects occurred in United Kingdom during the 1980s with several organisational forms such as Women Artists Slide Library and Circle (distributing film and video artwork by women) with a network of national women and refugee women, feminist bookstores and libraries in London, etc. (Deepwell, 2019, p.71). The feminist art historians Rozsika Parker and Griselda Pollock were part of the founding members of the feminist group in London called the Women's Art History Collective, a project that worked through women's meeting towards exploring art and gender. The group was formed by women of "all classes, ethnicities, sexualities and geopolitical histories". After the experience in the group, they configured their influential work Old Mistresses: Women, Art and Ideology published in 1981 (Pollock, 2013 p.xxvii), in line with Nochlin's radical call for what Pollock defines as feminist interventions in art's histories:

...that it was insufficient to petition the art historical establishment in museum or university, publishing house or dealership, to correct their skewed and inadequate ideas of who makes art. We need to challenge the entire apparatus and its underlying ideological function that distorts all of our understandings of who we are and who we can be (p.xxvii).

In Western Germany, after visiting the Feminist Art Programme at Fresno in California Institute for the Arts, Ulrike Rosenbach established the Schule fur kreativen Feminismus in 1976 in Cologne, "as a venue for female artists to come together to discuss their work and problems, to address women's 
cultural history and to explore applications for feminist ideologies in creative work" (Wentrack, 2018, p.167). She brought her impressions of the Californian feminist art movement and the community and collective methodologies. She published in 1980 Schule fur kreativen Feminismus: Beispiel einer autonomen Kultuarbeit describing her philosophy and methodologies for a feminist art that she had applied in her school. Wentrack (2018) argues as well, that this and other feminist spaces in Germany have been ignored by general feminist history, "while these efforts functioned as real spaces outside of established patriarchal social structures but also created a shared intellectual space for feminist engagement" (p.167). Wentrack (2018) also talks about the women's group Stichting Vrouwen in de beeldende Kunst [Women In the Visual Arts Foundation, SVBK] formed in 1977 promoting women's experiences through artistic expression and exhibitions and promote their contribution to society in the Netherlands, which established archives, conducted surveys, curated exhibitions, offered courses and supported the research of oral histories (p.167). She describes these two last women's initiatives as utopias, based on the concept developed by Foucault in 1967 in his text Of Other Spaces, where he explained that utopias are 'emplacements with no real space' (p.168).

In countries under a communist regime such as East Germany and Poland, there were allwomen artists groups representing heterotopian modes of artistic and social collaboration, like the Kunstlerinnengruppe (1984-1994) in Erfurt working with film, video and performance (Altmann, p.248) and the series of women's exhibitions that were organised in Poland during the 1970s and other all-women shows in the turn of the $1980 \mathrm{~s}$, that within the communist context ${ }^{48}$ were not related to the women's movement although they demonstrated the results of a cooperative co-working forms of selforganised projects by female artists (Jakubowska, 2018, p.229). In Portugal, after the end of the dictatorship in 1974, there was organised an all-women exhibition called Portuguese Women Artists

\footnotetext{
${ }^{48}$ Many of the women's rights that Western countries were seeking still by the 1980 s were part of the common egalitarian communist system, therefore the feminist movement did not find fertile ground in countries like Poland (Jakubowska, 2018, p.229)
} 
at the National Society of Fine Arts in Lisbon in 1977. Marcia Oliveira (2018) exposes how far from relating its work to the political ideology of feminism, Portuguese women artists in the 1970s developed an avant-garde style more adventurous than their male counterparts, and how they achieved to establish a position in the art world "not only equal to men, but frequently superior to them" (Hatherly in Oliveira, 2018, p.228).

Deepwell and Jakubowska (2018) conclude that the three general aspects all these women initiatives had in common were: to gain visibility for women's issues, to improve conditions for women artists, to create space where women's creativity (and subjectivity) could develop ${ }^{49}$. Unlike the feminist curatorial projects from the 1990s on, these self-organised artists-run projects took place in small and alternative galleries, with occasional local support, without "professional" curator involved:

This reality, the creation of a singular and self-define space where it was possible to realize their own proposal for art, was often the results of a considerable struggle in the face of limited opportunities.... Instead, many of these essays discuss how ideas of women's culture and separatism for women to discover who they are (a definition of self) had considerable value at this time as a proposal for a new future for women as both cultural producers and audiences. These women-only exhibitions were widely understood as providing a visible demonstration of what women could do if they acted together and as offering new perspectives about what art could be (Deepwell \& Jakubowska, 2018, p.11).

Through both the North American and the European all-women artists networks, I can presume an identification of a series of predecessors of my contemporary case studies, despite the unawareness most of the time of the previous work.

\footnotetext{
${ }^{49}$ The two first of these three aspects are common in our case studies, as I will point in the discussion section.
} 


\subsubsection{All-women Art Groups in the 1980s}

Back to the United States, despite a decreasing effervescence of feminism activism (Henry, 2004, p.13) along the 1980s some collectives would inheritance the collective and horizontal strategies from the previous feminist art groups. 1985 was last first year of the UN Decade of Women, but women were still highly underrepresented in practically all art museums in Western countries. The Guerrilla Girls collective was an explosion of rebellion, criticism and radical activism in the art and feminist sphere. Always keeping anonymity under the gorilla mask, since 1985 they have developed all kinds of tactics to address art institutions in United States and recently in Europe, pointing the lack of diversity in terms of gender, race and sexual orientation and the general sexism that most of the art institutions have in their collections. They have also published reports with statistics on diversity in the art world, informing the public about the glass ceiling, edited books, edited posters, etc. (Lippard, 2002, p.97). In the following chapter I will discuss how the digital art world inherited the discriminatory structures of the visual art world, and the numbers that the Guerrilla Girls have been outlining are still repeated in the new media art institutions. Other all-women groups in USA in the 1980s were ${ }^{50}$ : Las Comadres was formed in 1980 by a group of Hispanic artists women, with the objective of "putting together an exhibition on the environment" (Navarreta, 1982, p.16). Susan Bee and Mira Scho founded the journal M/E/A/N/I/N/G in 1986 in response to the changes in the 1980s art world that favored institutional critique and theory to open a space for critiquing the mainstream, patriarchal art world. The genderqueer collective LTTR formed in 2001 to support "sustainable change, queer pleasure, and critical productivity.” The Ridykeulos collective, founded by A.L. Steiner and Nicole Eisenman in 2005 explore their genderqueer, feminist agenda that opens up the category of "women". Other collectives such as Kerr+Malley reacted to specific issues such as the oppression of

\footnotetext{
50 To have a complete list of all the all-women groups in different arts along the 1980s in the United States of America we refer again to the compilation by Cyntia Navarreta (1982).
} 
women and abortion rights while the collective fierce pussy focused on queer activism (Wentrack, 2019).

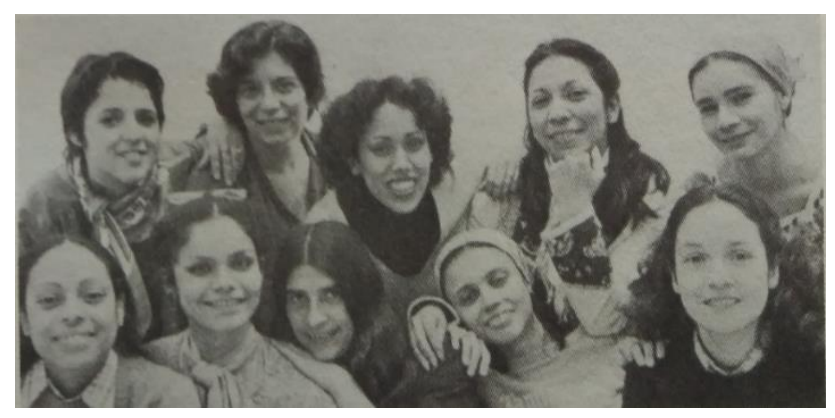

Figure 25 Las Comadres, New York. Photo by Nydza Bajandas. Retrieved from Navarreta, 1982.

\subsubsection{International all-women art exhibitions and organisations}

The abovementioned international exhibition Women Artists: 1550-1950 co-curated by Sutherland Harris and Linda Nochlin, showcased the artwork by female artists in Texas, Pittsburgh and New York. In 1977 it was continued by Women Artists International, 1877-1977, organised by a group of German artists. It was exhibited in Schloss Charlottenburg in Berlin. It included European and more than thirty contemporary American artists, which catalogue had an essay by Lucy Lippard (Navarreta, 1982, p.24).

International all-women organisations that have appeared since then are were: The Women's Caucus for Art (WCA) founded in 1972, together with the College Art Association (CAA), The Women's Action Coalition (WAC) was founded in 1992, and the Women Beyond Borders ${ }^{51}$, founded in 1991 in Santa Barbara, is a grass-roots collaborative transnational association that connects artists, curators, critics and sponsors from all around the world under the theme: "building community as the art form, founded by artist Lorraine Serena". Today it gathers women from fifty countries, it has

\footnotetext{
${ }^{51}$ Available at <https://womenbeyondborders.org>
} 
organised fifty exhibitions, more than nine hundred artists boxes, ten publications, 250 workshops and presentations, and eight thousand students and participants (WBB, 2019).

Regarding WCA, this NGO started during the United Nationals Decade Conference on Women since 1975, which members, leaded by members Nancy Cusick and Cynthia Navarreta, participated in all the UN conferences, including the conferences in 1980 and 1985 in Copenhagen and Nairobi (Bowie, 2019). For the occasion of Copenhagen, they celebrated the registered as the first international conference of women artists in Carlsberg Glyptotek Museum from $14^{\text {th }}$ to $30^{\text {th }}$ July. Women from all different disciplines gathered together to enjoy a programme of panels, performances, readings, films, videos and exhibitions (Navarreta, 1982)

\subsection{HER STORY - Women in Computer Arts}

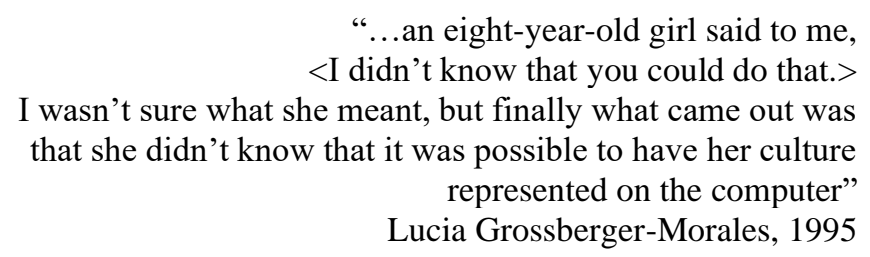

\subsubsection{Women in Computers}

Talking about women in digital arts means to talk about the history of women in computer art, originally called cybernetics, which history cannot be separated from the social and political context. As Christian Paul (2016) says, from virtual reality to the Internet: "the technological history of digital art is inextricably linked to the military-industrial complex and research centers, as well as consumer culture and its associated technologies" (p.11). According to Judy Wajcman (2000) this conception of technology has been socially and culturally assumed as white and masculine, leaving other technological occupations historically developed by female groups or non-developed societies, outside 
of the term (p.447). The invention of the electronic digital computer is considered the most influential development in the past century, englobing most of the time the word technology when referring to it (Ensmenger, 2012, p.756). Despite its roots and cultural gendered assumption within it, some scholars have retrieved numerous notable contributions made by women that have been hidden in the construction of computer history (Light, 1999; Wajcman, 2000) and therefore in computer arts (Taylor 2013). When the hardware was pure engineering, the software were manual mathematics calculations, the very original roots of the patterns encoded on paper in the $19^{\text {th }}$ Century that developed in coding and computer programmeming were made by women (Light, 1999; Grier, 2007; Ensmenger, 2010; Evans, 2018). As Judy Wajcman states, the feminist project has been in charge of uncover and recover the women hidden from history since the late 1980s, with other notable Science and Technology Studies (STS) scholars have worked in this historical uncovering women's contribution in the computer technology development, and also in the analysis of cultural assumption of the masculine roots of technology, upon the conception of what technology really means and the gender relations within the construction of technology (Wajcman, 2000, p.447).

When British historian Sadie Plant published Zeros +Ones in 1997, she manifested an emerging awareness of women in relation with computer technology. However, within all her baggage, she misses the contribution of women to computer arts. Women in computer-based arts have emerged there where there were labs to experiment with the new machine. When Apple and IBM provided interdisciplinary spaces for scientists, engineers and artists to work together, women played an outstanding work. Since Sadie Plant, an increasing campaign to engage more women in technology uses the list of female contributors in computer science as motivator strategy, however, even contemporary artists forget to mention women in early computer arts. As I will discuss in this chapter, it was a woman artist of color, who first made art with an Apple II, it was women artist who developed their own software for computer arts, it was women artists who founded the first art and technology 
programmes in North America and Europe, it was women artists who made the first animation movies, women artist who curated the first international cybernetics exhibitions, who created handmade sound synthesizers, etc.

Feminist and STS scholars have contrasted the real role and contribution that women made in the development of technology and computers, in contrast with the image that - intentionally- has been historically preserved and filtered (Light, 1999). Another main point they have considered is the social appreciation of gendered roles and the appreciation of the tasks developed based on gender (Schafer \& Thierry, 2015). We will focus on the history of technology related to computer arts through computer programmeming, and the seminal contribution women made in it (Taylor, 2013). Until the 1990s, it is considered that women were practically absent from the history of computing and early computer arts, however, they made significant contributions in many parts and segments of its development (Linda Shafer in Misa, 2011, p.455):

It's the accumulation of all those steps, executed simultaneously and collectively, that prefigured our connected, calculating, big-data world. Alone, women were the first computers; together, they formed the first information networks. The computer as we know it today is named for the people it replaced, and long before we came to understand the network as an extension of ourselves, our great-grandmothers were performing the functions that brought about its existence. (Evans, 2018, p.25)

For instance, the Art historian D. Taylor (2013) suggests that the women involved in the calculations of the first American computer made the first computer art through their collaborative work and scientific visualizations; it was the precursor of the next computers which would produce the first computer generated-art in the 1960s. All these and other are uncovered stories that evidence the malecentered perspective which Western history has been constructed after wars, "the result is a distorted 
history of technological development that has rendered women's contributions invisible and promoted a diminished view of women's capabilities in this field” (Light, 1999, p.482).

Contrary to the telegraph, radio and TV, a notable contribution of women was part of the technological process of computers, not as users but as developers. As I will discuss in the following chapter, in the middle 1990s the position towards technology experienced a shift of perspective by feminist scholars and a new wave of positivism embraced feminist theories possibilities of the Internet and computer of the networks (Wajcman, 2010). In 1995 Sadie Plant published an article titled The Future Looms: Weaving Women and Cybernetics where she retrieved the story of the mathematician and writer Ada Lovelace, and the first steps in what would become the computer programmeming language (software).

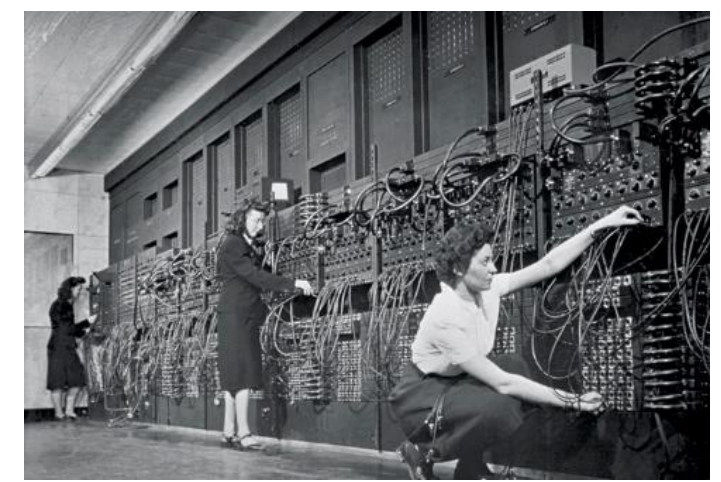

Figure 26 Marylin Wescoff and Ruth Lichterman, two of the programmemers in the switchboard of ENIAC

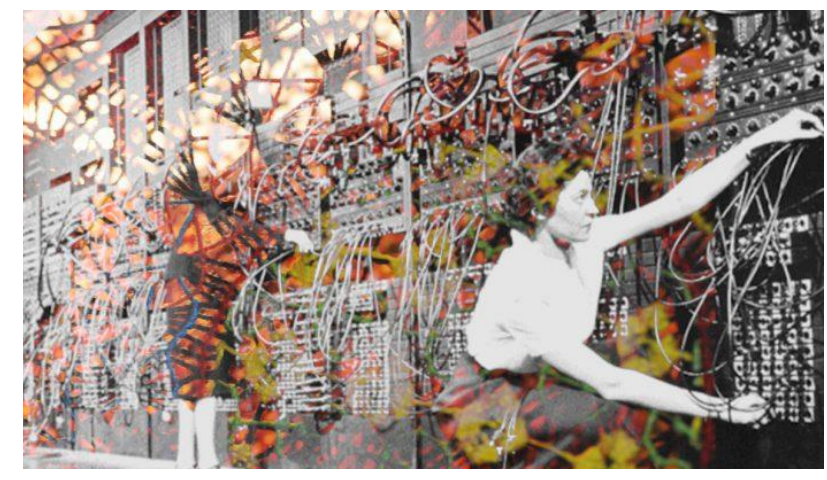

Figure 27 Right: composition by Roma Vaquero Diaz, author of Mujeres tejedoras de tecnologia, 2017

Inspired by the difference feminist Lucy Irigaray's work, Plant (1995) was innovative to identify the relation between the logical structure within the traditional female tasks and machines like the weaving loom, sewing and knitting- with those performed by women in ICT -concretely coding and programmeming - despite the disputes based on female essentialism in technology and programmeming. She has positively influenced later works worldwide on cyberfeminism. The retrieval of Ada's figure has meant for women in technology to have a kind of eponymous prophet in their field, 
many associations and projects for women in computer science have been established under Ada's name, for example the Ada Initiative ${ }^{52}$, the Association for Women in Computing's Ada Lovelace Awards ${ }^{53}$ and the Ada Project in Carnegie Mellon University ${ }^{54}$. Plant also retrieved other female figures like Captain Grace Hooper, who was also known as "the Ada Lovelace of the new machine.

Other figures were Margaret Hamilton, and before in war times, the ENIAC girls, who during the II World War the calculation for the automate ballistics computations for the first America's electronic computer, named ENIAC (Electronic Numerical Integrator and Computer) developed in Army Ballistic Research Laboratories (BRL) in Aberdeen, Maryland. (BRL). Its calculations for artillery firing tables was manual and passed from being a man's job in the IWW to be performed by women manually. These manual mathematical calculations were commonly developed by women, from military purposes, or for example in Astronomy. Manual programmemers or human software, like the stories of the astronomy laboratories in the late $18^{\text {th }}$ Century to early $20^{\text {th }}$ in main universities in United States and Europe (Grier, 2007), and in the first laboratories of the NACA (National Advisory Committee for Aeronautics, later NASA) since the 1930s (Hodges, 2008), like the Rocket Girls of the Jet Propulsion Laboratory (JP) (Holt, 2016). The book Hidden Figures by Margot Lee Shetterly (2016) talks about the black women mathematicians, human computers who helped Win the Space Race during WWII and though the Cold War

Light (1999) and Wosk (2003) explain how during the IIWW women were recruited for all types of tech employment, performing technological and military tasks as any other male counterpart, and their role as human computers was crucial for the development of the military strategies and technological development such as the Internet.

\footnotetext{
${ }^{52}$ See <www.adainitiative.org >

${ }^{53}$ See <http://www.awc-hq.org/ada-lovelace-awards.html >

${ }^{54}$ Available at <www.women.cs.cmu.edu/ada>
} 


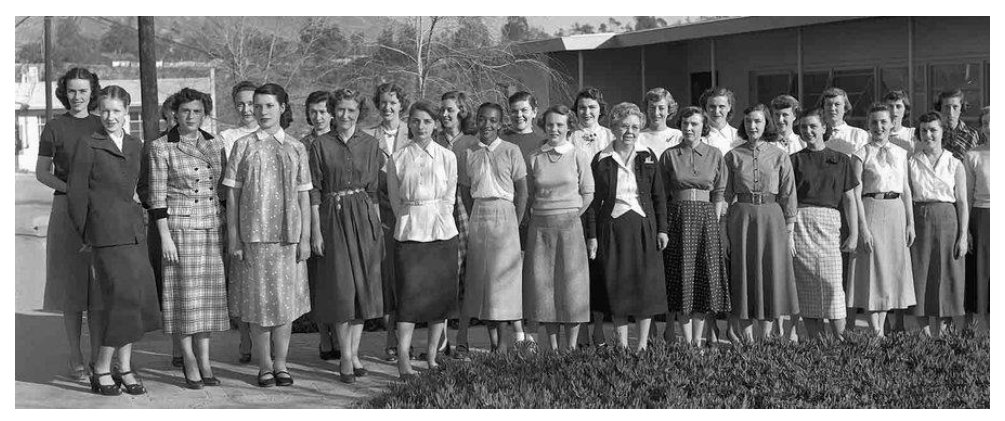

Figure 28 Groups of computers at NACA (in 1958 NASA), circa 1935, in charge of satellite trajectory calculation and others.

Once II WW was over, women were pushed back to their homes and their domestic roles, and during the years of transition in 1940 to 1960s propaganda was an excellent method to achieve this by governments in US (Ensmenger, 2010) and the UK (Hicks, 2017), for example, leaving mathematical jobs for women just as teachers (Light, 1999, p.480). In the decades of Western countries development after wars towards capitalized and democratic neo liberal societies, computers were rapidly industrialized and then commercialized, and as it will be discuss in the chapter on computer arts, it was a field in its infancy, unrelated to pure engineering and absent of masculinized structures, where companies looked for brilliant and intelligent minds to hire in the high demanding expansion of the industry (Ensmenger, 2010, p.117). In the legacy of the female clerical works of the $19^{\text {th }}$ Century, computer programmeming was a feminized occupation before the archetype of the tech geek would appear in this gendering process of technology tasks (p.137). The high requested tasks of complex mathematical processes (programmeming) were considered female work associated with rudimental manual labor, in contrast with the masculine world of hardware, analysis and industrial engineering (Taylor, 2013), and this work was “equivalent to roughly a thousand hours of computer labor". (Evans, 2018, p.11).

Academic works like the publication by Nathan Ensmenger in 2010 Making Programmeming Masculine, show how the studies of computer science and mathematics were still part of women's interests in high numbers in North America until the 1980s. 
On the one hand, women did play a critical role in early computing, particularly in computer programmeming. Compared to most technical professions, computer programmeming was unusually open to females. But on the other hand, in the late 1960s the computer programmeming community was also actively making itself masculine, pursuing a strategy of professional development that would eventually make it one of the most stereotypically male professions, inhospitable to all but the most adventurous and unconventional women. [...] It had to be made masculine. (Ensmenger, 2010, pp.115-16)

Also, the recent publication by Marie Hicks Programmemed Inequality, that studies the active contribution to Colossus war computer by thousands of women from 1930 to 1946 in Great Britain force, and how the British government took female employees apart along the 1960s from such Industry (Hicks, 2017). Those clerical works as software programmemers were considered female professions until the middle 1980s, where the number enormously and rapidly decreased (Ensmenger, 2010). As in computer arts, while the field remained in its infancy and it lacked of classical structures of specialization, women had a notable place, but just when it started to become a professional discipline through multiple exclusionary tactics including biased hiring rubrics, coded management language, denial of access to pension benefits, and sexist advertising (Hicks, 2017), women were falling in numbers.

A combination of socio-cultural factors: the archetype of the nerd appeared in this technocultural process, commercial of computers addressed to boys (despite the interest of girls) ${ }^{55}$, science fiction movies with strong masculine stereotypes related to technology and science (Henn, 2014), and some scholars point the fact that the profession name shifted from programmemer to software engineer, becoming a negative influence on female attraction to the field (Ensmenger, 2010,

\footnotetext{
${ }^{55}$ More information about this point at <https://n.pr/2xEWz99>
} 
p.137). Engineering fields suffered a previous and similar masculinization process from $19^{\text {th }}$ Century to $20^{\text {th }}$ when “American engineers employed discourse, language and narrative strategies and practiced a style of engineering that supported the gendered division of cultural labor in the technology fields" (Oldenziel, 1999, p.11).
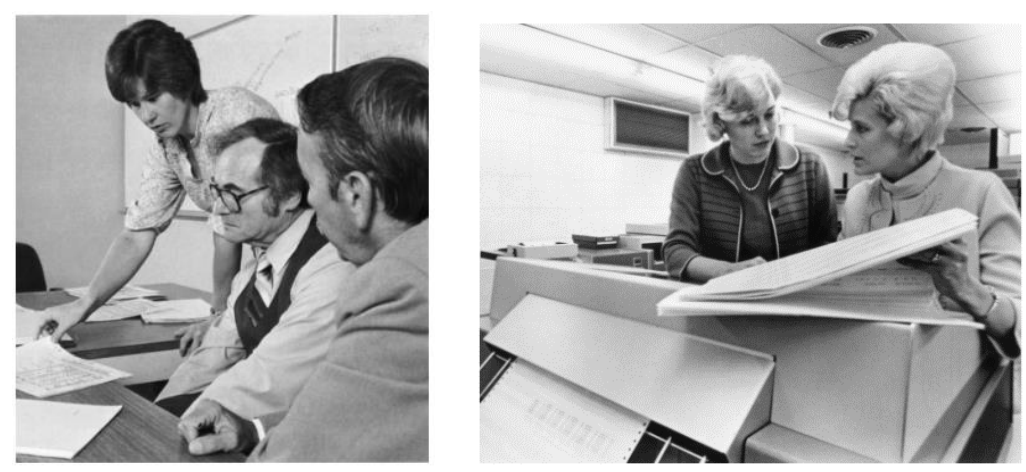

Figure 29 "Women computer scientists working with colleagues". (Courtesy of Charles Babbage Institute.) in Misa, 2011.

The reason behind the lack of female interest that still today predominates computer science in most of the Western Countries, is still a matter of research and investigation in many research centers, cultural studies departments, feminist associations and governmental entities. In Gender Codes: Why women are leaving computing, edited by Thomas J. Misa, we also find contradictory confessions related by women in computer professions about the gender-neutral work environment, the same equal opportunities that contradict the crisis in the 1980s of female employees computer industry suffered (Abbate, 2010, p.213). To the contemporary question "Where are Women in Computer", therefore we should rather question why a particular vision of the discipline, based on masculine ideas and values, dominated the study of computer programmeming (Ensmenger, 2010, p.137). Contemporary studies demonstrate the impact of gender stereotypes of scientists and technologist in media (Cheryan et al., 2015) Based on the statement of Judy Wajcman "technology is in itself a social construct" (1991), research investigations like the one lead by Carol Frieze and Jeria Quesenberry in Computer Science Department in Carnegie Mellon University are an example of strategies to retrieve female interest in Computer Science. They achieved the gender equity with $50 \%$ of female students in computer science 
studies in CMU in 2018, providing "evidence to show that a focus on culture offers the most insightful and effective approach for investigating women's participation in CS" (Frieze \& Quesenberry, 2012) ${ }^{56}$. Another evidence is that in Europe women in computer science and technology fields are higher in numbers in some countries that were part of the Soviet Union, and internationally numbers vary drastically compared to Western societies: in India, in Indonesia, in Iran, in Arabia Saudi, among others (UNESCO, 2017).

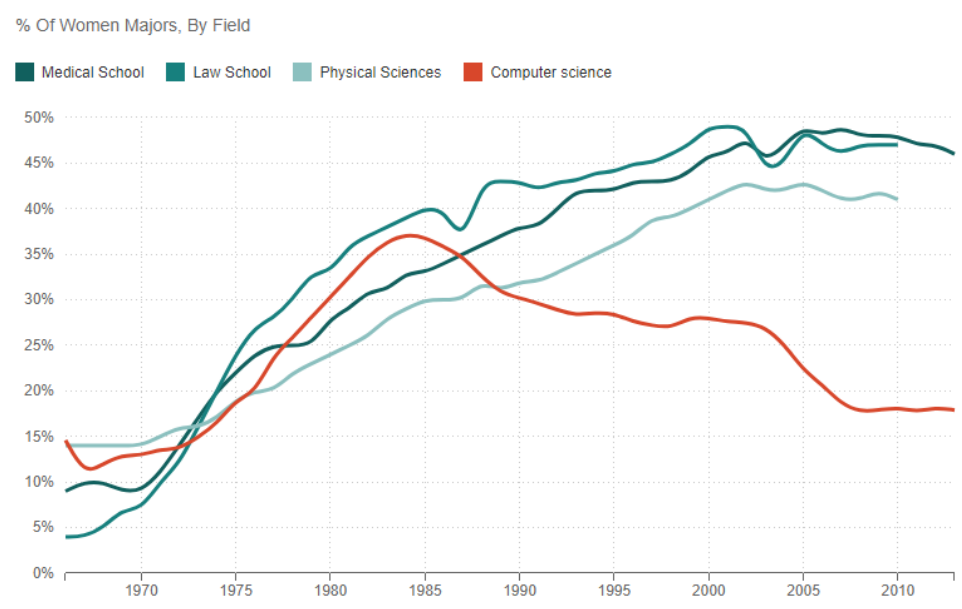

Figure 30 "What happened to Women in Computer Science in United States?" Source: National Science Foundation, American Bar Association, American Association of Medical Colleges. Credit: Quoctrung Bui/NPR. Data United States of America

Feminist associations and organisations use historical female contributions to technology, art and science as an inspirational referent to keep fighting the gender gap and discrimination in the technology fields. In 1972 American Society of Engineering Education was founded, followed by The Association for Women in Computing (AWC) in United States was funded in 1978, starting to ally and talk about the discrimination and need for change (Taylor, 2013).

\footnotetext{
${ }^{56}$ I will go back to this reference in the chapter 4.3. on Women in New Media Arts today when describing ATENEA Project methodologies and contextualization.
} 


\subsubsection{Women in Computer Arts}

"In 1979, I saw the Apple II Computer. That night I had a powerful dream. In the dream I had found a black box embedded in the sand next to the ocean. When I opened the box small dots of light burst out and danced in the night sky. At that moment, I knew the computer would be my artistic medium."

-Lucia Grossberger Morales-

The inheritance of the technologies developed during wars gave rise to the artistic and humanistic experimentation field of computer arts, and as it happened with radio and radiophonic art, digital computers started to be a new medium for creativity. As a fact, the machines that followed ENIAC in BRL developed the first and second prizes by Computer Art Contests in 1963 for their computer-generated art images, meaning the birth of computer arts (Taylor, 2013). As we saw in the electric age and the telegraph, theories about the human and computer relationship started to be disseminated since the beginning of computer domestication. The term cybernetic is originally found in a Plato dialogue, in referring to the description of all matter in regarding to communication theory, and much later the physic Ampere used it in 1834 (Tornero, 2012, p.11). However, the term is commonly assigned to the mathematicians and philosopher Norbert Wiener when in 1948 he applied the ideas of the computer system to the human and living organism control functions (Cox, 1989, p.11). He designated the importance of the feedback role in a communication system, and the principle of information contained in messages behind life and organisation (Paul, 2016, p.4): "the scientific study of control and communication in the animal and the machine" (Wiener, 1965). In this sense, cybernetics explained for first time the phenomenon of information exchange in systems, theorizing the parallelism between the electro-magnetic signals and neural networks of humans and other animals, treating information as a generic substance, like zeros and ones for computers (Shanken, 2003, p.19)

Like it was happening parallelly in Fluxus happenings, art practices were influenced by oriental theories related to Zen, spirituality, consciousness and in short, a break with old Western structures to 
create art based on "participación y desmaterialización” (Giannetti, 2002). There was an increasing component of participation in the artmaking, bringing closer art and life, giving relevance to the medium over the message ${ }^{57}$, and the practices within computer arts worked upon this too. The accessibility of the computer industry allowed visual artists to get in computer technologies, and following the genealogy of generative, algorithmic art forms found its roots in the avant-garde art movements (Huhtamo, 2016, p.75). The first steps of cybernetic art can be found in Europe within the legacy of constructivism and kinetic art: Hungarian-born artists Nicolas Schöffer and his first cybernetic sculptures CYSP $O$ and CYSP I (titles combining the two first letters of Cyberfenetics and Spatio-dynamique) in 1956. Two years later, the scientist Abraham Moles published Théorie de l'information et perception esthétique, which outlined "the aesthetic conditions for channeling media" (Shanken, 2003, p.17).

Computer arts provided a promising gender-neutral tasks performance that attracted women to the field. During the expansion of computer industry together with leading research universities, female artists got notably involved, leading and attending many of the early programmeming courses (Taylor, 2013). In her essay Up for Grabs in 2013, the Art historian Grant D. Taylor studies the influence of north American women artists in the shaping of digital art, and he also argues the fallacy that computer technology was inherently masculine, while at the same time became a sanctuary for some women artists. He also points a very relevant factor for the discursive development of the present work, which is that visual artists and feminist theories were generally against technology, factor that stigmatized women in computer arts doubly (2013). However, women artists joined the world of computer arts, also known as cybernetic arts, in a notable manner, they collaborated and worked in mixed groups and

\footnotetext{
${ }^{57}$ In line with the theories developed by Marshall McLuhan along the 1960s on media.
} 
made an important contribution to the development of computer graphics and computer-based arts, which has been ignored until recently investigations (Taylor, 2013; Cox et al., 2018).

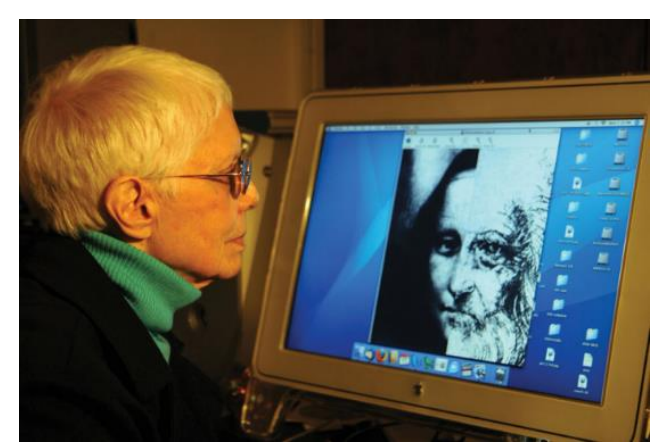

Figure 31 The computer artist Lillian Schwartz's Analysis of Mona Lisa "MonaLeo" 1984

Although by the 1960 s there was a general conception within feminists that perceived technology as masculine, against nature and inherent to patriarchy (Wilding, 1998; Wajcman, 2009), a series of women artists found the emergent field of computing more open compared to the patriarchal power structure of mainstream artworld, and more interesting to join than the commercial computer science field (Taylor, 2013). Described as the Virtual Renaissance, the new intersection between humanities, science and technology was positively perceived by many as a new digital age. It was a shift in the scientific and artistic paradigm, where the new profile of artists would be a hybrid between art, technology and science (Taylor, 2014), many artists saw a prophecy of a social and artistic change in history: "bringing together the two cultures of art and science could help create a new international economy by which women could contribute to and earn a living in the arts and sciences" (Cox et al., 2018, p.32). The canonical text by Donald Knuth's The Art of Computer Programmeming published in 1968, established an already started field of interdisciplinary investigation between artists, technologist and scientists, that formed the Renaissance teams (Cox et al., 2018). Donna J. Cox was part of these teams, together with other pioneer in computer arts, Ellen Sandor was NCSA (National 
Center for Supercomputing Applications) at University of Illinois (UIUC), which director was part of SIGGRAPH team. This team reflected the possibilities that this new cultural renaissance allowed, new forms of expression and education, changing people's lives, empowering women to achieve in their workplace and to create business of their own. Women and men together developed new techniques of computer graphic visualization, using innovative interactive software (Cox et al., 2018).

As computer science expanded and professionalized during the 1960s, computer graphics started to develop, and some distinctive laboratories were opened in the United States and Western Europe. These laboratories were appreciated as very egalitarian, as they were focused in finding creative and innovative hybrid minds, regardless the gender, although the androcentric character of computing would start to increase later. Women artists joined university research centers such as: MIT, NYIT, Brown University, and the University of Illinois, and others started at corporate settings, such as Bell Labs, TIME Corp and 3M. Through interdisciplinary and experimental collaboration, these labs created revolutionary visual technologies like Graphic User Interface (GUI) and provided accessibility of computers to artists to work without commercial pressures together with engineers, no possible in other way (Taylor, 2013). Bell Telephone Laboratories for instance, was the first high scale contribution to the world that together with artists like Robert Rauschenberg, brought together the interest of engineers and technicians into interdisciplinary and performative creations with artists from the early 1960s (Tornero, 2012, p.11). Bell Lab created a collaborative model that other research centers followed and influenced the contemporary academic digital arts field: [female and male] "engineers and artists took a variety of art forms-graphics, music, choreography, film, and animation — and exposed them to the new powers of digitization”. In New York in 1966 The Evenings: Theatre and Engineering, was the first of a series of events that became known as EAT (Experiments in Art and Technology), where female computer artists like Lillian Schwartz took part (Taylor, 2013), however female participants reached only 10\% (Huffman, personal communication, $19^{\text {th }}$ March 2019). 
Also in 1966, the Project Art and Technology (A\&T) was founded in the Los Angeles Country Museum (LACMA), when L.A. was already a high requested place by big new technology companies (Tornero, 2012, p.36), which had an unfortunate impact with its exhibition in 1971 Art and Technology with no woman in the panel. As a reaction there was the formation of LACWA Los Angeles Council of Women [Artists] (Way, 2016, p.186)

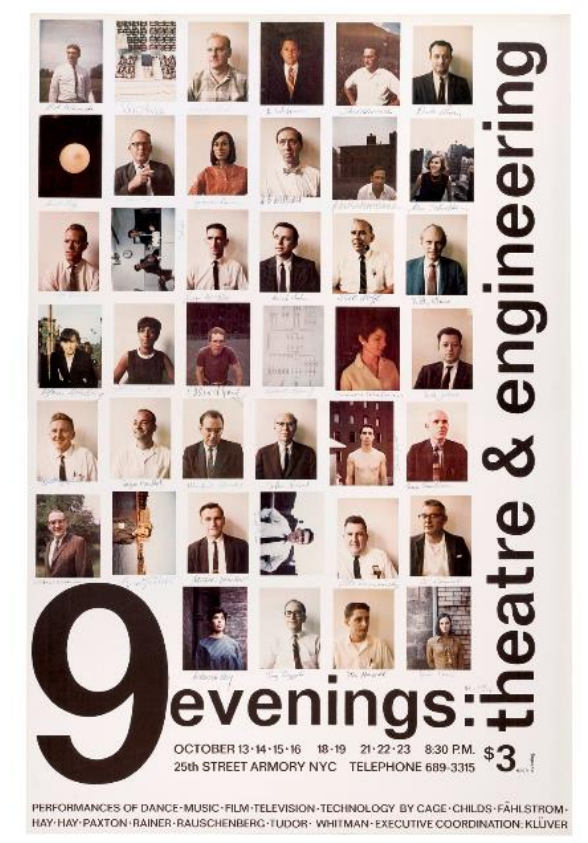

Figure 321966 The Evenings: Theatre and Engineering

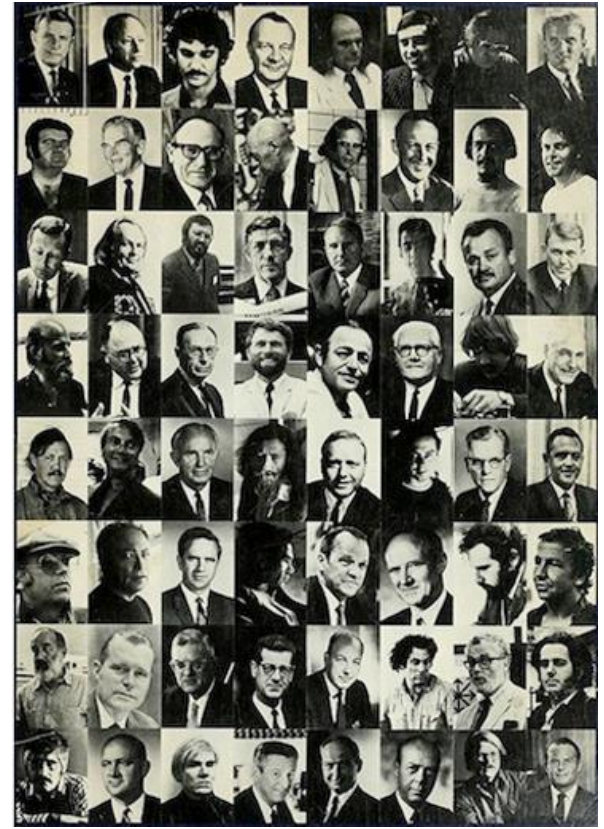

Figure 33 Art and Technology Poster, 1971, LACMA, Los Angeles.

Computer art was inconsequential to normative art and remained totally rejected and stigmatized by the mainstream art world until the 1990s. Maybe due to this stigma, visual artists used the expression "the kiss of death" to describe the art or artists that got involved in computer techniques (Brown in Taylor, 2013), altogether with the feminist negative impression of technology, that more women didn't got involved in the field. Due to this, and together with its apolitical position, in its infancy the computer arts provided a new virgin area to experiment, it had unconstructed gender bias and it was disconnected from old institutionalized structures (Taylor 2013). The computer art, later called multimedia and cybernetic arts (1960-1990s) (Paul, 2016, p.1) created its own world, its own ghetto by opening centers, journals, exhibitions, societies etc. (Taylor, 2013) and rapidly netted its 
transnational network, formed by engineers, designers, scientists, artists and large private and government institutions (Fritz, 2016). In 1947 the first association for computing was founded, which organised the annual Computer Arts Festival since 1965. From its Special Interest Groups, SIGGRAPH, the one on Graphics and Interactive Techniques, is the annual conference on computer graphics within the ACM core since 1974. Since then, SIGGRAPH has been hosting international scientists, artists and technologists for decades, becoming a key international meeting point for those interested in computer graphics technologies and interactive techniques, and video games, becoming soon a transnational community (Fritz, 2016, p.50) that, as we will see, will be node for women artists network (Cox et al., 2018, p.24 ). In 1968 Leonardo Art\&Science Journal ${ }^{58}$ started, achieving its initial goal of "becoming an international channel of communication for artists who use science and develop technologies in their work" (MIT, 2013). The period between 1968 to 1973 were "good times" for computer art expansion, with international exhibitions like New Tendencies held in Zagreb ${ }^{59}$ dedicated to computer-generated art, promoting art as a form of research in the hybrid of art and science, functioned as an international network before the Cold War, hosting owners, art critics, art historians, and theoretician (Fritz, 2015, pp.55-57)

When women participated and got involved in the labs, like the artists Rebeca Allen and Copper Giloth stated, gender was not taken in consideration when showing and performing their artistic and technical skills, "creative thinking gave someone credibility" (Taylor, 2013). The most notable contribution by women in early computer arts were in the development and shaping of the digital arts, in terms of technique, theory, cultural management and specially, in education (Taylor, 2013). The first steps of computer art in 1950s-1960s were mainly focused on art generated by computers, the term 'artist-programmemer' was coined in 1962 to describe the new hybrid profile of the creator who

\footnotetext{
${ }^{58}$ Available at <https://www.leonardo.info >

59 Yugoslavia, by contrast, was for some time one of the world centers of computer art (Bozhinov, 2015, p.7).
} 
develops his or her own code and software. Some women artists who also developed her own software, made a crucial influence in the forms of design, by for example, providing patterns and styles of design different to those made by male colleagues. Taylor notes some arguably tendencies to subjectivity and personhood through organic and human forms in the women artists work, in contrast to the disembodied, masculinized and geometrical abstractions inheritance from late modernist movements of their male counterparts. Two main pioneers in computer arts, Collette Bangert in 1967 and Lillian Schwartz in 1968 were the first women to employ the computer to generate art, and Schwartz for example, was one of the first American artists to use computer-coding language for her motion graphic based film and video art (Lenz, 2014).

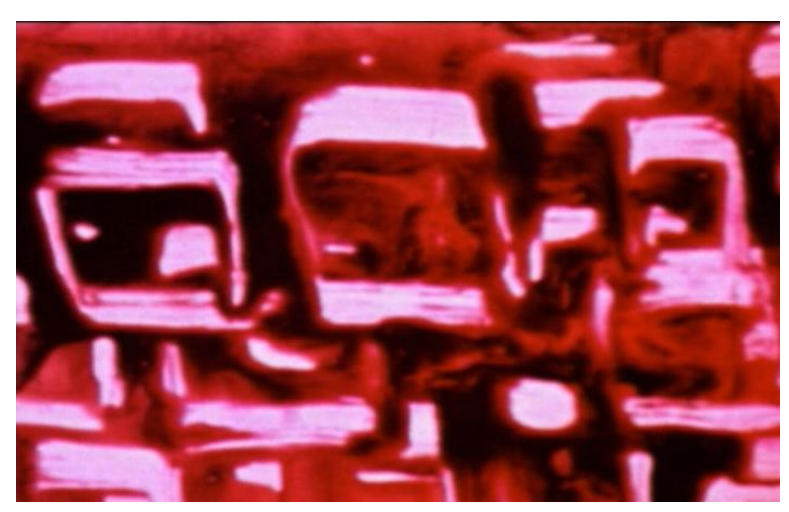

Figure 34 Frame of Pixillation a four-minute film by Lillian Schwarz 1970 commissioned by AT\&T Bell Laboratories.

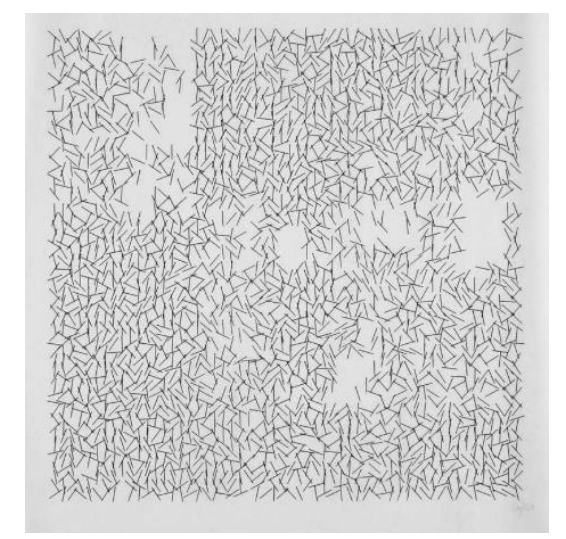

Figure 35. Interruptions (1969) by Vera Molnar is a plotter drawing. The image was made by a pen attached to a computer-controlled drawing machine - in this instance an IBM 370 with an IBM 2250 cathode ray tube (CRT) monitor and plotter.

Another female pioneer in computer arts was the Hungarian artists Vera Molnar resident in France, she was the most significant women artist in Europe who used digital technology in the 1960s. Also the American Rebecca Allen, first Emmy Award-winning computer animation artist; among others, the Czechosloval Zdeňka Čechová, today president on the Union of Czech Computer and Multimedia Artists, who "authored computer graphics as well as designs for carpets, tapestries and other textiles, all-computer generated. Later, she would expand into multimedia and video art in an artistic career which continues to this day" (Bozhinov, 2015, p.30). The north American Grace Hertlein 
was the only female artist that took part in the programme dedicated to computer arts, Tendencije 4 in the last edition of the first international exhibitions that took place in Zagreb from 1961 to 1973, She started using computers to make art in 1968 as well. Parallelly, women working with electronic installations during the 1950s and 1970s also worked collaboratively, being part of an artistic group, the "half of an artistic team", they were part of the experimental group shows of the Avant Garde. Women artists like the Japanese Atsuko Tanaka, she gave rise to the 'electronic sculptures' with her piece Electric Dress in 1956. She was part of the Happenings in New York and Japan with Jiro Yoshihara, and a founding member of Gutai Art Association. Liliane Lijn, one of the pioneers in the intersection of scientific though and arts, experimented with interdisciplinary explorations through performance, text and new media with her early light sculptures and Poem Machines. Nadie MagnenatThalmann, academic and artists leading research in virtual humans for the last thirty years (Huffman, 2009).

As educators, curators and theoreticians, women played an important role in this phase of computer arts. At the Institute of Contemporary Arts in London in 1968 took place the first large exhibition of early computer arts, Cybernetic Serendipity. Although all the artists involved were male, the exhibition was curated by a woman: Jasia Reichardt, whose experimental work promoted the global interesting computer art and served as a referent for future exhibitions - it was taken next year to Washington and San Francisco- (Shanken 2002, p.155). Multi and interdisciplinary practices in visual arts, poetry, music, dance, film, animation were included, work of technology-based art: robots, electronic music, multimedia installation, using the theme of cybernetics to explore the connection between creativity and technology (Cox et al., 2018, p.86). Reichardt's curatorial contribution and her later theoretical work The Computer in Art (1971) and Cybernetics, Art and Ideas (1971) made her "the most astute commentator of the computer art phenomenon". Other female theoretical contributors were Grace Hertlein, founder of Computer Graphics and Art magazine, who wrote extensively on 
computer arts, and Ruth Leavitt with her compilation of artists essays called Computer and Artists in 1976. Additionally, the same women computer artists, such as Lillian Schwartz, Vera Molnar, and Collette Bangert, used to write and publish their visionary theories, shaping computer art discourse and promoting the creation for the next generation (Taylor, 2013).

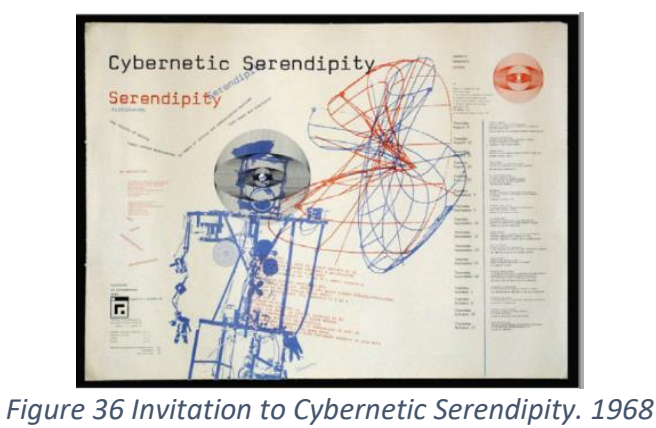

Figure 36 Invitation to Cybernetic Serendipity. 1968

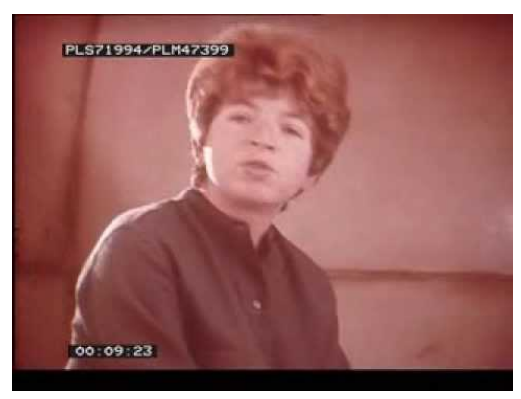

Figure 37 Jasia Reichardt presenting Cybernetic Serendipity, 1968, London. Fragment of the video, retrieved from www.youtube.com/watch?v=n8TJx8n9UsA

The abovementioned conference SIGGRAPH, developed in a forum, a meeting point for women in digital arts, that "migrated from the Midwest to both coasts and abroad but could reconnect, stay in touch, and share their work through the annual conference events" (Cox et al., 2018, p.24) SIGGRAPH became a main supporter of computer arts under the leadership of women artists (Taylor 2013). Within it, women computer artists published educational and research works and had a notable presence in many editions of the SIGGRAPH exhibitions (Cox et al., 2018, p.25). The participation of women in SIGGRAPH conferences and exhibitions was such that in one in 1989 for example, the number of female and male artists was almost equal (Taylor, 2014). Darcy Gerbarg and Copper Giloth achieved organizing an ongoing exhibition together with the SIGGRAPH conference in 1981, which included a group of pioneer women artists. Copper Giloth would curate the following two annual SIGGRAPH exhibitions, with the 1983 Exhibition of Computer Art becoming a highly successful international show. Women in computer arts also curated international exhibitions promoting their 
local work, like Barbara Sykes in 1987, Video and Computer Art: Chicago Style (Cox et al., 2018, p.30)

Although second wave feminism was happening in parallel to the evolution of cybernetic arts, the impact that feminism had was noticed by the positive results of the gender equality laws and the female participation in the labor force. Contrary to visual and performing arts, women in computer arts didn't take part of the feminist art movement, neither they worked on gender issues within their artwork. Moreover, the only theoretical source for computer artists was the new field of technoscience for its "mythology, vision, and technical knowledge" (Taylor, 2014, p.248), while the postmodern humanistic theories that were shaping the arts outside, had no impact in the first decades of digital arts. Instead, postmodern theories were a critical point for them:

However, many postmodern critics, in their languid historicism, fail to recognise the real 'new', and this period where the old is dying and the new cannot be born results in many morbid symptoms. Many view electronic/computer media as evil, as a primary contribution to the negation of humanism. This technophobic attitude handicaps any emerging technological aesthetic. Unfortunately, computer art was born in the transition between modernism and postmodernism. While both paradigms broach computer art issues, for the most part these issues have been relegated to technological biases (Cox, 1989).

As their male colleagues, women artists were completely focused on the possibilities of creation and communication of the medium until the late 1980s, leaving apart polemic topics within the art. On the other side, as we previously saw, feminist artists were successfully developing their artwork through new media like videoart, photography, film to experiment through performative interdisciplinary techniques a feminist discourse (Mayayo, 2007). Although computer-based art and its following and telematic art have a completely unrooted history of primarily male practitioners, it had a very bad reputation for feminist theoreticians and artists until late 1980s. Maybe this is one of the reasons that 
took apart many women artists to get involved. But the fact is that women in early digital arts wanted to "disrupt," "push," "subvert," and "reconfigure" digital technology (Taylor, 2013). Nevertheless, the major contribution by them was perhaps in the field of education, acting like educators in digital arts courses or building the first digital arts and new media programmes, in United States and in Europe. Many women opened main centers and programmes that are active today, like the United States Information Agency (USIA), the Generative Systems Department at The School of the Art Institute of Chicago, the Art and Technology programme at The School of the Art Institute of Chicago, the UCLA's Center for the Digital and the Design | Media Arts at the same institution, between others. In Europe Interface Cultures in Linz with Christa Sommerer. Women computer artists founded, collaborated or supported these programmes had to face many difficulties by the leaders of the institution's and male work colleagues from the art departments (Taylor, 2013). For example, a recent publication by Judy Malloy for the catalogue of the $50^{\text {th }}$ Anniversary of the Art School of Chicago "The Women Who Shaped Art and Technology Studies" (2019), talks about courses started in the early 1970s by women artists such as Sonia Sheridan who began the Generative Systems programme at the Institute. Along the 1970s and 1980s within the laboratories and the transnational networks of computer-based arts, female and male artists, technologist and Scientifics worked together in what Donna Cox calls Renaissance teams, creating most of the works collaboratively and collectively, influencing each other and improving the technology thanks to the cooperation of all of them. Sound artists like Barbara Sykes and Laurie Anderson started their artistic exploration within the computerbased art communities, being inspiration for other through the network of SIGGRAPH, for example (Cox et al., 2018, p.24). Laurie Spiegel, composer, software creator and visual artist, is known widely for her pioneering work with many early analog and digital electronic music systems, including the GROOVE system at Bell Telephone Labs, and Music Mouse, a software-based musical instrument for Macintosh, Atari and Amiga (Gallery@CALIT2, 2011). 


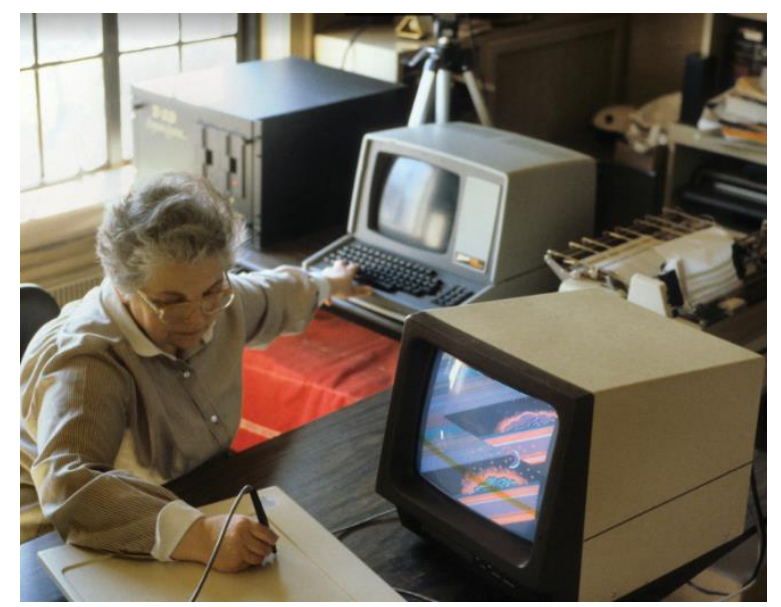

Figure 38 Sonia Sheridan manipulating the Cromemco Z-2D system with EASEL software, 1982. Courtesy The Daniel Langlois Foundation for Art, Science, and Technology, Sonia Landy Sheridan fonds.

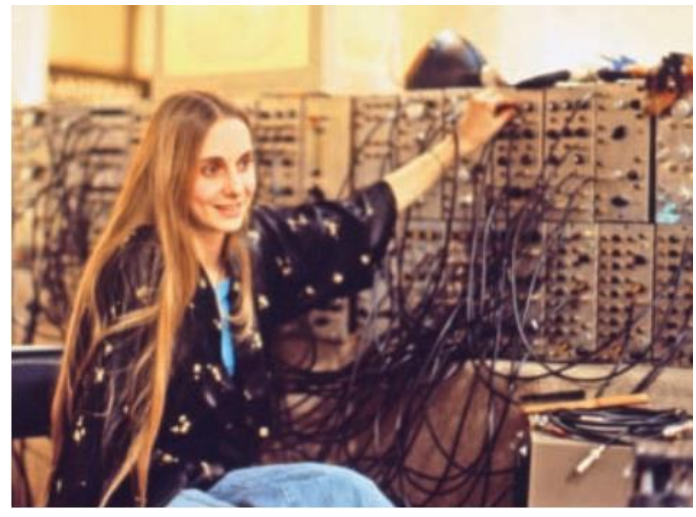

Figure 39 Barbara Sykes jamming and performing on the image processor during "Environmental Symmetry," 1977, a day-long multimonitor, interactive performance environment that included audience participation, dancers, and musicians. Courtesy of Barbara Sykes

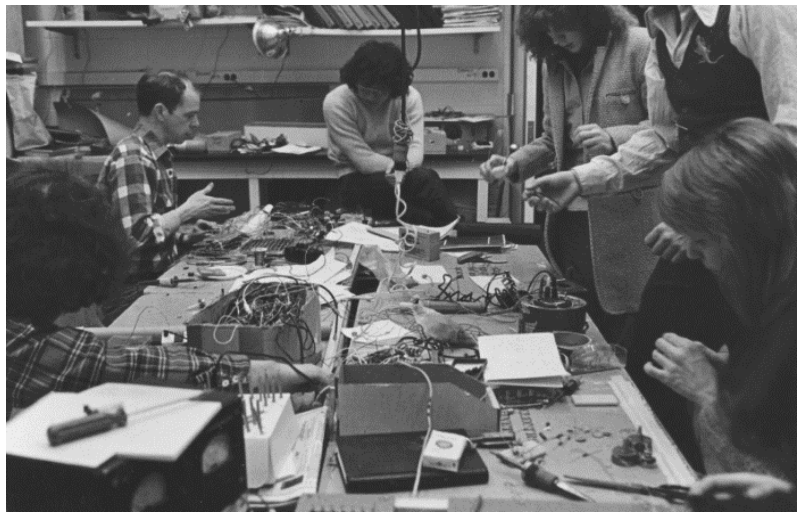

Figure 40 Steve Waldeck teaching electronics and kinetics to his female and male students at the School of Art Institute of Chicago, late 1970s, in ats@50, 2019

Female artists in electronics like Steina Vasulka, Lynn Hershmann-Leeson and Adrienne Wortzel, during the 1970s and 1980s were also inventors and creators that experimented with new interactive telerobotic processes. They also worked on the female-body concept, and despite the maledominated field, with their interdisciplinary and hybrid educational-artist profile "these women creatively combine their knowledge of science, engineering and art, and create electronic visions, digital divas and robotic figures that have become strong examples and role models of female intelligence for the current generation of artists" (Huffman, 2009). 


\subsection{All-Women Artists Networks - La rette come Arte}

"The distance from this sentence to your eye is my sculpture" Friedman, 1974, p.45

The power of alliance and collaboration for women in arts has been outlined in the previous chapters, the establishment of networks that enables the creation of alternative spaces. Networking can be understood far from uniquely a social practice, but also artistic, to network means to "create relationship networks, to share experiences and ideas" (Bazzichelli, 2008, p.37). In referring to the concept of network as an artistic practice, I use the concept by Tatiana Bazzichelli (2008) "the art of networking", "as a metaphor of art as a network: art that creates network" (p.26). Although since the 1980s this term relates to computer networks, the origin of the art of networking has been pointed in analog practices by some authors such as Bazzichelli (2008) and Couey (2003), as artists have always appropriated the communication systems for their practices (p.71). Networking has been related to Mail Art or Correspondence(art), despite the different roots of each (Held, 1995, p.17), Bazzhichelli (2008) for example describes Mail Art “as the true mother of networking”, existing in periods before electronic networks appeared, for example during Manierism (p.27). A clear artistic application of mail communication started in the 1950s, as a reaction to the centralized mass media (radio, TV, newspapers) to retrieve a many-to-many communications. Dada artists such as Beltroch Brecht experimented with radio in Europe, creating Radiophonic Art pratices (Molina, 2011). Mail Art was a private phenomenonof correspondence experimental art within the circle of artists of Nouveau Realisme, the New York Correspondence School and Fluxus Movement, which network developed into a community (Friedman, 1995, p.16; Vesna, 1997). The best way to define what mail art and Flux Mail means is the Eternal Network, an eternal non-formalized network based on addresses exchanging one-to-one, one-to-many, that from its beginnings has involved hundreds of people who also self- 
produced mail related media (Bazzichelli, 2008, p.37).

\subsubsection{Mail Art, Fluxus and the Eternal Network}

While the Nouveau Realisme and The New York Correspondence School kept their correspondence art between the same members, Fluxus took the practice outward, becoming an open collective practice (Friedman, 1995, p.8): Flux Mail. Fluxus was born in a period influenced by conceptual art - the desmaterialization of art-, experimental performances and the work of John Cage, Allan Kaprow and Merce Cunningham between others, the object trouve / readymade, neoDada, etc., Despite its open structure, anti-categorisation and anti-institutional spirit, Fluxus became a transnational network thanks to its theoretical leader and "manager" Maciunas and with the help of Shigeko Kubota, through concerts, editions, anthologies, etc. (Schmidt-Burkhardt, 2003).

Fluxus was a heterogeneous art group active from 1960s to 1970s, and in all its different periods was formed by about thirty female and male artists from United States, France, the Netherlands, Denmark, Czechoslovakia and Japan, with internal and external collaborations (Schmidt-Burkhardt, 2003, p.9). Fluxus became a real expanded transnational network of hypermedial artists (Bazzichelli, 2008, p.33). Hypermedia alludes to the interdisciplinarity of media employed (analog instruments, new media like video, etc.) and the different formats (dance, theater, music) influenced by the theories of Marshal McLuhan in works like Understanding Media (1964), where he stated that: "no medium has its meaning or existence alone, but only in constant interplay with other media" (in Harren, 2015). Intermedia defines the hybrid of fluxus-events, fluxus-concers and happenings, an inheritance from Dada movement, performances with the objective of bring together art and life, between artistic practices and concrete experiences. Fluxus events and happenings are the best definition of networking by creating free communication and nonhierarchical sharing platforms created by the artists, where he or she and the public would confuse (Bazzichelli, 2008, p.30), where artists would not restrict to any 
particular medium but experiment with them, a hybrid of analog and new media, and employed in nonconventional forms (Hendricks, J. in Schmidt-Burkhardt, 2003, p.9).

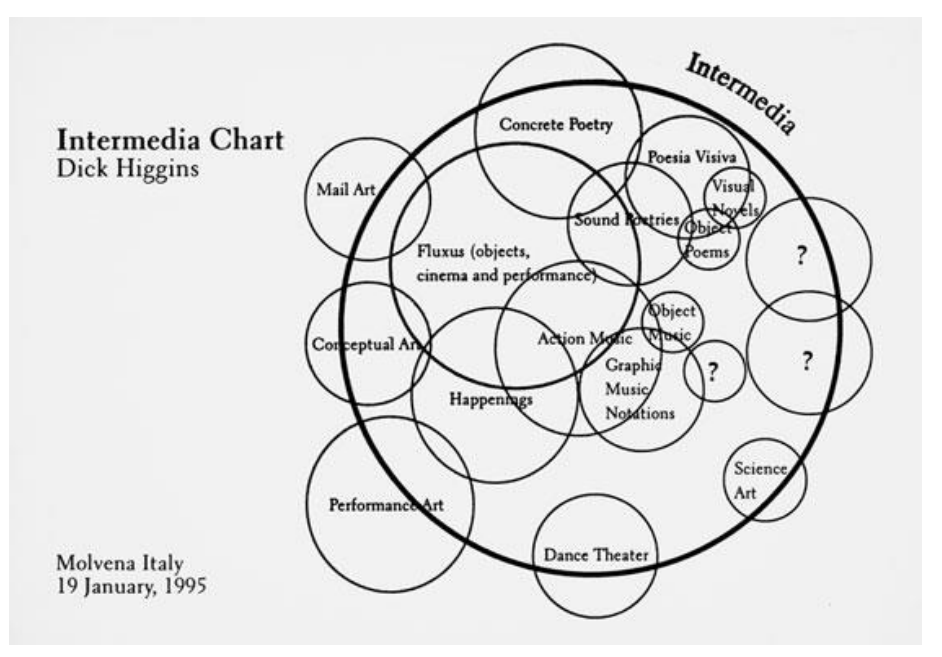

Figure 41 Dick Higgins, Intermedia Chart, 1995, offset lithograph on paper. Dick Higgins Papers Collection, Charles Deering McCormick Library of Special Collections, Northwestern University Library. CEstate of Dick Higgins

After the avant-garde movement and their experimentation with communication tools, Fluxus movement is the best example of the influence of information and communication technology in arts, before the computers and the Internet. An evidence of the innovative interdisciplinarity and intermedia formats Fluxus members applied, are the works of the pioneer of video art, Nam June Paik.

\subsubsection{Female Networks within the Networked Art: Women in Fluxus}

"Men make manifestos, women make friends" Freya Zabitsky, circa 1987

From Fluxus members, men and women developed personal practices within the same fluxus spirit and collaborated between them interchanging and combining knowledge, skills and ideas. Before the women's liberation movement would take an important space in media and arts, Fluxus movement was formed by disparate members, with no distinction of gender, culture or ethnicity, with different backgrounds of expertise, a fact that contradicts the general male-dominated panorama in visual arts - 
for example, Abstract Expressiosnism- (Terpenkas, 2017). Women worked together and with men, they experienced an egalitarian art group and practices, before the start of feminist art (SchmidtBurkhardt, 2003, p.75). As Mieko Shiomi said (in Yoshimoto, 2009):

The best thing about Fluxus, I think, is that there was no discrimination on that basis of nationality and gender. Fluxus was open to anyone who shared similar thoughts about art and life. That's why women artists could be so active without feeling any frustration.

Some of the women in Fluxus who worked with new media in their work were Shigeko Kubota and Charlotte Moorman, in collaboration with Nam June Paik. Shigeko was Paik's wife, and she was the first artist to adopt the portable video camera Sony Portapak in 1967 (MoMA, 2018). She was the VicePresident of Fluxus, together with Maciumas co-organised and assisted the events, and the distribution of the Flux Mail (Terpenkas, 2017).

Charlotte Moorman, known as "the Jeanne d'Arc of new music" (described by the composer Edgar Varese), founded in 1963 the New York Avant Garde Festival, which she directed until 1980, one of the first festivals with new media and electronic art works ${ }^{60}$. Moorman created intermedia performances with Nam June Paik with for decades. The artists Kate Millet The theoretical results of her experience in Fluxus in a posterior phase her work would influence the theoretical development of the movement and the feminist art (her famous statement, "the personal is political" (Fredrickson, 2009). IN 2010, an exhibition organised by Sheelagh Bevan with David Senior at the The Museum of Modern Art Library, "Women in Fluxus' retrieved the important role and alliance between the fluxwomen.

\footnotetext{
${ }^{60}$ Video art, painting poetry, jazz, documentations, happenings, air art, actions, events, films, sculpture, kinetic light art, electronic music, lighting design, computer art, projections, environments, things, dance, earth art, structures, inflatables, synthesizer art." Annual Avant Garde Festival of New York, available at:

<https://www.eai.org/supporting-documents/752/w.1238.0>
} 
Fluxus developed in the decade leading up to the women's movement, and the prevalence of female participants in its diverse activities was unprecedented. The women featured in this exhibition created various forms of intermedia art-falling somewhere between visual art, poetry, performance, and sound art; they acted as interpreters of works by others and hosted seminal concert series that enabled avant-garde movements to flourish. In doing so they contributed to the expanding parameters of artistic expression that characterized their era while redefining “women's work” for the female artist (MoMa, 2010).

In 1975, under the name Women's Work (as Judy Chicago would name the tasks for her students in the experimental first feminist programme in Fresno), a group of Fluxus female artists self-published collection, bringing together for first time textual scores exclusively by women. It was edited by Alison Knowles and composer Annea Lockwood (MoMa, 2010).

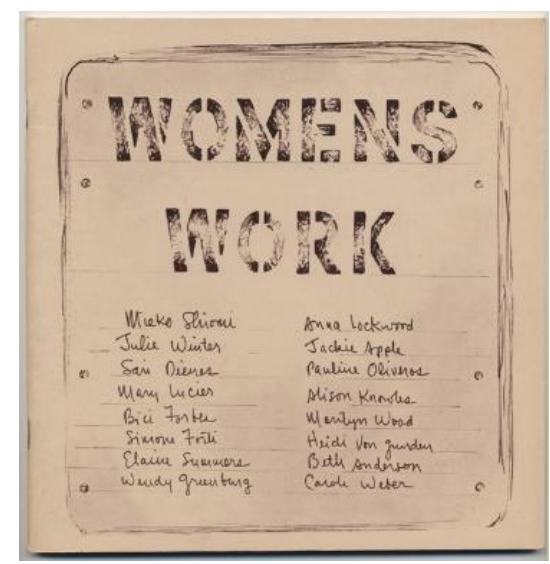

Figure 42 Anna Lockwood et al. Women's Work (selfpublished, 1975)

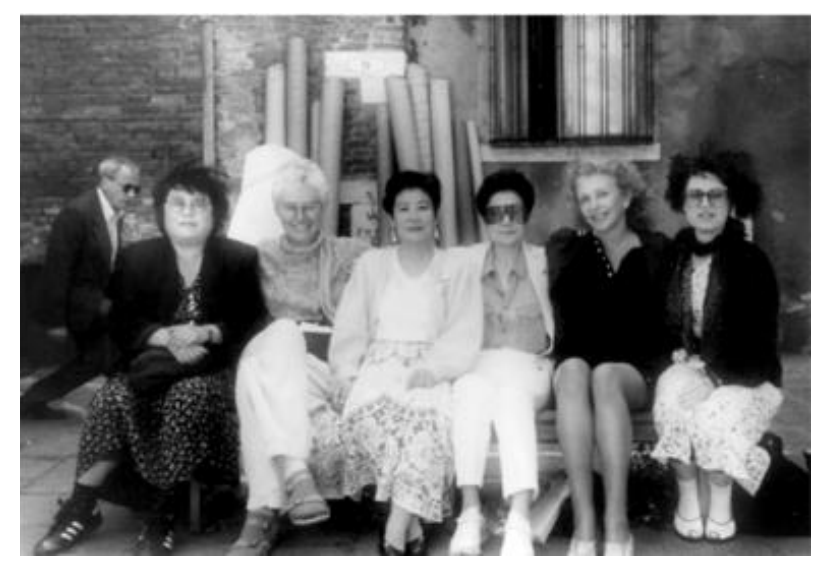

Figure 43 From left: Shigeko Kubota, Alison Knowles, Mieko Shiomi, Yoko Ono, Carolee Schneemann, and Sara Seagull, at the Fluxus exhibition "Ubi Fluxus, Ibi Motus"

All members of Fluxus were professional and personally connected, and women specially. This is a picture of some of the female fluxwomen during the 1990 Venice Biennale, with director Achille Bonito Oliva in the background. Photo Larry Miller, 1990. 


\subsubsection{Women's Networks in Mail Art}

The Flux Mail grown to a point that in 1972 reached 1400 names and addresses, publicized and distributed gratis around the world to artists, organisations and publishers. Analog Mail Art, contrary to electronic mail art, reached a wider number of countries due to the less limitations by technology accessibility for electronic emails (Ascott, 2003). The list was a core part of the first FILE Magazine artists' directory. (Friedman, 1995, p.8) The Eternal Network flourished despite the indifference of the established art world, but despite their reactionary spirit, it "quickly became a male art - another form of the old boys network" (Vesna, 1997). Like it would happen in the electronic networks, women in mail art found "difficulties with the rules and hierarchies that emerged with the mail art manifestos" (Vesna, 1997). For example, mail artist Frey Zabitsky designed in the middle 80s a rubber stamp with the slogan: "Men make manifestos, women make friends"61 (Friedman, 1995, p.15).

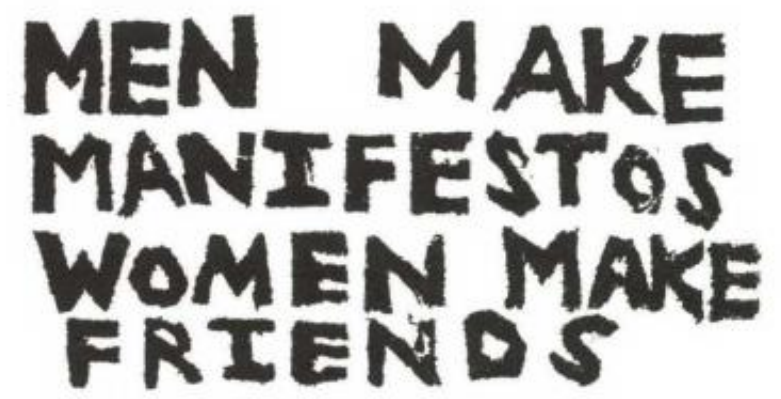

Figure 44 Freya Zabitsky, Men Make Manifestos, U.S.A., 1987(?). Handcarved Rubber Stamp. Retrieved from Friedman, 1995.

In 1978, artist Anna Banana, who self-published VILE, a magazine dedicated to mail art, defended the concept that the medium is more important than the aesthetic, and in order to create community through correspondence Banana dedicated one volume of VILE to Fe-Mail Art ${ }^{62}$, an

\footnotetext{
${ }^{61}$ It relates us to the VNS Manifesto (3.2.1.)

${ }^{62}$ Here we find an evident predecessor of Faces Mailing list (see section 3.3.2.)
} 
exclusive mail art by over one hundred women internationally with a successful feedback (Ferranto, n.d.): women from the USA, Canada, Australia, Japan, Brazil, England, France, Holland, Germany, Spain, Italy, Hungary, Poland, Czechoslovakia, Yugoslavia and Argentina. Luminaries such as Yoko Ono, Martha Wilson, Alison Knowles participated. According to Ferranto (n.d.), Banana wrote in the introduction in 1978:

Women have embraced mail-art because it is a medium through which it is easy to assert oneself. It also gives me a sense of community on an international level, fostering the idea that peaceful co-existence, caring and concern for people of other nationalities is possible.

Seven hundred copies were printed September 7, 1978. As Victoria Vesna pointed a couple of decades ago (1997): "This magazine could be the most significant predecessor of network projects designed specifically for women artists.”

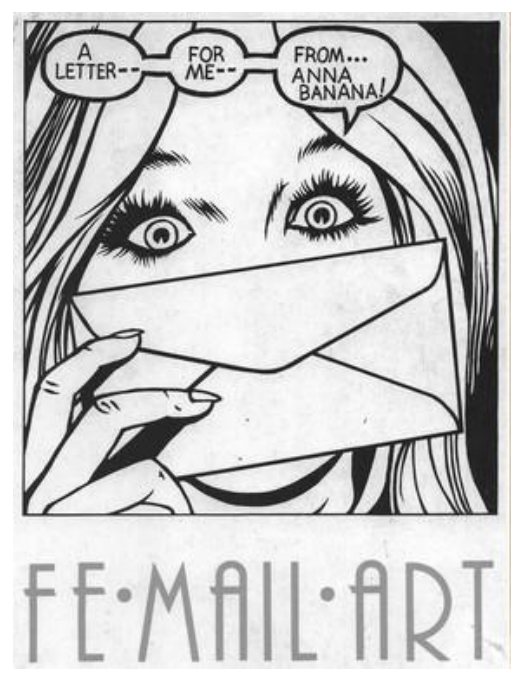

Figure 45 Pat Larter, rubberstamps. Letter to Lomholt 1978-11-19. Envelope. Pat and Richard Larter, Australia

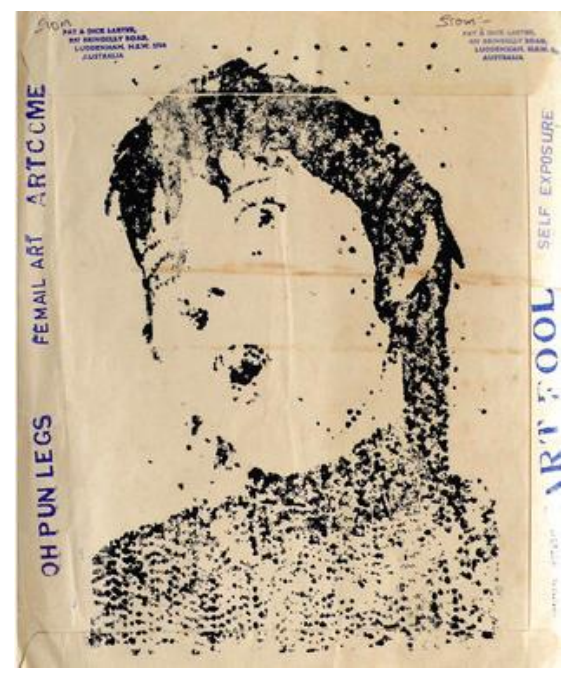

Figure 46 Anna Banana, front image, VILE vol. 6, no 3. The Yellow Book 1978-00-00., Canada.

This fe-Mail Art stamp would still be active until the 1990s - relate to Victoria Vesna work in 1995, who brought the Fe-Mail Art to f-email to one step further in the electronic networks. 


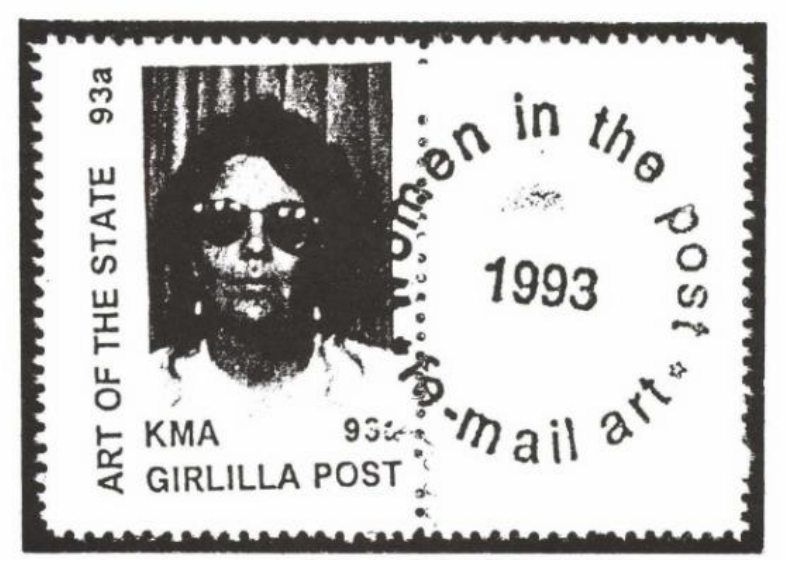

Figure 47 Beth Jacobson, Girlilla Post, USA, 1994, Handcanceled Artists' Stamp.

\subsubsection{Women Weavers: Women in Telecollaborative Arts}

"I am a weaver. But only in the beginning did weaving mean the process of intertwining threads to make cloth. Mostly I have practiced it by connecting people, ways of thinking, and forms of knowledge to shape culture."

Anna Couey, 2016

Telematic arts refer to the projects who started to use computer mediated and telecommunications networks as an artistic medium (Ascott, 2003, pp.222-23). While the artistic approach through computer graphics during the 1960s and 1970s was mainly focused on the possibilities of the system in generating objects and images and animation, after the 1970s and during 1980s and early 1990s some artists aimed to create networks through new media that allowed them to connect in live, a communication and technological revolution predecessor of the World Wide Web (Giannetti, 1998). The telematic network implied mobility that impacts the experience of the medium as the experience of the environment, the notion of reality changes, to a flexible, mutable, virtualized. (Giannetti, 1998, p.17). In 1984 William Gibson used the term cyberspace in his novel Neuromancer trying to draw a relation between cybernetics and computer telecommunication. However, while cyberspaces refer to a virtual location to the mental individual state while experiencing telematic 
networks, telematic "emphasizes the emergence of a collective consciousness" (Shanken, 2003, p.52). North American artist Anna Couey (2003) described this "conceptual weaving" of art-life process as "the opportunity to map the world according to different sensibilities and to form reciprocal communications across geographic, political, perceptual, and temporal borders" (p.64). Open communication system enables an open democratic cyberspace that erases the notion of authorship (Giannetti, 1998). Communication networks are based on perpetual communication systems, enabling the expansion of ideas and the building of communities. Couey (2003) describes these networks from an artistic approach as sculptural forms, becoming organic and independent by the social daily use (p.60). The achievement by women in telecommunication art has been to create through these virtual sculptures, spaces of horizontal communication, acknowledging the new language and new set of relationships this implies (p.80).

Contrary to computer arts, women in communication arts were not focused in creating new media images, instead they were motivated by the creation or the use of electronic communication systems to create a virtual space of connection for different individuals cross-borders and crosscultures. Women in computer arts and computer graphics, likewise women artists didn't perform intentionally a feminist art or took a polemic political perspective in their work. However, the work by women through telematic arts made a notable contribution redefining the ways mass communication systems can be designed and questioned the hierarchical -traditional- Western art production. Their work directly got in the daily living, performed collaboratively and interactively with communities and people, working together with community-based organisations, social justice activists, scientific researchers, industries and the education system (Couey, 2003, p.79). Following the legacy of the Fluxus happenings and being part of the new media activism that was taking place in many art practices (Chandler \& Neumark, 2005), communication art projects had a clear intention to involve the public as collaborators in the process of art making, to connect art and life, investigating the potential of 
horizontal communication. Women artists have specially created alternative models for the production and dissemination of information through telecommunication networks:

Women artists who build electronic communication environments, connect people to each other, share stories, and develop communication tools are taking steps toward altering social communication at a systemic level—as art. In so doing, our work not only provides a platform for our own voices but opens channels of communication for others who have been denied their voices — bringing disparate worlds together to create a world that reflects and respects all. (Couey, 2003, pp.57-59)

Some of the telematic, telecollaborative and networked art works were made by groups and collectives formed by both women and men. One of the first artworks to use telecommunication technologies was done by the Canadian artists Vera Frenkel in 1974 in collaboration with the Bell Canada Teleconferencing Studios. She produced the work String Games. (Chandler \& Neumark, 2005).

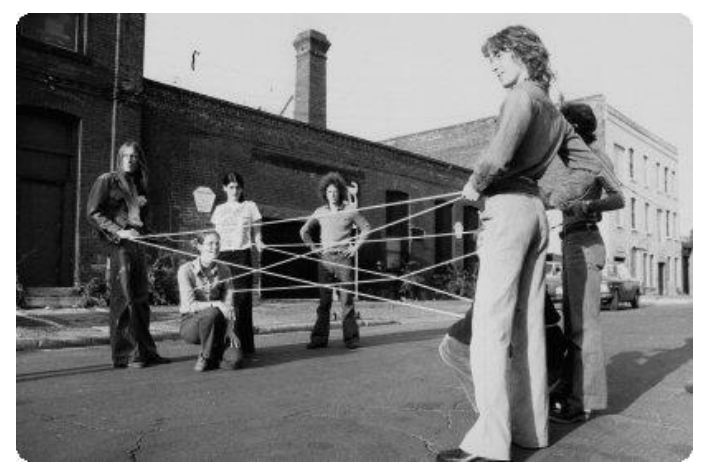

Figure 48 Vera Frenkel, String Games: Improvisations for Inter-City Video (Montreal-Toronto, 1974)

In the USA, Sarah Dickenson enabled connectivity cross-borders to international artists through slow-scan television, two-way cable TV, and computer networking. With the Communication sphere Group at the Massachusetts Institute of Technology from 1977 to 1985, she enabled an exchange across cultures of their ideas, concepts, and work (Couey, 2003, p.58). One referent of the early telecollaborative art was the work performed by a collective formed by Kit Galloway and Sherrie Rabinowitz, who have been developing innovative and outstanding communication performative 
works with tele-collaborative technologies since the middle 1970s until the 2000s, applying in their work the Internet and 3D visualization tools with the time (Galloway \& Rabinowitz, n.d). From 1975 to 1977 they developed the series “Aesthetics Research in Telecommunications”, Satellite Arts Project was part of it. In this seminal work in telecommunication art history, they addressed the experimentation with issues related to telecollaborative arts and virtual space performances. "A space with no geographical boundaries" was part of the title, creating a virtual space by connecting two performances in remote places (Bazzichelli, 2008, p.96): "A new way of being in the world", what could also now be described as inhabiting cyberspace, in which cyberspace is an electronic place defined by communications exchanged among individuals on all sides of the media (Couey, 1991).

The ideas developed in Satellite Art Projects regarding a "life in virtual space" lab extended the notion of "the image as place" and as a "virtual performance", were later applied in projects like Hole in Space, two simultaneous performances connected through satellite in 1980 and ART-com in 1982 a multi-disciplinary laboratory, between others (Couey, 2003). Their attempt to connect "different communities and cultures" through performative and interactive communication networks took a bigger dimension in 1984 with Electronic Café Network, set in Los Angeles in five local eateries (Couey, 2003, p.58). The previous year they started defining the concept of telecollaborative network, connecting informal public through multimedia communication venues (Galloway \& Rabinowitz, n.d.).

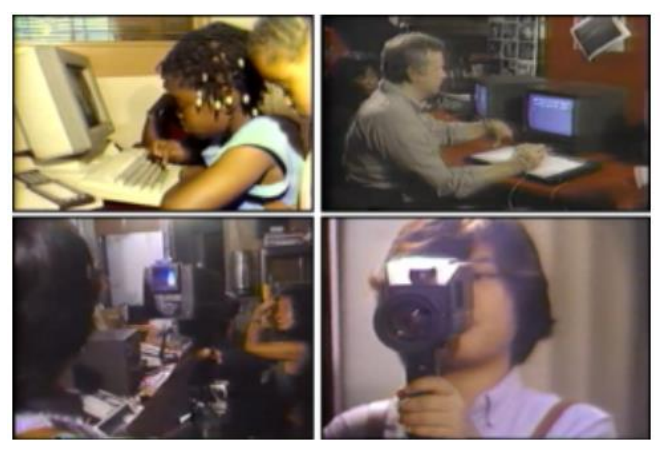

Figure 49 Mobile Image, Electronic Café, 1984. Photograph of live event in Los Angeles. Courtesy of Kit Galloway, retrieved from Levine \& Glahn, 2016. 
Performed during seven weeks during the 1984 Summer Olympic Arts Festival, these artists offered a social model by integrating multiple-media telecollaborative technologies, art and community (Galloway \& Rabinowitz, n.d.). Electronic Café "advanced a notion of technology as a fundamentally sociopolitical practice". Within ECN, they founded the art collaborative mobile image, which constructed their own "telecollaborative network" (Levine \& Glhan 2016) by interconnecting five Coffee shops in five neighborhoods with different ethnicities, creating a virtual shared space, bringing closer art and life. The cultural diversity was a model for integration (Giannetti, 1998, p.17)
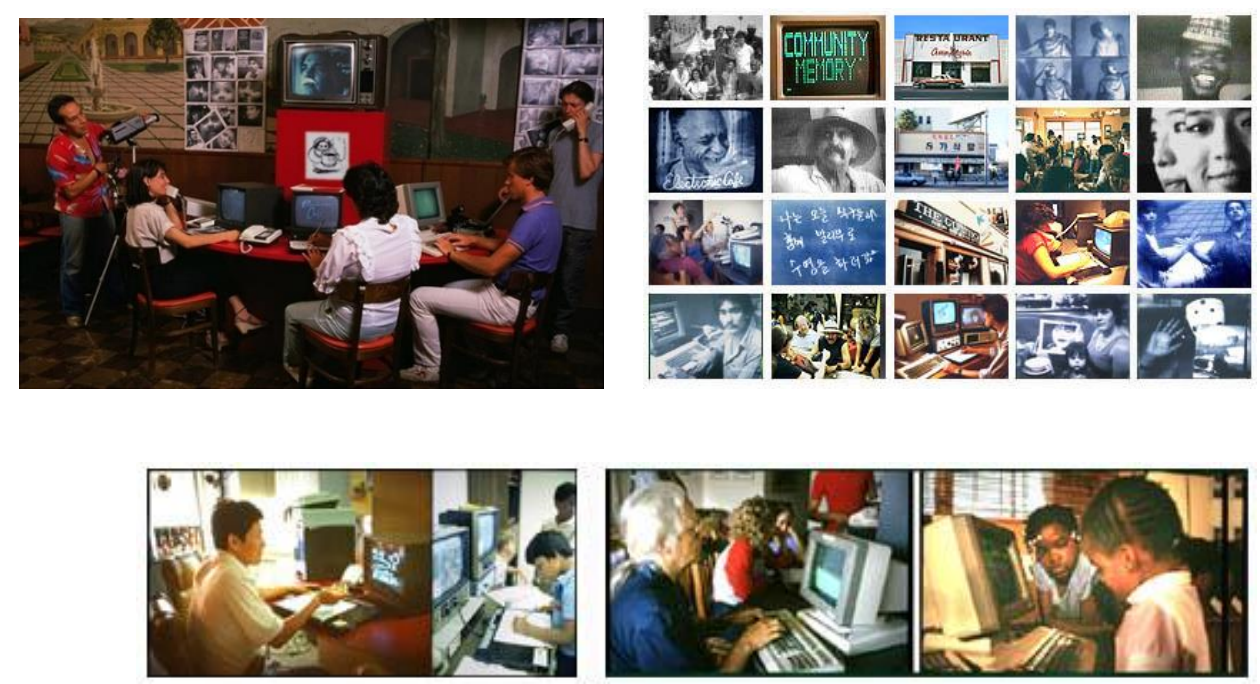

Figure 50 Images of Electronic Café Network, Galloway \& Rabinowitz 1984. Retrieved from www.ecafe.com

After Electronic Café, the artists opened the first links with Paris of Electronic Café International, from the wish to build a community, a permanent multimedia collaborative public network, a telecommunication lab "where they could connect with other people" and build an international network, in the convergence of intimate, public and virtual space as an experience. A creative integration, technically, socially and artistically: "ECI creates a networked lab, to support collaboration and co-creation between people in different cultures, countries and language groups" (Galloway \& Rabinowitz, n.d.). 


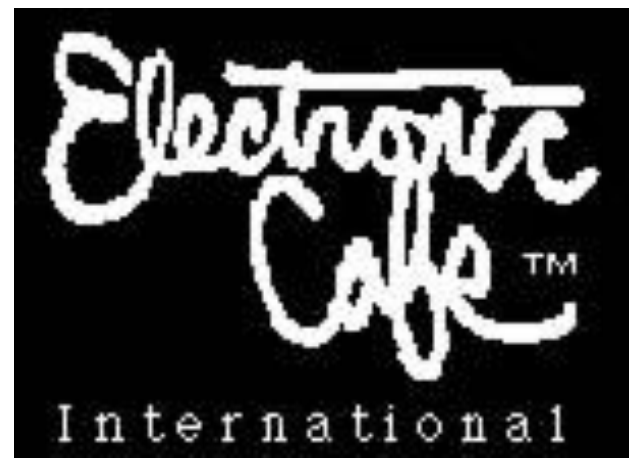

Figure 51 Figure 45 Logo Electronic Café International, 1888. Retrieved from www.ecafe.com

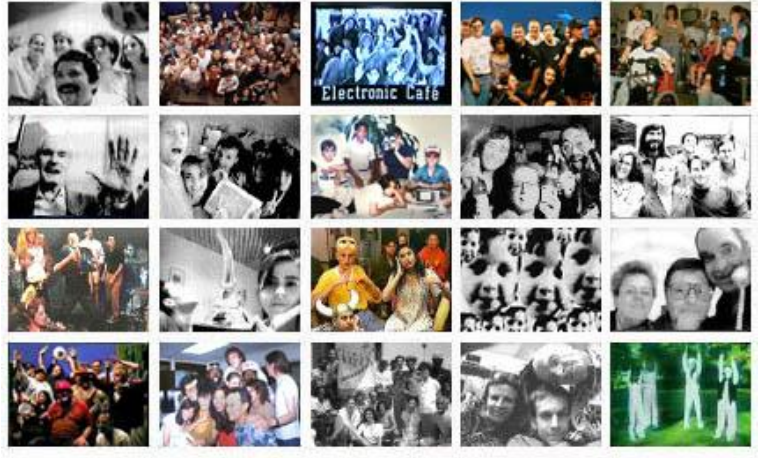

Figure 52 Tele/PoetryNet, Galloway \& Rabinowitz. Retrieved from www.ecafe.com

Since its founding, ECI has produced an extensive range of live multipoint performances, involving virtual-reality technology. Within ECI, Tele-Poetry was the first videophone poetry network gathering different scattered locations in 1989, allowing poets from LA encounter "the interests, cultural diversity, and aesthetic agendas of poets in other places, circumstances, and political contexts" (Galloway \& Rabinowitz, n.d.). Although these artists didn't consider their work feminist, contemporary lectures of their telecollaborative art pieces and premises relate their work to the theories of technofeminism, to the methodologies of networked feminism (Way, 2016), or to the aims of transnational feminism, as I presume.

In Europe, there were telecollaborative works like Planetary Network, organised by Maria Grazia Mattei, Roy Ascott, Don Foresta, Robert Adrian Tom Sherman and Tommaso Trini for the Venice Biannual in 1986. The work experiddmented with remote communication by connecting positions in England, Canada and Australia by fax technology. A creative dialogue between-send receiver created by a transmission of network of words and images (Bazzichelli, 2008, pp.95-6):

The creative use of networks makes them organisms. [...] To engage in telematic communication is to be at once everywhere and nowhere. In this it is subversive. It subverts the idea of authorship bound up within the solitary individual. It subverts the idea of individual ownership of the works of imagination. (Ascott, 1984) 
Telematic arts, like "organic communication systems" enable new behaviors, new realities, relying on the effects, rather in the identity or objectification (Couey, 1991).

\title{
2.4.5. Computer Networks and Mail Art
}

\author{
"As a sculptural form, communication networks address \\ issues of dissemination of ideas and of community building \\ (for networks exist only to the extent of their use). When \\ successful, communication networks blend into daily living, \\ becoming a part of the social landscape — organic sculptures \\ that take on a life of their own." \\ Couey, 2003, p.60
}

The above described community of artists in Mail Art became an "usual global village", who brought the Eternal Network into telefax, electronic mail and computer networks (Friedman, 1995, xv). First the Fax machine and then Mail Art networking, expand the possibilities of erasing geographical and institutional boundaries" for artists seeking for a new artistic identity (Coco in Friedman, 1995, p.121) Electronic computers empathized ancient tendencies of connectivity. The following images by two female artists in the 1990s reflect the heart of a networker, which is anachronic:

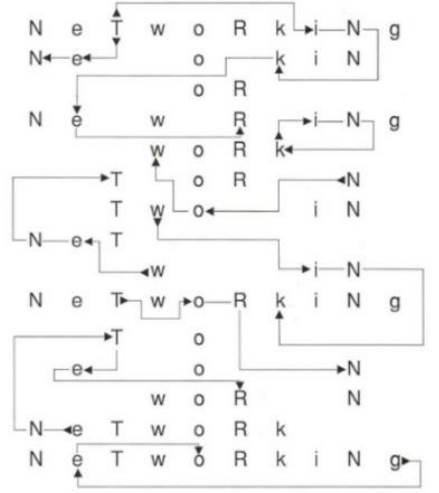

Figure 53 Figure 12. Kathy Ernst, Networking, U.S.A., 1991. Computer generated visual poem

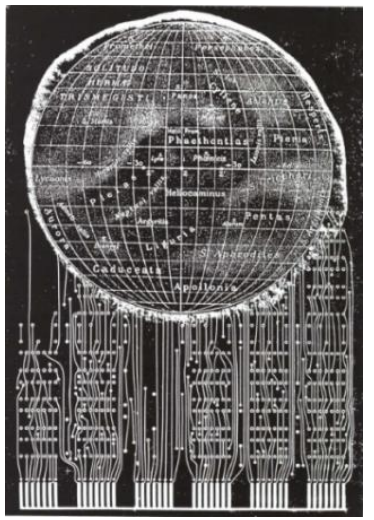

Figure 54 Carol Stetser, Page from Currents, U.S.A., 1992, Artists' Book. 
With the development and domestication of computer networks and Internet tools in advanced capitalist countries, the communications systems changed, and telecommunication artists went from connecting electronic devices networks towards building a network, to use the existing infrastructure of the computer network and Internet itself. Therefore, the shift from telematic networks to computer networks affected to the electronic meeting place, the cybrespace. While in telematics it provided "for culture an extensive non-localized place, for the most intimate and inclusive dialogue and exchange", the computerized network enabled an electronic arena as meeting place for creative work (Ascott, 1984): "Virtual communities. social networking It also meant the appearance of specialized communities connected through electronic mailing lists and listservs" (Couey, 2003, p.63).

The communities engendered via computer networks are organisms. Like physical communities they evolve and are influenced and defined through user participation. Like physical organisms, the extent of their impact on the ecosystem depends on their interaction with other organisms. Creative use of computer networks implies, from a user standpoint, experimentation with forms of communication and user interaction. From a systems standpoint, creative networking involves investigations into levels of user interaction in virtual space, community building and cross-pollination, or the creation of links between previously disparate communities (Couey, 1991)

The concept of connectivity and the simile between the virtual and electronic computer network with organism in telematic arts was also worked in the sixties within the Artificial Intelligence field, named connectionism, that would study the relation between computer and the neuronal networks in human brain (Cilleruelo, 2006, p.29). Later, the rhizome concept by Felix Guattari and Gilles Deleuze (19721980) based on botanical rhizomes would impact the theories of the Internet for its principles of connectivity, heterogeneity, multiplicity, signifying rupture, cartography and decalcomania. A rhizomatic network rejects the organisational structure of the root-tree system, and ceaselessly 
establish connections "between semiotic chains, organisations of power, and circumstances relative to the arts, sciences and social struggles" (Deleuze \& Guattari, 1987, p.13).

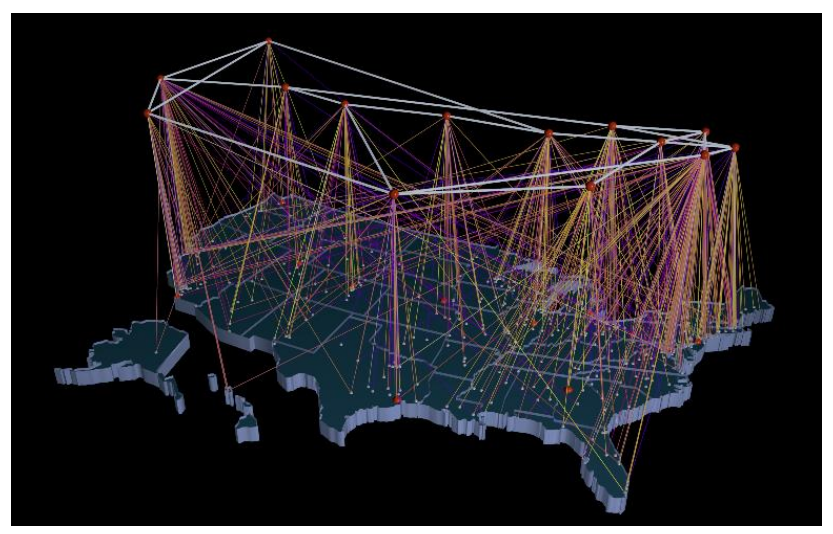

Figure 55 NSFNET 1991 visualization by Donna Cox and Robert Patterson, National Center for Supercomputing Applications, University of Illinois at Urbana-Champaign

Connectivity on the Internet allows an utopian attempt of individual realization through established social nodes in the network, based on information exchange, oppose to the concept of aggrupation (Cilleruelo, 2006, p.31). Virtual communities are the microorganism of the Net, result of the social interactivity and connectivity in the cyberspace of hypertext and graphic interFaces:

In terms of the way the whole system is propagating and evolving, think of cyberspace as a social petri dish, the Net as the agar medium, and virtual communities, in all their diversity, as the colonies of microorganisms that grow in petri dishes (Rheingold, 1993). 


\title{
2.4.6. Virtual Communities
}

\author{
"This seems to be the case wherever \\ and however computers are linked: \\ we go online to find information, \\ but mostly we go online to find one another." \\ Evans, 2018, p.130
}

The Web and the Internet are not interchangeable concepts, the use of computer networks for social networking existed before the Internet. In 1994 the National Science Foundation's NSFNET, the successor of the ARPANET, gave rise to the network we know today, together with the Internet service provides appearance (Shanken, 2003, p.69). The collective project lead by Elizabeth Feinler in the Network Information center formed by students, engineers and scientists developed ARPANET, the roots of the Internet during the 1965-1975 (Bazzichelli, 2008, p. 145). When it was still a privilege of an elite of researchers, within this academic network the Internet structure was established based on the networking and human activities towards a substantial impulse for the development of technology (p.146) When the ARPANET moved from academic networks to civic ones, the instantaneous messaging passed to be an open communication network (Evans, 2018, p.130), and virtual communities like Echo NYC ${ }^{63}$ or The WELL ${ }^{64}$ appeared before the graphical Web pages, when people used to go online to directly dial into host computers to exchange files and post messages (Shanken, 2003, p.69). Feinler used the APARNET itself to stay on top of network business. Using her networked terminal, she "connected with colleagues across the lab and at sites across the country, often talking to people she'd never met in the flesh" (Evans, 2018, p.130). From the local access FreeNets, to the BBS (Bulletin Board System) then FidoNet connected them all into national community of villages (Evans, 2018, p.130). One of the early works about computer-mediated communities was the one by Howard Rheingold, when presenting The WELL (Whole Earth'Lectronic Link), a BBS for West Coast

\footnotetext{
${ }^{63}$ See <www.echonyc.com>
}

${ }^{64}$ See <www.well.com> 
intellectuals in United States, one of the first virtual communities still ongoing, formed with a computer-conferencing company and the Whole Earth Review. The WELL has been dialing worldwide since 1985, enabling people through chat rooms and electronic emails to have public and private conversations (Rheingold, 1993). The WELL had a predominance of male users (what will be called later by cyberfeminists an old boys network), and in 1990 the Echo NYC internet saloon was founded by one of its female users the New Yorkine Stacy Horn, creating the 'East Coast Hang Out'. She started the project in her apartment in Greenwich Village, and her main objective was to make a virtual space attractive for female, she achieved to provide a virtual space for equally women and men as never existed before. When by 1980s female presence in the internet was $10-15 \%$ in United States, she made from Echo a half women's presence, with women's issues chats and even female-only forums like the Women in Telecommunications (WIT) (Evans, 2018, p.132)

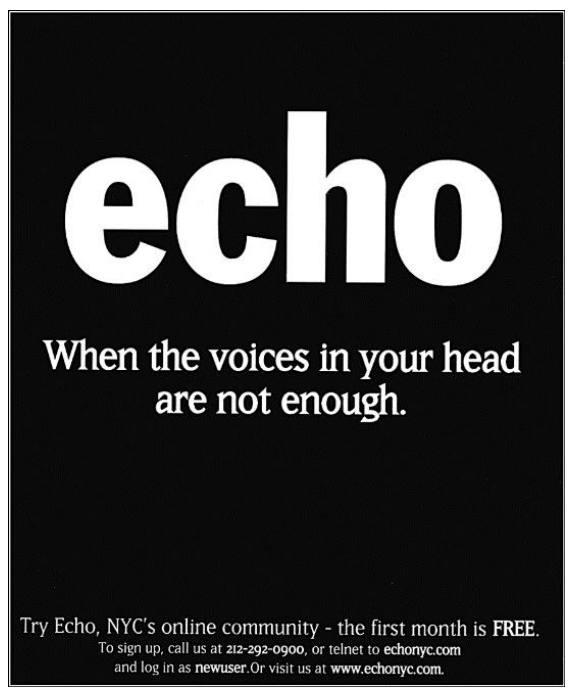

Figure 56 Echo NYC announcement, in Evans, 2018.

Rheingold (1993) discusses the WELL as a virtual village -alluding to McLuhan theories-, pointing out the psychological benefits of the virtual communities, in an individual and social scale. But, as Claire Evans (2018) notes, he forgot to mention EchoNYC. Both The WELL and Echo 
combined the face-to-face meetings with the virtual encounters, strategy that enabled the success of the reinforcement of the social networks within the community.

Because of its potential influence on so many people's beliefs and perceptions, the future of the Net is connected to the future of community, democracy, education, science, and intellectual life -some of the human institutions people hold most dear, whether or not they know or care about the future of computer technology (Rheingold, 1993).

Lourdes Cilleruelo (2006) widened Rheingold's description when talking about virtual art communities, adding three basic premises: nonhierarchical communication and interaction between the members, a network identity established and the relationship between the members must rely in their connectivity, not in their geographical location (p.30).

\subsubsection{Networks within the network}

Simultaneously, the stigma that computer-based and telematic arts was carrying since its beginning made the community change its name to digital arts, as computer arts as a term was already hardly denigrated (Taylor, 2013). However, in the middle 1990s the world of digital arts was profoundly growing, and its network was reinforced by the new communication and information technologies. Previous networks to the Internet in art and technology world like [New] Tendencies, E.A.T., and the Computer Arts Society enabled a creative use of digital technologies for actively participating in social contexts and bridged both society's and art's transition from the industrial age to the information society, from cybernetics to digital arts (Fritz, 2016, p.65). The increasing amount of institutions, magazines, journals, departments, media labs, conferences, festivals provided space for local and national networking while being part of the transnational network of artists, scientists, technological, theoreticians, educators, curators, etc. Others functioned as international networks like 
the both longest lasting journal Leonardo and the longest lasting Festival in digital arts and culture Ars Electronica, founded in Linz in 1979. Additionally, the above-mentioned SIGGRAPH was an international meeting point and network, the Camerino Festival of Electronic Art in Rome the DEAF (Dutch Electronic Art Festival in Rotterdam since 1987 and Transmediale in Berlin, since 1988, with high scale international exhibitions, conferences, talks, concerts, workshops, etc. (Fritz, 2016, pp.612). Australian Network for Art and Technology, for example, was founded in 1988, still ongoing is a nonprofit organisation programmeming workshops, publications and immersive residences. This meta network (Fritz, 2016, pp.61-2) gave rise to an international interdisciplinary creative space, in rapid expansion and development, defined by Vittorio Fagone as "third culture", which filled the gap between science and humanities (Fagone in Bazzichelli, 2008, p. 95). It was within this scenario of international collaboration that the networking artists worked via computer and telematic networks, and from which internal social networks appeared (Bazzichelli, 2008, pp.95-6). By then, digital arts experienced a branch of technologies and definitions within it that makes it very complex for a definition, embracing telecommunications, robotics, 3D, electronics, interactive art, Net.Art, etc. Theoreticians like Claudia Giannetti (2005), studied and described the radical changes that digital technologies and telecommunication media produced in art, towards the establishment of a digital aesthetic theory. Within all the categories and practices, in digital arts the core element was dominantly social, as its main purpose was to create new modes of existence: digital art is therefore not produced by the social but is social (Paul, 2016, p.4). The art of networking became such a practice that the Prix of Ars Electronic -the most appreciated prizes in new media arts worldwide- added a new category for Virtual Communities in 2004 (Cilleruelo, 2006, p.11).

Within the network of digital arts, collaboration was a necessary strategy to access the community of specialized knowledge (Cox et al., 2018, p.43), and those community were built through computer networks, since the early phases of Internet. In this previous phase of Internet spread 
accessibility, women artists and cultural workers took part in the computer-based communication networks building. Concretely for artists, developing computer-networks means that the process and structure of community making are the art itself, developing relationships within the diverse groups. As in telematic arts, they aimed to expand affordable access for international cultural communities, developing links between them online:

Some artists have envisioned a public cyberspace in which individuals of varying cultures and interest collectively and continually evolve new realities. [...] Perhaps the most significant cyber artwork of this century will be the development of interactive communication systems that are globally and socially inclusive and diverse - a collaborative cross-community and cross-cultural project (Couey, 1991).

The first international computer network developed by artists was ARTEX (Artist's Electronic Exchange Network), founded in 1980 and active until 1991. It was an ASCII e-mail system, that “intercontinental, interactive, electronic art-exchange programme designed for artists and anybody else interested in alternative possibilities of using new technologies" (Bosna, 2005). The ARTEX community of international artists organised a number of telematic art events during the 1980s related to the collaborative making of text-based works, like: La Plissure du Texte, the collaborative writing of a fairy tale, produced by nodes of artists in Europe, Canada, the United States and Australia, organised by Roy Ascott and the abovementioned Planetary Network, in which internationally located nodes of artists sent news to each other and to a central exhibition node in Venice, Italy (Couey, 1991). Art Com Electronic Network (ACEN), started in 1986, it was a San Francisco based online magazine forum "dedicated to the interface of contemporary art and new communication technologies", still running as a "virtual artists space" for creative collaborations between the cyberspace pubic and the artists. ACEN runs on The WELL, as a conference, taking part as an on-line art gallery (Couey, 1991). ACEN was a project by ArtCom, an artists' organisation founded in 1975, dedicated to new media arts, 
being ArtCom an artwork itself, exhibiting, presenting and publishing for more than twenty years conceptual, performing, correspondence, video, television and communication art, in addition to art publishing. ACEN was Founded by Carl Eugene Loeffler and Fred Truck, a group of women artists (Anna Couey, Nancy Frank, Donna Hall, Darlene Tong, and Lorna Truck) contributed notably in its design and implementation. Artists Judy Malloy and Abbe Don also took part in ACEN community with their hypertext collaborative works. Couey 2003 ACEN offered electronic publications, mail system, and a virtual shopping street with shop reading art (Bazzichelli, 2008, p.100). ACEN performed new geography and culture links by interaction and connectivity of international dispersed communication nodes. Art.artcom was one of the first projects as a newsgroup on USENET, a network system, distributed as a conferencing system, providing global communication and participation.

ACEN is also developing mechanisms for data exchange so that projects and information generated on local nodes are reciprocally disseminated across the network. Its concern is to decentralize and broaden communication between diverse cultures and minds (including socioeconomic backgrounds, interests, experiences and perspectives) and to explore what can happen with combinations of communities (Couey, 1991)

Many women artists including Malloy and Anna Couey were part of ACEN community, and two of them -Sue Harris and Phillip Bannigan- formed ArtsNet in 1990 on Pegasus, an Australian node of an international network of conferencing systems for the social justice community, the Association for the Progressive Communications (Couey, 2003, p.62). Both ACEN and ARTEX were host for international art networking events and had as a result works that based on the concept of audience as art co-creators, interactivity, art as the information exchange between communities from diverse cultures and professions. 


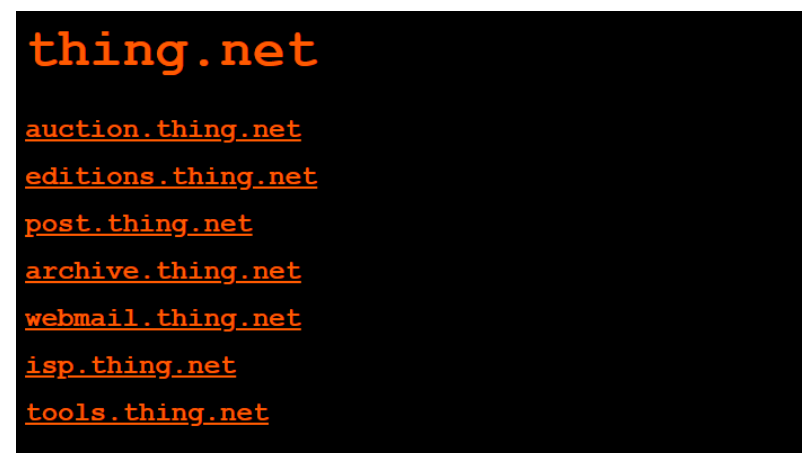

Figure 57 Screenshot of the main page of www.thing.net, 2019

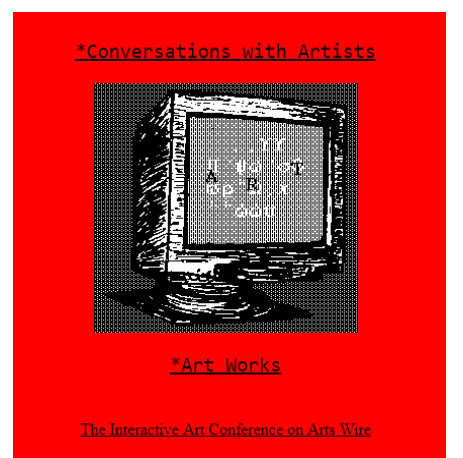

Figure 58 Screenshot of the website "Conversations with Artists*Art Works" The Interactive Art Conference on Arts Wire. http://www.artswire.org

In 1991, Gisela Ehrenfried together with Wolfgang Staehle started The Thing ${ }^{65}$, the first project of major importance to emerge, created a network of Thing nodes in Europe, one of the first platforms of BBS communication, it was a point for debate about new media art, and later for net.art. It was accessible via the New York telephone network, and it offered its content "via BBS and services as internet provider", with regional branches (Bosma, 2004 in Bazzichelli, 2008, p.100).

In 1992 Anne Focke started an online system for artists and art organisations, Arts Wire, on the Meta Network in United States, focused on the culturally diverse community building, where Anna Couey was the first network coordinator. Couey Judy Malloy joined in 1993 as FrontDesk Editor of Arts Wire ${ }^{66}$ Current. Arts Wire provided a communication network for the arts community, with the "strong voices of artist and community-based cultural groups" as a core (Arts Wire, 1997 in Malloy, $2016)^{67}$.

\footnotetext{
${ }^{65}$ Available at <www.thing.net>

${ }^{66}$ Available at <http://www.artswire.org $>$

${ }^{67}$ Available at <https://web.archive.org/web/20010617032854/http://www.artswire.org:80>
} 


\title{
2.4.8. Women in early Net Art: Networked art works in the formative years of the
}

\section{Internet}

\author{
"CYBERART: the art of communication systems" \\ Anna Couey, 1991 \\ "The interconnections between communication networks \\ and places enables a kind of conceptual weaving- \\ the opportunity to map the world according to different \\ sensibilities and to form reciprocal communications across \\ geographic, political, perceptual, and temporal borders."
}

Anna Couey, 2003, p.64

The boundaries of telematic art expanded in new directions with the proliferation of computer networks in the late 1980s and 1990s. Low-cost personal computers were available for artists, and the development of the online data communication and the hypertext enabled the multimedia practices of the World wide Web: the creation of hypertext markup language (HTML) and the free distribution of graphical user interfaces. The number of users grew exponentially during the 1990s in North America, Western Europe and Australia, and later the WWW became artistic medium itself, enabling the creation of other hybrid forms of technology in art like robotics, artificial life forms, virtual reality simulations, extending the domain of telematic arts by connecting various and remote user interfaces (Shanken, 2003, p.70). The abovementioned networks were the publishing formats of the early html hypertext works.

Artists are using computer networks, and it is impacting not only their methods of dialogue and distribution, but their creative process and aesthetic output [...] Cyberspace is computer generated space that humans can enter and therein interact and cyber art is art created and existing within cyberspace. Granting computer networks their due status as operational cyberspace, cyber art then includes the art formed via computer networks. Taher than being static objects, cyber art works can be more accurately termed creative communication systems. (Couey, 1991) 
The World Wide Web is a network based on interconnecting visual pages built in a shared language called HTML or Hypertext: structured pages of text, images and video dotted with interconnected links between one and another. The WWW influence not only the way we navigate, but the way we communicate, how we understand the world (Shanken, 2003, p.69). Within the Internet and computer networks, artists continued to experiment with the legacy of the 1970s and 1980s in regarding to collective creation, interactive works and the establishment of relationships among individuals. The definition of networking art that Bazzichelli describes, finds new formats in the electronic networks. The artists were those in charge of the network but who does not determine the artistic process, "which should be free and spontaneous, amenable to the personal creativity of everyone who wants to interact." (Bazzichelli, 2008, p.94). Italians Marco Deseriis and Giuseppe Marano defne net.art as "the art of Connection" and the Catalan David Casacuberta explains this absence of authorship towards a collective creation in his book Creación colectiva: en Internet el creador es el público (2000).

Due to the limited accessibility and the high cost of technology tools, telecommunication art has commonly been accused of being an elite art, an art that is not open to all publics. However, women in telecommunication and networked arts have always aimed to work challenging the corporatestructure designs by designing their own languages and tools, towards a more horizontal agenda (Couey, 2003, pp.76). Within the contradiction of technology development and commercialization, these artists attempted to connect ties cross-borders and cross-cultures despite acknowledging along the years that women are majority of the poor worldwide: "Our work has not yet impeded the increasing centralization of media corporations or the privatization of communication networks - the advance, as VNS Matrix calls it, of Big Daddy Mainframe” (Couey, 2003, p.79). Through their telecollaborative and telematic performances and installations, these women showed an intention to extend themselves to reach other individual experiences, creating horizontal spaces for communication, reflecting the multiplicity of all of us (Couey, 2003, p.80). 
Early examples by women artists using the Net towards a more participative, collaborative and horizontal space were the works in the community artists networks abovementioned. For example, north American artist Judy Malloy collaboratively produced the early html art project Bad Information Base No. 2, part of ACEN, to question the veracity of computer-delivered information, she started gathering "wrong, misleading and inappropriate" information in 1986 to catalogue and organize in a definitive database, today accessible on the net (Couey, 2003, p.59). The artwork: "engaged people who do not consider themselves artists in consciously creating art content. As an information project, it redefined the public as experts in information production" (p.59). Despite the linkage between feminism and computer arts it is not considered to occur yet, some of these women artists did consider their work feminist "whether or not its content specifically explores gender issues" (p.79). From my perspective, I can identify certain feminist issues in these early works by women in computer networks art, while not all of them identified themselves as feminists "in content or intent". Another example by Judy Malloy, was the first to programme a hypertext novel for Apple in 1986, named Uncle Roger: an online narrabase that was part of ACEN as well (Malloy, 1991).

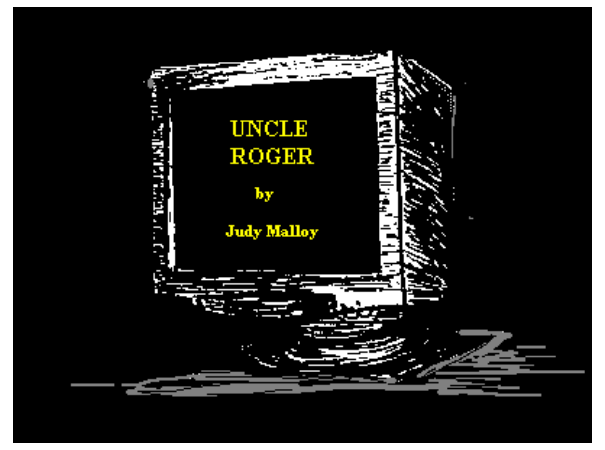

Figure 59 Uncle Roger by Judy Malloy, 1986-1988 retrieved from The WELL

Malloy was a self-taught computer programmemer, conceptual artists, and single mom by then. Uncle Roger is a collection of three linked databases files, each one a pool of information, where the public interacts with the data creating his or her own story (Malloy, 1991, pp.195-202), a structure that 
today is called hyperfiction. This and other following hypertext works, represent for her a feminist approach towards new electronic narratives:

[my works] are based on the feminist approaches of making the woman the subject rather than the object of the work, of connecting the reader with women's lives and thoughts; of validating daily and personal experience as a way of understanding and expressing a culture; of creating a collaborative and/or interactive environment." (Malloy in Couey, 2003)

Other female artists working in telematic and computer-based networks, focused on public-access for cross-cultural encounter of communities and the art/life hybrid are Nancy Buchanan with her work Portraits (Couey, 2003, p.60), Anna Couey with American Indian Telecommunications where Anne Falllis operated her project the Dakota BBS (Bazzichelli, 2008), both of them, together with ), Arts Wire (US), ArtsNet (Australia), the WELL (US), and Usenet (international) were part of Cultures in Cyberspaces in 1992, "an open participation virtual panel on the development and import of artistic and cultural activity on computer networks" (The WELL, 1992). It was a temporary communication network that aimed to connect in conversation five online communities from different cultures (Couey, 2016). Related to radio networks, Heidi Grundmann founded in Vienna Kunstradio-Radiokunst in 1987 dedicated to artworks for radio. Still ongoing, it is a forum for networked sound projects that function on the waves and on the Internet (Couey, 2003, p.64). Isabella Bordoni and Andrea Sodomka preferred collaborative communication systems and approaches to make art, using any type of communication media to explore of crossing borders. Sodomka utilized radio and the WWW in 1994 in State of Transition. Bordoni founded in 1985 a theatrical ensemble Giardini Pensili, and in 1993 collaborated with Kunstradio-RadioKunst collaborative and cross-disciplines work Realtime. In that year Aida Mancillas created Project Artnet, the digital manifestation of an electrnic artist book developed collaboratively towards cross-cultural artist community encounter. The project engaged children from different ethnically diverse backgrounds and connect the project was exhibited at 
SIGGRAPH 1993 as part of Matrix: Women Networking, organised by Lucia Grossberger Morales and Anna Couey ${ }^{68}$. Elisabeth Schimana in 1996 created the fugue, a collaborative concert that happened simultaneously online, on air, and on-site (Couey, 2003, pp.66-72). Schimana and Sodomka would lead years later the projects of IMA series Fiction and Machine Divas on women artists in technology ${ }^{69}$.

${ }^{68}$ See section 3.1.4

${ }^{69}$ See point 3.4.6.2. 
[This page intentionally left blank] 


\section{III.}

MAPPING

ALL-WOMEN

INITIATIVES

IN ART AND TECHNOLOGY 


\subsection{Early all-women curatorial projects in the United States}

All-women festivals were happening in visual and video art since the 1970s in United States, however it was not until middle 1980s that women in computer arts got together for a collective curatorial project. Women in computer arts challenged tech companies such as Apple in its first days, which wouldn't believe someone could make art with the first personal computer (Grossberger, personal communication 2019). When the visual art world didn't accept any electronic format as an art work and the feminist activists still kept a critic position towards technology, women in computer arts explored and experimented with the new electronic media while it was still free from gender stereotypes, but it had just a high request of skilled and creative minds (Cox et al., 2018; Grossberger, personal communication 2019). As I above-mentioned, without referring directly to feminism in their work, women with a strong feminist commitment started to develop art works with computers and they organised collectively showcases of their work. The following curatorial and organisational projects manifested a clear alliance between the sometimes few but outstanding women in the field, and a sense of belonging and joy to work together. Moreover, some of them evidence a clear institutional support for women in the field. Artists women of color of Latino American origin played an important role in these organisational forms and art practices. By the end of the 1980s, the lineage of all-women events was reaching the new media art formats, from the Woman's Building in Chicago in late $19^{\text {th }}$ century, spreading again through the Woman's Building and the feminist Art Programme in California to the rest of the USA.

\subsubsection{Women and Technology 1986}

The earliest all-women self-organised curatorial project I have identified is dated in 1986. In the Women's Studio Workshop ${ }^{70}$ in New York, the feminist and artist Barbara Nessim curated an exhibition dedicated to Women in Computer processing and Video Art: Women and Technology, Video

\footnotetext{
${ }^{70}$ See $<$ https://wsworkshop.org >
} 
and Women in Computer Arts, a space still active dedicated to women's artistic work providing courses, workshops and residencies. While feminist video festivals were happening in the USA, this was the first self-organised event that would combine advance computer skills.

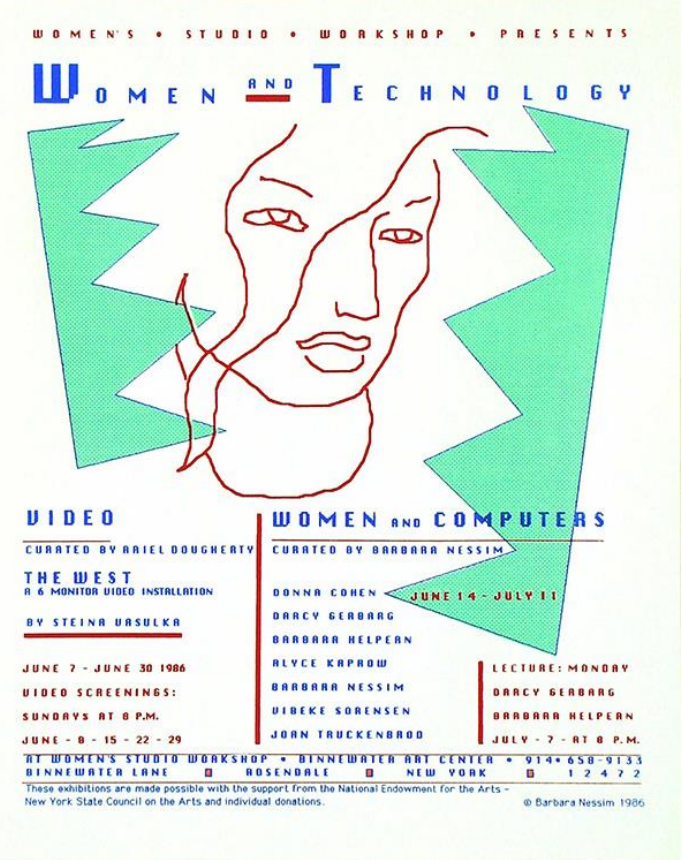

Figure 60 Women and Technology, silkscreen print, Barbara Nessim, 1986. Museum no. E.62-2013

(C) Victoria and Albert Museum, London/Barbara Nessim. Retrieved from Lenz, 2014.

Barbara Nessim's work was previously exhibited together with other national women artists in the $11^{\text {th }}$ Annual Women's Week Celebration organised by The Aerospace Corporation, called Meet the Challenge, Shape the Future, celebrated from $3^{\text {rd }}$ to $7^{\text {th }}$ March in 1985. In the programme there was an exhibition dedicated to Women in Computer Art called The Future of Today, where computergenerated artworks by nationally prominent women artists were presented: video, slide, film, interactive and hardcopy graphics. It featured artists such as Barbara Nessim and Lucia Grossberger, and Women of the 1985 SIGGRAPH projected a series of slides (The Aerospace Corporation, 1986). There was also a space dedicated to Women in Space, where the founders of Hypatia Cluster presented the organisation. Hypatia was focused on the encouragement and involvement of women in space science and engineering. As an informal organisation or network, the people involved performed 
activism and talks and workshops to engage more women in the field in special science. It was founded in 1981 in San Francisco, California, by Marita Dorenbecher and Amy Marsh, after the first flight of the Space Shuttle (Michaud, 1986). The name referred to the neo platonic figure of Hypatia of Alexandria. The basis of the organisation was based on the belief that women's emergence in space exploration is an evolutionary catalyst with positive effects for all humanity (Marsh, 1981, p.5). This context exposes an existing culture of all-women informal organisations with institutional support in art, technology and science in the United States in the middle 1980s.

\subsubsection{Addressing Images, 1991}

"Great minds think alike" English proverb, conversation with Lucia Grossberger, 2019

The first phases of the domestication of the computer would bring new formats of creativity by women happening parallely in different points of the world. In 1991 the term cyberfeminism was used simultaneously by Paterson, Plant and VeNuS (Guertin, 2003 in Paasonen, 2011), while in California collective self-organised all-women exhibitions started to happen in new media arts. In August 1991, American artists Lucia Gorssberger Morales and Marta Thoma presented the art works of a group of fifteen white women and women of color computer artists, including themselves, an allwomen collective exhibition entitled Addressing Images, located in San Jose, California, open from $19^{\text {th }}-17^{\text {th }}$. The exhibition showed works on different multimedia interpretations of dress images incorporating interactive computer technology (Thoma, 1991). It was the result of a year of curatorial process. Artists featured were: Magi Bollock, Lorraine Capparel, Jennifer Colby, Kathryn Dunlevie, Lucia Grossberger, Monroe Hodder, Joan Karlton, Pat Keefe, Jone Manoogian, Bonny Novesky, Beth 
Regardz, Beverly Reiser, Nila Rusnell, Willy Scholten, Marta Thoma, Cardi Toellner and Kathryn Weinstein (Grossberger \& Thoma, 1991).

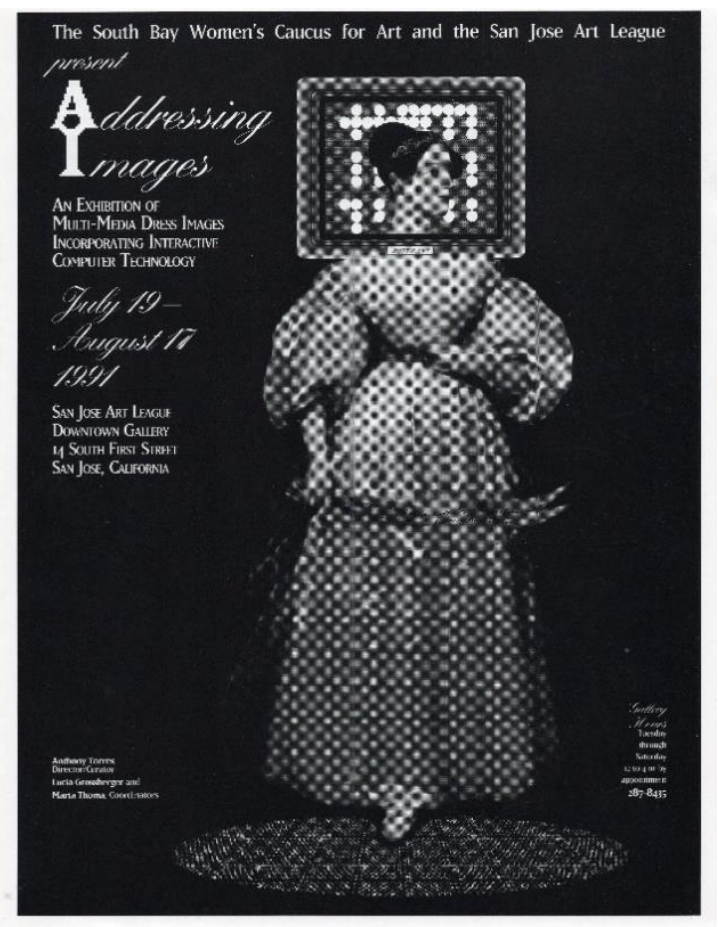

Figure 61 Addressing Images. Exhibition poster designed by Beth Regardz and Lucia Grossberger, 1991. Courtesy: Lucia Grossberger.

Although it counted on the support of some local and regional cultural centers such as South Bay Women's Caucus for Art, the curatorial project was made with practically no funding. Grossberger, a Bolivian-origin California-based artist, was a pioneer in computer-generated art by then (one of the first artists making art with Apple 2). Like Grossberger explained, there was a poor bibliography to learn emerging technology, therefore collaboration and sharing were the main source to access tech formation - essential characteristics of the Renaissance Teams (Cox et al., 2018), that she aimed to extend to Addressing Images (Grossberger, personal communication 2019). Despite the collaborative and supportive attitude that male and female counterparts showed in these teams, the male dominated environment made Grossberger "miss women around" her work environment, that is the reason why she organised several all-women curatorial projects in the early 1990s: "I needed to express my feminist perspective, it has always been important to me to build a space on my own for a group of women": 
...in the 80 s when I started working with computers it was all men. I was really a feminist, I was with the movement, but when I wanted to work with computer I had to work with men and I knew that, but I missed my female collaborators. So, we did some projects where it was all women, and I was relieved to be with women, I felt like I was coming home. My very first exhibit was in The Women's Building in Los Angeles, I really felt these are my people (Grosberger, personal communication 2019).

The theme of Addressing Images aimed to connect traditional art forms with technology from women's perspective. The art works presented different interpretation of dress through new computer-generated art forms: "This has been a special opportunity for participating women artist to learn about computer art because computer artists have been willing to share their knowledge" (Thoma, 1991). To my understanding, it is relevant to note that the portrait of Ada Lovelace here was already used as metaphoric illustration before Sadie Plant's publication The Future Looms (1995) and Zeros+Ones (1997). The relation between women, computer technology and textile was presented here before the British feminist author would publish one of the most influencing texts in the history of cyberfeminism on women and technology. Furthermore, there was an intentional symbolic composition of the women's head as a computer-monitor and allusions to the dress as a female cultural and historical attribute (Thoma, 1991). Such conceptual connections encourages me to see them as predecessors of cyberfeminist theories. The allusion to Ada Lovelace image combined with computer technology will be taken also in Remedios Zafra lecture in Madrid in Fundación Telefonica Ada Lovelace y el Futuro (2017) and in her (h)Adas book (2006), also in e-virgenes exhibition by e-mujeres ${ }^{71}$ showcased internationally, and many others. Moreover, doing an exhibition on multimedia in South California by early 1990s was something outstanding, as the term multimedia was conceived by visual artists as a combination of formats and techniques within painting, far from the new electronic and digital

\footnotetext{
${ }^{71}$ See point 3.4.4.1.
} 
techniques (Grosberger, personal communication 2019). As VNS, Grossberger and Thoma were aware of Donna Haraway's first publication Simians, Cyborgs and Women in 1991, which was very influential in the field since its launching, however, they do not manifest a direct influence as the following collective VNS.

\subsubsection{Women and Technology L.A. SIGGRAPH, 1992}

The general environment at the technology labs such as IBM, Apple, etc. was male dominated, however the situation in SIGGRAPH ACM events was rather different. SIGGRAPH has been described by female artists active in the 1980s and early 1990s as an organisation established thanks to the contribution of several women, with events with the participation of "a lot of women" (Grossberger, personal communication 2019). For instance, earlier it was mentioned in the $11^{\text {th }}$ Annual Women's Week Celebration, that SIGGRAPH women had a special slide session in the event. On the $5^{\text {th }}$ December 1992 , Los Angeles SIGGRAPH celebrated a special one-day symposium in Los Angeles called Women and Technology, organised by Coco Conn:

Through emphasis on interdisciplinary dialogue and creative collaboration across previously separated cultural and institutional boundaries, programmes like Women and Technology provide a forum for charting diverse territories of contemporary culture, while offering new vocabularies and tools of the information age for remapping the future (Conn, 1992).

Topics included were: professional directions, communications and media, architectures of gender, the technologized body, women's empowerment and change. Artists and theoreticians, experts in computer networks, social issues and cyberspace that took part of the symposium were: Anna Couey, Anne Fallis, Brenda Laurel, Sherrie Rabinowitz, Allucquere Rosanne Stone (Sandy Stone) and Carolyne Strauss. For instance, Strauss was the founder and director of Hypertelsaloon, a non-profit 
corporation established in 1992 addressing new creative means of challenging and empowering people to get involved in new media worl, Stone had organised The Second International Conference on Cyberspace, and Couey was co-developer of the Art Com Electronic Network, al.artcom, one of the first to organised cyber art ' online galleries' and coordinator for Arts Wire, an online computer-based network providing immediate access to information and dialogue regarding art and artists (Conn, 1992).

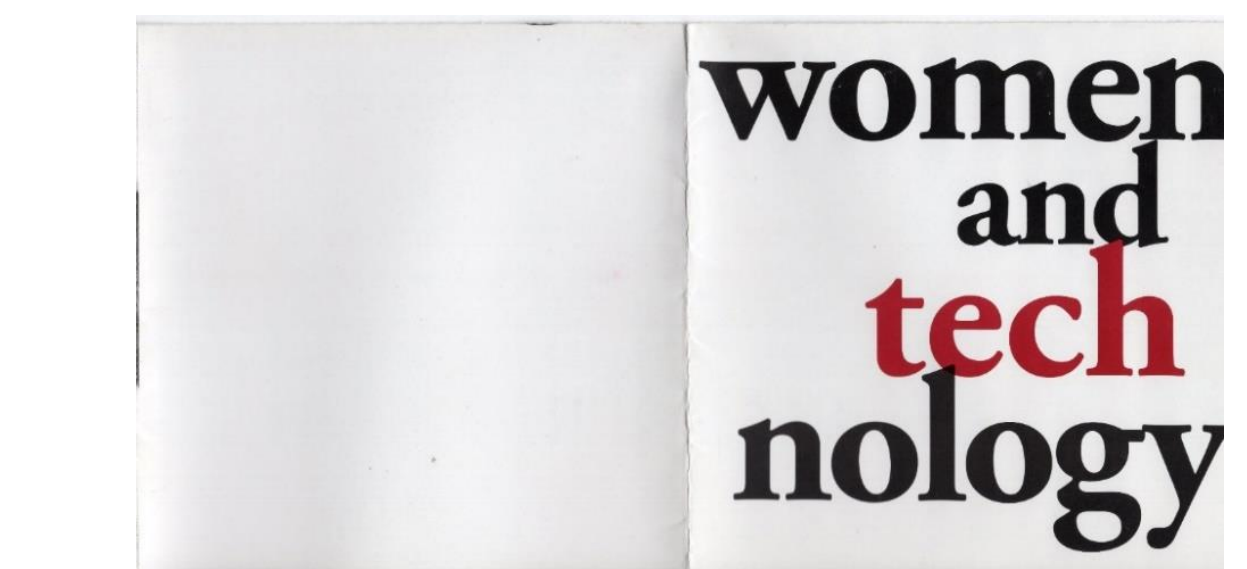

Figure 62 Catalog/invitation letter page from 'Women and Technology' Symposium, L.A. SIGGRAPH, 1991. Courtesy: Lucia Grossberger.

Additionally, there was also a display of artworks by Abbe Don, Lynn Hershamn, Sara Roberts, Lucia Grossberger, Lori Ann Twobolls, Judy Malloy, and more. Screenings by Rebeca Allen and Anne Fallis work on on-line networking. The space for networking, discussion, and open debate between speakers and audience was for many perceived as the first professional space to participate that connected them with other women theorists, artists and practitioners, experience a knowledge exchange on feminist theories in regarding technology and cyberspace: "it was a small, intimate gathering, with substantive discussion among participants [...] I was first exposed to Sandy Stone thinking there, and I met Brenda Laurel as well [...] Women and Technology is where opportunities were for women in tech" (Couey, personal communication 2019). 


\subsubsection{Matrix: Women Networking, 1993}

For the edition of 1993 of SIGGRAPH the $20^{\text {th }}$ Annual Conference on Computer Graphics

and Interactive Techniques was celebrated in Anaheim, California, from $2^{\text {nd }}$ to $6^{\text {th }}$ August, in the Tommorrow's Realities space. There, an all-women exhibition on computer networks was part of the programme. The exhibition was titled Matrix: Women Networking and it was curated by Anna Couey and Lucia Grossberger Morales. It featured the work of six women artists in computers networks an exhibition of telecommunications art projects by women "from differing cultures that addressed public collaboration, cultural identity in cyberspace, and the role of women and other marginalized people in the development of a global communications medium." (Couey, 1993).

The term cyberspace was previously used within the telegraph and then the telephone community during the electric age to describe this disembodied experience in an invisible gender-neutral space of communication (Marvin, 1988, p.233; Jepsen, 2000) it is a parallelism with the Digital Age like the concept of hacking (Standage, 1999, p.109). In the artistic field, it was first used by a woman, the Danish artist Susanne Ussing in the 1960s-70s, who together with her partner architect Carsten Hoff formed Atelier Cyberspace (Lillemose \& Kryger, 2015). They were the first artists to apply cybernetics to architecture, therefore their concept of cyberspace "was simply about managing spaces. There was nothing esoteric about it. Nothing digital, either. It was just a tool. The space was concrete, physical" (Hoff in Lillemose \& Kryger, 2015). 


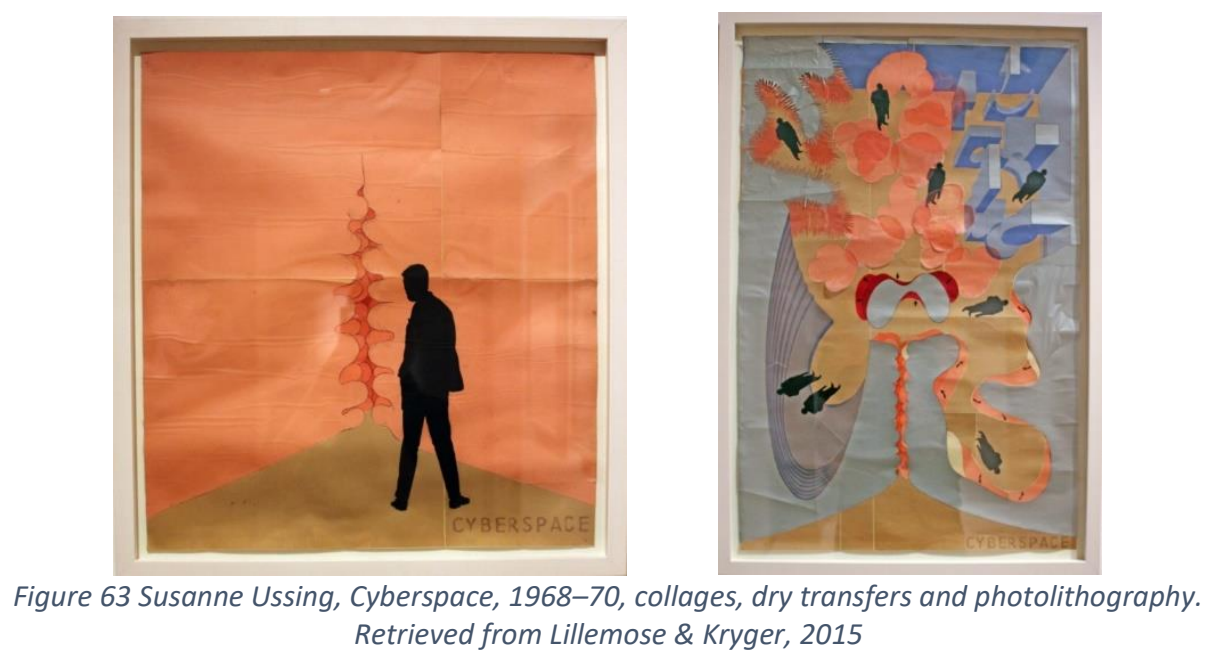

However, the concept of Matrix and cyberspace in the computer networks scene became part of the collective 'consciousness' within the artists and theoreticians since the 1984 cyberpunk science fiction publication by William Gibson, first in the short story Burning Chrome in 1982, and then Neuromanecer, "to describe a disembodied digital parallel reality reached via neural connections where all the world's data is stored" (Paasonen, 2011, p.4). Publications like John Quarterman's The Matrix: Computer Networks and Conferencing Systems Worldwide (1990) or the Matrix Information and Directory Services (1991), shows the influence in language and a conceptual framework to describe online space by people working with computer networks. the Australian net art collective VNS Matrix, inspired by Haraway publications, would take agency on the terms of cyberspace and matrix from a 'new' feminist perspective. However, Gibson's matrix term and cyberspace were also used simultaneously from a feminist perspective in other all-women alliances. One year after the emergence of VNS, in San Francisco Lucia Grossberger came up to Anna Couey with the idea of an all-women exhibition proposal named Matrix for SIGGRAPH:

So, the term [matrix] was in the air, part of our consciousness - but not gendered. But what VNS Matrix did, and what I remember Lucia bringing to our thinking for the Matrix exhibition, was a feminist use and claim to the term. (Couey, personal communication, 2019) 
Focused on communication cross-borders and cross-cultures, Couey and Grossberger noticed the potential that computer networking could enable, and that it was mostly 'white male culture' shaping the space. Their motivation was to make women's work visible through the work of white women and women of color. Additionally, both artists aimed to point ways that women artists were working to build a space not only to "ourselves but for all people" (Couey, personal communication, 2019). In the legacy of telecollaborative art, Matrix: Women Networking, showed ways in which telecommunication technology are used in communities, in society. While SIGGRAPH was known for showcasing cutting edge technology, Couey and Grossberger internationally intended to use technology that was already in use and focus in social dynamics. Issues of cultural equity and pluralism were important aspects to Matrix: Women Networking (Couey personal communication, 2019): “Our goal in focusing on the low end is to call attention to the technological disparities that exist in our society, and to raise questions about their impact" (Couey \& Grossberger, 1993).The exhibition outlook was a combination set of six computers in pedestals formed by the work of Lisa Cooley, Judy Malloy, Lorri Ann Two Bulls (Oglala Sioux), the Chicana artist Aida Mancillas, Couey and Bolivian-origin Grossberger. Six interactive and participatory works by white women and women of color were presented, four of them text-based interactive online projects, including feminist perspectives, cultural preservation awareness, social issues such as immigration, multiculturality and multilingual issues, kids games, art from American natives, between others. (Couey \& Grossberger, 1993) Matrix: Women Networking was an exhibition made by women open to all genders, highlighting the artists' strategies of both empowerment and inclusivity in digital space, aiming to engage the public in the creative process. The projects were designed to be short-term events, rather than sustained networks. (Couey, personal communication, 2019) It was a curatorial project based on women networking with the audience through their work, most of it text-based to "ensure the broadest access possible, employing interactivity as a means of directly engaging the public in the creative process" (Couey \& Grossberger, 1993): 
...interactive works of electronic literature, computer graphics, games using encryption and virtual performance. MATRIX features works by women of differing cultures and artistic backgrounds who are working with computer networks as a means of creating collaborative works with artists and non-artists alike, to decentralize the creative process, to educate about and preserve their distinct cultures and communities, and to provide online access to population groups who would otherwise be the have-nots of the information age. [...] Like the network itself, the MATRIX events are generally loosely defined more as potentiality than as clearly defined events. The artists assume that once these ideas are seeded on the Net they take on a life of their own, guided by all those on the net who wish to participate.

\subsubsection{UTOPIA/DYSTOPIA, 1995}

Couey, Mancillas and Grosberger got together again two years later with other twenty-seven north American women computer and media artists, feminist activists and writers in Spring of 1995 in San Francisco. UTOPIA/DYSTOPIA was the name of The Third Annual Conference on Feminist Activism and Art Framework, organised by The $\mathrm{LAB}^{72}$ in collaboration with SF Camerawork. The event was directed and curated by Zoeuy Kroll together with the organizing women committee members. Artists like Kathy High $^{73}$ were part of the National Advisory committee. The Conference was focused on providing a forum for feminist, activist and artists to address common issues of concern, to exchange ideas and information, that would serve to form new diverse community networks (Kroll, et al., 1995). Speakers and performers talked about ideal and dystopian scenarios for "the empowerment of female culture in the new millennium", through a wide range of formats related to community, from Zines to public access TV, from alternative art centers to the internet. The conference focus was on the "processes by which communities are formed, with respect to both traditional and

\footnotetext{
${ }^{72}$ See <https://www.thelab.org >

${ }^{73}$ Current member of FEMeeting (point 3.4.5.10.) and REFRESH (point 3.4.3.6.)
} 
new community networks sustained through interactive technology, the evolution of community through art rooted in social consciousness", from public television to the emerging technological networks of communication "to promote social and cultural equity for women in the 90s" (Kroll et al., 1995). In this edition, the programme had a special session dedicated to technology, coordinated by Barbara Lee, it is an example of the first collaborations between feminist activists and computer artists along the 1990s. Discussion panels, performances, workshops and interactive installations by white women, women of color and trans women had place in UTOPIA/DYSTOPIA.

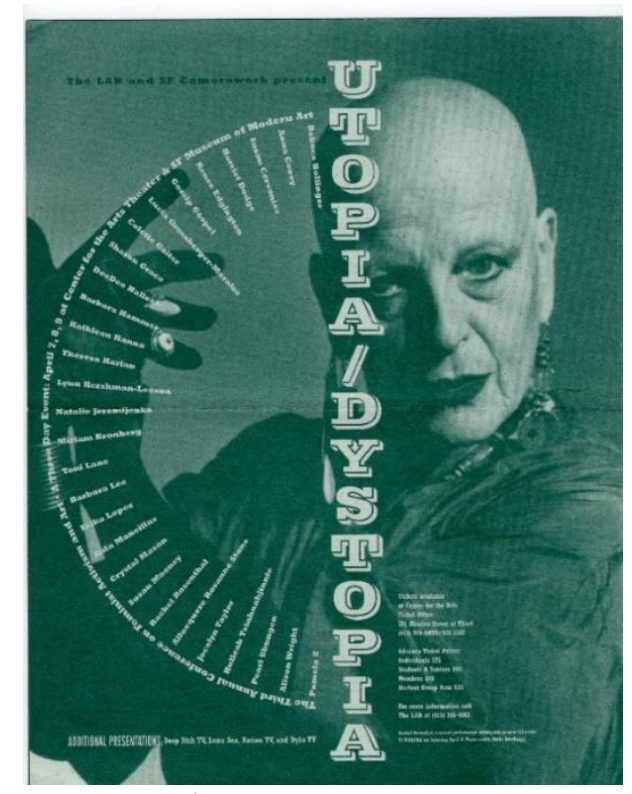

Figure 64 UTOPIA/DYSTOPIA poster, designed by Rex Ray. San Francisco, April 1995. Courtesy of Lucia Grossberger

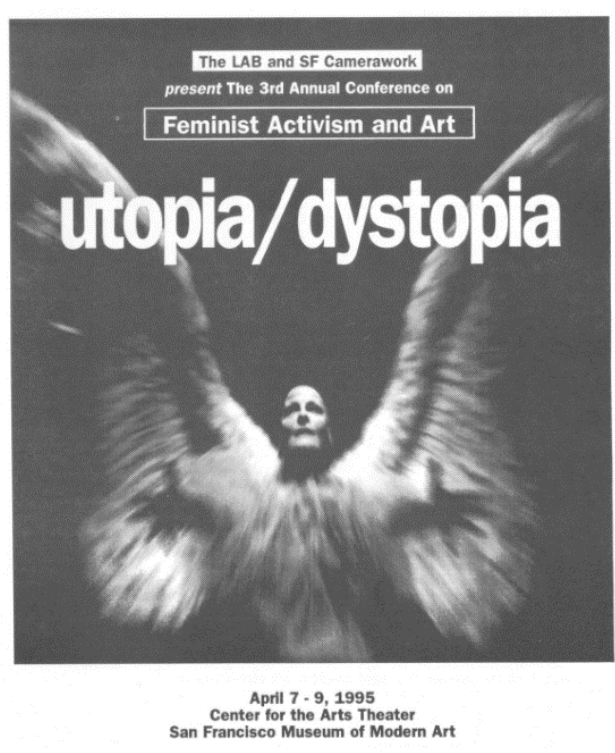

Figure 65 UTOPIA/DYSTOPIA poster, 1995. Courtesy of The $L A B$

In conjunction there was a Technology Programme, a series of interactive works in new technologies developed by an all-women exhibition group called Virtual Female. The group works aimed to explore the construction of gender in social systems and in cyberspace, technological and biological functions, narrative, structures, the operations of human and artificial memory, and the architecture of private and public spaces. Artists featured were Rebeca Bollinger, Gail Wight and Kristine Yaffe, Colette Gaiter, Christine Tamblyn, Marjorie Franklin. With topics such as: mistaken 
identities, seduction, alphabetically sorted, easily remembered/conveniently forgotten, gender equity in cyberspace, artificial intelligence, interracial conflicts, gender discrimination, biomedical tools, digital prints (Kroll et al., 1995). Additionally, there were workshops. Anna Couey for example, gave a workshop and a presentation on telecommunication art by women and its evolution on the Net, presenting strategies for weaving feminist consciousness into the social fabric of the Nets towards new possible models to construct the future. She was by then Web Project Coordinator at The WELL, online sever experimental with virtual community. The conference also featured an online networking system for cultural activist that was formed during the event, providing two parallel spaces for attendants (Kroll et al., 1995).

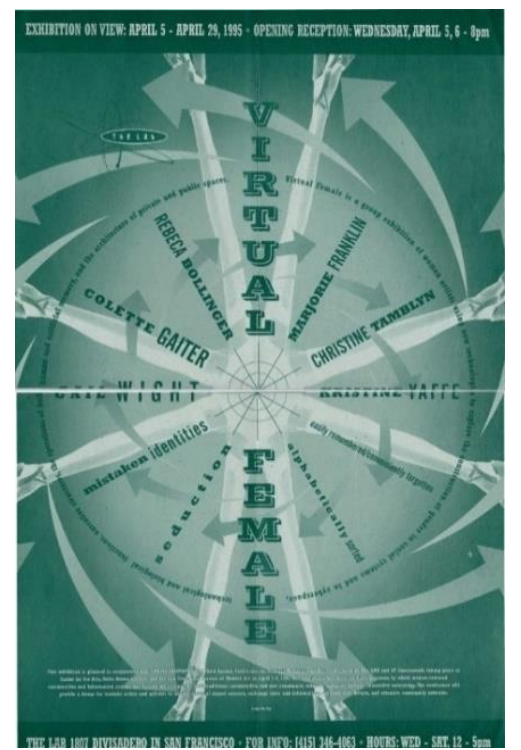

Figure 66 VIRTUAL FEMALE, in UTOPIA/DYSTOPIA poster, designed by Rex Ray. San Francisco, April 1995.

The event took place at Center for the Arts, Yerba Buena Gardens and the San Francisco Museum of Modern Art on April $7^{\text {th }}$ to $29^{\text {th }}$. The LAB is an artistic and cultural center that since the early 1990s has supported emerging experimental, media, visual and performing artists. SF Camerawork is a nationally non-profit, regional artists' organisation whose purpose is to stimulate dialogue, encourage inquiry, and communicate ideas about contemporary photography. UTOPIA/DYSTOPIA was partially funded by the San Francisco Museum of Modern Art and the Angelica Foundation founded artists scholarships. 


\subsection{Feminist alliances and activism in cyberspace}

"[...] it is hard to decide who is weaving the web of illusion and who is caught in it"

Irigaray, 1985

Women in computer-generated arts were developing works from innovative approaches to cyberspace within all its conceptions in and beyond computer networks since the 1960s. However, these female avantgarde artists showed an awareness for the possibilities of technology which was an exception in general society. Feminist and women STS (Science and Technology Studies) scholars didn't start to appreciate the possibilities of new technologies for women until the early 1990s and the start of the Digital Age, when a combination of emerging postmodernist theories in feminism and technoscience together the domestication of the Internet tools would drive the feminist approach to technoscience and new media arts to a different perspective. As it happened in the Electric Age, the idea that the Internet can transform conventional gender roles, altering the relationship between the body and the self via a machine, is still a popular theme in the so-called postmodern times (Wajcman, 2006, p.12). Feminist and women STS scholars started to analyse the mutual shaping of technology and society, focusing on gender and related stereotypes, sharing an awareness of the necessity of feminist politics of technology as a "key to achieve gender equality" (Wajcman, 2009). For example, Judy Wajcman summarizes Cynthia Cockburn conclusions based on the premise that "technology itself cannot be fully understood without reference to gender" (2009).

Moreover, as I have mentioned in chapter 2.4., in Anglo-American countries the gender stereotypes on technology increased and rooted in general society along the 1980s, giving rise to figures like the geek which publicity and science fiction reinforced, provoking the fall of high numbers of female students in computer science (Ensmenger, 2010, p.137). However, with the inclusion of the Internet in the personal computers the female users retrieved the interest in information and 
communication technologies, were they have felt discriminated for decades (Ensmenger, 2010; Schafer \& Thierry, 2015). These phenomenon, however, is not applicable to all capitalized countries, as women in countries in the Soviet Union (URRS) had a different history and relation with technology, factor that explains the different numbers today of women in computer science in post-soviet countries ${ }^{74}$.

Donna Haraway' essay A Cyborg Manifesto (1985) is probably one of the starting nodes in feminist theories towards a new phase regarding gender, society and technology, together with the works of Sandy Stone, Virginia Berret, Laura de Lauretis and later Sadie Plant and Rosi Braidotti, between others. Haraway's essay, later published as part of the book from 1991 Simians, Cyborgs and Women: The reinvention of nature, was widely read in different countries, and her concept of cyborg as part of humanity, transformed the gender relations in technoscience, opened new perspectives in feminist analysis to explore the relation between women's life and technology. Challenging so-called second-wave feminist essentialist theories, her Cyborg theory is perceived as the start for a new feminist 'imaginary' in what ICTs and biotechnologies make possible (between nature and technology, inessential, beyond gender and race, etc.), would end with the general pessimistic feminist perspectives on technology (Wajcman, 2009). She proposed high-tech as a form to go beyond antagonist dualisms (self/other, culture/nature, etc.) that support Western traditions such as patriarchy and colonialism, giving rise to a new wave of optimistic theories on technology gender and race abolition, acknowledging that such categories does not exists independently of technoscience practices, but both are constituted in each other (Haraway, 1998). Haraway demonstrated that science and technology are linked to capitalism, militarism, colonialism and racism -her concept of situated knowledge-, her contribution deconstructed scientific knowledge as historically patriarchal (Sollfrank, 2018, p.3):

\footnotetext{
${ }^{74}$ See global reports like UNESCO, 2017.
} 
Haraway's concept of the cyborg offered a concrete conceptual tool for rethinking socialistfeminist politics in the age of technosciences. It became an icon for the dissolving borders between the biological and the cultural, between the human and the machine, and thus a symbol for the queerification [sic] of old dichotomies, for it was only beyond previously conceived boundaries that new forms of social and political praxis would be possible.

Haraway never related herself to cyberfeminism (Paasonen, 2011, p.10), however, due the allusions on her work to the artificiality of corporality, the collective nature of the cyborg's subjectivity, and its inherent politics of interconnectivity, she became the main theoretical motto for cyberfeminism (Sollrank, 2018, p.4). In arts, the domestication of the Internet and the appearance of the Graphical User made computer arts became mainstream "like they never were before, there were a bunch of new artists coming to this space" and experience new networks based on real with face-to-face connectivity (Couey, personal communication 2019). This period in New Media Arts along the 1990s was described by Cook and Sara Diamond (2011, p.21 in Cox et al., 2018, pp.42-3) in their work Euphoria and Dystopia as:

The period of the early ' 90 s through to 2005 saw intensive technological change: the massive adoption of 'new media' and its normalization as 'digital media,' and the rise, fall, and reemergence of an information-, technology-, and communication-boom economy... Virtual reality, simulations, and data visualization moved from the margins and became mainstream industrial and research practices. Technologies became relatively fail-safe and user-friendly.

This techno-social phenomenon made feminist artists and theoreticians appreciate features of computer networks and cyberspace that only a few could experience before in telecommunication and telecollaborative arts. Women artists that were active since the 1980 s were already experimenting with the possibilities of cyberspaces in telematic arts and computer networks applying feminist concerns (Couey, 2003). Furthermore, in the 1990s, the softwares to create computer-generated art were 
evolving and the complexity to produce art work opened a space for more humanistic and personal approaches (Vesna, 1998; Grossberger, personal communication 2019), like it happened with video art, the accessibility and affordability of personal computers and Internet tools, women artists could developed feminist discourses in a new media, and postmodern theories would start to influence for first time new media arts (Cox et al., 1989). The evolution of the mainstream feminism was influenced by the emerging postmodern theories which were concerned about contemporary issues such as gender identity, intersectionality, transgenderism, ... This factor made possible the merge of the conception of a feminist art on new media arts evolving parallelly in different perspectives, terminologies and topics.

In 1991, the emergence of virtual communities and the access by general public to the World Wide Web through the first Web browser, have been considered as the start of the Information Age, and a democratization of the information and communication technologies (Castells, 2001). This aperture provoked the explosion of different theories regarding, social relations, identity and creativity in Western countries, and women started to reflect upon the relation between cyberspace. In 1991 six women came up simultaneously with the term cyberfeminism (Guertin, 2003 in Paasonen, 2011), having a special impact on women artists. In the UK, cultural theoretician Sadie Plant referred to cyberfeminism when starting to talk about feminizing influence of technology on western society as a start of her future postfeminist theories. In Canada, new media artist Nancy Peterson published an article in $\mathrm{ECHO}^{75}$ virtual salon -first virtual community with women-only forums ${ }^{76}$ - called cyberfeminism $^{77}$, when she was asked as an artist about her opinion on technology and feminism. Same summer, in Adelaide, a group of four young artists created the Cyberfeminist Manifesto for the $21^{\text {st }}$ Century (VNS, 2019). In a recent interview to Nancy Paterson, she said (2014):

\footnotetext{
${ }^{75}$ See <https://www.echonyc.com>

${ }^{76}$ See section 2.4.6.

${ }^{77}$ Article available at <https://bit.ly/2FCWWFE>
} 
I wanted to write something that would be progressive and distinctly North American...I proposed 'Cyberfeminism as a philosophy' [...] I was thinking about the way we could use technology, as women, because we're somewhat marginalized... so that we could understand virtuality. Because we're always being told our experiences are negated - so we could understand virtual reality really well.

As I will discuss in the next chapter, there has never been a consensus to explain what cyberfeminism is, acknowledging from the start the wide range of types within it (VNS, 2019). But we can state that cyberfeminism manifested the entrance of feminist activism in the 'new' virtual space of computer networks, in words of Paterson (1991) "cyberfeminism as a philosophy has the potential to create a poetic, passionate, political identity and unity without relying on a log and language of exclusion”:

It offers a route for reconstructing feminist politics though theory and practice with a focus on the implication of new technology rather than on factors which are divisive. [...] transgressing order and linear organisation of information, cyberfeminists recognise the opportunity to redefine 'reality,' on our terms and in our interest and realize that the electronic communications infrastructure or 'matrix' may be the ideal instrument for a new breed of feminists to pick up and play.

However, Paterson's essay was not as disseminated worldwide as the other references, being almost 'forgotten' according to some authors such as Paasonen (2011, p.6). Pasoneen links the scattered articulations of the emerging cyberfeminism along the 1990s with the cybernetic principles of “autonomous systems and self-organisation”. (p.7), As we abovementioned, the feminist positions towards technology and cyberspace would differ politically and theoretically, yet cyberfeminism would spread through and beyond the Anglophone world due to its openness and diversity together the innovation in digital media technologies (p.7), even until nowadays. Cyberfeminism would soon take over the utopia of free of gender bias cyberspace to start addressing gender issues such as sexual 
harassment online in virtual communities. Issues like racism within cyberfeminism took place as well and women of color artists felt that discrimination within the field (Grossberger, personal communication 2019). As per our research topic, regarding cyberfeminism what concerns us the most are the collective practices that merge from the alliance of women and machines.

\subsubsection{VeNuS MATRIX}

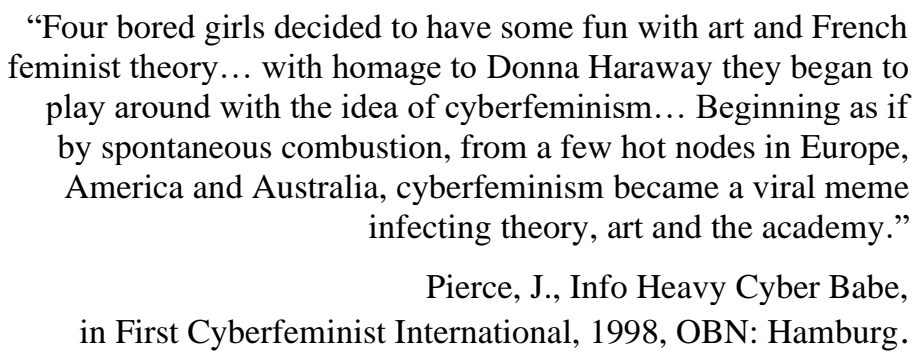

Since 1991 to 1997, a collective of young artists in Adelaide revolutionized the feminist practices on the cyberspace and Net Art. A combination of cyborg theories from Haraway and Stone with a touch of second-wave French feminism, technoporn, slim aesthetics, cyberpunk and above all, parody that didn't leave indifferent many contemporary women in the field:

I saw their work in 1994, at ISEA in Helsinki, it was amazing. A pink fur environment, that you entered, very sexual. They were a marker, at a moment when The Net was early, and they were huge motivators (Huffman, personal communication30 ${ }^{\text {th }}$ May 2019).

Virginia Barratt, Julianne Pierce, Francesca da Rimini, Josephine Starrs are arguable the first selforganised collective of women working as a collective in art and technology. In the legacy of the Riot Grrls DIY formats, VNS performed art works addressing the issues of the techno cowboys aiming to remap "cyberculture with a feminist bent" (VeNuS, 2019). For six years VNS developed installations, events, computer games and interactive works, imagery and propaganda as well, that was distributed 
through the Internet -fax and emails-, magazines and billboards, most of the time becoming viral, like their first work developed in the summer of 1991, The Cyberfeminist Manifesto for the $21^{\text {st }}$ Century, that was translated to different language becoming viral within the transnational network of new media arts and feminists (VeNuS, 2015).

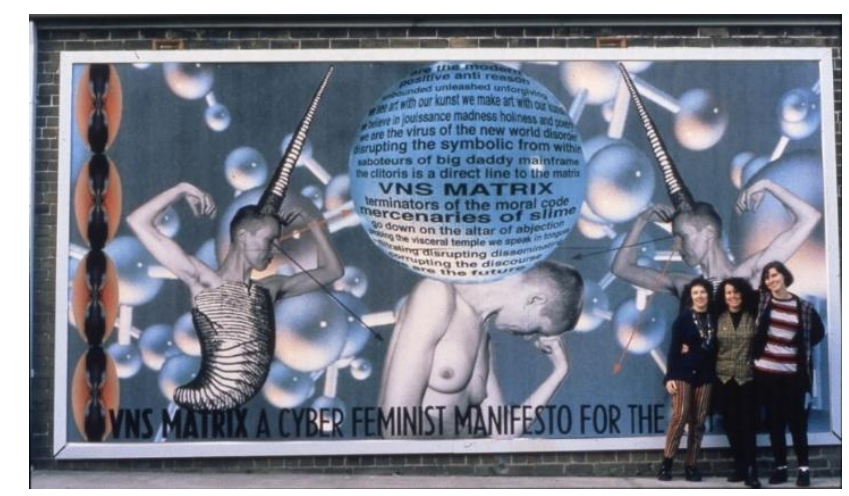

Figure 67 Three of VNS members posing in front of a billboard based on the Cyberfeminist Manifesto, shown on the side of Tin Sheds Gallery, Sydney, in 1992. Source: www.rhizome.org

The Australian collective applied Haraway's perspective on vocabulary as a subversive tool having a successful impact. Their statement: "we are the virus of the new world/disorder/rupturing the symbolic from within/saboteurs of big daddy mainframe/the clitoris is a direct line to the matrix", became the main motto for the emerging cyberfeminists -and even today, together with other "blasphemous exhortations against technopatriarchies and capitalist powers" (VeNuS, 2015), like “suck my code" from the Bitch Mutant Manifesto from1994. Despite the homage to Haraway's cyborg, VNS works have been highly appreciated by its radicality in terms of provocative and explicit sexual content, and their cyberpunk parodic symbolism relation between female sexual organs and the cyberspace, the 'cunt imagery' from feminist art in the 1970s. VNS experimented with the alliances and affinities with technology as women, taking possession of cyberspace (Angerer, 2004) but never seriously attempting to dominate the Net. Rather, the members aimed to raise issues concerning women and technology through artistic strategies like irony and inversion of cultural stereotypes (da Rimini, 
1997 in Walsh, 2016) through the virtual spaces of MUDS and $\operatorname{MOOS}^{78}$, game cultures, creative writing and media art (Paasonen, 2011, p.5):

...cyberfeminism was a catalytic moment, a collective memetic mind-virus that mobilized geek girls everywhere and unleashed the blasphemy techno-porno code that made machines pleasurable and wet. a linguistic weapon of mass instruction, the VNS manifesto struck at the mass erection of the techno patriarchal order. we loved with machines, in a most unholy alliance. as I watch pussy riot declining to be "clean and proper" bodies in a most filthy way, I feel the morphing cyborg feminist lineage stretching through time and space. VNS matrix were dirty (cyber)space cowboys, echoes of the objectionable in orbit, space junk (in every way) in the stratosphere! (Barratt, 2015)

As VNS portrait themselves, they acted like a virus, they did and are still the most inspiring collective in feminist practices on the net and new media, both for artists and activists. Contemporary cyberfeminist groups that are still active and that have recently emerged will be discussed in the following chapter, such as SubRosa ${ }^{79}$ and enREDades ${ }^{80}$. VNS' members have worked together punctually after they disbanded in 1997, and in 2017 they were part of the Panel in Ars Electronic in the framework of the $20^{\text {th }}$ Anniversary of Faces Mailing List ${ }^{81}$.

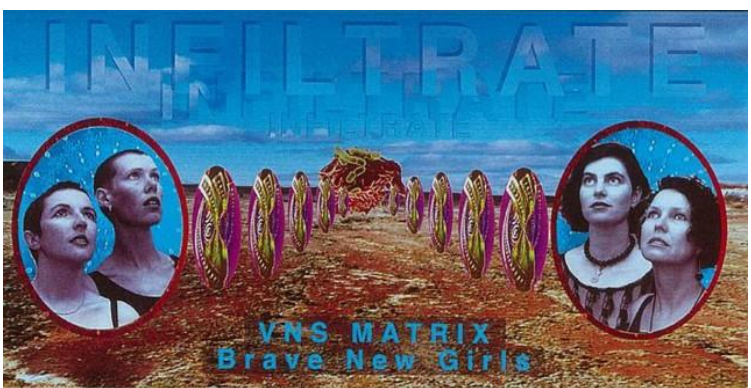

Figure 68 VNS Matrix postcard, 1994. Left to Right Francesca Da Rimini, Virginia Barratt, Julianne Pierce, Josephine Starrs. Image courtesy of Virgina Barratt via Motherboard

\footnotetext{
${ }^{78}$ MUDs (Multiple User Dimension, Multiple User Dungeon, or Multiple User Dialogue (MUDs) and MUD ObjectOriented (MOOs) are real-time computer environments, similar to chat, where groups come together at the same time to discuss common issues. From Encyclopedia of Networked and Virtual Organisations, 2008. IGI Global.

${ }^{79}$ See point 3.4.3.1.

${ }^{80}$ See point 3.4.6.6.

${ }^{81}$ See section 3.3.6
} 


\title{
3.2.2. Social Cyberfeminism: The cyberspace and all-women activist groups
}

\author{
"En su diccionario, María Moliner define el vocablo redes como: \\ conjunto de tuberías, cables de conducción, vías de comunicación o cosas \\ semejantes que se entrecruzan y organizan entre sî" \\ Cristina Fraga
}

Along the 1990s, the impact of cyberfeminism spread beyond the artistic sphere, especially in social justice and communication fields. Spanish author Montserrat Boix (2001) would refer to the term social cyberfeminism in referring to the feminist alliances that started to happen internationally on the Internet around and after the last international women's conference in Beijing in 1995. United Nations organised four International women's conferences that took place along two decades in four cities: Mexico City (1975), Copenhagen (1980), Nairobi (1985) and Beijing (1995), providing a “fruitful opportunity to explore changing relationships among women's organisations transnationally" (Basu, 2000, p.68). The first decade (1975-1985) was named the UN Decade of Women, and the second one was characterized by the merging of all-women networks that connected local and global activism (p.68). The last one celebrated in Chinese city was named Action for Equality, Development and Peace. The conference created an electronic space organised by a forty women team from twenty-four countries that supported the connectivity of one hundred visits during the event (Boix, 2002). Such global connectivity of women based on the Internet networks marked a new phase in the women's movement. Like it happened with the all-women women and feminist groups when invaded the radio waves through free and community radios along the 1980s and 1990s in UK, Europe Australia and USA (Mitchell, 1998), women activists found another medium to expand their "horizons and capacity to connect" and "improve their conditions", as Judy Wajcman (2004, p.20) said, "women are [were] reinterpreting the technologies as tools for political organizing and the means for creation of new feminist communities". Emerging spaces of cultural resistance through international collaboration and connectivity that happened thanks to the support of institutional entities, cultural organisations, NGOs, 
political groups from the North and South globe (Basu, 2003, p.84). While some authors argued that this made the feminist movements become "increasingly bureaucratized" (Sonia Alvarez, 1997 in Basu, 2003, p.68) others like Valentine Moghadam (1996) saw the establishment of these transnational networks as a chance for women to organize from North to South globe countries to bring local issues to a global impact (Basu, 2003, p. 68). As Montserrat Boix says (2001), for the first time the right to communication was manifested as a basic human right and an "strategic element for social change that women claim in the fight for equal rights". Feminist activist claimed the space of the Internet as a tool towards agency in order to "invertir la relación de fuerzas porque temenos los contenidos y las prácticas"; feminist theoretizians like Boix (2001, p.34) claimed the "necessity for an offensive, even aggressive strategy" in order to take agency on the media as creators and go beyond the mere use of consumers: "as political subjects, as audience". Early all-women international mailing lists and discussion forums were created for this event and remained active, new were opened, and the networks of feminist activism spread over the electronic networks worldwide (p.31). The group of women from the Latino American association APC $^{82}$ (Asociación por el Progreso y de las Comuniaciones), founded in 1993, played a relevant role in Beijing together with collaborators such as GreenNet in London, ALAI in Ecuador, Boston Women's Health Book Collective, American International Health Alliance, Casa de Colores, Center for Women's Global Leadership, Femnet, Equality Now, Global Fundation for Women, Isis Internacional y De Mujer a Mujer (p.30). Other all-female social activist networks that were functioning in print and passed to electronic, and new ones talking on the impact of ICT on women that appeared just after this event in 1996 and 1997 were Penelopes in France, Server Donne, Medea and Il paese delle Donne in Italy, Cybersolidaries and Womenspace in Canada, Creatividad in Mexico and Mujeres en Red in Spain, Creatividad Feminista in Mexico (Boix, 2001, pp.36-8), some of them would take part of the first Cyberfeminist International that I will discuss in the following

\footnotetext{
${ }^{82}$ APC-Mujeres, oficial website <www.apc.org/espanol/about/apcwomen/index>.
} 
chapter. Beijing marked a change on the political agency of women towards the use of ICT and the level of interconnectivity cross-borders through the computer networks of the Internet (p.32).

\subsubsection{First all-women online exhibitions}

International all-women art exhibitions started to take place within the UN Decade of Women. Like we discussed in chapter 2.2.4.1. for the UN International Women's Conferences, the NGO of the United Nations Women's Caucus for Art participated in all the conferences, being part of the considered the first international conference of women artists in Copenhagen in 1980 (Bowie, 2019). For the last one which took place in Beijing in 1995, WCA organised an international all-women visual arts exhibition named Global Focus: Women in Art and Culture, coordinated by Nancy Cusick with the National Museum of Women in the Arts, which was brought to other places after the conference. Another all-women art exhibition was Beijing and Beyond launched by Carole Richard Kaufman (Bowie, 2019).

Online showcases were organised for this UN Conference to be virtually published while the event took place, they were the first all-women exhibitions online. One of them was the one organised by Muriel Magenta World's Women Online ${ }^{83}$, which I will discuss in the following block, an online archive of women's computer-based art works. In Australia, Melinda Rackham, Louise Manner, Ali Smith, Sandy Indlekofer co-curated WWWO Wollongong World's Women Online. The WWWO website $^{84}$ was created within an academic framework as part of the Fourth UN Women's Conference but nowadays is lost. Melinda Rackham and the others produced a national Australian all-women collective online exhibition that showcased early digital works from thirty Australian women that included Francis Dyson and Mez Breeze (Rackham, 2013). Originated in Arizona, it was one of the largest, the most extensive and most innovative websites created by then in Australia. It included works

\footnotetext{
${ }^{83}$ See point 3.4.3.1.

${ }^{84}$ Available at <www.ouw.edu.au-wwwo>
} 
by women who never used computer before, aiming to show their works and "to encourage and consider new technologies", it brought together artists, writers, researchers, performers, designers, sociologists, IT experts, educators, etc. (University of Wollongong, 1995)

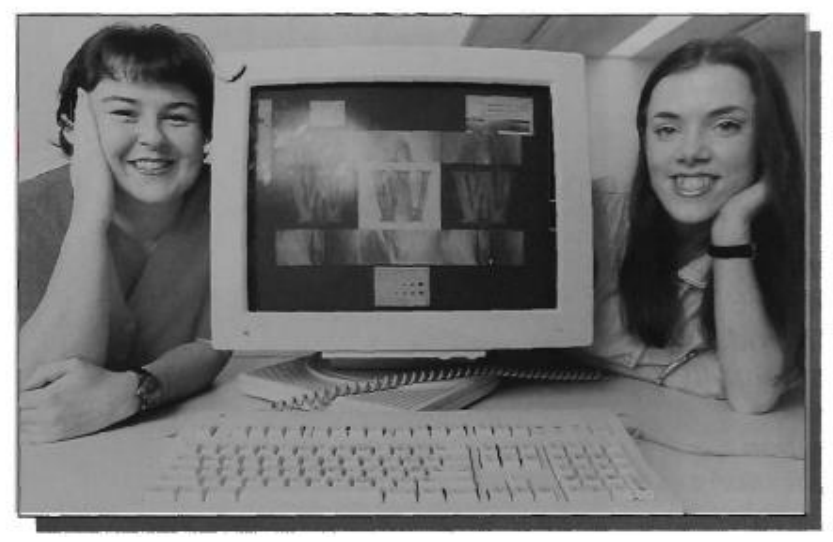

Figure 69 Wollongong's World's Women Online (WWWO) curators Melinda Rackham (left) and Louise Manner, with the Home Page of WWWO displayed on screen. Louis. Source: www.ouw.edu

In this same line, artist Victoria Vesna created also in 1995 her artwork $f$-e-email, inspired on computer mediated extension and physical snail mail networks such as Women Beyond Borders ${ }^{85}$. It was designed to address "communication as an essential medium for gender issues", claiming virtual spaces created by and for women who "utilize networked technologies, promote education in digital arts for women and link out the women's networks on or offline" (Vesna, 1997).

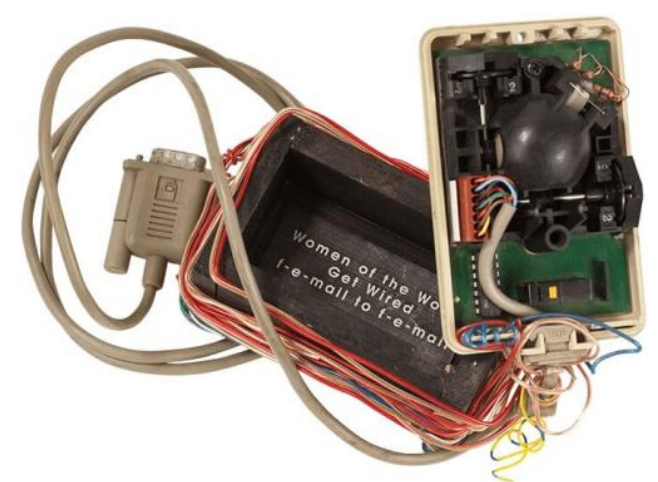

Figure 70 Wired F-e-mail, Victoria Vesna, 1995. In the body of the piece we read: "Women of the World, Get Wired f-e-mail to $f$-e-mail".

\footnotetext{
${ }^{85}$ Available at <www.womenbeyondborders.org>
} 
Women Beyond Borders is an ongoing project, a non-profit cross-cultural exhibition founded in 1991 by Lorraine Serene and a group of colleagues aiming to encourage "dialogue, collaboration and community among women [...] designed to transcend barriers". The project has grown until involving ten thousand artists from "Afghanistan to Zambia" with more than fifty venues held in different places around the world until today (WBB, 2019). It is an early example of what new ICT meant as means of connectivity for women artists cross-borders, cross-languages and cross-cultures at an organisational level along the 1990s. Vesna's work therefore alludes to the early all-women -cyberfeminists- networks, which are "specifically designed by and for women. Computer mediated networks, inherently chaotic, non-linear and fluid are natural environments for women artists to experiment, exchange ideas, create support systems and flourish" (Vesna, 1997).

\subsubsection{All-women Radio Networks}

Radio networks had enabled communication and connectivity cross-borders since the late $19^{\text {th }}$ Century (Föllmer \& Badenoch, 2018, p.11). It was in the 1970s, together with the so-called second wave feminism, that feminist programmes started to appear in line as free radios and pirate radios, like an advent of the still to come virtual blogs and communities online (Schaffer \& Thierry, 2015). There were also community radio programmes lead by women. Before the social media and digital networks, communities of women were getting together virtually on the waves as a form of activism and alternative creation of public space (Mitchell, 1998) Examples like the Young Ladies Radio League, founded in 1939 and still active, organizing international meetings of women radio amateurs, providing an open archive in their platform to encourage women to engage in radio amateurism ${ }^{86}$. In 1949 the Dutch feminist and historian Lilian van der Goot founded the International Association of Women in Radio and Television, inspired by the transnational feature Minners Wives (1939). Another example is

\footnotetext{
${ }^{86}$ See more at <https://ylrl.org >
} 
Women's Radio Group (WRG), before known as Women's Airwaves (WAW), fighting for the underrepresentation of women on air. Established as Women's Radio Workshop in 1979 their programme of activities included training women for mainstream and community radio stations, which promote alternative uses of media by women collectively (Mitchell, 2000, p.95):

Since the birth of the Italian free radio movement in the 1970s, which spread in various forms throughout Europe and beyond, community (sometimes pirate) radio has offered an alternative voice to groups not always well-served in the public service or commercial radio sector. (Föllmer \& Badenoch, 2018, p.19)

The relationship between the free radios and the women's movement first steps in the 1970s is clear, as with the implantation of a democratic system in every country they started to be opened. Additionally, low cost DIY kits and new engineers in telecommunications allowed collectives to open free radio stations as forms of political and social expression. Those feminist groups in Italy formed Radio Lilith and in France Radioteuses These radio groups created international network, which shows the emancipatory potential of the radio. These radios would inspire the feminist free radio station in Spain after the end of the Franco dictatorship (Pérez-Martínez, 2015). Women's issues started to be part of the general programmes of free radios, and unlike the female-oriented or women's radio programmes we mentioned above, the feminist free radios tried to fight the gender roles and the concepts of femininity that mainstream media was promoting (Pérez-Martínez, 2015). Radio Venus women's group in Barcelona would open Grup de dones de Radio Venus, with previous steps in Radio Gavina feminist programmeme El programmea de la dona. In 1993, “first working group composed exclusively of women appeared within the Network Interknonnexiones, promoted by Radio Dreyckland in Germany in 1989". The Women involved in free radio started to get connected internationally, in events like "Encuentro Internacional de Mujeres de las Radios Libres" (International Meeting of Women from Free Radios) held in Valencia in 1986, and the one in 1992 in Mexico, the 
Women's International Network was established within AMARC (Asociación Mundial de Radios Comunitarias), the organisation that has been representing the free and community radios since 1983 (Pérez-Martínez, 2015).

\subsection{All-Women Creative Networks}

Between 1994 and 1995 in Europe the first networking platforms around the Net Culture appeared, offering low-cost spaces for discussion and networking, for example: De Digitale Stad in Amsterdam (1994), International City Federation in Berlin (1994), the Public Netbase in Vienna (1995), Digital Media Lab in Ljubliana (1995) and the Backspace in London (1996). It was in 1995 when the first international mailing lists dedicated to topics of the new media art and digital culture started to appear. The most relevant were Syndicate (1995), with Inke Arns ${ }^{87}$ as co-moderator; Nettime $^{88}$ (1995), Rhizome ${ }^{89}$ (1996, first in Berlin then moved to New York), 7-11 (1997), and Faces (1997), among others (Bazzichelli, 2008, p.101). Faces was the first women-only mailing list in new media arts and digital culture, officially launched in 1997 by Kathy Rae Huffman, Diana McCarty and Valie Djordjevic. However, virtual communities and networking servers for artists -and managed by women- already existed since one decade before: Art.com, The WELL, ECHONYC, etc ${ }^{90}$.

\subsubsection{First Creative Networks on Net Culture in Europe}

Nettime was formed in 1995 during a meeting called <nettime> at the Venice Biennale, part of the Club Berlin event. It became a list soon, and they organised its first event in Ljublkana in 1997 called The Beauty and the East (Huffman, personal communication, 19 ${ }^{\text {th }}$ March 2019). Nettime became the most famous international mailing list on Net culture, a European avant-garde network with leftist

\footnotetext{
${ }^{87}$ She is co-curator of Computer Grrls in 2019, see table 1 in section 3.4.1.2.

${ }^{88}$ www.nettime.org

${ }^{89}$ www.rhizome.org

${ }^{90}$ See section 2.4.6.
} 
political ideologies and critical visions on technology, activism and art. It raised by reaction to the 'Californian ideology', the American predominant line, described by Diana McCarty as neo-liberal of a white male techno-elite (Bazzhichelli 2008, p.102). Nettime went beyond the boundaries of the mailing list, it established itself a network of people, projects and proposals regarding Net Art and Net Culture, that gave rise to a series of publications, international platforms, encounters and community (p.102). From the early 1990s the world of cyberarts and computer arts started to get over its stigma within the art world, its name changed to digital arts, embracing a wide range of interdisciplinary practices and artists profiles that combine engineering, pure science, natural science, arts and others. The world of new media arts kept on growing and its networks continued expanding through the already established international Festivals, which increased their audience and programme, and those new ones that were founded like ISEA International (Inter-Society for the Electronic Arts) founded in the early 1990s in the Netherlands (Fritz, 2016, p.60). The best example is, when in 1997 the institutional legitimation of the Net Art in the contemporary art world was manifested during the Documenta $X$ festival in Kassel, Germany. European collectives, organisations, projects and artists, participated with their proposals and networks: "Documenta X, there was also the first attempt to map the network of European digital culture" (Bazzichelli, 2008, p.179).

As Tatiana Bazzichelli notes, the Italian scenario of simultaneous development of the Net Art and the networking practices "which developed mostly within the counterculture artistic and activist realities, near the hacker scene" is very relevant to understand the coming formats of collective and creative networks (p.103) -as my case studies. Despite the series of theories that started to analyse the social potential of virtual communities (Rheingold, 1993), the creative networks that started to appear in new media arts are a combination of virtual and face-to-face encounters, essential for the establishment of the community: 
...the construction of networks and shared contexts doesn't take place only in virtual space, it passes mainly through a dense succession of physical events: meetings, exhibitions and festivals, that allow the various souls of net.culture to share ongoing experiences, and to deepen personal contacts and construct social moments (Marco Deseriis \& Giuseppe Marano, 2003, in Bazzichelli, 2008, p.182).

The new media art world is since its beginning a transnational network happening in a sort of parallel dimension separated from the general visual art scene, as a unique place where only people enamored with the creative possibilities and artistic approaches of new technologies gathered. It didn't and doesn't matter where one is located, once you are in, you will start meeting faces over and over in different parts of the world. However, this space that was built on its own, had soon its own its grassroot networks. Along the following two chapters I will discuss how, despite the new communication tools that merge in the digital age and the net culture, personal encounters together with the most classical formats are key for the reinforcement of networks of alliance (Crack, 2008).

\subsubsection{Faces Settings}

Although the emerging creative networks and mailing lists like Nettime promoted an open participation and possibilities of expression, there was an evident lack of women's participation in the forums: "The male culture of scientific, business, and military based structures and biases built into communications technology is daunting and alien to many people from different cultural, racial, and class sectors" (Nettime 1999, p.21 in Smite, 2012, p.76) Women in the field found the mailing lists on

net culture, specially Nettime, “overwhelmingly male" (Huffman, personal communication, $19^{\text {th }}$ March 2019) and difficult to crack, despite the attempts by the servers to address the contemporary cyberfeminist issues. (Nettime, 1999, p.21 in Smite, 2012, p.76). Women's participation in virtual communities, forms of communication based on gender and identity in cyberspace were by then an issue that many tried to investigate, as the correlate virtual sexual harassment. 


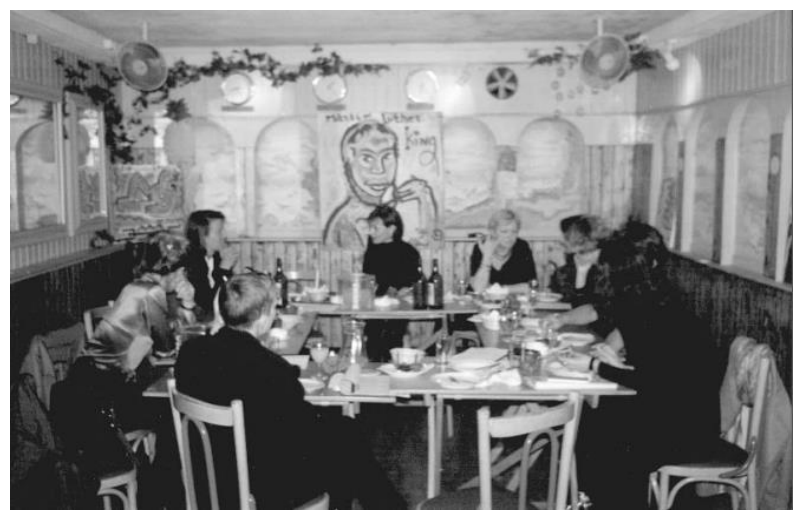

Figure 71 Face Settings, September 1996, dinner in Rotterdam, the Netherlands. Courtesy: Kathy Rae Huffman

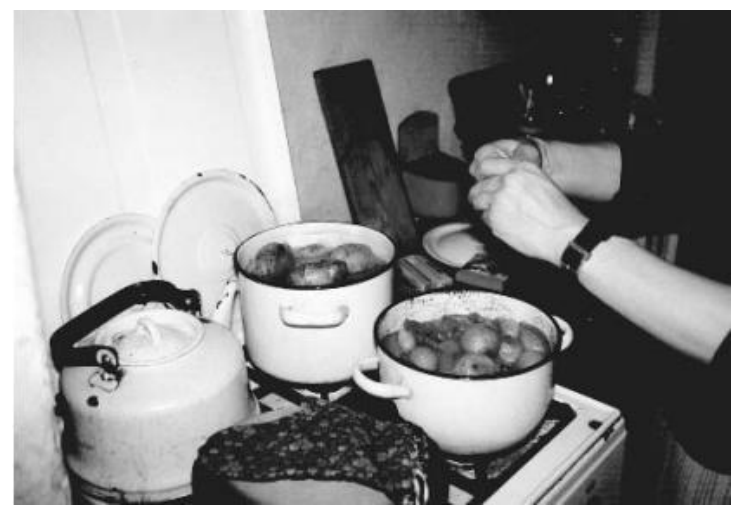

Figure 72 Face Settings, October 1996, in St. Petersburg, Russia. Courtesy: Kathy Rae Huffman

By 1996, Eva Wohlgemuthh, a conceptual Austrian artist, and Kathy Rae Huffman, North American media curator, producer and networker, started Faces Settings ${ }^{91}$, a co-cooking and communication Internet project based on an investigation focused on women's communication online and offline. The idea came after sharing personal experiences related to communication based on their cultural background and their gender during their previous Internet project Siberian Deal, a cyber diary artwork, after which they decided to work together on a project dedicated to connecting women: "in Europe, the lack of structure, encouragement, or reward for women working in the new communication technologies was obvious to us" (Huffman, 2003, p.401). Additionally, the International Festival of Contemporary Arts - City of Women ${ }^{92}$, in Europe had its first edition in 1995, in Slovenia, reactivating the feminist spirit in the European art network (Huffman, personal communication, $9^{\text {th }}$ July 2019). Both had already organised several dinner parties with other female artists and also given workshop training artists to create websites (Huffman, 2017). Face Settings were a series of dinner-performances events developed from 1996 to 1998 in twelve-women-groups located in five border regions, together with interviews and other research methods that Huffman and Wohlgemuth performed collectively

\footnotetext{
${ }^{91}$ Available at <http://thing.at/face >

92 See <http://www.cityofwomen.org/en>
} 
through their professional networks on events in new media arts. Combining "women, cooking and communication", they designed a series of events that would connect the local activities with the virtual platform, linking and promoting the members work online (Huffman, 2003, p.401).

The objective was to build a network based on: communication online (defined groups in each location), online representation (the web site, linking the real local events between the regional groups), live performing installation events (local dinners in groups of twelve, creating a feeling of vocational and familiar encounter), artifacts (rewards exchanging), publications (a cookbook catalog compilation of the dinners) and a series of goals: "the questions Face Settings raises are various, and are evolving. Personally, I am interested in the process of establishing a female network and establishing personal links in each of the Face Settings locations" (Huffman \& Wohlgemuth, 1998, p.41):

Face Settings dinner events were to be enjoyable events, celebrations with low stress and lots of personal care (for ourselves and the women we meet). Pleasure connected to food and the sharing of information would be a topic to introduce in our dinners. We hoped to establish real communication that would grow in the digital environment, eventually linking the regional groups in a collaborative cooking performance event (Huffman, 2003, p.401).

Face Settings was not intended to be defined as a cyberfeminist project, however, due to the negative reaction of some male counterparts in some cities towards a women-only project, they felt the necessity to a "make strong position" (p.405). Following this interest on female communication, Huffman developed another project together with Margarete Jahrmann called 'Pop TARTS' during 1996 and 1997 as an online journal on net culture from a female perspective for the German online journal Telepolis. Like Face Settings, it was a project aiming to build up networks and online community among women in the media arts and theory through online and offline communication (Huffman, 2017). 


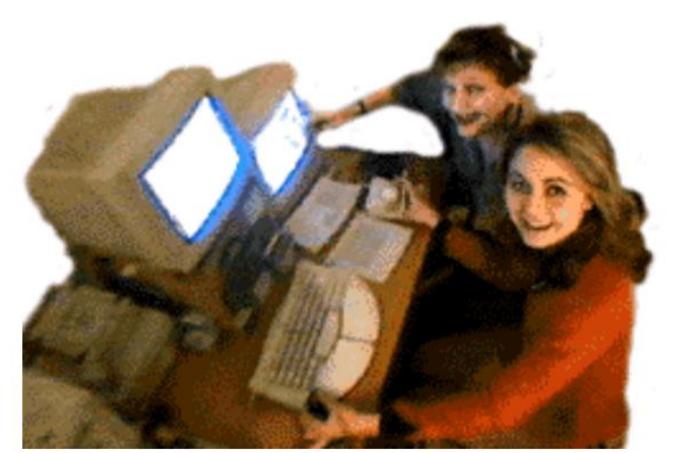

Figure 73 Kathy Rae Huffman (backfront) and Margarete Jahrman on Pop TARTS, 1997. Source: www.heise.de

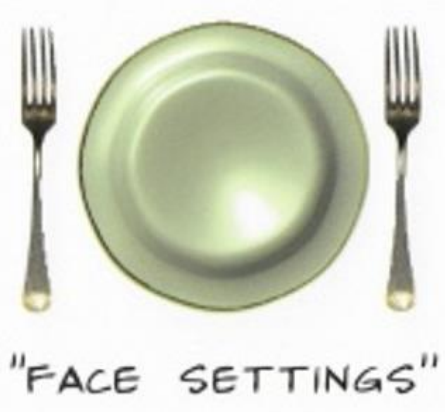

Figure 74 Face Settings image. Courtesy: Kathy Rae Huffman

\subsubsection{Faces Mailing List}

During the second Faces Settings dinner held in Vienna in December 1996, media artist Diana McCarty joined, and together with Huffman -both were in the first Nettime meeting in 1995- both came up with the idea of a mailing list moderated that would help to keep the participants of Face Settings events connected and informed, which was also a way to have an own space to communicate and support each other outside the competitive discussion list of Nettime (Huffman, personal communication $9^{\text {th }}$ July 2019). It was named Faces and it was launched in Spring 2017, with a controversial presentation during Syndicate meeting in Liverpool $L E A F$, experience that just reinforced the necessity for a private channel to discuss and share "without men trying to overhead our conversation” (Huffman, 2017). In an encounter in Berlin, Valie Djordjevic joined the project and by next summer the mailing list had increased their membership, experiencing a content growing, in part due to the collaboration with the first event organised by the cyberfeminism international alliance Old Boys Network, the Cyberfeminism International at documenta $X$ in Kassel $^{93}$ at the Hybrid Workspace. Members of the International used the mailing list to communicate and organize the exhibition, and additionally to discuss openly about meanings of cyberfeminism and possible politics and practices on

\footnotetext{
${ }^{93}$ See following point 3.3.4.
} 
the Net (Wilding, 1998). As we abovementioned, documenta $X$ was the first international event for Net Art, and Face Settings would participate with a show of online communication projects by women and prepared the opening dinner for all the women cyberfeminists, "offering support and solidarity to the project" (Huffman, 2003, p.40):

Our theory tries to explore these and other questions about connectivity and online presence. We have created an environment which we think is a female environment on the net. This also means it does not have to have black backgrounds. It is a well-known fact that the Internet is a male environment, populated by a mere $15 \%$ women in Europe. Although statistics vary from survey to survey, all agree that the fastest growing category of users in Europe are (young) women. A strong online community of women already exists in America and Australia, and terms like CyberFeminist or Grrl are often used to describe websites and ideas surrounding this topic (Huffman \& Wohlgemuth, 1998, p.78)

Some members of the Cyberfeminist International were part of Nettime: McCarty, Huffman, Josephine Bosma and Faith Wilding, etc. (Huffman, personal communication, 19 ${ }^{\text {th }}$ March 2019). The collaboration between Faces and OBN members with other European initiative contacts (such as Les Penelopes, webgrrls, etc) was crucial for the building and establishment of two simultaneous transnational nodes of women in new media arts and ICT activists, which, despite its predominant initial European profile, has influenced the following years of activism, art practice and creative networks and collectives. Due to this, Faces ended up having the widest contact list knowledge about "where the women were" in new media arts (Huffman, 2017), a question that was and still is predominant in the new media world. Later, all women involved in one way or another have been part of cyberfeminist and all-women projects in new media arts, ICT and gender somehow. I will comment on OBN in the next chapter. 
The year 1997 was an important date for the establishment of women's networks and alliances in through the Internet networks (Boix, 2001), so it was for those in new media arts. After Kassel, Faces Settings was also part of Ars Electronica Festival, where they set up a big action: "soup making amidst [sic] all the tech workstations”, offering daily soup to all. There in Linz, artist Eva Ursprung invited them to an exhibition next year in Graz, where she was curator at that time (Huffman, personal communication, 2019).

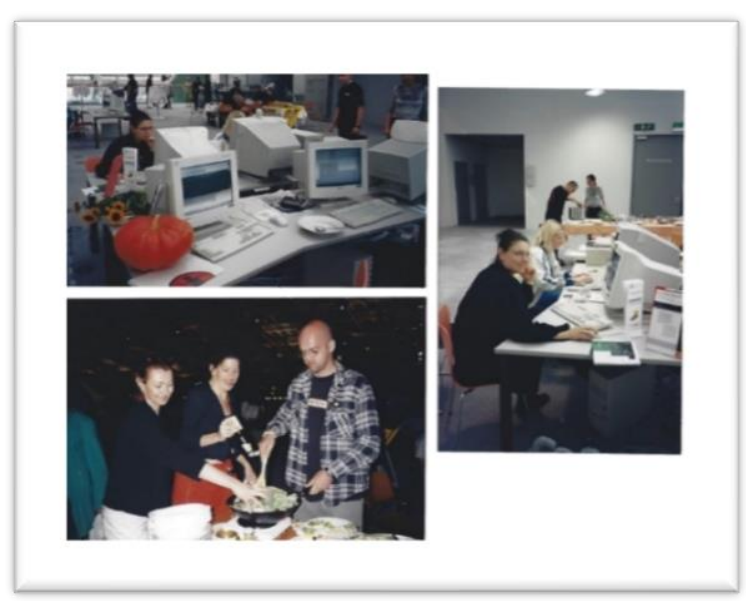

Figure 75 Composition of images from the office workshop and soup pint at Ars Electronica 1997.

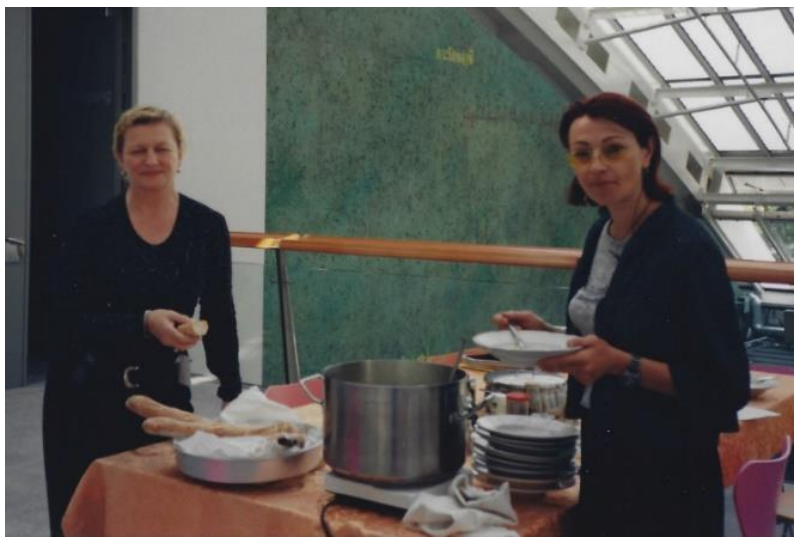

Figure 76 Kathy Rae Huffman and Eva Wohlgemuth, in the soup point at Ars Electronica 1997. Courtesy: Kathy Rae Huffman

The meeting in Graz next year was named Face 2 Face, celebrated from $6^{\text {th }}$ to $11^{\text {th }}$ July at the Forum Statdpark. For the event, Huffman and Wohlgemuth organised an exhibition, a symposium and a RealAdudio workshop that started and ended with a roundtable. It gathered more than forty women from the give designated Face Setting countries (Russia, The Netherlands, Austria, UK and Spain)and some male guests-. Most of them already belonged to Faces mailing list, and came together to present their work, projects in each country, to meet, communicate, and exchange ideas about female communication online, and to cook. The topic of the exhibition was selected by Eva Ursprung to address the practices and strategies of online presence: The Body: Identity and Community in 
Cyberspace. As in the general practices of cyberfeminism in the 1990s, the main topic was the body (Huffman, 2003, p.408).

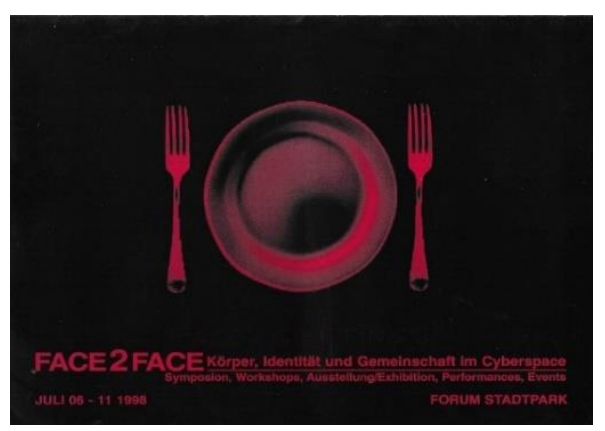

Figure 77 Poster Face2Face in Graz, July 1998. Courtesy: Kahty Rae Huffman

As Wohlgemuth and Huffman presented the Face Setting projects -while combining it with their professional and personal life-, the interested by women in joining the project through the mailing list kept on growing, driving it to a different direction as the initially expected: "the growth of Faces, in some way, marked the decline of Face Settings" (Huffman, 2003, p.408). For example, Face2Face was celebrated in other locations together with a strong virtual online discussion, it brought topics on communication practices regarding how women speak and communicated differently based on their culture and gender and how that affects their presence online. Faces started to interest women from different countries, ages, social backgrounds, education levels and fields related to online communication and Net Art, who felt somehow discriminated or apart: "These women were already seeking out the rest of us" (Faces, 2006). Nettime was an excellent resource for everyone in the field, however:

It was early times for Nettime, and some women felt that they were regularly shut out of conversations (or slammed down). So, we felt great to launch our own forum for sharing of information, not pontificating over theoretical platforms. (Huffman, personal communication, $19^{\text {th }}$ March 2019) 
Unintentionally, Faces became a creative network of women in media arts transnationally, established through self-organised informal meetings happening in the grassroots of international conferences, festivals, exhibitions, symposiums, becoming a point of support, solidarity and intimate space. Founders and members of Faces represented a linkage cross-borders, unifying East and West Europe, transatlantic and transcontinental connections, a work that has been done voluntarily and based on collaboration, with no structural hierarchies besides the moderation of the mailing list discussions.

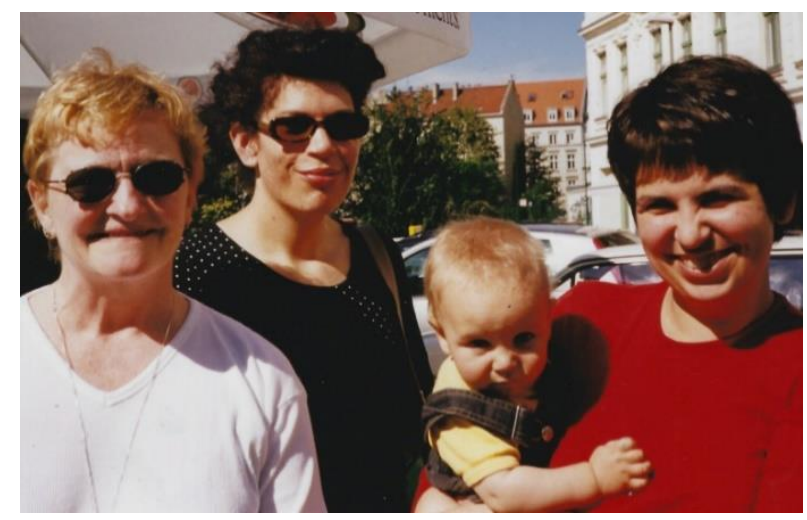

Figure 78 Founders. Left to right: Kathy Rae Huffman, Diana McCarty, Valie Djordjevic, circa 1997. Austria. Source: Digicult

The mailing list was moved to three different servers due to the lack of financial resources (currently in servus.at, managed by Ushi Reiter), it soon became an online forum of discussion for international issues on art, technology, communication and online policy. Also, a new format to announce, promote and share communication and projects by female artists, curators, professors, researchers, producers, etc., what could have not been possible in other circumstances. Segregation was the key strategy, men were not allowed to subscribe to Faces, despite the controversy of the "new radical format of women-only" (Derieg, personal communication 2018):

We decided it had to be only women, otherwise we would have another Nettime (with ranting men - smart but ranting nonetheless). We wanted something that would connect women, not to give them a platform to intimidate others' (Huffman 2010 in Smite, 2012, p.77). 
They also decided not to name the project feminist, as the term was not accepted in consensus, despite all the members shared common purposes in the community:

I think using the word is not as important as having the same political aims of increasing the visibility of women, same money for the same jobs (that is even true for freelancers in the art world), getting rid of male bias, including other topics that were seen as female and there for less valid in art etc. Especially in the beginning of the list we talked explicitly if we should call ourselves "a feminist mailing list" but agreed that it was more important to be inclusive than to get hung up on a term (Djordjevic, 2017).

Transwomen and female-identified folks are welcome to join Faces ${ }^{94}$. Through informal contacts and by word of mouth, in 2002 the mailing list reached four hundred international members beyond Europe countries from the initial thirty members of the first year. Currently the list reaches almost five hundred subscribers (Huffman, personal communication, 2019). In terms of quality, women in Faces represent a significant body of work, knowledge and output in the field of media arts. Members of the list are outstanding and acclaimed figures in academia and the creative world, with notable contributions to new media art history, feminist hackerspaces, free feminist radios, cultural centers, etc. ${ }^{95}$ :

In keeping with the emphasis on network building, Faces occasionally hosts informal get togethers, diners and open mic sessions parallel to various media events. There real-life meetings offer a chance for some good old-fashioned face to face and generate a powerful female presence that highlights how many women actually do work in media. Of course, in the

\footnotetext{
${ }^{94}$ Sandy Stone, famous transwoman, was one of the first members on Faces. As used to happen in most of the women-only virtual communities, the filter for subscription by the moderatos suffered faced many problematics, due to the controversies of virtual identity and transgender identity.

95 A few examples: Diana McCarty works in reboot.fm 88.4 FM in Berlin, the members of genderchangers and organizers of /ETC, and also Aillen Degreier and Ushi Reiter are part of THF!, Cornelia Sollfrank and other core members of OBN, Runi Hofmuller organizer of esc, in Graz, and genderchanger, etc.
} 
international context of media art and culture, the question remains 'where are the women?' (Faces, 2006).

\subsubsection{Old Boys Network}

While by the end of 1990s many authors were speculating and publishing apocalyptic and pessimistic works on the end of history, cyberfeminists artists and activists attempted to build a new emerging and undefinable movement, based on the wish to shape the future, to build new meanings through strategies of collaboration in cyberspace (Paterson, 1997). As I have already discussed, cyberfeminist started to spread from VNS Matrix and Sadie Plant until reaching all women's networks involved with technology in Western Countries and beyond. In Spring 1997 in Berlin, a group of women in the emerging Net Art world founded an international coalition committed to the “appropriation, creation and dissemination" of cyberfeminism (Sollfrank, 1999, p.6). As an ironic allusion to the male-dominated scene (new media arts festivals, hackerspaces, computer science studies) and in the emerging creative networks and communities in the digital arts field such as Nettime, they named the initiative Old Boys Network (OBN). Following formal and academic formats (Halloway, 1999), OBN content strategy was based on collecting referential material, analysis, connecting people, ideas and machines -alluding to Sadie Plant theory-, connecting the past and the future, producing new material and distributing information through available networks. To do so, until 2001 they organised three editions (First, 1997, Next 1999, Very 2001) of Cyberfeminist International encounters and they also built a digital platform ${ }^{96}$ with a mailing list and organised other punctual events. Their virtual and real encounters gathered the participation and collaboration of associated members from different parts of the world. The founding members were: Susanna Ackers, Julianne

\footnotetext{
${ }^{96}$ See <www.obn.org>
} 
Pierce (from VNS Matrix), Valentina Djordjevic, Ellen Nonnenmacher and Cornelia Sollfrank, however, as an open network, the contribution and following implication and collaborations would grow and variate depending on the year and activity, with artists and theoreticians such as Verena Kuni, Helene von Oldenburg, Claudia Reiche and Yvonne Volkart, among others. Situated as 'third-wave' feminists, OBN membership criteria was based in the cyberfeminist attempt to differentiate itself from "the exclusionary second-wave feminist strategies" like the women-only spaces (Wilding, 1998) and the added controversy it carried during the 1970s and 1980s in United States. OBN welcomed any individual who would identify as a woman, independently of their biological sex (OBN, 1991). However, this was not the first time that OBN members applied strategies of all-women self-organised groups for the first time. Before the founding of the international cyberfeminist network, Cornelia Solfrank and Ellen Nonenmacher had co-founded in Germany two all-women/feminist collectives: Frauen und Technik (fut) [Women and Technology] (active in 1992-1993) and -innen [inside] (active in 1993/4-1996/1997).

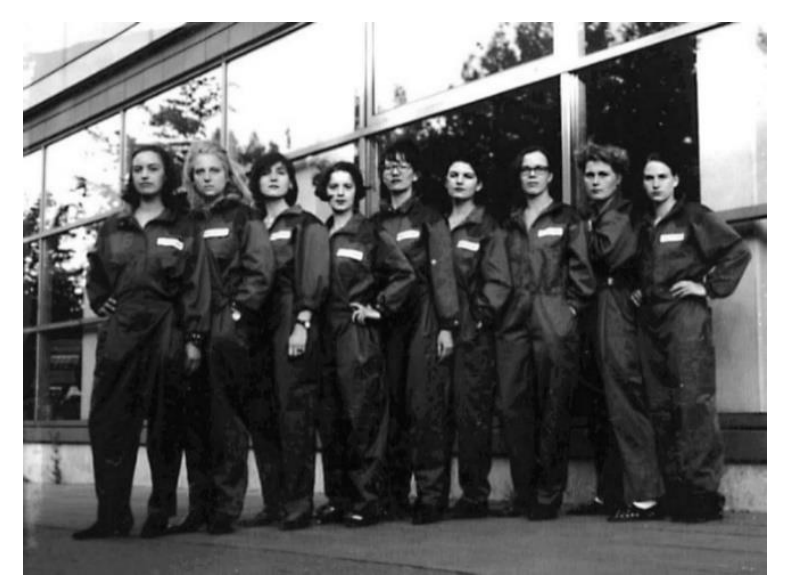

Figure 79 Members of the collective Frauen und Technik, 1992. Courtesy: Cornelia Sollfrank

Frauen und Technik was an artists group founded in 1992 by a group of ten female artists that were students at the art school in Hamburg. They developed performative interventions and experiments with interactive television contributions to Piazza Virtuale, the art television programme of Documenta IX in Kassel, title of their TV show was envy-of-penis-games. -innen was formed from 
four members of fut by the end of 1993: Sollfrank, Nonnemacher with Korinna Knoll and Janine Sack, continuing with live performances and media interventions such as Narcissism in the media after Lacan, interactive television games New Media-Old Roles, intervention at CeBit Hannover in 1996. Unlike OBN, these two groups were collectives dedicated to do art projects together, while the cyberfeminist network was focused on building platforms for others, infrastructure work and organizing events (Sollfrank, personal communication $8^{\text {th }}$ July, 2019).

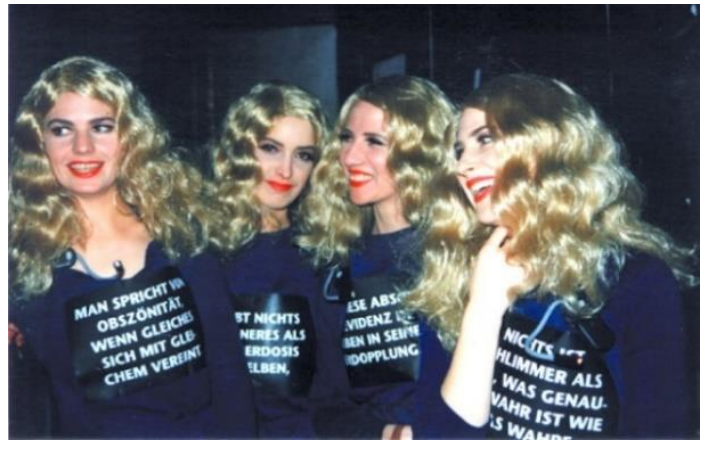

Figure 80 pictures of -innen collective. From 1994 to 1996.

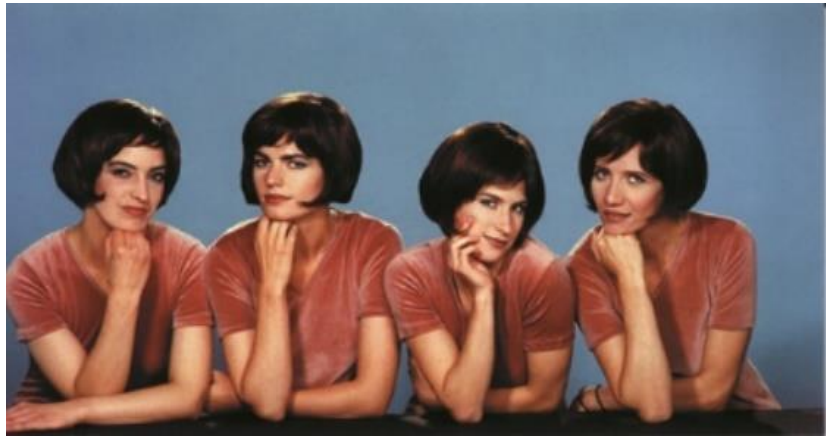

Figure 81 pictures of -innen collective From 1994 to 1996.

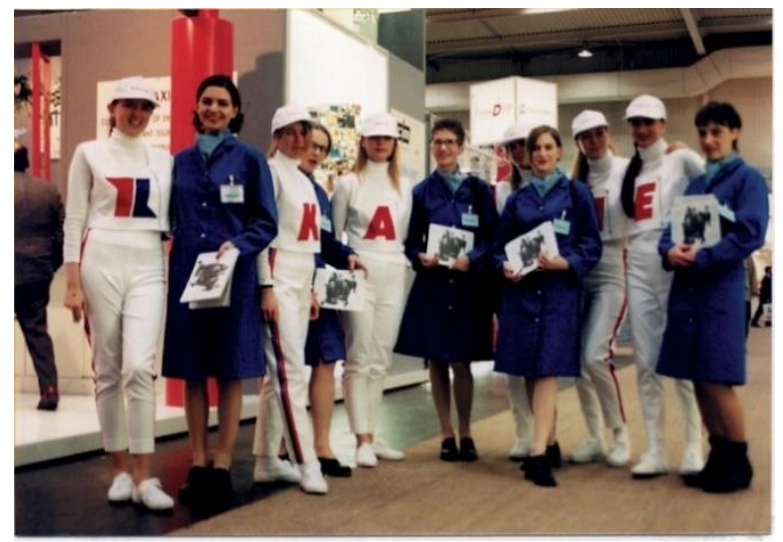

Figure 82 picture of -innen collective, members in blue suit. From 1994 to 1996.

At the First International in documenta $X$ in Kassel in 1997, OBN invited cyberfeminists from different countries to be part of the Hybrid Workspace. Thirty-seven women from seventeen countries participated in the interviews, open radio, dinners, exhibition, talks, debates, and work on the following questions (Sollfrank, 1998, p.1):

1. What is Cyberfeminism? What is hidden behind the fusion of cyber and feminism? 
2. What does Cyberfeminism have to do with Feminism? Will the addition of cyber give good old feminism another chance to fly, or is there a possibility for completely new content and new challenges?

3. How do cyberfeminists deal with the new technologies?

Acknowledging the vast variety of feminist theoretical and practical positions, OBN claimed for political action through artistic practices as productive connecting link, further than identifying oneself as a woman (Sollfrank, 1999, p.1). In this encounter of cyber and feminism, new meanings were being drawn. Following cyberfeminist and third-wave feminist theories, OBN would work upon new forms of theory and practices regarding women's relation with machinery and new technology, computer technology as feminine (Plant, 1997), the "production of gendered bodies" in the [female] cyberspace (Stone, 1991) and the constructions of the self and community through technology and cyberspace (Turkle, 1996) (Halloway, 1999).

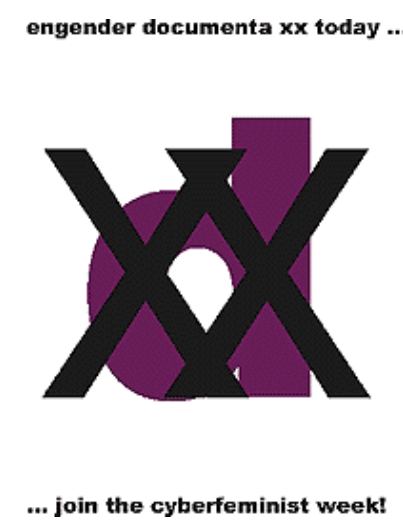

Figure 83 Advert/Logo for IC by Verena Kuni, in documenta $x$, Kassel 1997. Source: www.obn.org

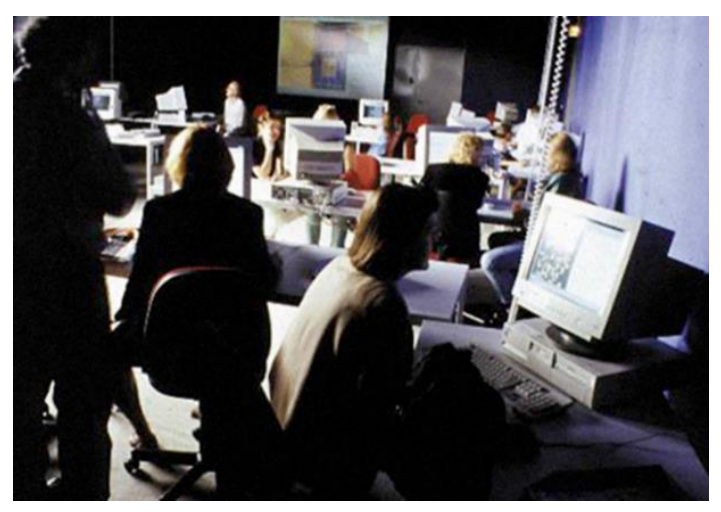

Figure 84 Women artists at Hybrid Workspace in documenta X, Kassel, 1997. Courtesy: Kathy Rae Huffman.

\subsubsection{Rhizomatic alliances}

One of the main interests of OBN was the speculation on what cyberfeminism are for each of the participants which developed in the collectively elaborated list of 100 anti-theses of cyberfeminism, 
published online ${ }^{97}$, which contains sentences in different languages, exposing the international aspect of the alliance n100. Cyberfeminism has not one language. The style might remind to some Dada manifests. Some of the anti-thesis that we would like to outline are the following:

cyberfeminism is not nettime; cyberfeminism is not without connectivity; cyberfeminism ist keine theorie; cyberfeminism ist keine praxis; cyberfeminism ist keine tradition; cyberfeminism is not an institution; cyberfeminism is not separatism; cyberfeminism is not romantic, cyberfeminism is not post-modern; cyberfeminism is not neutral, cyberfeminism is not lacanian.

It was always present an invitation to further description in the international encounters, and still today in the OBN website. This position refusing to describe what cyberfeminism is, was applied by Sollfrank as her artistic strategy based on "creating a new comprehensive label for an interdisciplinary genderrelated discourse on the net" (Sollfrank, 2002). However, as a network, a non-structured movement, collectively created, each of the members and participants of OBN manifested by her own her understanding of what cyberfeminism or should be. Marion Leonard (1997) would relate this multiplicity of definitions to the description by Elizabeth Groz's of multiplicity as "an ever-changing montotalisable collectivity, an assemblage defined [...] through its capacity to undergo permutation and transformation, that is, its dimensionanility" (p.112). As Leonard notes in the riot grrrls zines, in OBN there is no cultural representative product, but an emphasis in offering multiple personal comments by those involved in the network, who are "delighted in the possibilities opened up by allowing different people to produce their own interpretation" (Leonard, 1998, p.112). As Leonard, we relate this decentralized, underground culture nature of the riot zines and $F A C S$ and $O B N$ network to the notion of rhizome by Deleuze and Guattari (1987), which in contrast to the dominant metaphor of

\footnotetext{
${ }^{97}$ Available at <http://www.obn.org/cfundef/100antitheses.html>
} 
a tree structure, the rhizome visualises a network that multiplies via lines of connection which are not controlled from a primary location: "Riot grrrl isn't centralized, it's not organised, we've no leaders, no spokeswomen" (Ablaze! \#10:15 in Leonard, 1998):

...[rhizome] is composed not of units but of dimensions, or rather directions in motion. It has neither beginning nor end, but always a middle (milieu) from which it grows and which it overspills.... The rhizome operates by variation, expansion, conquest, capture, offshoots. (Deleuze \& Guattari, 1988, p.21 in Leonard, 1998, p.112)

\subsubsection{Cyberfeminism}

From all the attempts that have occurred to describe cyberfeminism by different theoreticians interested in women, gender and new information technologies, what concerns to us is the position regarding organisational practices and alliances. As Sollfrank would state in 2002 in The truth about cyberfeminism:

Cyberfeminism is beginning to appear with some frequency in the context of art, politics and science. It's clear ending --feminism-- suggests a political demand or strategy. But it also might indicate an artistic method. Maybe Cyberfeminism makes artistic practice politically effective, or suggests artistic methods in politics? And what does "politics" mean within this context?

Cyberfeminist art practices on the net were also in the legacy of collage and montage techniques from the artistic and political activism and strategies of parody and masquerade from the context of feminist art and queer theory (Kuni, 1998, p.71). As theoretician Paasonen stays (2011) "The anti-theses are telling of the importance of both international networking and playful irony in cyberfeminism" (p.13). Scholars like Braidotti in Cyberfeminism with a difference (1998) would relate the cyberfeminist art and activist groups would join the legacy of the Riot Grrls and grrrl zines, DIY and punk strategies. 
The Grrrl groups (cybergrrl-ism: 'webgrrls', 'guerrilla girls', 'bad girls') on the Net, who manifest the importance of parody, irony, humor, and expression of feelings towards a new feminine subjective and cultural representation on the net (Wilding, 1998).

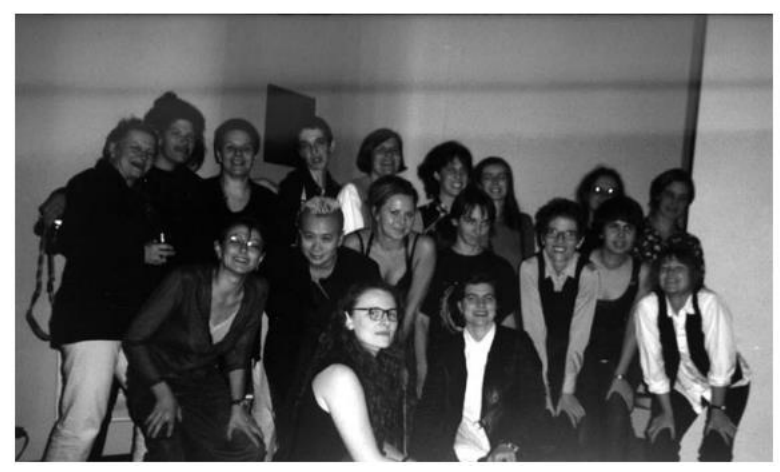

Figure 85 Participants in the First Cyberfeminist International after the dinner at Hybrid WorkSpace at Documenta X, 1997. Courtesy: Kathy Rae Huffman

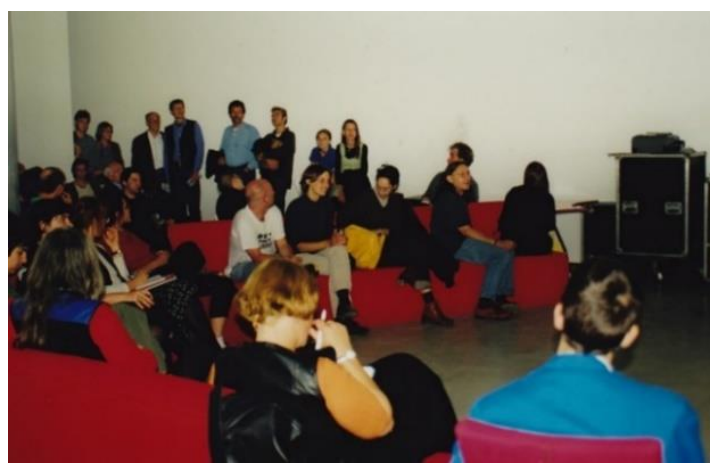

Figure 86 Photograph from the First Cyberfeminist International, part of the Hybrid WorkSpace programme at documenta X. Source: www.rhizome.org

OBN defined itself as plural: "The mode is the Message - The Code is the Collective!" (OBN, 2001). Verena Kuni (1999) would outline in OBN and the importance of Cyberfeminist networking:

Far more than merely a strategic alliance, OBN operates on the basis of personal sympathy as well as mutual acknowledgment and recognition - a community who obtains its agency by the way of its common sense about dissent as a common sense - many-voiced instead of an univocal chorus-line that needs to be guided by a conductor or a leader. Important is continuous exchange, discussion, and transdisciplinary collaboration, especially in the sense that old boys - though coming from different disciplines, referring to different theoretical backgrounds, having made different experiences, relating to different methods - have a common basis and field of work: cyberfeminism. And the fact that we all are prepared and willing to develop common cyberfeminist strategies is another unifying moment (p.71) 
Participants in the First International Cyberfeminist didn't know each other before, but the event meant the main node of the transnational network of theoreticians in gender, art, media culture, technology and cyberfeminism, such as Verena Kuni, Cornelia Sollfrank and Faith Wilding, who was part of the hacker activist collective Critical Art Ensemble (CAE) and founded the feminist collective subRosa in $1998^{98}$. Faith Wilding (1998) would join the female voices (like Montserrat Boix) that started to empathize by then the necessities of alliance towards a clearer political position through ICT:

Subversive uses of the new communications technologies can facilitate the work of a transnational movement which aims to infiltrate and infect the networks of power and communication through activist, feminist, projects of solidarity, education, freedom, vision, and resistance. [...] Cyberfeminists must resist utopic and mythic constructions of the Net and strive to work in activist coalitions with other resistant netgroups. Cyberfeminists need to declare solidarity with transnational feminist and postcolonial initiatives, and work to use their access to communications technologies and electronic networks to support such initiatives.

During the three editions, feminist and all-women networks, non-profit organisations in ICT and art participated: Gender Changers Academy ${ }^{99}$, Faces ${ }^{100}$, Das Kunstlerinnen Archive (The Women's Artists 'Archive), bildwechse ${ }^{101}$, Feminist Indymedia Austria, Les Chiennes de Garde - The first Feminist Interactive Website in France ${ }^{102}$, [plug in $]^{103}$, MAKE - the organisation for women in the

\footnotetext{
98 See point 3.4.3.1.

${ }^{99}$ See <www.genderchangers.org>

${ }^{100}$ See <www.faces-1.net>

${ }^{101}$ See < www.bildwechsel.org >

${ }^{102}$ See <www.chiennesdegarde.org>

${ }^{103}$ See <www.weallplugin.org>
} 
$\operatorname{arts}^{104}$, Constant VSZ ${ }^{105}$, subRosa ${ }^{106}$, Les Penelopes ${ }^{107}$, thealit ${ }^{108}$ and Webgrrrls ${ }^{109}$, (OBN, 1997; 1999; 2001) between others. Aiming to collect a wide range of interdisciplinary approaches regarding cyberfeminism, OBN created a series of virtual and real encounters combining theory and practice, which gathered the most active women in new media arts in the late 1990s and early 2000s. In the transnational network this research aims to visualise how the three international cyberfeminist events played some of the key nodes to understand the whole overview of women in media arts and networks until today.

Although cyberfeminism refers to activism in cyberspace, collaboratively OBN built spaces for production of knowledge and art practices in real and virtual, regarding new visions of feminism politics in the cyberspace, (re)building the women's history in technology. During the three editions and since then, numberless of papers, texts, essays, books, etc. have been published -within the network and beyond ${ }^{110}$ - regarding the meanings and strategies of cyberfeminism, and its (short) history. During the years several collective projects have come from OBN network. Some of the collective curatorial projects are exhibitions such as Cyberfem Spirit in $2002^{111}$.

Through all the contributions and work within OBN network as the results of the events, OBN built a cyberfeminist archive that is still available on their platform: interviews, contacts/network, publications, etc. It is not the first digital platform to promote a network of women in new media arts ${ }^{112}$

\footnotetext{
${ }^{104}$ See <www.womensart.org.uk>

${ }^{105}$ See <www.constantvzw.org>, founded in 1997 in Brussels is a non-profit artist-run organisation promoting activities in art, media and technology, departing from feminist and open culture. They have a section dedicated to cyberfeminism in wwww.cyberfem.constantvzq.org

106 See <www.cyberfeminism.org>

107 See $<w w w . l e s p e n e l o p e s . o r g>$

108 See $\langle w w w . t h e a l i t . d e>$

${ }^{109}$ See <www.webgrrls.de>

${ }^{110}$ Cyberfeminists part of the three IC influenced women authors in Spain like Montserrat Boix, Ana MartinezCollado and Remedios Zafra.

${ }^{111}$ See point 3.4.4.2.

112 See Muriel Magenta's platform Women On-Line in 1995 section 3.2.3.
} 
but it's probably the first one (together with the old website of Faces) to archive artistic and theoretical content and a manifesto, serving as bibliographic reference for its contemporaries and next generations. It also works as a node in the web providing links to other all-women and feminist networks, collectives groups, projects, etc. working on ICTs and art ${ }^{113}$.

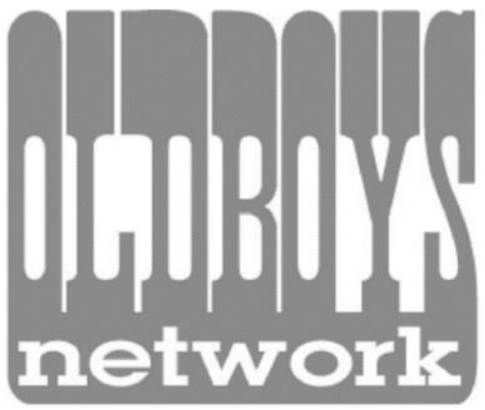

Figure 87 first logo of $O B N$, retrieved from First IC

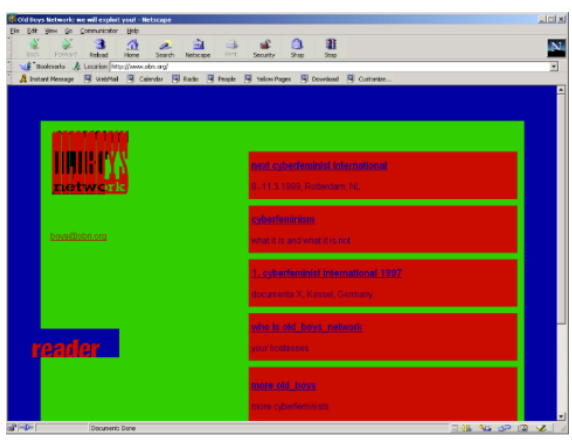

Figure 88 screenshot OBN platform in 1998. Source: rhizome.org

\subsubsection{Why to get together?}

Despite the attempts to build a Cyberfeminist Future and collective strategies, after the third IC in Hamburg in 2001, the activity of OBN decreased from a nuclear transnational connection to punctual activities and collaborations. Nevertheless, from the three IC, new projects appeared within and outside the network, like subRosa, /ETC, Donestech, XOyl, Cyberfem, THF, etc. After the event in 2001, the summary of the conclusions was that there was no unanimous answer given to the question "What is the feminist aspect of cybefeminism?" (OBN, 2001, p.14). If cyberfeminism is like feminism, and therefore is a developing philosophy (Hawtohorne and Klein, 1999, p.2), all the cyberfeminists should share the same perspective. Furthermore, if biological sex is no longer the unifying point, but the political position (Sollfrank, 1998), how can a transnational union take place for a long period,

\footnotetext{
${ }^{113}$ Old version of the platform: <https://www.obn.org/kassel>; current one https://www.obn.org.
} 
existing controversies and varieties of opinion? As Faces pointed in the publication of the Very IC (2001): "Perhaps the most important question is what pragmatic response will fulfill the needs of a thriving community of interrelated networks of women actively working with media?” (p.28). Wilding (1998) would point the necessity to establish clear objectives and a political position to make a real change in society through new technologies and definition as a political strategy (p.9). Wilding (1998) and Rossi Braidotti would point the crucial understanding of the history of feminism towards building a new movement in a transnational level:

I am very concerned not to lose the connection to the past. I am only in favor of cyberfeminism, so long cyberfeminists remember that there is a long history to this, and we're not starting from scratch! We cannot lose 30, 40, 60, 100 years of accumulation of knowledge and experience. We must draw these connections. (Braidotti in Muller, 1999, p.76)

Women are attempting to achieve such a connection cross-border since the $18^{\text {th }}$ Century in the roots of the women's movement (Scott, 1992; Rupp, 1994; Moghadam, 2015, p.54). As active artists and feminist in the north American second-wave, Wilding evidences the contradiction of the so-called third feminism or postfeminism in cyberfeminism, its rejection of the previous feminisms, yet the strategies that they follow are in the same line: women only lists, self-help groups, chat groups, networks, and woman to woman technological training: "the repudiation of historical feminism is problematic because it throws out the baby with the bathwater and aligns itself uneasily with popular fears, stereotypes, and misconceptions about feminism" (wilding, where is feminism in...). Wilding (1998) acknowledges the previous work made by feminist movements and its reinterpretation it in a new socio technological context, is in her opinion, the way to create feminist politics on the Net (p.10).

Authors like Hawthorne \& Klein (2003) stated that "in the era of Cyberfeminism, connectivity has a new meaning", reminding that "connectivity is the heart of feminism", retrieving the notion of sisterhood in the first and second-wave that challenged "patriarchal ideologies of women as enemies 
of one another" (p.7). And despite the "fragmenting forces of postmodernism economic rationalism and globalization" (Brodribb, 1992; Klein, 1996 in Hawthorne \& Klein, 2003, p.7), women around the world have continued to explore those issues which we have in common, while recognizing our diversity: "As we have come to understand, focusing on difference alone, fragment us, separates us and disenfranchises us politically" (Hawthorne \& Klein, 2003, p.7). Wilding pointed in the collaboration between Faces and OBN key strategies for alliance cross-borders. As we abovementioned, at the Hybrid Workspace in documenta X Kathy Rae Huffman and Eva Wohlgemuthh with Faces Setting organised the aperture with a dinner, in the same space. For Wilding and CAE (1998, p.22) Faces also provided the mailing list as a communication tool, essential for the development of the event topics, organisation and discussions. As a chain of nodes through time, members of OBN and Faces, together with other cultural groups, brought feminist and women's practices to a new generation of women artists, such as the dinners in the work(art) space.
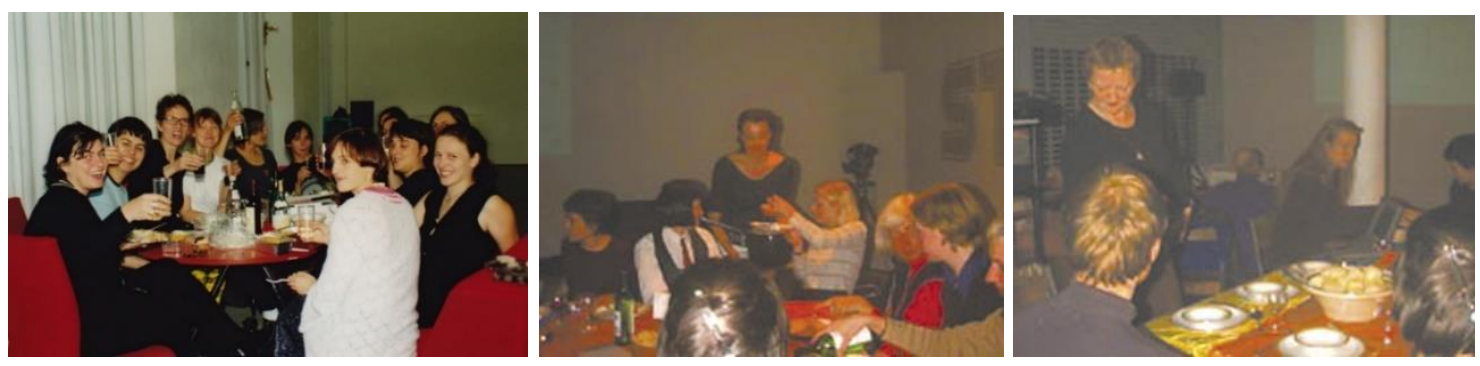

Figure 89 Participants in the First Cyberfeminist International socializing during the dinner at Hybrid WorkSpace at Documenta $X$, 1997. Source (left): www.rhizome.org; (middle and right) www.Faces-I.net

Faith Wilding had previously been a main member of the Fresno Feminist Art Programme and of the Woman's Building in the 1970s in California with Judy Chicago (The Dinner Party nights), reason why she was capable to link the second-wave segregation strategies in art groups with the new forms of alliance in cyberfeminism, following the point on the necessity for a knowledge from the feminist history (1998, p.9). During the dinner in Kassel, she made a presentation showing a series of food and dinner slides from the feminist art movement. The strategy of an informal and intimate dinner 
to create a community of women who most of them didn't know before, succeed (Wilding and Sollfrank, 1998):

Cyberfeminism is currently drawing upon social and cultural strategies from past waves of feminism. For example, dinner parties that celebrate women's achievements and serve as convivial coalition building events are a famous part of feminist history, as witnessed not only in the fundraising dinner parties held by female suffragists, but also in Judy Chicago's Dinner Party; in Suzanne Lacy's art/life performances; in Mary Beth Edelson's "Last Supper" detournement; and in the countless feasts prepared and served to each other by feminists all over the world in the past decades. (Wilding \& CAE, 1998 p.22)

Wilding pointed Faces Settings as an "organizing" but also "educational" tool for cyberfeminists, a strategy of real encounters that is more productive than only virtual communication and that should keep on going in order to:

“...form affinity groups to facilitate building a transnational, transcultural movement" [...] And what better way than a dinner party to dissolve the estrangement so often produced by even the friendliest online communications? Indeed, the virtual medium must not replace the affective and the affinity-building functions of presence (Wilding \& CAE, 1998 p.22)

Critics towards the segregationist strategies of all-women and feminist groups have existed since the early first women's movement (Rupp, 1997) until today, in fact, separatism is still one of the main strategies in the all-women and feminist networks in art and technology, despite the controversy within the factor that created the union (biological sex, ideology, gender identity, etc.). The statement from 1998 by Wilding still inspire contemporary activists and artists in all-women and feminist hackerspaces such as Toupin (2014) and Wuschitz (2014) . She claimed the necessity to retrieve old separatist 
activities as a "useful tactic" that can hold "efficient pedagogical situations", which are key to succeed within "structures of domination" for minoritarian groups, especially those that are focused on the “decolonization of the cyberspace" such as cyberfeminists (Wilding, 1998)

Wilding, together with Critical Art Ensemble made clear (1998) that small alliances and coalitions are a potential theoretical solution, while not depending on burocratic processes. Cyberfeminist politics has been scattered and practiced on the micro level in networking, women's technology workshops, and various other kinds of critical interventions' (Merck and Sandford, 2010, p.72).

Cyberfeminists have begun to open the contested territory of the Internet for interrogation, play, and pleasure — as well as for new feminist political campaigns, education, critique, tactical interventions, activist alliances, and all manner of collaborations both local and international. New cyberfeminism has just begun to scrutinize, publicize, and contest the complex effects of technology on many aspects of women's lives; and to fashion a politics of presence and embodiment that insists on full engagement with the discourses of technology and power. (Fernandez \& Wilding, 2003, p.27)

Along the years cyberfeminist artists have performed local activities with international projection, however their activity decreased after the first years. Scholars like Paasonen point the change in the context, and the obsolescence of the cyberfeminist strategies in the new internet tools (2011). Through the evolution of the three international encounters, new topics were pointed as more relevant, like manipulation of human body through technology and genetic engineering, new forms of global control through technology electronic networking, secure privacy, etc. (Sollfrank, 2001). 
If feminism is to be adequate to its cyberpotential then it must mutate to keep up with the shifting complexities of social realities and life conditions as they are changed by the profound impact communications technologies and technoscience have on all our lives.

As a network, cyberfeminism was made of both similarities and differences. While scholars bent towards carefully defining the concepts they use have been troubled by the ephemeral and elastic nature of the "cyberfeminism", for others this elasticity, combined with snappiness, has contributed greatly to its attractiveness since then, critics, new waves, essays, new terms cyberfeminism, xenofeminism, postcybefeminism... (Paasonen, 2011, p.16). On the one hand, the range of Internet users has grown considerably more heterogeneous in terms of location, age, gender, class and ethnicity in comparison to the early and mid-1990s. Mobile internet applications have been crucial to this transformation in many developing countries. In Europe, North America, East Asia and Australia in particular, the domestication of the Internet as a communication and information medium has both contributed to the diversification of the range of internet uses and supported a discursive move away from "cyberspace" The dot.com collapse of the year 2000 the latest marked the end of the hype and cyber enthusiasm of the previous decades. Riot Grrl 'zines, with the DIY movement, have largely disappeared as other than historical documents while GeekGirl - the most famous 1990s grrrl/cyberfeminist zine run by Rosie $\mathrm{X}$ - has resurfaced as a blog. The threshold of online publishing, participation, and customization is lower than ever before (Paasonen, 2011, p.18).

So, why have cyberfeminist workshops, panels and initiatives become rarer within European media arts? And why is the term currently mainly deployed in academic discourses? In the case of $\mathrm{OBN}$, the explanations have to do with the lack of resources, the burden that the active group members experienced when organizing the internationals (Sollfrank, 2002) and disagreements and conflicts among the group members on the uneven credit and 
acknowledgement related to collective projects (Reiche, 2002, Oldenburg, 2002). In words of Paasonen (2011):

Moving beyond this one particular - albeit highly influential - network, I suggest that the fading of the attraction of cyberfeminism has centrally to do with shifts in the discursive environments that gave rise to these initiatives in the first place [...] Rephrasing the question, one might then ask if the strategies of cyberfeminism should be readjusted in the current technological landscape [...] In order to be both effective and affective, cyberfeminism would need to move beyond the negativity and reactivity of irony, and shift towards more productive engagements with contemporary technocultures in order to map out possible solutions for current social and economic inequalities that also take seriously the attraction and appeal of these very systems (pp.17-21).

\subsubsection{Faces today}

Where is the success in just a mailing list?

\section{Faces celebrated in 2017 their $20^{\text {th }}$ Anniversary: 20 years of FACES}

There is a lack of academic documentation on all-women initiatives in new media arts, which I attempt to fulfill through the present thesis. Faces had for first time a Wikipedia entry ${ }^{114}$, made by Arghyro Paouri and Helen Varley Jamieson and published on November 2018. In an interview with one of the first members of the list, Austrian media artist Anja Westerfrölke, she said:

Traveling to media festivals, in Brussels, Munich, Berlin, Paris, ... And there was always this concept of meeting, in the beginning ... but it was something [built] with no money, just some

\footnotetext{
${ }^{114}$ See <https://en.wikipedia.org/wiki/Faces_(online_community)>
} 
connections with a big effort to be present at these festivals as women. So, we ended up often in some back rooms, we had these instant presentations... [there was] no concept about it yet, there was not so much media yet, typical things, but these was going on a lot for years, there was always this experience of what you do, what you need, that it is hard. We were trying to parasite, but it was not really well, then it started changing for good (Westerfrölke, personal communication, 2018).

Women from all ages, with a wide range of backgrounds and profiles found in Faces a way to be connected to each other's activity and work, providing a linkage between those more focused locally to those more active at the international panorama of new media arts: "I don't have much relationship on the many global possibilities outside, only on the list" (Westerfrölke, personal communication, 2018). At the same time, initial members of the list point this sense of belonginess and togetherness that they experienced through the combination of informal meetings and the virtual communication on the mailing list. In the same interview Westerfrölke told me:

It is important to understand Faces mailing list. This togetherness. There is a togetherness of places, you know, the placement when you sit at the table, and you have something in between the table and your plate, a little tablecloth. Yes. It's out of hard material, you know, this kind of plastic notice. And so, and this is the place and the face sounded good together. The face and place met. And this all was because Kathy like to cook. There was always a togetherness of meeting women and exchanging digital work or media or possibilities. So, this meeting in person is a condition that the exchange in the communication is really working, differently or better, and this for my experience is proved (Westerfrölke, personal communication, 2018).

In the same interview Ushi Reiter, who works in the server of Faces, told us that with Faces, as a woman in new media arts, she experience to have a contact with common interests in every city she would visit: "you have a network of trust and you know if you go there or there, there is a face and you 
immediately have a connection point. That was very strong” (Reiter, personal communication 2018). In fact, an introduction is generally redacted by new members, and common emails in the mailing list are title 'Any faces in [location] for [x] event?', and then spontaneous Faces meetings come up. I remember, when I first met in person Diana McCarty, she was giving a lecture in Transmediale 2018. When she finished her presentation, she announced the Faces meeting in the bar, and I noticed there was something further than a simple mailing list there. "Faces shows how the use of new communication technologies opens up new possibilities for women to communicate, express themselves and work creatively within the translocal space of digital networks" (Smite, 2012, p.77). Kathy Rae Huffman built the original website of Faces together with a female collaborator in the previous server in New York. It consisted in hundreds of links of websites by women, arranged in categories, with most pictures of the members taken by the same Huffman over the years. Unfortunately, when the site migrated to Servus server in Austria, this website was lost (Huffman, personal communication, 2019).
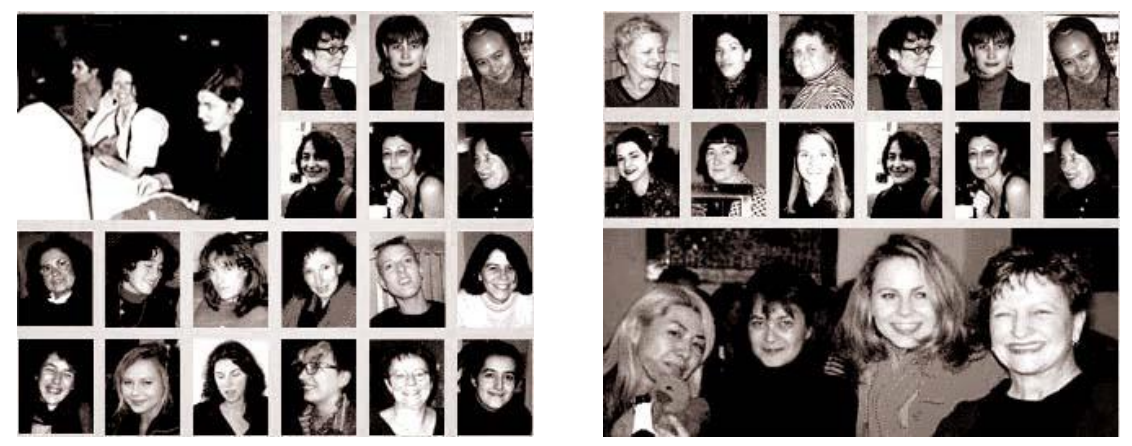

Figure 90 screenshots of the splash page, original site of Faces in 1998. Source: http://archive.Faces-I.net/en/Faceshtml.html

The Web 2.0 has made possible more accessibility of women to cyberspace, social networks replace old mailing list formats (like CIPke and FemTechNet groups, for example), and concepts like networked feminism seems to work as synonym of cyberfeminism (Paterson, 2014). However, FACES has not been transferred to any social network (Facebook, Twitter, etc.), as the founders consider that to maintain a network, a community, it is basic to know all the participants somehow: 
First of all, Faces is still small enough to know most of the women on the list. You can't say that about Facebook ... Faces is much more personal, and even if one doesn't post, one feels a loyalty to the idea of it, the tradition of it, and the potential for it to bring new information and ideas between women. (Huffman 2010 in Smite, 2012, p.78).

Despite punctual misunderstandings or disputes (comprehensible in a community based in a virtual environment), FACES is frequently described as a welcoming and friendly atmosphere, notably by the own founder's contribution and attitude (Wohlgemuthh, McCarty and specially Huffman), a key factor for their stability and permanence as a creative network. Rasa Smite, artist and researcher on networks, investigated in 2010 on FACES. She points the success in the:

...community feeling on the founders themselves and their ability to take care of the community can be compared to that of a hostess caring for her guests [...] The implicit duty of taking care of everybody within the Faces community is the main reason for providing sustainability of the 'Faces' network. (2014. p.79).
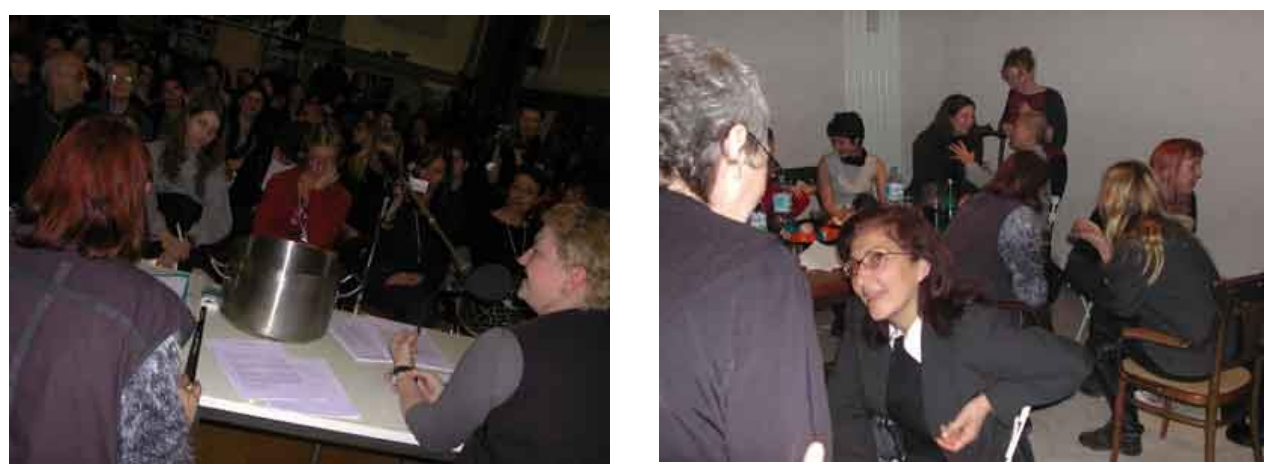

Figure 91 Figure 83 Images from FACES in Paris, cyberfemmes sur le mode de la démo party. organised by Kathy Rae Huffman, I'Ecole nationale superieure des beaux arts de Paris and Nathalie Magnan, 8th Decembre 2000. Source: : http://n4314.free.fr

Smite (2012) also concludes that the real-life events were fundamental to create a feeling of community, or belonginess (p.79). She sent a survey through the network to gather some qualitative data seeking to know the interests by the members in the mailing list and its significance as a creative network and community. Considering the variable of participation depending on the person and their 
understanding of 'community', "almost all participants admitted that this mailing list and community is important to them on a personal level while the contribution on the level of their professional work is providing more visibility for women in new media arts" (Smite, 2012, p.79). Here we quote some of the most interesting impressions from Smite's work:

Maria Ptqk from Spain: 'I guess the biggest value is on the personal level, in the sense that it provides me with the feeling of being part of a community, even if we don't know each other.'; Anna Karvalho: 'Other people may have a different perspective. To me it hasn't been so important. Perhaps because I also do not participate that much, I may have the shy kind of personality.'; Alla Mitrofanova from Saint Petersburg who participated in the mailing list from the day it was founded: '[Faces] is a very important episode of the early network culture.'; Alexandra Weltz: 'For me it is a mailing list which provides community and the notion of there still being women around who are concerned about feminist issues and art'; Eva Ursrpung: 'network AND community. Wherever you go, there will be a member of Faces to welcome you'; Nina Czegledy: 'In addition to the mailing lists, many informal face-to-face meetings, dinners etc., have been organised at various conferences. The exchange and atmosphere is really great at these events and re-enforces the mailing list communication. ... In my opinion these and other features contribute to the "community" environment'; Helen Varley Jamieson: 'Network/community. It is a meeting place for like-minded people, for sharing and exchanging and supporting one another'. (in Smite, 2012)

There are as many Faces' stories as many Faces are: “every 'face' would tell you a different perspective of the mailing list and the impact it made on her and her professional life" (Reiter, personal communication, 2018). Although the activity and dynamics within the mailing list have decreased along the years, the environment is still the same. As Huffman said to Smite (2012): "I think it is basically the same, sharing, caring, and collaborative environment it once was" (p.79). 


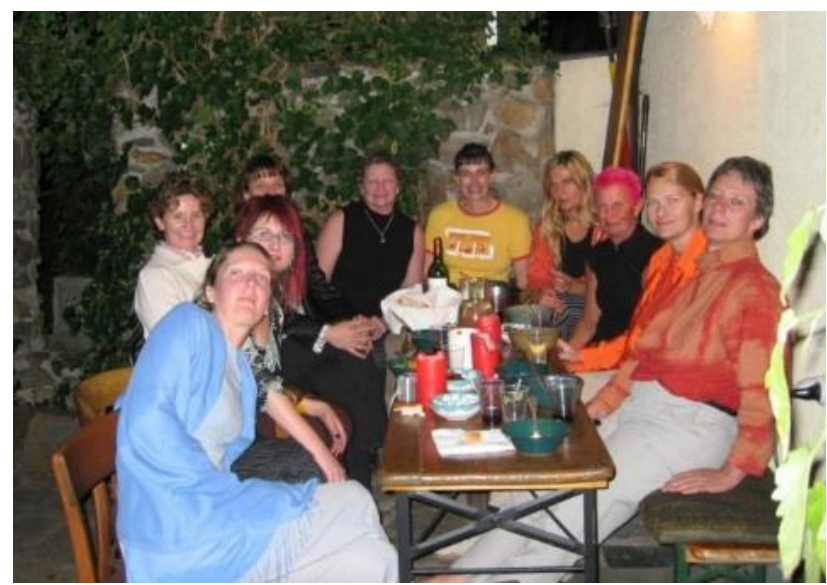

Figure 92 Faces meeting at Ars Electronica in 2000. Courtesy: Kathy Rae Huffman.

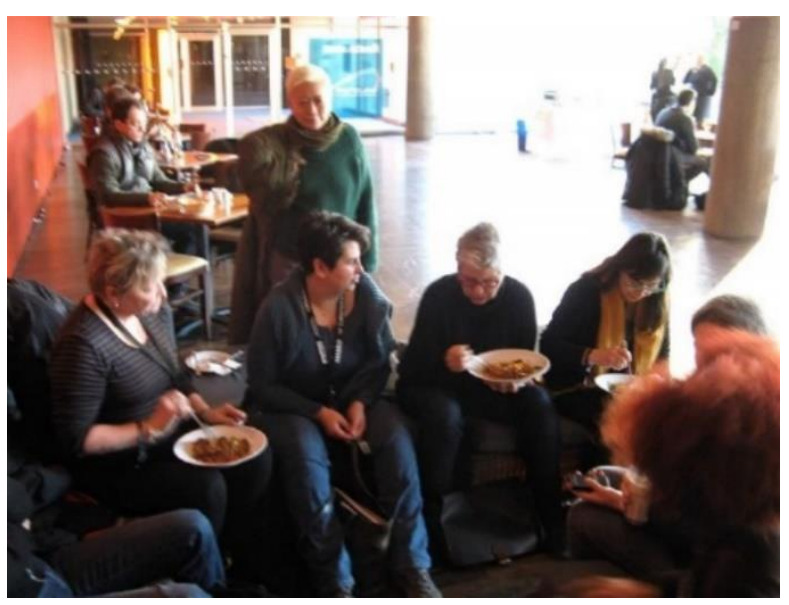

Figure 93 Faces informal lunch at Transmediale Festival in Berlin, encounter in the edge. Courtesy of Kathy Rae Huffman

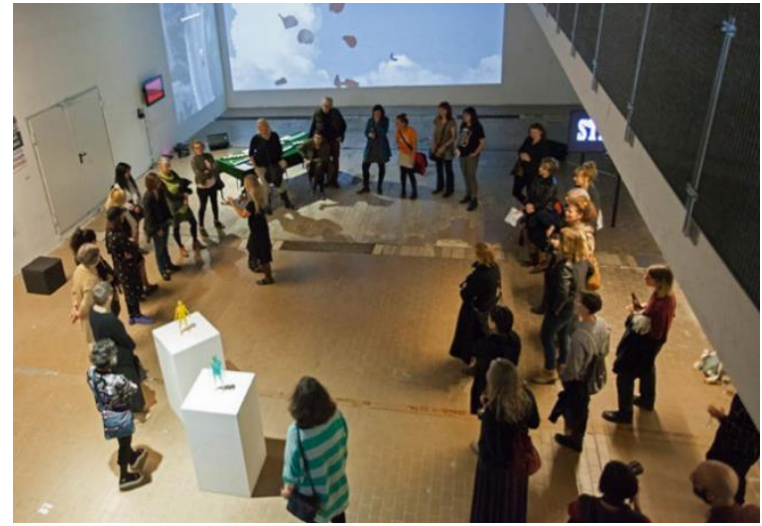

Figure 942017 20Th anniversary exhibition in Graz and at Ars Electronica, Linz

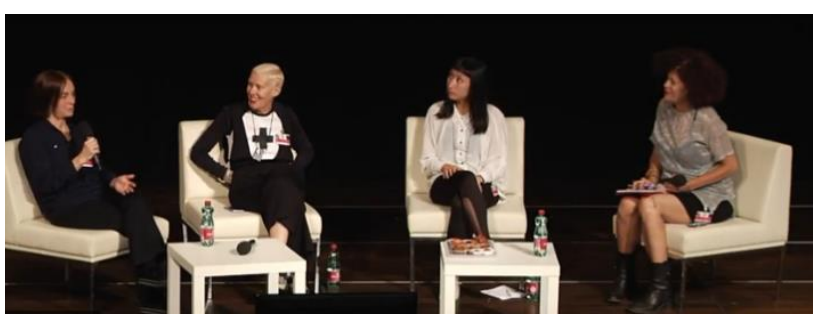

Figure 95 From C to X: networked feminisms. Left to right: Alla Mitrofanova, Virginia Barratt, and Annie Goh and Diana McCarty

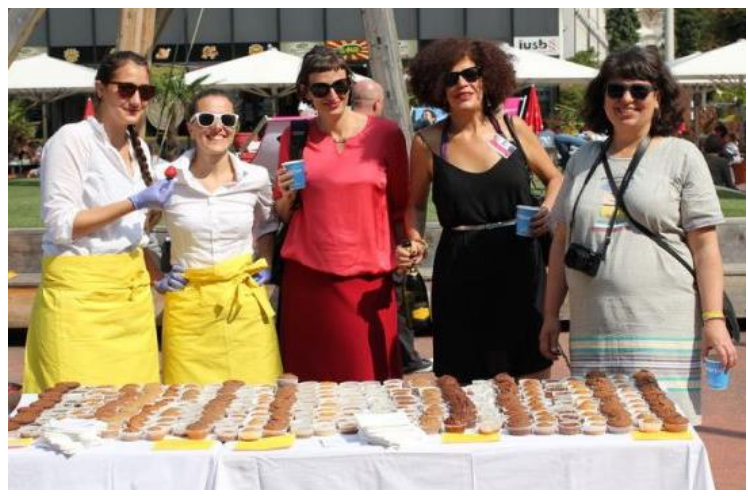

Figure 97 Cupcakes for Faces 20th Anniversary in Ars Electronica 2017. Left to right: Ushi Reiter, Diana McCarty and Valie Djordjevic. Retrieved from www.faces-I.ne 


\subsection{Mapping: All-Women Initiatives in Art and Technology}

\subsubsection{Interactive Visualization Map: All-Women Initiatives in Art and Technology ${ }^{115}$}

I have developed an interactive visualization map with My Maps Google application. However, this is a first prototype, I plan to bring this data to an open source tool (Open Street Map) ${ }^{116}$ that enables the customization of the map according to my project.

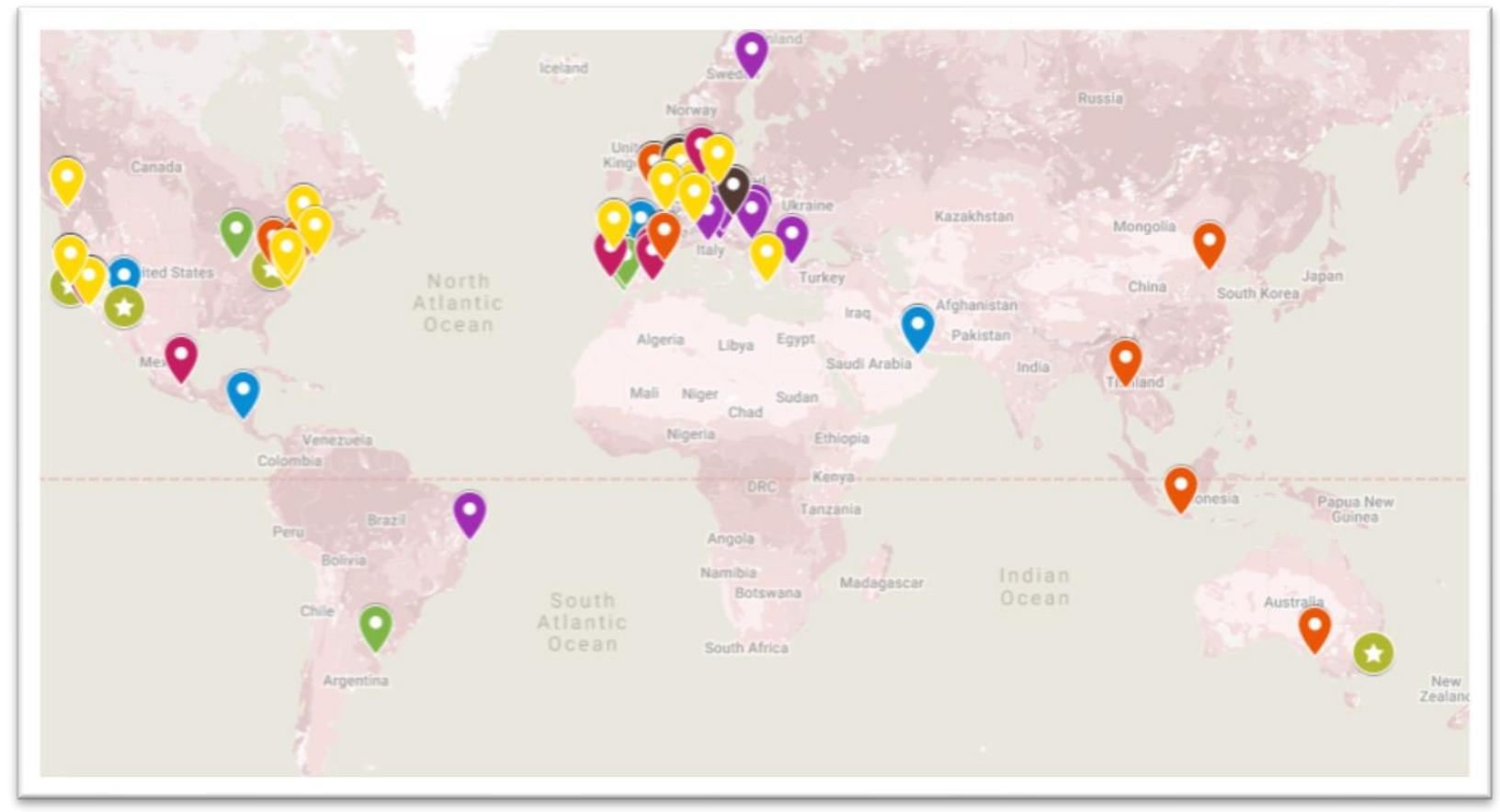

Figure 98 Visualization Map All-Women Initiatives since 1986, self-organised and institutionalized since 1986. Retrieved from <http://tiny.cc/rlmw9y>

115 Interactive map available at: 〈http://tiny.cc/rlmw9y >. Further changes and updates will be visible online. This visualization map will be added to $<w w w . a t e n e a . i n / r e s e r a c h>$ as an open tool providing referential content for feminist, women's and art studies.

116 See <www.openstreetmap.org> 


\subsubsection{All-Women self-organised initiatives in Art and Technology}

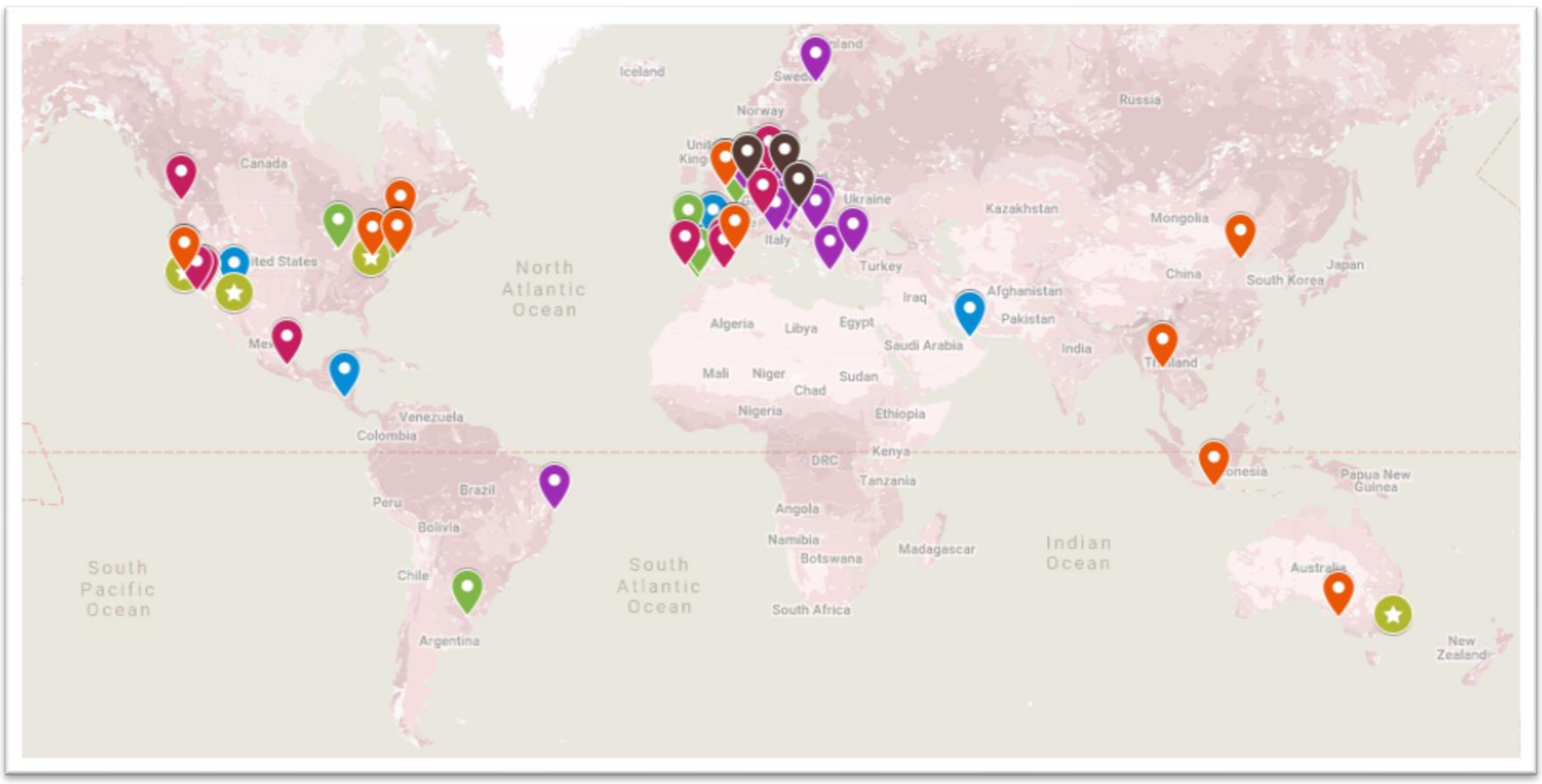

Figure 99 Visualization Map All-Women Self-organised Initiatives since 1986. Retrieved from <http://tiny.cc/rlmw9y> 
Table 1 All-women self-organised initiatives in Art and Technology since 1986 worldwide

\begin{tabular}{|c|c|c|c|c|c|c|}
\hline $\begin{array}{c}\text { TYPES OF } \\
\text { INITIATIVES }\end{array}$ & NAME & $\begin{array}{c}\text { FOUNDER(s) } \\
\text { /initial members }\end{array}$ & YEAR & LOCATION & WEBSITE & $\begin{array}{c}\text { SOCIAL } \\
\text { NETWORKS }\end{array}$ \\
\hline \multirow[t]{4}{*}{$\begin{array}{l}\text { Creative } \\
\text { Networks }\end{array}$} & Faces mailing list & $\begin{array}{c}\text { Kathy Rae Huffman, } \\
\text { Diana McCarty, Valie } \\
\text { Djordjevic }\end{array}$ & 1997 & $\begin{array}{c}\text { Vienna, Austria } \\
\text { /transnational }\end{array}$ & https://Faces-1.net & \\
\hline & Old Boys Network & $\begin{array}{c}\text { Susanna Ackers, } \\
\text { Julianne Pierce, } \\
\text { Valentina Djordjevic, } \\
\text { Ellen Nonnenmacher \& } \\
\text { Cornelia Sollfrank }\end{array}$ & 1997 & $\begin{array}{c}\text { Kassel, } \\
\text { Germany } \\
\text { /transnational }\end{array}$ & www.obn.org & \\
\hline & female:pressure & $\begin{array}{l}\text { Susanne Kirchmayr aka } \\
\text { Electric Indigo }\end{array}$ & 1998 & $\begin{array}{c}\text { Vienna, Austria } \\
\text { /transnational }\end{array}$ & www.femalepressure.net & $\begin{array}{c}\text { Twitter, } \\
\text { soundcloud, } \\
\text { mixcloud, } \\
\text { paper.li: } \\
\text { @ female_pressure } \\
\text { Intagram: } \\
\text { femalepressure_of } \\
\text { ficial; YouTube: } \\
\text { femalepressure } \\
\text { Vimeo: } \\
\text { femalepressure } \\
\text { Tumblr, } \\
\text { Wordpress, } \\
\text { Bandcamp: } \\
\text { femalepressure }\end{array}$ \\
\hline & $\begin{array}{c}\text { Gender Changers } \\
\text { Academy }\end{array}$ & Sara Platon \& Tali et al & 1999 & $\begin{array}{l}\text { Amsterdam, } \\
\text { TheNetherlands }\end{array}$ & www.genderchangers.org & \\
\hline
\end{tabular}




\begin{tabular}{|c|c|c|c|c|c|c|}
\hline \multirow[t]{8}{*}{ Collectives } & VeNuS MATRIX & $\begin{array}{c}\text { Faith Wilding } \\
\text { Virginia Barrat } \\
\text { Jualianne Pierce } \\
\text { Francesca da Rimini } \\
\text { Josephine Starrs }\end{array}$ & 1991 & $\begin{array}{l}\text { Adelaide, } \\
\text { Australia }\end{array}$ & www.vnsmatrix.net & \\
\hline & SubRosa & Faith Wilding & 1998 & $\begin{array}{l}\text { Pittsburgh, } \\
\text { United States }\end{array}$ & www.cyberfeminism.org & \\
\hline & Donestech & $\begin{array}{l}\text { Nuria Verges, Eva } \\
\text { Cruells, Alex Hache }\end{array}$ & 2006 & $\begin{array}{l}\text { Barcelona, } \\
\text { Spain }\end{array}$ & www.Donestech.net & $\begin{array}{c}\text { Twitter } \\
\text { @donestech }\end{array}$ \\
\hline & Hypen Labs & $\begin{array}{c}\text { Carmen Aguilar y } \\
\text { Wedge \& Ece Tankal }\end{array}$ & 2014 & $\begin{array}{l}\text { New York City, } \\
\text { London, } \\
\text { Barcelona } \\
\text { /transnational }\end{array}$ & www.hypen-labs.com & $\begin{array}{c}\text { Twitter: } \\
\text { @ hypen_labs }\end{array}$ \\
\hline & Deep Lab & Addie Wagenknecht & 2014 & $\begin{array}{l}\text { Pittsburgh, } \\
\text { United States }\end{array}$ & www.deeplab.net & $\begin{array}{c}\text { Facebook: } \\
\text { @ DeepLabinterna } \\
\text { tional; Twitter: } \\
\text { @ deeplab }\end{array}$ \\
\hline & GirlFx & $\begin{array}{c}\text { Lauren Goshinski, } \\
\text { Allison Cosby, Eileen } \\
\text { Angulo \& Isabella } \\
\text { Parajole }\end{array}$ & 2016 & $\begin{array}{l}\text { Pittsburgh, } \\
\text { United States }\end{array}$ & & $\begin{array}{c}\text { Facebook } \\
\text { @girlfx; } \\
\text { Instagram:_girlfx }\end{array}$ \\
\hline & REFRESH & $\begin{array}{l}\text { Heather Dewey- } \\
\text { Hagborg et al. }\end{array}$ & 2016 & $\begin{array}{c}\text { New York, } \\
\text { United States / } \\
\text { transnational }\end{array}$ & www.refreshart.tech & \\
\hline & $\begin{array}{c}\text { Hackers of Resistance } \\
\text { HORs }\end{array}$ & -- & 2017 & $\begin{array}{l}\text { San Francisco, } \\
\text { United States }\end{array}$ & http://wearehors.xyz & $\begin{array}{c}\text { Twitter: } \\
\text { @ wearehors; } \\
\text { Instagram: } \\
\text { wearehors } \\
\text { Vimeo: wearehors }\end{array}$ \\
\hline
\end{tabular}




\begin{tabular}{|c|c|c|c|c|c|c|}
\hline \multirow[t]{12}{*}{ Exhibitions } & $\begin{array}{l}\text { Women and } \\
\text { Technology }\end{array}$ & Barbara Nessim & 1986 & $\begin{array}{l}\text { New York } \\
\text { United States }\end{array}$ & & \\
\hline & $\begin{array}{c}\text { IMASeries } \\
\text { IMAfiction 'Hidden } \\
\text { Alliances' }\end{array}$ & Elizabeth Schimana & 1990 & $\begin{array}{l}\text { Hainburg, } \\
\text { Austria }\end{array}$ & https://ima.or.at/en/imafiction & \\
\hline & Addressing Images & $\begin{array}{l}\text { Lucia Grossberger \& } \\
\text { Martha Thoma }\end{array}$ & 1991 & $\begin{array}{l}\text { San Jose, } \\
\text { California, } \\
\text { United States }\end{array}$ & & \\
\hline & $\begin{array}{l}\text { MATRIX: Women } \\
\text { Networking }\end{array}$ & $\begin{array}{l}\text { Lucia Grossberger \& } \\
\text { Anna Couey }\end{array}$ & 1993 & $\begin{array}{l}\text { Anaheim, } \\
\text { California, } \\
\text { United states }\end{array}$ & & \\
\hline & e-virgenes & $\begin{array}{l}\text { e-mujeres (Angustias } \\
\text { Bertomeu) }\end{array}$ & 2001 & Alicante, Spain & www.e-mujeres.net & $\begin{array}{c}\text { Facebook: e- } \\
\text { mujeres, Twitter } \\
\text { @emujeres }\end{array}$ \\
\hline & $\begin{array}{c}\text { Cyberfem: } \\
\text { The Spirit of Data }\end{array}$ & Helena von Oldenburg & 2002 & $\begin{array}{c}\text { Oldenburg, } \\
\text { Germany }\end{array}$ & www.edith-russ-haus.de & \\
\hline & Cyberfem & Ana Martinez-Collado & $\begin{array}{c}2009 \\
\& 2014\end{array}$ & Castellon, Spain & www. cyberfem.net & \\
\hline & X0y1 & Remedios Zafra & 2009 & Sevilla, Spain & www.x0y1.net & \\
\hline & Her Environment & $\begin{array}{l}\text { Allie Shyer \& Chelsea } \\
\text { Welch (Iryne Roh, L } \\
\text { Barnes, Nina Berman) }\end{array}$ & 2015 & $\begin{array}{l}\text { Chicago, United } \\
\text { States }\end{array}$ & www.herenvironment.com & $\begin{array}{l}\text { Facebook:@heren } \\
\text { vironment } \\
\text { Instagram: } \\
\text { her_environment }\end{array}$ \\
\hline & $\begin{array}{c}\text { Technology is not } \\
\text { neutral }\end{array}$ & $\begin{array}{c}\text { Gordana Novakovic, } \\
\text { Annd Dimitriu \& Irini } \\
\text { Papadimitriou }\end{array}$ & 2016 & $\begin{array}{l}\text { London, } \\
\text { England }\end{array}$ & $\begin{array}{c}\text { www.technologyisnotneutral.co } \\
\text { m }\end{array}$ & $\begin{array}{l}\text { Facebook Group: } \\
\text { TINN2-16 } \\
\text { Twitter: } \\
\text { @ Not_Neutral16 }\end{array}$ \\
\hline & $\begin{array}{l}\text { Making/Breaking The } \\
\text { Binary }\end{array}$ & $\begin{array}{l}\text { Kelsey Halliday } \\
\text { Johnson }\end{array}$ & 2017 & $\begin{array}{l}\text { Philadelphia, } \\
\text { United States }\end{array}$ & $\begin{array}{c}\text { www.womenartandtechnology.n } \\
\text { et }\end{array}$ & $\begin{array}{c}\text { Instagram: } \\
\text { womenartandtech } \\
\text { nology }\end{array}$ \\
\hline & Vital Hybrids & Tiare Ribeaux & 2017 & $\begin{array}{c}\text { San Francisco, } \\
\text { United States }\end{array}$ & www.b4bel4b.com & \\
\hline
\end{tabular}




\begin{tabular}{|c|c|c|c|c|c|c|}
\hline & Afrocyberfeminismes & $\begin{array}{l}\text { Oulimat a Gueye \& } \\
\text { Marie Lechner }\end{array}$ & 2018 & Paris, France & www.afrocyberfeminismes.org & \\
\hline & Elas Fan Tech & Anxela Caramés & 2013 & $\begin{array}{l}\text { A Coruña, } \\
\text { Spain }\end{array}$ & $\begin{array}{l}\text { www.cargocollective.com/elasfa } \\
\text { ntech/ }\end{array}$ & \\
\hline \multirow[t]{4}{*}{$\begin{array}{l}\text { Exhibitions } \\
\text { online } \\
\text { /digital archive }\end{array}$} & $\begin{array}{c}\text { WWWO } \\
*\end{array}$ & $\begin{array}{c}\text { Sandy Indlekofer- } \\
\text { O'Sullivan, Melinda } \\
\text { Rackham, Ali Smith \& } \\
\text { Louise Manner. }\end{array}$ & 1995 & Australia & & \\
\hline & $\begin{array}{l}\text { The World's Women } \\
\text { On-line!* }\end{array}$ & Muriel Magenta & 1995 & $\begin{array}{l}\text { Arizona, United } \\
\text { States }\end{array}$ & wwol.is.asu.edu & \\
\hline & Electric Women & Lauren Valley & 2018 & $\begin{array}{l}\text { Pittsburgh, } \\
\text { United States }\end{array}$ & www.electric-women.com & $\begin{array}{c}\text { Instagram: } \\
\text { electricwomenonli } \\
\text { ne }\end{array}$ \\
\hline & feminist tECnOart & $\begin{array}{l}\text { WEAD, Pilar Praba, } \\
\text { Danielle Siembieda \& } \\
\text { Isabella La Rocca }\end{array}$ & 2018 & $\begin{array}{l}\text { San Francisco, } \\
\text { United States }\end{array}$ & $\begin{array}{l}\text { www.weadartists.org/ } \\
\text { feminist-technoart }\end{array}$ & \\
\hline \multirow{5}{*}{$\begin{array}{l}\text { Festivals } \\
\text { conferences } \\
\text { Symposiums } \\
\text { Encounters }\end{array}$} & $\begin{array}{l}\text { First, Next, Very } \\
\text { Cyberfeminist } \\
\text { International* }\end{array}$ & Cornelia Sollfrank et al. & $\begin{array}{l}1997- \\
1999- \\
2001\end{array}$ & $\begin{array}{c}\text { Kassel, } \\
\text { Rotterdam, } \\
\text { Hamburg }\end{array}$ & www.obn.org & \\
\hline & $\begin{array}{l}\text { /Eclectic Tech } \\
\text { Carnival }\end{array}$ & $\begin{array}{l}\text { Genderchangers Sara } \\
\text { Platon \& Tali et al }\end{array}$ & 2002 & $\begin{array}{l}\text { Amsterdam, } \\
\text { TheNetherlands } \\
\text { /transnational }\end{array}$ & www.eclectictechcarnival.org & $\begin{array}{c}\text { Twitter: } \\
\text { @EclecticTech }\end{array}$ \\
\hline & !Zelig.rc2** & Nathalie Magnan, et al. & 2002 & Paris, France & http://bit.do/e2hnq & \\
\hline & Enre/Dades & Maria Pérez-Hernández & $\begin{array}{l}\text { Since } \\
2006\end{array}$ & $\begin{array}{l}\text { Barcelona, } \\
\text { Spain }\end{array}$ & www.ptqkblogzine.blogia.com & \\
\hline & Fem.Elek & Marise Cardoso & $\begin{array}{l}2007- \\
2012\end{array}$ & $\begin{array}{l}\text { Barcelona, } \\
\text { Spain }\end{array}$ & & $\begin{array}{l}\text { Facebook: } \\
\text { femelek }\end{array}$ \\
\hline
\end{tabular}




\begin{tabular}{|c|c|c|c|c|c|}
\hline Gendertek*** & Parole di Queer & $\begin{array}{l}2010- \\
2011\end{array}$ & $\begin{array}{l}\text { Alicante, } \\
\text { Spain }\end{array}$ & www.gendertek.blogspot.com & \\
\hline FEMMEBIT & $\begin{array}{l}\text { Kate Parsons, Sharsten } \\
\text { Plenge Eva Aguila } \\
\text { Dahn Gim et al. }\end{array}$ & $\begin{array}{l}\text { Since } \\
2016\end{array}$ & $\begin{array}{l}\text { Los Angeles, } \\
\text { United States }\end{array}$ & www.femmebit.art & $\begin{array}{c}\text { @ FEMMEBIT } \\
\text { Twitter: } \\
\text { @ FEMMEBIT; } \\
\text { Instagram: } \\
\text { FEMMEBIT }\end{array}$ \\
\hline Current & $\begin{array}{l}\text { Ashlee Luk, Nancy Lee } \\
\text { and Soledad Muñoz } \\
\text { (Alexandra Chen) }\end{array}$ & $\begin{array}{l}\text { Since } \\
2016\end{array}$ & $\begin{array}{l}\text { Vancouver, } \\
\text { Canada }\end{array}$ & www.currentsymposium.com & $\begin{array}{c}\text { Facebook and } \\
\text { Twitter: } \\
\text { @ currentsymposi } \\
\text { um }\end{array}$ \\
\hline electronnes & $\begin{array}{l}\text { Anna Cholinska, } \\
\text { Shusha Niederberger, } \\
\text { Niki Wiese Schawalder }\end{array}$ & 2017 & $\begin{array}{c}\text { Zurich, } \\
\text { Switzerland }\end{array}$ & $\begin{array}{l}\text { https://creatrices.ch/electronnes- } \\
\text { the-women-art-tech-festival }\end{array}$ & $\begin{array}{l}\text { Facebook and } \\
\text { Twitter: } \\
\text { @electronnes }\end{array}$ \\
\hline $\begin{array}{l}\text { Cyborgrrrls: } \\
\text { Encuentro } \\
\text { Tecnofeminista }\end{array}$ & $\begin{array}{c}\text { Constanza Pina \& Casa } \\
\text { Gomorra }\end{array}$ & $\begin{array}{l}\text { Since } \\
2017\end{array}$ & $\begin{array}{l}\text { Ciudad de } \\
\text { Mexico, } \\
\text { Mexico }\end{array}$ & $\begin{array}{l}\text { www.cyborgrrrls.wordpress.co } \\
\text { m/home }\end{array}$ & $\begin{array}{l}\text { Facebook: } \\
\text { Cyborgrrrls } \\
\text { Twitter: } \\
\text { @ cyborgrrrls }\end{array}$ \\
\hline $\begin{array}{c}\text { Alliance Women } \\
\text { Media Arts and } \\
\text { Science AWMAS* }\end{array}$ & Marlene Matthew & $\begin{array}{l}\text { since } \\
2017\end{array}$ & $\begin{array}{l}\text { Santa Barbara, } \\
\text { United States }\end{array}$ & $\begin{array}{l}\text { www.ucsbosl.orgsync.com/org/a } \\
\text { wmas }\end{array}$ & $\begin{array}{c}\text { facebook } \\
\text { @awmatucsb } \\
\text { Twitter: awmatsb } \\
\text { Instagram: } \\
\text { @ awmat.ucsb }\end{array}$ \\
\hline $\begin{array}{c}\text { <Interrupted } \\
=\text { "Cyfem and } \\
\text { Queer }>* *\end{array}$ & $\begin{array}{l}\text { Daniela Seitz } \\
\& \text { Anja Weigl }\end{array}$ & $\begin{array}{l}\text { Since } \\
2017\end{array}$ & $\begin{array}{l}\text { Berlin, } \\
\text { Germany }\end{array}$ & www.interrupted.creamcake.de & \\
\hline
\end{tabular}




\begin{tabular}{|c|c|c|c|c|c|c|}
\hline & FEMeeting & Marta de Menezes et al. & 2018 & $\begin{array}{c}\text { Lisbon, } \\
\text { Portugal } \\
\text { /transnational }\end{array}$ & www.femeeting.com & \\
\hline & $\begin{array}{l}\text { Eco Futures } \\
* *\end{array}$ & Cuntemporary & 2019 & $\begin{array}{l}\text { London, } \\
\text { England }\end{array}$ & $\begin{array}{l}\text { www.cuntemporary.org/ecofutu } \\
\text { res-festival }\end{array}$ & $\begin{array}{l}\text { Facebook: } \\
\text { @ecoftutures }\end{array}$ \\
\hline \multirow{7}{*}{$\begin{array}{l}\text { Project } \\
\text { Organisation } \\
\text { Association }\end{array}$} & XXERO & $\begin{array}{l}\text { Aileen Deriegn, Ushi } \\
\text { Reiter, Anja et al }\end{array}$ & $\begin{array}{l}2000- \\
2002\end{array}$ & Linz, Austria & www. xxero.servus.at/ & \\
\hline & Undercurrent & $\begin{array}{l}\text { Maria Fernandez, Irina } \\
\text { Aristarkhova and Coco } \\
\text { Fusco (Faith Wilding) }\end{array}$ & 2002 & United States & www.bbs.thing.net & \\
\hline & MzTEK & $\begin{array}{l}\text { Sophie McDonald and } \\
\text { Sally Northmore }\end{array}$ & 2009 & $\begin{array}{l}\text { London, } \\
\text { England }\end{array}$ & www.mztek.org & $\begin{array}{c}\text { Twitter: } \\
\text { @ MzTEK } \\
\text { Fcbk: McTEK }\end{array}$ \\
\hline & M-Artech & Francesca Mereu & 2012 & $\begin{array}{l}\text { Madrid, } \\
\text { Spain }\end{array}$ & $\begin{array}{l}\text { www.martechplatform.wordpres } \\
\text { s.com }\end{array}$ & $\begin{array}{c}\text { Facebook: } \\
\text { @ Martechplatfor } \\
\mathrm{m}\end{array}$ \\
\hline & $\begin{array}{c}\text { Machine Divas (IMA } \\
\text { series) }\end{array}$ & $\begin{array}{l}\text { Andrea Sodomka } \\
\text { \& Eva Ursprung }\end{array}$ & 2007 & $\begin{array}{l}\text { Hainburg, } \\
\text { Austria }\end{array}$ & $\begin{array}{l}\text { https://ima.or.at/en/maschinendi } \\
\text { vas }\end{array}$ & \\
\hline & Momentum* & Muriel Magenta & 2013 & $\begin{array}{c}\text { Arizona \& New } \\
\text { Jersey, United } \\
\text { States }\end{array}$ & $\begin{array}{l}\text { www.momentum-women-art- } \\
\text { technology.com }\end{array}$ & $\begin{array}{c}\text { Facebook: } \\
\text { @MomentumWo } \\
\text { menArtTechnolog } \\
\text { y }\end{array}$ \\
\hline & enREDadas & $\begin{array}{c}\text { Gema Manzanares } \\
\text { Reyes \& Maria Martha } \\
\text { Escobar }\end{array}$ & 2013 & $\begin{array}{l}\text { Managua, } \\
\text { Nicaragua }\end{array}$ & www.enredadas.org & $\begin{array}{c}\text { Facebook, } \\
\text { Twitter: } \\
\text { @EnRedadasNi } \\
\text { YouTube and } \\
\text { Flicker: } \\
\text { EnRedadas } \\
\text { Nicaragua }\end{array}$ \\
\hline
\end{tabular}




\begin{tabular}{|c|c|c|c|c|c|c|}
\hline & $\begin{array}{l}\text { Female Laptop } \\
\text { Orchestra**** }\end{array}$ & $\begin{array}{l}\text { Research Project, } \\
\text { Collaborative Open } \\
\text { Composition }\end{array}$ & $\begin{array}{l}\text { Nela } \\
\text { Brown }\end{array}$ & 2014 & $\begin{array}{c}\text { London, } \\
\text { United Kingdom }\end{array}$ & $\begin{array}{l}\text { https://femalelapt } \\
\text { oporchestra. } \\
\text { wordpress.com/ }\end{array}$ \\
\hline & Void Lab & Xin Xin et al & 2015 & $\begin{array}{l}\text { Los Angeles, } \\
\text { United States }\end{array}$ & $\begin{array}{l}\text { www.projects.dma.ucla.edu/voi } \\
\text { dlab }\end{array}$ & $\begin{array}{l}\text { @ uclavoidLab } \\
\text { Instgram: voidlab } \\
\text { Vimeo: voidlab } \\
\text { github: voidlab }\end{array}$ \\
\hline & SisterSMATR & $\begin{array}{l}\text { Nona Hendryx, JoAnn } \\
\text { Chase \& Makani } \\
\text { Themba }\end{array}$ & 2016 & $\begin{array}{l}\text { New York City, } \\
\text { United States }\end{array}$ & www.sistersmatr.org & $\begin{array}{c}\text { Twitter: } \\
\text { @SistersMatr } \\
\text { Facebook and } \\
\text { Instagram: } \\
\text { @ sistermatr }\end{array}$ \\
\hline & Atenea & $\begin{array}{c}\text { Nuria Lloret } \\
\& \text { Elena Robles }\end{array}$ & 2016 & Valencia, Spain & www.atenea.in & $\begin{array}{c}\text { Facebook: } \\
\text { @ atenea.women.a } \\
\text { rt.tech } \\
\text { Twitter, } \\
\text { Instagram: } \\
\text { @ atenea_wat }\end{array}$ \\
\hline & WITCiH & $\begin{array}{l}\text { Bishi Bhattacharya \& } \\
\text { Matthew Hardern }\end{array}$ & 2017 & $\begin{array}{l}\text { London, } \\
\text { England }\end{array}$ & www.witcih.tumblr.com & $\begin{array}{c}\text { Facebook and } \\
\text { Instagram: } \\
@ \text { WITCiH } \\
\text { Twitter: @witcih }\end{array}$ \\
\hline & Superrr & $\begin{array}{c}\text { Julia Friesel, Marie } \\
\text { Kochsiek \& Tina } \\
\text { Baumann }\end{array}$ & 2017 & $\begin{array}{l}\text { Berlin, } \\
\text { Germany }\end{array}$ & www.superrr.net & $\begin{array}{c}\text { Twitter: } \\
\text { @ superrrnetwork } \\
\text { Instagram: } \\
\text { superrrnetwork }\end{array}$ \\
\hline & $\begin{array}{l}\text { Female First Session } \\
\text { (FFS)** }\end{array}$ & $\begin{array}{c}\text { Megane Quashie, Nour } \\
\text { ZaghLoul }\end{array}$ & 2018 & $\begin{array}{l}\text { Dubai, Arab } \\
\text { Emirates }\end{array}$ & www.femalefirstsessions.com & $\begin{array}{c}\text { Instagram: } \\
\text { femalefirstsession } \\
\mathrm{s} \\
\end{array}$ \\
\hline & Fem Tek Bilbao & Blanca Ortiga & 2018 & Bilbao, Spain & www.femtekbilbao.net & @FemTekBilbao \\
\hline Space-based & Studio XX & $\begin{array}{l}\text { Patricia Kearns, Kathy } \\
\text { Kennedy, Kin }\end{array}$ & 1996 & Quebec, Canada & www.studioxx.org & $\begin{array}{l}\text { Facebook: } \\
\text { @ studioxx; }\end{array}$ \\
\hline
\end{tabular}




\begin{tabular}{|c|c|c|c|c|c|c|}
\hline \multirow[t]{9}{*}{ Communities } & & $\begin{array}{l}\text { Sawchuck \& Sherryl } \\
\text { Hamilton }\end{array}$ & & & & $\begin{array}{c}\text { Twitter: } \\
\text { @StudioXX_; } \\
\text { Instagram: } \\
\text { studio_xx; Vimeo: } \\
\text { StudioXX }\end{array}$ \\
\hline & $\begin{array}{l}\text { Mz*Baltazar's } \\
\text { Laboratory }\end{array}$ & Stefanie Wuschitz & 2009 & Vienna, Austria & www.mzbaltazarslaboratory.org & $\begin{array}{c}\text { Facebook: } \\
\text { @MzBaltazarsLab } \\
\text { oratory } \\
\end{array}$ \\
\hline & $\begin{array}{l}\text { Mothership } \\
\text { HackerMoms }\end{array}$ & Sho Sho Smith & 2012 & $\begin{array}{l}\text { San Francisco, } \\
\text { United States }\end{array}$ & www.hackermoms.org & $\begin{array}{l}\text { Fcbk: Mothership } \\
\text { HackerMoms, } \\
\text { Twttr: } \\
\text { @ hackermoms }\end{array}$ \\
\hline & XX LAB & $\begin{array}{c}\text { Irene Agrivina } \\
\text { Widyaningrum, et al. }\end{array}$ & 2013 & $\begin{array}{l}\text { Yogyakarta, } \\
\text { Indonesia }\end{array}$ & www.xxlab.honfablab.org & Facebook: XXLab \\
\hline & Č I P k e & $\begin{array}{l}\text { Ida Hiršenfelder, Saša } \\
\text { Spačal }\end{array}$ & 2013 & $\begin{array}{c}\text { Ljubljana, } \\
\text { Slovenia }\end{array}$ & www.cipke.wordpress.com & $\begin{array}{l}\text { Facebook group } \\
\text { ČIPke }\end{array}$ \\
\hline & Ctrl+Shft & $\begin{array}{l}\text { Yerin Kim, Morgan, } \\
\text { Maryam Yousif et al. }\end{array}$ & 2015 & $\begin{array}{l}\text { San Francisco, } \\
\text { United States }\end{array}$ & www.ctrlshftcollective.com & $\begin{array}{c}\text { Facebook } \\
\text { @CTRLSHFTcoll } \\
\text { ective, Twitter: } \\
\text { @ctrl_shft; } \\
\text { Instagram } \\
\text { ctrlshftcollective, } \\
\text { Drip: } \underline{\text { ctrl-shft }}\end{array}$ \\
\hline & extantation & Tara Transitory & 2016 & $\begin{array}{l}\text { Chiang Mai, } \\
\text { Thailand }\end{array}$ & $\begin{array}{c}\text { www.extantation.wordpress.co } \\
\mathrm{m}\end{array}$ & $\begin{array}{c}\text { Facebook, Vimeo } \\
\text { and Twitter } \\
\text { @ extantation }\end{array}$ \\
\hline & Q-Space & $\begin{array}{l}\text { Jo-Dee, Peixuan Qiu, et } \\
\text { al }\end{array}$ & 2016 & Beijing, China & www.queerinbeijing.com & $\begin{array}{l}\text { Facebook: @q- } \\
\text { space }\end{array}$ \\
\hline & Prototype & $\begin{array}{c}\text { Erin Gatz \& Louise } \\
\text { Larson }\end{array}$ & 2017 & $\begin{array}{l}\text { Pittsburgh, } \\
\text { United States }\end{array}$ & www.prototypepgh.com & $\begin{array}{c}\text { Twitter: } \\
\text { @ prototypepgh }\end{array}$ \\
\hline
\end{tabular}

* initiatives partially conceived or supported by an art institutional framework

** These initiatives have not been described in the present dissertation due to proximity to deadline when discovering. 
*** These initiatives have not been described due to the dominance of music content in their programme compared to arts.

Note that many projects and organisations have organised punctual curatorial projects that have not been reflected in this table as a separated initiative. i.e. REFRESH with Refiguring Futures NYC 2019.

\subsubsection{Mapping all-women initiatives conceived within an institutional framework}

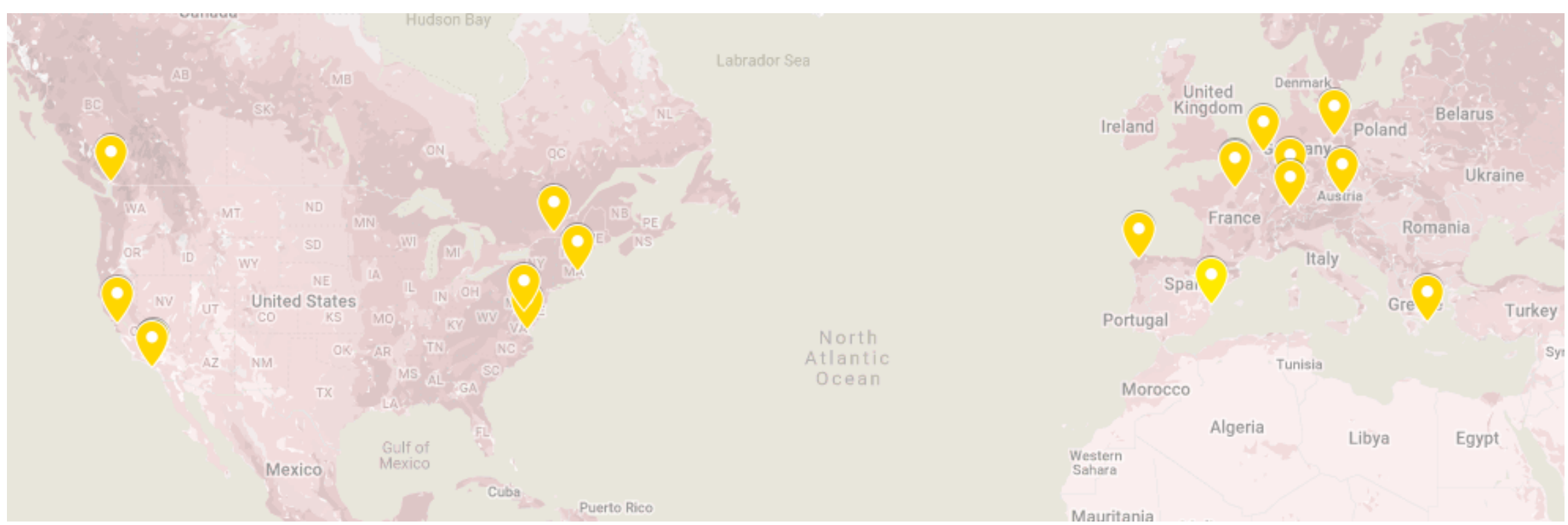

Figure 100 Visualization Map All-Women Initiatives since 1986 to 2020 conceived within an institutional framework or by art institution members. Retrieved from $<$ ttp://tiny.cc/rlmw9y> 
Table 2 All-Women Initiatives conceived within an institutional framework 1986-2020

\begin{tabular}{|c|c|c|c|c|c|}
\hline NAME & EVENT & ORGANIZER & YEAR & LOCATION & WEBSITE \\
\hline $\begin{array}{l}\text { The Future of } \\
\text { Today }\end{array}$ & $\begin{array}{c}11^{\text {th }} \text { Annual Women's } \\
\text { Week Celebration } \\
\text { Meet the Challenge/Shape } \\
\text { the Future }\end{array}$ & $\begin{array}{c}\text { The Aerospace } \\
\text { Corporation }\end{array}$ & 1986 & $\begin{array}{c}\text { El Segundo, California, } \\
\text { USA }\end{array}$ & www.aerospace.org \\
\hline $\begin{array}{l}\text { Women and } \\
\text { Technology }\end{array}$ & LA SIGGRAPH & Coco Conn & 1992 & Los Angeles USA & \\
\hline $\begin{array}{c}\text { UTOPIA } \\
\text { /DYSTOPIA }\end{array}$ & $\begin{array}{c}\text { The Third Annual } \\
\text { Conference on Feminist } \\
\text { Activism and Art } \\
\text { Framework }\end{array}$ & $\begin{array}{c}\text { The LAB, } \\
\text { SF Camerawork. } \\
\text { directed by Zoeuy } \\
\text { Kroll et al. }\end{array}$ & 1995 & San Francisco, USA & \\
\hline $\begin{array}{c}\text { Symposium on } \\
\text { Feminist New } \\
\text { Media Art }\end{array}$ & & & 2004 & $\begin{array}{l}\text { Montreal, } \\
\text { Canada }\end{array}$ & http://cri.histart.umontreal.ca/cri/fr/ \\
\hline $\begin{array}{c}\text { Rebooting } \\
\text { Cyberfeminism: A } \\
\text { Roundtable }\end{array}$ & $\begin{array}{c}\text { re:place: Histories of } \\
\text { Media Art, Science and } \\
\text { Technology }\end{array}$ & $\begin{array}{c}\text { Irina Aristarkhova } \\
\& \text { Faith Wilding } \\
\text { (HKW) }\end{array}$ & 2007 & $\begin{array}{l}\text { Berlin, } \\
\text { Germany }\end{array}$ & http://bit.do/e2hnQ \\
\hline CIMUAT & $\begin{array}{l}\text { Congreso Internacional } \\
\text { Mujer, Arte y Tecnología }\end{array}$ & $\begin{array}{c}\text { Mau Monleon \& } \\
\text { Empar Cubells } \\
\text { UPV } \\
\end{array}$ & 2010 & $\begin{array}{l}\text { Valencia, } \\
\text { Spain }\end{array}$ & https://bit.ly/2lLjKfo \\
\hline $\begin{array}{l}\text { Berlin's Media Art } \\
\text { Community: A } \\
\text { Female Perspective }\end{array}$ & & $\begin{array}{c}\text { Supermarkt } \\
\text { Tatiana } \\
\text { Bazzichelli, Faces } \\
\text { et al. }\end{array}$ & 2013 & $\begin{array}{c}\text { Berlin } \\
\text { Germany }\end{array}$ & https://bit.ly/2SeIkBy \\
\hline $\begin{array}{c}\text { Women, } \\
\text { Technology and } \\
\text { Creativity } \\
\text { Symposium }\end{array}$ & & $\begin{array}{c}\text { Berklee School of } \\
\text { Music }\end{array}$ & 2013 & $\begin{array}{l}\text { Boston, } \\
\text { USA }\end{array}$ & https://bit.ly/2LXPjgS \\
\hline
\end{tabular}




\begin{tabular}{|c|c|c|c|c|c|}
\hline FEMCODE & & $\begin{array}{c}\text { Amparo Carbonell } \\
\text { et al } \\
\text { Universitat } \\
\text { Politècnica de } \\
\text { València } \\
\end{array}$ & 2014 & $\begin{array}{l}\text { Valencia, } \\
\text { Spain }\end{array}$ & www.femcode.webs.upv.es \\
\hline $\begin{array}{l}\text { Women in } \\
\text { Computer } \\
\text { Graphics } \\
\text { (5 editions) }\end{array}$ & SIGGRAPH 2014 to 2018 & ACM SIGGRAPH & 2014-2018 & USA and Japan & https://bit.ly/2Y4o3nt \\
\hline $\begin{array}{l}\text { Hacking Feminism } \\
\text { Symposium }\end{array}$ & $\begin{array}{c}\text { CTM at Parsons School of } \\
\text { Design }\end{array}$ & $\begin{array}{l}\text { Patricia Clough et. } \\
\text { Al }\end{array}$ & 2015 & $\begin{array}{c}\text { New York } \\
\text { United States }\end{array}$ & www.ctm.parsons.edu.hackingfem \\
\hline $\begin{array}{l}\text { Technofeminism } \\
\text { Now }\end{array}$ & $\begin{array}{l}\text { Occasion of release of } \\
\text { Laboria } \\
\text { Cuboniks's Xenofeminism: } \\
\text { A Politics for Alienation }\end{array}$ & $\begin{array}{c}\text { Institute of } \\
\text { Contemporary Art }\end{array}$ & 2015 & $\begin{array}{l}\text { London, } \\
\text { England }\end{array}$ & http://bit.do/e2hpg \\
\hline $\begin{array}{c}\text { Celebrating } \\
\text { women in Media } \\
\text { Arts Symposium }\end{array}$ & $\begin{array}{c}150^{\text {th }} \text { Anniversary } \\
\text { Celebration } \\
\text { School of Art Institute of } \\
\text { Chicago }\end{array}$ & $\begin{array}{l}\text { Donna Cox, Janine } \\
\text { Fron, and Ellen } \\
\text { Sandor. }\end{array}$ & 2016 & $\begin{array}{l}\text { Chicago, } \\
\text { USA }\end{array}$ & $\begin{array}{c}\text { www.saic.edu/150/celebrating-women- } \\
\text { new-media-arts }\end{array}$ \\
\hline $\begin{array}{l}\text { Women in Media } \\
\text { Arts }\end{array}$ & Ars Electronica Archive & $\begin{array}{l}\text { Ars Electronica } \\
\text { Center }\end{array}$ & 2016 & $\begin{array}{c}\text { Linz, } \\
\text { Austria }\end{array}$ & www.archive.aec.at/womeninmediaarts \\
\hline $\begin{array}{c}\text { Post-Cyber } \\
\text { Feminist } \\
\text { International }\end{array}$ & $\begin{array}{l}\text { Institute of Contemporary } \\
\text { Art London (twenty years } \\
\text { since the First CI) }\end{array}$ & $\begin{array}{c}\text { Rosalie Doubal \& } \\
\text { Helen Hester }\end{array}$ & 2017 & $\begin{array}{l}\text { London, } \\
\text { England }\end{array}$ & http://bit.do/e2hp6 \\
\hline $\begin{array}{l}\text { My Mother Was a } \\
\text { Computer }\end{array}$ & William\&Mary University & Elizabeth Losh, & 2018 & $\begin{array}{c}\text { Williamsburg } \\
\text { USA }\end{array}$ & https://bit.ly/2JIVanw \\
\hline $\begin{array}{c}\text { International } \\
\text { Women's Panel }\end{array}$ & $\begin{array}{c}\text { Leonardo ArtScience } \\
\text { The Convening } 50^{\text {th }} \\
\text { Anniversary }\end{array}$ & Leonardo Journal & 2018 & San Francisco, USA & https://bit.ly/2XMa3dX \\
\hline $\begin{array}{l}\text { You Are Next: } \\
\text { Empowering } \\
\text { Women in the } \\
\text { Digital Arts }\end{array}$ & $\begin{array}{l}\text { You Are Next: } \\
\text { Empowering Women in } \\
\text { the Digital Arts. }\end{array}$ & $\begin{array}{l}\text { Sabrina Ho and } \\
\text { UNESCO }\end{array}$ & 2018 & $\begin{array}{l}\text { Paris, } \\
\text { France }\end{array}$ & http://tiny.cc/i7iv9y \\
\hline
\end{tabular}




\begin{tabular}{|c|c|c|c|c|c|}
\hline $\begin{array}{c}\text { Empowering } \\
\text { Women in the } \\
\text { Digital Arts and } \\
\text { Electronic Music - } \\
\text { Symposium }\end{array}$ & MUTEK 2018 & MUTEK Festival & 2018 & $\begin{array}{l}\text { Montreal, } \\
\text { Canada }\end{array}$ & http://tiny.cc/d0iv9y \\
\hline $\begin{array}{l}\text { Computer Grrrls } \\
\text { (Curatorial Project) }\end{array}$ & La Gaite Lyrique & $\begin{array}{l}\text { Inke Arns and } \\
\text { Marie Lechner }\end{array}$ & 2018-2019 & $\begin{array}{l}\text { Dortmund, Germany; } \\
\text { Paris, France; Eindhoven, } \\
\text { The Netherlands }\end{array}$ & $\begin{array}{c}\text { www.hmkv.de } \\
\text { www.gaite-lyrique.net } \\
\text { www.mu.nl }\end{array}$ \\
\hline $\begin{array}{c}\text { Mulleres e } \\
\text { Innovacion nas } \\
\text { Artes Intermedia }\end{array}$ & A Cultura e un dereito & $\begin{array}{c}\text { Rosa Sanchez } \\
\text { (ECOSS and Konic } \\
\text { Theatre) }\end{array}$ & 2019 & $\begin{array}{l}\text { A Coruña } \\
\text { Spain }\end{array}$ & https://ecoss.koniclab.info/programmea \\
\hline $\begin{array}{l}\text { Women in Media } \\
\text { Technology }\end{array}$ & $\begin{array}{c}\text { Athens Digital Arts } \\
\text { Festival }\end{array}$ & $\begin{array}{c}\text { Organisation of } \\
\text { Culture, Sport and } \\
\text { Youth of the } \\
\text { Municipality of } \\
\text { Athens (OPANDA) }\end{array}$ & 2019 & $\begin{array}{l}\text { Athens, } \\
\text { Greece }\end{array}$ & https://bit.ly/2ScGhxT \\
\hline Hysterical Mining & $\begin{array}{l}\text { Vienna Biennale for } \\
\text { Change } 2019\end{array}$ & $\begin{array}{l}\text { Kunsthalle Wien } \\
\text { Anne Faucheret \& } \\
\text { Vanessa Joan } \\
\text { Müller }\end{array}$ & 2019 & $\begin{array}{l}\text { Vienna, } \\
\text { Austria }\end{array}$ & http://bit.do/e2hqY \\
\hline $\begin{array}{c}\text { Producing Futures: } \\
\text { Post } \\
\text { Cyberfeminisms } \\
\text { (exhibition, talks } \\
\text { and workshops) }\end{array}$ & & $\begin{array}{c}\text { Heike Munder } \\
\text { (Director Migros } \\
\text { Museum fur } \\
\text { Gegenwartskunst) }\end{array}$ & 2019 & $\begin{array}{c}\text { Zurich, } \\
\text { Switzerland }\end{array}$ & www.migrosmuseum.ch \\
\hline $\begin{array}{c}\text { DIGITAL } \\
\text { POWER: } \\
\text { Activism, } \\
\text { Advocacy and the } \\
\text { Influence of } \\
\text { Women Online. }\end{array}$ & SIGGRAPH 2020 & Kathy Rae Huffman & 2020 & $\begin{array}{c}\text { Online } \\
\text { /Washington D.C. } \\
\text { USA }\end{array}$ & https://digital-power.siggraph.org \\
\hline
\end{tabular}




\title{
3.4.2. Creative Networks
}

\begin{abstract}
"As women, we have been taught either to ignore our differences or to view them as causes for separation and suspicion rather than as forces for change.

Without community, there is no liberation, only the most vulnerable and temporary armistice between an individual and her oppression. But community must not mean a shedding of our differences, nor the pathetic pretense that these differences do not exist.'
\end{abstract}

Audre Lorde, 1984

Due to the multilocality of the members, the visualization of the Creative networks has not been developed in the present dissertation, but it will be in the following phase through network visualization tools. The above-described creative networks of Faces Mailing list and $O B N$ are not included in the following description.

\subsubsection{1. female:pressure}

Named by its own members as "a worldwide network", female:pressure is the main international creative network and community dedicated to female, transgender and non-binary artists, managers, producers and curators in the fields of electronic music and digital arts. female:pressure ${ }^{117}$ is an example of transnational informal network that combines digital activism with real life encounters and activities. It was founded in 1998 by the Vienna based techno DJ and music producer Susanne Kirchmayr aka Electric Indigo, for twenty years of activism and networking she was committed to the professional promotion, visibility and support of women in Electronic Dance Music (EDM) scenes (Reitsamer, 2012). female:pressure joined Faces and OBN in the legacy of the Grrls movement, this creative and organised network has performed self-organised multimedia DIY formats of organisation, dissemination and networking, acknowledging the idea of female collectivity and

\footnotetext{
${ }^{117}$ See <www.femalepressure.net>
} 
political feminism (López Castilla, 2015). The network is cross-generational, and the formats of the projects are a platform with an archive, together with different social networks for the dissemination of the work of female artists, and two mailing lists. They have also developed the main reports on women in music festivals (FACTS surveys). Electric Indigo was part of the IMASeries in IMAfictions by Elizabeth Schimana (point 3.4.4.). Although it addresses visual artist too, its programme of activities has been mainly formed by sound artists and producers.

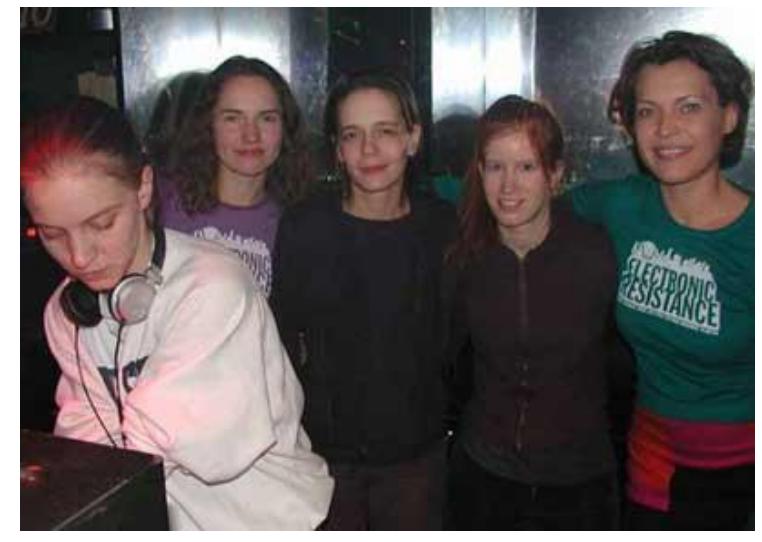

Figure 101 Image of female:pressure encounter. From left to right: pandora, lighta, dork, shroombab, indigo@U4 in vienna,

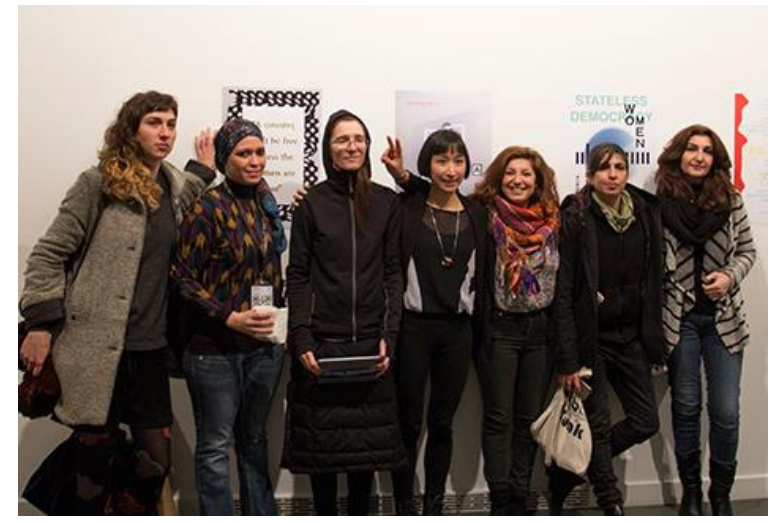

Figure 102 Image of female:pressure encounter. From left to right: empty taxi, angie balata, agf, annie goh, leyla boran, ipek Ipekçioglu, leyla ahmed @ ctm \#rojava panel in berlin, 2016

\subsubsection{Gender Changers Academy}

"We encourage women to crash computers and to put it all back together again. Preferably with an improved installation."

Gender Changers Academy

Described as an all-women non-profit organisation, Gender Changers Academy (GCA) is a translocal network of artists, activists and technologists that since 1999 has actively developed womenonly programmes on DIY open-source, feminist, hacker and artivism culture. It was founded in Amsterdam in 1999 by Sara Platon and Tali Smith with others, and later Donna Metzlar, Aileen Derieg, 
Reni Hofmuller, Audrey Samson, Ushi Reiter, Amaia Castro, Petra Timmermans, Helen Varley Jamieson and Vesna Manojlovic joined. They were originally part of ASCII (Amsterdam Subversive Code for Information) hacklab, which belong to those progressive, leftist, alternative groups that saw in electronic communication a useful tool for activism and organisation. The women in the group were from different parts of the world and none of them had a tech background, but their common idealistic passion to make the world a better place, the facilities for communication and networking they experienced with emails and the Internet and the discovering of Linux, as a Free Software that promotes collaboration, made them start a project to build feminist women's networks. Additionally, women were -and still are- highly underrepresented in the Free Software world, so they decided to learn by themselves and teach other women through DIY workshops, activities that evolved outside ASCII (Derieg, 2007). GCA represented a strongly committed female group that promotes recycled hardware, Free Software and open access for all:

By using and teaching others to use Free/Libre and Open Source Software we have more freedom and control over our work and projects in whatever we do, be it activism, art or technology or a combination thereof. [...] We believe that to be independent of the experts and so-called authority figures you need to be autodidactic and DIY. Fixing your bicycle, car, computer. In fact, women are already very technical. They use sewing machines, weave, spin and knit (it was weaving that lead to the first computer programmes). There will be communication barriers, a good metaphor for ICT. We will become Information and Communication Tweakers in order to break these barriers. (ETC, manifesto in Derieg, 2007)

The Genderchangers Academy "aims to break stereotypical roles related to technology and encourage and support women to use technology, art and grass roots networks as a tool for social change" (ETC, 2009). Gender Changers was chosen as a name to allude to the sexualization of the computer parts, claiming the term to a new meaning, symbolizing a person interested in the gendered aspects of 
technology. GCA philosophy is based on "sharing and facilitating learning in a self-directed, hands-on environment: less lecturing and more DIY practical experimentation" (Jamieson, 2004). GCA has developed artistic strategies towards examining the implications of the materiality of networks, exploring how social memory is related to hardware networked data archiving (GCA, 2015). GCA members were the first facilitators for a women-only Computer Hardware course in Amsterdam, and they are part of other feminist and all-women initiatives, for example Metzlar initiated the Girl Geek Dinner $^{118}$ social network also in Amsterdam,and is part of Sytersever ${ }^{119}$ (Metzlar, 2008), Reiter works in the server maintenance of Faces mailing list, where Derieg was an initial members, too. Segregation is a strategy applied to involve more women in technology:

The issue here is inclusion not exclusion. We re-access this choice constantly. Presently the conclusion is that the need remains for spaces where women can share experiences, break things, make jokes and ask so-called stupid questions amongst themselves. This approach is not the goal but a means. Life outside of the workshops is ever present (GCA, 2015).

Its structure is nonhierarchical, and its network has evolved and spread like a rhizome. Their womenonly workshops gave rise to other project, Eclectic Tech Carnival (/ETC) and this later to THF! ${ }^{120}$. Through their activities, GCA members have inspired other artists like Stefanie Wuschitz with Mz*Baltazar's Laboratory. They were part of the Very Cyberfeminist International in 2001 in Hamburg. However, despite being the main node in the feminist translocal network of artists activists in technology in Europe, in their several attempts to have an entry in Wikipedia have been shut down over and over again... (Derieg, personal communication 2018).

\footnotetext{
118 See <https://girlgeekdinners.com>

${ }^{119}$ See <https://systerserver.net>

${ }^{120}$ see point 3.4.5.1.
} 


\subsubsection{Collectives and groups}

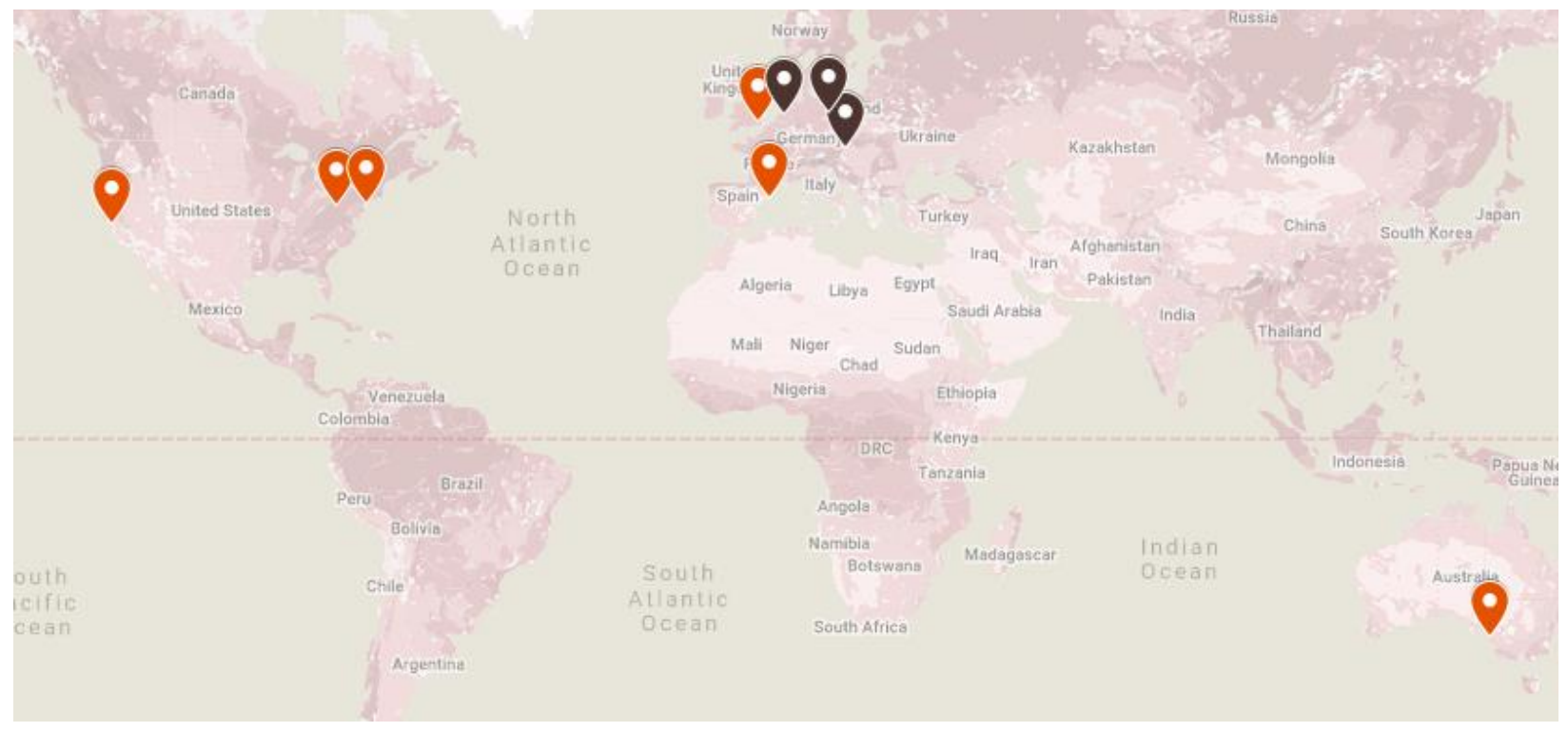

Figure 103 Collectives (orange) and Creative Networks (black/place of founding) mapping by its place of founding since 1991. Screenshot taken 18th July 2019

\subsubsection{1. subRosa}

In the confluence of political activism, technology, feminist art and theory, the artist Faith Wilding started a reading group at Creative Studio Inquiry in Carnegie Mellon the year after the First Cyberfeminist International. The group was called Sex and Gender in the Biotech Century, it addressed issues of science, embodiment and technology from a cyberfeminist perspective through art and theory (Wilding \& Willis, 2016). Wilding was part of the tactical media practitioners that founded the praxis of hacktivism, the collective Critical Art Ensemble (CAE), from where she brings a hacker activist spirit of the Electronic Civil Disobedience (Boix \& Nomada, 2003), a new form of digital resistance (CAE, 2001). She was also part of the first feminist art programme in California Fresno, and the Woman's Building with Judy Chicago, taking an active role in the first feminist practices in visual arts, media and performance (Wilding, 1994). She is one of the few cyberfeminists that argued the credibility of the liberation of women through new Information Technologies, like in her work Duration Performance exhibited at Ars Electronic in 1998. She was one of the main members of the $O B N$ network, writing since then until today influencing critical essays about the political conditions 
of women in cyberspace in terms of inclusivity, accessibility, age, race, sex and gender. If we could visualise the transnational network of women's activism in art and technology, Faith and subRosa are one of the spiders that netted some of the main nodes.

An emerging interdisciplinary group evolved from the initial reading class, becoming the core of the collective subRosa, it was formed by Steffi Domike, Christina Hung, Laleh Mehran, Lucia Sommer, Hyla Willis together with Wilding. This heterogeneous group experimented with new computer technologies, science and arts worked together since 1998 until 2004. Current members are Wilding and Willis. During two decades, subRosa has performed a significant contribution to the history of cyberfeminism as a transnational network of collaborations through performances, publications, workshops, residencies, interventions and installations. Within the cyberfeminist art practices, subRosa has demonstrated radical and critical positions, defining their positions against feminist equality and pancapitalism (Wilding \& CAE, 1998). Despite its roots in the academic framework of a private north American University, subRosa has developed its activity in different countries, establishing collaboration with different international artists and researchers.

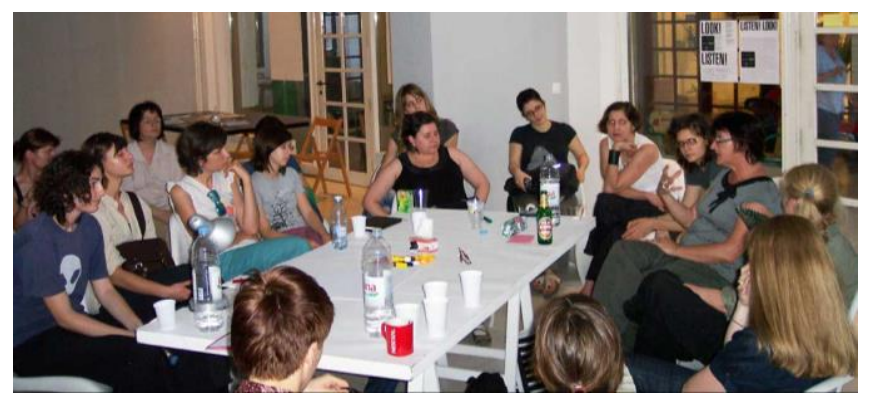

Figure 104 A 10-day subRosa residency in Zagreb June 2008, Courtesy of Faith Wilding

The practices of subRosa are hard to defined by their mutability, transdisciplinary, based on the creation of open-ended environments for the audience interaction with the objects. They reflect the inheritance of feminist and political activist art practices since the 1970s in the intersection with technology, they have developed a committed political radical activism and cyberfeminist practices of the Net-culture through different formats: texts, artworks, projects, etc. The collective started focused 
on the critical approaches of information and bio technologies to women's bodies, lives and work, specially Assisted Reproductive Technology (ART) as the impact of ICT on women's lives leading them to extreme physical and mental health problems (Fernandez \& Wilding, 2002, p.24). Facing a capitalism that controls bodies, sexuality, reproduction, and in short, all aspects of live, subRosa has proposed for two decades artivist coalitions by repressed collectives, who have applied biopolitical powers to producing democratic and liberating formats of expression, imaginative life and social production (subRosa, 2010) "Under such conditions, resistant feminist discourses of the "body" emerge as an explicitly biopolitical practice". Inspired by the work of the latino American feminist Silvia Federici, subRosa has developed its work based on the notion that the women's body is the factory of capitalist societies, appropriated by the state and men, forced to both reproductive and productive functions, is the land for exploitation as for resistance (Federici, 2004 in subRosa, 2010). In most of their performances and installations, the collective examines the female bodies conditions in the reproduction and consumption of medical and biotechnologies in the globalized fertility industry. Inspired by authors like Donna Haraway and Judy Wajcman, their work critiques that the new biotechnologies reproduce the old patriarchal divisions of activity/passivity, culture/nature, creating new social relations and subjectivities towards controlling people's bodies and bio-power, especially women and children. (subRosa, 2011, p.20).

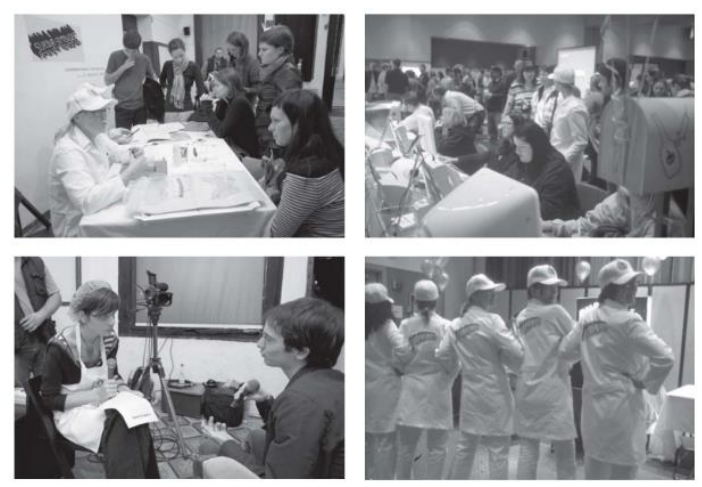

Figure 105 Left: subRosa U-Gen/Why are Women Like Chickens, and Chickens, Like Women? In City of Women Festival, Ljubljana, Slovenia, 13 oct 2008. Right: subRosa Biopower Unlimited! 23rd Annual New Media \& Art Festival, Bowling Green State University, Ohio, Oct2002 
The practices of subRosa evolved to a range of biotech and biopolotical feminist issues (subRosa, 2011, p.18). The collective has elaborated practices such as bio hacking, bio art, DIY biology, in formats of multimedia installations and performances, using the multiplicity of the body and female organs as the object of art work. Their works also reflect cyberfeminist concepts like critic and art-making through parody, posthuman condition, nomadic subjects and intersectionality. Gynepunk movement finds reference in subRosa collective performances on bodies, science and genitals. SubRosa has been part of international art and activist events, in Spain, she was invited by Ana Martinez-Collado to exhibit in the cyberfeminist exhibition Cyberfem in $2006^{121}$ and the researcher Maria Ptkq, who redacted her dissertation about the collective, invited them to the activist encounter Soft Power in the Pais Vasco in 2014, on natural science, biotechnology and art. In her dissertation she studies the evolution of the theoretical and practices contexts of subRosa works in the framework of feminist practice of technoscience that expand the foucaultian concept of biopower (Pérez-Hernández, 2017).

SubRosa never established a membership criteria for members election, and the position of the members towards the collective is as collaborators. The collective has collaborated with students and faculty from Women's Studies, Life Sciences, Visual and Media Arts departments internationally, and with a wide range of community groups, local artists and art institutions, organizing performances, participatory workshops, etc. The members and the collaborators have been able to communicate crossborders to programme and organised the wide range of work thanks to telephone and Internet communication (subRosa, 2011, p.18-9). SubRosa demonstrates how the new technologies enable collective organisation for critical positions beyond the cyberspace boundaries. Two decades of creative and critical collaborations that show a transnational network of alliances as a form of political and artistic resistance to technocapitalism and its harassing and controlling system. "By acknowledging

\footnotetext{
${ }^{121}$ See section 3.4.4.3.
} 
the power of embodied, nonverbal practices, cyberfeminists can subvert and deploy established forms of discipline to form and strengthen positive, powerful alliances" (Fernández, 2003).

As part of the educational feminist agenda, subRosa has worked in the design of new pedagogies that combine art, science and women's studies, applied in participatory forms of inquiry and knowledge through seminars, lectures, workshops realized in collaborator centers. In these formats elaborated strategies and tactics for 'becoming a feminist scientists' and presented bio-art projects from a feminist perspective, as an example of how participatory and performative art practices can promote public discussion about bio-genetic technologies (subRosa, 2011, p.23).

\subsubsection{Donestech}

Donestech is a collective located in Barcelona formed by researchers and activists Nuria Verges, Eva Cruells and Alex Hache. Donestech is one of the few all-women collective in Spain concerned about the inclusion of women in ITC at a local and national level, having developed academic and informal reports and investigation on the topic providing updated qualitative and quantitative data. Their position and approach are strongly political, based in promoting open source software and tools. Donestech was raised within a local and national network of all-women and feminist free radio, hackerspaces and projects on gender, technology and activism, such as Les Penelopes, Radio Paca, la Casa Encantada, Cybergrrl, ladyfest Europe, hacklab wh20001, devChix, Gender Changers, etc. (Vergés et al., 2009a) 


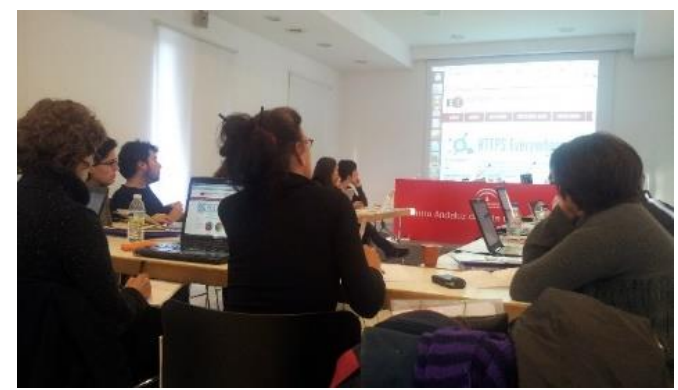

Figure 106 Workshop on cybersecurity and feminism in X0y1 2014

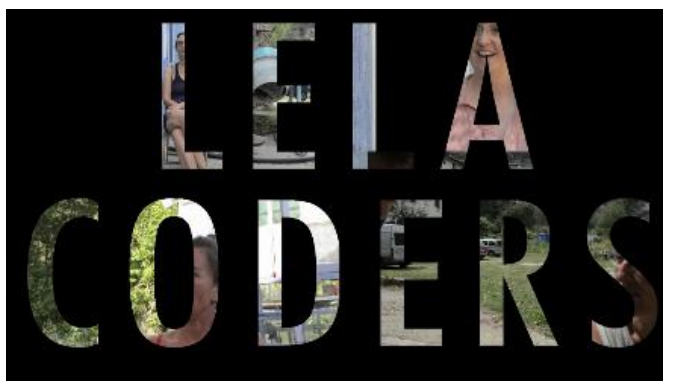

Figure 107 Logo Documentary Lela Coders Project.

Due to the profile of the members, Donestech worked between the academic and informal activism. The members have situated Donestech within the European network of all-women and feminist projects and on art and technology, becoming a relevant node in the transnational network. They have worked on collaboration and mutual support with other DIY all-women and feminist projects, such as /ETC-Gender Changer Academy ${ }^{122}$, XOy $1^{123}$, Fem Elek ${ }^{124}$, CIMUAT $^{125}$, Studio XX ${ }^{126}$, etc. In Fem Elek they developed a series of talks on gender and cybersecurity, the project Lelacoders was presented by Hache in Studio XX. Their methodologies are based in a combination of informal and academic formats: on one hand in alternative feminist hacker formats, promoting open source through workshops, collaborative creation, social transformation through art and technology, and on the other hand, developing reports at a national level on women accessibility in TIC, and the situation of women in art and new technologies, through a research studio on Catalan new media artists (Vergés et al., 2009b). Corresponding projects are Lela Coders $^{127}$ and Lelarts. Donestech plays a parodic game between the word Lela (in Spanish, dumb), to point the general cultural stereotype that women have in the use of new technologies. They have also developed work on the history of Catalan women in technology and art, and other on the history of women in computer science and hacker culture:

\footnotetext{
122 See point 3.4.5.1.

${ }^{123}$ See point 3.4.5.4.

${ }^{124}$ See point 3.4.5.3.

125 See Table 3 in point 3.4.2.2.

${ }^{126}$ See point 3.4.7.1

127 See <https://vimeo.com/lelacoders>
} 
Lelacoders (Donestech, 2009). Members of Donestech have developed research on other projects of women and ITC, such as e-mujeres ${ }^{128}$. In 2014 they were part of the organisation of the TransHackFeminist!, within the /ETC and Gender Changer members held in Calafou ${ }^{129}$, an ecoindustrial post-capitalist colony that works by self-organisation and self-management. Calafou is together with Donestech a node of connection in the translocal network of artists and activists in art and technology in Europe.

Donestech combines activism online and offline, with voluntary work and some punctual public funding. They aim to create spaces to produce knowledge collaboratively, from the perspective of women that are already developing technology. They have performed several experimental workshops on open source TIC, which are like the rest of their activities, free of charge. Donestech was committed to reinforce and stimulate the networks of collaboration and interactivity between women in technology, artists, developers and activists. Their digital platform is the virtual space for archival and promotion of their own activity and results, as well as space for promotion of other projects on the same topics: feminism, women, art, technology, hacktivism, etc. The objectives of the platform were based on "redes que enredan" (nets that networks): creation of social and telematic networks, make visible experience and artistic practices of women on technology, disseminate, present and organize encounters, talks, debates, publications and workshops... porque el roce hace el cariño (a Spanish proverb that means something like "close contact breeds affection”) (Vergés et al., 2009a). In fact, Donestech plays in their publications with the parallelism between knitting nets and netting on ICT, being involved in technology is a netting process of self-inclusion on tech (Vergés, 2012). In platform there is a section called Mapa Noticies, a visualization mapping of the worldwide publications on women and ICT, and further archive of content and links to other projects and publications.

\footnotetext{
${ }^{128}$ See point 3.4.4.1

${ }^{129}$ See <https://calafou.org>.
} 
Donestech supported Atenea 2018 conference ${ }^{130}$ but unfortunately, they couldn't be part of the panel on feminist associations.

\subsubsection{3. hypen-labs}

Hypen-Labs is a collective of women of color that works transnationally since 2014, composed by members from different countries and different STEAM areas, whose point of connection is Arts and a desire to inspire next generation of female creators on science, technology, pedagogy and innovative design. Although it is a self-organised collective, hypen-lab model of work relies between artistic production with new technologies and business model based on an awareness to build a future in a healthy way. Carmen Aguilar y Wedge and Ece Tankal conceived Hypen-Labs when they met in a master's programme, coming from architecture and engineering, they didn't expect to have so much in common, like similarly noticing a lack of female presence and cultural diversity in the creative spaces in their fields. Based on the Marian Wright quote: You can't be what you can't see, together they realized that they had the responsibility to create by themselves the content they wished to accessed when they were younger, a way to start telling their own stories and inspire future generations and represent women and communities of color: "our core mission is to use entrepreneurship, technology and [planetary-centered] design as a catalyst for change" (Aguilar y Wedge in MPavilion, 2019). The studio has a non-unified space, but three different locations: Barcelona, New York and London, where the main members are based.

\footnotetext{
${ }^{130}$ See chapter 4.3 .
} 


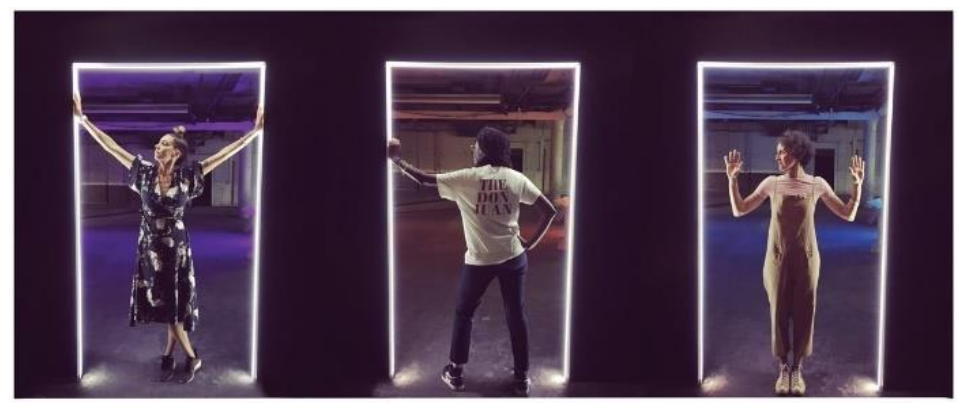

Figure 108 Figure 8 Left to right: Tankal y Wedge, and Baccus and Aguilar posing on her own installation work. Titled 'joining @mssngpeces Pushing immersive experiences through Design, Virtual Reality and Emerging Technology. Source: Twitter @hypen_labs

In 2016 Ashley Baccus joined the team, when they started the collaborative project NeuroSpeculative Afrofeminism, a three-parts interactive VR installation simulating a Neurocosmetology lab with pioneering techniques of brain optimization and cognitive enhancement with an exploration of the impact of images of black women empowered. Designed in 2017, it has been presented and exhibited in international media art festivals such as Ars Electronica 2018 and Transmediale 2019. The piece talks about women of color empowered, "a digital narrative that sits at the intersection of speculative product design, virtual reality, neuroscience, and transhumanism—all disciplines that currently lack overarching representations and perspectives of women of color" (Electric Women, 2019).

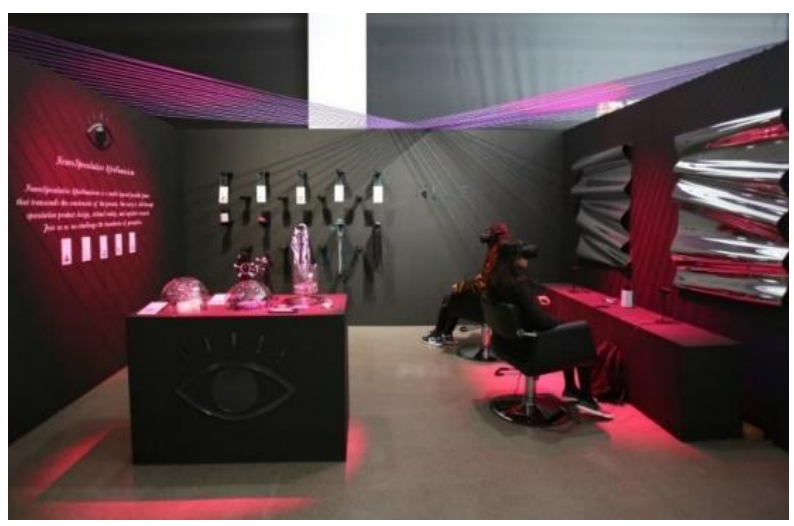

Figure 109 NeuroSpeculative AfroFeminism Installation, 2017. Tribeca, New York City. Source: Hypen-Labs

The international team is formed by Carmen Aguiler y Wedge, experience designer and Ece Tankal architect, together with Ashley Baccus, speculative neuroscientist; and collaborators: Dr Romy 
Gad el Rab, psychiatrist; Jian Shuihi Mad scientist; Elena Mitro, architect; Lajune Mcmillian, artist; Halime Maloof, 3D and digital artist; Anastasia Pistofidou, Ideas hacktivism and architect; Melani Hoff artist; Nitzan Bartov, game designer; Michelle Cortes, artist/technologist; Ale Diaz De Leon, architect. The structure and process of creation is fluid, there are no established hierarchies, each member involves herself as her availability, and the collective is open to further collaborations (Aguilar y Wedge et al., 2019), NeuroSpeculative Afrofeminism and Hypen Labs are part of Electric Women ${ }^{131}$.

\subsubsection{Deep Lab}

The same space that gave rise to subRosa collective in the late 1990s, in 2014 held the activities of Deep Lab. Artist and activist Addie Wagenknecht was for two years investigating on cryptology, blockchain technology and digital surveillance. She aimed to find a group of female artists and technologist from who to learn from and work collaboratively. When she was a fellowship at STUDIO for Creative Inquiry ${ }^{132}$, she proposed the idea to Golan Levin, the director of the studio at Carnegie Mellon Art School, who supported the project. She also got financial support from the Andy Warhol Foundation in Pittsburgh (Quinn, 2017). Addie brought formats and methodologies from feminist hackerspaces she had been part of before: hackatons, charrette, micro conference, working with open source software, collaborative creation, horizontal structures, etc. (Wagenknecht, 2015). As subRosa reflected on technoscience, capitalism and the impact of women's bodies in the late 1990s, Addie formed a group to investigate on privacy, security, surveillance, anonymity, and large-scale data aggregation are problematized in the arts, culture and society. Several international acclaimed new media artists, information designers, data scientists, software engineers, hackers, theoreticians, writers and journalists came together during a week in December 2014 to engage in critical assessments of contemporary digital culture (Wagenknecht, 2015):

\footnotetext{
${ }^{131}$ See section 3.4.4.2.

132 See <http://studioforcreativeinquiry.org>
} 
Hacking technology is a right, not a weapon. Because the deep web is largely void of a female presence-save for sexualized images-female hackers must engage with the future, in order to make our presence in history indelible. And so Deep Lab was born.

The results of the week-collaborative work are a 240-page book (free to download on the official website of the collective), a video album of the ten presentations called the Deep Lab Lecture Series, an $18 \mathrm{~min}$ documentary film about interviews with the participants.

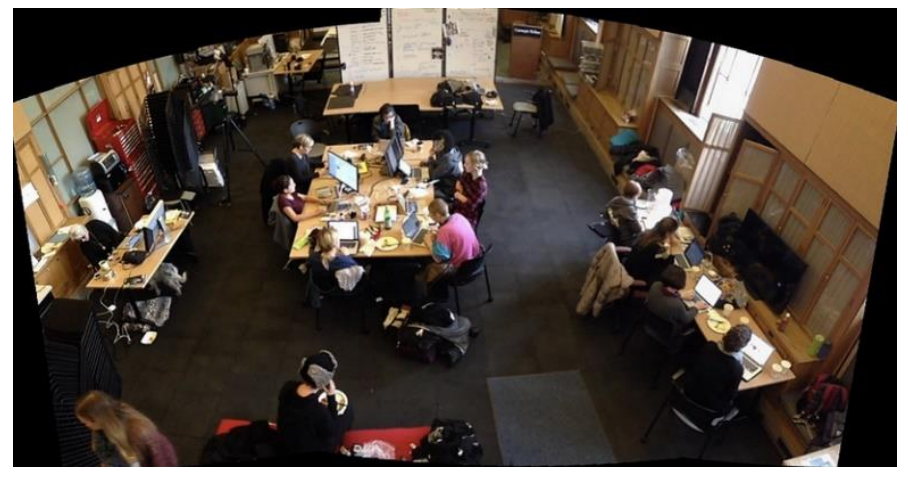

Figure 110 View of Deep Lab members working at STUDIO for Creative Inquiry at CMU, 2014.

Deep Lab promoted creative research that influenced emerging all-women projects in art and technology, such as Void Lab in Los Angeles ${ }^{133}$, by challenging the contemporary techno social and political system, the networks of information, the traffic of data, the impact on arts and society. Wagenknecht's methodologies are based on collaboration as a motivational strategy for creativity, she reactivated the studio at CMU as a node in the transnational women's network in arts and technology. Two years later, in 2016, she was part of the \#KissMyArs campaign ${ }^{134}$ and part of the founding members of REFRESH ${ }^{135}$, both projects together with Heather Dewey-Hagborg, along with others.

\footnotetext{
${ }^{133}$ See point 3.4.6.8.

134 see chapter 4.2.

${ }^{135}$ See point 3.4.3.6.
} 


\subsubsection{5. girlFx}

GirlFx (pronounced girl_friend) is a self-organised and interdisciplinary collective of women and non-binary artists, musicians, DJs, sound engineers, curators and entrepreneurs from different points of the East Coast in United States. Located in Pittsburgh, the collective actively stands for ownership and representation in the nightlife community by creating events with local and international artists that work on the intersection of sound, technology and visual arts (Goshinski, 2019)

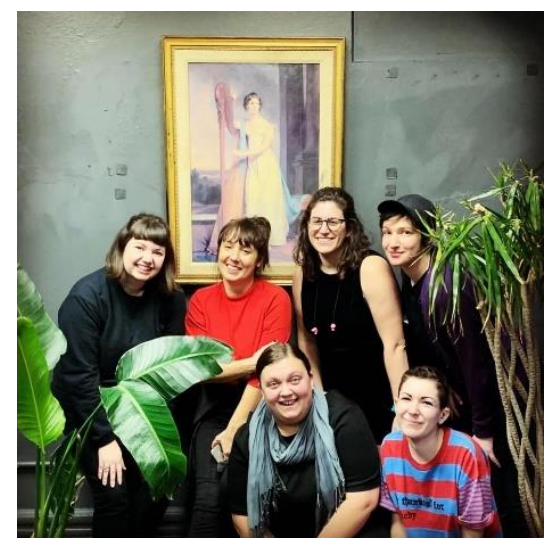

Figure 111 Left to right: Allison Cosby, Lauren Goshinski, Sydney Lytle, Ariel Norris, Julie Mallis, Evelyn Pandos, December 2018

Lauren Goshinski, co-founder of GirlFx, explained in our interview that when she co-founded VIA in 2011, the intention was not only to create a platform in Pittsburgh to connect sound, technology and visual arts, but also to face the lack of female as festival directors and in the night line-ups. Pittsburgh is considered a super male-dominated city. Aiming to make a cut in the industry, VIA festival was created as a laboratory as an open space for interdisciplinary artists, prioritizing gender parity, understanding intersectionality within the programmeming: awareness for trans women, gender non-binary folks, whiteness, social class. Despite these purposes, as the festival grew, certain questions started to be pointed in a side conversation by women and non-binary members and artists involved: "we were all like, Why don't we create a satellite, a subset of the project where we work on actively focused on promoting women, femme, non-binary folks in the work that we do" (Goshinski, personal communication, 2019). GirlFx condensed the intersectional programme of VIA and had a more 
crystalized mandate to have education as a key issue, the collective is aware that not only gender but social class are a primary barrier for equal treatment in the electronic arts field. GirlFx was founded in 2016 by four VIA members: Lauren Goshinski, Allison Cosby, Eileen Angulo, and Isabella Parajole, and currently counts on the membership of ten more. It has ten active operating members helping to run events and designing the programme. The hierarchy of the collective works on a horizontal decision-making structure, a collaborative methodology for discussions, where the agreement for the programmeming has to be general a look for a common base within the differences:

It is so hard to apply a fear intersectional programme that can confront with personal ideologies. We want to create groups by creating strength through coming together [...] Manifesto means nothing to me, multiple ideologies working together and make advances within the music industry and digital art scene [... nice to see what we have achieved in three years (Goshinski, personal communication, 2019).

As the organisational structure is flexible and horizontal, and the members work internationally presenting their work, they the personal influences from other organisations and methodologies, for instance, Goshinski investigates the curatorial methodologies in electronic arts and music festivals in Europe and applies them in the Pittsburgh art scene by accommodating them to the city context. GirlFx has an ongoing programme based on live events, workshops and residencies that seek to promote the work of local and international artists, connecting the local, the national and the international spheres. Despite its self-organised profile, the activities are held in collaboration with local institutions such as Carnegie Mellon Library, Studio for Creative Inquiry, ACE Hotel and Carnegie Museum of Arts, for example. Currently GirlFx offers three residencies in Pittsburgh: Hott Mass, Ace Hotel's In The Weeds and Tea Time. GirlFx is a local node in Pittsburgh that reflects the work going on in the international network. 


\subsubsection{REFRESH}

REFRESH is an all-women collective that works as a platform and a self-organised network, providing a programme of activities that seeks to create new structures for new visions, fresh perspectives of the future beyond the mainstream works in new media arts. REFRESH was officially founded in 2016. It was conceived by the encounter of \#KissMyArs campaign and other artists in science and technology. The campaign went viral when published in 2016 the low number of women awarded by the most important festival in new media arts: Ars Electronica, in twenty-nine years of Golden Nica prizes, only five women artists had been awarded ${ }^{136}$. The collective is formed by the co-founders and members of than campaign Heather Dewey-Hagborg and Addie Wagenknecht, Kathy High and Dr Camilla Mørk Rostvik together with Dorothy Santos, Lynn Hershman Lesson, Tiare Ribeaux, Maandeeq Mohammed and Salome Asega (REFRESH, 2019). The basis of the collective is to serve as an inclusive platform for sustainable artistic and curatorial practices:

REFRESH breaks down systemic cultural and economic oppression and offers validation, visibility, to populations that have been historically marginalized, including women, transgender and cisgender, people of color, LGBTQI, and disabled artists from around the globe $[\ldots]$ And we're doing this not to check some kind of diversity check mark, we're doing this because we really believe that this is where the most new and exciting ideas are happening, because the status quo is failing us and we desperately need new ideas (DeweyHarborg \& Santos, 2018).

REFRESH acknowledges that since the Guerilla Girls campaigns little has changed, and the interdisciplinary field of art, science and technology has inheritance discriminatory politics from the three disciplines, despite its novelty: "Despite the history, we believe art has a tremendous potential

\footnotetext{
${ }^{136}$ See chapter 4.2 .
} 
in the current cultural climate to open new trajectories and ethical choices by envisioning different possible futures. The status quo is no longer our status" (REFRESH, 2019). The collective represents the legacy of the DIY feminist strategies from the 1970s and the creative networks like cyberfeminists from the late 1990s, being part of the emerging contemporary forms of organised networks after the Web 2.0 and social media (Lovink \& Rossiter, 2018):

We're not merely stating and restating problems, but we are pulling from different realms of thought and practices such as punk, biohacking, do-it-yourself culture, with the aims of taking things apart and building something less oppressive, fumbling towards a progressive vision and liberatory future, showing spaces of possibility, but, we cannot refigure the future without friends (Dewey-Harborg and Santos, 2018).

Lynn Hershman Lesson is an acclaimed feminist artist in new media that took part in several allwomen curatorial projects in the early $1990 \mathrm{~s}^{137}$, Wagenknecht founded Deep Lab ${ }^{138}$ in 2015, in 2017 Tiare Ribeaux conceived and curated the feminist new media Vital Hybrids ${ }^{139}$ exhibition in the Bay Area of San Francisco, and Kathy High is part of FEMeeting ${ }^{140}$. They decided to build a room for one's own despite the multiple locations of the members, they have designed a programme of activities in collaboration with art spaces such as Hunter College Art Galleries in New York City where they held the first exhibition Refiguring the future, that was also accompanied by a conference, where they presented the collective and platform. The title was inspired by the artwork of Morehshin Allahyari, who defines a concept of "refiguring as a feminist, de-colonial, and activist practice" (Dewey-Harborg \& Santos, 2018). Two members of VNS Matrix, Virginia Barrat and Francesca da Rimini exhibited collectively. This combination of collective and collaborative organisational and

\footnotetext{
137 See chapter 3.1 .

138 See point 3.4.3.4.

${ }^{139}$ See point 3.4.4.7.

${ }^{140}$ See point 3.4.5.10.
} 
curatorial organisation, working by funding, the support by local art and cultural institutions, relate us to the early days of cyberfeminism (Pierce, 1998) and creative networks (Smite, 2012). New ICTs are for REFRESH a form of communication between the members, in addition they use digital platforms to archive digitally their work, the artworks exhibited, etc. However, its networks are based on real-life ties and real-life events.

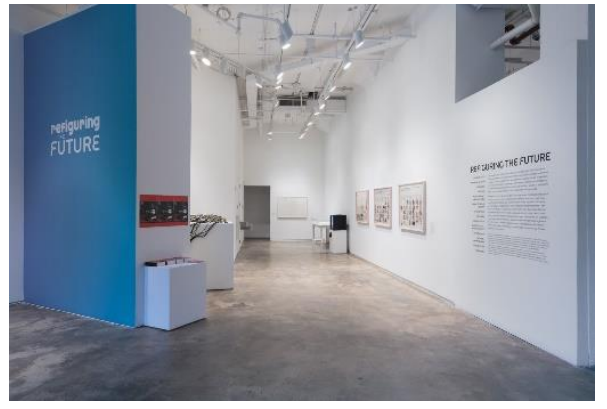

Figure 112 Refiguring The Future Exhibition, New York City, 2019. Exhibition organised by Eyebeam and REFRESH in collaboration with Hunter College Art Gallerie

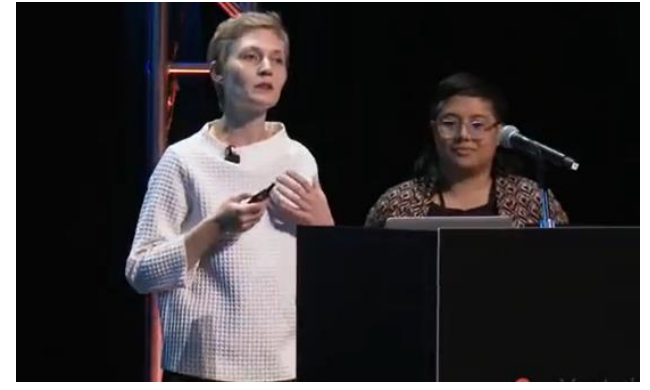

Figure 113 Heather Dewey-Hagborg and Dorothy Santos presenting REFRESH at Refiguring the Future in New York June 2018. Video available at <http://tiny.cc/6ckojz>

\subsubsection{Hackers of Resistance HORs}

The Hackers of Resistance (HORs) is a collective formed in San Francisco by three hacker women of color that create playful media at the intersection of art, interactivity and activism. As a reaction to the Silicon Valley tech industry and companies, HORs objective is to tackle hegemony and build community from an intersectional perspective by creating and curating post-colonial, nonwestern, queer and feminist speculative pieces. They combinate resistance strategies with hacker methodologies. HOR's pieces are hyperreal-multimedia and immersive theater, installations performances and video games, based on a feminist activism that create a universe on their own's. 


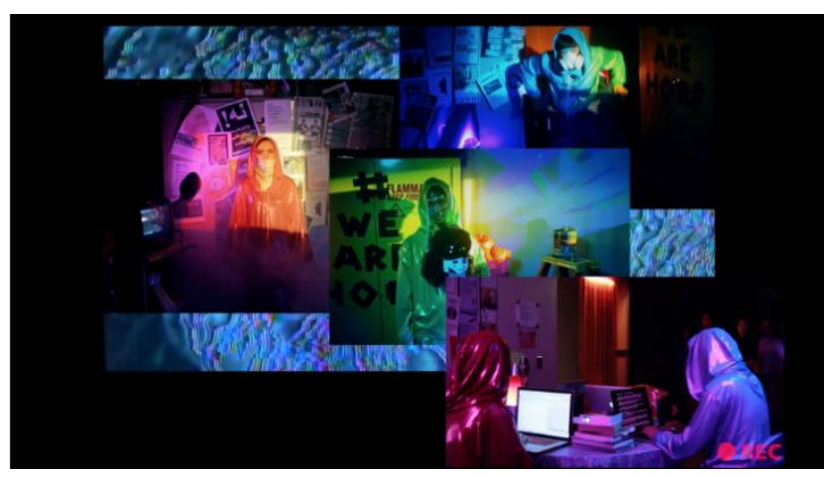

Figure 114 HORhouse, installation at Vital Hybrids exhibition: visitors are free to roam the HORs' makeshift hacker den where environmental storytelling provides a cyberfeminist take on cybersecurity, community resources, and DIY-DIWO experiments. Image credit: HORs

The collective was formed based on the own experience of the members in the digital media, film and game design industries, therefore their immersive works are addressed to create a utopian space for the oppressed collectively, placing women of color hackers as "superheroes willing to risk it all for solidarity", according to their manifesto "aiming to subvert a traditional white-Americancentered dystopian narratives" (HORs, 2018). The members define themselves as artists, activists, researchers, cyborgs, witches, co-conspirators and technologist of color that form altogether a queer transfeminist hacker collective to "build tools to defend our community, educate people to be secure, to demand and make ourselves heard, to fight back and hack tools of oppression" (HORs in Electric Women, 2018). HORs make recurrent allusions to community and alliances, I point the statement in the text above: "build tools to keep our global sisterhood-not-cisterhood", as a clear form to state that the alliance is not based on sex (that is referring to the term cis woman), in comparison with the global sisterhood of the 1970s claimed by Morgan. Their activism relies in Hacking, women's health and cyberdefense. Another way to build community is by partnership, the collective produce and performs a cyberfeminist work in regarding sexual rights, female sex organs and reproduction together with their sisters and girlfriends Marias Clandestinas, a cyberfeminist activist group from Latino America which works critics the DIY clandestine methods of abortion. The collective work by Maria Clandestinas and HORs is inspired by the DIY gynecology, it relates us to subRosa work, when they use the 3D printing and DIWObio (Do It with Others + biology) as a format to criticize a capitalist society that reproduces 
labour force and social injustice and reproductive rights (Hackers of Resistance, 2018). Their main formats are DIWO (Do It With Others), 3D printable kits, cybersecurity labs, bio-hacking, dildohacking. Other projects are related to anti-facial recognition, counter-surveillance, social engineering, always in the shimmery-neon aesthetics that characterizes the collective style, combining social-aware comedy and DIY charm to "address serious concerns like the fate of minorities in the hands of the current administration" (HORs 2018).

Hackers of Resistance performed a three-day workshop about hacking and cybersecurity that was part of Animating the Archives, project by The Woman's Building together with Metabolic Studios, in May- June $2017^{141}$. HORs was part of Vital Hybbrids exhibition curated by Tiare Ribeaux by the end of 2017, with their piece HORh4us, their immersive multimedia heist (HORs 2017). With this piece, HORs is also part of the online exhibition electric-women, curated by Lauren Valley. HORh4us installation invites visitors to freely roam the HOR's makeshift hacker den, creating a collaborative playful performance in regarding public health rights, cyber surveillance and community building. A storytelling is played in the background with the HORs manifesto provides a cyberfeminist take on cybersecurity, community resources and DIY-DIWO (Do it Yourself- Do It With Others) experiments. (Electric-women, 2017). HORs expand their network and have a tour dates planned in United States, also Europe and Japan in 2019. Their official website is an interactive virtual platform that fathers all their activity, information, textual and visual works, manifesto and contact form.

${ }^{141}$ More information on this available at <https://bit.ly/2xbpa5F $>$ 


\subsubsection{Exhibitions}

"Without the stewardship of museums and archives, technologically-driven work by female artists will literally disappear with the obsolescence of mechanical components and knowledge."

Amy Beste, 2018 (School of the Art Institute of Chicago)

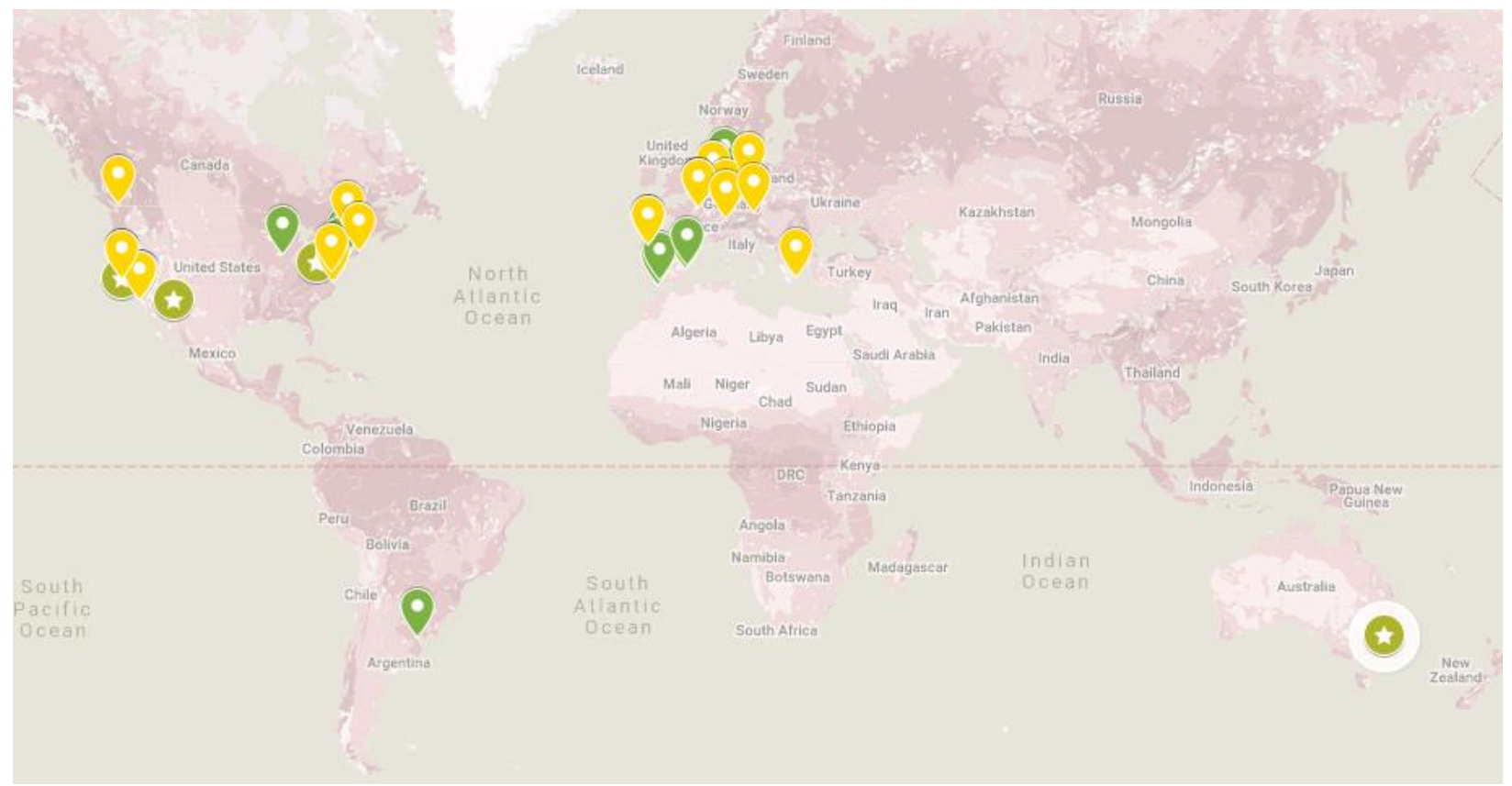

Figure 115 All-Women Self-organised Curatorial Projects Worldwide since 1986 (Star-icon: online exhibition location of the server, list in the following chapter). Screenshot taken 18th August 2019

\subsubsection{1. e-Virgenes}

From 2001 until 2014, the collective behind the feminist platform e-leusis, together with Artefinal Studio ${ }^{142}$, developed a series of exhibitions regarding new information technologies and women that were exhibited in different art spaces in Spain. Since 2001 e-mujeres, before 2007 called e-leusis, was the first was the first virtual platform dedicated to feminism content in Spain. E-leusis.net

\footnotetext{
${ }^{142}$ See <https://artefinal.com>
} 
was founded in 1999 by a group of seven young women with the old version of the Internet tools, "made by hand, cyberfeminists programmeming zeros+ones, without templates, in an unknown code that grew to add words, images, menus, sections, agendas, sentences, dreams and desires on the template" (Bertomeu, 2006). e-leusis members were socially active and participated from different parts of Spain and UK: Itziar Elizondo, Belén Hernández, Encarna Franco, Angustias Bertomeu, Concha Colomer. All of them were experts in different areas such as medicine, sociology, history, information and communication, education, etc. Today, we can find them in notable positions as feminists in politics and knowledge space. Not only inspired by the early cyberfeminist texts, the team of e-leusis was encouraged by international statements such as the one by UNESCO in 1998, that announced the need to create new spaces of information and services for women, who were still marginalized on the cyberspace, like the abovementioned $4^{\text {th }}$ International Women's Conference in Beijing, where it was claimed the equal accessibility to ICT for women, and it was promoted an alliance through these networks. Therefore, e-leusis based their methodology in the ancient strategy of women for establishing formal and informal networks was the clue for empowerment and self-management (e-leusis, 1999). Angustia Bertomeu and a growing group of women, aimed to create a space which designed would be based on the needs and desires of women, inspired by the concept of city, as the space where women manage life. Eleusis.net was in charge of the production was "The city of women on the Net/networked women?, a space for authority, freedom, exchange, sisterhood, business, poetics, etc we are not alone, there Is a women genealogy, net, create, founding..." 


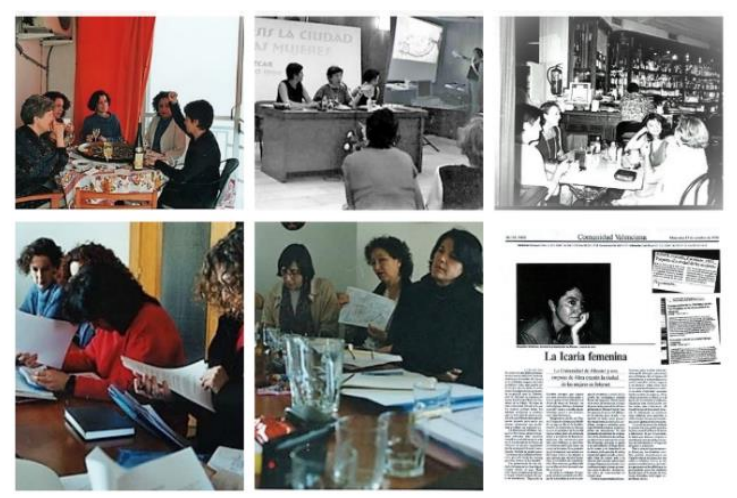

Figure 116 Compilation of images of the first e-leusis meetings in the early 2000s. Courtesy of Angustias Bertomeu

In that moment in Spain, it was hard to find someone creative with the characteristics Bertomeu the other members provided: educational, content management and feminism and technology (Bertomeu, personal communication 2019). Bertomeu for example, was asked to teach at university and public centers courses about gender and technology and TIC skills for women, which were the first programmes in this topic to be taught, and soon they would develop artistic works in this regard.

Entre el cyber y el suelo (Between cyber and the ground)

In November 2001, by request of the Instituto Andaluz de la Mujer IAM in Sevilla, e-leusis together with Artefinal Studio, exhibited a multiple installation formed by three parts: the body, the voice and sight, the creation and desire. When recognizing new spaces as a social place, it is when we can talk about women's politics, women's society, or women's art: “El cuerpo, la voz, la mirada, la creacion y el deseo. La gestion de la vida" (e-leusis, 2001).
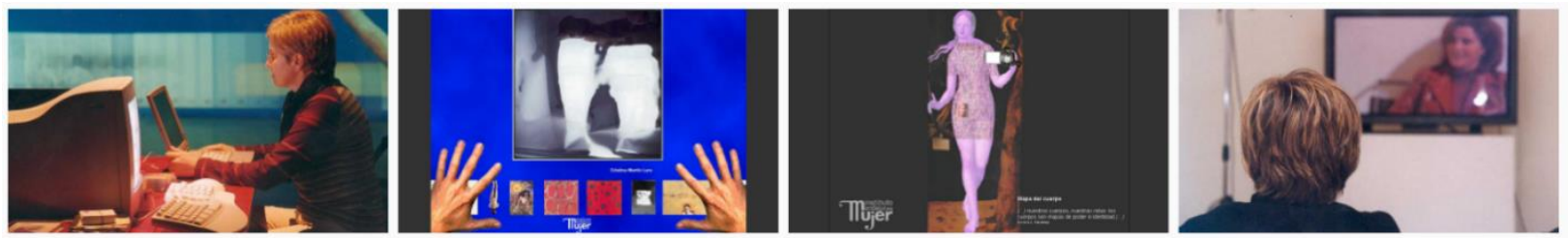

Figure 117 Screenshots of Bertomeu using different parts of the installation in 2001 


\section{e-Virgenes}

In 2003 e-leusis and Artefinal Studio presented e-Virgenes at the Kimmel Center in New York University, after receiving the award by the same university in the call Spectacle and Religiosity. The event and call was focused on research and practice works related to politic and social configuration of the Americas (Bertomeu, 2004).

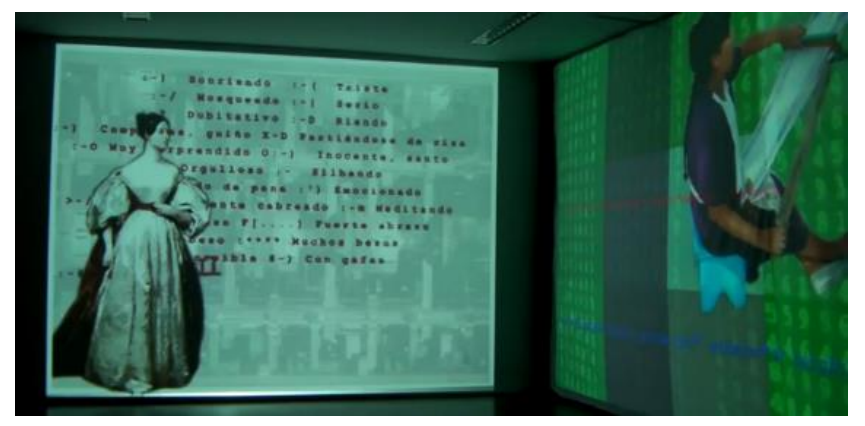

Figure 118 Screenshot from video e-virgenes, 2003

Composed by two projections, Eva and Las Evas Panamericanas, e-Virgenes is a metaphor of the knowledge transmission of the code society, the intrahistory, done by women in (Latin) America through transgenerational networks while performing tasks like sewing, singing, praying, netting, cooking. The inheritance of these genealogies goes to those women who instead "treat hardware, cook software, net pixels, surf on megas towards netting networks", on the other side of the Atlantic (Bertomeu, 2004). The exhibition is a digital artwork between the hypertextual narrative and multimedia from a political perspective, based on the premise 'personal is political' and the "bodies as maps of power and identity

e-virgenes was exhibited and presented in Cádiz (2003), Valencia (2004), Buenos Aires (2010) and Castellón (2014). In 2007 the domain migrated to e-mujeres.net with a new team, as the personal and professional responsibilities desegregated the organisation. Angustias Bertomeu maintained e-mujeres and keeps on working on gender equality courses in ICTs, publishing content about feminism, society and technology, they are committed to fight for gender equality and against violence 
towards women. In the platform they provide educational content, online courses, interviews, references, cyberfeminist texts, resources about sexual harassment and domestic violence and urbanism. Bertomeu is nowadays offering talks as guest lecture in open events and feminist meetings in Spain. Their activism is such that they even received calls by women who has suffered sexual abuse or domestic violence "Things have not changed at all [...] we must keep on fighting for our rights" (Bertomeu, personal communication 2019). In the Ateneo section, one can find the main members of the network of collaboration that they have established along these years, between who feminists such as Amelia Varcarcel, Maria Angeles Duran and Celia Amorós and others, are part. e-mujeres has netted a network of feminist from the generation like Mujeres en Red, who experienced the entry of democracy in Spain, sight for gender equality and believe in the solidarity and union between women through networks as a form of resistance by accessing new technologies of information.

\subsubsection{Cybefem: the spirit of Data}

The next year after the last First Cyberfeminist International, in December 2002, some members of the alliance in collaboration with other feminist and all-women networks that had taken part of the encounter, formed a one-month exhibition in the Edit Russ Hauss in Oldenburg: CONSTANT vzw. Vereniging voor kunst en media from Brussels, Les Pénélopes, from Paris, MAKE, the organisation for women in the arts - The Women's Art Library, London. This exhibition shows the productivity from the networking experience the year before in Hamburg, how projects come up after international encounters by the common wish to build together a space for women in new media arts. Helene von Oldenburg conceived the idea, which was curated by her together with Rosanne Altstatt, with the support of a European Cultural programme. Artists featured: Ursula Biemann, Heather Cassils and Cathy Davies, the women from the Gender Changer Academy, Diane Ludin with Francesca da Rimini (from VNS Matrix) and Agnese Trocchi, Jen Liu with Jenny Marketou, Die Patinnen Teil II, Cornelia Sollfrank, Pernille Spence, Linda Wallace. As Juliane Pierce said in 1998, the "updated 
version is cyberfeminism is about creating opportunities to meet and make work". Politic artistic practices by cyberfeminists happened at a micro level through networking, specific location practices, women's workshops and curatorial projects such as Cyberfem (Merck \& Sandford, 2010, p.72). I could presume that the following exhibition in Spain curated by Ana Martinez-Collado in 2006, was inspired by this one, as they share the title.

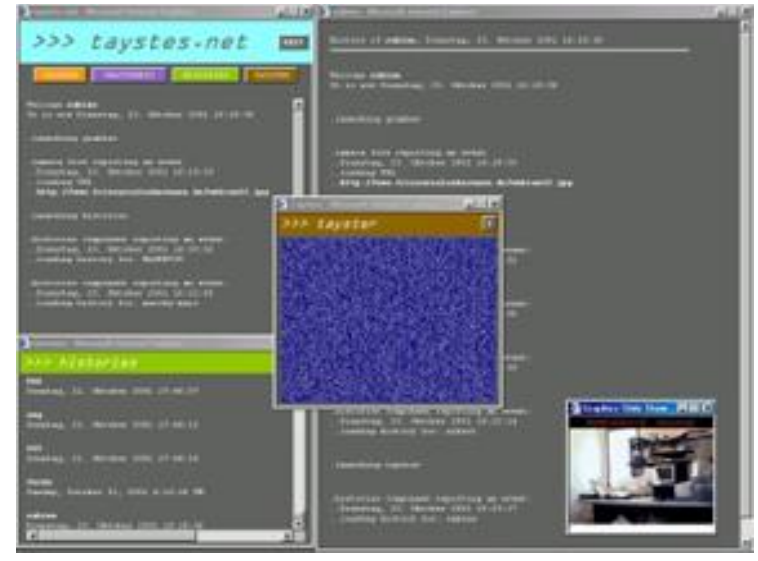

Figure 119 Artwork at Cyberfem by Jenny Marketou: "TaystesROOM: www.taystes.net

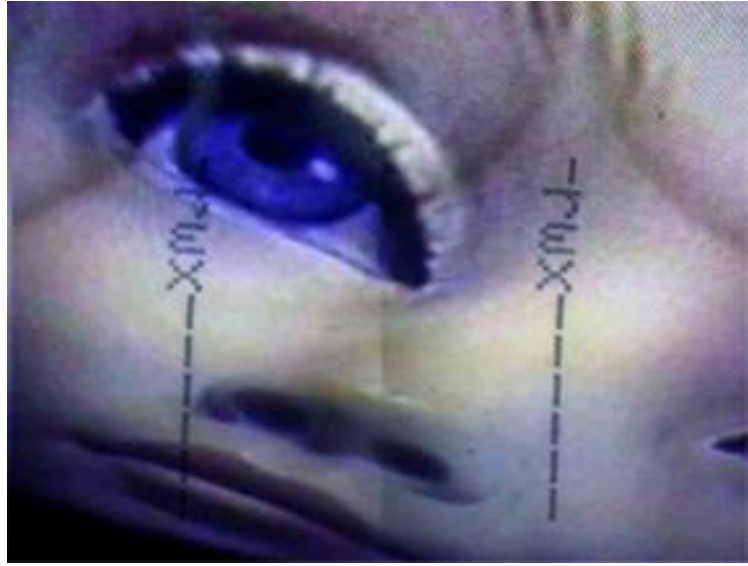

Figure 120 Artwork at Cyberfem by Diane Ludin, Francesca da Rimini, Agnese Trocchi: "ID_Runners". Available at https://ibiology.info/ursula/idrunner/index.html

\subsubsection{Cyberfem}

In 2006, the theoretician Ana Martinez-Collado edited and curated an international cyberfeminist exhibition Cyberfem: Feminismos en el escenario electronico. that served as a retrospective since the I International Cyberfeminist meeting in 1997. The exhibition was held in the Espai d'Art Contemporari de Castello (EACC), it worked as a node of encounter of national and international women artists and activists in new media arts such as subRosa and CAE, Victoria Vesna or Coco Fusco, happening for the first time in Spain. The artworks were accessible online in the platform created for this event for years. Through this curatorial project, Martinez-Collado aimed to gather the diverse feminist artistic practices developed through new technologies, considering the multiplicity of the notion of feminism(s) and therefore cyberfeminism(s). The exhibition insisted in 
this plurality of approaches and narratives through which women participation expends in the new technologies space. The main topics embraced identity, cross-relations between gender and new technological society and globalization and interculturality (Martinez-Collado, 2011, p.105). MartinezCollado retrieved two of the initial works by OBN group that in her opinion, are essential to understand the roots and keys of what feminism on the Net means, emphasizing its diversity within: the collective video Processing Cyberfeminisms and the 29 posters series Cyberfeminism Posters, exhibited in Hamburg 2001 Very Cyberfeminist International. (Martinez-Collado wanted to expose the main concepts of a feminism based on poststructuralism: nomadism, construction and deconstruction of identity, sexuality, hybridation, cyborg, together with concept of colonialism, environment, politics, migration, cybersecurity, etc. All these concepts were present through all the projects exhibited and on the virtual platform itself, in diverse formats from installation, biogenetics, video art, etc. Artists such as: Natalie Bookchin y Alexei Shulguin, Olia Lialina, Dora García; Red (Identity Runners, Lynn Hersmann, Victoria Vesna, Eva Wolhgemuth, Annie Abrahams, Margot Lovejoy, Cindy Gabriela Flores. Shu Lea Cheang, Linda Wallace. subRosa and Critical Art Ensemble, Jess Loseby; Julia Scher, Kristin Lucas, AnneMarie Schleiner \& Talice Lee; Elisabeth Smolarz, Evelin Stermiz OBN, Cornelia Sollfrank y Salomé Cuesta, Coco Fusco, Deb King, Marina Grzinic \& Aina Smid, Prema Murthy and Ana Navarrete (Martinez-Collado, 2011, pp.105-6).
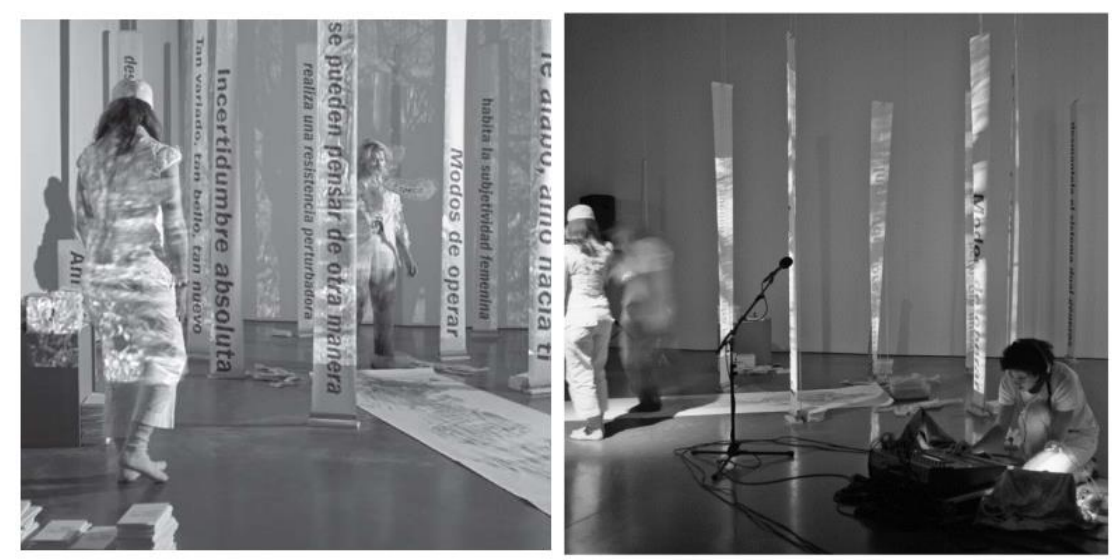

Figure 121 Images of subRosa performance at Ciberfem. 2006. Source: www.cyberfeminism.net 
From the artists that took part of Cyberfem, I would like to outline the contribution by Cornelia Sollfrank and Salome Cuesta, which proposals presented the 'core itself of the Internet', towards the establishment of networks, alliances, platforms for archival and informatic resources on practice and theory for women (Martinez-Collado, 2011, p.108). In this line, Ana Martinez-Collado would found a few years later ARES ${ }^{143}$, an online archive and platform on Spanish video art works, topics like identity, gender and feminism.

\subsubsection{Her Environment Series}

Allie Shyer and Chelsea Welch, two Chicago-based artists, founded in 2015 Her Environment Series, a project that works on creating an international space for people of color, non-binary, trans and women artists working in New Media. The project is focused on broadening the understanding between New Media practices and its multiple formats of art making, from performance to video and installation. Its objectives is to show art works that challenge the ways media can be used "in the maledominated culture that surrounds it" (Her Environment, 2018). Together with Iryne Roh, L Barnes and the punctual collaboration of Nina Berman in NYC, since 2015 they have been organizing in different art galleries in Chicago, and also in New York, bi-monthly digital expanded new media series that features the work of feminism spectrum artists, creating a synthesis between time based and objectbased media. They have organised until date exhibitions nine exhibitions with performances and live music in Chicago, and one in New York: They have also organised workshops in different cultural spaces in Chicago and New York for teaching coding and info graphics, animation skills, garment construction, etc., with guest artists as collaborators. The activities are charged underestimated donation and eventually fixed prices for live music sessions. With the money collected the team can raise the next events/exhibitions, in order to provide a fear financial support to artists. Her Environment promotes most of its work through their social network accounts in Instagram and Facebook, including calls for

\footnotetext{
${ }^{143}$ See <www.aresvisuals.net>
} 
collaboration, submissions of proposals for workshops and lectures, promotion of activities, networking, etc. Through their website the team provides an open submission form for artists and researchers. Through Instagram the members archive more informal moments. The curatorial practices carried by Her Environment in performances such as the last one Entanglements, relate us to the Fluxus happenings, when the shows provide a change to connect people in attendance with the artists, and the space transforms by the art and performance "so everyone is experiencing the same thing at once, it's something truly special” (Padmanabhan, 2019).

Other critiques claim that the series "is one of the most vital curatorial venues currently in Chicago", by doing two things: staging intervention in misogynistic art and culture institutions, and by presenting through provoking practices on the intersection of gender and aesthetics (Fidler, 2018). For instance, in regarding the exhibition Murmurs and Palpitations, Her Environment \#7, challenged the contemporary curatorial works about research, colonialism and globalism through new media such as performance, sound and video games.

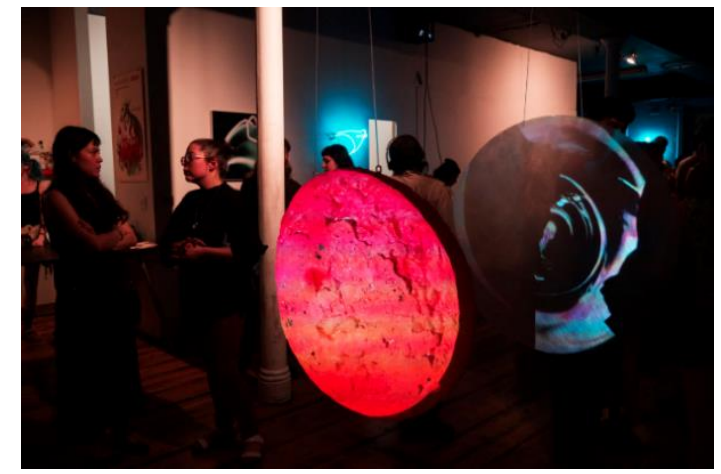

Figure 122 Iryne Roh, Body Lensing, view of the opening Dream Machines, 2016, TCC Gallery Chicago, Photo Credit: Carolina Poveda

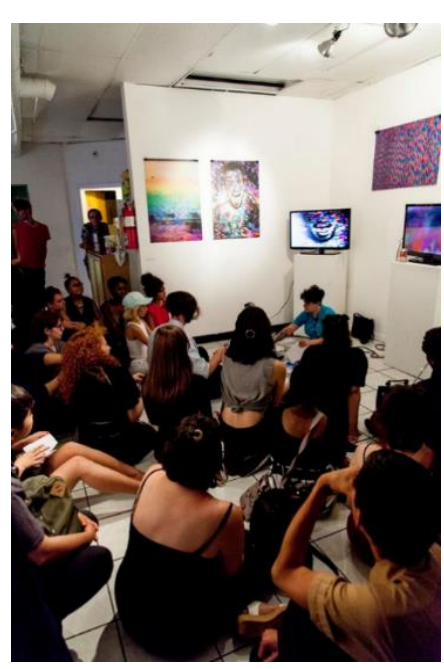

Figure 123 Comfort Film \&Her Environment: Homonyms, 2016, Comfort Station Logan Square. Photo credit: Cory Malnarick.

Her Environment Series calls "family" to whoever wants to support in any form the project. Subscription is open to request to updated of the next events and showcases via email. Her Environment 
has established a network in Chicago area through punctual activities in different spaces, whose work was based in the social and professional network of the founders. Through the social networks they reinforce the communication and their profile, but their live events are the main core of the series. Although I have located them within the curatorial projects, Her Environment is also a nomadic spacebased community.

\subsubsection{Technology is Not Neutral}

Technology is Not Neutral (TINN), was a touring exhibition that took place in London in 2016. The exhibition was held together with a symposium and a series of workshops. Technology is Not Neutral addressed the still contemporary issue of women underrepresentation in the digital and new media arts. To do so, the event aimed to celebrate the achievements of outstanding women artists that have contributed in the shaping of digital arts by presenting their work by themselves to the audience. The exhibition was curated by artists Gordana Novakovic, Anna Dimitriu and Irini Papadimitriou, and openly exhibited first at Phoenix Brighton Digital Festival (2nd - 25th September 2016) and then openly exhibited, at Watermans Gallery in London, from the $4^{\text {th }}$ November 2016 to the $8^{\text {th }}$ January 2017. International artists' works that were featured part of TINN were those of Ghislaine Boddington, Susan Collins, Laura Dekker, Anna Dumitriu, Bhavani Esapathi, Julie Freeman, Kate Genevieve, Sue Gollifer, Luciana Haill, Nina Kov, and Gordana Novakovic. Altogether presented a wide diversity of approaches and methodologies by different women artists, who leaded guided tours themselves explaining their work. The pieces exhibited had different formats: bio art, robotics, performance, data art, to digital print, kinectic art, telepresence, social media activism, drones choreography, etc. TINN is an example of a self-organised curatorial project in collaboration with institutional centers such as galleries, associations or academic departments. The exhibition was supported with public funding by Arts Council England, and with the partnership of The Computer Arts Society, UCL Department of Computer Science, Women Shift Digital, Watermans and Phoenix Brighton (Dumitriu et al., 2016). 


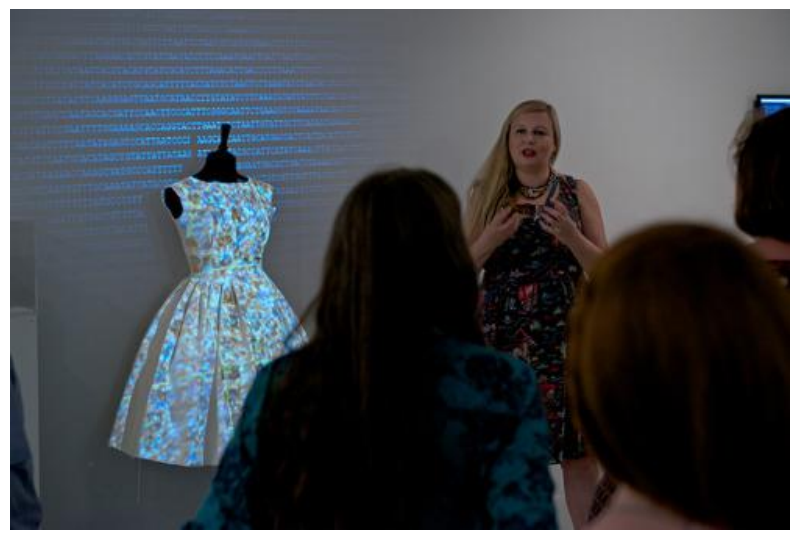

Figure 124 Anna Dumitriu on new genomic technologies explaining her artwork and introducing the technology to her hands-on workshop. Source: TINN 2016

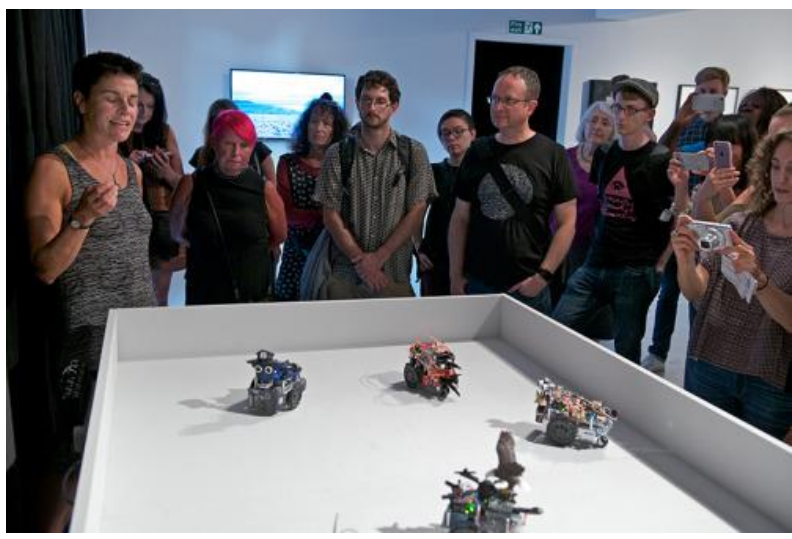

Figure 125 Laura Dekker presenting her work on robotics developed with Arduino. Source: TINN 2016

Every Saturday for one month one of the curators and an artists in the exhibition performed two free five-session workshops: Anna Dumitriu on DNI and genomic technologies and Kate Genevieve on Hacking Reality: Multi-sensory communication and immersive media. The symposium, under the same name, was celebrated on Saturday $3^{\text {rd }}$ December 2016, with presentations by some of the artists exhibited in addition to a series of female curators, artists and activists such as: Melanie Lenz, Patric Prince Curator of Digital Art, V\&A; Hannah Redler, Art Curator; Dr Josephine Berry, editor for the cultural politics magazine Mute; Dr Cornelia Sollfrank (by telematic conference), artist and Cyberfeminism Pioneer founder of $\mathrm{OBN}^{144}$.

\subsubsection{Making/Breaking The Binary: Women, Art and Technology 1968-1985}

During Autumn 2017 it was held in Philadelphia an exhibition, with a related illustrated publication and a series of screenings about the history of women in technology and new media art practices. The exhibition was originally a project conceived by the artist and curator Kelsey Halliday Johnson, who is the executive director of the multi-disciplinary and performing organisation $S P A C E^{145}$

\footnotetext{
${ }^{144}$ Described in section 3.3.4.

${ }^{145}$ See <www.space538.org>
} 
in Portland Maine. The project was granted by the programme Exhibitions and Public Interpretations of the Pew Center for Arts \& Heritage. In the legacy of the publication of Judy Malloy ${ }^{146}$ and the essays by Linda Nochlin's ${ }^{147}$, Johnson uncovers the hidden story of these women in the mainstream history of technology, to demonstrate the fallacy that "women artists are technological neophytes" (Johnson at Mir, 2017): "We need to constantly create spaces, opportunities, and critical dialogue around young female artists in our contemporary field" (Johnson, 2018). She applied an intersectional perspective in her curatorial work, retrieving figures of black women in NASA ${ }^{148}$ for example, an approach very well reclaimed by feminists in the last years. The core of the project was the exhibition, followed by screenings, concerts, performances and workshops. She curated the exhibitions and rest of the activities, but the overall project was run by collaboration with different cultural centers and spaces in the city like the collective Vox Populi Johson was member of.

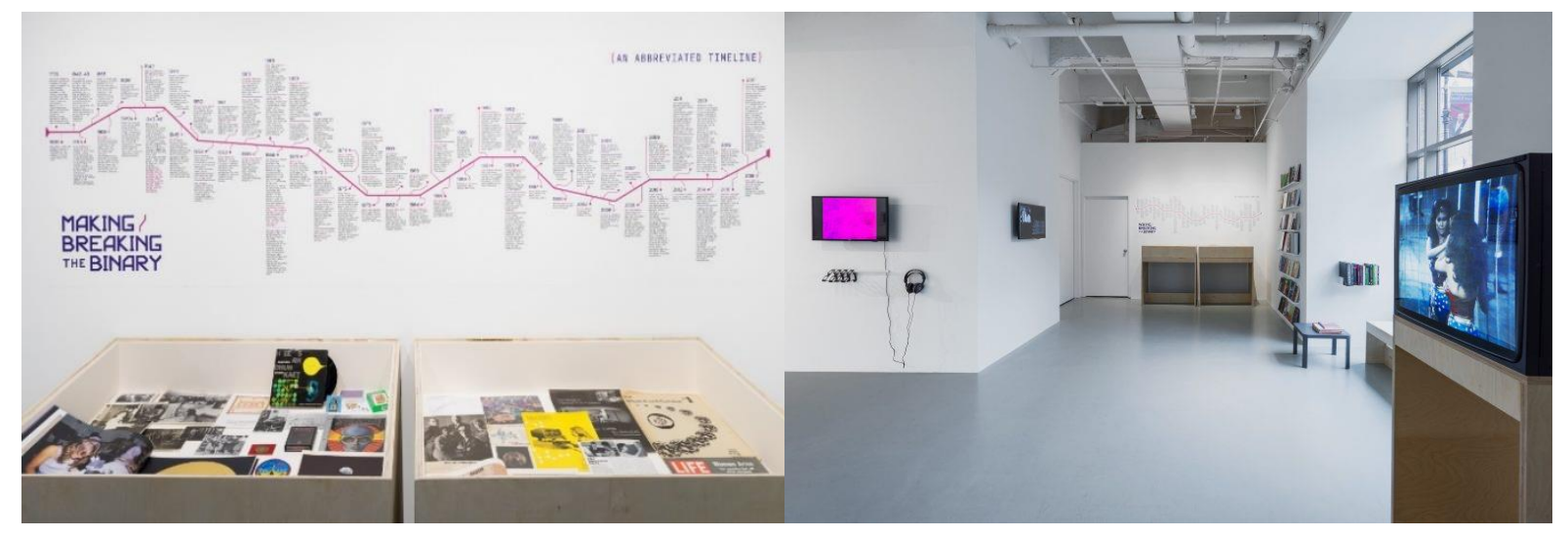

Figure 126 Making/Breaking the Binary: Women, Art, \& Technology, installation view

For the exhibition held from October to December 2017 at the Rosenwald-Wolf Gallery, Johnson compiled the work of fourteen international women artists and eight international women

\footnotetext{
${ }^{146}$ Reference to the book edited by Mallow: Women, Art and Technology, 2003

${ }^{147}$ Why Have There Been No Great Women Artists, 1971

${ }_{148}$ As part of the whole programme the film Hidden Figures based on the book by Margot Lee Shetterly about the black women who were the human computers of the NASA (National Aeronautics and Space Administration) during the Space Race, it took place at the beginning of 2017. The curator Kelsey Halliday Johnson made an introductory lecture relating the female figures of the Apollo
} 
composers whose works made them pioneers in electronic arts in the frame time of 1968 to 1985 . The exhibition is a long-overdue look at these innovators lives and works, both at individual and collective level, as they were members of a complicated and diverse community (Jia, 2017). Multimedia formats from interactive pieces, expansive, archives, audio stations, video art, installations and 2D prints and drawings. The exhibition gathered new media art works by visual artists such as Jennifer Bartlett and Lynda Benglis, and video and media art pioneers Sonia Landy Sheridan, Joan Jonas, Lynda Benglis, Shigeko Kubota, and Dara Birnbaum, computer artist Lillian Schwartz and filmmaker Lynn Hershman Lesson ${ }^{149}$. Artists: Beryl Korot, Jennifer Bartlett, Sonia Landy Sheridan, Lynn Hershman Leeson, Catherine Jansen, Pati Hill, Laurie Spiegel, Dara Birnbaum, Shigeko Kubota, Joan Jonas, Lynda Benglis, Mary Ross, Howardena Pindell, Lillian Schwartz. Composers: Laurie Spiegel, Éliane Radigue, Suzanne Ciani, Laurie Anderson, Pauline Oliveros, Wendy Carlos, Delia Derbishire, Annea Lockwood. Additionally, Johnson created a reading library that put in dialogue connection the visual exhibition with textual archive about women in technology, with the purpose to "further the scholarship of technology and art surveys in which women are underrepresented or not contextualized in the field of their peers" (Johnson, 2017). Female figures included: Ada Lovelace, NASA's "human computer;" Mary Allen Wilkes and Rebecca Allen. Besides the exhibition, there was a three-days programme of screenings at the International House Philadelphia hostel by The Lightbox Film Center was dedicated to the women sight through video art in 1970s and the impact it had in media art history. Three sessions of screenings with works such as short animation and experimental films by Lilian Schwartz, New Media and Chance, projecting avantgarde collations between female new media artists and the Merce Cunningham Dance Company, among others. Additionally, the collective Vox Populi organised a programme of screenings of video dance, with works by Laziza Videodance \& Lumia Project and Doris Chase. Video dance will be

149 These works relate us to the experimental times of early computer and video art I discussed in Chapter 2.4.2. 
shown as the experimental genre that emerged from film and video processing techniques in media recordings at the intersection of dance and the digital revolution at the 1970s. As special event, the acclaimed electronic musician Suzanne Ciani was invited to perform a concert in March 2017 and performed at the framework of the series MUSICA PRACTICA / ELETTRONICA VIVA and Ars Nova Workshop. Through the official website, the content of the activities has been archived, and through the section Blog, the profiles of female figures in STEAM $^{150}$ fields are periodically published, as well as in the Instagram account, as an attempt to create an archive that may serve as source of inspiration and information to the audience, specially girls.

\subsubsection{Vital Hybrids}

Between $15^{\text {th }}$ November to $15^{\text {th }}$ December 2017, on the other coast of United States, the B4BEL4B ${ }^{151}$ digital arts gallery at Oakland district in San Francisco dedicated a showcase of collaborative works by women and queer new media artists from Bay Area and LA, curated by the Hawaiian-American new media artist and curator Tiare Ribeaux ${ }^{152}$. The exhibition was possible through a private grant and brought together an interdisciplinary team of women and non-binary artists from backgrounds of performance, sound, programmeming, development, gaming, design, visual arts. The project was conceived by Tiare as collaborative project where women and queer artists would collaborate with people working with technology. The project grew in scope as more artists got involved and it ended up having two parts: the Performance Showcase which took place on $18^{\text {th }}$ November in the framework of Gray Area Art and Technology, and a month-long exhibition at B4BEL4B Gallery (Ribeaux \& Fleetwood, 2017). The works embraced topics of local and international relevance such as women's and transgender rights, visibility, safety, anti-xenophobia,

\footnotetext{
${ }^{150}$ Science, Technology, Engineering, Architecture/Arts and Mathematics (STEAM(

151 See <www.b4bel4b.com>

${ }^{152}$ See <http://www.tiareribeaux.com>
} 
processing trauma, etc. The pieces explored post-digital and post-gender identity, safety online and offline, anti-harassment, sousveillance, etc. through diverse formats such as video games, performances, VR experience, live motion tracking, data visualization, immersive installations, and more.

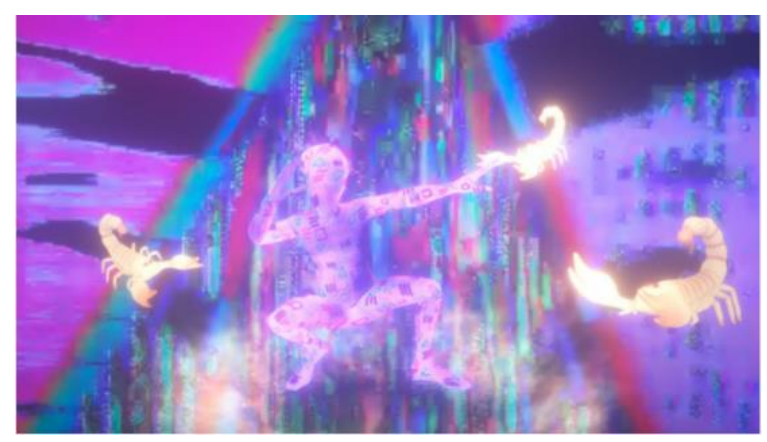

Figure 127 Jeep Jeep a video game art experience by Anna Luyisa Petrisko, Tonia B, Bela Messex, David Lyons. photo by Tonia B Artists that took part of Vital Hybrids include the collective HORs (Hackers of Resistance) ${ }^{153}$, Anna Luisa Petrisko, Atley Loughridge, Brittany Newell, Cali Rose, Frank Forner, Jaq H Dalziel, Jules Litman-Cleper, Kinetech Arts, Kim Ip, Laneya Billingsley, Lark V.C.R., Lauren Bedal, Micaela Tobin, Mirabelle Jones, Porpentine Heartscape, Pseuda (Nicholas Navarro), Rose Huey, Silk Worm, Stephanie Hewett, Tiffany Tonel, and Travis Bennett (B4BEL4B, 2017).

\subsubsection{Afrocyberéminismes}

Afrocyberfeminismes is a French research project that questions the contemporary positions towards digital arts in regarding Africa and its diasporas, the place of gender and race. The idea was conceived by the independent art curator Oulimata Gueye as a personal research project. The project consists in a collaborative organised digital platform, cyberfeminismes.org, and a cycle of artistic and cultural activities that was held at le Gaite Lyrique, in Paris along the last year 2018 (from $21^{\text {st }}$ February to $4^{\text {th }}$ July 2018). The project ins based and inspired on the publications of the Afro-American woman

\footnotetext{
${ }^{153}$ See point 3.4.3.7.
} 
science fiction author Octavia Estelle Butler (1947-2006) during the 1970s, one predecessor of the cyber(woman) or cyberfeminism. The cycle takes the legacy of these works towards an afrofuturism,

Le cycle Afrocyberféminismes s'inscrit dans le sillage de ses œuvres, notamment de son roman Le Motif qui traite du corps aux prises avec l'ingénierie biologique, de mutants aux pouvoirs psy, d'aliens, de vampires, d'esclavage mental. Mais aussi de la marginalité radicale, de l'éthique du pouvoir, du pouvoir du collectif, des rapports homme / femme, de l'empathie, du soin et de la résilience. On peut même voir dans le réseau qui va se constituer, une anticipation de l'Internet et de l'Intelligence artificielle (A Gueye, 2019).

The project was conceived and carried by Oulimat a Gueye (independent curator and art critique) together with Marie Lechner (artistic director of Gaite Lyrique programme) in coproduction with Xam Xam, African American Perspectives https://xamxam.org/. It is organised in collaboration with DICReAM, EnsadLab researchers and Partenaire Media Intense art Magazine. It counts on the collaboration on Mawena Yehouessi, Director arts and founder of the platform and collective of experiment (s) Black to the Future ${ }^{154}$.

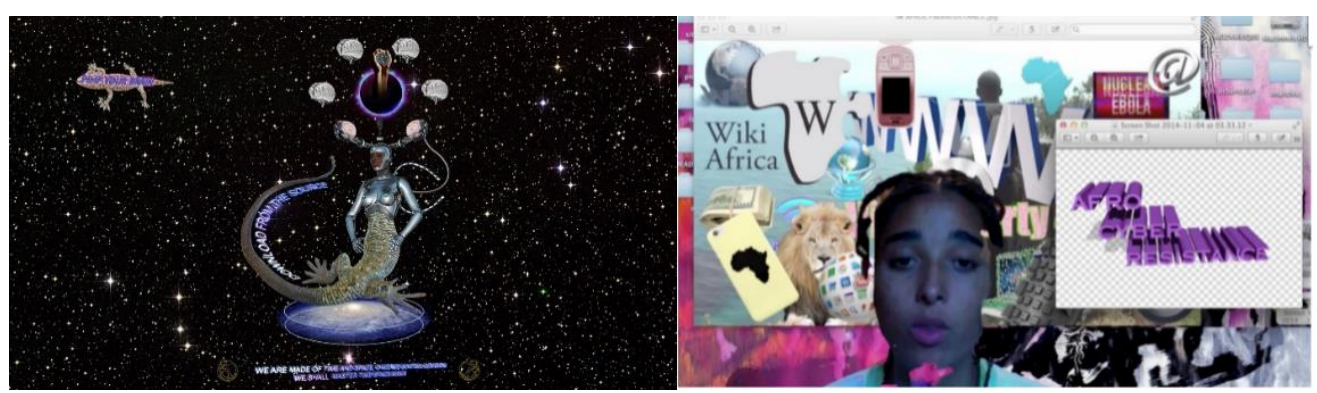

Figure 128 Visuel Inner Fire - Pimp my Brain de Tabita Rezaire (2016-2017)

The cycle of activities aims to tribute the black women pioneers of the Internet, as well as to act as an anchor in the present, echoing the commitment of the contemporary afrofeministes activities developers.

\footnotetext{
${ }^{154}$ See <www.blackstothefuture.com>
} 
Le cycle Afrocyberféminismes rend hommage aux pionnières noires d'Internet, aux développeuses qui traquent les biais du code, au Black feminism, au cyberféminisme, à l'Afrique, aux Afrodescendantes, aux Transgenres, aux Queers et à tous les cyborgs des marges (A Gueye, 2019).

For six months in La Gaite Lyrique, several conferences, talks, workshops and performances by francoafrican female artists and researchers were held. The platform works as an active project.

\subsubsection{Elas Fan Tech}

In 2013 in A Coruña, Galicia, from January to March took place an exhibition and programme of events dedicated to Women in Digital Arts organised and curated by the art historian Anxela Caramés, specialized in feminist curatorial practices in Spain. The exhibition named Elas Fan Tech (They [female] make tech in Galician language), is one of the few exhibition of women in new media arts together with the ones organised by Remedios Zafra and Ana Martinez-Collado abovementioned, but unlike those, the scope of Elas Fan Tech was not constringed by cyberfeminism, but the objective of the exhibition was to connect, promote and visualise works in which the femenine presence in the digital world is strongly affirmed (Caramés, 2016, p.439). Caramés organised the exhibition in addition to some artist residencies previously held, in the framework of the II Festival Miradas de Mujer, it was the only one contribution in the region. Elas Fan Tech emerged from the collaborative work with the Italian artist Francesca Mereu in the platform M-Artech, co-founded by both in 2012. Mereu and Caramés were speakers at Atenea roundtable on Women in Digital Arts in $2018^{155}$. The event gathered the work by twelve Spanish and other international women artists who explore in their work the possibilities of expression through new media formats: "Estas artistas se apropian de esa herramienta

\footnotetext{
${ }^{155}$ See point 4.3.5.2.
} 
que tradicionalmente ha sido considerada masculina, para abordar diferentes posicionamientos conceptuales y romper estereotipos" (Caramés, 2016, p.440).

Constelaciones de Mariana Carranza, Origin Story de Chris Sugrue, Visions Project and G011: Generación by Francesca Mereu , ¿Por qué estaría mal?, Naturaleza muerta by Yasmina Morán, Mutaciones del poder by Fátima Castaño, Red Ola de Inés Parcero, Little Boxes and Retrato de familia by Bego M. Santiago, Lilia Villafuerte from Warmikuna Yuyariniku. 2007, software art, Lilia Villafuerte, Anna Katarina Martin, Anaisa Franco with Frustration and Floating Land, Victoria Diehl with the series Vida y muerte de las estatuas, Nuria Cano Cuaderno de viaje and La mujer de Dallas (Caramés, 2016).

The exhibition was complemented by some video screenings, performances, workshops and talks in different points of the city, with the collaboration of the Universidad de A Coruña. Workshops of OPenFramworks, videomapping and free software, talks about Ada Lovelace and other female figures in science and technology history and the relation between feminism, women and technology in the contemporary Spanish society (Caramés, 2016, p.453).

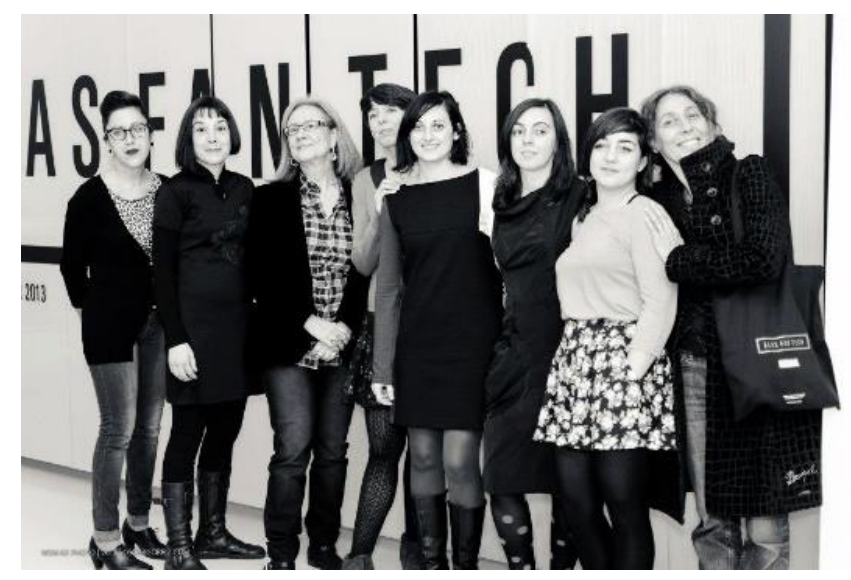

Figure 129 Elas Fan tech opening, 2013. Francesca Mereu and Angela, third and fourth starting from right side. Photo Credit: Oscar Gorriz 


\subsubsection{Online Exhibitions and Archives}

\subsubsection{The Worlds's Women on-line!}

In 1995, the artist Muriel Magenta established a networking project to be presented at the United Nations Fourth World Conference on Women in Beijing, China. As in Australia Melinda Rackham, Louise Manner, Ali Smith, Sandy Indlekofer organised WWWO ${ }^{156}$. Magenta aimed to use the Internet as a global exhibition format, focusing on the contribution by women artists as a vast resource of experience and culture. Since then, the increasing number of artists and projects made necessary a change of format. The project grew and developed into an online repository accessible online, that has reached to showcase imagery by thousand professional artists from sixty-four countries: "This site bridges language barriers through art imagery and promotes interdisciplinary collaboration between technologist and artists" (Magenta, 1995). The online platform provides a searchable list of artists by name, country and medium. Artists can request to join the world's women on-line. The impact that the platform had in the artists involved is appreciated by a gained recognition and opportunities through solo exhibitions, publications, catalogues, magazines and the establishment of other websites.
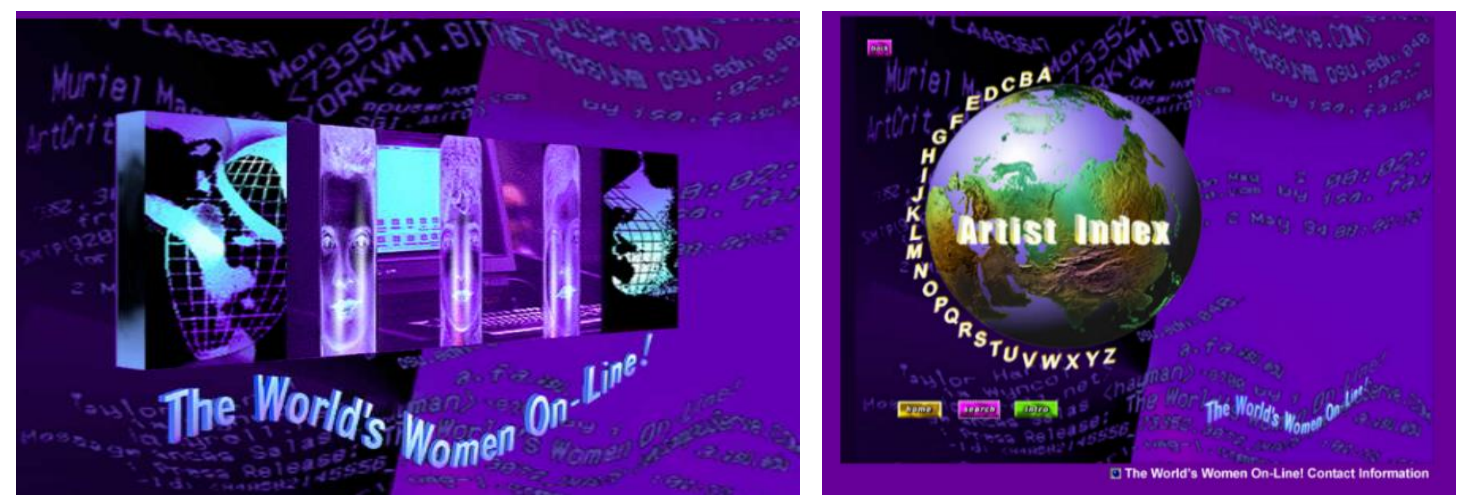

Figure 130 Screenshot of the main page (left) and search engine (right) of the website <http://wwol.inre.asu.edu/artists.html>

\footnotetext{
${ }^{156}$ Described in section 3.2.2.
} 
Muriel Magenta is professor at Arizona State University School of Arts, and she is undoubtedly one of the main nodes of the transnational network of women in new media arts that I have identified during developing my research. With this project and with Momentum ${ }^{157}$, Magenta has been creating since her early work projects with a strong social commitment for women, like 28 Women Documentary, about the history of the YWCA Haven House shelter in Phoenix. But more notably for my research, she has demonstrated that self-organised projects based on one's own network and collaboration can developed in successful results for women arts and technology. She and her work were very inspirational in the early and middle 1990s (Huffman, personal communication, $1^{\text {st }}$ July 2019). At this instance, the organizing team of The World's Women on-line! is formed by international artists and organisations from Western and Eastern Europe, North America and Middle East, This project was developed thanks to the information technology tools and servers of Arizona State University, Studies in the Arts, where Magenta teaches.

\subsubsection{2. electric-women}

In United States diversity in art spaces is still a challenge. A recent publication shows that $85 \%$ percent of artists in eighteen major museums are white, and $87 \%$ are male (Topaz et al, 2019). Women and People of Color (PoC) are frequently, referred as a targeted audience in the feminist art projects that follow an intersectional perspective, included those in new media arts as I have found along this present research. However, a young black girl in Pittsburgh who was coursing her fifth grade in the School of Arts in Carnegie Mellon University, found herself facing an enourmous lack of resources and references regarding women of color in the digital art world and online platforms, when she attempted to investigate about other women of color artists working in similar topics like she was

\footnotetext{
${ }^{157}$ See chapter 3.4.6.7.
} 
doing, social-media-based work through new technologies: "I would always find the same list of same five artists, and I found mysef running into this problem, where there was a unified voice for people of color at this intersection online?" (Valley, personal communication, 2019). In 2017, Lareun Valley unofficially launched her project, that was part of her academic work at CMU, where she felt motivated by the diversity of students she found when she joined the campus, compared to her previous experience before in the city (Valley in Addison, 2018). She named the project electric-women and it is focused on building a platform for female and non-binary artists at the intersection of art, science, technology and social practice (Electric Women, 2019). I had the pleasure to have a virtual interview with her to get to know more about electric-women. It was officially launched in May 2018, and it will keep including addittional artists and projects in the future. Valley passed from being an artist to be a curator, as she built the first online exhibition and repository of digital arts works by women of colour, desgined, managed and developed on herself, with the support of her supervisors at CMU (Valley, personal communication, 2019).

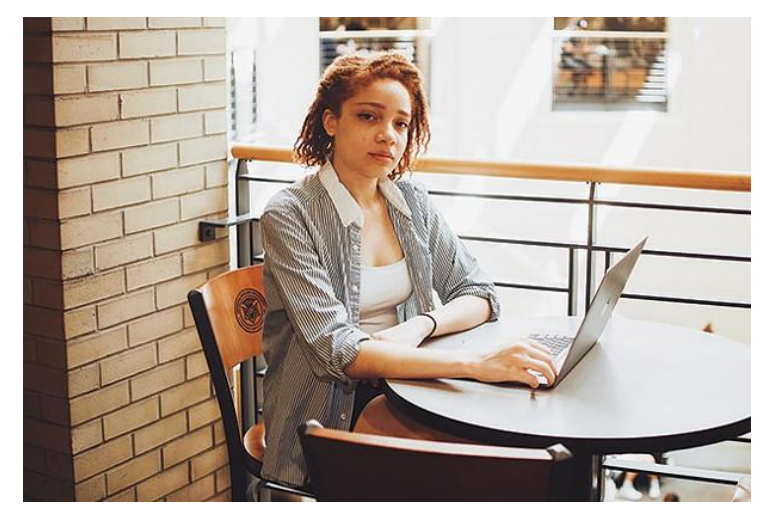

Figure 131 Lauren Valley CP Photo by Sarah Huny Young

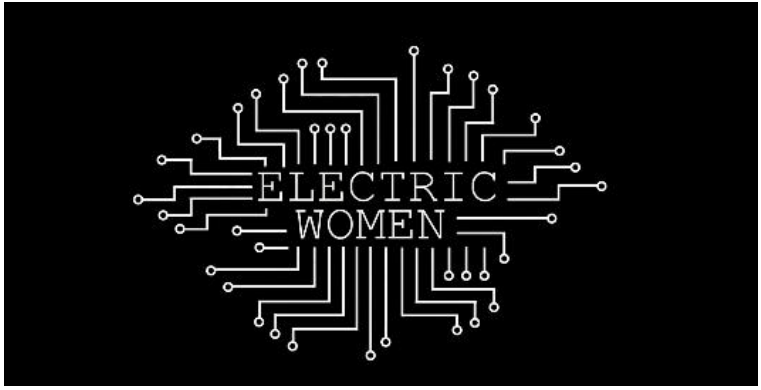

Figure 132 screenshot website wwww.electric-women.com

In order to locate the artists at an international level, Valley started contacting artists of color that she already knew and her two project supervisor helped her in the first steps of the investigation, with some positive and negative responses on the way, the project kept on growing until reaching thirty artists today: "I started with my own network with the artists that I already knew and then I asked for 
different artists recommendations, catalogues, different groups, etc." (Valley, personal communication, 2019). The reaction by artists has been very postitive, when each of them got to know about her project ended up saying that having such a resource to find other women like them is extremely helpful (Valley, personal communication, 2019). Also, at CMU, she felt surrounded by techy environment, what encouraged her as an artist to implement technology in her work. By 2017, when Electric Women started, Computer Science department achieved a historical number in US since the 1960s, 50\% of female students. In such an environment, Valley noticed the importance of the use technology not only as a creative tool but as a way to go beyond boundaries towards diversity and accessibility of knowledge:

With my own tech background, I took a few art technology classes [at CMU] but, just what I learnt now are free online courses what I did learnt a lot from CMU... I see the internet reducing the needs for the institutions, I was really interested in how to work with that, not only centered academic college resources, but finding the way to communicate with many different people regardless economic background, definitely seen that entry barriers with entering colleges. I want to find a way to work with that system but also work around it, so we increase the accessibility of people accessing these resources. (Valley, personal communication 2019).

Valley established by her own the first roots of a network of women and people of color in digital and new media arts, by building a virtual platform and reaching out as many artists as she was founding on her way. Her academic multicultural and technological environment motivated her, and a feminist intersectional perspective based on her own experience. Electric-women is not described as feminist in the first instance, but Valley considers its position feminist and intersectional.: "I am interested in featuring women and non-binary individuals and definitely I wanna make this community as inclusive as I possible can, so definitely no creating barriers at all, I try to make it very intersectional" (Valley, 
personal communication, 2019). Within a feminist scope, Valley found inspiration in the FEMMEBIT ${ }^{158}$ Festival in Los Angeles: "FEMMEBIT is more focused in this personal exhibition, a solid online space, really acted as this free information scene, it was an inspiration for what they were doing and I wanted to make this information source" (Valley, personal communication, 2019).

Artists of color interested in gaining some visibility or taking part of the platform can submit their work through the electric-women website. Artists included at the moment: Alisha B. Wormsley, Allison Maria Rodriguez, Anna Luisa Petrisko, Bonnie Jones, Emilia Yang, Gaby Cepeda, Hackers of Resistance, Hiba Ali, Hyphen-Labs, Ingrid Zhuang, Jennifer Chan, Joanna Cheung, Joy Poulard Cruz, Julieta Gil, Laleh Mehran, Lauren McCarthy, Legacy Russell, Lisa Park, Mary Maggic, Morehshin Allahyari, Nicole Maloof, Peiqi Su, Sarah Groff Hennigh-Palermo, Sixing Xu, Tale of Tales, Tamiko Thiel, Tonia Beglari, Wednesday Kim, Yo-Yo Lin and Yuehao Jiang. The project keeps on growing and expanding, as Valley herself states: "I am at this current point when in the future I can see this existing in a physical galley space or happening in an exhibition rounded this online community. I have already applied for different founding programmes...” (Valley, personal communication, 2019). Currently, Valley also plans to create a printed book version of Electric Women.

\subsubsection{Feminist tECnOart}

The ecofeminist organisation WEAD ${ }^{159}$ (Women Eco Artists Dialog) based in Oakland, California has been supporting women eco-artists, educators and wirers through networking, exhibitions and programmeming since its foundation in 1996. Last year, the organisation aimed to expand their network to women identified artists who works through technological formats on social injustice and environment topics. For these purposes, they have reached two artists Isabella La Rocca and Pilar Praba and the creative entrepreneur Danielle Siembieda, to collaboratively edit and curate an

\footnotetext{
158 See chapter 3.4.5.4

${ }^{159}$ See <https://weadartists.org>
} 
online exhibition named *feminist tECnOart*. The exhibition launched by the end of December 2018, and on the lineage of the same topic, *WEAD Magazine will publish in September 2019 the $10^{\text {th }}$ Issue, edited by Pilar Praba. The exhibition gathers seven artists whose practices are diverse: Kite (aka Suzanne Kite), Elizabeth Demaray, Lynn Mowson, Suzanne Anker, micha cardenas, Dornith Doherty and Maria Paz Gutierrez. It also holds the inspiring and innovative works of three female artists such as Skawennati, Natalie Jeremijenko and Breatiz da Costa. (Praba, personal communication, December 2018), to celebrate the under recognised contribution of women to history of technology (WEAD, 2018). This exhibition is one of the examples that illustrates the current increasing concern and awareness by feminist artists and activists in arts. On the official website we read the curatorial statement that faces the urgency of publications such as the 2018 Special Report of the United Nations Intergovernmental Panel on Climate Change, taking academic references such as Derek Rassmusen: "The illusion that pieces of earth's surface cold be owned by individual members of one species" (Qallunology: A Pedagogy for the Oppressor, 2001) and bioartist Natalie Jeremijenjo to underline the concerns raised by the artists in the exhibition. The artworks selected challenges stereotypes regarding truth, gender, race, ethnicity, sexuality, migration and technology from a critical perspective on sustainability and climate change awareness, whatever the economic system is, "we need to renewed approaches to accountability, reciprocity and sharing around the human, animal, culture, natural, tradition and technology" (Praba et al, 2018).

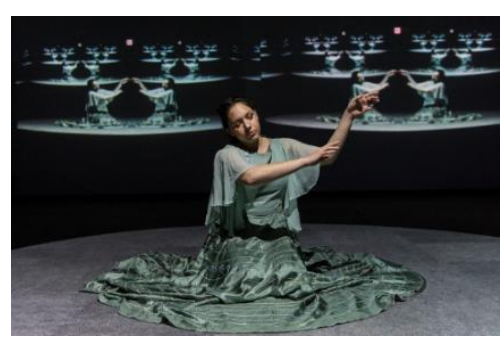

Figure 133 Kite, aka Suzanne Kite, is an Oglala Lakota artist who works with computational media, audio, and performance. 2017 work Everything I Say Is True

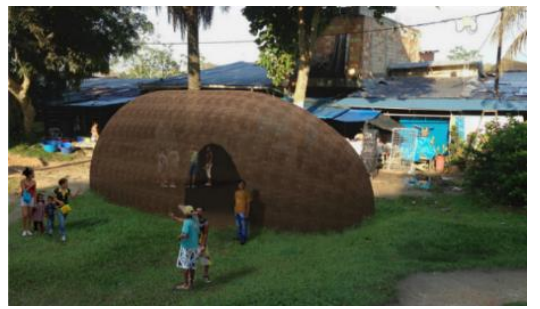

Figure 134 Maria Paz Gutierrez, Reclaiming Plant-Waste. Chilean artists that brings cultural aesthetic and resilient design together.

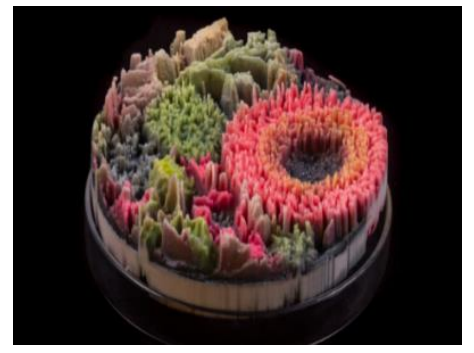

Figure 135 Suzanne Anker, bioartist combines new technologies and science with contemporary art, concerning bio-terrorism. 


\subsubsection{Festivals, Conferences, Symposiums and Encounters}

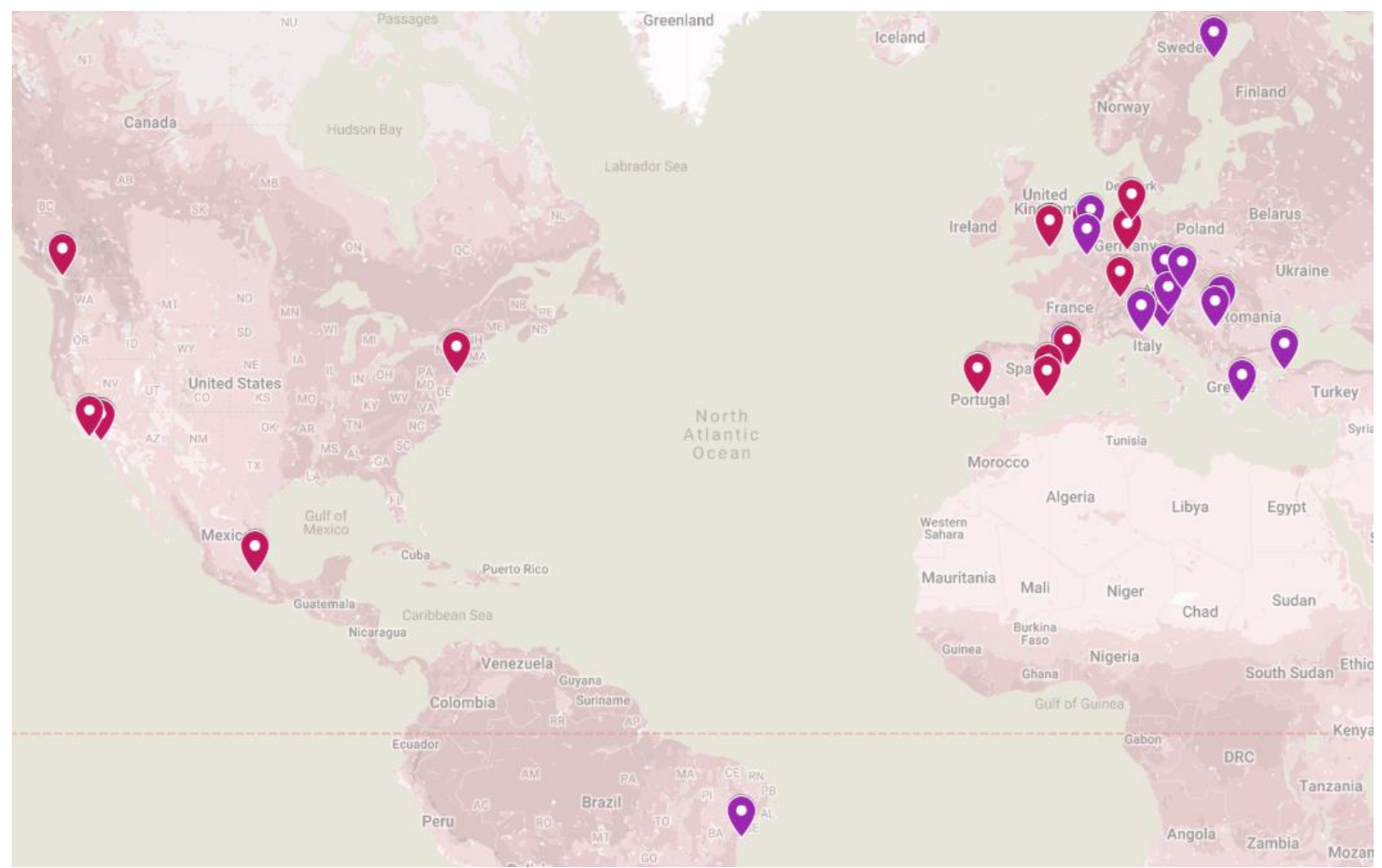

Figure 136 All-Women Self-organised Festivals, Conferences, Symposiums and Encounters at the intersection of Arts and Technology since 1991 (purple Eclectic Tech Carnival editions, in 3.4.5.1.). Screenshot taken 18th July 2019

\subsubsection{Eclectic Tech Carnival (/ETC)}

"I want freedom, the right to self-expression, everybody's right to beautiful, radiant things"

Emma Goldman

Eclectic Tech Carnival (/ETC) is a translocal and transnational gathering of feminist, artists, technologists and activists with a radical position towards technology and culture. /ETC emerged from Gender Changers Academy (3.4.2.2.) workshops and became a project on its own. Its network has spread around Europe and beyond, it increases and evolves along with the interest and participation. /ETC seeks forms to face domination, patriarchy, capitalism and neoliberalism through technology and 
art. It is a collaborative, open and nonhierarchical event collectively organised by an informal network of women artists, computer engineers, technologist and activist. IT is addressed to women and female identified, transgender and queer folks, interested in skills sharing and amplify one another's voices (ETC, 2018). The format of the workshops and activities can be taken and applied anywhere, always keeping the basis of a strong commitment to promote opensource software, open hardware and free speech by creating a space for debate, learning, critique and joy (/ETC, website), carefully avoiding festivalization, "a hierarchical situation of invited and paid presenters and paying "consumers", so that the original intention of skill sharing and learning together is not lost” (Derieg, 2007).

It is an on-road event, an example of a translocal/ transnational, informal, DIY-DIWO, creative network, that has been built collaboratively by different members in different locations in different periods, self-organised and self-funded, working in based-space events. Between events its network remains connected and organizes virtually, with a weekly meeting on IRC at 20.00 every Monday. It was collaborated with Mz*Baltazar's Lab, CIPke, Donestech, Calafou, etc. And in every specific /ETC there is a combination of alliances and collaboration between individuals and centers to make the events possible. The list of /ETC until date is the following: 2002 in Pula, Croatia, 2003 in Athens, Greece, 2004 in Belgrade, Serbia, 2005 in Graz, Austria, 2006 in Timisoara, Romania, 2007 in Salvador, Brazil, 2007 in Linz, Austria, 2008 in Amsterdam, The Netherlands, 2009 in Umeå, Sweden, 2009 in Istanbul, Turkey, 2010 in Brussels, Belgium, 2011 na pravi me Festival, Beograd, Serbia (organised together with Mz*Baltazar's Lab), 2012 Make me Eclectic Festival, Vienna, Austria, 2012 in Ljubljana, Slovenia (organised together with CIPke), 2014 TransHACKfeminist! camp (THF!) 4-11 August in Calafou, Catalonia, Spain (together with Donestech);2018, Bologna, 8-13 ${ }^{\text {th }}$ October (/ETC, website) and Athens in October 2019. The organizers belong to different generations, some of them over their 60s, the spirit of /ETC has influenced other artists that started their project on their own, such as Mz*Baltazar laboratory in Vienna (Wuschitz in Beaudoin, 2016). 


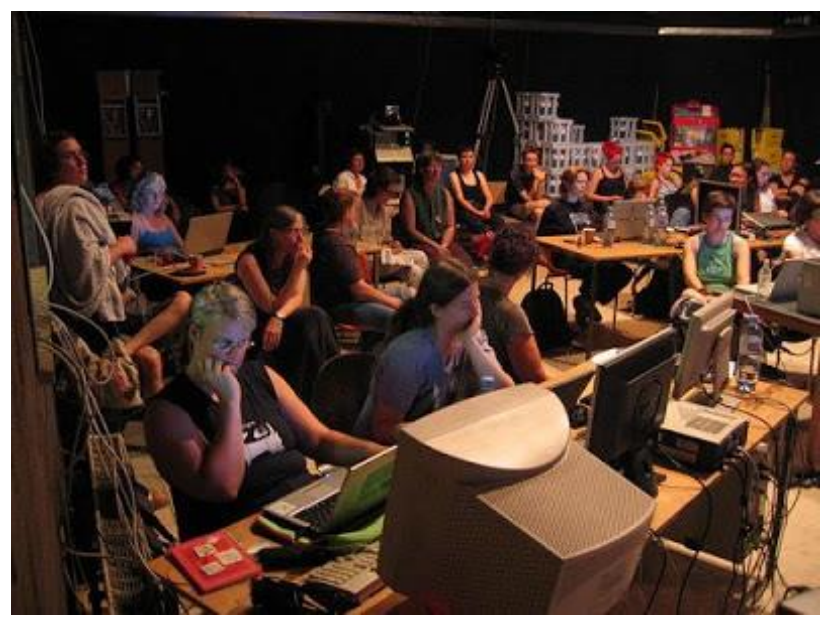

Figure 137 ETC 2007 in Linz

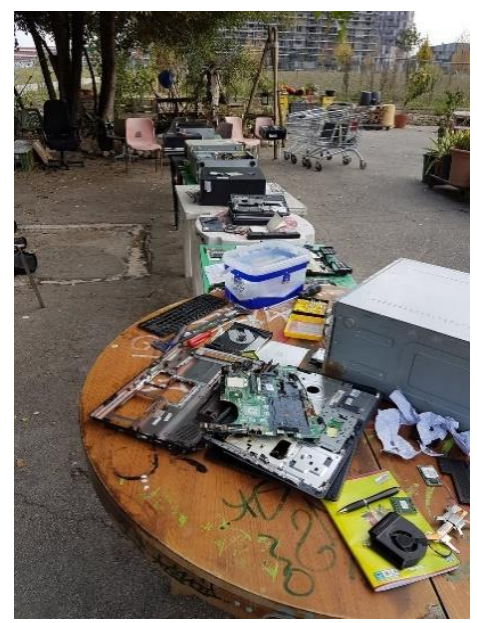

Figure 138Material for workshop Things can break, ETC 2018. Bologna

Within all the creative networks of women in art and technology, /ETC is probably the most radical and collaborative. Furthermore, /ETC members such as Ushi Reiter (Faces) and Reni Hofmüller have created a satellite of /ETC who are more interested in a social resistance by addressing liberation of technologies and breaking social constructions such as gender -the most persuasive technology ever created-,: The TransHackFeminist!, a hacker transfeminist intersectional encounter which has only been held once until today, in 2014 in Calafou, Catalonia, and gathered around one hundred people. They work on gynepunk practices and feminist servers building (THF!2014). They have also redacted a Transfeminist manifesto ${ }^{160}$.

Similarly, as with Faces mailing list, the openness of the network based on the participation of a wide range of women creates controversy that helps the project to grow:

The diversity of backgrounds and languages spoken with varying degrees of proficiency among the Gender Changers from the beginning and then among all the different /etc women has always been a source of potential conflicts and misunderstandings, but also one of the group's

\footnotetext{
${ }^{160}$ Available at https://bit.ly/2X3vJBU
} 
greatest strengths. Contact, discussions and mutual support and encouragement are maintained in between carnivals through several mailing lists, web sites and IRC (Derieg, 2007).

\subsubsection{Enre/Dades}

In spring 2006, the researcher and curator Maria Ptqk (María Pérez-Hernández) organised a cyberfeminist encounter in Spai Jove Boca Nord in Barcelona on new Information Society from a gender and feminist perspective. The same month, for the women's day motive, the first edition of Fem.Elek was held in the city ${ }^{161}$. By that time, Maria Ptqk was part of the feminist Catalan free radio Radio Paca (who was in the initial network of Donestech collective), where they were already reflecting upon gender and technology issues and felt the necessity to create an event in collaboration with other collectives to address this topic (Pérez-Hernández, personal communication, 2019) The encounter gathered members of the main cyberfeminist networks and theoreticians such as Cornelia Sollfrank from Old Boys Network, Valie Djordjevic from Faces mailing list and the most acclaimed theoretician in cyberfeminism in Spanish language, Remedios Zafra, who had recently published Netianas: to be born woman in the Internet era. The guest speakers exemplified the types of alliance between women with technology, that cyberfeminism promotes and encourages since its roots, all of them presented their creative network and latest work. There were also presentations about sexuality, representation and video games by Flavio Escribano. Maria Ptqk built a call for cyberfeminists after ten years of the Internet boom, though it she brought together international feminist new media artists and theoreticians, experts and founders in networked culture in the cyberspace. She created a three days space for dialogue, debate and exchange between local audience and professionals with

\footnotetext{
${ }^{161}$ See point 3.4.5.3.
} 
international artists and activists. There were offered free and open panels, debates, workshops, screenings and DJ sessions, with a space for kids (Pérez-Hernández, 2006).
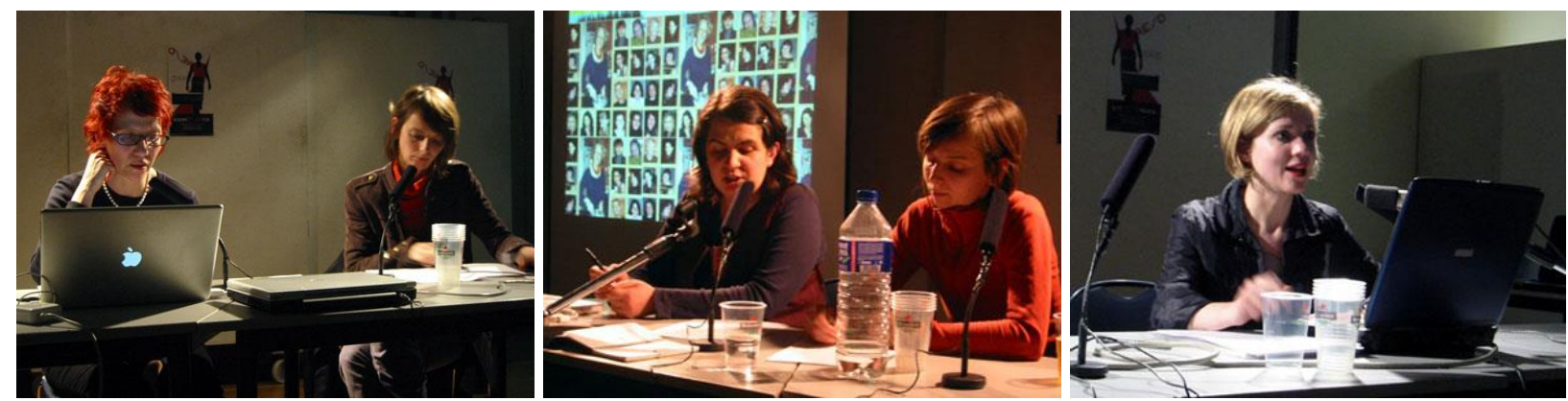

Figure 139 Speakers left to right: Cornelia Solfrank, Valje, Remedios Zafra. Photo Courtesy: Maria Pérez-Hernández

The objective of the encounter activities was to make technology closer to women combining technique and theory formats. Through the workshops, techniques and concepts in regarding to cybersecurity, live coding, audiovisual edition, free software, activism and networks, publications on the Net, identity and representation-cyborg, female empowerment through information technology and sound composition for radio and networked communication with Radioswap and the feminist free radio Radio Paca. Dj sessions by Vj Normal c-alas, Dj Novias a la fuga and Ladyfest Spain. The three days reinforced the node on the network that connects Barcelona and Spain cyberfeminist scene with the international nodes. The event was finished with an open discussion by all the guest speakers about the experiences. Maria Ptqk organised in 2009 and 2010 in the Pais Vasco a cultural programme of activities named Softpower ${ }^{162}$ on biotechnology where cybefeminist collectives such as subRosa and feminist theoreticians such as Beatriz Preaciado took part (Pérez-Hernández, 2014)

\subsubsection{Fem.Elek}

During five years in Catalunya took place a Festival dedicated to women, arts and technology originally edited and curated by the artist and cultural activist Marise Cardoso, in collaboration with

\footnotetext{
${ }^{162}$ See <http://www.mariaptqk.net/soft-power>
} 
the Convent de Sant Agustí cultural center and other artists. In 2006 Cardoso had been producing for a few years her previous festival PULGAS MIX, dedicated to new tendencies, fashion, music and cinema. PULGAS Mix was held in Centre Civic Convent de Sant Agusti ${ }^{163}$ in Barcelona, a center that focuses its programme in artistic and cultural activities and new technologies, which proposed her to organize an event for the women's day for 2007. Cardoso came up with the idea of building a mini festival dedicated to women, new technologies and electronic arts, due to the interest of the center in those formats and her background in the field. To promote their visibility, the first edition gathered local women artists and activists, Cardoso had already established a local network of professional and artistic contacts from which she could design the programme of performances, $\mathrm{Dj}$ producers, audiovisuals, installations, etc. Despite the low budget and being Cardoso by herself in the curatorial side, the results of the first edition were successful. That brought the project to the next editions, where Cardoso invited other artists to join: Alba G. Corral would join her for the organisation of the visual arts side and Beth Pibernat (Vinelette) for the communication side. The collective Donestech would collaborate in different editions. During all the editions, the festival was not conceived and presented as feminist, although the members were involved in feminist issues, but it was specifically dedicated to promoting women in electronic arts, and open to all genders as public (Cardoso, personal communication, 2019).

The festival kept on growing by the own organizers' contacts and networks, bringing together international artists and collaborators. The artistic formats embraced from music, visuals to video dance, installations, robotics and interdisciplinary performative practices. For example, LesFatales Catalan feminist $\mathrm{Dj}$ collective was part of the festival in different editions. The activities by fem.elek went beyond the festival boundaries and they also organised some external activities, like the itinerant actions in NIU (Espai Artistic Contemporari) in Barcelona, a series of small formats of the festival

\footnotetext{
${ }^{163}$ See <www.conventagusti.com>
} 
through performances, live music, audiovisuals, and some sessions in La Bascula, for example. The collective Donestech would take part of the activities collaborating actively, organizing sessions about women, feminism and TIC. They also counted on the collaboration of other international collectives from their own network, who helped with the graphic designs, and organizing collaborative actions in the events. During our interview, I was interested to know if they were inspired by other all-women and feminist projects, like female:pressure:

We were in touch, actually, but it was after the first edition of fem.elek, when I was in Berlin for female:pressure festival in 2009. That was more club nightlife oriented, and ours was a festival based on performances, of course, with final apotheotic moments in the dancefloor, but we had more experimental moments, we were not club style (Cardoso, personal communication, 2019).

Looking at the programme, still available on the Net, and some videos on YouTube of the performances and concerts, the question about "why did it finish?" comes to own's mind. Cardoso explains that although fem.elek received some public funding in some editions and the Center provided all the infrastructures and technical support, the festival kept on growing in such a manner that the voluntary work was not enough, and it was just over expanding the limits of time and dedication from the members, who were not payed as all the budget was going for production and to pay a very humble fee to the artists (Cardoso, personal communication, 2019).

Fem.elek provided a creative space for encounter for women artists from different fields involved in new digital technologies, artists who were just starting found a platform of support. It was a gathering together of local people and people from different countries and all genders, that were interested in the work by women in electronic arts. It was fundamentally based on collaboration and cooperation, and for five years and five editions the Festival provided a social and artistic contribution 
that was notably outstanding, working as a new node of connection and support for women in electronic arts.

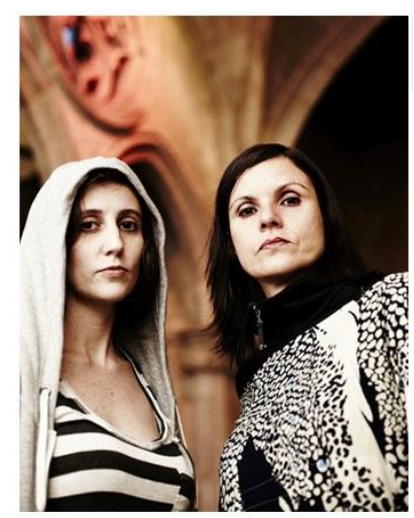

Figure 140 Beth Pibernat and Marise Cardoso, 2011, photo by Eduardo Miera

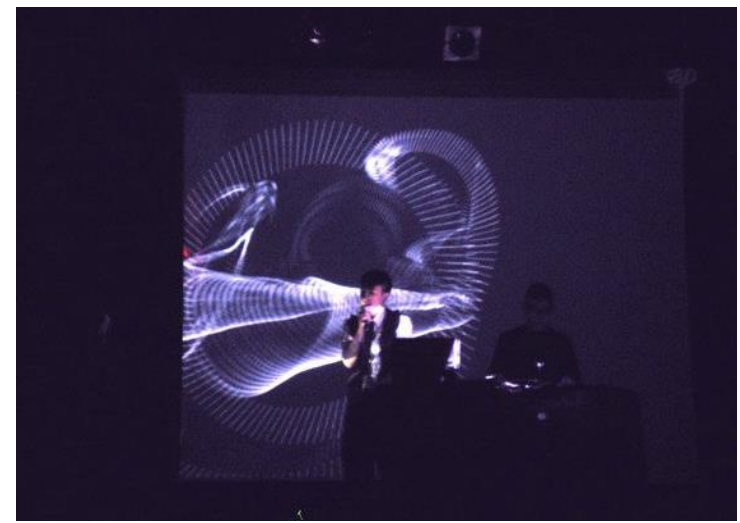

Figure 141 STENDHAL SYNDROME + ALBA G. CORRAL (visuales) @ Les Basses 2010

Marise Cardoso also founded in 2011189 MHz Creative Frequency ${ }^{164}$, an independent platform and business tool but nowadays she lives and works in Arab Emirates, and Alba G. Corral and Beth Pibernat continue their professional work as artists. Fem Elek was the precursor of other allwomen encounters such as Dia de la Mujer a Les Basses in Barcelona in 2009; Gendertek Festival ${ }^{165}$ in 2010 and FemArt Revoltes in Barcelona in 2011 (López Castilla, 2015, p.253)

\subsubsection{4. $X 0 y 1$}

In 2009 Remedios Zafra founded $X O y 1^{166}$, a platform for the research and creative practice on identity and network culture, which title was inspired on the publication by Sadie Plant, Zeros+Ones (1997). The project has been founded by public grants that had allowed Zafra to create virtual network and a series of live events for women artists and activists, an encounter in 2009 and a seminar in 2014, both in Centro Andaluz de Arte Contemporaneo in Sevilla (Zafra, 2014). Within the platform of x0y1,

\footnotetext{
${ }^{164}$ Available at <www.nsista.net/189mhz>

${ }^{165}$ See table 1 at point 3.4.1.2.

${ }^{166}$ Available at <www.x0y1.net>
} 
users can find the statements as a form of manifesto about what XOyl is (not), which remind us to the cyberfeminist manifesto 100 anti-theses $^{167}$, but unlike that, X0y1 states what they are looking for, in their virtual collaborators. The project is therefore addressed to anyone that addresses with a critical attitude the systems of domination that are hidden on the Internet, which impose subjectivities and symbolic identities. Inspired on Haraway, X0y1 was looking for political proposals towards a use of technology as a political tool towards resistance and an approach to humanity. Zafra states that the art and feminism can help us to re propriate the virtual space, to identify the elements of power (in a foucauldian sense) that creates new forms of domestication in users (Zafra, 2009).

The platform gathers a section called Proyectos XOY1 where theoretical and creative projects on identity and networked culture that were presented to the call for the Encounter and the Seminar are archived. The publications and texts since 2009 are also archived here, creating an online repository of cyberfeminist content. In addition, the web provides a contact email for users to send their proposals and be part of the repository, sending their contributions on identity, networked culture, towards promoting artistic and social projects. The platform provides a list of links to other feminist projects on cyberfeminism and related, working as a node of virtual connections to other initiatives.

For the encounter in 2009 and the seminar in 2014, a section called Banco de Ideas was open, in order to gather proposals by users and future attendants of the event, enabling a collective storm of ideas that brought together a combination of social and artistic proposals towards making "the Net into something different and better that what we have already in the off-line world, and that is related with gender and the Internet" (Zafra, 2009)

${ }^{167}$ See chapter 3.3.1. 

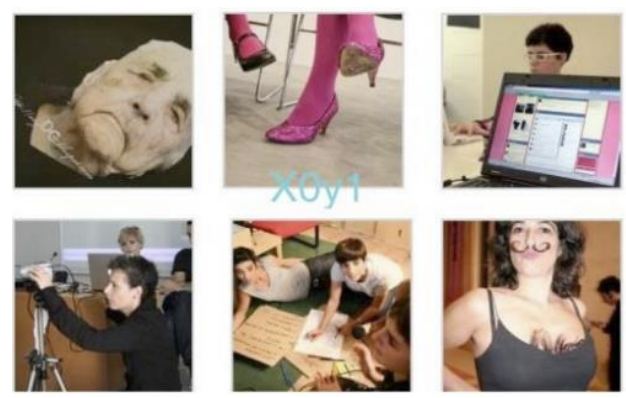

Figure 142 Compilation of images of XOY1 activities, retrieved from www.xOy1.net/proyectos

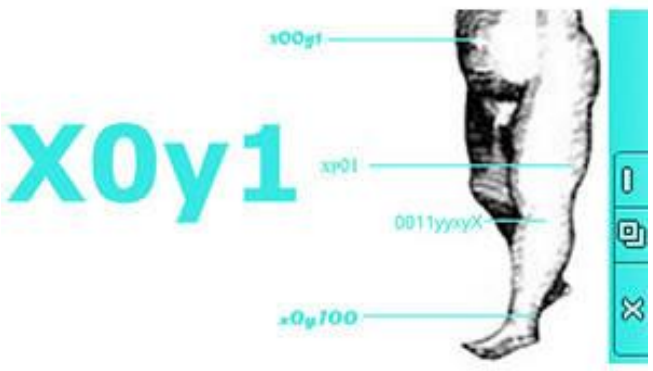

Figure 143 Logo X0y1

Encuentro x0y1, 26-30 octubre 2009, Centro Andaluz de arte contemporáneo, was a four days meetup where female students, artists, activists, cyberfeminists and theoreticians such as Montserrat Boix and Alex Hache, Eva Cruells and Nuria Verges from Donestech, for instance, gathered together for the first time. The content of the event was based in a previous call for contributions and artistic proposals, in order to build up a programme based on practices about gender and the Internet from critical socio-political perspectives that reflect upon the social construction of sexual difference and network society in cyberspace.

The International Seminar x0y1 Art and Digital Industries: from a gender and cyberspace perspective held in 2014, also in the Sevillian art center, was organised by Zafra together with her research group Gender, Art and Cyberspace. The event gathered for the second time women cyberfeminists, artists, activists, researchers from different parts of Spain, in a programme of formed by keynotes, roundtables, talks, performances and workshops, like the one made by the Catalan collective Donestech, who also presented the documentary about their project Lela. All the contributions are digitally archived on the platform, as the results of the collective section Banco de ideas. During these two editions and while the platform was being formed, Zafra netted a national network that brought together women from different generations to discuss and reflect upon the 
influence of cyberspace in society from a gender perspective. The events collected a series of art and activist proposals with strong political content developed individually and collectively.

Zafra is arguably the most influential author in Spanish about cyberfeminism, gender and cyberspace, committed to a political approach towards new technologies from a gender perspective, pointing out precarity issues for women on clerical tech jobs and cyber harassment, between others more philosophical like the construction of the self, identities, etc. In 2010 she published Un cuarto propio conectado (A room of one's own connected), where alluding to Virginia Wolf's essay that take us to all the legacy of all-women art spaces, Zafra connects the claim of an own space of creating with the virtual space for the creation of the self while being connected to the cyberspace. She also published Nettianas: to be born women in the Internet (2005) and (h)adas (2016), were she continues the legacy of Plant by relating female labors inspired on the figure of Ada Lovelace and the relation between women and with ICTs and the clerical labors.

\subsubsection{FEMMEBIT}

In the city of the Woma's Building, forty-three years later FEMMEBIT starts as a platform and a triennial Festival focused on uniting an all-female roster of artists based in the city. The artistic practices FEMMEBIT promotes are video and new media mainly, with special attention to multimedia virtual reality. The name itself alludes to the combination of femm+bit, an archetype of contemporary female artist working with new media and digital interfaces. The platform and the festival are produced collaboratively and through extension of resources by the founders Kate Parsons (artists, FLOAT) who was part of Void LAb UCLA in 2015-, Sharsten Plenge (WOAH- We are Open Art Houses), Eva Aguila (Coaxial Arts Foundation) and Dahn Gim (Independent Curator, MAKINGOUT.LA), together with Janna Avner, and Richelle Gribble (Director, The Nook Gallery). Most of them are involved in mixed art galleries or art projects. The Festival programme is based on multi 
formats such as symposiums, screenings and exhibitions, that according to the objective of the project, seeks to open a space for women working with and between technologies towards analyzing society, new ideas born through active creation, proposing new forms to work together "to shape, share, and grow a future receptive open to progress" (FEMMEBIT, 2019). FEMMEBIT works on donation as financial funding to make their events. They request for financial collaboration through the platform GoFundMe.com, and they use their social network profiles to encourage audience to make donations. The first edition of FEMMEBIT Fest 2016 presented works and discussions that explored the artist's identity in a corporate world, concepts of the screen as avatar and persona, and the way the anatomy of video as a user tool, enables the possibility to sculpt an empowered female form. The festival showcased artists in different stages of their career, placing creators in context to improve narratives that are explored in their own practices (FEMMEBIT, 2019). FEMMEBIT Fest 2016 created a space for encounter and sharing as a local node with an impact beyond the city of LA (for example, Lauren Valley from Electric Women was inspired by their event to initiate her project).

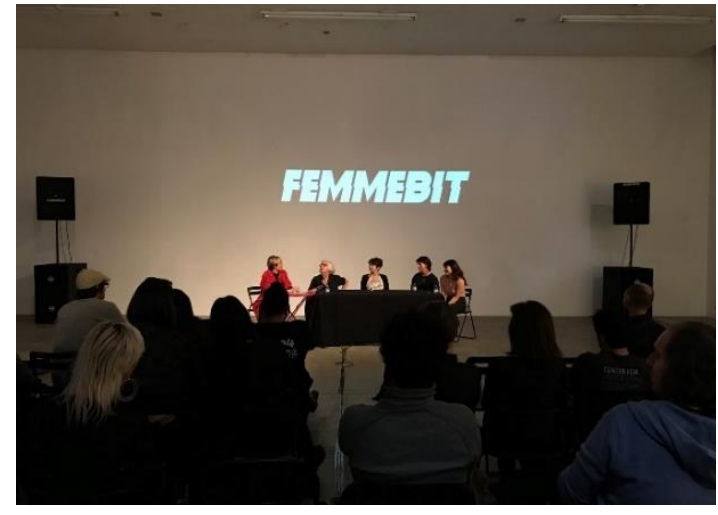

Figure 144 Panel on 2016 with Rebecca Allen, Shelley Holcomb, Holly Willis, Candace Reckinger and JJ Stratford

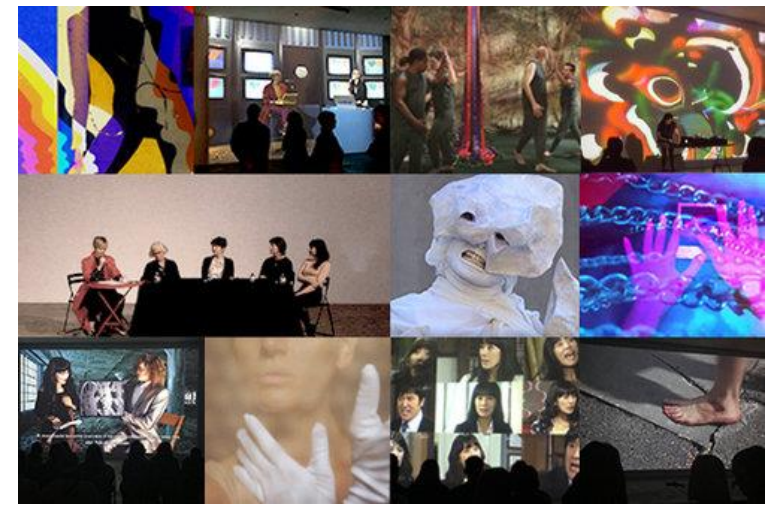

Figure 145 Compilation of highlights images of FEMMEBIT Fest 2016

FEMMEBIT Fest in 2019 will take place from 31st May to 2nd June, in CIVIC CENTER STUDIOS in LA. The event will exhibit the work of over seventy-five "diverse, enterprising and innovative women" (FEMMEBIT, 2019). Before this event, for the women's month in March, 
FEMMEBIT organised a few fundraising events in the city, like the exhibition at The Other Art Fair, where they presented a showcase of art works that challenged perception through the vivid mediums of virtual reality, metallic paintings, and vibrant digital prints. Featured artists are for example, Amanda Stojanov, from Void Lab, who I had the pleasure to interview ${ }^{168}$, together with Tara Dilloughery, the members of FEMMEBIT Richelle Griblle and Kate Parsons and Janna Avner. FEMMEBIT also organised a Yoko Ono tribute concert in a pop-up exhibition of AR and video works by a group of female artists. FEMMEBIT have built a space on her own by open donations and collaborative work in the city that in 1970 saw that early Art\&Technology exhibition with no female on the main page.

\subsubsection{CURRENT: Feminist Electronic Art Symposium}

The dream of a new future, theme of CURRENT, a feminist intersectional symposium for Electronic Arts celebrated in Vancouver. In 2006 in Vancouver two electronic artists, Shlee Luk (Minimal Violence collective ${ }^{169}$ ) and Soledad Muñoz came together to build by themselves a space that provided what they couldn't find in the electronic arts and music sphere, neither in the DIY spaces in their city, because of their sex and their ethnicity. It was designed as an attempt to create a creative space that Luk and Muñoz wanted to exist (Wilson, 2017). Inspired by the Pacific Northwest's feminist electronic collectives with which they have partnership, such as S1, TUF, Intersessions and continuing with Munoz own's project Genero, an all-women label and artist collective, they first designed a showcase for women and non-binary folks. Through their long friendship a network of connections between Vancouver, Portland and Seattle was established, that is the reason why they considered the CURRENT a Pacific North West Coast node of encounter: here the importance of geographical location for community and network establishment. After the first edition and aiming to

\footnotetext{
${ }^{168}$ See chapter see chapter 3.4.6.8.

169 See < https://soundcloud.com/minimalviolence>
} 
repeat, they planned to extend the formats in the programme with talks, workshops and performances, so they reached out Nancy Lee (head of local electronic music alliance Chapel Sound) for the panels organisation, who would join the team. CURRENT evolved from a showcase to a symposium, and it has a strong feminist commitment: "not saying the work feminism, it's an erasure". And that factor favorited them, for the second edition they received the three grants they applied for and could make real their project of building a space to make women's contribution to electronic arts more visible, the \#meetoo movement benefit them. Luk, Muñoz and Lee designed CURRENT not just as a festival, but as a project with which change society and culture, by creating spaces and opportunities they felt that there were not available for them (Wilson, 2017): "We just want equity [...]we gotta keep pushing, we are not even half way, not even quarter way". Muñoz herself states that as a result of her research about equity in electronic lines, $8 \%$ were men of color, $12 \%$ women of color, and $38 \%$ white women, "feminism is about putting those numbers at a level". In their three editions, they avoid using the word inclusion despite the wide aperture of artists they are looking for, because for them, the concept of inclusion means that there is a preexisting norm that includes people onto it:

We do as current, we are always to change culture, in every way possible, I am very fortunate to have found people on that truck with me. It is very hard in Vancouver to be incorporate in diversity, it is really hard to find spaces, and also the most affected are the women of color [...] For us is just us, people who is doing cool things in the city, that is the thing. People accuse of choosing only people of color, we are choosing the best, and that happen to be of color. Honestly, focusing on people, because it is so hard to be a person of color and have a space where you work hard five times, and you see that. Because it is hard (Muñoz, personal communication $5^{\text {th }}$ November 2018).

CURRENT is an event committed to intersectional and feminist approaches that seeks to change culture through cultural and artistic activities, providing space for women, trans women, non-binary, people 
of color, indigenous, to empower those people who feel in a periphery, a periphery that shouldn't exist, or that should be the center (Muñoz in Dubber, 2017)

I attached myself to feminism that is not based on having a vagina. That is the big different though, all the have pussy movement for me is ridiculous, inviting sex workers into talks, and stuff like that, a feminism that really subverts any kind of works [...] Intersectionality is so important. Can come in so many different way, it comes from whatever your body experiences, it is so hard to imagine a life where you are not everyday in. you do a feminism Bell Hooks, there must be as many feminism as many people are. Feminism is finding equity in difference [...] We feel with current we want to do a total subversion of an hegemonic thought and so, it's about more deconstruction, is about showing the grade, the structure. If we, this is how current works, women, non-binary people and PoC are organizing, our numbers are completely reverse, men are helping us. Who help us? All men, no influences (Muñoz, personal communication, 2018).

CURRENT as a symposium has been celebrated in 2017 and 2018, when Alexandra Chen joined the team. As Munoz states, a notable positive thing for her is that the networks are getting smaller, for example, like hosting one member of female:pressure as speaker in one edition. Last generation of feminist creative networks are being invited by the new ones, who keep on going with self-organised strategies. Current keeps what they call, a current school, in terms of providing and creating alternative ways to teach in the workshops, going further from showcase festivals, they edited this new edition focusing on how it is possible to pass on with knowledge (Muñoz, personal communication 2018). 


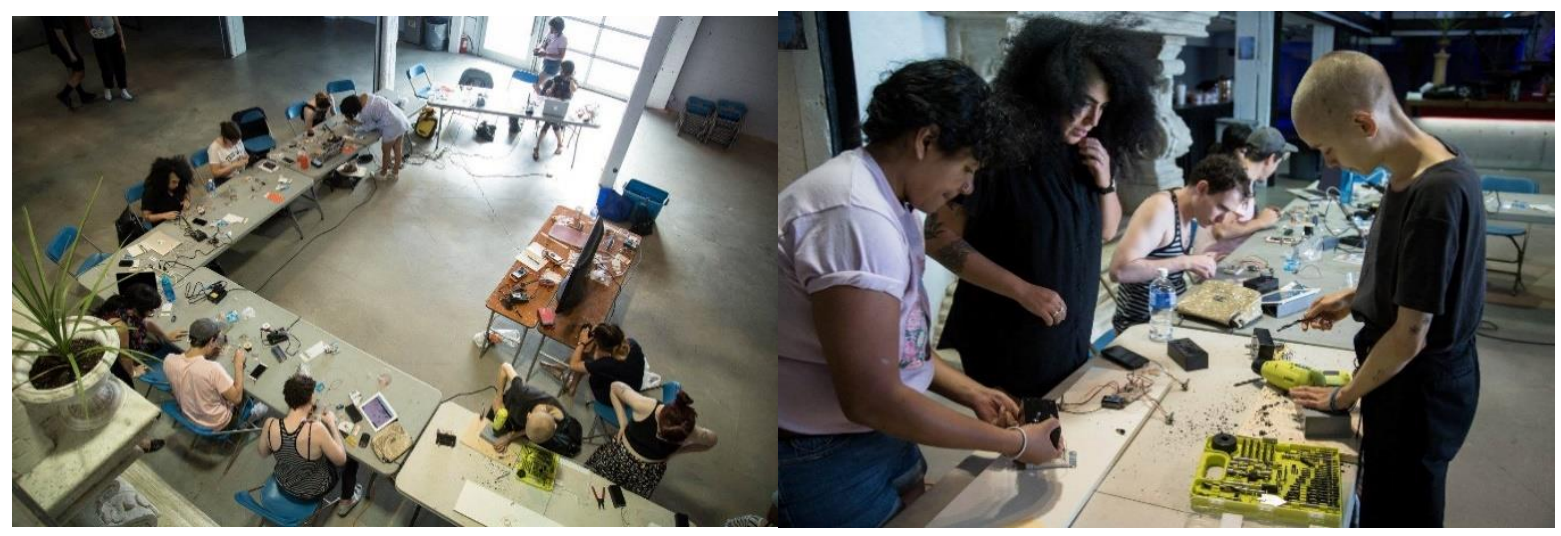

Figure 146 Arduino workshop CURRENT 2017

CURRENT goal is to gather and disseminate feminist content through ideas crossing, and international knowledge sharing. Their activities are free and open for all ages in public, panels and workshops. The project aims to incentive the local community towards promoting equality in the Electronic Arts Ecology (Current, 2017). In order to dream a new future, their methodology is focused on supporting artists, but it has a notable educational commitment too by planting seeds and come up with policy recommendation for the City of Vancouver through the panels: "this way, the less represented in the electronic arts realm today can not only be present today, but in charge in the future". (Wilson, 2017). Their criteria for artists selection is based on the feminist premise: to find equity in difference: "Therefore, the criteria is women and non-binary people, people of color in the electronic arts, which can go pretty far" (Muñoz, personal communication 2018). Munoz declares herself (and the project) a vegetarian of white men.

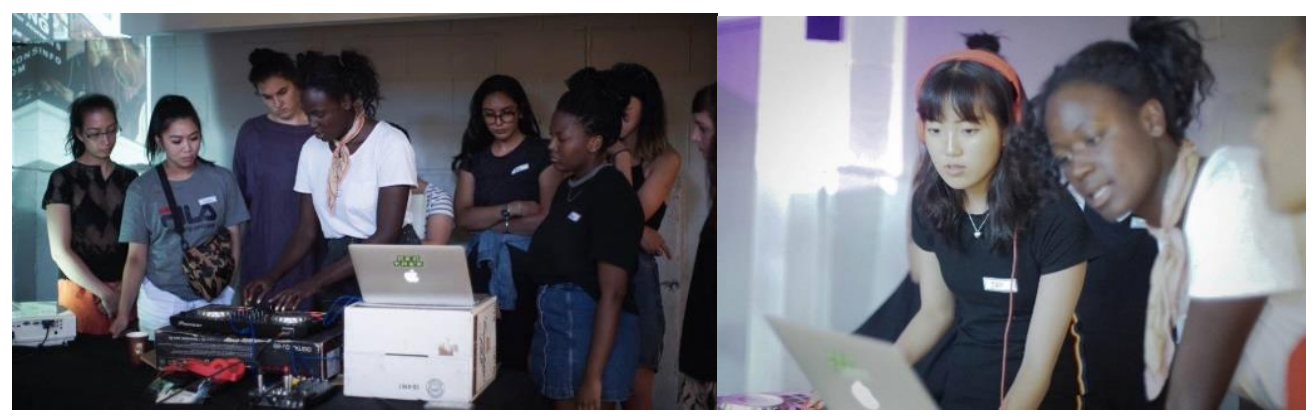

Figure 147 Shanique Kelly giving a workshop on electronic live composition, CURRENT edition 2017 
Lee says. "That's one of the many things we've all experienced promoters and booking agents say, that women artists don't attract as many people, and that's why they're relegated to opening. The popularity of Current shows that it's just not true (Wilson, 2017). CURRENT works by collaboration of the members of the network, and their structure evolves towards opening, the new events design aims to involve new participants as organizers. For the 2019 edition they organised in collaboration with Chicago's Backyards Series a panel in Chicago (where Munoz was doing her Masters) in May. The panel was followed by a discussion and a musical set. The topic of the panel was a comparison between the DIY scene, government, support and community in each city (Vancouver and Chicago), and the possibilities for artists to impact, change and benefit the music and culture (Current, 2019). Currently there is a call open for a three-day payed Mentorship Programme to support emerging cultural producers, curators and event organizers in Vancouver. The call encourages Indigenous folks, men of color, queer and trans people to apply (Current, 2019). Participants will take part of the event planning in the 2019 iteration of CURRENT.

\subsubsection{7. electronnes}

electronnes was a two-days non-curatorial festival on women, art and technology that took place in September 2017 in the Offspace Projektraum of the Dynamo in Zürich. For two days electronnes held exhibitions, artists talks, open studio, workspace, workshops, discussions and performances. The event was self-organised by a group of three women artists, educators and researchers: Anna Cholinska, Shusha Niederberger, Niki Wiese Schawalder. They are also mothers, two of them single mothers, and who were part of a wider group that had been previously meeting for a year to dialogue and share their work. The group that preceded electronnes organisation, was a group of women from all over Switzerland belonging to different art and culture communities. A group of very diverse backgrounds, political, technical and artistic backgrounds and approaches, which Shusha 
Niederberger brought together inspired by the work of Addie Wagenknecht in Deep Lab ${ }^{170}$, who was exhibiting in House of Electronic Arts Basel, where Susha was working:

electronnes grew out of a loose community of women who work in art / culture and technology [...] Inspired by DeepLab, Shusha invited all women she knew from the field to gather for an exchange and discussion. The first meeting was mainly about getting to know each other and sharing experiences. There were women present of different generations and so experiences were really diverse. Other meetings were a show-and-tell, where everybody showed their work and discussed interests and methodologies (electronnes, personal communication 2019).

This heterogeneous community gathered three times in 2016 , with no attempt to settle an identity or develop a coherent mission, neither within the terms of feminism: "but there really was no consensus about the status of it being feminist. Especially some of the younger women felt uncomfortable with the term" (electronnes, personal communication 2019). One member, Anna Cholinska, who is also a member of créatrices $^{171}$ organisation on women visibility in media in Switzerland, proposed the design and organisation of an event within the framework of the MiniMaker Faire. Towards formulating a coherent event identity, the group settled the name electronnes, and it would be a festival that would gather all the diverse ideas present in the group. Despite the openness of structure and the initial excitement and brainstorming of ideas that the group had, the organisation team became into three: Anna, Niki and Shusha.

In this process, a key group of three people formed, who were active and able to advance the process:. Interestingly all three of them are mothers of young kids up to teens, two of them single mothers, and all of them highly engaged in other jobs and projects. Among us, a special kind of understanding prevailed, resulting in a very productive atmosphere, with everybody working in her

\footnotetext{
${ }^{170}$ See point 3.4.3.4.

${ }^{171}$ See < https://creatrices.ch>
} 
small timeframes available, and being grateful of everything the others were doing. This process of forming a key team was never formally approved, as well as we never set up a formal structure (electronnes, personal communication 2019).

Described as non-curatorial small programme, they achieved to get some small founding that covered the event expenses. electronnes aimed to raise questions regarding the profile of the members: the role of technology in culture and society. Moreover, it was open to all genders and ages (electronnes, 2017). electronnes created a digital platform that unfortunately it is not accessible anymore, where they redacted the following manifesto. I give some fragments:

maybe it is just a feeling? / it is still an issue / "electronnes" has no theme, but many contents and forms. It is an attempt to make female practice in the

field of art/technology visible, even in a small city like Zurich. It is not important whether the works directly address feminist concerns, although some do. "electronnes" is not about feminism. / "electronnes" is feminist in the sense that it provides visibility for the actions of women* and is based on the collaboration and mutual support of women*. /"electronnes" is a beginning / What unites us is the interest in a network, in encounters, and for the specific themes and qualities that a female* only group makes possible (which we discover again and again) (retrieved in a personal communication with electronnes 2019).

Although the manifesto expresses their interest in the network culture, the members expressed that the organisation and production of electronnes left them exhausted, and also a bit disillusioned about working in open networks. Despite the positive experience Anna, Niki and Shusha had working cooperatively and the feedback attendants gave, they decided not to keep on with the project, which remains barely active in its social network pages. After electronnes they managed to organise a small 
workshop in December addressed to adults and kids, but mainly to comply with the funding conditions (electronnes, personal communication, 2019).

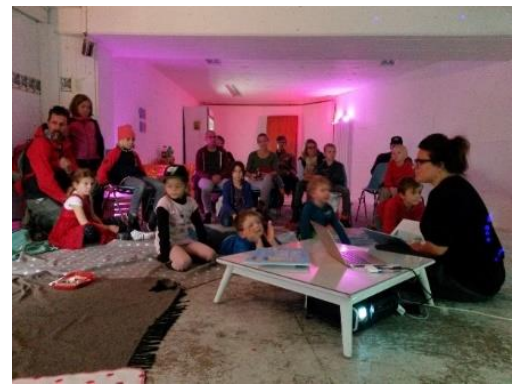

Figure 148 Workshop for kids on mathematics, art and electronics, September 2010

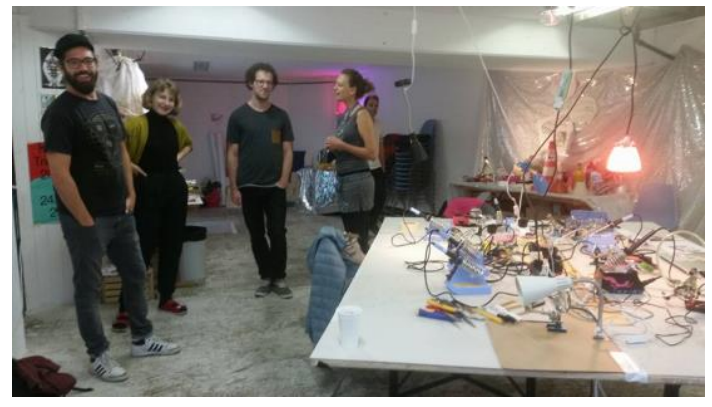

Figure 149 Experimental megaphone workshop by Anna Cholinska with some participants

Shusha Niederberger works with Cornelia Sollfrank (founder of OBN) in research, member of purple noise, researching and lecturing on women and technology, and feminist commons. She is in contact with feminist hackspace $M z^{*}$ Baltazar's Laboratory in Vienna, and artist-run institution constant Brussels (feminist server etc) (electronnes, personal communication 2019).

\subsubsection{Cyborgrrrls: encuentro tecnofeminista}

Cyborgrrrls is an annual encounter happening in Ciudad de Mexico that seeks to build a critical space for art and dialogue about gender, technology and capitalism between a feminist perspective that embraces the concepts of cyberfeminism, technofeminism and hackerfeminism. Its name continues on the legacy of the youth feminist subculture of the riot grrrl and the new technologies of the Internet (Valentine et al., 1998). The name and title represent the fusion of the cyberfeminist and grrrl, DIY legacy, together with the following technofeminist theories of Judy Wacjman. The encounter has gathered around one hundred international artists, activists and technologists who have collaborated through performances, workshops, talks, fanzines, videos, film, etc. In two editions -and one coming, it has become the main node in the Latino American network of cyberfeminists, hackerfeminists and artists in electronics, that connects with rest of American points and Europe networks in art and tech. 
The idea of such an encounter was conceived during a conversation between the Chilean artist Constanza Pina and a member from Casa Gomorra, in Ciudad de Mexico, when they were concern about a format to promote technology from “women's perspective, made and developed by women and for women" (Piña, 2017). Pina is also co-founder of the first media lab in Chile dedicated to DIY electornics, Chimbalad. They projected technology in relation with Pina's artistic work Corazon de Robota, that relies between the cyborg concept of Haraway, technofeminism of Judy Wacjman and the cyberfeminism of Sadie Plant: gender is not relevant anymore, technology is culturally shaped and the relation between female and informatic/electonic tasks. For the founders, technology embraces any analog and artistic tasks such as cooking, drawing, serigraphy and sewing to programmeming and coding. As Pina said:

Latin America, as the rest of the world, is quite machista. I develop another idea of technology. Technology can be knitting, sewing, programmeming, cooking; the first manifestation of technology is fire, therefore, I avoid establishing hierarchies between technologies or diminishing people who work in technical labor. It's true. Most of the time I arrive at places where only men work. But my work is my activism, I am a woman working with technologies, teaching other women to work with electronics, to revalorize techniques, manual and craft practices, traditionally made by women. To me, there is no such thing as gender anymore. The word «Robot» comes from the Czech word «Robot», which means forced labor or the tedious work that the «man» does not want to do. For me, Corazón de Robota means tedious work made with love (Piña in Gonda, 2017)

The scope was to gather feminist conversations to think how to construct technology by ourselves, with different purposes outside capitalist framework, that is, for pleasure and joy, to create the world in a different way. Constanza Pina and Casa Gomorra organizers started establishing a network of 
technofeminist women through other feminist collectives in latino America such as ADD FEM ${ }^{172}$, the feminist collective in the Electronic Rancho in Ciudad de Mexico that works on cybersecurity and cyberdefense for women online from collective methods

The encounter was designed in an antiacademic format, seeking to provide a joyful space for dialogue, personal exchange of different approaches through artistic and activist practices (Piña in Radio Zapote, 2017). Cyborgrrrls terminology relates to the combination of witches, magic and female rituals with technology and anarchism, for instance, the concerts and video performances are described as coven:

El Cyborgrrrls es una fiesta crítica, hackfeminista, tecnoanarquista y ciberlibertaria para recrear la tecnología y los estereotipos estéticos y de género. Un espacio para compartir ideas y afectos, para reprogrammear tecnologías, hackear el cuerpo y confabular estrategias de desobediencia técnica, mediante conjuraciones ciberbrujísticas y electromágicas.

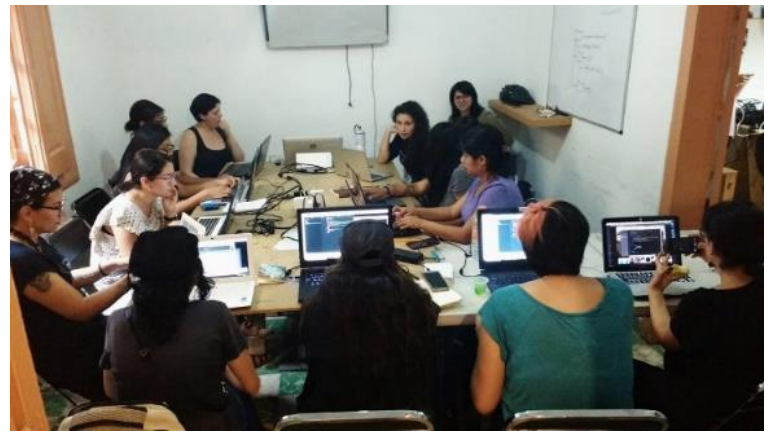

Figure 150 Open Software Workshop Photo: Constanza Pina 2018

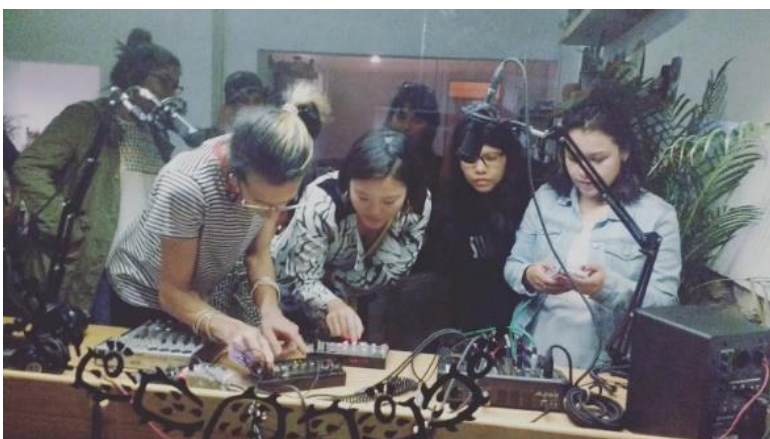

Figure 151 Workshop Fuck the Soundcheck women against violence in the soundchecks

The format has increased since first edition, and in the last one in 2019 the activities lasted thirteen days, selected through an open call for proposals and through professional invitations. It gathered around one hundred technofeminists that worked on collective alliances online on cyberpunk, wearable technologies, gynpunk, cyberfeminism, cybersecurity, transhackfeminism, radio networks,

\footnotetext{
${ }^{172}$ Available at <https://ranchoelectronico.org/add-fem>
} 
electronic composition, video art, visual arts, performance, fanzine, etc. Guests and collaborators of Cyber Grrrls belong to other feminist collectives such as Pechblenda Lab, Fem.Tek ${ }^{173}$, where Constanza Pina made a workshop in 2018, and EnREDadas ${ }^{174}$.

Cyborg Grrrls is celebrated in Ciudad de Mexico, in MedaLabmx, Casa Gomorra and El Rancho Electronico, in collaboration with other cultural centers such as, Radio Nopal, Centro cultural Border, Terrazarticife, Cine Nueva. The encounter is completely self-organised and self-founded., accepting donations via PayPal. Pina has brought her passion for interdisciplinary art practices with DIY and open source technology to the formats of the encounter, creating an own community in Mexico City that is becoming a node of connectivity within Latino America, America and Europe

\subsubsection{Alliance of Women in Media Arts and Science (AWMAS)}

In 2017 Marlene Mathew was a new PhD student at University of California in Santa Barbara in Media Arts and Technology when she decided to start a project for women in the field. Previously, she had graduated in Music Recognition and Perception in NYU where she was the president of SWiTCH, the student run club at that provides at the university support for women in technology students graduate and undergraduate. The experience in the organisation and the research she had developed about women in audio and technology ${ }^{175}$ lead her to the paradigm of why so many women have difficulties in STEM fields: a lack of mentorship where women can find support, is one of the answers Mathew found (Mathew, personal communication 2019). When she joined UCSB campus she found the same issue:

Because you do not have a lot of women in New Media or STEM fields, if you have women who have STEM degrees the do not remain, they drop out, and one of the reasons they do that

\footnotetext{
${ }^{173}$ See point 3.4.6.10.

174 See point 3.4.6.5.

175 Women in Audio: Contributions and Challenges in Music Technology and Production, 2016. Available at <http://www.aes.org/e-lib/browse.cfm?elib=18477>
} 
is because they say there not a lot of mentorship for them, so they leave to do something else (Mathew, personal communication 2019).

The design of $A W M A S$ (Alliance of Women in Media Arts and Technology), the new UCSB campus organisation, is based on these results. She found AWMAS as a form to connect the spread women in campus. It is an interdisciplinary organisation that reflects the current situation in Media Arts field: a low number of female but with a wide range of disciplines and backgrounds in arts, science and technology. The objective was to provide a platform to empower women to succeed in academically and professionally, a programme of activities with guest mentors "for women to come together, share ideas, networking, collaborate and meet other women which can show some mentorship or mentoring them, some kind of example for this outcoming media artists". (Mathew, personal communication 2019). Mathew had the support of her supervisor and she started organizing AWMAS with a series of activities and meetings in campus ongoing during the academic course. Additionally, within the general programme, she thought about the conference format because it the most suitable way to accomplish the main objective: bring together and make interact women from different fields, at different stages, who could exchange their work and research and inspire the young generations. The conference would bring the organisation from a local to an international connection.

The first edition of the conference was celebrated in February 2018 and the second February this year, 2019, in UCSB campus, and both were composed by key speakers, talks, workshops, installations, scientific posters and a concert. The event is a peer review conference with an open call for papers and art works for international applicants. Mathew started establishing a network by connections by contacts, recommendations and self-introductions, she had to find people to oversee the conference sections procedures. In California she contacted Victoria Vesna, who besides taking part of the conference she also co-supervises her dissertation, and through her chairman, she connected 
with Kathy Rae Huffman (co-founder of Faces), who accepted to join to curate the exhibition part in both editions.

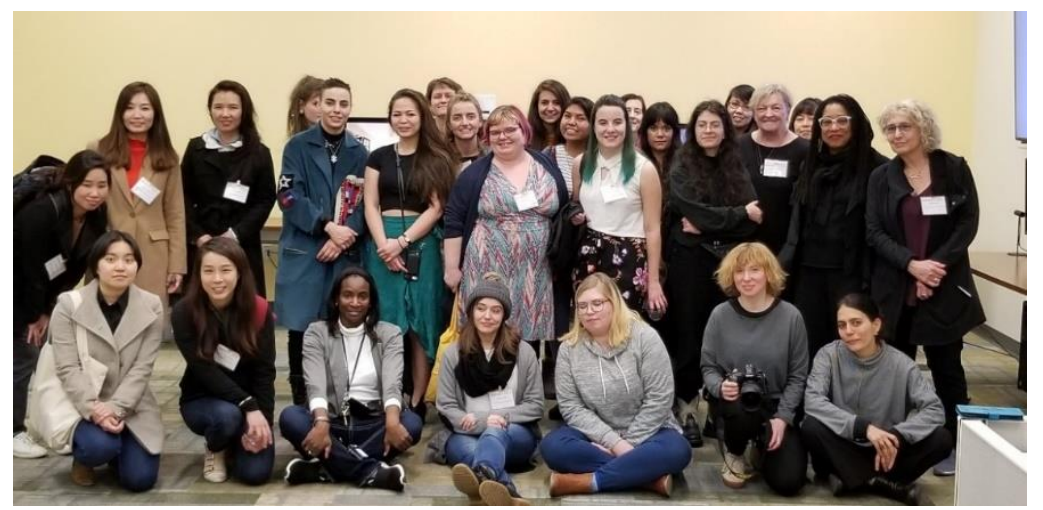

Figure 152 AWMAS Opening 7th February 2019. Organisation team and artists.

For Mathew the factor of bringing together artists and audience was important to establish a direct dialogue between the art installations and them. AWMAS is not described as feminist, although Mathew considers it to be. As a woman of color, she finds the most relevant responsibility as feminist to enable open accessibility for men to attend the events towards creating consciousness regarding to women:

Part of feminism is also that we have to educate the men, even if we are only women supporting each other if we are educating men about women issues, $[\ldots]$ to make them understand women are also important. We should work together, some organisations want to separate, but I believe we must be more inclusive to educate the men (Mathew, personal communication 2019).

AWMAS conferences have brought together women from different generations: artists, educators, scientists, engineers, musicians, researchers, students have found in California this node of connection to support each other, to dialogue and exchange interdisciplinary knowledge and creativity. As a campus organisation student run, they are responsible for their own founding, for what they request in advance to some campus and off campus and businesses to donate. The conference also charges a fee 
of $50 \$$ for the whole event. The project is two years old and it is growing, the next step is to increase their membership and keep creating more awareness about the need of female figures as mentors:

One thing I have notices is that membership is not easy for them, a lot of female don't think there is any issue about underrepresentation, that is also a problem they do not see a need of this type of organisation a priority, they don't realize (Mathew, personal communication 2019).

\subsubsection{FEMeeting}

After twenty-one years of the founding of Faces mailing list and Old Boys Network, a group of established women artists, professors and researchers decided to create a transnational meeting by their own, dedicated to Women in Art, Science and Technology. From their own professional and personal network, the members gave rise to the organisation of the event: the creation an international encounter for women to reflect upon the status quo of contemporary science and art. Founders of FEMeeting are: Marta de Menezes (who conceived originally the idea of the encounter), Dalila Honorato, Kathy High (member of REFRESH ${ }^{176}$ ), Victoria Vesna, Laura Beloff, Maria Antonia Gonzalez Valerio, Maria Manuela Lopes. All of them are relevant nodes in the transnational network of art, science and technology: artists, educators, professors and researchers belonging to different American and European programmes in the topic in academic centers.

Through their own social and professional network, they have promoted the event, gathering other artists, professionals and emerging researchers in art, gender, science and technology in Portugal, where the meeting has taken place both editions. The first edition of FEMeeting was in $15-19^{\text {th }}$ June 2018, in different locations in Portugal (Lisbon, Evora and Sao Luis- Odermira), the edition in 2019

\footnotetext{
${ }^{176}$ See point 3.4.3.6.
} 
from May $30^{\text {th }}$ to June $5^{\text {th }}$ (in Vila Nova de Milfontes, Lisbon and Oporto). FEMeeting is organised together with Cultivamos Cultura.

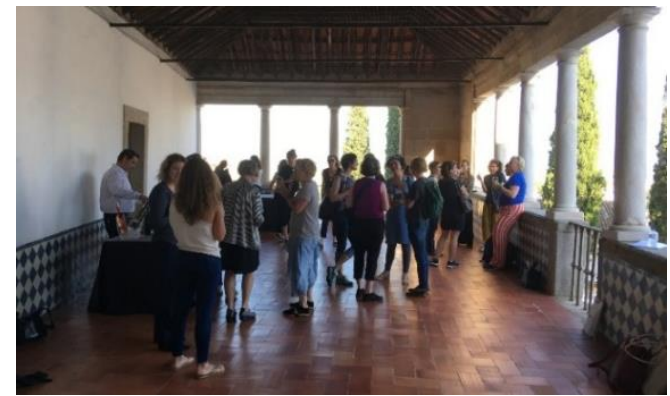

Figure 153 Image of the first FEMeeting in 2018, retrieved from the official website: www.femeeting.org

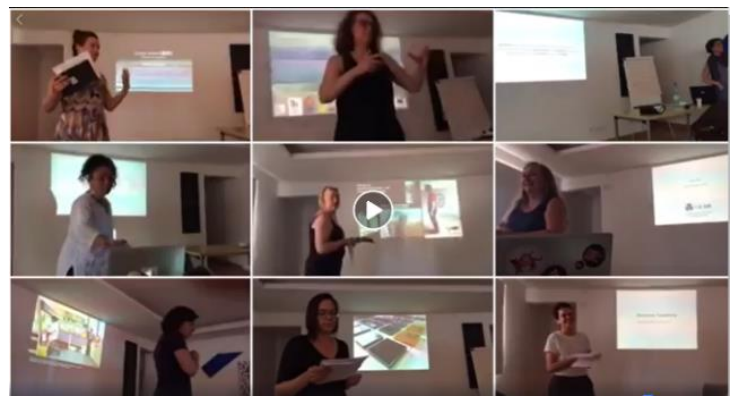

Figure 154 Composition of different talks from FEMeeting 2019 video, by Marta de Menezes.

FEMeeting is based on the relevant work developed by women in international events in art, science and technology. Instead of most of my case study, FEMeeing is focused on visible presence of women in conferences and festivals as faculty, artists, scientist, curators or other interdisciplinary role. The meeting aims to bring together women from different ages and academic stages to share and disseminate their projects through presentations, creating a space to reflect on the contemporary status quo of contemporary science and art (FEMeeting, 2018).

The presentation and lectures activities are complemented with informal and intimate activities such as lunches, dinners and guided routes around the area of the happening, and other events open to the public. By this combination of academic and informal encounter, the selected locations in Portugal experienced the establishment and reinforcement of a network, bringing illusion to new generations of female art and science researchers, and encouraging the veterans for future FEMeetings events. This transgenerational and translocal event connects experiences cross-borders and cross-time. All the attendants and organizers share the audiovisual documentation through Facebook, expressing their gratitude and pleasure to have taken part of the event. Due to the location of the event, the accessibility 
might not be affordable for many researchers and artists, what might be a reason for not spreading the network in a higher level.

FEMeeting criteria of work selection is based the concept of woman as a cultural construction that must be challenged, nonconsensual and multiple in its roles, arousing cultural imagining. Any individual who identifies as a woman, independently of their sex is welcome to take part of the FEMeeting space, "a space for the co-habitation of individuality and uniqueness" (FEMeeting, 2018).

\subsubsection{Projects, Associations and Organisations}

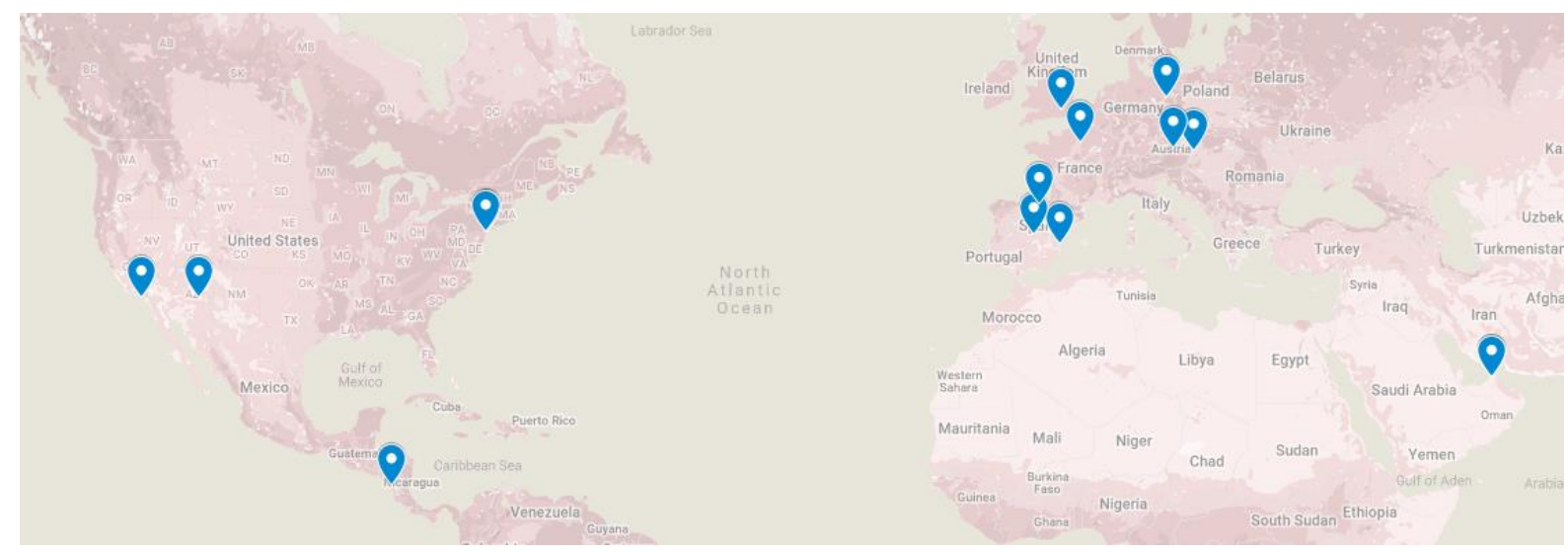

Figure 155 All-Women Self-organised Projects and Organisations at the intersection of Arts and Technology worldwide

\subsubsection{XXERO}

From Faces network in 2000 a group of women in Linz created XXERO, a collaborative, moobased environment, together with a series of encounters and events: Uschi Reiter, Aileen Derieg, Anja Westerfrölke with the collaboration of Valie Djordjevic, Kathy huffman Rae, Diana McCarty, Florence Ormezzano and Kerstin Weiberg. The project lasted three years, however, they were part in 2001 of Ars Electronic Festival, and other media festivals in Europe (through the dockings). The idea of $X X E R O$ came up during a Faces meeting, looking for a tool to examine the diverse perspectives on new technologies and their impact on people's life from a political and social perspective. The two 
parts of the project -the MOO and the real-life events- worked as a whole, providing participants a tool to interact and contribute, share and exchange on their opinion of new technologies. The real-life events happened in private and in public, being the network of women working together the content and the medium: workshops, lectures, a table in the café... XXERO was conceived as an open collaborative tool that would grow based on participation, engaging people in a pre-web technology in an innovative way when the WWW was growing towards a simpler consumer entertainment, it was an ideal environment for "a collaborative development of ideas, projects and art works" XXERO character was like "an experiment to explore these opportunities and create a space where, through the combination of individual ideas, something new can emerge that is more than just the sum of its parts".

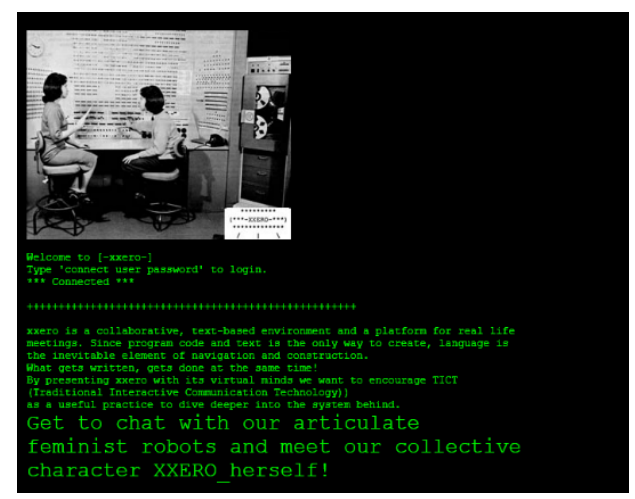

Figure 156 Screenshot from the website hosted by Servus server in Linz. Available at <www.xxero.servus.at>

Despite the attempt to build a translocal community based on real and virtual interaction, the project didn't continue after 2002. However, participants gather good memories of the experience (Westerfrölke, personal communication 2019):

For a few years I really enjoyed these online encounters. As someone who never got into programmeming here I discovered some structures of code together with content, got into language and translation. We exchanged on feminism and had to define theory by creating text for the bots you met being around in this text environment. All quite playful and in practice with a result to experience later again. 


\subsubsection{Undercurrent}

Four women artists, feminists and researches in technoscience and women's studies, immigrants or daughters from immigrants in United States, came together in 2001 with a project on the critic relation between cyberfeminism, new technologies, postcoloniality and globalization. Undercurrent project was based on a mailing list to create online discussion and debates on "unspoken questions about the racial political of net.culture, new media and cyberfeminism", with a strong critic position to cyberfeminist the so-called postfeminism, postcolonial theories on the net culture, which portrait cyberspace as liberating leaving issues such as gender and race solved. Maria Fernandez founded the project in collaboration with Faith Wilding, who had been part of the three International Cyberfeminist in Germany, and founded in 1998 subRosa collective, together with Irina Aristahrkova, Coco Fusco, as moderators. Their initial statement (Fernández, et al., 2002) in the mailing list ${ }^{177}$ was:

As much as we support the democratic goals of many who have contributed to alternative discourses within net.culture, we do not agree that the ideal of a digital commons, feminist or otherwise, necessarily transcends the problematic logic of race and racism. We are deeply skeptical of such assumptions because we understand that race and racism involve much more than skin, bodies, overt segregation or physical violence. We argue instead that race is manifest in both the essentializing ventures of law and science and in the arenas of performativity that denaturalize and de-essentialize embodiment, including cyberspace."

Undercurrent acknowledged that women of color, poor people and "third world" people in contemporary techno capitalist society which is "wracked by economic polarization", therefore they are those more likely to "experience overwhelming abject relations to technology":

\footnotetext{
${ }^{177}$ Undercurrents list is currently closed. The full archive of the list can be accessed at The Thing: www.bbs.thing.net
} 
If we concentrate exclusively on the potential for "gender performativity" brought about by genetic reengineering and the liquid architecture of virtual reality as experienced by a select and privileged few, we believe that as feminists committed to social change and the respect for human rights, we would be forsaking an ethical responsibility to bear witness to how digital media, voyeuristic and militarist internet entertainment culture and privatized medicine all partake of the sadistic impulses of global capitalism that objectify, dehumanize and impoverish the majority of the world's women.

Undercurrent openly addressed artistic practices in cyberfeminism, challenging the tools and methods to really develop an activist cultural practice that analyses how new technologies and the political and economic system contribute to disempower millions of poor women all around the world. Members were notably skeptical to the technocratic approaches by women artists, evidencing the necessity of a political awareness for the creation of innovative art through media. Undercurrent started as a small and private space, aiming to engage women from different continents, focused on women of color, on the intersection of new media and postcolonial studies towards collaboration and intervention. As the list grew, they achieved the engagement of men and women engaged based on "affinities, desires, aspirations as well as fears" (Fernandez, 2002, p.2) The project was founded with a strong social commitment to support women exploited in tech industries, they created Invest in the $X$ to gather founding to support women workers in Tixuana (las maquiladoras) under violated laws. They expected to publish a book with the results of the mailing list (Fernandez et al., 2002), unfortunately, the project didn't last, and the group dissolved. 


\subsubsection{IMA Series: Hidden Alliances. IMAfictions and Machine Divas}

In the 2018 edition, Ars Electronica Festival dedicated an exhibition to the IMAfiction, a series of portraits dedicated to female media artists with a focus on sonic art of the IMA Institute. The exhibition presented a research project lead by the musician and composer Elizabeth Schimana, who together with the artist Andrea Sodomka jointly established in 2005 the IMA Institute of Media Archeology ${ }^{178}$, a cultural and research institute that has dedicated itself to acoustic media and research at the analogue/digital interface and to the subject of women, art, and technology (Ars Electronica, 2018). The basis of the Institute is fundament in the media archeology approaches, aiming to contribute to the transformation of society and civilization via the media. Although the Institute members are from both genders, Schimana wanted to make the visibility of women, art and technology a matter of media archeology field. "Because, in my head, I have a key: at least 50:50" [women-men], "no ifs, and or buts. If more curators had such a key in their head, then festival programmes would look very different." (Schimana in Graf, 2018).

Moreover, the structure of collaboration and work of the instate makes it to be a transnational network, despite its location in Austria. On one hand the board members have been part of networked art projects, such as Schimana in Kunstradio in Vienna, on the other hand the institute counts on the participation of international members and also artists and researchers as collaborators, involved in different activities and projects, for example with Kathy Rae Huffman and Ushi Reiter organizer members of Faces mailing list, and Faith Wilding from subRosa. Towards embedding current art production in a historical context, the series encouraged international networking and cooperation between artists and institutions: "this network can and should be conceived as cross-disciplinary in order to flesh out the accompanying theoretical framework. Cooperation projects should not just occur passively but are also actively encouraged (IMA, n.d.). Though digging -media archeological

\footnotetext{
${ }^{178}$ See <www.ima.or.at>
} 
excavating- the institute has brought to light productions by women through two series of its own: IMAfiction and Machine Divas. For the institute, Women, Art and Technology are 'clearly and positively linked', and the necessity of a room for one's own is still a reality for women, as in literature, as in "media arts, electronic arts, computer art, sound art, radio art, ... Today the core message is as relevant as it was in 1928". The abovementioned publication edited by Judy Malloy on Women, Art and Technology in 2003 encouraged the creation of these two series along the conceptual lines of the work and methods of women/artists in connection with technology. IMA is about to launch a book on this series entitled Hidden Alliances, with an extension of twenty women artists featured who together "wave a fascinating network of relationships" (IMA, 2019).

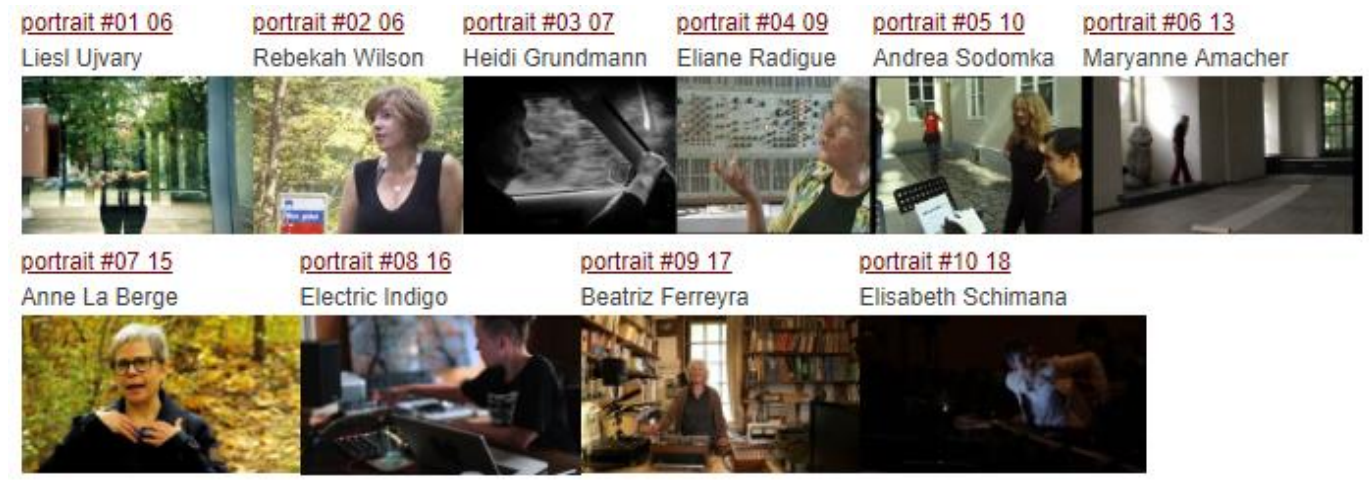

Figure 157 List of the ten portraits of IMAfictions. 2018. Retrieved from <www.ima.or.at>

Within IMA Series, Andrea Sodomka, together with the media artist Eva Ursprung started a collaborative research and networking project called Art Engineers vs. Machine Divas. A RetroUtopian Investigation of Machine Theater in May 2007. The project was focused on women artists using technology in an expanded concept of theater space, with the objectives of creating a pool of information on these women and to formulate new questions to specify and define their contemporary role in this special field. The term Machine Diva invites to the reflection of self-definition questions and possible shared identities. The project consisted of interviews to international media artists whose work was somehow related to the concept of Machine Theater, that is, who developed their work 
between Internet stages, space art projects and robotics, whose professional profile evolved from the 'artist engineer' from early 20th Century to new current forms of creation in relation with machines. In it contributed international net media artists and researchers such as Eva Woglgemuth, Eva Ursprung, Nina Sobell, Andrea Sodomka, Janneke Schonenbach, Boryana Rossa, Nicole Pruckermayr, Helen Varley Jamieson, Kathy Rae Huffman, Christina Goestl, Tina Auer, Monika Fleischmann, CYM, Diana Burgoyne and Avatar Body collision (is Vicki Smith (New Zealand), Helen Varley Jamieson (Australia), Leena Saarinen (Finland) and Karla Ptacek (England). The final results of the research were presented at the IMA Salon \#7 at Ars Electronic Festival that year, continued with a panel and open discussion by Inke Arns, Kathy Rae Huffman and Eva Wohlgemuthh. The rituals of gathering together for sharing food 'salon breakfast', 'long drink', the concept of salon itself, as a place for intimate encounter, are a strong recurse by networks of women artists in media arts. Thanks to this work of digging, networking, netting, the IMA series retrieved hidden alliances and female works that are now part of media art history. Machine Divas has been continued to happen locally in Graz with Eva Ursprung (Huffman, personal communication, 2019).

\subsubsection{MzTEK}

MzTEK is a non-profit organisation founded in 2009 by Sophie McDonald and Sally Northmore in London for women artists, techies and tinkerers. It is dedicated to give support and education to women in the fields of new media, computer arts and technology through workshops, talks and self-initiated tinker sessions. The founder's motivation relies on the imbalance between women and men working the fields of arts and technology in United Kingdom and Europe. The organisation is run collectively, with a board of directors and producer members. The organisation is 
based at the Center for Creative Collaboration in London ${ }^{179}$ and its supported by Hackney arts institution space ${ }^{180}$. MzTEK methods are self-organised DIY events hosted in Hackney space and some are done through collaboration with other projects, entities, centers, institutes and universities.

$M z T E K$ aims to erase gender stereotypes about technology, so the workshops are addressed uniquely to women, promoting a space where technology can be accessed by women from a more confident position, encouraging women to learn skills for creative technological projects, avoiding the general tendency by men to take the leader position in groups (Angliss, et al., 2009). The organisation has a strong educational component that belongs to activist tendencies in Craft and DIY movement, providing a noncompetitive space to get in the learning of technology through affordable courses. They design introduction workshops in an educational atmosphere for women from all ages, providing them a first step in technology where home and low-cost objects are used to create technology in a more creative way. The traditional craft methods are brought to electronics and computers, who are taught from a practical and theoretical approach for beginners (Angliss et al., 2009): “The culture of DIY is applied to coding and knowledge production, as well as developing practical skills and resources" (Carpenter, 2010).
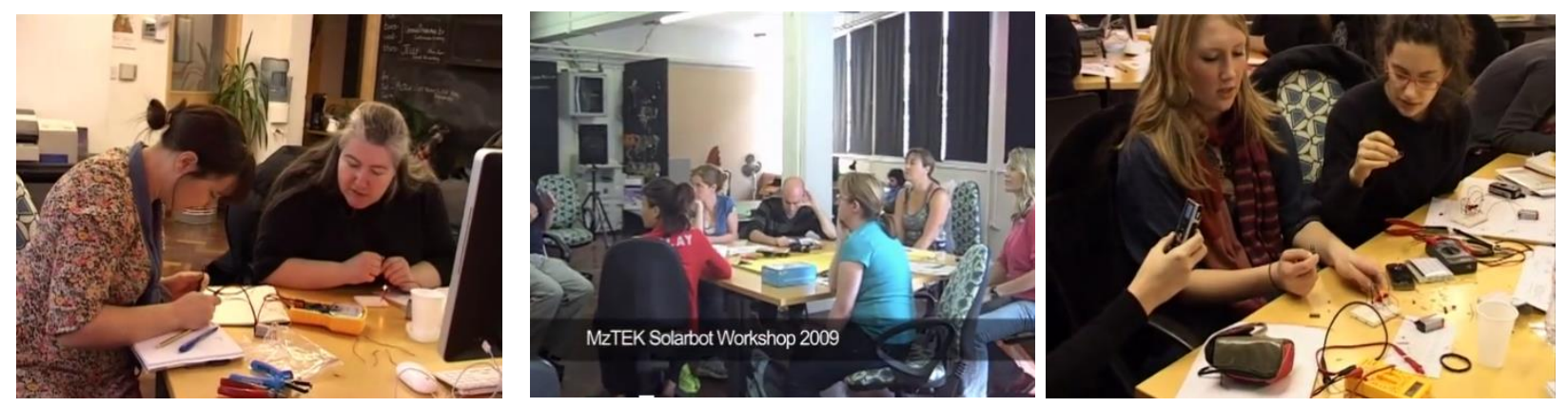

Figure 158 Screenshots of Electronics Introduction Workshops in 2009. Available at https://vimeo.com/9226266

\footnotetext{
${ }^{179}$ See <http://creative-collaboration.net>

${ }^{180}$ See <http://www.spacemedia.org.uk>
} 
Emile Giles, a producer member who joined the organisation in 2010 explained the importance of creating access for women to learning opportunities in technology, in order to:

- Build a community where there is a place for women and their ideas in the tech world

- Disprove the stereotypes and prejudices

- Get women confident and contributing to the world of arts and technology - in turn feeding their research and ideas into the science and technology fields (Giles, 2012)

Workshops teach a wide range of DIY technologies such as Arduino, audiovisual edition skills or wearable tools, and the series of talks have brought together hackers, thinkers, curators, artists and researchers (Giles, 2012). Initially the website asked suggestions from users for technology skills to be taught. (Angliss et al., 2009). One of the main purposes of the organisation was to create a platform for networking by creating together, so they have established an alternative space for learning community in London with connections abroad. Through their programme of activities in London, $M z T e k$ offered 'opportunities for women to creatively explore and expand their experience of working with technology and create a network of women techie artist' (MzTek 2009-2013 in Way 2016). Scholars and professors as artists have collaborated in MzTEK activities, promoting alternative uses of technology like open sources tools in alternative self-organised spaces outside academia. Through their exhibitions they have also bring international acclaimed women artists in computer and electronic arts, like the Chi-TEK exhibition and workshops in 2011 hosted in the Victoria \& Albert Museum, that had a TEA PARTY for the artists presentations. This format of TEA PARTY related us to the dinner events of the feminist art by Judy Chicago, the dinners in Faces mailing list and OBN. MzTEK plays recurrently with this relation between traditional female formats and tasks and the modern technological profile. In the platform, MzTek provides a subscription to the Mailing list to keep updated, although their main activity stopped being shared through it and their social networks in 2016. 


\subsubsection{M-Artech}

M-Artech is a digital platform that works as a creative network community and repository for women from different grades in science, arts and technology. It was self-organised in 2011 by the Italian artist Francesca Mereu. She and the art historian and curator Anxela Caramés conceived the idea of a project about the topic of women, art and technology during CIMUAT, the conference held in 2010 in Valencia about women, art and technology in the public sphere ${ }^{181}$. By then Mereu was working in Madrid at Medialab Prado ${ }^{182}$ research group VLAB 4D that was in which a wide group of scientists, researchers, artists and technologists were part, in this scenario she found the right place to start any type of self-organised project to make visible and connect the unrepresented work by women in new media arts in Spain and abroad (Mereu, 2012). Firstly, they designed a series of events, conferences, exhibitions that later evolved into the idea of founding by themselves an organisation based on a platform as a technological medium. The project was not institutionalized, and it never received any type of financial funding. Such organisation would serve to connect women artists and researchers working in arts, science and technology, in order to make visible their work and promote dialogue and dissemination of knowledge through social networks online and offline such as meetings, talks, workshops, exhibitions (M-Artech, 2012) The project was presented in Media Lab Prado 2012 within the framework of Miradas de Mujeres, and later in Elas Fan Tech in A Coruna, exhibition that was part of $M$-Artech events programme and curated by Anxela Caramés ${ }^{183}$ (Mereu, personal communication, 2019). In MediaLab Prado in Madrid the project was presented by Mereu together with the developers of the platform content and design: Beatriz Garcia and Luisiana Rodriguez and Elizabeth Ross expert in social and art communities who is was part of 3multiverse, collaborator of

\footnotetext{
${ }^{181}$ See Table 3 in point 3.4.2.2.

182 See <www.medialab-prado.es>

183 See chapter 3.4.4.9.
} 
CIMUAT conference in Valencia. M-Artech started with a double scope in the online and offline sphere.

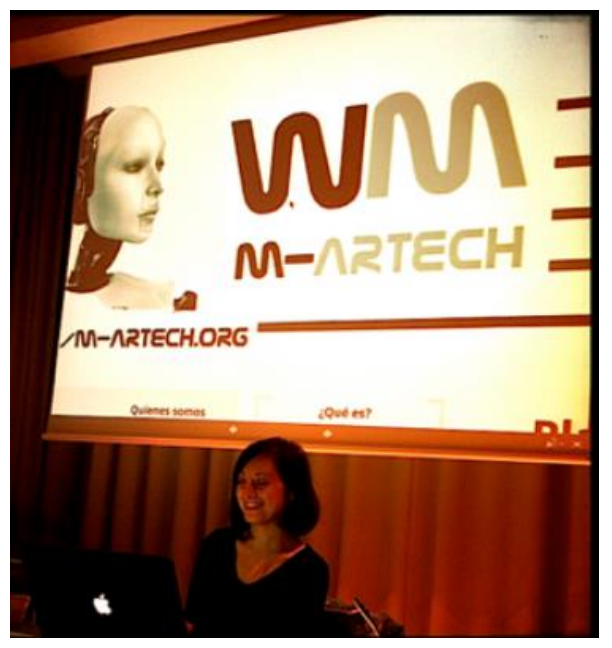

Figure 159 Mereu presenting M-Artech in Elas Fan Tech photo by Anxela Caramés, 2013

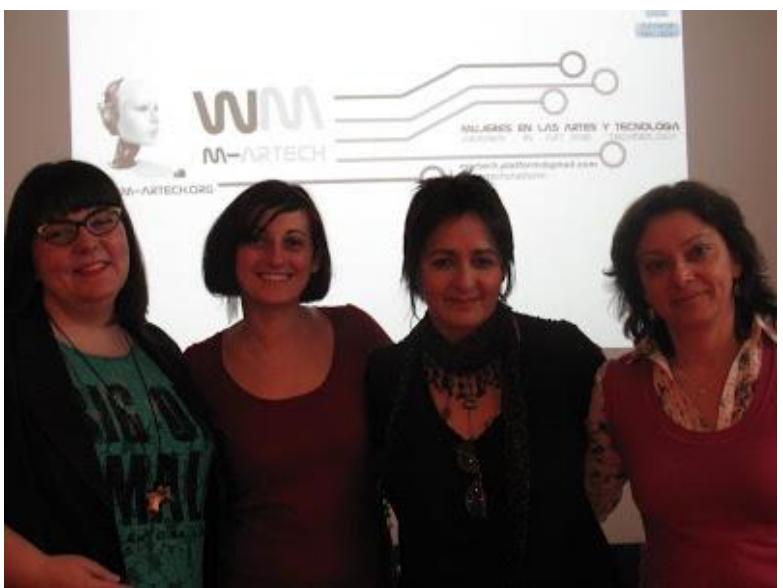

Figure 160 Left to Right: Beatrix Garcia, Francesca Mereu, Elizabeth Ross and Luisiana Rodriguez at the presentation of M-Artech in Medialab Prado Madrid, March 2012. Photo Credit: Elizabeth Ross

On the one hand the online platform was the technological medium towards disseminating the contemporary work by women and making it visible to related institutions and active research groups, and on the other hand to connect them in order to allow the emergence of new collaborative projects, "el medio para tejer nuestras redes de contacto" (M-Artech, 2012).

Aiming to build a digital repository through networks management, M-Artech opened an international call for women artists and researchers interested in interdisciplinary practices in science and technology, who could send their work and professional archival in order to create a public data base with the profiles, art/scientific works, articles and the appropriated information (M-Artech, 2012). The repository is open, and encouraged the participation of all publics, committed with the open source culture. M-Artech proposed a cooperative and collaborative methodology of work that was not common in Spain by then, members aimed to inspire new educative models (Mereu, 2013).

M-Artech was inspired and supported by Plataforma de cultura digital de Chile, 3multiverse, dones\&dones, MAV, CIMUAT, Subemergentes, and additionally had as referents and connection: 
Netzspannung, Flossie, and Leonardo women's publications that gave rise to Judy Malloy publication in 2003. Elena Asons was presented as a inspirational female figure for the project founding, as a pioneer in the conexion between art, science and computer science (M-Artech, 2012). The platform also gathered a blog and introduced links to connect to other initiatives such as: CIMUAT, Flossie, Hipermedula and MzteK, Mujeres y Ciencia, Donestech, FemTechNet, Generartech, femBot collective, Reset, medialab-prado, women\&Software libre.

Due to the lack of financial resources, $M$-Artech remains as the prototype of the project it aimed to be. The platform and social networks are still running by Francesca Mereu, that serve for news posting and networking.

\subsubsection{EnREDadas}

Under the title: "(women) networked by Art and Technology", this platform based in Nicaragua performs a cyberfeminist educational activism through online and offline formats since 2013 . The founders, Gema Manzanares Reyes and Maria Martha Escobar are both social communication journalists specialized in radio and printed press and gender studies and women's rights. In the legacy of the social cyberfeminism described by Montserrat Boix since the $4^{\text {th }}$ International UN Women's Conference, Manzanares and Escobar started this collective project based on the reflection of the potential of the Internet from a feminist perspective, questioning the commercial use of it and the lack of spaces for women, as content consumers and producers (enREDadas, 2014). In fact, as prosumidoras, a term used by the Spanish cyberfeminist theoretician Remedios Zafra when referring to women using and habiting the net not only as producers but as creators, encouraging a cyberfeminism from a political, not hierarchical and artistic approach towards creating a new world (Escobar, 2013). Zafra's publications are the main source of methodology and terminology for enREDadas, also of the Latino American network of cyberfeminists they are part of with their allies Ciberseguras in Mexico, together with have celebrated three editions of the FemHacks, hackatons 
under the name of Zafra's term '(h)Adas' (2016): Adas ConectAdas: reconstruyendo la RED desde Mesoamerica (EnREDadas, 2017).

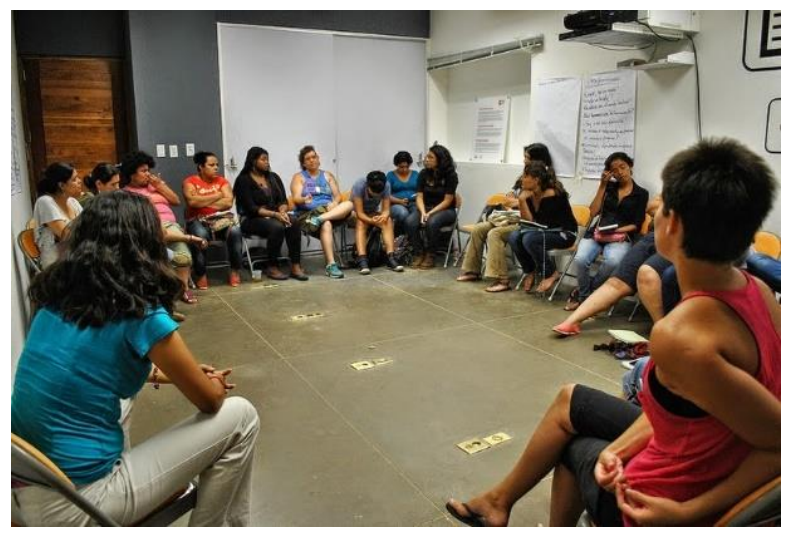

Figure 161 Cybferminism introduction Workshop 2017

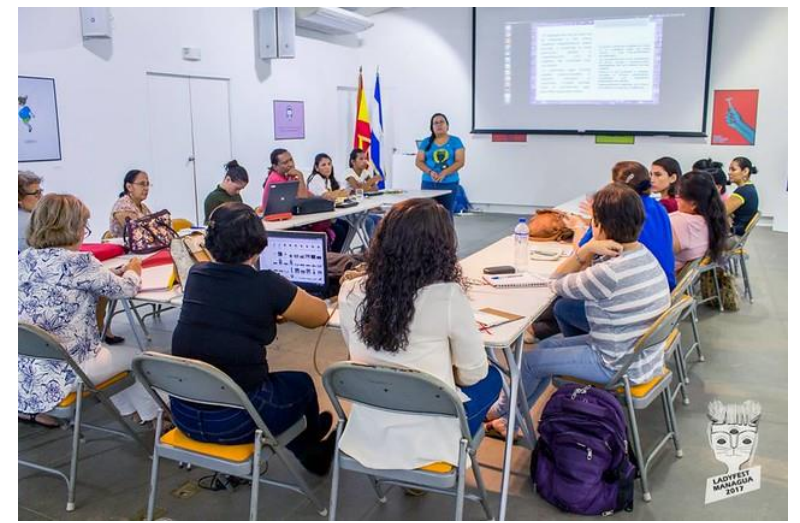

Figure 162 Workshop Cortos Creativos, 2017

EnREDadas'strategies are based in community building and network alliances, by connecting feminist networks with technological communities, women activists and women in art and technology through flows of work and collaboration. Through their offline and online programme of activities, they address a transgenerational audience, where all genders are welcome to an open space for dialogue to encourage an ethic use of technology, promoting open source tools and topics such as: gender, identity, cyberfeminism, free software, cybersecurity, virtual harassment, human rights, feminist art and artivism. EnREDadadas sees technology as a tool for social change, a way to decrease the gender gap in women's accessibility to the Internet (enREdadas, 2014). Their strategies are based on community building and embrace strategies from informal to more academic, combining art practices with technological skills through collective activities such as games, exhibitions, conferences, panels, discussions, film screenings, documentaries and DIY workshops. They also organize Editatona, Wikipedia edition workshops towards women visibility in Wikipedia and with Ladyfest, screenings of documentaries, movies and video poetry made by Nicaraguan women. The events are organised in collaboration with universities such as Universidad de las Mujeres and Centro Cultural de España en Nicaragua. The concept of connectivity and networked activism is present in all their activities, like 
the exhibition Violencias Conectadas (2016) The attendants of EnREDadas events belong to different genders and generations and professional backgrounds. "No estamos por estar, estamos para hacer el cambio", EnREDadas was part of the Worlwide Forum of Internet Governance in 2017, in the discussion with the Chilean NGO about re-apropiation of the Internet as space of creation and collaboration between women (EnREDadas, 2018).

\subsubsection{Momentum: Women, Art and Technology}

In 2013 Muriel Magenta, artist and professor of Art at the Arizona State University, founded Momentum, together with Judith Brodsky and Ferris Olin from Rutgers Institute for Women and Art. Momentum is a network project to celebrate the achievement of women in the field of art and technology. The project aims to establish a collaborative dialogue space through digital imagery and the written world. Momentum, subtitled Women, Art and Technology, involves at larger an international community of women who had both established an emerging use of technology as their form of expression in their artwork. Magenta has an unarguable experience and background both in computer and new media art formats and in community building and women's networks. As I discussed in chapter 3.2.3., she founded Women on-online! in 1995 for the International Women's Conference in Beijing. Unlike the project of 1995, Momentum designed an offline programme as an online platform. In our telephonic interview Magenta (2018) explained to that for her, the reason behind a women-only project is based on the different spirit women working with technology have in their artwork.
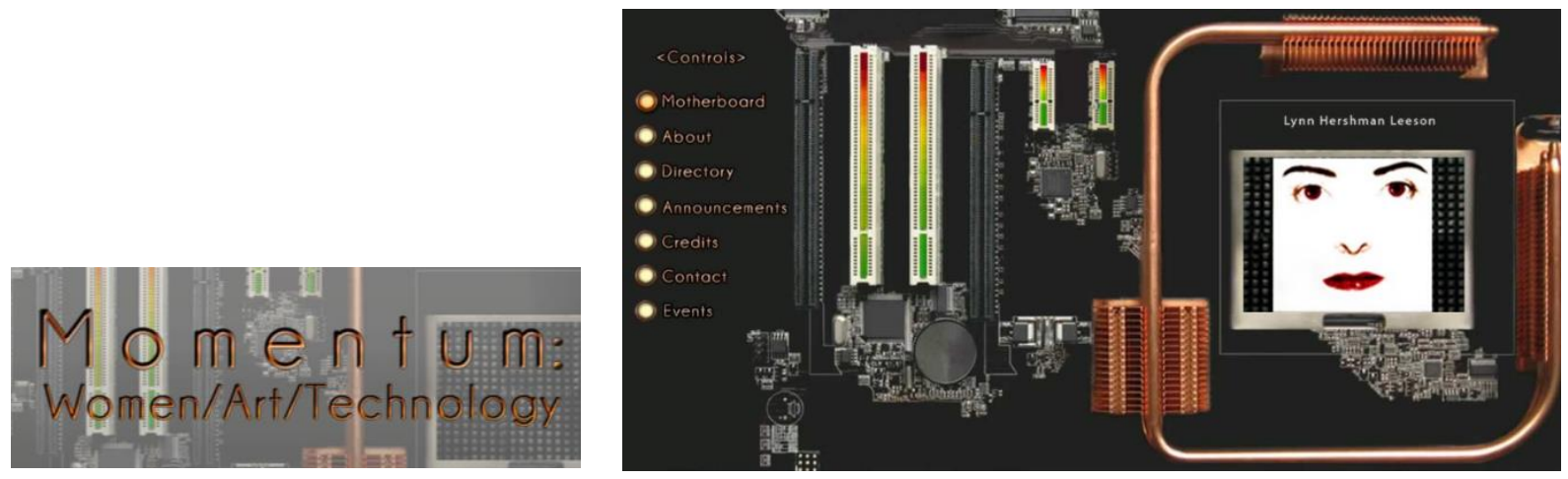

Figure 163 Screenshot main page Momentum website at https://bit.ly/31TurwS 
Momentum platform development also involved the work of research assistants of Magenta. To note that in the digital platform, the 'Home' section has been called Motherhood. It works like a platform to archive activity content and as a repository of professional women's work through the directory (of women art professionals using technology): Artists, authors, Art historians, curators, educators, technologists: between who: Rebecca Alleen, Lynn Hershamn Leeson, Jennifer Hall, and Tamiko Thiel, Paul Christiane, Julie Wosk, Monika Fleischmann, Nancy Paterson, etc. Momentum programme has a series of events that has been held in four different cities in United States (New York, San Francisco, Arizona, Los Angeles, Chicago, Denver, etc.): exhibitions, symposium, film screening and public discussions. The events curated by Magenta brought together not only women artists in new media but also women scientists, researchers and curators.

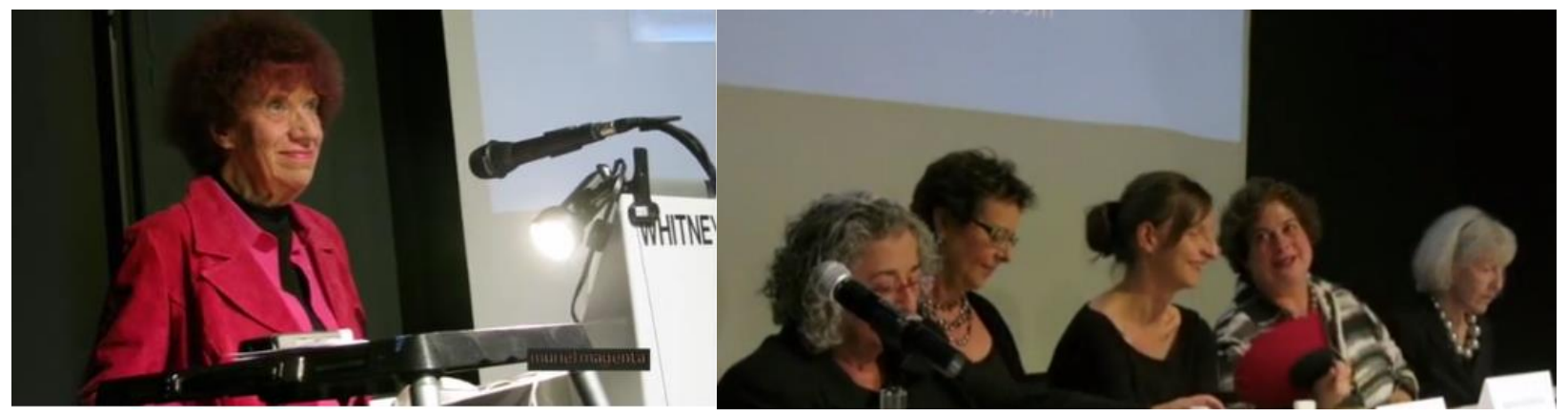

Figure 164 Screenshot of the video excerpt from the Momentum: Women/Art/Technology special event on the theme of "Art Practice," held at the Whitney Museum of American Art, Film and Video Gallery, June 13, 2013. Left Muriel Magenta, Right artists presented Adrianne Wortzel, Janet Echelman, Ferris Olin and Karolina Sobecka

Until 2015, the project consisted in the digital platform, a series of events curated and organised by Muriel Magenta, and a sister Momentum component administered by the Rutgers Institute for Women and Art. The Institute developed a parallel Momentum (accessible in the own Rutgers Institute website $^{184}$ ) project through a series of exhibitions and events under the same name that were held in New Jersey in the institute spaces: exhibitions, public lectures and residencies. The Rutgers Momentum platform holds another directory of artists with open submission and the MTV: Momentum Technology

\footnotetext{
${ }^{184}$ See $<$ https://bit.ly/2FA5DR7>
} 
Videos, an online archive of the online festival of video art works. Although the main topic is the same, Women, Art and Technology, the series of exhibitions by Rutgers that works independently in terms of vocabulary and terminology, in coherence with the gender studies programme of the institute. Two exhibitions, Moment, Women/Art/Technology in 2014-2015 and Trans Technology in 2013 with Bryce J. Renninger and Christina Dunbar-Hester, Guest Curators. These exhibitions were specially focused in topics of gender and feminism that just in women's work visibility (Rutgers, 2019).

Although it is not reflected online, Magenta told us in our interview that she continues with Momentum in her classes, where she makes students develop projects through new media art formats with excellent results (Magenta, personal communication 2018).

\subsubsection{Void Lab}

Void Lab was a feminist student organisation in UCLA that was active from 2015 to 2017 in the Media Arts Master Programme. In the current course 2018-2019, twelve females over three males in addition to three non-binary and queer are the number of students ${ }^{185}$. However, just five years ago the number was notably lower, when only two female students found themselves in an urgency to start any type of alliance by themselves. First named Clit Lab, its name changed in 2016 to Void Lab when more female students joined in the new academic course, and the number grew from two to five, but still low compare to male -that were eleven- (Stojanov, personal communication 2018). In our personal interview, early member of Void Lab, Samanta Stojanov (2018) told us that the collective came to talk about technology, art and equality, "going beyond the binary male-female and a feminism based in sex organs", the collective widened its members to trans, queer and non-binary, gender non-conforming people in campus that looked for forms of identity expression through new media arts:

\footnotetext{
${ }^{185}$ Data collected through my own surveys for this research
} 
We were the minority to talk about our voices were not being heard, we were feeling ignored, at the same programme of school there were some professors who didn't have a teacher assistant female in five years, he only wanted to hire women were not getting the same opportunities. We were really happy to see that changed a lot during the time I was there, even professors changed the attitude (Stojanov, personal communication 2018).

Despite the original founders and the first organisational work by Xin Xin, the project became collectively built, where everyone who applied to join became a co-founder, following the premise towards a feminist intersectional form of organisation:

...web team, no hierarchies, we tried to build it kind like not to have a leader of the party, I think that worked in a lot of ways, essentially for that groups were created Void Lab was a way to put ideas out there, to give ourselves a voice a place a collective a support group for people who cannot is about gender race, nationality origin, accent, economic level, we can share the negative experience in this space (Stojanov, personal communication 2018).

Void Lab was based on compassion and self-reflection, towards celebrating the differences by collaboratively contributing to the events in singular styles for leadership and empowerment. The collective wanted to go against the misconception of equating hegemony with solidarity and to transcend every border imposed by institutions and society at large (Void Lab, 2016). The scenario in the Media Arts programme was a reflection of the general situation in the white male-dominated tech world in California, while the diversity of races and languages in the state, and especially in Los Angeles is very high. Void Lab members found in their campus and other collaborator spaces a form of activism and resistance. The group was formed by around one hundred students, educators, artists, designers and technologists that had periodically meetings in campus to organize workshops, exhibitions and panels, including workshops for kids, all that was managed with a grant from a programme for equity and diversity that they received. With the grant they were able to pay 
undergraduate students to work. Faculty members such as Vesna, Rebeca Mendez (from FEMeeting) and Lauren McCarthy supported their project. Together with Vesna, they organised an exhibition and a panel in Ars Electronica in 2017: Feminist Climate Change, in the same edition that Faces celebrated the $20^{\text {th }}$ anniversary ${ }^{186}$ (Faces, 2017).

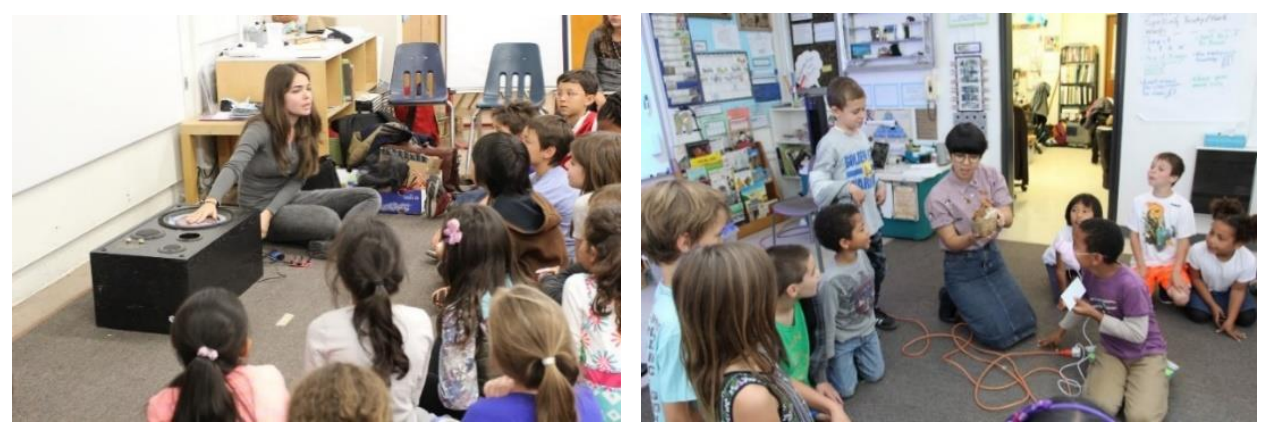

Figure 165 Collaborated with K-12 students and the Lab School with littleBits to integrate electronics into art installations with the intention of exploring sound and light. Photo credit: Janelle Castillo.

Despite the openness of the membership, Void Lab was criticized as discriminatory by some students and campus colleagues. However, it had a positive impact in the faculty members and the academic programme, which changed when Void Lab spread outside UCLA with the graduation of its members. In our interview, Samantha Stojanov stayed the following:

The collective needs to last forever. The people who came after me they were amazing, the culture has changed, Void Lab presence there changed things. I don't even know if feminist is still the same. now the anti-discriminations, postcolonial bases are part of the programme, we expect the professors to have a critical understanding, I am sure it is not over, I feel it has changed, maybe the whole culture is changing, is short of change inside of every individual (Stojanov, personal communication 2018)

Void Lab design was inspired by the hacker artists collective Deep Lab in Studio for Creative Inquiry in Carnegie Mellon University. Within the project, new related projects were born, such as

\footnotetext{
${ }^{186}$ See chapter 3.3.6.
} 
Descentralizing the Web ${ }^{187}$, by Symrin Chawla, Amanda Stojanov, Leah Horgan, Devin Johnson, Emily Eck about the gender bias and inequality in internet culture and Feminist Pornographic Collective Consciousness ${ }^{188}$ by Yuehao Jiang, Xin Xin, Sanglim Han, Echo Theohar and FEMMEBIT $^{189}$. Members of Void Lab are still in contact through their own mailing list, some started to teach at university, others follow with their careers as artists, and all of them agree that the experience in Void Lab changed their life for good (Stojanov, personal communication2018).

\subsubsection{SisterSMATR}

SisterSMATR is an all-women organisation based in New York that designs activities addressed to young women of color in SMATR: Science, Mathematics, Arts, Technology and Robotics. They also offer courses in music and entrepreneurship. It was funded in 2016 by the musician and multimedia artists Nona Hendryx, the social justice advocate and innovators JoAnn Chase and Makani Themba. In United States the numbers of women of color at universities, especially in STEAM fields, is very critic. While women of color are $39 \%$ of the female population, less than $10 \%$ of all bachelor's degrees in computer science, being Latin women the more underrepresented. Among all female employed in ICT occupations, only $12 \%$ are Black or Latin women. Within the 177 Silicon Valley firms, less than $2 \%$ employees are Black, Latin or Native American women. Although women of color are $80 \%$ of the emerging female-led small businesses, in tech Black women account for less than $4 \%$ of female-led startups (Kapor Center/ASU CGEST, 2018). The organisation seeks to disrupt the patterns of exclusion by "supporting young women of color to break through negative socialization and providing training, tech and mentoring resources to help them become more capable and competitive in the work world" (SisterSMATR, 2018):

\footnotetext{
${ }^{187}$ Available at $\langle$ https://bit.ly/2X401tf $>$

${ }^{188}$ Available at $\langle$ https://bit.ly/2FyZcO8>

${ }^{189}$ See point 3.4.5.5.
} 
SisterSMATR lives at the intersection of arts and technology to create opportunities for young women of color to take STEAM to the next level. Our unique approach leverages music and art to engage young women in robotics and other technology. We focus on supporting those attending schools with limited arts and technology instruction to provide opportunities to experience cutting edge technology, coupled with dynamic forms of cultural production, intended to inspire and prepare them for a brighter future.

SisterSMATR designed a school programme called The Fab Lab at the Long Island City, where groups of girls from 13 to 16 years received courses on creative technologies (animation, sound, robotics, graphic design, film/video and coding), and they visit major technology company studios in different disciplines to experience the professional environment of arts and technology, mentorship and inspirational figures. The organisation also provides resources through subscription to the newsletter (SisterSMATR, 2018):
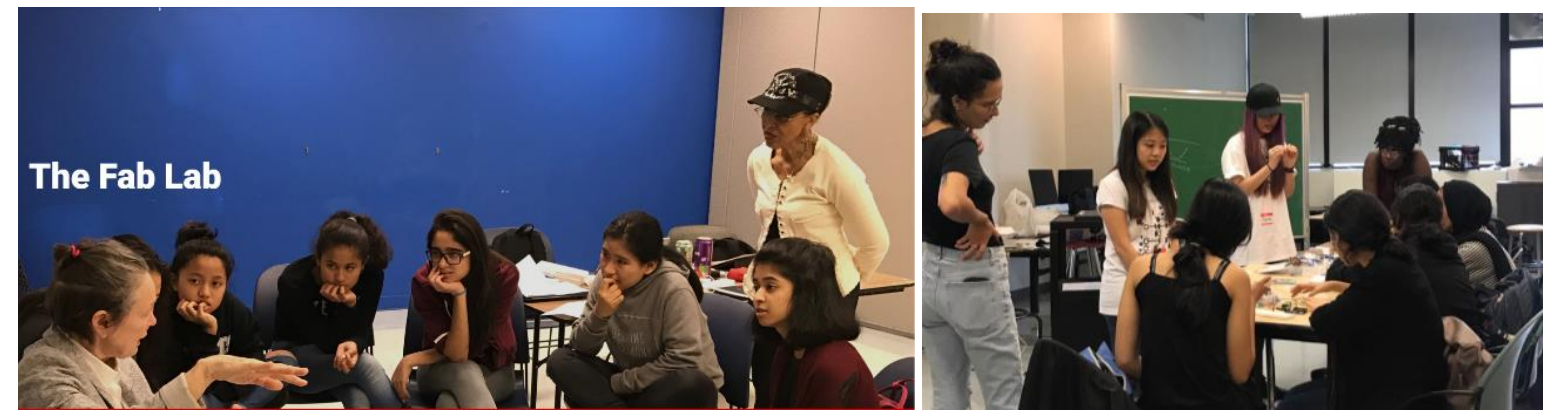

Figure 166 SisterSMATR, Group in The Fab Lab, working course 6th October 2018. Photo Credit: Nona Hendryx.

\subsubsection{WITCiH}

In 2017 the interdisciplinary and intercultural artist Bishi Bhattacharya and the producer Matthew Hardern, aka Glamorre, both based in London, founded WITCiH, a project dedicated to increase women's visibility in creative industries. WITCiH is addressed to female in technologies, 
electronic arts and STEM, with a focus on gender. The project is supported through public funding by Arts Council of England. WITCiH is a manifestation of Bishi professional and artistic personality, combining production, creativity, music, art, technology and entrepreneurship. Her Bengali inheritance gives her a intercultural profile, she also combines different art practices, music, traditional clothing with avantgarde designs, and showing a strong commitment to empower women through platforms such as WITCiH. The brief manifesto states as follows (Bhattacharya, 2018):

Science, Technology, Engineering \& Mathematics (STEM) have always had an intimate relationship with The Arts; WITCiH aims to explore \& expand our knowledge of women working at that intersection - past, present \& future. WITCiH is female focused \& welcoming to all people throughout the spectrum of gender \& identity. WITCiH aims to educate $\&$ inspire people through an understanding of Women in Tech, set in an historical context. WITCiH aims to highlight, celebrate $\&$ showcase women currently working in technology with a clear focus on creativity \& the arts.

The project works through its social networks and a blog website in Tumblr and a programme of real activities. WITCiH uses their social networks not only to promote their activities, but mainly to share information about contemporary female artists in new media and electronics, providing biographies, official websites, and interesting data towards making more visible women's creative work. They also share content about women in history of computing and electronic music and new media arts, and videos about gender and technology and women in tech. In December 2018, WITCiH celebrated its first Festival, funded by PRS, under the title: The State of Gender? Reflecting upon the situation of women in the tech industries, developing and pushing them to "the forefront of change" (Bhattacharya, 2018). 


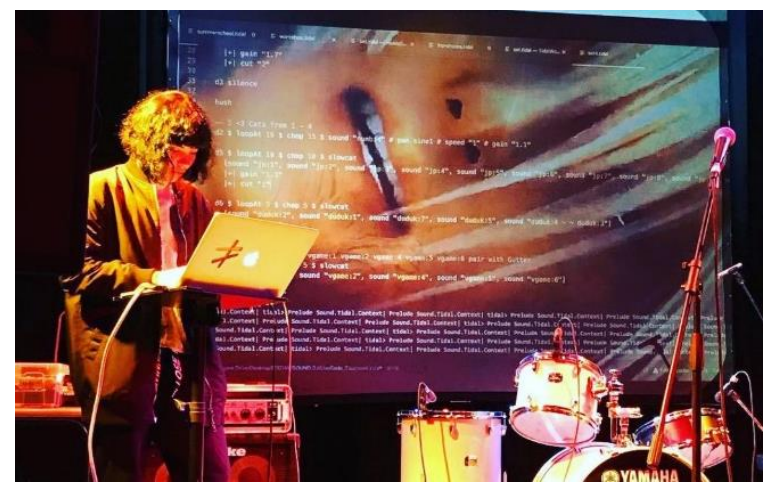

Figure 167 Chagall performing on 26th September 2018. Chagall is part of PRSF Keychange. www.keychange.eu

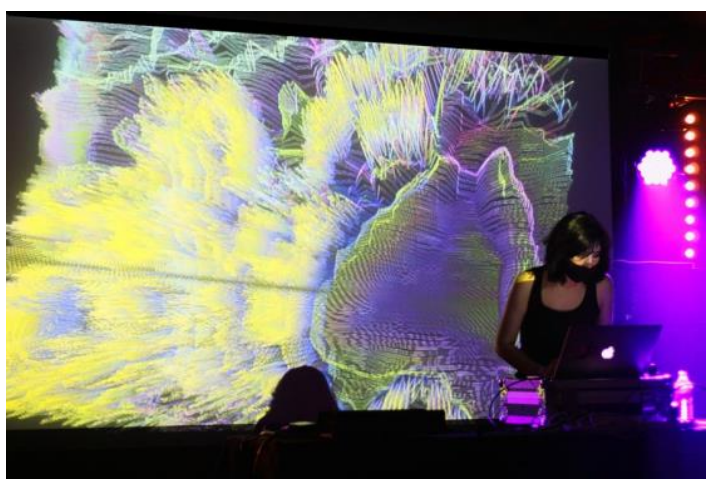

Figure 168 Miri Kat, Live Code performance 26th September 2018

The festival was held from $26^{\text {th }}$ to $28^{\text {th }}$ December 2018 , and WITCiH was presented as a commissioned platform. Bishi created a space for local and international female artists, such as Lia Mice, Miri Kat, Rebekah Ubuntu, Vicky O'Neon, four of the most exciting up and coming female \& non-binary artists in the UK today. Also, Bishi, Chagall, Di Mainstone, D.N.W., Gazelle Twin (guest lecture), Output Arts, and Vicky O’Neon. (Bhattacharya, 2018). After the festival, Bishi has organised several activities (Summer Series: musical performances, food, talks \& demonstrations) during May, June and July 2019 at the Barge House, some performed by herself and others with guest artists such as the live performances by Abi Wade and Laura Kriefman. She has also taken part with WITCiH of the annual Woman with a movie camera summit, organised by the British Film Institute in June 2019. WITCiH plans to open a Pantreon account to work on donations. Bishi work relies notably on networking, she is a very active woman that takes part of women women and involves some of the members in her activities.

\subsubsection{Superrr}

Based in Berlin, Superr is a community formed by female, trans and non-binary people in the arts, science, technology and also journalism, activism and others. It started in 2015 with the director 
and co-founder of Prototype Fund ${ }^{190}$, Zara Rahman and Julia Kloiber out from a series of female colleagues' meetings. In 2019 it was launched as a project committed to ethic in technology, committed to equal opportunities and diversity, promoting collaborative work, collective exchange and learning. Founders were aware of the disconnection between the female professionals. Since then they have a programme of regular meetings, running campaigns, community spaces building "there were a lot of conferences and events but the conversations we were looking for was more than small talk on the margins of a conference" (Superrr, 2019):

Connecting a diverse group of people is at the core of Superrr. We strive to connect people from many different backgrounds - from medical doctors, to anthropologists, social workers, artists and technologists, all of whom have a shared interest in some aspect of positive social change. Diversity doesn't only make our meetups and discussions more interesting, it makes the community more resilient and strong.

The project is divided in two main formats: The Lab and the Community. Regarding the community building, Superrr encourages the implementation of their simple formats in other cities by other new members. Currently they are preparing a meet up in London for the first time in February. Their formats are based on real encounters to stablish ties, exchange experiences and promote collaboration between professionals of different disciplines.

${ }^{190}$ See <prototypefund.de> 


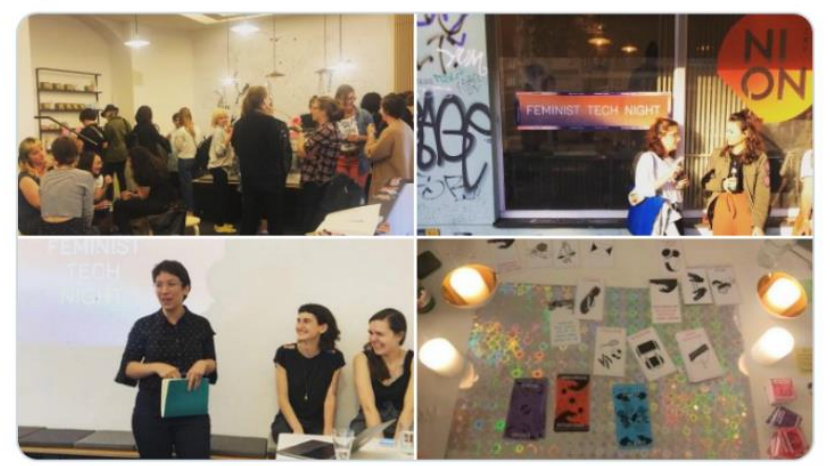

Figure 169 Feminist Tech Night hosted by Superrr in Berlin on May 2019. Retrieved from official twitter Superrr account.

Described as a research and advocacy organisation, Superrr Lab is focused on promoting ethical uses of technology while encouraging people in the field, supporting artists, writers and activists that aim to "make a better world" (Superrr, 2019). They collaborate with public and private originations to create more inclusive projects. Currently they are running Feminist Tech Fellowship with Mozilla Foundation, working on how feminist positions can improve research on technology, and also on Implicit Development Environments Research Group (IDE) ${ }^{191}$, founded by the Ford Foundation.

\subsubsection{Fem Tek Bilbao}

Fem Tek is a feminist project in the Pais Vasco that seeks to create knowledge building spaces at the intersection of contemporary artistic practices through technology from feminist perspectives. In 2018 Hika Ateneo cultural center in Bilbao chose Blanca Ortiga to develop a project in such terms, who from her professional and personal network proposed a list of artists and the design of Fem.Tek. The starting framework was to look for the connection nodes in contemporary arts, technology and feminisms, from a practical perspective within art practices but also with a special interest in the research aspect of them: "Fem Tek es un programmea expandido en el tiempo y en sus contenidos y

\footnotetext{
${ }^{191}$ Available at < https://superrr.net/project/implicit-development-environments-research-group>
} 
disciplinas que, desde las prácticas artísticas contemporáneas, trata de generar espacios críticos de debate y producción de saberes” (Fem Tek, 2018):

The design of the programme is committed to a feminist methodology based on the awareness of the precarity of the conditions of production based on gender, therefore the activities are design towards avoiding such conditions (Ortiga, personal communication 2019). Fem Tek methodology is based on "new modes of making: to make from our position, create network, to measure consciously, to remunerate artists fairly, disassemble distances, connect global and local and appreciate the creative and research work" (Fem Tek, personal communication 2019). The plan of expansion of the project and funding is mainly concern about providing fair work conditions to guest artists, therefore the main objective is to establish a strong local node in Bilbao with translocal connections. The project, selforganised between Hika Atenea and Ortiga, has the support governmental and cultural institutions in Bilbao. The first programme of activities has been performed from October to December 2018 and was formed by workshops, talks, experience nights (performances), an open lab and a virtual artist residency. The guest artists that leaded the activities were Spanish female artists that have international recognition, such as Maria Castellanos, Irantzu Valera, Monica Rikic, Saioa Olmo, Jara Rocha, Snelting, Rachel_Runner, Jana Jan, Paralux, Quimera Rosa and Rebeca Wikilson. The Chilean artist Constanza Pina aKa Corazon de Robota also leaded a workshop. The activities have been held in the spaces of Hika Ateneo and the Fine Arts School, and have embraced topics and techniques from biohacking, cyborg post-porn and cyberpunk, new wearables, bio art, hacking, coding, DIY synthesizers, cyber harassment, etc. 


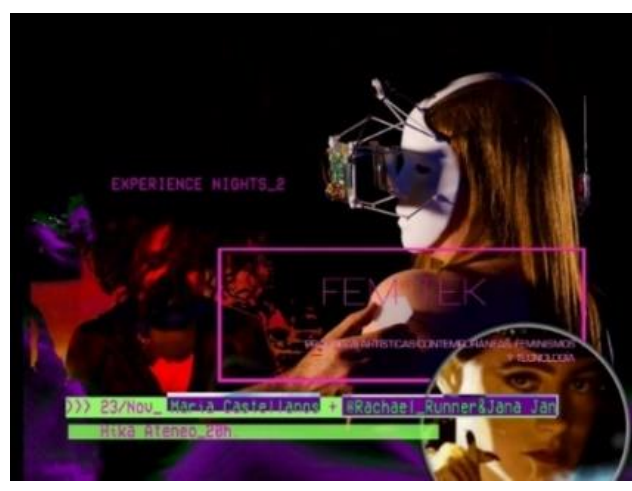

Figure 170 Announce Maria Castellanos and Rachel_Runner and Jana Jan performances 2018

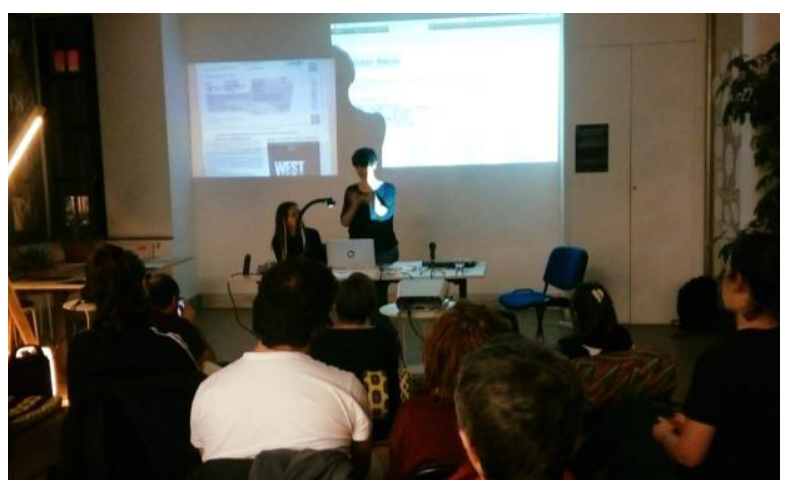

Figure 171 Jara Rocha, Saioa Olmo and Femke Snelting talk in November 2018

At the Hika Ateneo, the third Tuesday of each month there is an Open Lab, an open space for knowledge sharing towards dialogue and experimentation in arts and technology. Based on their objective of supporting the research and creative projects accommodating to diverse life conditions, Fem Tek offers a virtual artist residency where the artists/collective can develop a project without space or time restrictions, designing themselves their schedule and communicative plan (Fem Tek, 2018).

In the short period of development of the project, Ortiga has brought her professional network in new media art practices to Bilbao, establishing a node of activities and culture making that is strongly committed to establish connections from a position that avoids to precarious the artistic conditions of production. In Spain the situation of precarity for people involved in culture and art making, especially women, is a current issue that they have to struggle with. The lack of financial support and resources for independent curators, artists and creators to achieve a minimum level of salary creates a general situation of frustration and tension between cultural centers and artists, factor that it is known between the professional network itself. As Remedios Zafra (2017) explains in her latest publication:

En los últimos tiempos, sin embargo, ha ocurrido que la valoración del ejercicio artístico se ha socializado del lado de la afición y el placer como aquello practicado en tiempos ociosos y considerado difusamente como actividad laboral [...] No tardamos en advertir que el sistema 
cultural se vale hoy de una multitud de personas creativas desarticuladas políticamente. Multitud alimentada de becarios sin sueldo, contratados por horas e interinos, solitarios escritores de gran vocación, autónomos errantes, doctorandas embarazadas, colaboradores y críticos culturales, polivalentes artistas comisarios y jóvenes permanentemente conectados que casi siempre "compiten" (pp.19-21):

From this position of awareness, Fem Tek has design a sustainable programme that allows the project to keep growing without exhausting the people involved in it: "we have by now a local projection for financial support, the application process is an additional work, the way to make the project sustainable". Fem Tek plans to establish collaborations with consciousness, achieving first basic funding to create informal relations, factor that is essential from feminist perspectives (Ortiga, personal communication 2019). This point relates us to the context that lead Fem Elek in Barcelona to its end, by not being able to provide a fair work remuneration to the guest artists ${ }^{192}$.

Through their Facebook and Twitter account they share their activities through events, disseminate their achievements and contents and reinforce the network by widen it virtually beyond Bilbao local boundaries.

\subsubsection{Space-Based Communities}

"What is essential is that feminist hacking entails a combination of technical competence, feminist principles, and socio-political engagement.

Prominent feminist principles of the new hacker culture include collectivity in the form of common action, informal and formal transfers of knowledge on the basis of feminist pedagogy, and the production of visibility - and not in the sense of individual or collective positions but rather in the sense of exposing hidden mechanisms of the technological realm, of the "off-spaces" that are never in

\footnotetext{
192 See chapter 3.4.5.1.
} 
the picture and yet are constitutive for what is seen. Such things include the physical, economic, and material structures in which technologies are embedded. The foundation of this emancipatory and oppositional culture is a redefinition of the relation between online and offline spaces, which is in turn based on the production of its own new spaces and structures"

Sollfrank, 2018

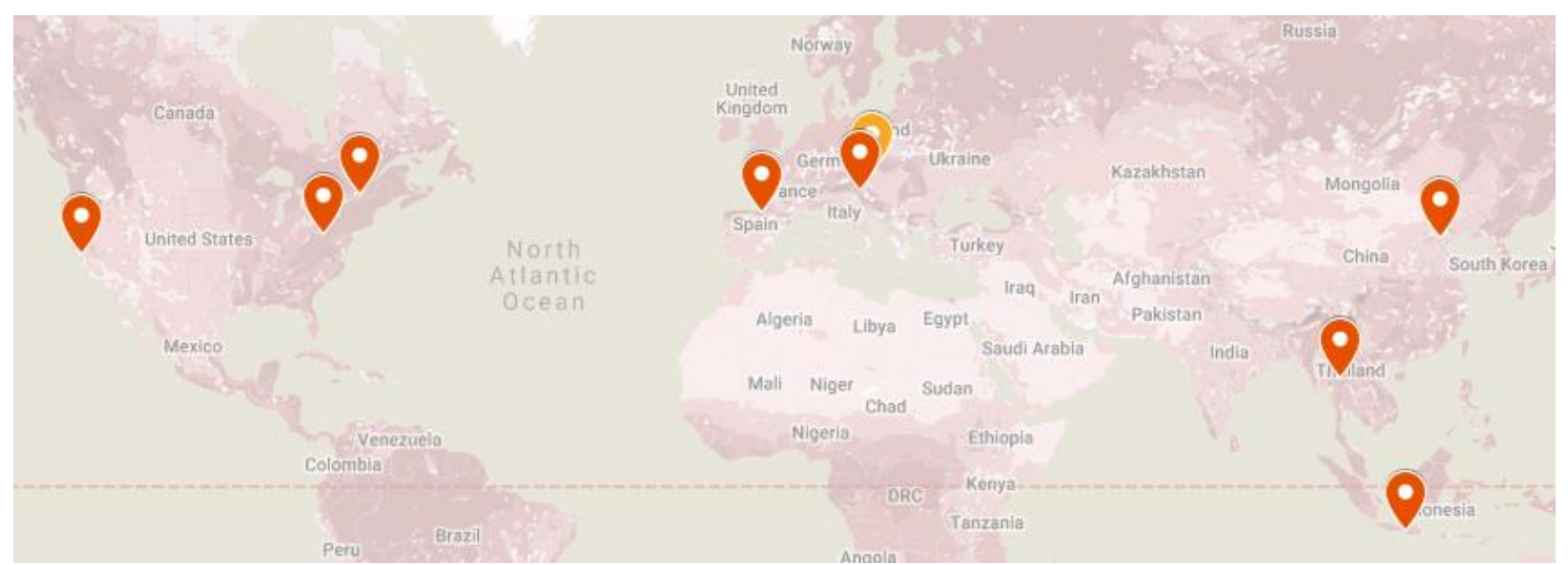

Figure 172 All-Women and Feminist Self-organised Spaces at the intersection of Arts and Technology since 1998 worldwide. Screenshot taken 18th July 2019

\subsubsection{Studio $X X$}

While cyberfeminism was flourishing in European net artists networks after the emergence of VNS Matrix, in Canada, the arguable first media art center dedicated to women is Studio XX, was founded in 1996 in Montreal by the professor Kin Sawchuck, the filmmaker Patricia Kearns, the sound artist Kathy Kennedy and the cybernetic Sherryl Hamilton. Aware of the low number of women involved in technology and the high expansion of new Internet and digital tools, they planned Studio $X X$ as an alternative space to institutions, where women could take an active part of the technological development through emerging media art practices. Studio $X X$ is a self-organised cultural center committed to the support and promotion of Canadian women media artists that has enabled an international work exchange and that has established its own community through more than two 
decades of activities, providing open accessibility to its network to artists, students, educators, researchers, creators, and anyone interested in the intersection of art and technology.

The Studio supports projects from individuals and communities who use and design more accessible technologies, from artists who experiment with recycled materials and free software, from those who work with post-internet practices, and from people who define the Do-It-Yourself and Do-It-Together ethics. Studio XX supports feminist artist communities in three ways: the production of artworks in digital art through artists' residencies by providing space, equipment and specialized resources; the dissemination through the presentation and promotion of artistic works; training through workshops and activities (Studio XX, n.d).

Studio $X X$ is characterized by its multiplicity of formats within the concept of networked feminism and cultural activism, embracing "micropolitics and challenging sexism and misogyny insofar as they appear in everyday rhetoric, advertising, film, television and literature, the media and so on" (Munroe, 2013, p.23). The center provides a space for critical creation and discussion and a list of activities (workshops, talks, performances exhibitions, community and educational activities) that confronts the still gender disparity in terms of access to technology, unequal salaries and gender participation in major media arts events in Montreal and technology sectors and the Arts. Over the years, their activities have gradually evolved until a wide number of events and formats of content publication and diffusion based on the network of collaboration with other professionals, cultural and academic centers: Wired Women Salons or Salon Femmes Branchées, The XX Files, radio programme on CKUT, The HTMlles, feminist festival of media arts and culture,.$d p i$, electronic feminist publication of art and digital culture created in 2004, The Matricules Archive Project, an archival of the artwork created over the years in the center created in 2008 in collaboration with the National Film Board of Canada, Laboratory, a space well technically equipped and accessible for members to work and create, Programme of 
residencies for artists and specialized training, providing a collaborative creative environment and the technical tools and resources to produce their work and Slow Tech Programme, 2017-2020. The community that Studio $X X$ has created during more than two decades has grown with the project and the range of activities. Focused in mutigenerational audiences, the studio brings together young generations with first wave of feminist media artists in Montreal.

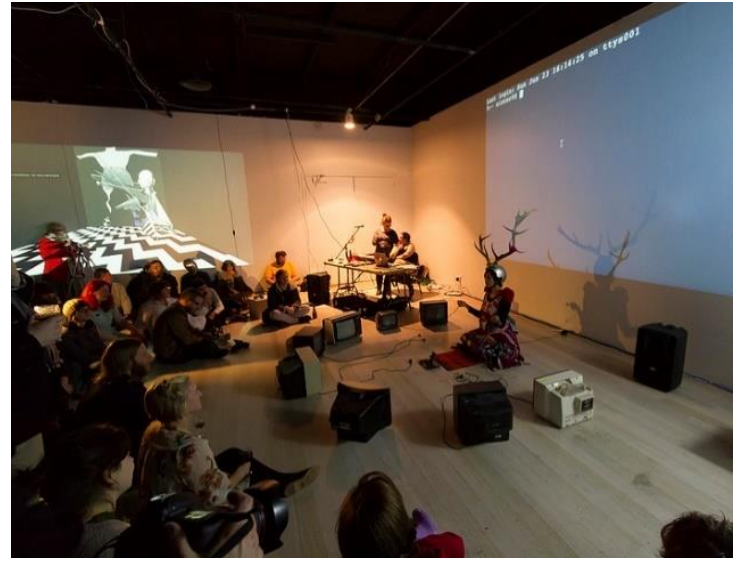

Figure 173 Studio XX. Networked Art Forms and Tactical Magick Faerie Circuits. 2013. Photo: Aaron Horsley

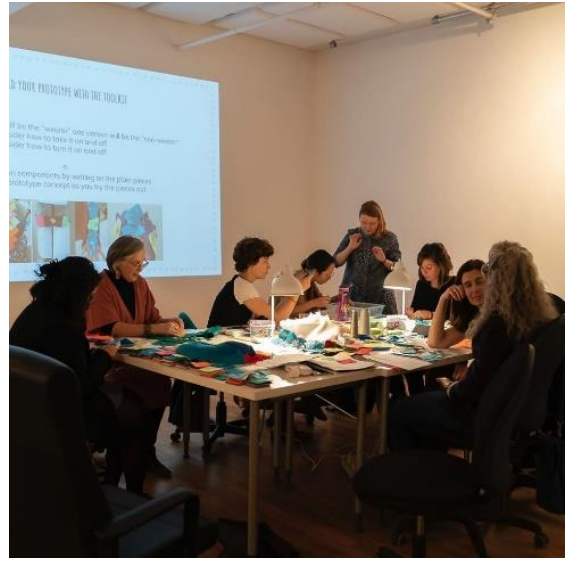

Figure 174 Workshop Built your Prototype with the Toolkit, 2019. Retrieved from Studio XX Official Facebook Page.

\subsubsection{2. $\check{C} I P k e$}

ČIPke is a self-organised women-only initiative in Ljubljana dedicated to creating a learning space in science, technology and media art. It was founded in 2013 by the new media and bio artists Ida Hiršenfelder and Saša Spačal who aimed to design and organize a practical educational programme based on workshops for women and a space for conversation about and with women working in this fields. $\check{C I P k e}$ activities are held in Rampa Lab, a hacker laboratory in art, science and technology addressed to youth at the Kersnikova Institute, a non-profit cultural organisation founded by the students of University of Ljubljana. A mentor from the institute, Staša Guček, joined the ČIPke later and altogether run and nurture the community. The concept of women-only workshops for technology learning was originally conceived within the Eclectic Tech Carnival ${ }^{193}$ celebrated in 2012 in Kiberpipa

\footnotetext{
${ }^{193}$ See point 3.4.5.1.
} 
within the framework of the Red Dawns $-13^{\text {th }}$ international Feminist and Queer Festival. Kiberpipa programme manager was the musician and sound artist Luka Prinčič, a feminist programmemer who advocated for open source technologies, who worked also for Kersnikova Institute. ČIPke in Slovenian means lace, it was chosen as name for its dual meaning, referring to culturally considered female textile tasks and new computer terminology:

1. čipke plur. n.: laces: a delicate fabric made of yarn or thread in an open web like pattern.

2. čip n. Electronics: chip: an electronic component processed to have specified electrical characteristics in an integrated circuit.

3. čipke plur. n.: laces: a plural abbreviation of the name of mathematician Ada Lovelace who created the first algorithm intended to be processed by a machine.

Founders of $\check{C} I P k e$ emphasize that "women can equally well deal with patterns and logic in electronic circuits and software, and we propose a look at technological professions that go beyond sexual divisions" (Hiršenfelder \& Spačal, 2015). ČIPke plays with this terminology around its platform texts, netting community building terminology with knitting electronic patchwork and lacing collaborations: "Our laces are braided through an international and local network of inspirational hacklabs, initiatives, festivals, individual makers with whom we create better conditions for work, research and socializing" (ČIPke, 2013). $\check{C} I P k e$ uses the term $\check{C} I P k a s$ to refer women involved in their activities who becoming part of the community. 


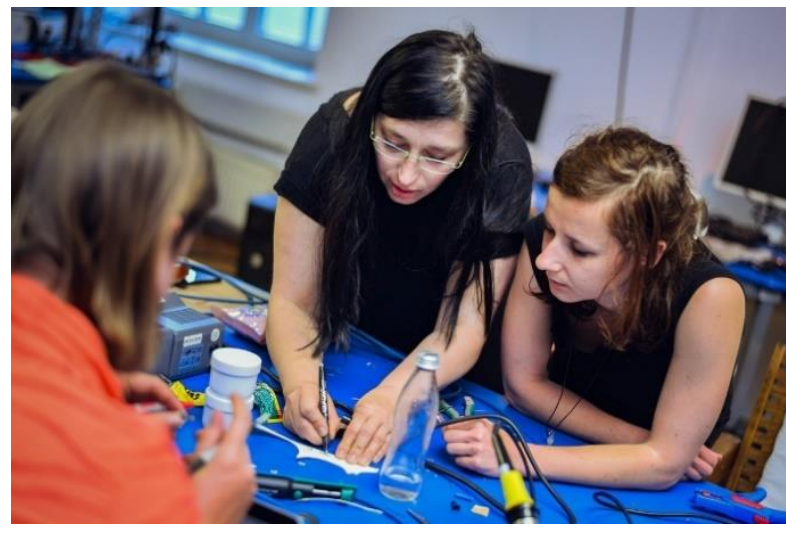

Figure 175 CIPke Images of Workshop by Robertina Šebjanič Underwater Lounge about underwater acoustics and sound spectrum in May 2016

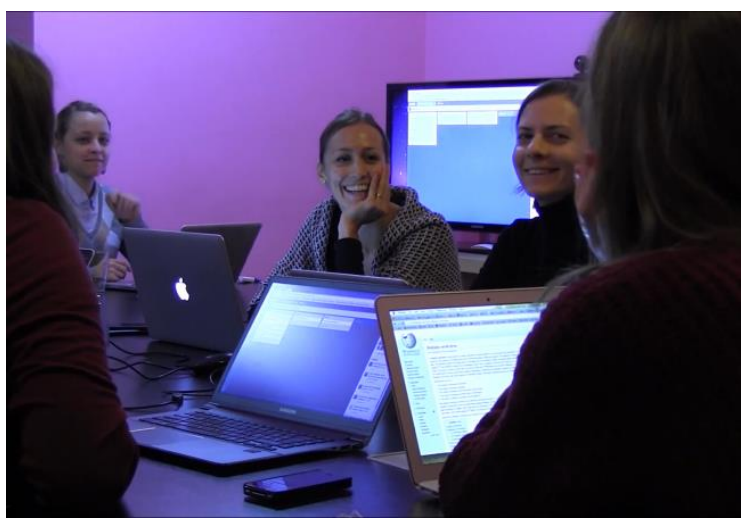

Figure 176 CIPke members meeting. Screenshot of CIPke::: Flow Documentary (Trailer) 2014. Available at https://vimeo.com/84292161

Under the title: "initiative for women with a sense for technology, science and art", Hiršenfelder, Spačal and Guček organize five workshops a year for women, to learn skills on electronic patchwork: robotics, electronics, wearable technologies and open source programmeming for graphic design, video editing and sound synthesis, between others. $\check{C} I P k e$ is committed to provide free educational by creating free of charge workshops to empower women of different social strata and economical resources with available material for mentors and attendants. $\breve{C} I P k e$ promotes a learning environment where women do not feel pressure by the lack of technical knowledge, avoiding sense of competitiveness and do not fear to make the most basic questions, as no previous knowledge is needed to attend the workshops: "You do not need any previous knowledge to join $\check{C} I P k e$ workshops, only a curious eye, ear and eager fingers". They exclusively work with open and free software and open source licensing tools, and most of their workshops are based on DIY technology (ČIPke, 2013).

Although $\check{C} I P k e$ activities happen at a local level, through their professional network and an open application form the founders reach international female artists to lead the workshops, that are organised one year in advance. The initiative is open to collaborations, suggestions and challengesolving. They organize one year in advance the programme, formed by five workshops pear year, weekly meetings, the activities are financially supported by Ministry of Culture, the City of Ljubjlana, 
the JSKD and the ŠOU in Ljubljana (Hiršenfelder \& Spačal, 2015). The weekly meeting happens at space in Rampa Lab as well, as an open laboratory for mutual learning available on the evenings every first and third Monday in a month, hosted by Staša Guček, for any $\check{C} I P k e$ member who wants to work or socialize (ČIPke, 2013).

$\check{C I}$ IPke community does not require membership, it is built by real encounters and digital spaces. In April 2013 they opened the $\check{C} I P k e$ Facebook group, through which the network expands crossborders, enabling a connection between the local and international activity. Currently, the group has a membership of nearly seven hundred women, and a daily content shared in English and Slovenian. Additionally, $\check{C} I P$ ke digital platform works as a blog of news, publications and video library related to women in computer history and new media arts, and archival of their own activities and artists involved. In it, they also share news about other projects related to Women, Art and Tech such as Momentum $^{194}$. Within the menu, Friends section shows $\check{C} I P k e$ network beyond Slovenia with other artists, centers and projects, or events like the EU Code Week in 2018. In 2014 CIPke began to establish a network of women-only hacking laboratories in the Balkans, idea that was born within discussions of the same artists and colleagues in new media arts: "we recognised that in most of the countries of the former Yugoslavia there was a lack of technical and computer skills. We planned to exchange mentors, knowledge and experiences with colleagues from Serbia, Montenegro and Austria" (Hiršenfelder \& Spačal, 2015). In 2012 Slovenia had a 39,9\% of female graduates in science fields, and a 24,4\% in engineering studies (Huyer, 2015, p.92). In 2016, while $40 \%$ of women in Europe were scientists and engineers, countries like Lithuania, Bulgaria, Latvia, Croatia and Slovenia had above the $50 \%$ of female representation, over countries like Germany and Austria (32\%) (Eurostat, 2018). ČIPke was created on the imitative of the musician and sound artist Luka Prinčič, a feminist programmemer

\footnotetext{
${ }^{194}$ See point 3.4.6.7.
} 
who advocated for open source technologies, who worked for Kersnikova Institute. founders point the inequality in the work employment not only because of gender discriminations in Slovenia:

but rather on the complex socio-economic situation in which gender discrimination plays one of the roles. Workers and workers are faced with a complex spectrum of social, economic and class barriers, which are still more often preventing women than men from doing their job smoothly. In addition to gender discrimination, the old age discrimination of both the elderly and the young is at work in Slovenia too. [...] The trick of capitalism is that it does not recognise class and other forms of systemic discrimination, but reduces it to personal freedom, which is completely false (Hiršenfelder \& Spačal, 2015).

In 2015 ČIPke published a self-produced research documentary TOK/FLOW about the situation of women who work in science, technology and media art field in order to investigate the working conditions and communication nodes in male-dominated fields as such. Through the investigation they also noticed: "a significant difference between the prevailing male programmeming environments where colleagues try to "over-code" or over-encrypt one another, while the dominant female programmeming environments try to encode together". ČIPke work has enable the creation of new projects for gender equality in technology, such as Project Sister's Lab ${ }^{195}$, started in 2016 as a spin-off of $\check{C} I P k e$. The project makes international exchange of young students and mentors for Do It Yourself (DIY) and Do It Together (DIT) workshops on technology to empower women through mutual learning and teaching (ČIPke, 2016).

\subsubsection{Mz* Baltazar Laboratory}

$M z$ *Baltazar's Lab is a collective hackerspace in Vienna that organizes and holds DIY opensource workshops, exhibitions and artists talks on the intersection of arts, science, technology and

\footnotetext{
${ }^{195}$ Available at <https://bit.ly/31WzX20>
} 
feminism from an intersectional perspective. New media artist Stefanie Wuschitz started with the idea in 2009 when she was organizing the Eclectic Tech Carnival in Umeå, Sweeden, while she was part of a fellowship in HUMLab University of Umea. Since she had attended the /ETC a few years before, she kept on her the illusion of creating a space for women and other folks who feel isolated and discriminated in the tech world, as she felt herself in many tech courses. The joyful and collaborative spirit of /ETC and its organizers Gender Changers Academy, encouraged and inspired her to organize a similar feminist project on her own to experience not only to use, but the building of technology through art with a social awareness (Wuschitz in Quinn, 2018). The research of Wuschitz got on deep for the following years and made her develop the design of a radical feminist hackerspace based on DIY workshops with open source software, space-based communities, and the concepts of agency "the idea that people are empowered through knowing how to do things and how to help themselves" (Wuschitz \& Reis, 2016)-, and the concept of "hacking as a performance of femininity" from Haraway (Wuschitz, 2014, p.27). Within this framework of investigation, she developed her PhD dissertation about feminist hackerspaces, and during its process she performed collaboratively workshops in different locations of the world, as Mz*Baltazar's Lab. The founding of the hackerspace in the city of Vienna took place in 2011, when she and the group of female artists who joined the project felt they needed to have a room for our own within the hacker space they were part in Vienna -MetaLab ${ }^{196}$ (Wuschitz \& Reis, 2016). The results of her research were manifested in the design of the Mz*Baltazar's Lab and were published as a doctoral thesis in 2014: Feminist Hackerspaces. The lab was not founded to provide women an extra help, "but rather, it was established through recognizing the value of offering different learning environments for complex tool” (Wuschitz, 2019). Inspired by women-only art spaces in New York in the 1970s, such as $\mathrm{SoHo}^{197}, \mathrm{Mz}^{*}$ Baltazar's Lab based her

\footnotetext{
196 See <https://metalab.at>

${ }^{197}$ See chapter 2.2.2.
} 
methodology in a strong critical position against capitalism and promoting free education (Wuschitz \& Reis, 2016):

Mz Baltazar's Lab aims at generating a culture of fearless making! An environment that fosters creativity, activism and provocative thinking! We try to build an accessible, inclusive, open, safer and radical space, from which to evolve as people and as community. Open Source Technology is at the root of our philosophy, it enables us to share and collaborate without restrictions. We need this space to experiment with things as gender, hardware or ourselves (Mz*Baltazar's Lab, 2019).

$M z^{*}$ Baltazar's Lab aims to allow people to demythify technology, alluding to the legacy of stories that form culture, as a process of removal of this mythical character that is associated with technology, a certain conception of masculinity and its related ideology. Instead, Mz*Baltazar's Lab wanted to offer a space for different points of view. Based on Critical Art Ensemble perspective, they believe voluntary separatism by an already marginalized group is a way to resist and create a space where to create freely, far from prejudices and cultural expectations based on gender stereotypes, enabling women and other folks to develop a different way to interact with technology and art. Mz*Baltazar's Lab defines its strategies as subversive, by following the feminist approach of deconstructing and interchanging the gender of the words, for example, in their workshop called Arduina (Wuschitz \& Reis, 2016).

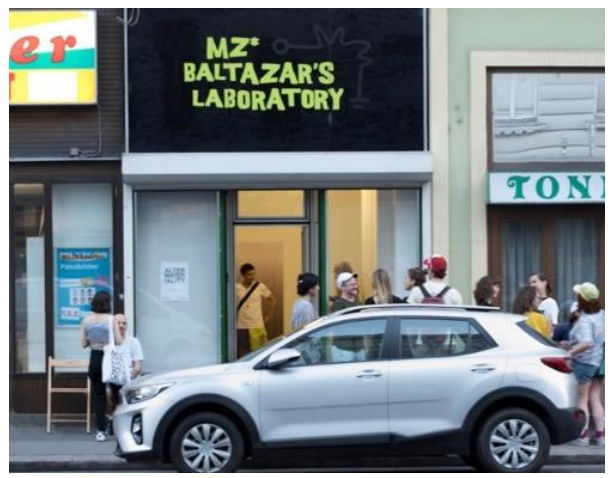

Figure 177 Lab in Sechshauserstraße. Source: @MzBaltazarsLaboratory Facebook

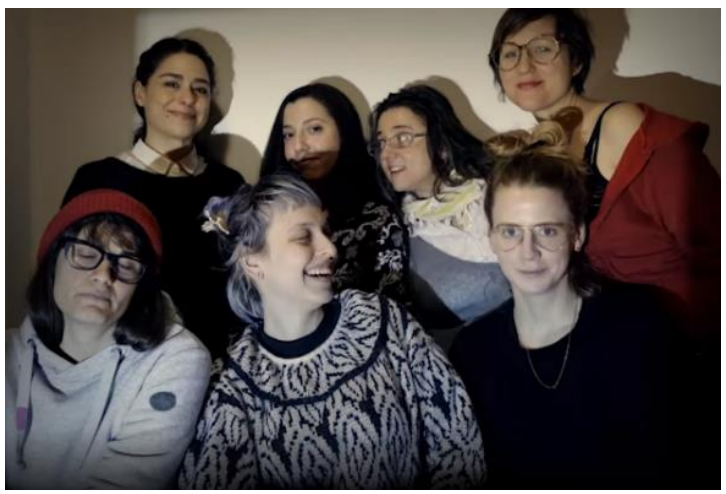

Figure 178 Current Mz*Baltazar Lab members, photo retrieved from Quinn, 2018 
Members of the space have been changing during the years, but always have belong to a diversity of artistic and technologist backgrounds. Currently they are: Stefanie Wuschitz, Lale Rodgarkia-Dara, Patricia J.Reis, Ana Loureiro, Sophie Thun. As a non-profit space, all their work is voluntary. They have organised two festivals: MAKE ME (na pravi me) five days festival that took place in Belgrad in 2011 organised together with local NGO Women at Work and the three days MAKE ME ECLECTIC festival took place in Vienna. In the space they organize and held workshops by their own members and guest artists and technologists, and they also curate exhibitions of non-binary artists in the front door window of the store, under the title Leuftsteuer (Mz* Baltazar Lab, 2019). Due to the political situation in the Austrian government, the financial support has decreased, fact that has affected the activity of the space. Nevertheless, they continue holding periodical exhibitions, talks and workshops. Currently the space is funded by the Bundeskanzleramt Österreich.
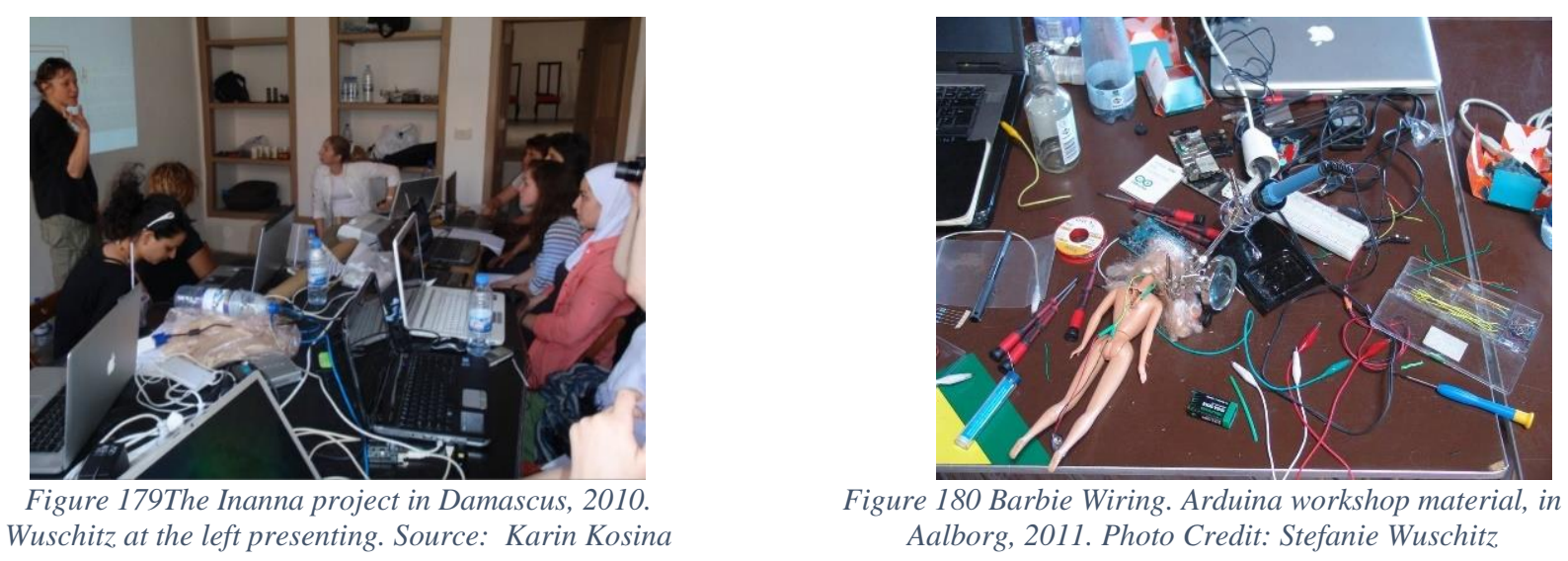

$M z^{*}$ Baltazar's Lab is based on networking and community building as a political position, sowing seeds around the world through workshops like those in Copenhagen, Indonesia, Thailand, Taiwan, Brussels and Syria. In the legacy of /ETC, the project works in an open format that anyone can appropriate and change, accommodating it to a new context. Members believe that personal 
connections and sharing experiences through face-to-face events are the most important, more than having a network online (Wuschitz \& Reis, 2016).

\subsubsection{HackerMoms}

Since 2012, in the city of San Francisco a hackerspace founded by a group of ten mothers is still a unique place that promotes that personal and professional can work together for women. This group of women from different disciplines (artists, writers, designers, educators, makers, etc.), decided to open their own space after a long period of meetings in each other houses with a hired babysitter. Conscious of the "negative" consequences that motherhood can carry for a woman's career ${ }^{198}$, HackerMoms built a space where not only their two facets could merge, but their kids would take benefits from watching them creating, making and working together:

Children learn best through modeling, and children who observe passion and commitment in a parent towards something not only learn to respect it, but to create it in their own lives eventually. It's good for children to see and make space for their parent's needs certainly, but it is also essential that they grow up knowing that they deserve the same (Matalone \& Smith, 2012).

Considering the supposed feminist spirit of feminist hackerspaces, one would expect these (like those presented in this thesis), to be more accommodative to all type of women's necessities, however, like traditional or general hackerpsaces, feminist hackerspaces are generally formed and attended by youth ages of women and underrepresented collectives. Based on a hacker spirit, HackerMoms were early committed to "hacker the hackerspaces" in order to make fit mothers in its model. Broadly described as a "creative life lab for mothers", HackerMoms is considered "pioneer in the emerging family-based

\footnotetext{
${ }^{198}$ In chapter 4.3.3. I will discuss the contemporary issues that women professionals must face to combine their professional careers and their personal lives, outlining the impact of motherhood in their work life.
} 
DIY culture". Until today it is the only hacker space suitable for children care, accommodating real mother's necessities (HackerMoms, 2019):

We wanted something that didn't exist, a kid-friendly hackerspace to explore our creative sides. HackerMoms is like the mythical village that raises the child and the mother together. HackerMoms is founded on the idea that mothers need a creative outlet and safe environment of encouragement, stimulation, support and permission to explore new ideas.

They run fundraisers to collect funding for the space in Oakland-Berkeley and their programme of activities. With open membership and collaboration with other hackerspaces in San Francisco, they have created the Failure Club and the Business Incubator programmes. Additionally, they make workshops and courses, not only on creative technology techniques but also on music, health care, sexuality for mothers, etc. for adults, families and kids.

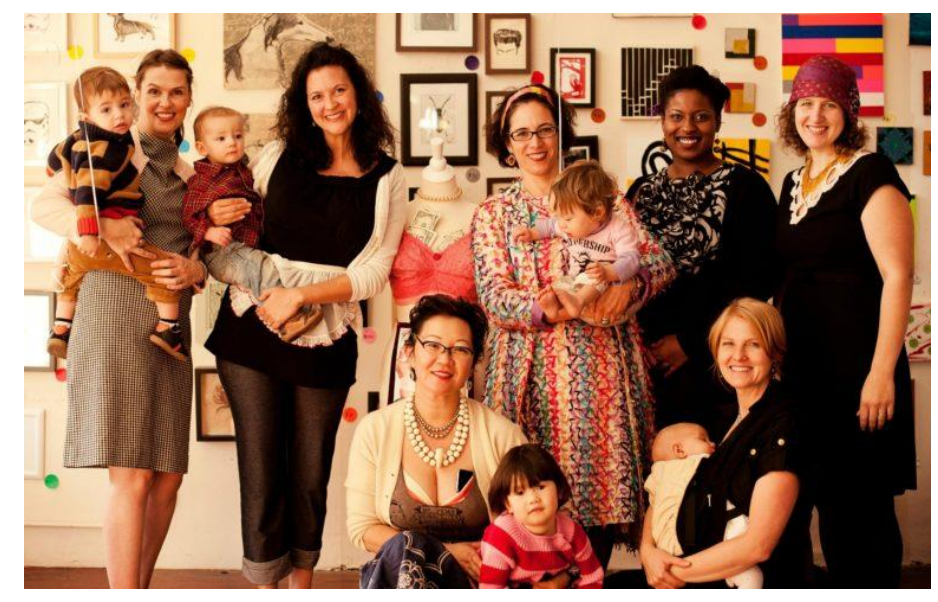

Figure 181 Picture of HackerMoms and their kids. Source: www.hackermoms.org

\subsubsection{XXLAB}

Like Stephanie Wuschitz remained impressed by her experience in an /ETC edition, she inspired a group of young artists and technologists in one of the workshops she performed during her PhD abroad. It was in the cultural city of Yogyakarta, in Indonesia in 2013, the group involved in the 
activity remained impressed by the feminist and hacker formats, that they decided to form their own creative space. From a seed sowed, a new plant grew. XXLab is an all-female collective and space formed by an interdisciplinary group of programmemers, artists and designers interested in the intersection of art, science and open technology: Irene Agrivina Widyaningrum, Ratna Djuwita, Eka Jayani Ayuningtias, Asa Rahmana, Atinna Rizqiana Following the line of the European feminist hackerspaces, they provide an open ongoing programme of workshops on DIY and DIWO (Do It with Others) with open software technologies and art practices with electronics. The space is funded by the HONF Foundation ${ }^{199}$, which has HONF Fab Lab ${ }^{200}$ in the same city, and they count on the technical support of some faculty members. XXLab was awarded with by Ars Electronica Festival in 2015, a Golden Nica in with her project SOYA C(O)U(L)TURE.

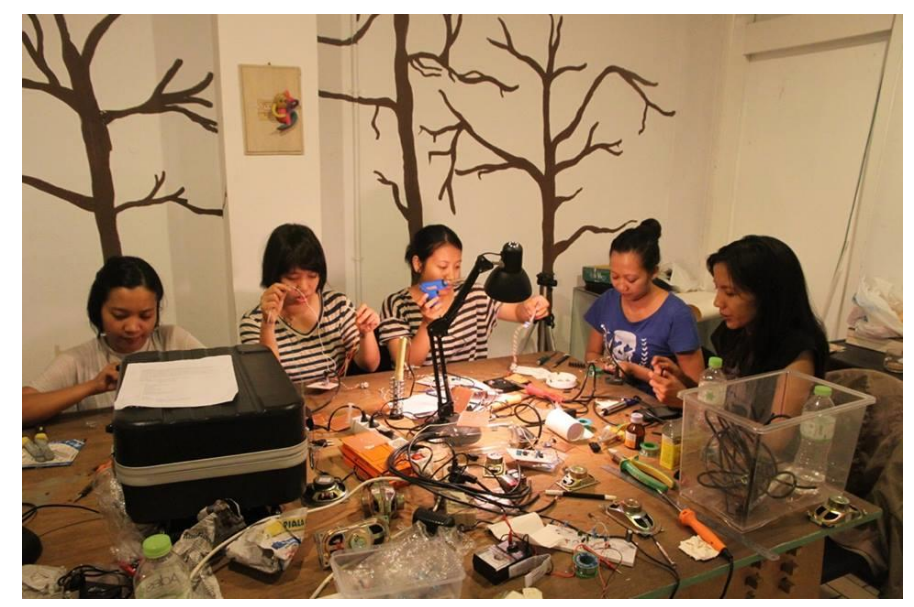

Figure 182 XX Lab XXLab space. Photo Credit:Yudhistira Purwa Anugrah

\subsubsection{SHFT+CTRL Collective}

Dozen young female artists have demonstrated that it is still possible to build a space of one's own in the expensive living Bay Area of San Francisco. After finishing their Masters, they were looking for a creative space where to keep on going with their art production, project which developed into an

\footnotetext{
199 See <http://www.natural-fiber.com>

${ }^{200}$ See <http://www.honfablab.org>
} 
all-female space, a cultural point that would benefit the community (Morgan in Burke, 2015). In June 2015 they founded Ctrl+Shft (a play on the computer key stroke) gallery space, as a symbol of their reclamation of power, while interrogating what it means to build and be part of a community (Ctrl+Shft, 2019). They self-built their twelve studies and additionally a three-room gallery, all made with scrap materials from old CCA studies that was torn down. Despite the high costs and the lack of space, 'there is always room - we got together twelve people and made room' (Yerin Kim in Burke, 2015). They were inspired by the alternative art spaces founded by non-commercial methods in the East Bay and the few lasting in New York City and Los Angeles.

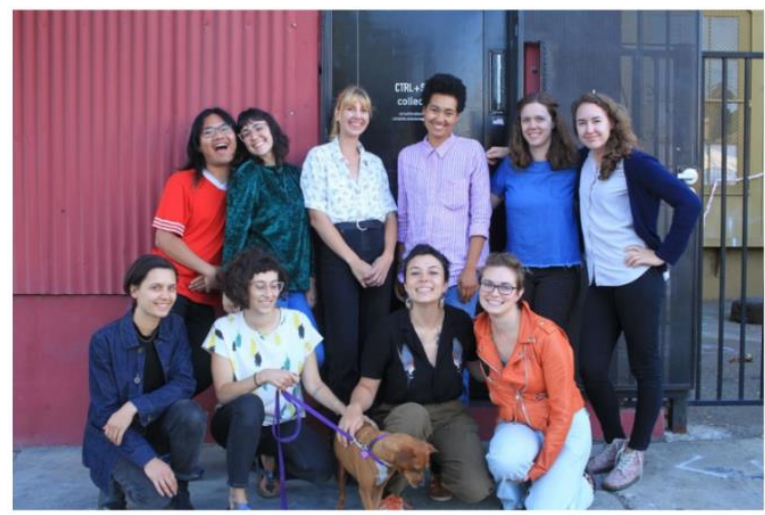

Figure 183 Ctrl+Shft members at the door's space. Source: www.ctrlshftcollective.com

Surprisingly, almost twenty years after of the founding of Old Boys Network, and forty after the establishment of the Woman's Building and the feminist art programme Fresno, in one of the main global capitals these artists felt the need to create a space far from patriarchal structures, as they described the art school in California, where they felt like 'kind of a boy's club thing', a 'pressure cooker'. They felt motivated by the lack of opportunities for female and non-binary artists, particularly those of color, in the art world. The fact that the situation has not changed despite the so-called evolution of four waves of feminism, mainly in locations that were protagonist in feminist history, like California, and that are on the top of the technological development like San Francisco. At the end, it is always necessary a room for one's own to be able to freely create and produce: 
Maybe I'm generalizing but... from my professional experience so far, its only been women helping me. There hasn't been a manly situation where they are offering me space, or they offer me shows [...] Its literally just been women [...] that should be pretty telling (Maryam Yousif in $\mathrm{Yu}, 2017)$

The gallery is committed to provide space for underrepresented identities in the art world, that is: women artists, artists of color, and queer and non-binary artists (Ctrl+Shft, 2019). The activities they have organised during these four years belong to multimedia art formats: installations, video art, digital arts, sculptures, photography, etc. Ctrl+Shft does not only provide a space to support underrepresented artists, but it has created a community and reinforced the network of feminist and female artists in San Francisco, like the feminist spaces did in the 1970s and 1980s: "There were a lot of members who felt that there were conversations around race, gender, and other political things that people wanted to explore as a group" (Erica Molesworth in Yu, 2017). Ctrl+Shft has built an alternative space with methodologies that seemed to be disappeared, collective work, DIY style, providing space for others, nonhierarchical system, a supportive and feminine energy and environment (Yu, 2017). They have been organizing fan zines, talks, and community meeting events, and hold events organised by other feminist initiatives as well. They call itself $C t r l+S f h t$ family, to those who participate in any form in the production, organisation, attendance and collaboration of the space. The project has provided open membership, and the group of members has changed during the years, with struggling moments due to the increasing rent costs of the area (Yu, 2017). Ctrl+Shft is a member of the Intersection for the Arts, organisation that provides to Bay Area based artists and organisations with resources, community and cultural space in order to be able to develop their practices sustainably.

\subsubsection{7. extantation}

e $x$ t a $n$ t a t $i$ o $n$ is a self-organised and self-funded artist-run performance and residency space, located in Chiang Mai, Thailand. It was founded in August 2016 by the artists Tara Transitory 
(aka OneManNation ${ }^{201}$ ), formed and active between Europe and South Asia, working on the explorations of gender, space, performance, sound and art. The space opened its doors in March 2017. Described as ephemeral, experimental, experiential, this space was established on the bases of interest of the founders, towards promoting conversations on art from a critical poetic perspective in forms of events and happenings through performance/live art, dance and music, multimedia and more: "a place where magic is retrieved, where being lost means being found a vice-versa" (extantation, 2016). Critics to the occidental definition of modernity and progress, the space marks its interest in art practices that explore other notions, approaches, perspectives, experiences and bodies. Without alluding to the term feminism, in their statement they expose a strong commitment for giving a place to "the extant, the forgotten, the marginalized, the uncategorised, the invisible, and for the ones in-between". The space calls for proposals by women artists, trans, queer, working-class, activists, writers, communities, people with disabilities, providing a space of dialogue to create and perform for those who are “displaced, disempowered and dispossessed" (extantation, 2016).
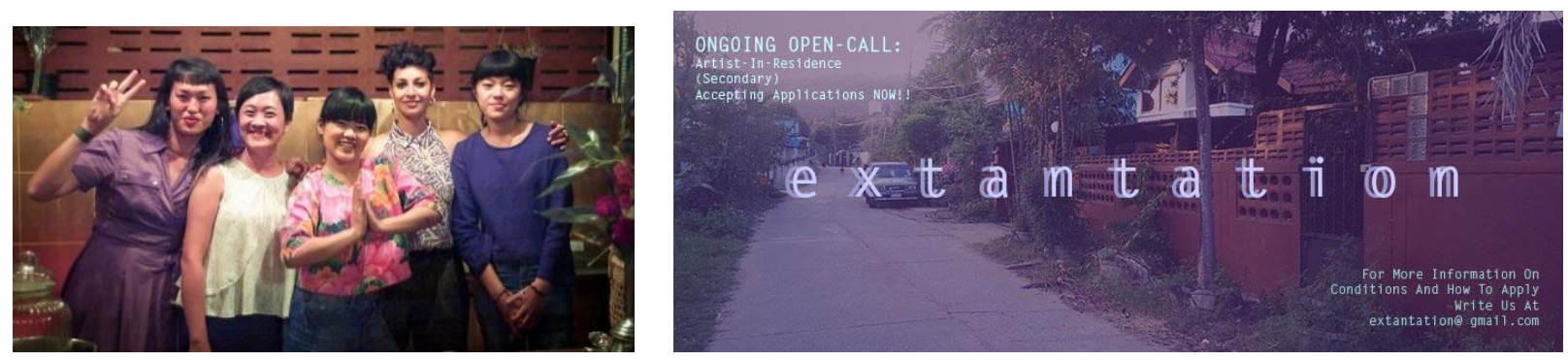

Figure 184 Images from extantation events and open calls. Retrieved from <www.extantation.wordpress.com>

The space encourages works on topics related to gender, postcolonial and community issues in regarding to local and national cultural context. The activities they held are: regular live events, performances and artist presentations; two different artist-in-residency programmes (AIR); sociopolitically relevant visuals: documentary screenings and video-art; installations of sound, video and performance; a platform where for dialoguing; workshops; studio rental.

\footnotetext{
${ }^{201}$ See <www.onemannation.com>
} 


\subsubsection{Q-space}

In the grow of independent art spaces in Beijing, in April 2016 a group of queer artists founded a feminist grassroots community makerspace. It promotes diversity as the key to solve social issues, and it is mainly addressed to women and LGBTQ+community, aiming to provide a safe space with supportive environment based on radical queerness of inclusion of all people from all backgrounds and the importance of non-hierarchical action (Q-Space, 2019). The space works by donations and has an ongoing programme of workshops with different technological equipment in three formats: Graphic design skills programme; An open maker space with 3D printing and manual skilled collaborative techniques like silkscreen printing: we think, we make, and it is a simple as that; A Physical Theater: basic physical theater skills through body expression, movement and collective exercises. (Q-Space, 2018).

我们Can do it! With its slogan, the space defines itself as a community driven project absolutely dedicated to encouraging the creative part of women and other folks by designing a programme and environment completely collective, horizontal and respectful, based on the knowledge and experience exchange and continues collective learning, far from tech world aspects like competitiveness. By enforcing values at the core of the community based on co-learning, self-love, inclusivity, awareness and non-violence, the space encourages lqbtq+ and specially women to "trust they have something valuable to share with the world" (Q-Space, 2018) In Q-Space one can also find the formats of "community making" through food and intimate space creation, such as feminist the QScreen Salon (feminist screenfilmings) and the research \& café sessions. These strategies relate us to the first encounters of women media artists in the middle 1990s in Europe, still repeated decades after. Additionally, Q-Space is so much focused in creating an inclusive space towards a respectful communication, that they organize the Language Corner, a periodical event in forms of dinners where people through cooking their home country food establishes contact and presents him or herself to the 
rest of the community. Through these intimate and informal practices, in addition to other open community activities, the space engages diverse individuals and establishes a local network of members who find in the makerspace an alternative place to feel creative and open for knowledge exchange. I find a notable similitude with the strategies, methodologies and ethics of Prototype Feminist Makerspace in Pittsburgh, what shows a node of connection between two scattered places from two different continents, where both projects changed the way technology is perceived for women in order to encourage them to make, but also promote a community building through personal exchange and experiences

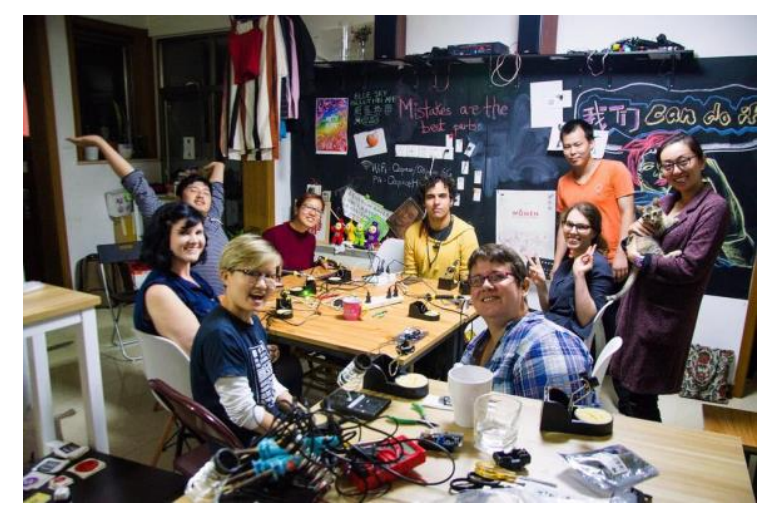

Figure 185 Q-Space Maker Space Photo by: Elna Van Dyk. October, 2016

Beijing was a crucial place for the women's movement in a global level, when in 1995 the city held the Fourth UN World Conference on Women: Action for Equality, Development and Peace, convened by the United Nations that culminated with the signing of the Beijing Platform for Action by 180 national governments, establishing a commitment for gender equality and the empowerment of women globally (UN Women, 1995). Since then the city has developed a series of feminist activities and an ongoing part dedicated to LGTB rights movement, for example with Beijing Queer Film Festival happening since 2001.

In Beijing it is celebrated since the Beijing 2008 Olympics Cultural Project the Media Art China Series and within its framework the The TransLife International Triennial of New Media 
$\mathrm{Art}^{202}$.Additionally, for two editions since 2016, Beijing holds the Media Art Biennale BMBA ${ }^{203}$ organised by China Academy of Fine Arts and co-sponsored by other local art institutions. Q-Space work must be taken in consideration, taking into account that in China feminist organisations are rather censored (Q-Space, personal communication 2019).

\subsubsection{Prototype}

With the moto "Building Equity Through Making", Prototype is a feminist makerspace located in Pittsburgh that was founded in 2017 by Erin Gatz and Louise Larson as a response to the white maledominated makerspace culture of the city, Gratz has made annual reports where she presents the null income women entrepreneurs have in Pittsburgh. The project is committed to provide space for gender and racial equity in technology and entrepreneurship, in regarding to this they opened this year Incubator project. To achieve these purposes, Prototype:

- Offers pay as you can workshops. Creative technology skills and entrepreneurship coaching.

- Engaging members in a professional network of women and non-binary people and feminists of all genders, anyone who is down for the cause is welcome to become a member. Currently the spaces gather one hundred fifty members.

- $\quad$ Providing access to tools and equipment (Gatz, personal communication 2018)

The space is open eight hours seven days a week, accessible for all members, to who they provide a personal key. Membership is $50 \$$ a month, but they offer the possibility to pay $5 \$$ a month for those who cannot afford the standard price. They also provide additional support for transportation cost cover, childcare and free dinners for the attendants, in order to encourage mothers and working-class women to attend their workshops and events, especially women of color.

\footnotetext{
${ }^{202}$ Available at <https://bit.ly/2KBdhih>
}

${ }^{203}$ Available at <https://bit.ly/2X2Bf83> 


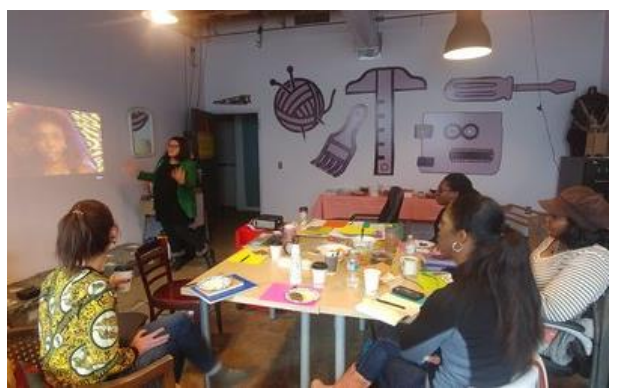

Figure 186 Prototype Femnist Makerspace, 2017. Source: www.prototype.pgh.com

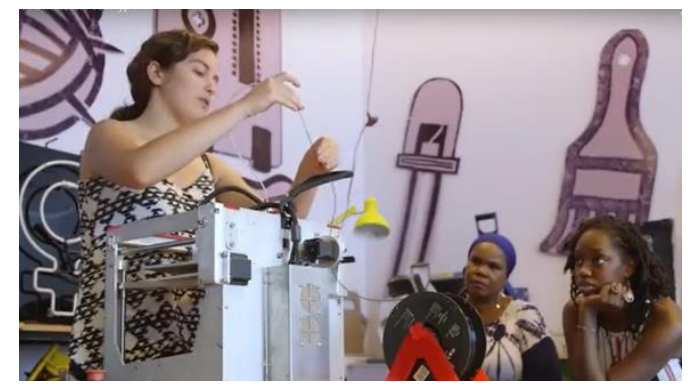

Figure 187: Images from video interview on WQED Pittsburgh. Retrieved from <https://www.youtube.com/watch?v=RuQ3rOu1j7l>

The space applied for a grant addressing women of color, with which they could hire a third person to work in the space. In a small place in Melwood Ave in North Oakland, this collectively run space is part of an eight art studios house, working voluntarily but the girl hired with the grant, they provide workshops from 3D Printing to coaching in salary negotiation, Arduino, or laser cutter. Gatz had previously initiated feminist collectives in the fanzine scene in Pittsburgh. However, she had also experienced with nonhierarchical space groups, but she did want hierarchical project she and Louise are directors for prototype while being flat (Gratz, personal communication 2018):

We see our organisation as a prototype as the kind of world in the way we want to live in, treating our members as users of this prototype that we are seeking a feedback on. They come, they have suggestion to improve it, we are adaptive, we listen, we take into account, we always asking to improve engineering, design process - we see ourselves as a prototype product.

Prototype has created a strong local network in Pittsburgh by participating in other activities like $A R T$ $A L L D A Y$ and organizing periodically encounters for networking and knowledge sharing. Due to the personal networks of the members their projection goes beyond borders. 
IV.

WOMEN IN

NEW MEDIA ARTS

TODAY 


\subsection{Questionnaire: "Women's Networks and Feminist Organisations in Arts and}

\section{Technology"}

In December 2018 I launched a survey with a list of questions related to my interest regarding the all-women and feminist self-organised associations, platforms and collectives, its networks of collaboration and influence within them, in addition to some questions regarding the situation of women involved in arts and technology fields. During my first years of research, I started to acknowledge that the transnational network I had started to track had some limitations based on the virtual searching and culture, in terms of location, language and accessibility. I was aware of the invisible barriers that Internet has in terms of a complete accessibility to all-women existing projects in arts and technology, as the barriers that the professional network might have depending on the personal context. Therefore, the main purpose of the survey was to collect qualitative data about other all-women and feminist organisational networks by asking the artists and collectives that I had already identified and have previously contacted. I followed the premise that through contacting the artists that I knew, as they could bring to my research further case studies from their own personal and professional network, that I could have not found within my own means.

Additionally, as a second objective I have applied the survey for another purposes related to my research state of the art. I added some questions aiming to collect qualitative data in regarding personal experience based on gender discrimination in the professional field and work environment, also about the term feminism and cyberfeminist and some other inquiries that are present along my research and description of the case studies. The responses I obtained, and the corresponding statistics helped me to visualise a current and updated opinion by women involved in fields of arts, science and technology. However, they are not in any form whatsoever an attempt to establish an overview of the general context of women in new media arts, due to the relative low number of participants and the 
diversity within them in terms of ethnicity and location, which is also relative and imitated by my own position in the transnational network (language, personal encounters, professional network, etc.).

Nevertheless, if not by the quantity of the participants, most of the women who have taken part of the survey are very important figures in arts, science and technology fields, with creator, educator, researcher, curator and activist profile, and also entrepreneurs in creative and cultural projects. The majority are founders and main members or collaborators of self-organised all-women and feminist platforms, associations and collectives in arts and technology. Moreover, some are part of the history of cyberfeminist alliances that in fact, I have studied while describing my case studies and the state of the art. Such participants are founding member of OBN, Faces mailing list, Women Make Movies, VIDEOLETTERS, female:pressure, Current Symposium, Matrix: Women Networking, Making Breaking the Binary, M-Artech, FemTechNet, She Makes Noise, e-mujeres, Female Laptop Orchestra, electronnes, MzBalthazar's Lab, Women in Creative Technology Berklee, CIPke, Void Lab, Sounds Queer, enre/dades, Ctrl+Shft, cyborgrrrls, AMIT, Atenea, and the director of Women in Media Arts archive from Ars Electronica Center.

Hence, the data collected taken into consideration is not quantitative but qualitative, because of the people who contributed to it. Together with the data collected through interviews and digital ethnography, gives a panorama on the self-organised networks, projects and platforms since the middle 1990's and their perspective as organisational members. In addition, women who have participated in my survey belong to different generations, which provides a wider perspective from critical analysis to my research. The answers gathered also give me an overview of the current situation of women in arts, science and technology fields related, than help me to visualise the context and necessity for allwomen and feminist platforms and projects in new media arts. Furthermore, mapping the case study has allowed me to recognise influences, alliances, connections that will serve me for future research on networks visualization. 
Therefore, I can describe the objectives of the survey as the following:

- To access further data on self-organised spaces and all-women/feminist collectives.

- To get an overview of the current situation of women in new media art and arts/technology fields.

- $\quad$ To get the opinion on alliance and segregation as strategy by women in arts and technology.

- $\quad$ To understand the context that gives rise my case studies.

- To collect data about nodes of influence, collaboration and common referents.

Collecting answers from women of different generation has been very relevant for my research as well, as one of my purposes is to understand what has or has not changed since the first self-organised all-women projects and cyberfeminists and see if the perspective on the topic changes based on age. With the survey I didn't aim to have a huge impact, I expected around one hundred responses in four months, number that I successfully reached. I have shared the survey through the digital platforms, social networks and mailing lists of women in media arts, science and technology, that I have abovementioned (FemTechNet, Faces, CIPke, etc.), in addition to personal email contact to founders of initiatives. I would like to thank the team of Women in Media Arts archive at Ars Electronica Center for having provided a generous support and collaboration since the first moment they get to know about my research.

Although it was been received by many users of the specialized networks and virtual communities with enthusiasm, not many of the members of these networks decided to participate. The number of participants could have been higher compared to the audience addressed, but that is a factor that is out of my control, and I am satisfied because it provided the data initially expected.

The survey has been designed with Google Forms and visualised with Advanced Summary by Awesome Table plugin for Google Chrome. 


\subsubsection{Results}

To have an overview of the participants: the average age of the participants is 45 years, $40 \%$ of whom are $31-45,26 \%$ are $45-60,13 \%$ are over $60,19 \%$ are $23-30$, while remaining under 23 years. Partially conditionate by my personal context, majority of participants are from Central Europe countries (25.3\%), North America (24.2\%), and Mediterranean Countries in Europe (20.2\%); 13.1\% West Europe countries and the rest from Latino America, East Europe, Middle East and East Asia. Locations numbers of East Europe, South America and Mediterranean countries in Europe lightly increase when asking about origin place of the participants. From all the participants, ten identify as gender queer, four as non-binary, one as non-categorised, and one as nonbinary trans $*$ feminine queer. $86 \%$ of them uses social networks to promote their work or establish a network in their professional field, of which $72 \%$ thinks they help for those purposes. Facebook is the most used $(74.7 \%)$, followed by Instagram (56.6\%), Twitter (45.5\%), WhatsApp (28.3\%), ResearchGate (16.2\%) and Telegram $9.1 \%$.

$32 \%$ of participants have a professional experience in art and technology fields for more than 20 years, $23 \%$ ten to twenty years, $20 \%$ for five to ten years, $14 \%$ three to five years, resting $8 \%$ one to three years.

$72 \%$ of the participants have an artistic professional profile, $46 \%$ are researchers, $31 \%$ curators, $29 \%$ lecturers or professors, $21 \%$ musicians, $17 \%$ producers, $15 \%$ project managers, $12 \%$ teachers, $12 \%$ performers, dancers and/or actress, $8 \%$ entrepreneur, $7 \%$ programmemers and $6 \%$ engineers and $6 \%$ graphic designer. $45 \%$ completed a college degree, $26 \%$ completed academic courses and $64 \%$ from the total has academic degree complemented with self-learning. $78 \%$ works in an interdisciplinary team or with professionals from other disciplines, whose profile is mostly artist $(83 \%)$, researchers $(66 \%)$, programmemers $(56.4 \%)$, musicians $(57.4 \%)$, performers, dancers and actress $(58.5 \%)$, designers $(55.3 \%)$, curators $(52.2 \%)$, lecturers and professors $(46.8 \%)$, engineers 
(44.7\%) educators $(41,5 \%)$, technicians $(42.6 \%)$, producers $(41.5 \%)$, scientist $(37.2 \%)$, project managers $(33 \%)$, developers $(30.9 \%)$, architects $(22.3 \%)$.

$88 \%$ of the participants are or have been involved in all-women or feminist initiative, project, association or collective in art and technology. Breakdown of their role is $16 \%$ are founder, $21 \%$ cofounder, $17 \%$ partner, $17 \%$ active member, $8 \%$ collaborator, $13.6 \%$ members, rest punctual collaborators such as artists. It can be noticed that from the participants, a third part has been involved from 2015 , followed by a notable number that has been active for more than ten years since late 1990s until today, and those who were involved in the late 1990s for a short period.

From the list of feminist and all-women projects, platforms and collectives I showed, 58\% knows Women, 40.4\% Female Pressure in Media Arts AE, 28.3\% Faces mailing list, 27.3\% FemTechNet, $18 \%$ OBN, 18\% TransHackFeminist, 23\% Atenea, 14\% MzBaltazarLab, 12\%FemTeckBilbao, 16\% VNS Matrix, 13\% Deep Lab, 12\%/ETC, 9\% Genderchangers, 11.1\%, Ada Lab and $10 \%$ FLO. More than $62 \%$ do not know feminist and all-women projects in art\&tech outside western countries.

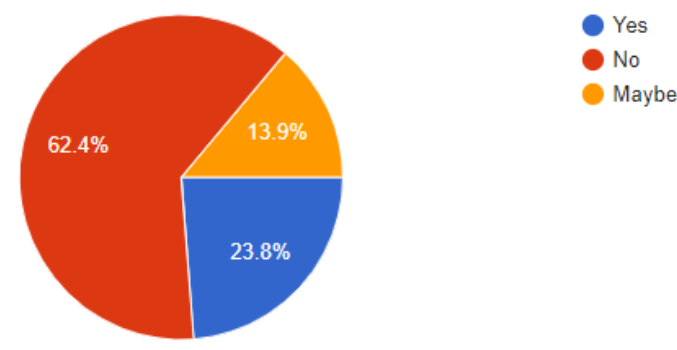

Figure 188 Visualization chart to the question Do you know feminist projects in art and tech outside western countries?

$51 \%$ has noticed some type of change or improvement in the context of gender equality in arts and technology, $32 \%$ maybe and $14 \%$ has not been involved time enough to notice a change. Then, to 
the question: What is the main reason for the creation of women-only and feminist initiatives nowadays? 65\% marked Gender Gap in Tech, 65\% marked Women are unrepresented, 63\% marked Patriarchy, 63\% marked Lack of women in decision-making positions, 61\% Gender gap in arts, 57\% marked Sexism, 56\% marked Gender gap, 56\% marked Male-dominant work environment, 54\% marked White-male hegemonic ideology, 53\% marked Misogyny, 51\% marked Less opportunities for women, 44\% White heteronormative and supremacy, 43\% Male oppression to women, $43 \%$ marked Women enjoy working together, 37.4\% marked Lack of spaces for social critique and dialogue. Only $12 \%$ thinks women feel safer in such spaces. $57.6 \%$ states that women and feminist groups have revolutionary and alternative forms of expression through arts and technology (question I designed based on cyberfeminist theories), while $37.4 \%$ is not sure and rest denies. $68 \%$ thinks that all-women and feminist initiatives help and support women and other folks in their field, $19 \%$ is not sure, $13 \%$ think they don't. $61,6 \%$ thinks women-only spaces and platforms are necessary in this field, $24,2 \%$ maybe, $14.1 \%$ they are not. Surprisingly, all those who have denied this statement have been founders or main members of all-women and feminist self-organised projects, they also think feminist projects tend to be more diverse than women-only. However, majority of those who have been involved think however, that they help and support women and other underrepresented folks.

$63 \%$ thinks safe spaces (no male presence) encourages women to learn technology, $31 \%$ is not sure. In the paradigm between only-women versus feminist projects, $53.7 \%$ thinks that feminist ones are more diverse and helpful than women-only, $35.8 \%$ is not sure. 50\% thinks men should be accepted in feminist initiatives, and around $40 \%$ is not sure and points the relativism of the context and project objectives, leaving a low $10 \%$ who state that men should not be allowed at all. $39 \%$ thinks women and women-identified, or people who do not identified as male, are more collaborative and supportive. $14 \%$ thinks they are not, and rest points the importance of the context, education, culture and personality rather than the sex or gender identity. 
As any type of political or ideological movement, feminist and women-only initiatives may be exclusionary with people with other perspectives. $24 \%$ agrees with this statement, $18 \%$ denies it and $58 \%$ cannot make a such a general statement, pointing the importance on the type of feminist position towards a real openness. In regarding the confussion that sometimes people has between the term equity and equality, I redacted one question to see how many of the participants were sure about the difference. $35 \%$ thinks that equity defines better than equality the real necessities of feminist and women-only projects, $10 \%$ thinks it does not, $23 \%$ is not sure and $32 \%$ is not sure what equity really means or is confused with the meaning of the term. Coming back to cyberfeminist theories, I redacted the question "Technology can make humans achieve posthumand condition (abolition of gender, race, social class)", $51 \%$ said maybe, $23.2 \%$ yes, $24.2 \%$ it does not.

In regarding women visibility and equal opportunities, $84 \%$ belivees women are still unrepresented or underrepresented in the art\&tech world, $7.1 \%$ maybe, $9.1 \%$ they are not anymore. $80 \%$ believes her expertise field is male dominated, $16 \%$ is not sure. Over $76 \%$ believes that other folks are less represented based on others than gender. From the answer we outline those pointing "anyone that is not white and make", and outline those on people of color, non-white people, indigenous folks, aborigines, older people, LGTBQ folks, people with disabilities, immigrants and refugees, working-class people, non-western people, non-binary and non-categorised people.
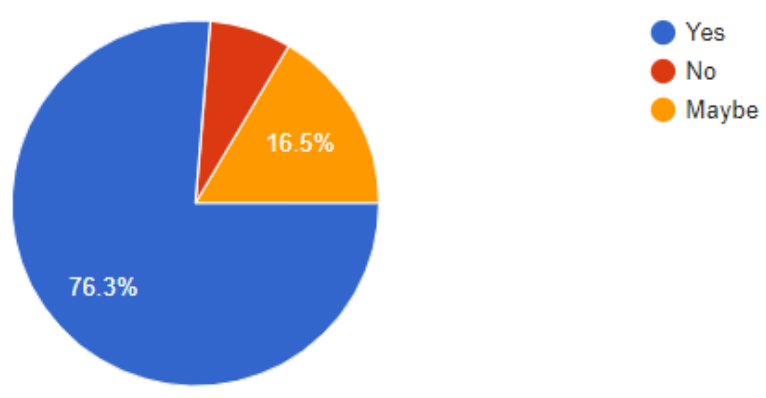

Figure 189 Visualization chart of the question Do you think there are other minority folks also unrepresented? 
74\% knows the term cyberfeminism, 17\% don't, 9\% is not sure. From those who do, 35\% notices an improvement from the first cyberfeminist wave to the current ones in the change of generation, $54 \%$ is not sure, $11 \%$ don't. Founder of OBN, first international cyberfeminist alliance, states that the difference in new wave of cyberfeminism is: including material aspects of technology, condition of production, natural resources, waste, energy, climate change, corporate slavery (Solfrank, 2019).

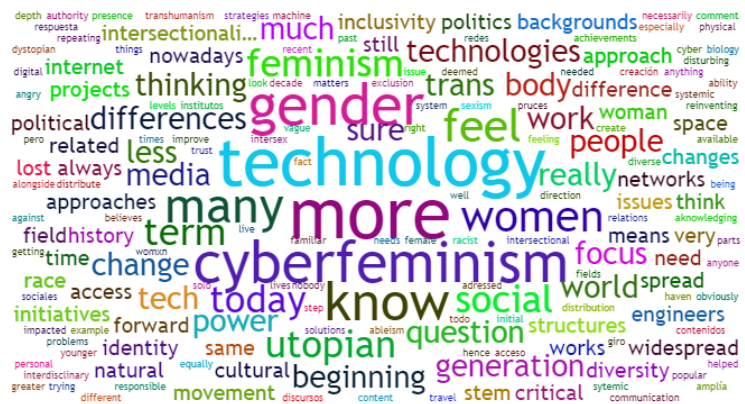

Figure 190 Differences with first wave of cyberfeminism. Answers visualization with Advanced Summary by Awesome Table

$82 \%$ of participants consider themselves a feminist, while $13 \%$ is not sure. This identification with feminism is based on: half of answers absolute gender equality, quarter for sex differences towards gender equity, $20 \%$ abolishing gender, and below $18 \%$ radical feminism (although this answer is arguable due to the confusion of the term 'radical' in feminism).

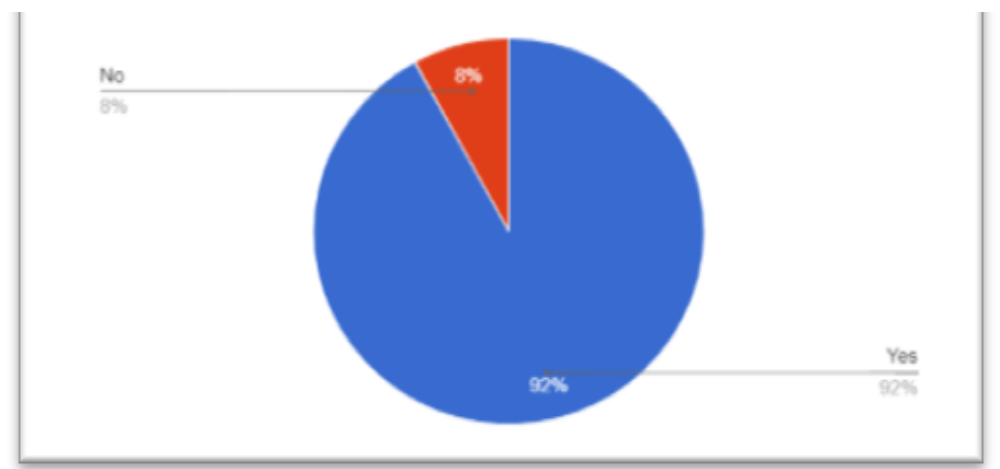

Figure 191 Visualization chart of: Have you felt any kind of unequal treatment in your professional experience based on your gender? 
72.5\% think Silicon Valley current commercial technological development is male-dominated, fact that explains the lack of interest by women in tech and coding. $16.5 \%$ is not sure. Related to sexual harassment or gender discrimination, $92 \%$ has experienced unequal treatment in her professional experience based on her gender in her workplace (galleries, seminars, festivals, academia). Most of the answers point to personal experiences related to less appreciation of the work made by females, lower income, less payed for punctual projects when not unpaid, they are lower requested for a job, capabilities undervalued, not respected as professionals, preferability of males by entities, less opportunities, less income, and some others are related to sexism, prejudices, paternalism, misogyny and sexual harassment, among others.

My first day in Civil Engineering Studies, Calculation Docent said: "Now please all women chose a husband quickly, do not waste my time, because that is the only thing you are here for" (survey answer from Jeanine Vargas, Bolivia, 2019)

$55.6 \%$ has experienced unequal treatment in professional environment based on other facts such as social class, gender identity, age, sexual orientation, ideology and others. $20.2 \%$ says maybe, $24.2 \%$ don't. The age factor is very relevant, half of the participants over age 45 years have pointed out that age is in addition to gender, a factor of discrimination: "The connection of age and gender. As an older woman myself, I notice the combination of female-old is very bad for a professional career". (survey answer from Pia Palme, over sixty years old, artist researcher, musician and performer from Austria). This opinion shared by other from Denmark over sixty years old professor of art and science:

Also - there is a clear difference in being middle-aged and older woman than younger woman. When one looks at events - the invited guest are primarily males and some females who are primarily under forty years. It is not only gender discrimination, but age discrimination makes older and very experienced women completely invisible. 
Others have pointed together with age, disabilities, for example: Disabilities should be mentioned somewhere as women with disabilities are the most prone to discrimination and suffer the most violence (survey answer from Valerie Vivancos, 54-60 years old Parisian artist). 55\% has experienced any kind of sexual harassment in her professional space (mental or physical).

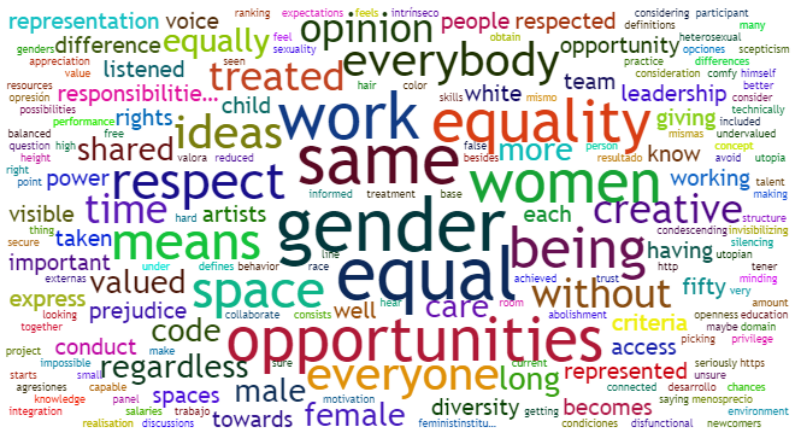

Figure 192 What means gender equality to you at your workplace? Answers cloud visualization with Advanced Summary by Awesome Table

\subsubsection{Discussion}

Most of participants agree all-women and feminist spaces are necessary in the field, and from those who do not think that women-only platforms and spaces are so, I think it is important to note that none is from North America, half of them are from Mediterranean countries in Europe and the other half from Central and West Europe, and some from South America.

I can presume that for user's perspectives, gender equality has not been achieved, over half of them state to have experienced some type of discrimination at the work environment based on their gender, having faced negative experiences in different situations. However, most of them believe there has been some change or improvement in the art and tech world. Three quarter parts of the participants believe other folks are underrepresented, considering factors of discrimination age, social class, ethnicity, race, gender identity. The general awareness for underrepresented folks increases as the support for segregation uniquely from white-male individuals grows towards a safe space building. 
Over $60 \%$ of participants believe spaces with no $\left(\mathrm{cis}^{204}\right.$ white-heterosexual) males presence encourages women and other underrepresented folks to learn technology. There is a notable general thinking in many of the participants (as happened during many interviews), to mark a distance from women-only strategies from the 1960 s and 1970 s, to show a more 'intersectional' approach, meaning that the collective identity of the feminist space should not based on biological sex or gender, but rather open to all but the dominant ones (cis white-heterosexual male). There is a strong general awareness for people of color, indigenous, LGTBQ folks, and other underrepresented minorities, demonstrating that most of the feminist positions are not 'only' concerned on women. I would like to note that, despite the general awareness for people of color, other ethnicities, etc., none of the participants is a PoC (considering black people, Afro-Americans or Afro-European), and a low number are Hispanic or Asian. I would also would like to note, that the statements on intersectionality that most of the participants show to follow, are arguable new strategies in contemporary feminist groups, some scholars have described all-women, women-only and feminist types of self-organisation with a general concern on minorities, poor, people of color, etc. since the temperance movements (Scott, 1993), the first transnational women's associations (Rupp, 1997), and the so called second-wave feminism (Spain, 2016). Although many contemporary feminist scholars have described the previous feminist groups to the so-called third wave of feminism, as generally white middle upper-class dominating, bourgeois and even racists (Land, 2004) considering that most of the bibliography is Anglo-American.

The confidence on technology as a form of empowerment is not claimed in high numbers, while a more radical position towards economic and ideological system is notable in the majority. Here I note a difference between the first cyberfeminist theories and the following technofeminist approaches.

\footnotetext{
${ }^{204}$ Cis: short of cisgender "Denoting or relating to a person whose sense of personal identity and gender corresponds with their birth sex" (Lexico, powered by Oxford). <https://www.lexico.com>
} 
I have noticed that the contemporary terminology regarding gender identity politics/ queer theory is known and use by most of the participants, although hopefully, some have rejected to use these terms. Additionally, most of the participants have put emphasis in stating that feminism is not women-only. Half of the participants over age 45 notices an improvement in the art and tech world, but still most of them thinks women are underrepresented. I am especially interested in the answers of the eldest participants who were founders of all-women projects about the change since the 1990s, such as Anna Couey, co-founders of Matrix: Women Networking ${ }^{205}$ (1993). Despite noticing an improvement in the art and technology world, Couey thinks women are still underrepresented and sees in new waves of cyberfeminism an integration of race and postcolonialism topics.

There are many more voices than there used to be. Thinking about technology, gender, and the body has continued to evolve. Access to technology is much more widespread and embedded in daily life. However, use of technology for surveillance and control has greatly increased; most people of all genders have lost power (Couey, survey answer 2019)

However, she believes all-women initiatives can find alternative ways of expression through technology by:

...giving voice to women's experiences and ideas, by claiming and shaping technology as a feminist space, and by creating space for all oppressed peoples to speak and participate. By complicating and making plural a master narrative/s. By restructuring power (Couey, personal communication 2019).

Regarding this same question, Kathy Rae Huffman, who also sees an improvement in the art and technology world, states that female perspective is unique. This statement that she has manifested since she started Faces Settings with Wohlgemuthh, is controversy by those participants who were confused

${ }^{205}$ Discussed in section 3.1.4. 
about the generalization and essentialism of the questions in regarding relation of sex-genderpersonality. Lucia Grossberger Morales, co-curator of Addressing Imagens (1991), and of Matrix: Women, Networking (1993) states (2019), like a notable number of participants, that there is an awareness in the new generations towards gender fluid issues, going beyond gender, far from the second wave feminism "aggressively seeking gender equality". Nevertheless, majority of participants have marked 'absolutely gender equality' in the list of purposes of feminism and feminist projects. Artist Helen Varley Jamieson, comments in regarding the repetition of topics and strategies in new cyberfeminist generation, because:

...many younger women don't know anything about the history of cyberfeminism and this means they are repeating / reinventing things. But there are many differences especially to do with how we live with technologies today, how social media has impacted on our lives, that were obviously not issues a decade ago (Helen Varley Jamieson, survey answer 2019).

This lack of historical knowledge about previous work will be discuss in the Conclusions Chapter. I have also noticed a notable confusion with feminist terms equity and equality, which from my perspective, makes difficult the political and ideological position on feminism. In general terms, the positions on feminism are as diverse as the individuals, although I can state that there is a general trend, tendency or ideology within feminism that most of the participants share. The general tendency enabled me to state that new topics of concern are on social environment, biotechnology, politics of power, gender identity, social injustice, body politics,

The results of the survey and the qualitative data (long answers on personal experiences) will be published on Atenea's official website ${ }^{206}$ after the submission of the present dissertation.

\footnotetext{
${ }^{206}$ See <www.atenea.in/research>
} 


\subsection{Current Situation Women in New Media Arts}

As I discussed in chapter 3.2., in 1995 the International Women's Conference in Beijing there were commitments that were launched on women's accessibility to digital tools, the Internet, towards a potential inclusion of women in the job market, the strategies of alliance on the net as forms of empowerment for women and women's platforms (UN Women, 1995). There were all-women curatorial projects happening since middle 1980s in North America in computer arts, however, it was not until the domestication of the Internet and the first graphical web browser in 1991, and the resurface of feminism and its new perspectives on technology, that the first all-women alliances started to appear. These alliances aimed to face the problematic regarding the small numbers of women and minorities involved in computer-based information technologies and arts in capitalized countries (Leigh Morbey, 1992, 2000), in addition to the gender discrimination they felt in their own professional network (OBN in First Cyberfeminist Inernational, 1997). Both social and artistic cyberfemnists exposed alliance and empowerment through digital tools as strategy for emancipation and resistance (Plant 1997; Vesna, 1998; Boix, 2002; Zafra, 2011).

Since then, the domestication of the Internet, personal computers and mobile devices has spread enormously even beyond Western countries, the development of new technologies in media arts has increased immeasurably, and with it the professional network of new media arts (festivals, programmes, galleries, magazines, journals, conferences, etc.). As I have seen in the present work, the founding of feminist and all-women self-organised projects and platforms is a growing constant strategy applied in different parts of the world. However, the universal accessibility and the abolition of gender barriers and biases in the digital world are still a contemporary issue, especially for women and other barriers based on wealth and social class and technical literacy, especially in non-Western countries (Gill, 2005; Couey, 2003). As happened in 1970 in the Californian exhibition Art and Technology when men formed all the programme, in 2016 the main Festival in Digital Arts and 
Creative Industries, Ars Electronica, received a harsh critic by a group of female new media artists that in the legacy of the Guerrilla Girls, launched the campaign \#KissMyArs. Founders of REFRESH started it: Heather Dewey-Hagborg ${ }^{207}$ in collaboration with Addie Wagenknecht, also founder of founder of Deep Lab ${ }^{208}$, Camilla M $\phi r k$ R $\phi s t v i k$ and Kathy High, from FEMeeting ${ }^{209}$. The campaign was based on an investigation by Dewey-Hagborg of the number of female artists who had been awarded with the most acclaimed prize in New Media Arts, the Golden Nica, investigation that showed that nine out of ten were men, throughout its 29-year of prize history (Dewey-Hagborg in The Guardian, 2016). REFRESH was conceived during this campaign process.

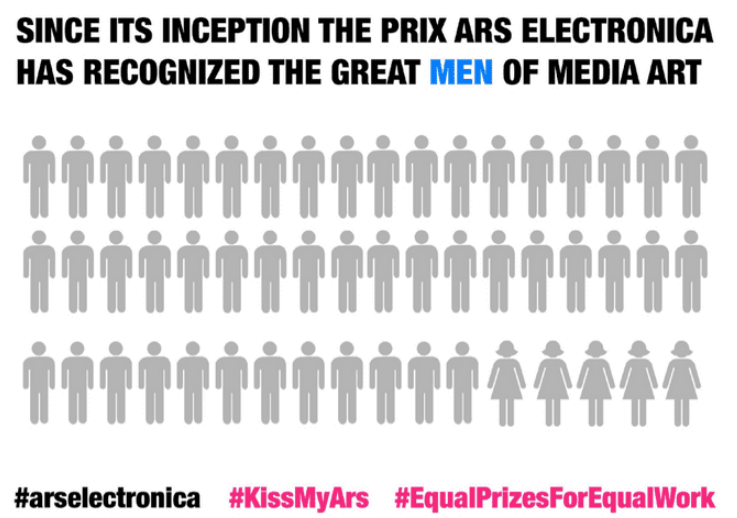

Figure 193 \#KissMyArs campaign design, retrieved from The Guardian <https://bit.ly/2cpdovk>

Paradoxically, the prize is represented as a female-body figure, "the perfect metaphor of how women are represented" (Wagenknecht in The Guardian, 2016). Nonetheless, it is a fact that a lower number of women than men have applied to the price, which may explain the equivalence in women awarded. But, from these applicants one can find outstanding female artists in computer-based art and new media arts such as Rebecca Gomperts, Lillian Schwartz, Mariam Ghani, Pinar Yoldas, Daisy Ginsberg, Holly Herndon, Kaho Abe, and Ai Hasegawa. Dewey-Hagborg has experienced what means

\footnotetext{
${ }^{207}$ See point 3.4.3.6.

${ }^{208}$ See point 3.4.3.4.

${ }^{209}$ See point 3.4.5.10.
} 
to be a woman in tech, and work in a completely male-dominated environment, finding surprising facts like her salary was substantially lower than her make colleagues, with less experience:

All at once in a single moment I became conscious of myself ... as a woman whose skills and experience and creativity were devalued. As a woman out of place [...] As women in art and tech we are consistently under-recognised, under-funded, and written out of history $[\ldots]$ We are made to feel that our work must simply not be as good as that of our male peers, and if only we made better work we would attain the same accolades and accomplishments as they did. Last year I finally realized that this was bullshit (Dewey-Hagborg in the Guardian, 2016)

Ars Electronica Festival was deeply affected by \#KissMyArs campaign, by the end of the same year the center published a section on their digital archive on women in media arts. However, the project was started a few years before as an internal proposal to seek the female artists for the organisation of the exhibitions and conferences (Costamoling, 2017). The retrieval from the database of all the women artists involved in the festival had been arduous work that was developed by Florina Costamoling and Cristina Radner. The archive and global visualization map that is called Women in Media Arts ${ }^{210}$, and today is open to contributions by female artists that have not been taken part of the Festival but would like to be visualised in the digital platform. Even so, the reception of many female new media artists, especially those who commit their work from a radical activist perspective, have expressed their discomfort with the project (Reitner, personal communication 2018).

The situation for women artists is critic in the general art panorama. As REFRESH collective points, since the question formulated by The Guerrilla Girls in 1989 Do women have to be naked to get into the MET Museum? little has changed (2019):

\footnotetext{
${ }^{210}$ See <http://archive.aec.at/womeninmediaarts>
} 
A painstaking review of the statistics in 2016 confirmed that more than $90 \%$ of winners of a major festival in the arts self-identified as male, and two out of the 100 top selling artists at auction are women. The difference in price between the most expensive female and male artists is also vast; \$44.4 million vs. \$179 million. Women have been largely excluded from history, criticism, and curation of major art historical movements, even when they participate in great numbers as in the case of Abstract Expressionism.

\subsubsection{Institutional awareness on Women in Creative Industries and New Media Arts}

As I discussed at the beginning of this dissertation when talking on women in early computer arts, the experimental field of new media arts that once on its infancy would welcome good minds despite their gender, soon inherited the politics of the art and science culture, "perpetuating the oppressive structures of both domains" (REFRESH, 2019). The awareness of the underrepresentation of women in new media arts has spread beyond the self-organised all-women initiatives reaching the world of the new media arts institutions and the creative industries. This general awareness has given rise to international programmes developed by big institutions which see the problem related to the lack of women in the STEM ${ }^{211}$ fields affecting also the creative industries. Just one year ago in 2018 the UNESCO, together with the cultural entrepreneur and philanthropist Sabrina Ho, have started an international project on Women in Digital Arts and Creative Industry part of UNESCO's Create|2030 Talks, called You Are Next: Empowering Women in the Digital Arts. This partnership is born from two situations: on the one hand, the awareness of the creative economy digitalization, and on the other hand, the low numbers of participation of women in digital arts. UNESCO has developed global reports such as RE|Shaping Cultural Policies ${ }^{212}$ published in 2017 that shows the "significant inequalities

\footnotetext{
${ }^{211}$ Science, Technology, Engineering, Mathematics (S.T.E.M)
}

${ }^{212}$ Available at <https://bit.ly/2KsguAI> 
between women and men as creators and producers of cultural goods and services in all sectors of the digital creative industries from book publishing to music, cinema or visual arts". The report also shows that, paradoxically, women are less connected and benefit in less percentage of the digital literacy and skill training programmes ${ }^{213}$. There are other current problematics in the tech fields, for example the fact that women are less likely to be hired, therefore they are still underrepresented in dissemination spaces such as conferences and creative industry marketplaces. Another fact is the lack female senior management and women in leading positions, and those women who are entrepreneurs remain "invisible in the digital creative industries even though they represent half of those employed in these sectors worldwide" (UNESCO, 2018).

The conclusions of this UNESCO report agree with the qualitative data collected through my survey and interviews, both reflecting a permanent problematic for women in new media arts since the late 1990s, as freelancers or creative industry members. This problem is neither exclusive in Western countries nor within gender barriers. In Western countries the socio-economic barriers are stronger than gender for example in order to be able to afford new media programmes and achieve a fair visibility in the field (UNESCO, 2018). In non-Western countries, the situation is more complex due to infrastructures, resources, etc., creating a harder situation for women in new media arts and creative industries. You Are Next is concretely focused on women artists and digital creative industry entrepreneurs from the Global South, considering that due to their socio-economical context, they face additional challenges, remaining even more isolated in the new media world. This global awareness raising initiative has been designed "to create opportunities for women under 40 from the global South and support their access to funding, infrastructure, equipment and co-production opportunities in the

213 This data makes invites to reflect upon the report from the 4 th International Women's Conference in 1995 mentioned in chapter 3.2.2. 
digital creative industries". Last year 2018 You Are Next has funded four international projects leaded by women (UNESCO, 2018):

- \#BeYourVoice in Mexico: a project to provide girls with skills in virtual reality technology;

- WAVE in Palestine: a training programmeme to provide young women with audiovisual education and skills-based training;

- DigitELLES in Senegal: a digital programmeme to provide young women in the music industry with technical training and entrepreneurial skills;

- Academy of Digital Arts in Tajikistan: creation of a digital academy for female cultural entrepreneurs in Tajikistan and Afghanistan.

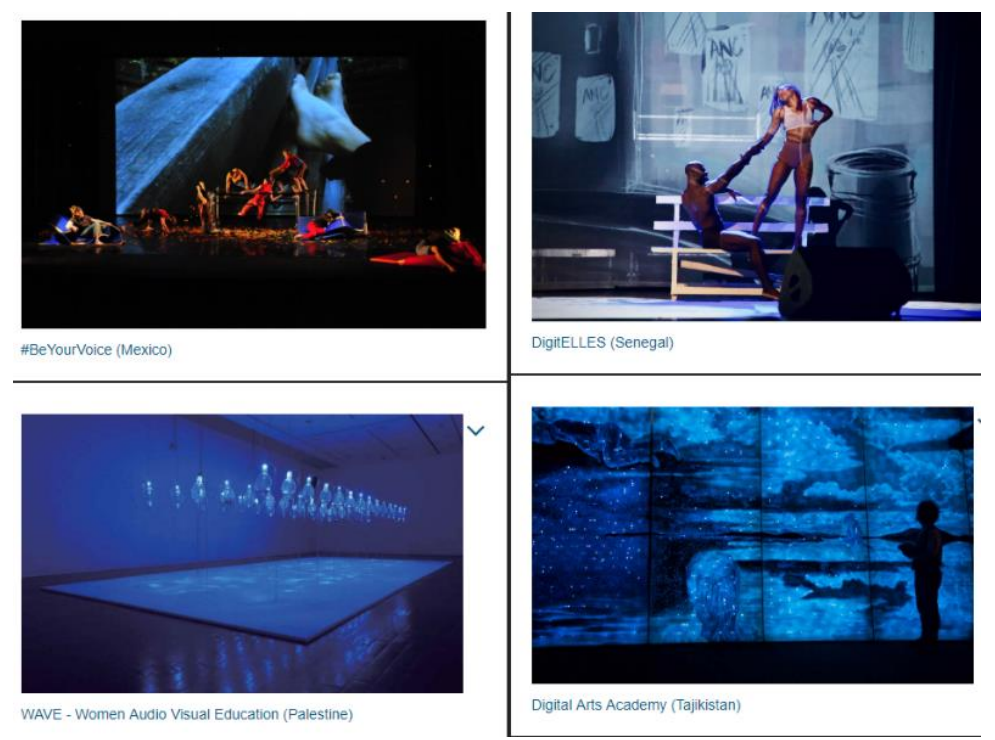

Figure 194 Four new projects awarded, UNESCO-Sabrina Ho, You are Next, 2018. Retrieved from <https://bit.ly/2Zz7rRW>

At a European level, one can also find projects addressed to women in New Media Arts and Creative Industries within the framework of the Creative Europe Programmeme (2014-2020). One of the founded projects are the one leaded by Auditorio de Galicia, Wom@rts ${ }^{214}$ : Women Equal Share Presence in the Arts and Creative Industries, an international cross-discipline consortium and non-

\footnotetext{
${ }^{214}$ See < www.womarts.eu>
} 
profit project co-funded by the Creative Europe Programmeme that aims to "highlight and support the creativity of women from a cross-sectorial perspective" and supports "women's equal share presence in the Arts, in terms of visibility, promotion and access to the market" (WOMARTS, 2018). Between others,Wom@rts addresses the Cultural and Creative Industries (ICCs) of Fine and Visual Arts including lens-based media and new digital tendencies. The Creative Europe programme has also funded together with the PRS Foundation ${ }^{215}$ the international initiative Keychange ${ }^{216}$ dedicated to "empower women to transform the future of music and encourages festivals to achieve a 50:50 gender balance by 2022" (PRS Foundation, 2019).

Another funded project by the Creative Europe Programmeme $(2014-2020)^{217}$ was the $15^{\text {th }}$ edition of the annual Athens Digital Arts Festival celebrated last June 2019 with a special memorial to women concretely in the "cruel, male-dominated are of technology and art", called Women in Media Technology: The Matrix of the Future ${ }^{218}$, an open air of ten film screenings of digital cinema and animation (Athens Digital Arts Festival, 2019). The programme of screening sessions of films made by women aimed to raise public awareness on women's situation at workplace in the creative industries and digital arts by promoting their work. The festival points the "problem of gender discrimination" as "one of the oldest and most deeply rooted", especially in the subcategory of art, the area of technology and innovation, which faces "this types of bias between the two sexes" with a male-dominated scene from the beginning "with the exception of female authors" (ADAF, 2019).

In this twenty-eight-year retrospective I find some similitudes. Since 1991 the concept of Matrix is still used as a symbol of the empowerment of women through the new media and the arts, unfortunately to face a similar situation for women which has reached the institutional awareness from

\footnotetext{
215 See <www.prsfoundation.com>

216 See < https://bit.ly/2L92lq2>

${ }^{217}$ More information on the programme available at $<$ https://bit.ly/2HsdUri $>$

${ }^{218}$ Available at <https://bit.ly/2ScGhxT>
} 
the first self-organised women artists groups that emerged in the grassroots of the new media world. From the 2003 publication edited by Judy Malloy and the MIT Press called Women, Art and Technology (a compilation of essays on women's new media art works published -by the Leonardo Art\&Science journal-, there have been several publications on theoretical concept related to gender, art and tech such as cyberfeminism, xenofeminism, etc. However, only the School of the Arts Institute of Chicago (ISAC) has edited two publications on the history and contribution of Women in New Media Arts in the State of Illinois: the publication edited by computer artists Donna Cox, Janine Fron and Ellen Sandor called Women in New Media Arts: Perspectives on Innovative Collaboration (2016) which was celebrated with a one-day symposium called Celebrating Women in New Media Arts, and the Catalogue of the Art and Technology Studies celebrating fifty years of the programme ats@50 (2019), with a section dedicated to the contribution of women artists to the New Media Art Programmes in United States edited by Judy Malloy called The Women Who Shaped Art and Technology Studies.

\subsection{Atenea: mentoring and networking project in STEAM}

Atenea is a project founded within the framework of this present research work during the first stage of my predoctoral fellowship as research assistant in the Instituto de Diseño y Fabricación at Universitat Politècnica de València. The project has grown parallelly with my dissertation, becoming its practice research The idea was conceived in 2016 together with my supervisor Nuria Lloret. It started as an early attempt to build a creative network of women at the intersection of Arts and STEM fields which could potentially encourage the establishment of new interdisciplinary and collaborative projects. The project has been running with us both as the core team, some colleagues from other departments and institutions joined the initiative, who have collaborated as much as their academic schedule and routine has allowed them. Due to the lack of financial resources and economic support, as for the small group involved and availability, the project has kept a considerable number of goals 
and milestones based on such circumstances. Nevertheless, we are proud of the community and network that we have netted, the projects and networks that we have reactivated and the programme of activities that we have carried out in two years, after its official launching as a digital platform in early 2017, moment when the project started to be disseminated through international events as well.

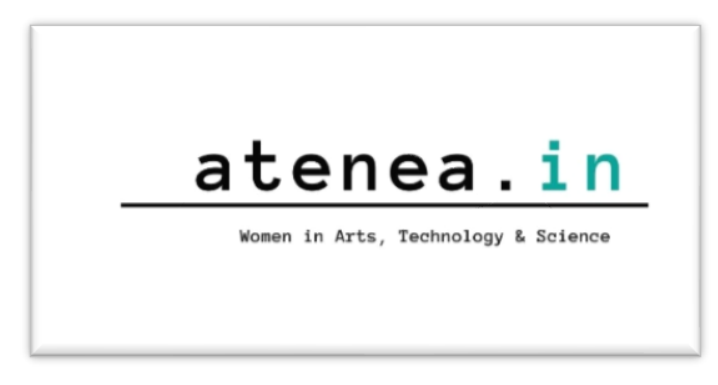

Figure 195 Atenea's Logo.

The concept of Atenea was raised from both on personal and professional experience by working in research environments such as our university, where technical and artistic disciplines are not integrated neither produce cross-disciplines projects, and consequently students and professional women remain isolated from each other's work. With Atenea, Prof. Lloret and me aimed to build a creative space for women on disciplines which are generally scattered in academia, like it is the case engineering schools and the School of Arts and the Conservatory of Dance at Universitat Politècnica de València. The situation in our campus is an example of what generally happens between Arts and STEM fields (Jacobs, 2014): events and programmes are happening at the campus with no intersection between the students and researchers of such disciplines, leaving spaces of collaboration and knowledge exchange unexplored. Concretely on women, the percentage of female students in the Art School and Conservatory differs drastically from that in Computer Science or other Engineering Schools (Puchades Pla \& Cerda-Hernandez, 2019). There is an increasing bibliography on research about the benefits of the interdisciplinary and cross-disciplinary projects in academia, and the combination of Arts to STEM ${ }^{219}$ fields for innovative educational methodologies (Root-Bernstein,

\footnotetext{
219 Also known as STEAM or STEM+Art
} 
2015; Costantino, 2017; Liao, 2016; Sochacka et al., 2016), some focusing particularly on the benefits for women (Dahle et al., 2017).

\subsubsection{Team}

Atenea's team is formed by other female academics, researchers and artists, who contribute with their expertise, professional network and support. We also count on the collaboration of other male colleagues. Additional collaborators from other institutions such as Universitat de Valencia are involved in specific events of Atenea, when we also count on the collaboration and support of male colleagues of our departments and research groups, such as the male members of Soundcool Project ${ }^{220}$, DCADHA and CALSI. Atenea's members are part of different faculties, departments and research groups in and out UPV, therefore the project works within the campus environment, but it is not founded or supported by the university in a formal or official manner. It is self-organised and nonprofit, currently expecting to be registered as a cultural association. Atenea works collectively and all the work is done voluntarily but mine during the period of my fellowship. Hierarchies are simple but not limiting, everything works upon the basis of the project therefore any suggestion and proposal by any member is welcome to be commented by the group. In general terms, Prof. Lloret and I lead the project, as we are those who dedicate most of our time and work, however, in every event the colleagues involved are given the chance to design and execute additional proposals by themselves. There are no strong hierarchies within the different grades of academic career between all Atenea members, despite our positions, we are all project mates with similar level of authority and responsibility. In other words, it is a network which grows for specific events, Prof. Lloret and I oversee designing the scenario to put the seed in, and any collaborator is welcome to contribute along the branches may grow.

${ }^{220}$ See <www.soundcool.org > 


\subsubsection{Objectives}

In Atenea we are aware that the renaissance spirit that the digital and new media art practices have is due to the diverse profiles and professional backgrounds of the team members and the same $\operatorname{artists}^{221}$. However, due to gender, age and social class factors that end up in discrimination, women remain isolated or behind in the new media art world ${ }^{222}$. The situation of women in STEM fields is truly critic from the early first stage of pre-grade studies in Spain as well, following the general panorama in Western countries (as we will see in the following point). Prof. Lloret and I projected Atenea as a platform where those women in visual and new media arts could meet women in STEM and women entrepreneurs, to encounter who could have not met in any other form due to the separation of the spaces of knowledge such as university schools. This platform aims to encourage the creation of new collaborative and transnational proposals at the intersection of the artistic, scientific and technological profiles.

Atenea is a project which objective is to create a virtual and real space for encounter between women in arts, technology, science and culture in order to promote their work and encourage the founding of new collaborative interdisciplinary projects. Consequent subobjectives are the establishment of a creative network by articulating the own Atenea community and by functioning as a node in the transnational and translocal network of alliances that already exists in these fields. Another subobjective is to promote the work of professional women as female inspiring figures for young generations and to provide open formative and educational content online and offline, and. Our main strategy is based on networking, and we approach our aims through three formats: digital platform and social networks, programme of real space-based activities and academic dissemination.

\footnotetext{
${ }^{221}$ See point 2.4 .2
}

${ }^{222}$ See section 4.1.1 


\subsubsection{Context}

The context that Atenea faces is related to the contemporary issue of the critical low number of women involved STEM fields, gender inequity in art spaces and the glass ceiling that exists in high academic and research positions. These factors are combined with research that works on the advantages of the intersection and combination of Arts and STEM for educational and innovational purposes.

\section{Women in STEM fields}

Although the situation of women in STEM is not the same worldwide, Spain together with other Western countries (such as Germany, Austria, France, UK, United States) share the low numbers of female students enrolled in higher education programmes in Information and Communication Technologies and Engineering. Global statistics show that women interest is notably is higher on education, health care, art and humanities and social science over ICTs and engineering, where hardly reaches 30\% (UNESCO, 2017).

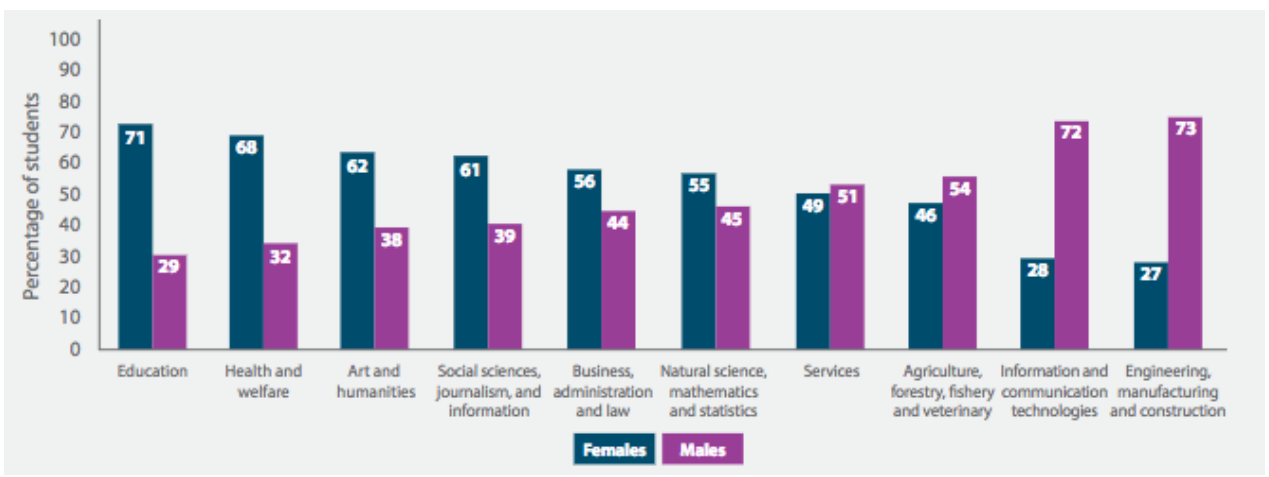

Figure 196 Share of female and male students enrolled in higher education, by field of study, global average. Data Source: UIS 2014-2016 on 115 countries (UNESCO, 2017)

Concretely in our country, from the total number of graduates in our country in higher education in 2017, only 3\% are in technological careers. Among the total of graduates in these careers, only $14.6 \%$ are women, a number that has decreased in recent years. This happens in degrees of professional formation, as well as in university levels. Spain one of the countries in Europe with the 
lower presence of women in ICT careers (Eurostat, 2018). The need to increase the presence of women in ICT sectors goes beyond the common goal of gender equality in all sectors relevant to the national economy: teams with higher levels of diversity are more innovative, companies with a high female presence are more competitive and more resistant to economic crises (DigitalES, 2018). In addition, in Spain women suffer a higher unemployment rate than men and occupy $74 \%$ of part-time jobs and $62 \%$ of discontinuous fixed contracts. Digitization and robotization are threats of labor exclusion for women, so betting on their inclusion in STEM areas and the digital sector is a strong weapon to avoid job precariousness. In addition, salaries in ICT areas are $20 \%$ higher, even for women $30 \%$ higher compared to other positions of the same level in another sector in many cases. The UNESCO report published in 2016, Cracking the Code: Girls in STEM, announced that in 2020, 98\% of STEM jobs will require ICT skills, where there will be around 1 million jobs worldwide in programmeming due to the shortage of specialized personnel. At a global and European level, women also represent $3 \%$ of graduates in ICT.

\section{Women in Arts in college and museums}

On the other side of the spectrum, the percentage of female students enrolled in art studies in United States and UK for example is over 60\% (Freelands Foundation, 2019), and over 70\% in Spanish Art Schools for the last thirty years (MAV, 2015). In Spain in 2017, 62\% of those enrolled in visual arts and design were women, in dance $92.1 \%$, in dramatic art $60.4 \%$ and in music $53.8 \%$ (Ministerio de Educación y Formación Profesional, 2019). Through my doctoral experience, I have noticed that masters of multimedia art and digital arts have more gender equality in their classrooms in Europe and North America compared to the general visual arts ones. However, the number of women artists in galleries, art ferias and leading academic positions decreases, provoking the known as glass ceiling or scissor effect (Masegosa \& Márquez, 2016). Maula Reilly (2015) published an article claiming the still 
existing inequality in the art institutions despite the improvement after more than four decades of Nochlin's essay "Why there have been no great women artists". The article presented a compilation of results from global reports conducted in the United States and Europe, based on studies on the presence of women artists in the most important galleries from 2007 to 2014. In museums such as MoMA or the Guggenheim the number of individual exhibitions by women artists until 2014 did not exceed 30\%, and in European institutions the Jeu de Paume was the one that reached the highest percentage skimming $40 \%$ in the same range of dates (Reilly, 2015). In United States diversity in art spaces is still a challenge, not only by gender but also race. A recent publication shows that $85 \%$ percent of artists in eighteen major museums are white, and $87 \%$ are male (Topaz et al., 2019).

In 2016 The Guerrilla girls launched an activism project on diversity in European museums, to 383 museums based in different countries of Europe. They collected interesting that like 21 of the museums that responded have less that $20 \%$ women artists in their collections, of which 7 are Spanish. Only two museums from the whole that responded have $40 \%$ or more women artists in their collection. Ateneum in Helsinki has only $12 \$$ of women, museums like Manchester Art Gallery in UK collection is $80 \%$ male and $85 \%$ white, Museum Nacional Centro de Arte Reina Sofia in Madrid collection is $87 \%$ works made by men (Guerrilla Girls, 2016). In UK, female art students outnumber men students, however, only $28 \%$ of female artists are exhibited in major commercial galleries in London, $22 \%$ are part of solo shows (Freelands Foundation, 2019).

Mujeres en las Artes Visuales (MAV) is the national association that leads the activism on women in visual arts by reporting the most updated data on women in art spaces and institutions. This year report \#MAV2019, declared that ARCO (the most important art fair in Spain) had a 6,13\% of Spanish female artists in the last edition, within the $26,5 \%$ of total of international female artists. In the report they also note that this number increases internationally due to the Latino American galleries that were part of ARCO, which presented same number of female and male art works, achieving a fair parity. On the 
other hand, MAV activist work has achieved that new emerging art fairs such as JUST MAD, HYBRID and DRAWING, have accomplished gender parity in a successful way with $47 \%, 62 \%$ and $50 \%$ respectively (MAV, 2019).

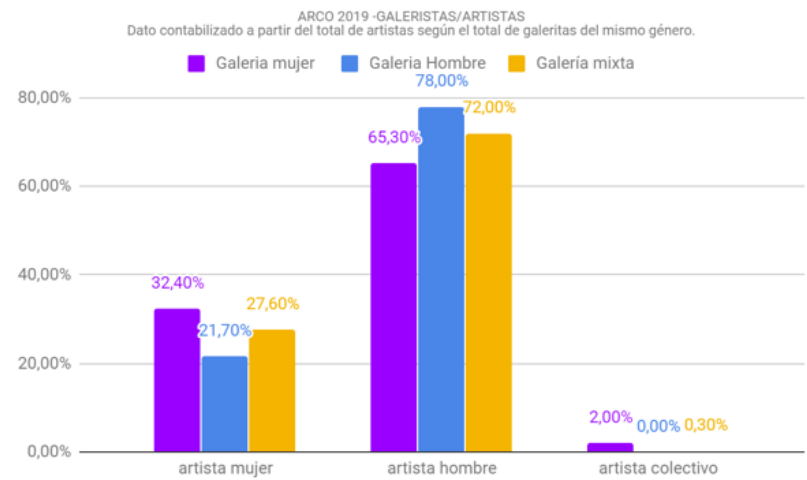

Figure 197 Percentage by gender of artists exhibited by gender of gallery director in ARCO 2019. \#MAV2019

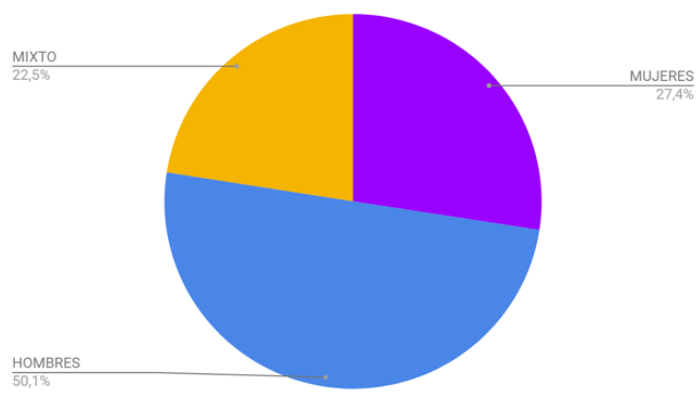

Figure 198 Percentage of artists by gender exhibited in Spanish Galleries in ARCO 2019. \#MAV2019

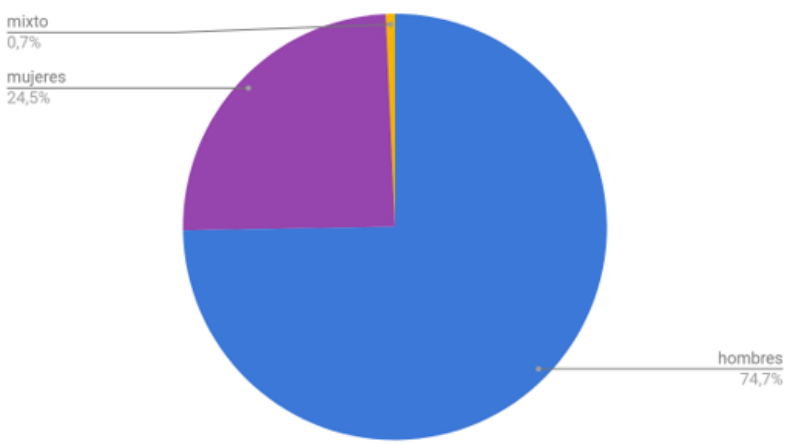

Figure 199 Percentage of artists by gender exhibited in European Galleries in ARCO 2019. \#MAV2019 


\subsubsection{Glass Ceiling}

When observing the female presence in educational or leading positions in art institutions, the number decreases significantly, as we abovementioned, named as glass ceiling or gender scissors. From the profile of student to professional, whether as an educator or artist, women go from occupying a majority in the classroom to a minority in the workplace. The study carried out by the Association of Women in Visual Arts in 2015 in Spain reports that 30\% of the presence of teachers in the Art Masters in Spain, consisting of some without the presence of women teachers. It has achieved a $54 \%$ presence of women in artistic research but from this level to the highest of Grade A - professor- decays the percentage to $16.9 \%$, and $2 \%$ in the role of rector of Faculties of Fine Arts (INE, 2017). At a national level, Atenea's partners AMIT (Asociación de Mujeres en Investigación y Tecnología), publishes annual reports together with Unidad de Mujeres y Ciencia, inspired in the She Figures series, European annual reports by European Commission. Such reports show statistics on employment in different stages of education by gender, presenting a gender scissor evolution after Grade C in academia, from $50 \%$ of $\mathrm{PhD}$ graduates to $21 \%$ of employed women in lead positions in research labs, academic departments or schools.

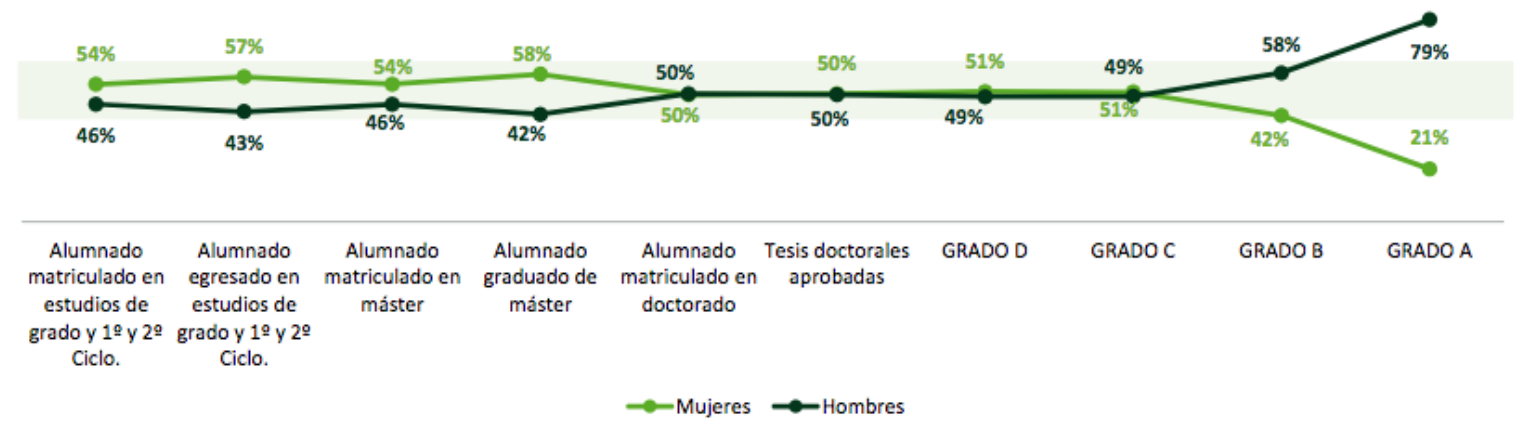

Figure 200 Percentage by gender during all grades of education in public universities, data from 2014-2015. INE, 2017

Worldwide, data from 2014 published by UNESCO in 2017, shows that from undergraduate and master studies, women reach 55\%, however, until the postdoctoral level and the researcher hired does not reach $30 \%$. Of that percentage of graduates, around $30 \%$ belongs to the STEM field. Of that 
$30 \%, 3 \%$ are ICT, construction and engineering $8 \%$ and natural sciences, mathematics and statistics $5 \%$, remaining health and care with $15 \%$. The number as not increased but decreased in the last decades: On the other hand, the percentage of women in programmeming and / or IT positions was $36 \%$ in 1991, which decreased to $26 \%$ in 2014 (UNESCO, 2017). Based on statistics published by the Ministry of Health and Equality, in 2015 in our country the rate of graduates in science, mathematics, engineering, industry, computing and construction, $31.4 \%$ reflects the number of men and a $13.3 \%$ that of women. The study estimates that in $2020,98 \%$ of the STEM disciplines will require knowledge of ICT.

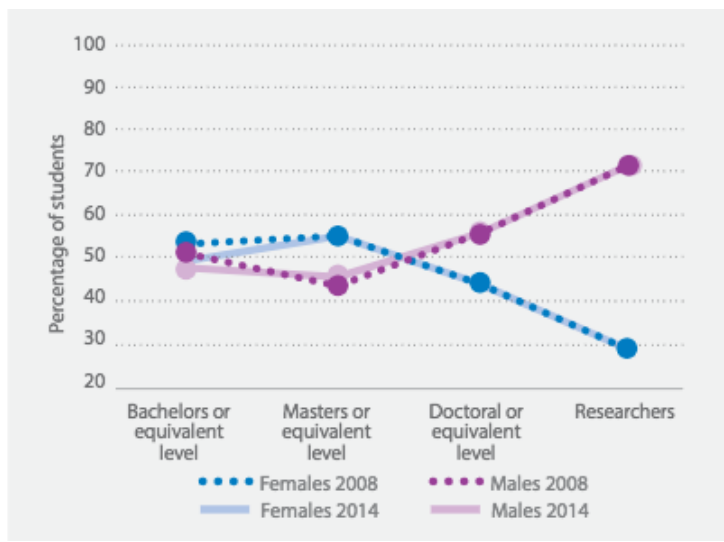

Figure 201 Proportion of women and men in higher education and research, world average. Source: UNESCO, data from 20082014, on 226 countries. (UNESCO, 2017)

At the global scale, according to the UNESCO 2017 report, $28 \%$ of the total university research personnel belongs to the presence of women. This study shows that the gender difference worsens as the level of education rises to higher education (Fig. 192).

Based on the statistics published by the Ministerio de Educación in Spain on its official website, in 2015 the presence of women as a teacher in public universities had already reached $40.5 \%$ and $58 \%$ as research staff (especially the postdoctoral phase). However, the percentage is very different when it is broken down by university categories, decreasing considerably towards the A - professor degree by $20.8 \%$, and $10 \%$ as rectors of faculties or higher schools (Fig. 193) Example of the absence of 
female figures in the academic field, is the fact that only 17 women have won the Nobel Prize in physics, chemistry or medicine since Marie Curie in 1903, while 572 have been awarded to men.

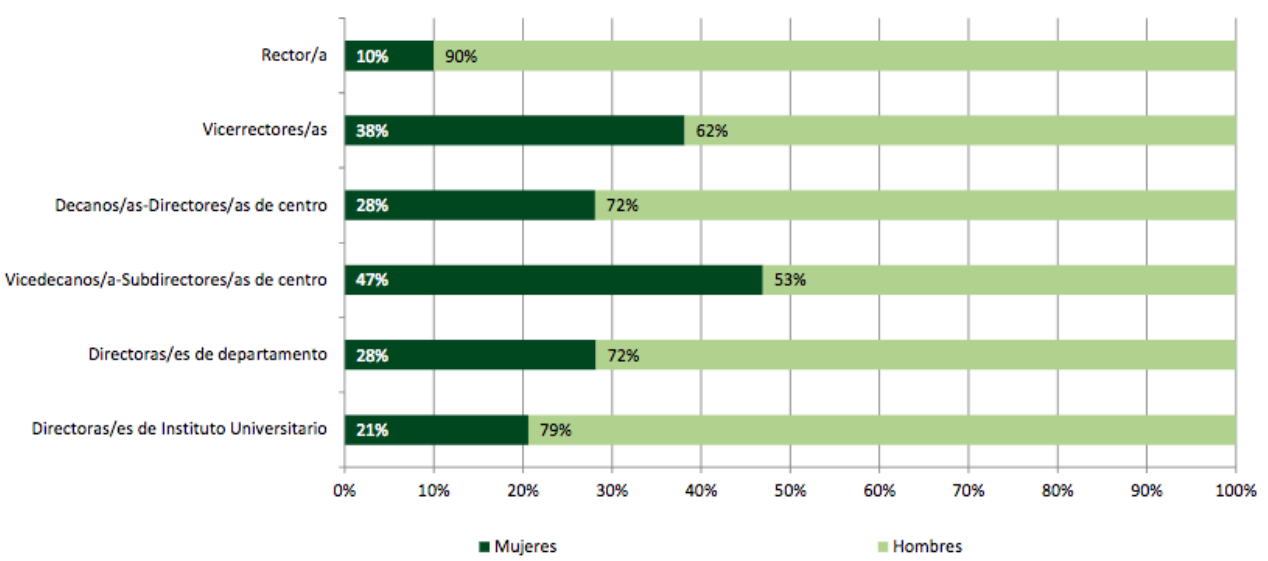

Figure 202 Distribution by gender in decision-making positions in public and private universities in Spain, data from 2015 (INE, 2017)

\subsubsection{Barriers}

On the one hand there are research works that attempt to illustrate the barriers of young women to enroll STEM fields, and on the other hand, there are reports that study the reason why from the few women that join STEM fields as labor force, a considerable number abandons or finds difficulties. We outline those studies that point the combination of factors that "reduces the proportion of women at each stage of a scientific career" (Huyer, 2016, p.98):

- $\quad$ the graduate-level environment

- the maternal wall/glass ceiling

- performance evaluation criteria

- the lack of recognition

- $\quad$ lack of support for leadership bids

- unconscious gender bias 
The material wall/glass ceiling refers to women researchers or in high positions find frequently themselves in the situation of choosing between two sacrifices: their job or their family. Maternity wall starts to affect also men's life (Huyer, 2016, p.98). In United States for example, $43 \%$ of women and $23 \%$ of men had left full-time STEM job after becoming parents, and this is due to the lack of tolerance and support that STEM professions have in terms of caregiving responsibilities (Cech \& Blair-Loy, 2019).

The inclusion of women in professional STEM fields promotes scientific excellence and improves the quality results, as different perspectives are added creativity, strong biases are reduced, and knowledge and stronger solutions are promoted. The benefits of diversity are promoted in academic and business environment in US and Europe for its benefits and results from a social and a practical perspective (Frieze \& Quesenberry, 2015; UNESCO, 2017). Contemporary research exposes cultural and educational factors as barriers for girls to be attracted to STEM carriers, as the number of female students varies notably from Asian countries such as Indonesia and India for example, where women are equally involved in computer science studies and workplace, with those in United States, Germany and Austria, for example (Galpin, 2002; Lagesen, 2008; UNESCO, 2017; Seager, 2018).

\subsubsection{Methodologies - References}

Based on social feminist Judy Wajcman, Carol Frieze and Jeria Quesenberry in their publication Kicking butt in Computer Science (2015) state that the following points are relevant when designing a methodology for a programme to engage women in STEM:

- Women do not need a 'female-friendly' curriculum

- Cultural change is the key

- Culture can be changed at the micro level

- Cultural factors are more important than gender differences

- Institutional support is critical 
- $\quad$ Success stories are important

Atenea incorporates itself to the legacy of feminist and all-women and feminist curatorial and organisational projects that have taken place in Spain since the socio-political transition in the late 1970s (Caramés, 2016), concretely joining the scarce list of those dedicated to women in new media arts. As I discussed in the chapter 3.4. on the listing of associations and initiatives, just a few in Spain are dedicated to the same purposes as Atenea, from which most of them are still hardly active or paused and others occurred punctually. Those are: Fem Tek ${ }^{223}$, Elas Fan Tech ${ }^{224}$, Cyberfem $^{225}, X_{0 y I^{226}}$, Fem

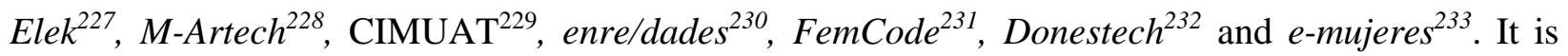
important to note that some controversy exists around the concept of "women's curatorial project" and those considered as "feminist". Some feminist scholars reject the idea that any type of curatorial collective project might be labeled as feminist by the only fact that is formed by members whose union and selection is based on their sex (female), but rather, they state, it should be the feminist content the criteria to be applied for the selection (Caramés, 2016, p.236). This is an arguable position which from Atenea we clearly disagree with, position that many of our case study share with us, as they do not declare their project to be feminist although during our interview they manifested a feminist commitment that was evident by the own content of the project (personal communications with Goshinski, 2018; Mathew, 2019; Cardoso, 2019; Hiršenfelder \& Spačal, 2019; Valley 2019). We consider that Atenea is a feminist project due its own objectives and methodologies understood in its

\footnotetext{
${ }^{223}$ See point 3.4.6.12.

${ }^{224}$ See point 3.4.4.9.

${ }^{225}$ See point 3.4.4.3.

${ }^{226}$ See point 3.4.5.4.

${ }^{227}$ See point 3.4.5.3.

${ }^{228}$ See point 3.4.6.5.

${ }^{229}$ See table 3 in section 3.4.2.2.

${ }^{230}$ See point 3.4.5.2.

${ }^{231}$ See table 3 in section 3.4.2.2.

${ }^{232}$ See point 3.4.3.2.

${ }^{233}$ See point 3.4.4.1.
} 
socio-cultural framework. Moreover, the content of the theoretical and practical works promoted in ATENEA is expected to achieve a certain quality despite its intentional or unintentional feminist content. This controversy on considering feminist an all-women project has been noted along this dissemination when observing analytically the historical and theorical filters that has been implied when labeling the first all-women self-organised projects in computer arts ${ }^{234}$.

Atenea 's strategies are based on feminist methodologies such as:

- Collaboration and participation in the team processes and research towards social transformation (Hesse-Biber, 2013)

- Networked feminism, community building and alliances through ICT.

- The establishment of a creative network and the reinforcement of the nodes through real encounters.

- Experiences of production of knowledge by self-organised and DIY curatorial activities based on cross-border and cross-discipline collaboration.

- By linking academic institutions with non-profit cultural spaces towards the production of new spaces of knowledge.

- Awareness of other barriers beyond gender when designing the programme and addressing the audience: social class, age, ethnicity, functional diversity.

- $\quad$ By promoting interdisciplinarity

- $\quad$ Promoting open-source culture and DIY, hands-on workshops as methodology.

Collaboration as methodology is a complex and powerful tool that must be developed, reviewed and improved by researchers, academics as well as nonacademic activists. To our understanding, this will create alliances that would go beyond institutional structures and that would redefine methodologies

\footnotetext{
${ }^{234}$ See chapter 3.1 .
} 
for constructing norms together with a feminist consciousness to break hierarchies (Benson \& Nagar, 2006). Usually understood as the combination of different people, places and contexts, collaboration has been recognised for its ability to play a critical role in generating new dialogues and knowledge across socio-economic, geographical and institutional boundaries. Collaborative research is based on (Benson \& Nagar 2006):

- the authority does not reside only in the leading researcher.

- neither the perspective of the interpreter nor that of the narrator is privileged.

- the new meanings and proposals are born not only of consensus but also of sharing perspectives and productive disagreement.

The different dimensions of research, action, reception, follow-up have been considered during the process, contributing depth to the collaborative project. Applied feminist methodology tends to interdisciplinarity and collaboration, promotes critical thinking, the construction of new realities and allows social inclusion (Artz, et al., 2017). Collaboration is a tool for the reconstruction of knowledge beyond academic and institutional boundaries, where individual activities are part of the joint project (Benson \& Nagar, 2006). In research in engineering, interdisciplinary and participatory feminist methodologies have been applied successfully in projects of STEM areas for the promotion of creativity and innovation. The formation of interdisciplinary groups in branches of engineering and technology with members of artistic formation has shown to obtain much more fruitful results in terms of originality and enriching experience for the members (Borrego et al., 2007).

\subsubsection{Referents and alliances}

During the development of the present research and the analysis of the different case studies we have acquainted new methodologies and strategies towards alternative curatorial practices semiinstitutional: self-organised initiatives that combine diverse academic members and at the same time lack of institutional and financial support. Additionally, we noticed that some similar events were happening at the same time in different parts of the world (or in previous years), and we were not aware 
from them when designing Atenea programme. For instance, AWMAS conference ${ }^{235}$ took place in February 2018 when we had already planned Atenea 2018 Conference, workshops and exhibition, what is a surprising fact due to the lack of connection we had with the AWMA@ team by then.

The main tasks regarding alliances and networking of Atenea have been performed not only virtually but in real encounters through international events attendance and through the personal and professional network by Prof. Lloret and me. Like I outlined in most of our case studies, the face-toface interaction is clue to the establishment and reinforcement of an own community (Rheingold, 1993) and a creative network (Smite, 2012).

\subsubsection{Formats}

To achieve the abovementioned objectives, Atenea's strategies and methodologies were designed in three formats:

1. Virtual platform and social networks

2. Programme of activities

3. Academic dissemination

These formats and strategies are based on concepts such as networked feminism, workshop as methodology, curatorial activism, and case study research. A combination of real and virtual space would reinforce the establishment of a transnational/ translocal network that consequently would enable the project to achieve diverse goals. On the one hand, the platform and the social networks allow the project to access the virtual world and therefore access other organisations and networks only virtually approachable, in addition to disseminate Atenea's activity to a wider audience that is not geographically related. On the other hand, the design of real encounters based on panels, workshops and related activities creates a space for knowledge exchange and creative experience, making the local

\footnotetext{
${ }^{235}$ See point 3.4.5.9.
} 
space a node of connectivity cross-borders while improves the cultural community in the city. Additionally, a combination of informal and formal networking would enable the cross-disciplines and fields of the project. As Remedios Zafra said in her lecture at CIMUAT in 2010, it is necessary to create networks and alliances between entities and centers from different natures, such as universities, galleries, cultural centers, research labs, etc ${ }^{236}$.

\section{Digital Platform: atenea.in}

While since the early domestication of the Internet social cyberfeminists have considered the cyberspace a land for women's activism and a weapon towards alliance (Boix, 2001), contemporary feminist scholars have named as networked feminism the digital engagement by feminist organisations, collectives or individuals that is performed through digital platforms and social networks. Networked feminist practices reinforce the sense of "digital sisterhood or digital alliance" (Fotopoulou, 2014, p.991) that cyberfeminists previously declared as part of their own cyber activism: "such computational visions of social change, in other words visions of social change and sisterhood in which networked connectivity and ICTs are central, shape to a large extent the priorities of feminist activists" (p.993).

The wider rhetoric of digital networks as sites of "non-hierarchical modes of connection" (Terranova, 2004) and as elementary components of democratic participation (Downey, 2007) underpinned the narrations of all participants. Networked feminism in this vision was a decentralized structure, which allowed women's groups to connect in an optimum way; it is ubiquitous and inclusive. Being part of 'the network' for many interviewees implied belonging in a wider movement that did not adhere to the limitations of waves. (Fotopoulou, 2014, p.995). As we have analysed in chapter 3.4., feminist and all-women collectives may use digital platforms and social networks as: their main space of activism, art practice format or just as a mere form of digital engagement to connect virtually and

\footnotetext{
${ }^{236}$ See < http://www.nonsite.es/?p=1568>
} 
cross-borders with other feminist and women-only networks. Atenea platform has been designed as an open space for the following main objectives:

- To archive online Atenea's content and activity.

- To provide access to other existing feminist and women-only networks and projects on the topic.

- To provide access to open educational content by other institutions and the own members of the network

- To offer free membership to become an Atenea

- To promote the professional profile of the current members

- As a future step we plan the creation of a B2B space on the official website for digital encounter between women in STEM and women in Arts.

Moreover, Atenea is linked to the present dissertation, therefore, the results of this present research are published in the section called 'Research'237 through the visualization map presented in chapter 3.4. The sections of the website are: Team, Events by year (archival of text and audiovisual of the conferences, exhibitions, workshops, scientific committee, calls), Atenea 's (link to the member's official website), educational content, Research (all-womean and feminist networks mapping based on the present research), Our Network (organisations and collectives that collaborate with Atenea and vice versa and contact. We have provided an option to request membership and join Atenea.

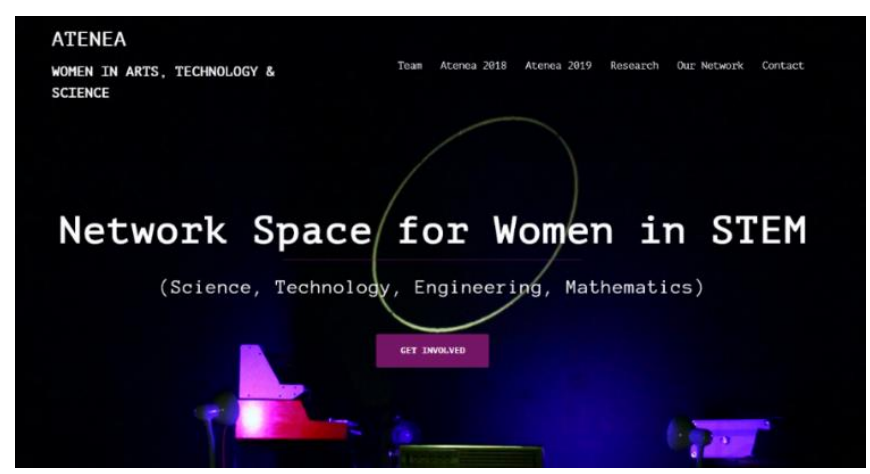

Figure 203 Screenshot website ATENEA www.atenea.in.

\footnotetext{
${ }^{237}$ See <www.atenea.in/research>
} 
We launched the official pages in the main social networks in Europe: Facebook, Instagram and Twitter, and also an account in YouTube and Flickr to archive the audiovisual content. Atenea's hashtags are \#atenea_project and \#atenea_wat (women, art and technology) together with those specific of the activities \#atenea2018 and \#atenea2019. Atenea social networks are used to promote the project virtually, in addition to:

- disseminate Atenea activities and achievements through the virtual network

- share other related content, achievements of Atenea's members

- access the translocal/transnational virtual network of initiatives in the topic

Creating a virtual community needs a constant activity to access the virtual transnational network one the topic and gain some visibility and recognition (Brandt \& Kizer., 2015). Some initial approaches and alliances have taken place through social network conversations, like our connection with Fem Tek Bilbao, Q-Space, Deep Lab, Current and Donestech, for example. The social network that we use the most is Facebook, where we have achieved 416 followers $^{238}$, however Instagram and Twitter have enabled us to know more initiatives through hashtag searching.

\section{Dissemination of the project}

Atenea has been presented, disseminated and promoted in international events such as the Woman's Week Madrid 2019, at the I Conference International Science, Feminism and Masculinities, Valencia 2019, in both places we organised a customized panel; at LASER Rendez-Vous at UCLA ArtSci Lab, Nanosystem Institute California, USA in 2018; 3rd Conference on Visual Culture, Barcelona 2017, at Sonar + D and KIKK Festival 2017, at Foro MAV 2017 Madrid, at European Women in Technology, Amsterdam 2017.

\footnotetext{
${ }^{238}$ Data retrieved from Atenea's Facebook page on January 2020.
} 


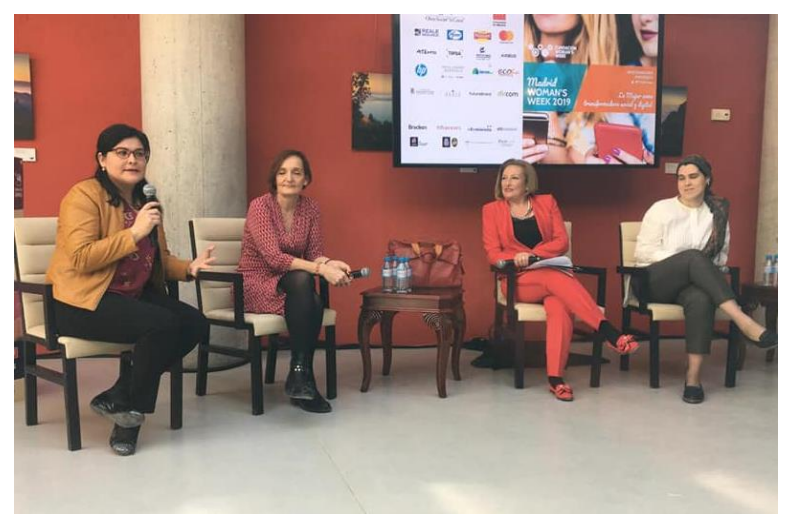

Figure 204 Atenea at MWW 2019 on Women and Digital Technologies, Madrid, 2019. Left to right: Narce Guzman, Nuria Lloret, Ofelia Santiago as moderator and Elena Robles. Photo Credit: Narce Guzman

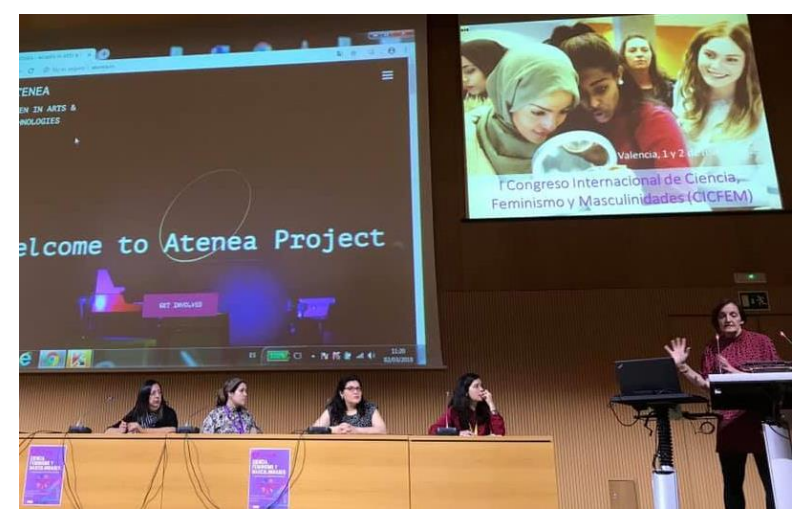

Figure 205 Atenea's Panel at CICFEM 2019, Valencia. Left to Right: Luisa Tolosa, Elena robles, Narce Guzman, moderator and Nuria Lloret. Photo Credit: Narce Guzman

\subsubsection{Programme of Activities}

Until today, the programme of face-to-face activities that we have designed and developed are:

- Annual International Conference (formed by keynotes, panels, presentations, workshops, performances, live music, screenings)

- Annual International Exhibition

- Programmea Mentoras / Mentorship Programme

\subsubsection{Atenea International Conference 2018}

The first Atemea event took place in Valencia from the $26^{\text {th }}$ to $29^{\text {th }}$ of June in 2018 . We organised an international conference, together with a series of workshops and an international exhibition. Altogether under the title Atemea 2018. Mujeres: Aristas, Tecnologas, in English version Atemea 2018. Women in Arts and Technology. The main objective was to create a meeting space for women in new media arts and women in STEM fields, in order to:

- $\quad$ Promote national and international female professionals.

- Enable a space for networking 
- Encourage the creation of new emerging interdisciplinary projects

- Connect women and institutions from scattered disciplines

With the parallel activities (hands-on workshops and exhibition):

- To promote female figures as mentors (educators-technicians) in techno-artistic practices

- Give a curatorial space for emerging female new media artists

The event was organised by Atemea's core team in collaboration with faculty members from other departments at UPV and other academic entities such as Universitat de Valencia, Berklee School of Music and Conservatorio Superior de Danza de Valencia, which contributed with the design of specialized panels. The programme of activities was mainly held in different locations at the UPV campus, and additionally we had a panel happening at Universitat de Valencia, organised by the scientific committee members from the educational department at UV. We also counted on the collaboration of a group of female volunteers who developed an amazing job and made possible the conference to work out. We are also indebt to the technicians in Departamento de Escultura and DCADHA, and to Stefano Scarani, who helped us to provide all the technical support to the artists.

Atemea 2018 was part of Bienal Miradas de Mujeres 2018 ${ }^{239}$, organised by MAV (Asociación de Mujeres en las Artes Visuales Contemporáneas). The scientific committee of the conference was formed by both female and male faculty members from Facultad de Bellas Artes (DCADHA, Departamento de Escultura, Departamento de Dibujo), Escuela Superior de Ingeniería Informática, Escuela Técnica Superior de Ingenieros en Telecomunicaciones, Universidad de Valencia, Conservatorio Superior de Danza de Valencia and Berklee School of Music. Some members from the Art School were organizers of FEMCODE in $2014^{240}$.The programme was formed by specialized panels on: Women and New Media Arts, Women on Performing Arts, Generación Espontáne:

\footnotetext{
${ }^{239}$ See <www.bienalmiradasdemujeres.org>

${ }^{240}$ See table 3 in point 3.4.2.2.
} 
Proyectos extracurriculares en la UPV, Music and Technology, Women's Networks and Associations, Technological Pioneers in collaborative projects in movie industry, Women, art and innovative education in $20^{\text {th }}$ Century: New challenges and proposals, Technological practices in art, in plural feminine and panel on Digital Communication. Additionally, we had three keynotes by two international female figures that Atemea had the pleasure to invite: the art theoretician Ana MartinezCollado, the National Plastic Arts award artist Concha Jerez and for the closure Nuria Oliver, computer scientist expert in Artificial Intelligence, Big Data Analysis and Human Computer Interaction. Martinez-Collado is expert in cyberfeminism and women in video art. In her keynote she made a retrospective of her feminist and curatorial projects on women and new media, from the exhibition on cyberfeminism Ciberfem $^{241}$ to the foundation of $A R E S^{242}$, digital archival platform for video art works in Spain. Oliver is Director of Data Science Research at Vodafone and Chief Data Scientist at DataPop Alliance. Her keynote Where are Women in Technology? exposed controversial statistical and qualitative data about the current situation of women in technological work environment, from research labs to companies.

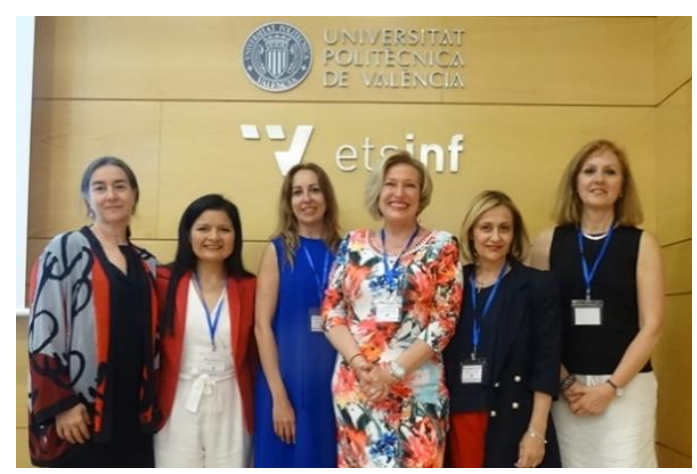

Figure 206 speakers from the Panel on Spanish all-women associations in Spain, representants of MAV, Girls in Tech Spain, AMIT, Madrid Woman's Week, Plataforma de Genero UC3M

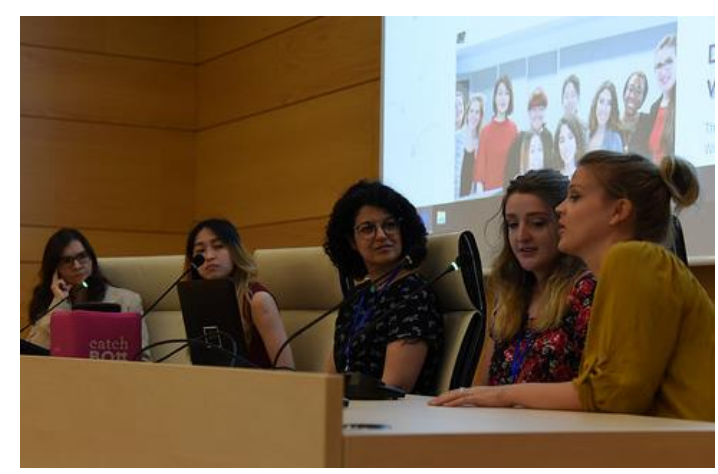

Figure 207 faculty and students from Berklee School of Music Valencia at Music and Technology panel. Photo Credit: Laura Tabares

${ }^{241}$ See point 3.4.4.3

${ }^{242}$ Available at <www.aresvisuals.net/archivo> 


\subsubsection{Atenea Exhibition 2018: Women in Art and Tech}

During the week that the conference took place, we organised an exhibition at the Sala Josep Renau at Facultat de Bellas Artes de San Carlos, which the Decanato de Cultura provided as a form of support for the event. The exhibition was formed by works selected through an open call and it had two formats: the exhibition space for installations, video and interactive pieces, and the high-scale screening and performative space. The call embraced diverse formats related to media arts: video art, sound art, interactive art, performative, game art, installation, electro acoustic, telematic arts, robotics, video art, sound art, etc. I leaded the curational work together with the Professor and artist Maribel Domenech, and the collaboration of the musician and research Montse Briceno for the sound and music proposals. Three of us were the artistic committee for the call. The opening took place on the $25^{\text {th }}$ June at 20:00. The exhibition held the art works by Beatriz Herráiz; Ana Martí y Adolfo Muñoz; Susana Sanchez; Cristina Santos Sara \& Sarah; Cristina Asensio y Cristina Cotelo; Ana Morales; Dela Delos; Sara Álvarez; NoDOS(3); Mau Monleón; Pepa L.Poquet; Stefano Scarani and Julia Chine; Silvia Binda Heiserova; Sandra López Estrada; Rosa Saez, Selene Sanchez and Roser Domingo; Ana Herrero; Blanca Montalvo; Claudia Molina; Sal Viral; Marta P.Campos. Salomé Cuesta projected her work Mujeres STEAM, a estudio ${ }^{243}, 2018$ interactive timeline.

${ }^{243}$ Available at <https://goo.gl/YxYpBu> 


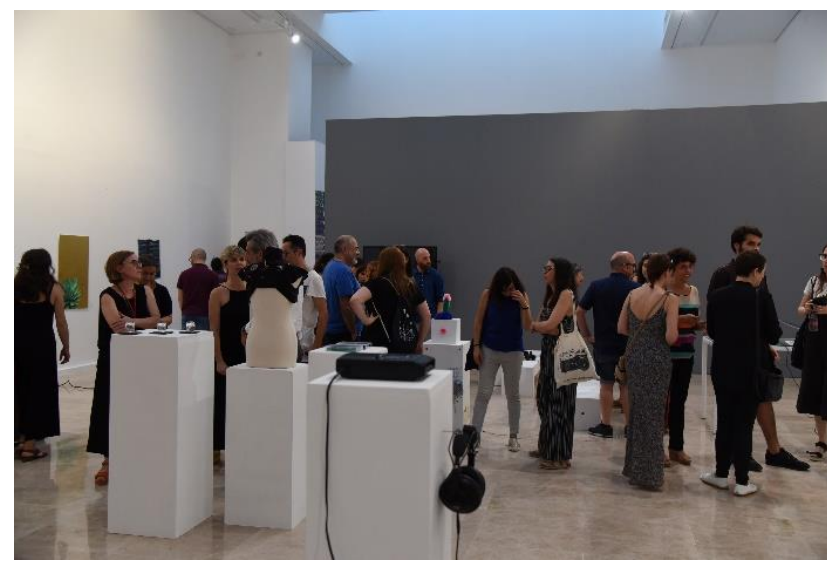

Figure 208 Images of the opening. Photo Credit Laura Tabares

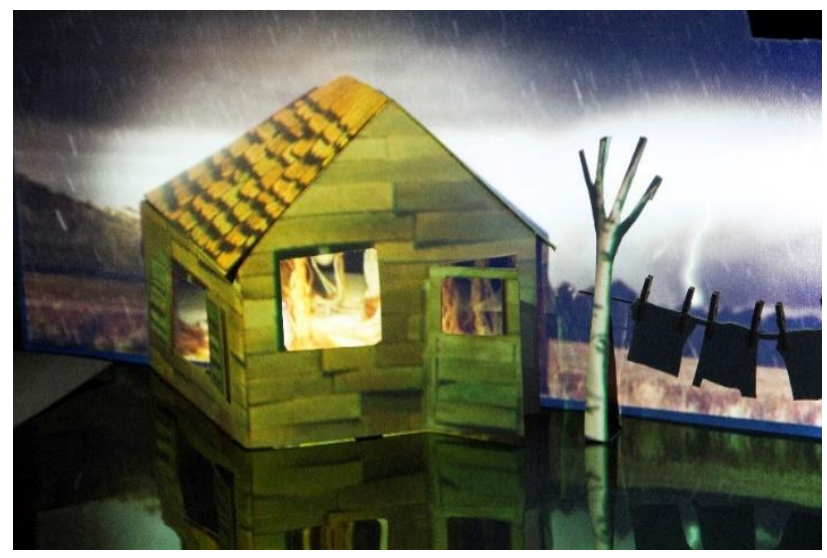

Figure 210 Beatriz Herráiz, Thread, 2017. Photo: Stefano Scarani

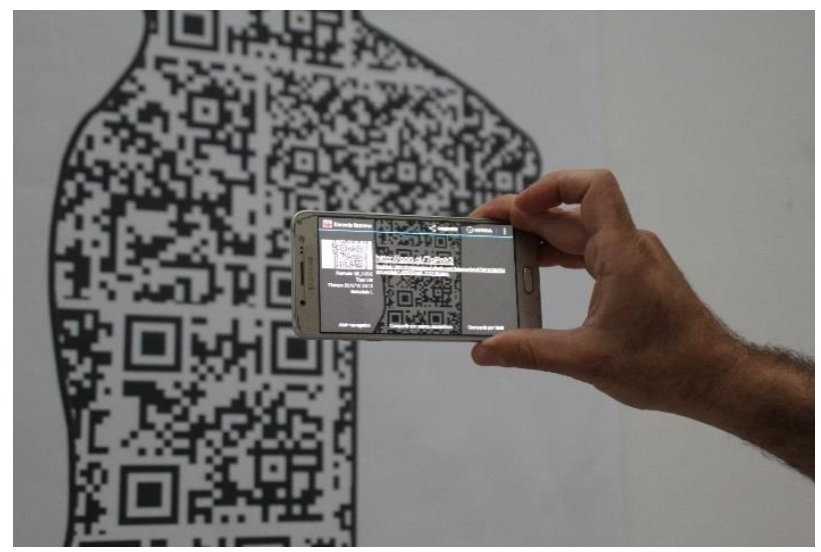

Figure 212 Susana Sánchez Las ausencias son las evidencias, 2018. QR code printed on female silhouete to read online news on female femicide Photo: Sandra Estrada

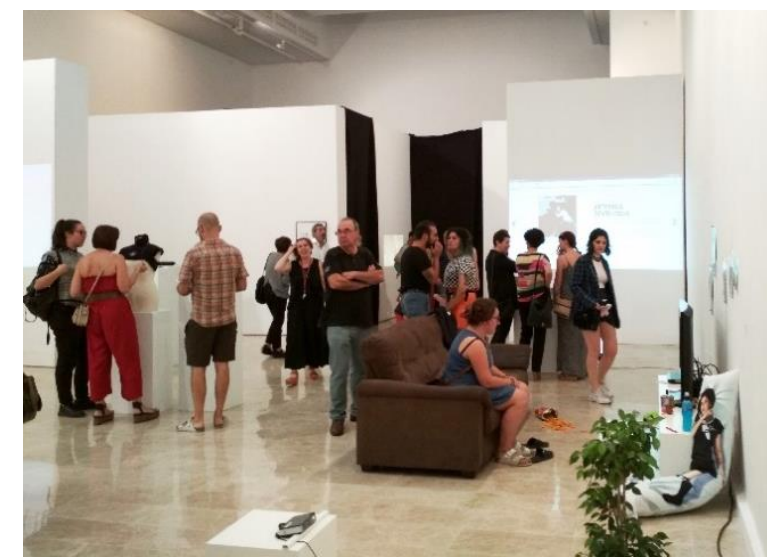

Figure 209 Images of Atenea 2018 Opening. Photo Credit Raquel Brelt

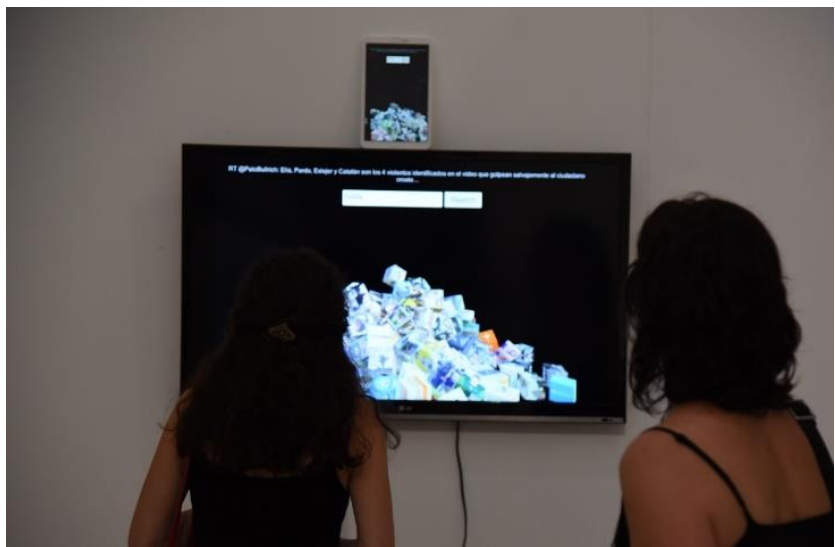

Figure 211 Ana Marti and Adolfo Munoz, The Battle of the Pictures, 2017 generative artwork, time-based search engine. Photo: Laura Tabares

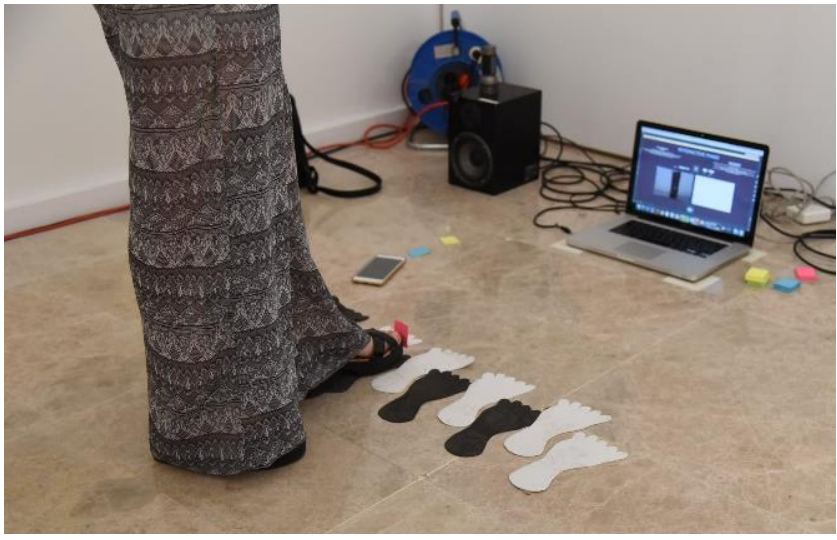

Figure 213 Selene Sanchez and Roser Domingo, Interactive Piano, developed with Max/MSP. Photo Credit: Laura Tabares 


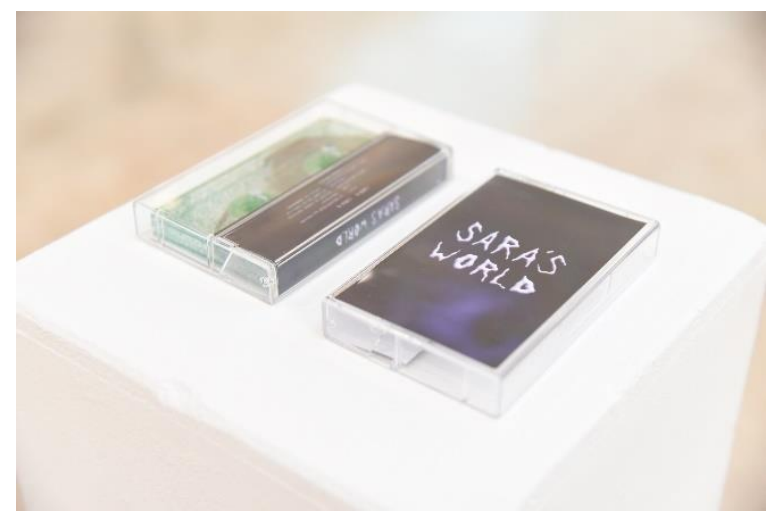

Figure 214 Sara \& Sarah, "SARA'S WORLD". Cassette, auto-edición. 2018. Unusual and experimental way to use technology with low-cost objects, experimenting with the limits of sound though synthesizers.

Photo credit: Laura Tabares

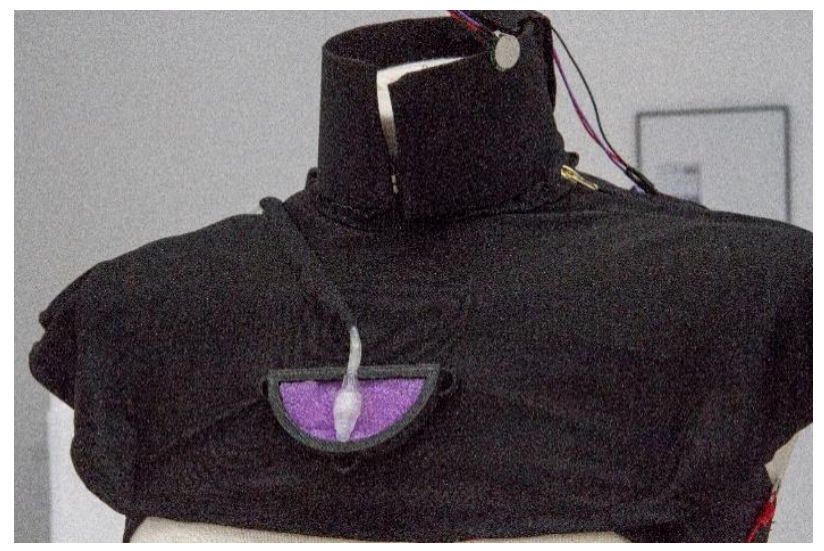

Figure 216 Marta P.Campos, "Anxiume", 2017 acronym from anxiety and perfum, technological wearable combined with parfume essential oils testing, the piece works on the human reaction to certain social situations with perfums, dealing with psycological emotions. Photo Stefano Scarani

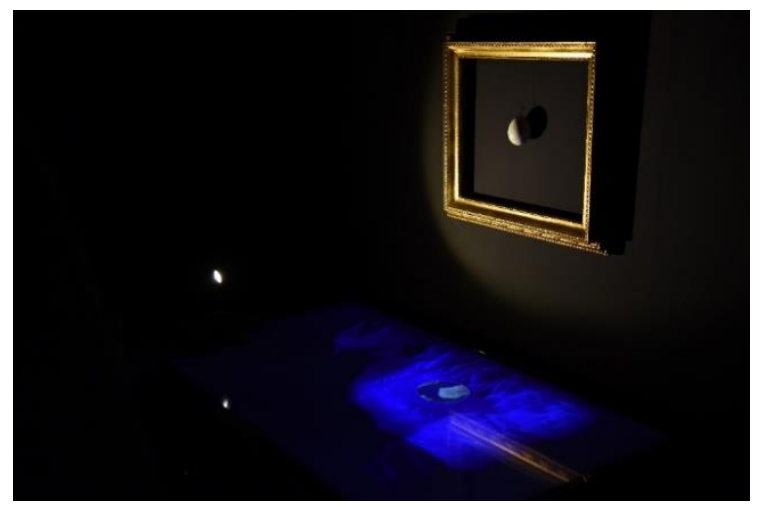

Figure 217 Julia Chiner and Stefano Scarani, "Il velo", interactive installation produced by Tangatamanu on Max/MSP, 2018. Photo Credit: Laura Tabares

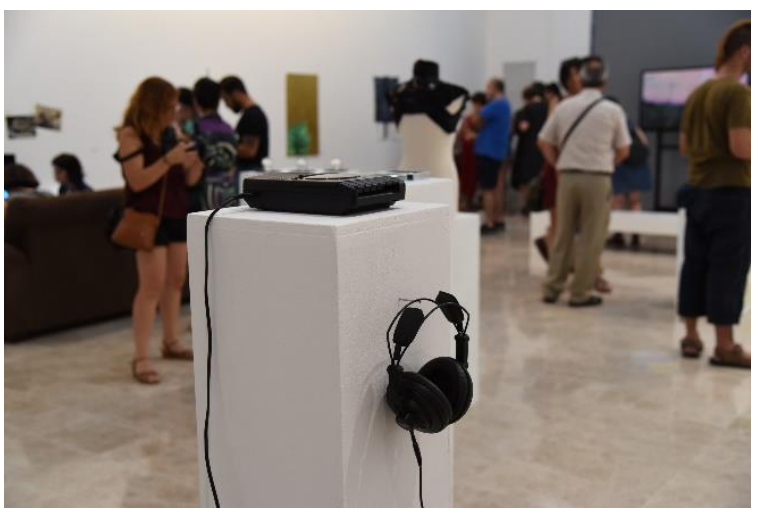

Figure 215 Sara \& Sarah, "SARA'S WORLD". Cassette, auto-edición. 2018. Unusual and experimental way to use technology with low-cost objects, experimenting with the limits of sound though synthesizers.

Photo credit: Laura Tabares

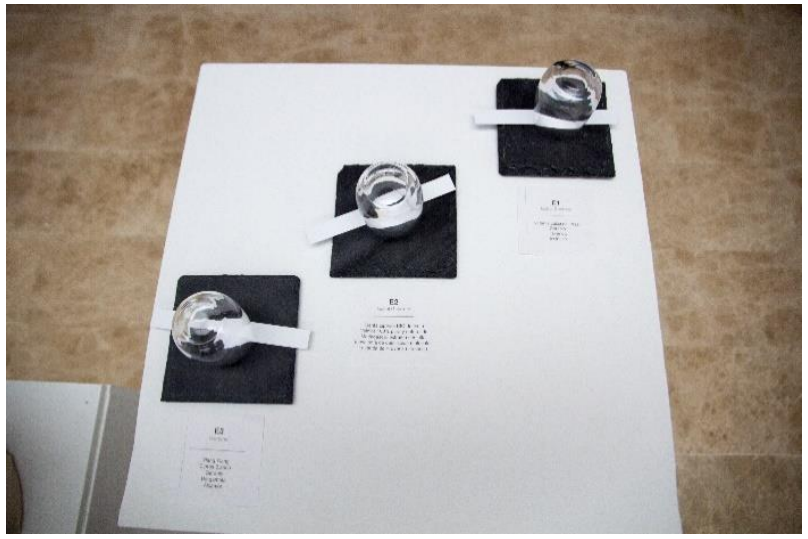

Figure 218 Marta P.Campos, "Anxiume", 2017. Photo Credit Stefano Scarani

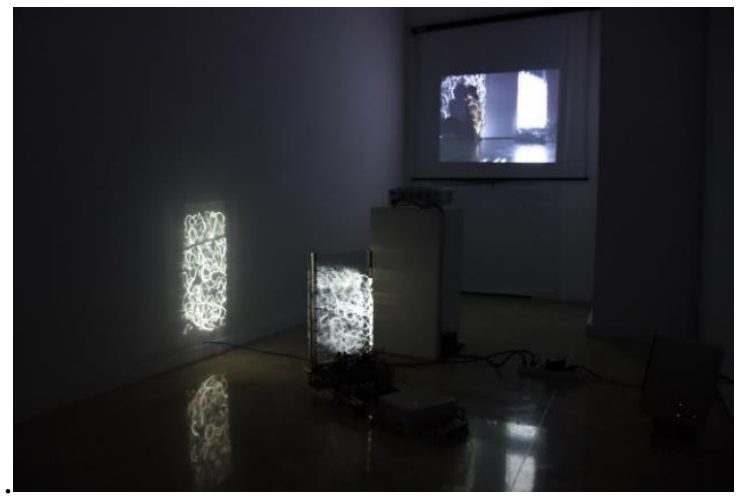

Figure 219 Sandra López Estrada, "Erritmia Neuronal", 2018. Experimental installation on body, sound and light. Photo Credit: Laura Tabares 
Performances and Screenings: At the Auditori Alfons Roig on Friday $29^{\text {th }}$ June, the audiovisual works by Cristina Yglesias, Roser Domingo, Virginia Panigua, Nikcy Miller, Delia Boyano, Sandrine Daumier, Maria Staiano were presented at high-scale screen. Additionally, we had the performances of Kris Ospina, Giorgia Partesotti, Doris Hakim y Kira Perez and the guest artists Rocio Silleras, Julia del Rio and Sara de Umbria.

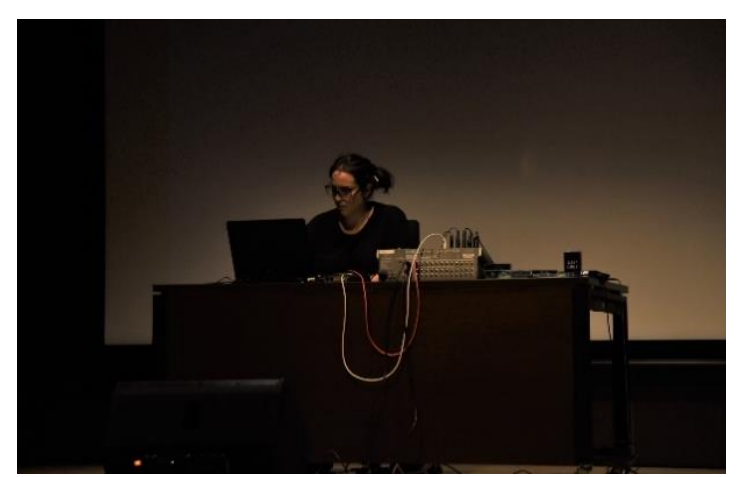

Figure 220 Images of Julia del Río during her sound performance. 2018. Photo Credit: Laura Tabares

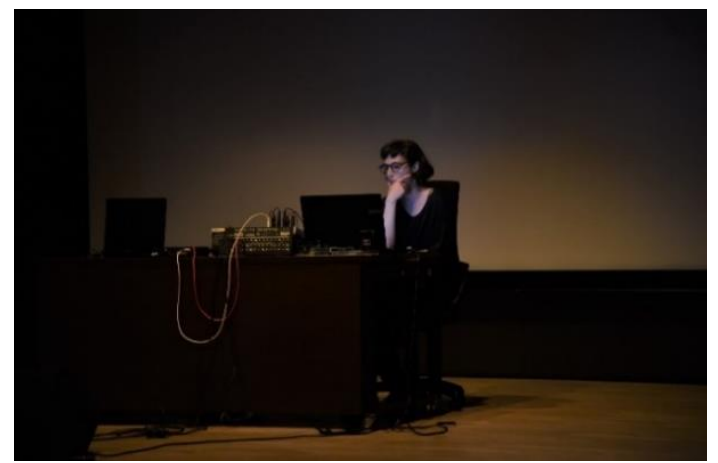

Figure 221 Sara Rasines during her sound performance. 2018. Photo Credit: Laura Tabares

Workshops: Atenea organisation committee organised a series of five workshops leaded by four guest artists and one by two of the organisational members. Workshop 1. Cine Expandido by Bego Santiago, video mapping techniques and the artist's work production; Workshop 2. Nela Brown. Laptop Orchestra Composition with open software Workshop 3. Aurora Diago. Audiovisual techniques applied to scenography scene; Workshop 4. Montse Briceño, Elena Rita Pelejero and Jorge Sastre: Soundcool Collaborative Music Composition Application; Workshop 5. Alayna Hughes, Virtual Reality and Music, Curiosibot Project ${ }^{244}$, developed in Valencia.

\footnotetext{
${ }^{244}$ See <www.curiosibot.com>
} 


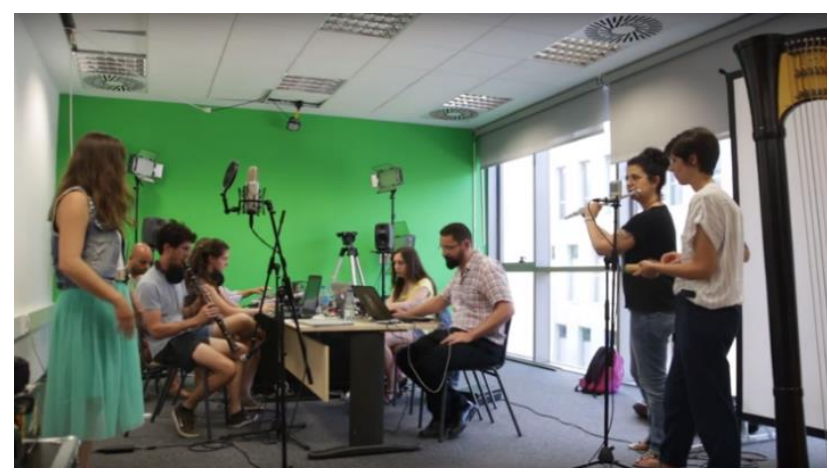

Figure 222 Laptop Orchestra Composition Workshop by Nela Brown. Photo credit: Cristina Santos, Video available at https://bit.ly/2Xj92xN

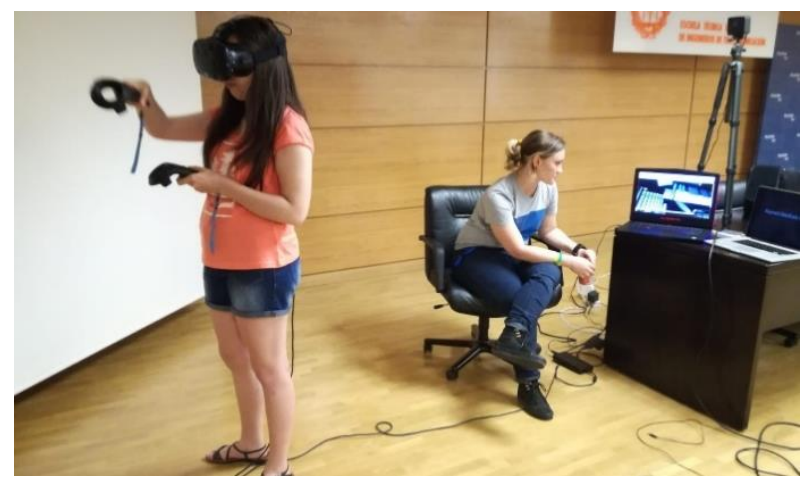

Figure 224 VR and Music by Alayna Hughes 2018 (W5). Photo credit left Elena Pelejero; Photo credit right: Pep Sales

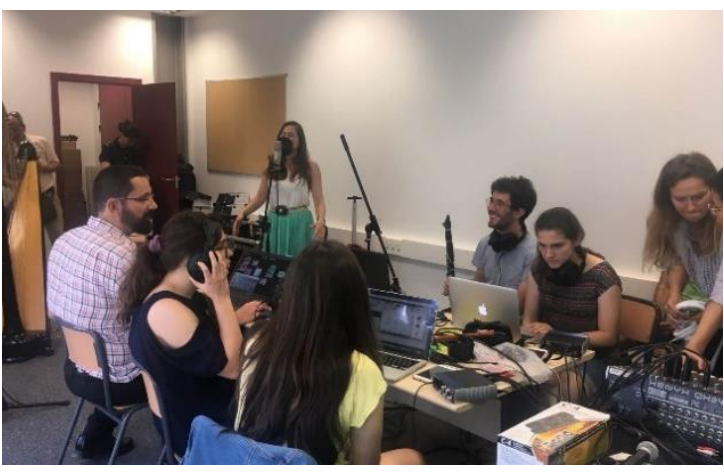

Figure 223 Laptop Orchestra Composition Workshop by Nela Brown. Photo credit: Cristina Santos

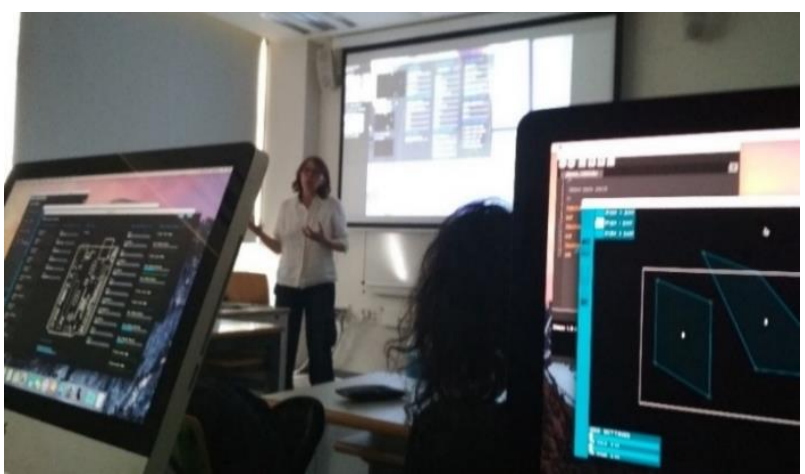

Figure 225 María José Martínez de Pisón workshop on programmeming with Gamuza, (W6)2018. Photo credit Raquel Brelt

The second day of the event we organised a dinner for the guest speakers and the artists at the exhibition in La Fabrica de Hielo, in El Cabanyal neighborhood. We sought to create an informal encounter at an intimal space towards reinforcing the networks between the participants of Atenea 2018. Additionally, we had a Dj set live session Deriva: Meet with the gender [x] by the guest speaker Natalia Pinuel, director of the feminist festival She Makes Noise in Madrid ${ }^{245}$.

\footnotetext{
${ }^{245}$ See <https://shemakesnoisefestival.tumblr.com>
} 


\subsubsection{Atenea International Conference 2019}

For the 2019 edition we counted on the collaboration of LAS NAVES Centre d'Innovació supported by Ajuntament de Valencia, which provides cost-free cultural and artistic activities to different generation audiences in Valencia City. Together with the center team we have organised the second edition of the conference and exhibition, counting on their financial support to make it possible. Atenea 2019 repeated the main formats of panels, workshops, performances and exhibition, with the addition of live music. It took place in LAS NAVES center, and the programme was adapted to the requirements of the spaces available, but always following our methodologies and objectives. The event was celebrated from 23 th to $25^{\text {th }}$ October, with the opening of the exhibition taking place the first day. For this edition, we designed transgenerational activities, aiming to involve different collectives and generations from in and outside the academia.

We organised an exhibition with artworks selected through an open call, lower in numbers compared to the previous one as we want to compensate with a fee to the artists of 100 Euro. The programme of live-music events with one or two Dj sessions for each evening, there were as well live performances: one by Raquel Meyers, one by DansPXL company ${ }^{246}$, and the last day Lucia Peiró artist performed a feminist performance with the results and the students of her workshops textile, that is specially addressed to women from all generations.

\footnotetext{
246 This performance as their presentation in the Dance panel was cancelled due to the meteorological circumstances which cut off the roads from Barcelona to Valencia.
} 


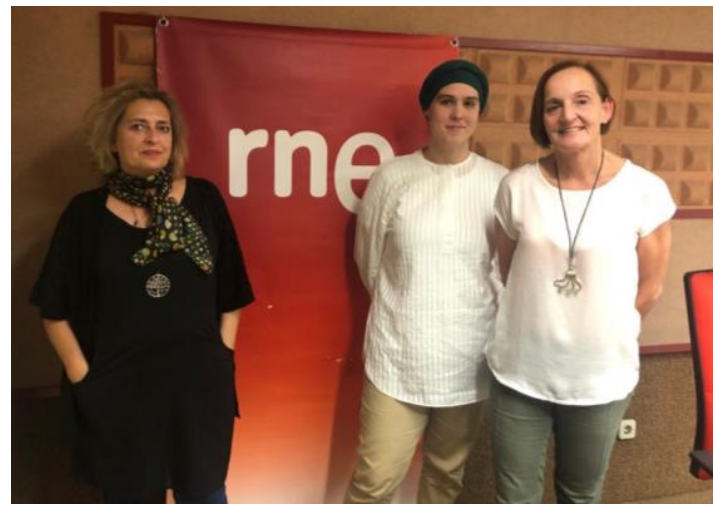

Figure 226 Atenea interviewed in the radio programme "Si no puedo bailar..." from RNE3, RTVE studio in Valencia, October, 2019. From left to right: Lucia Peiro, Elena Robles and Nuria Lloret.

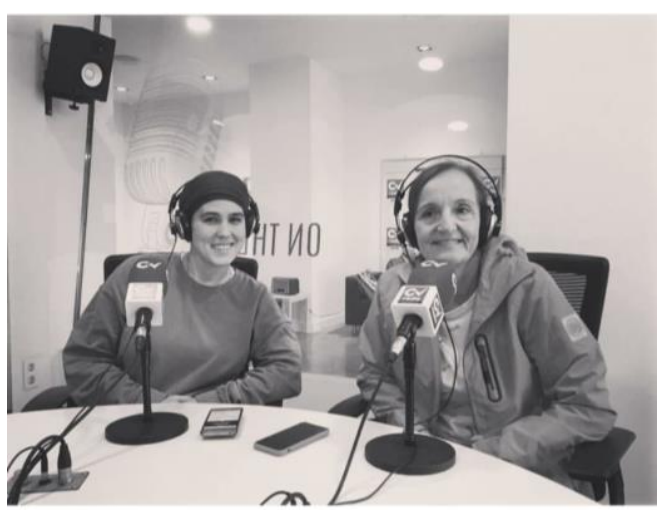

Figure 227 Atenea interviewed in the Cultural Section of Radio Comunidad Valenciana, October 2019. Left to right: Elena Robles and Nuria Lloret

Panels of expertise were: Women on Electronic and Digital Arts, Mentorship in STEM, Environmental Awareness from Bio Art, Dancing with software, Audiovisual Ecosystems, Women as editors, Women Producers in Storytelling, Art and Design: Women building the visual, Feminist Art and Entrepeneurship.

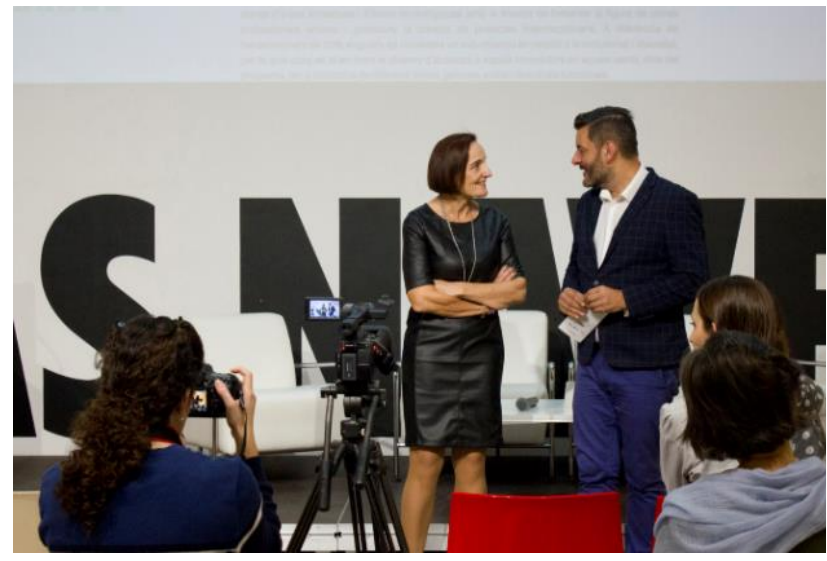

Figure 228 Opening with Atenea's Director Nuria Lloret and the Concejal de Innovación from the Excmo. Ajuntamnt de València

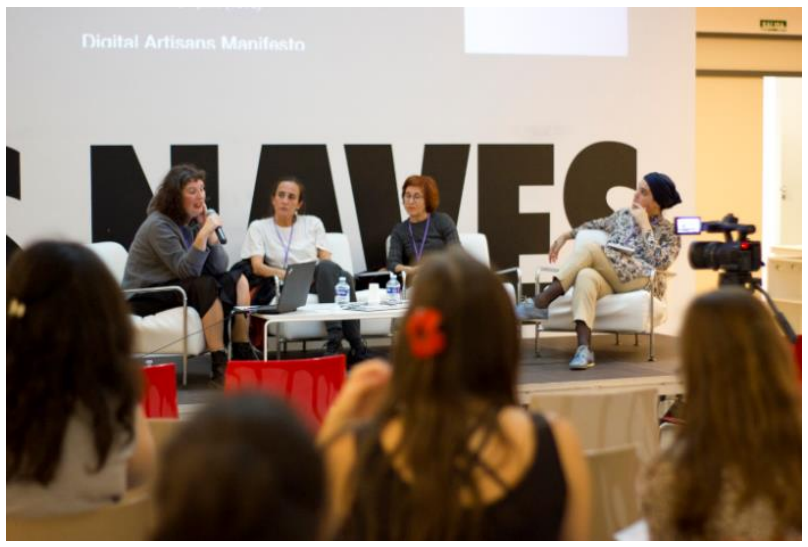

Figure 229 Panel on Electronic and Digital Arts with Alba G. Prado, Raquel Meyers and Ramona Rodríguez. Rosa Sánchez de Kónic Theatre joined in streaming. 


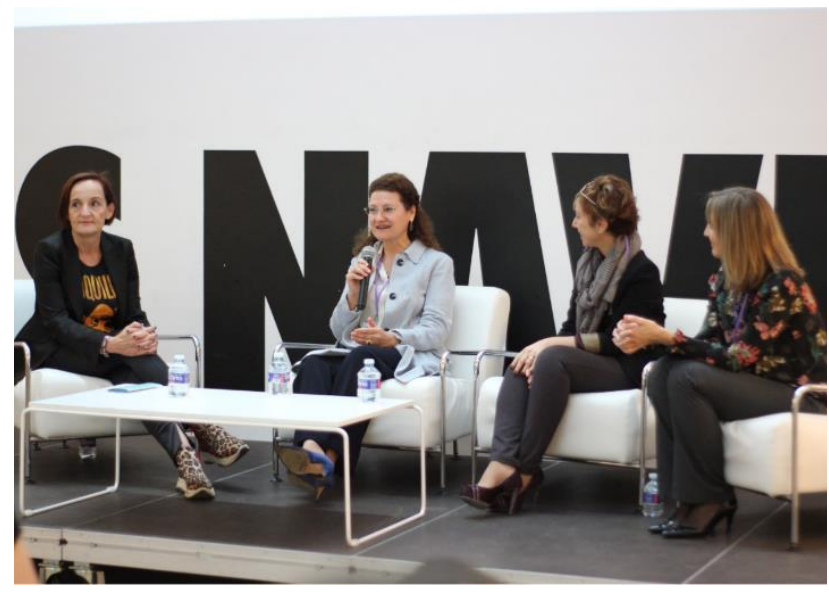

Figure 230 Panel on Mentorship in STEM Mercedes Siles, Catedrática de álgebra en la Universidad de Málaga y Vicepresidenta de la Real Sociedad Matemática Española, María José Valero, Talent Growth Management, desde la RSC es la Embajadora Regional de la Comunidad del Technovation Girls y Victoria Majadas, Gerente Editorial Prensa Valenciana y Presidenta asociación Big Ban Angels (Valencia). Photo Credit: Laura Simó

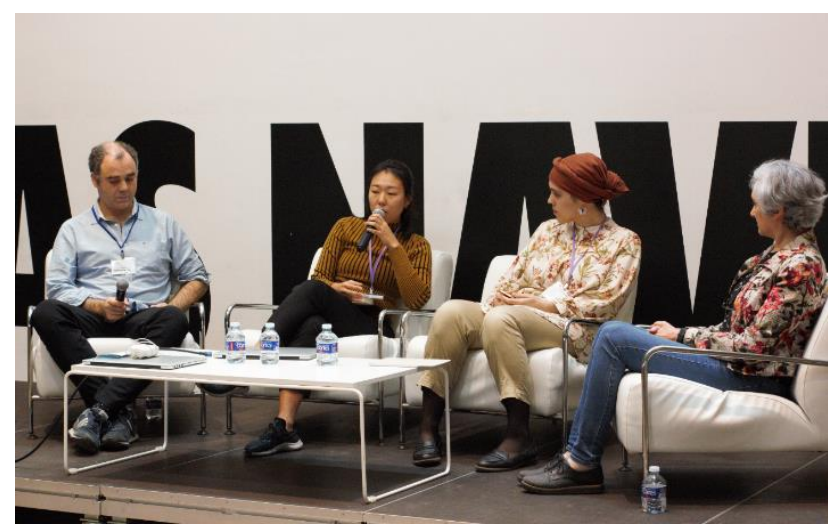

Figure 232 Panel on software and performing arts. From left to right: Pablo Palacio, Aesun Kim, Carmen Giménez Morte (moderator). Photo credit: Laura Simó

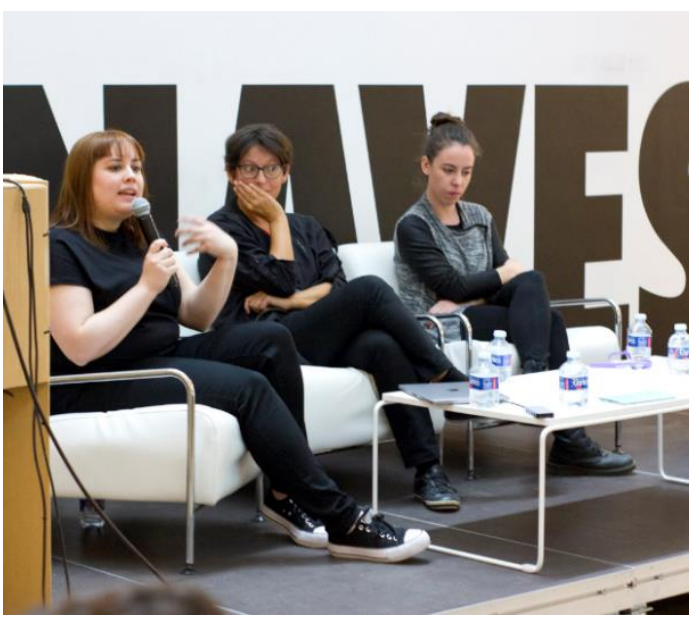

Figure 231 Panel on Bio Art. Speakers from left to right: María Castellanos, Clara Boj, Clara Molinicos. Photo Credit: Laura Simó

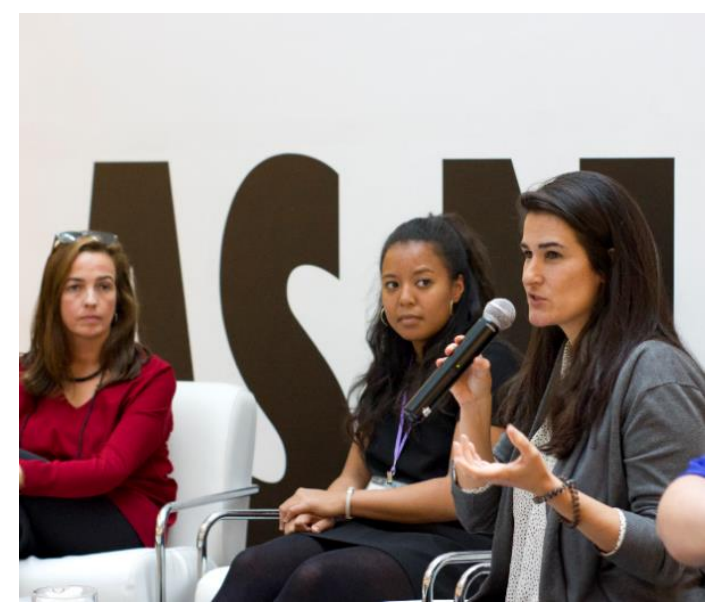

Figure 233 Panel on Audiovisual Ecosystems. Left to right: Marga Cabrera, Kim-Marlène Le, Sandra Mora 


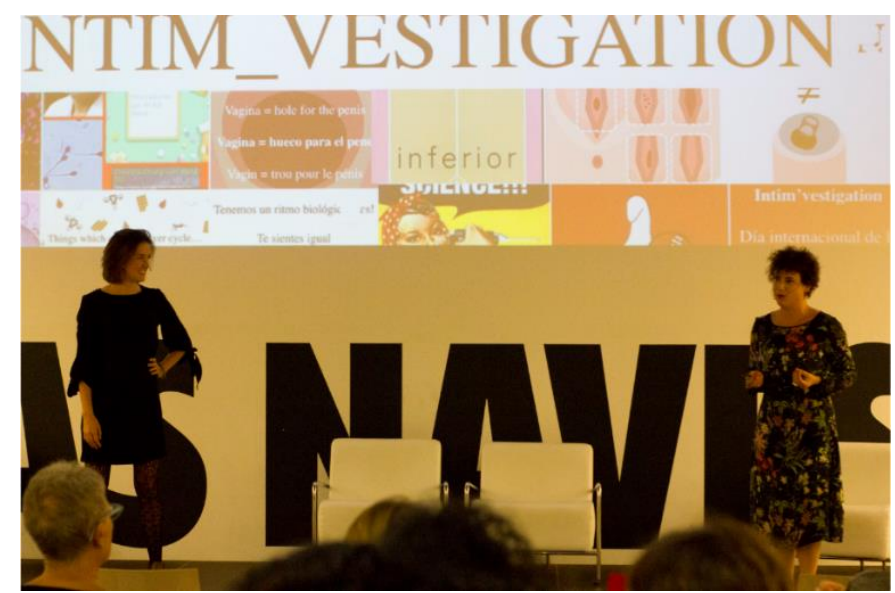

Figure 234 Feminist monologue by Maria Gombert and Ana Peiró.

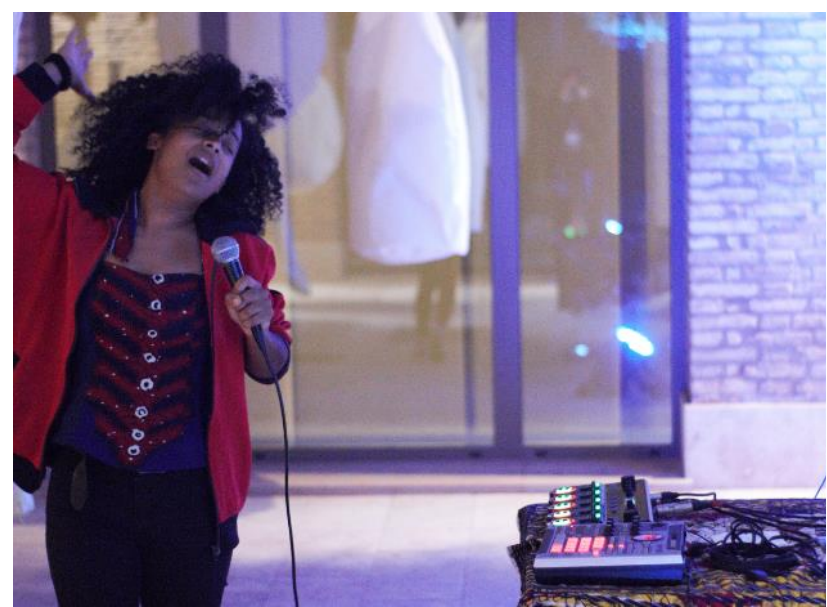

Figure 235 Live Music. MounQup. Photo Credit: Laura Simó

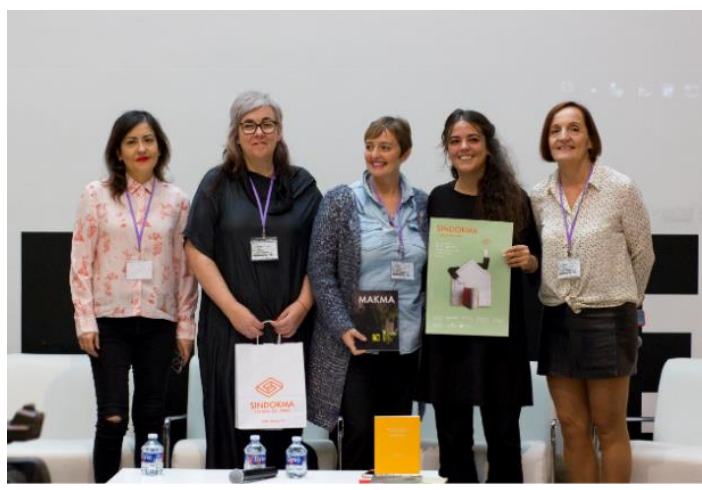

Figure 237 Panel on Women in Graphic Edition con Merche Medina (MAKMA y Sindokma), Carmen G. Palacios y Manuela Martínez Romero (LALATA Revista Ensamblada) and Andrea Familiar.

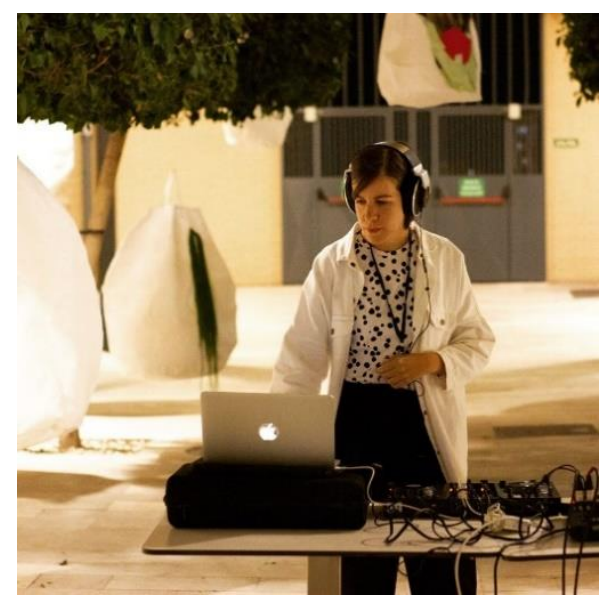

Figure 236 Live Music. Ana Banana Dj. Photo Credit: Laura Simó.

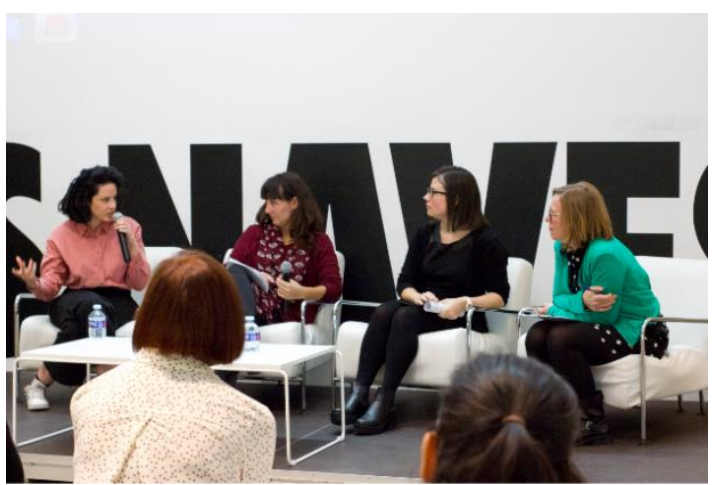

Figure 238 Panel on Women in Animation with María Manero, Rocío Benavent Méndez, Sofía Herrero, Moderadora: Beatriz Herraiz (Valencia). Photo Credit: Laura Simó 


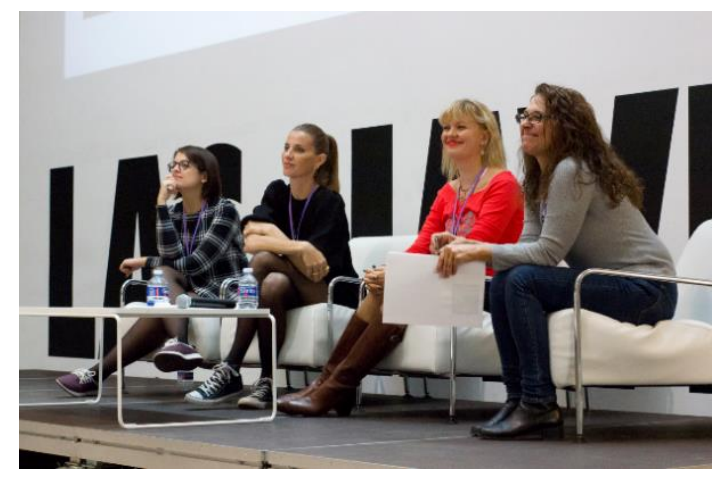

Figure 239 Panel on Art and Design: Mujeres en la construcción de lo visual. Photo Credit: Laura Simó

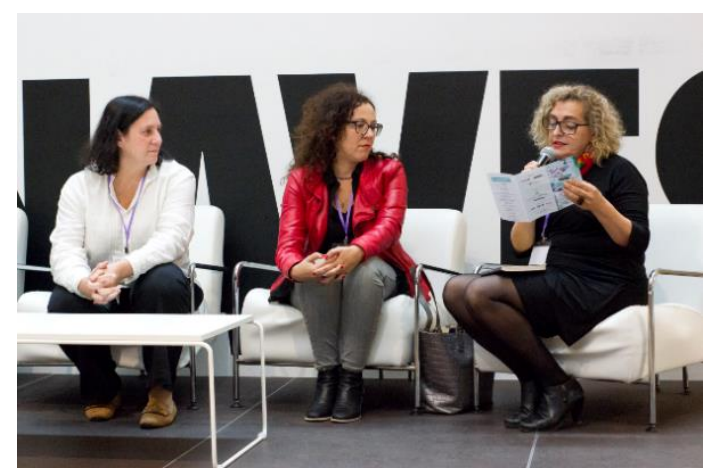

Figure 240 Mesa Panel on Feminist Art and Entrepeneurship. Photo Credit: Laura Simó

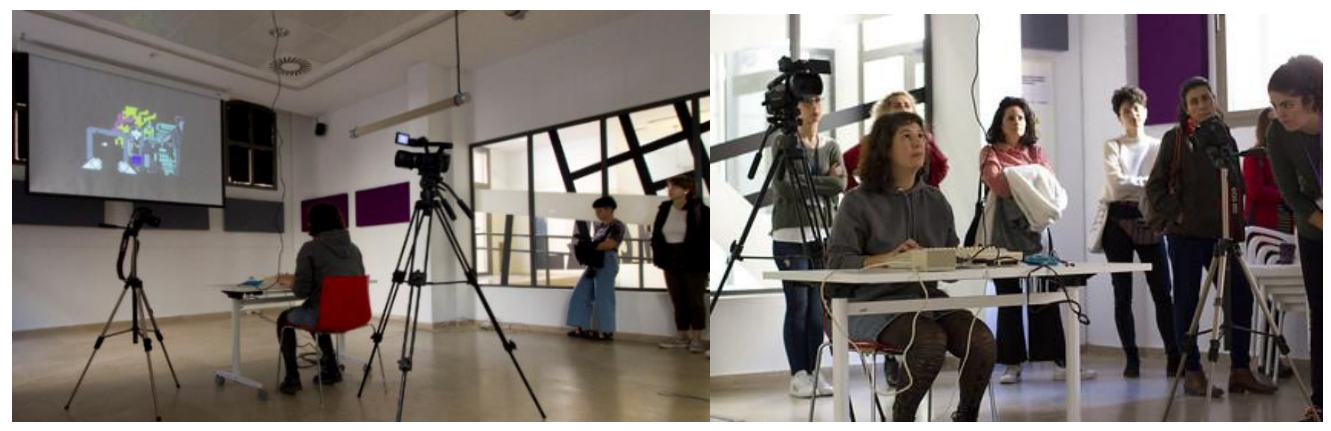

Figure 241 Performance 8bits animation by Raquel Meyers (Bilbao, sala Think Tank)

\section{Workshops:}

For this edition we organised four workshops: Workshop on Mecanografía Expandida, Workshop on

Audiovisual experimentation with soft interfaces, workshop on virtual and mixed reality and workshop on textiles and feminism.

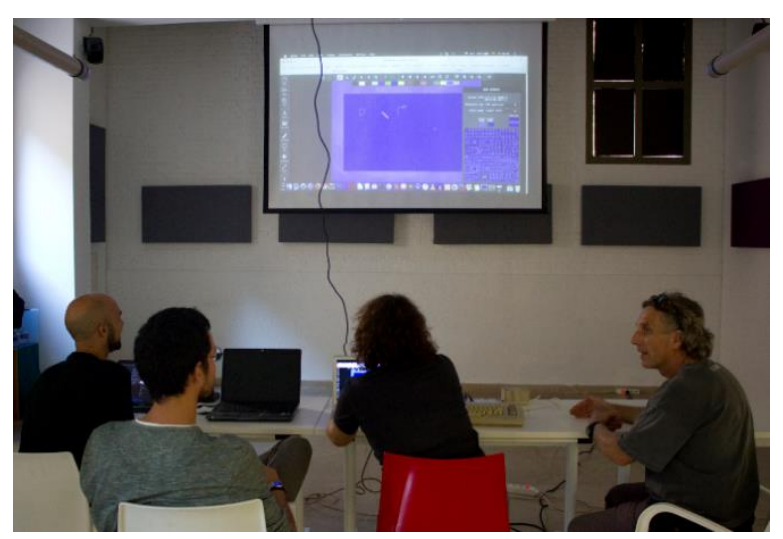

Figure 242 Raquel Meyers (Bilbao): Workshop on mecanografía expandida

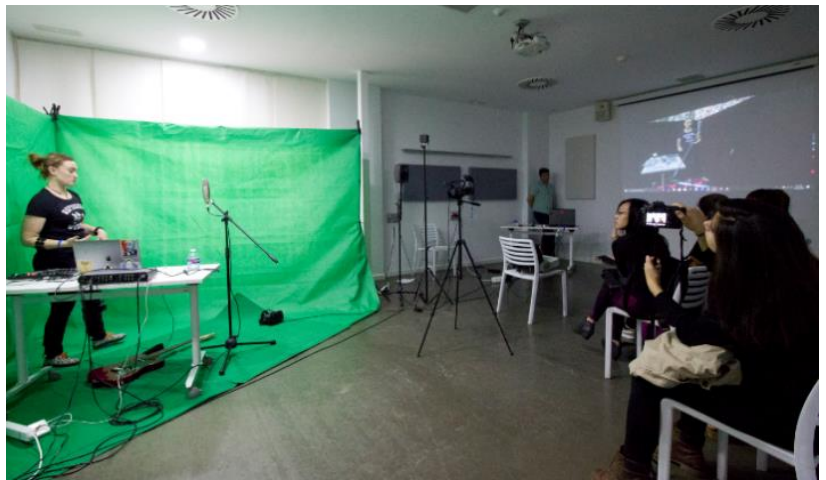

Figure 243 Alayna Hughes: Mixed Reality and Music 


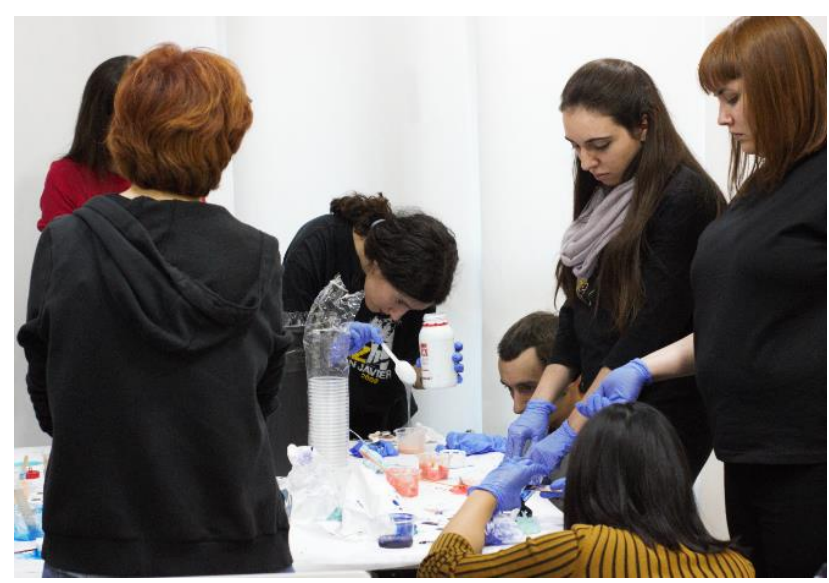

Figure 244 María Castellanos Workshop "Experimentación audiovisual con interfaces blandas"

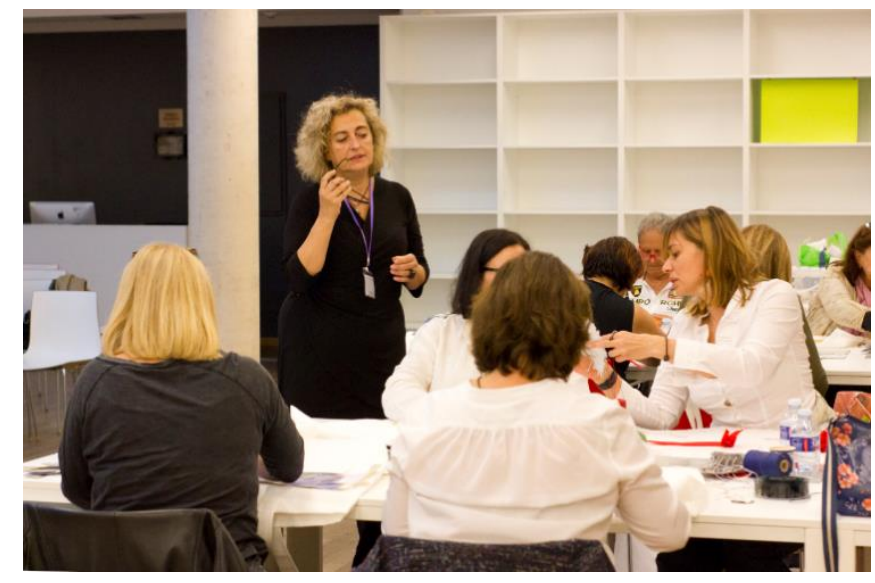

Figure 245 Lucia Peiró Lloret Workshop: "Les Portadores, feminismo y textiles"

\subsubsection{Atenea Exhibition 2019: Women in New Media Arts}

Inauguración del recorrido expositivo de piezas seleccionadas a través de una convocatoria pública, 11 piezas e instalaciones de arte digital y nuevos medios de artistas locales, nacionales e internacionales. Las piezas fueron expuestas en diferentes espacios diáfanos de Las Naves en ambas naves y en ambos pisos. La instalación de la artista residente se colocó en el patio entre la nave 1 y la 2 y sirvió como escenografía para las dos sesiones de música en directo.

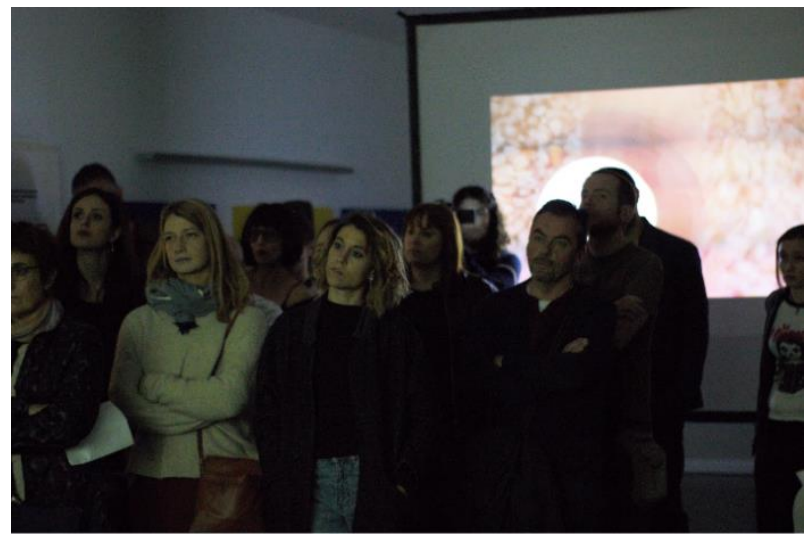

Figure 246 Captions of the exhibition route. Photo credit Laura Simó

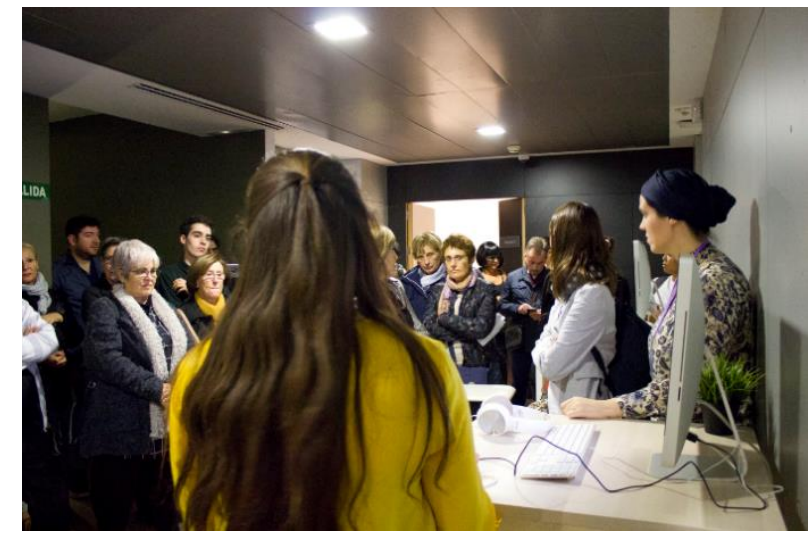

Figure 247 Captions of the exhibition route II. Photo credit Laura Simó 


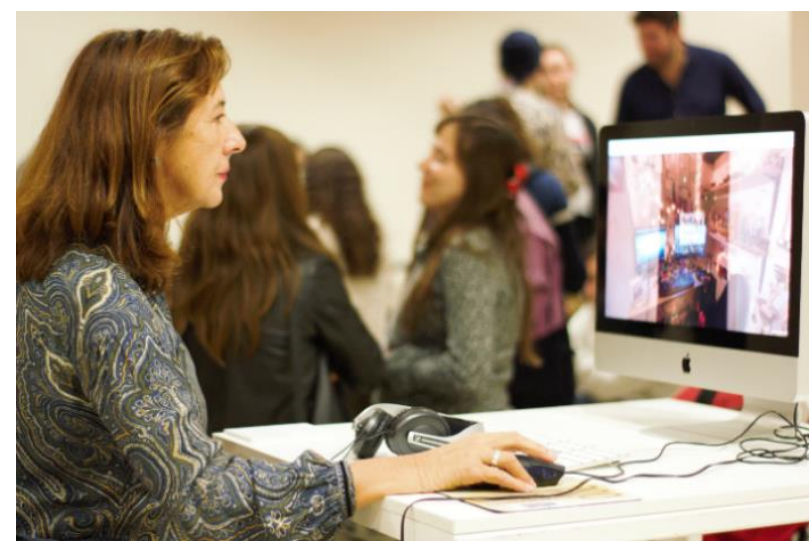

Figure 248 Captions of the exhibition route III. Photo credit: Laura Simó

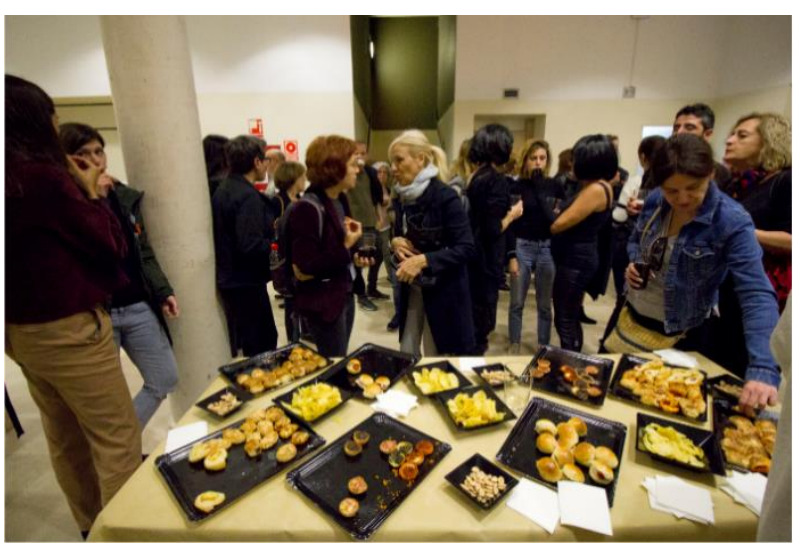

Figure 249 Catering at the end of the opening

\section{Artists exhibited}

1. Ramona Rodríguez (Valencia) Panel \#6-30. Linz soundscapes

2. Marina García Jiménez, Stefano Scarani y Magda Meseguer (Barcelona, Valencia). Madre (2019).Instalción Multimedia

3. Clara González García (Valencia). Reset the Forest: Interactive Reforestation Device (2019)

4. Aesun Kim (Korea, Austria), A Spiritual Space. Wearable. Fashion \& Tech

5. Maru García (México) The culture (2018). Medusomyces gisevii (SCOBY), Salvinia natans

6. Teresa Novelo (México, Valencia), Interlineal Instalación sonora/visual

7. Christina Yglesias (Los Angles), I always have and I always will (2018) and Run for your Love (2018)

8. Roser Domingo Muñoz (Valencia), Autocrea (2019)

9. Sandrine Deumier (Barcelona), Falling (2019).

Virtual Reality animation.

10. Marina González Guerreiro (Valencia), Work Hard Dream Big

11. Obra y Performance de NoDOS(3) (Valencia) Acción\#8 “flânerie aural” 


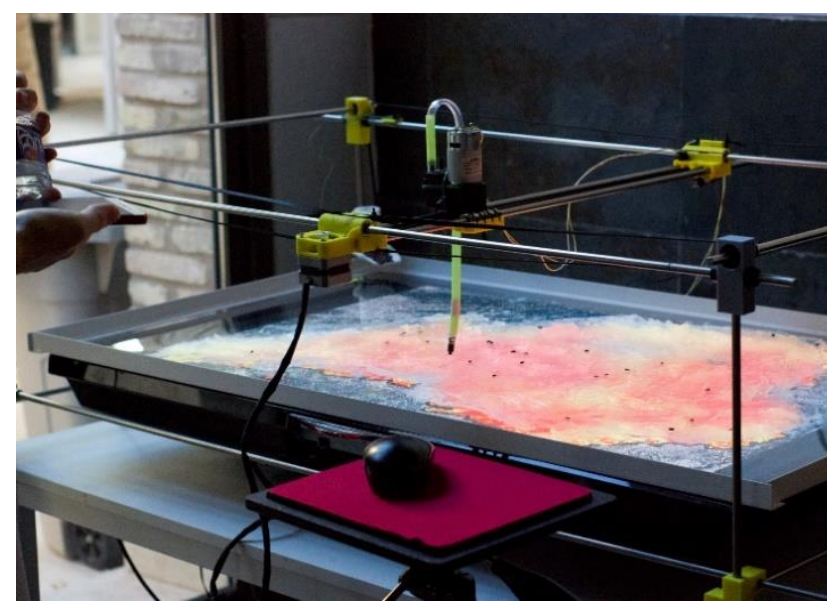

Figure 250 Clara González García (Valencia). Reset the Forest: Interactive Reforestation Device (2019)

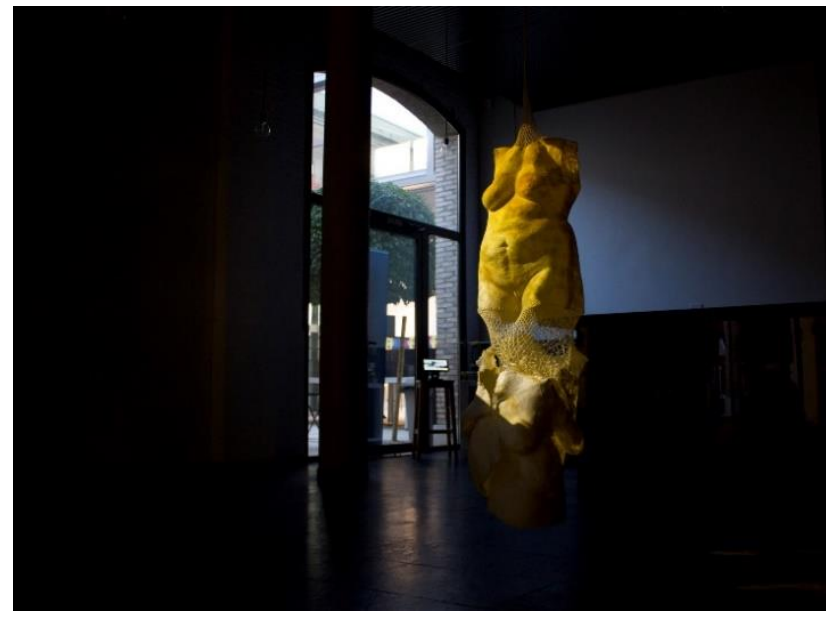

Figure 251 Marina García Jiménez, Stefano Scarani y Magda Meseguer. Madre (2019).Instalción Multimedia

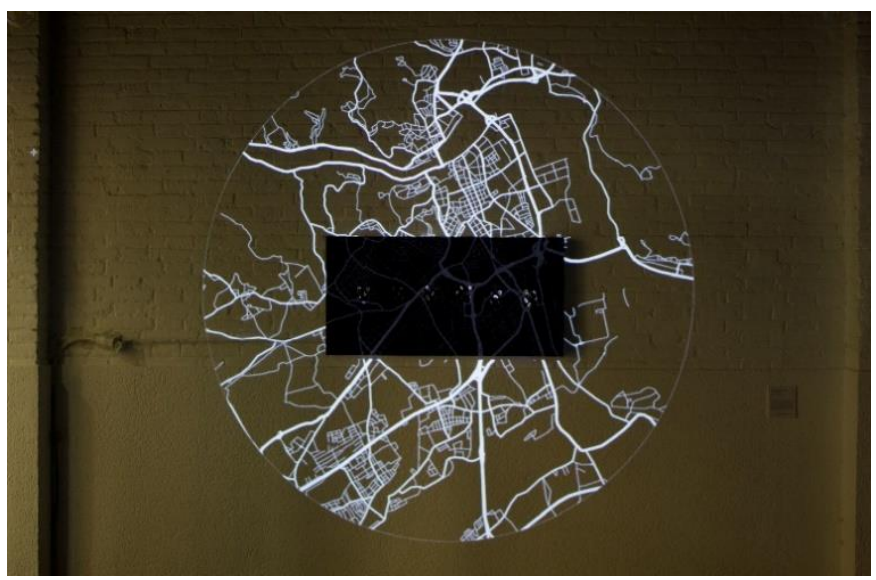

Figure 252 Ramona Rodríguez. Panel \#6-30. Linz soundscapes

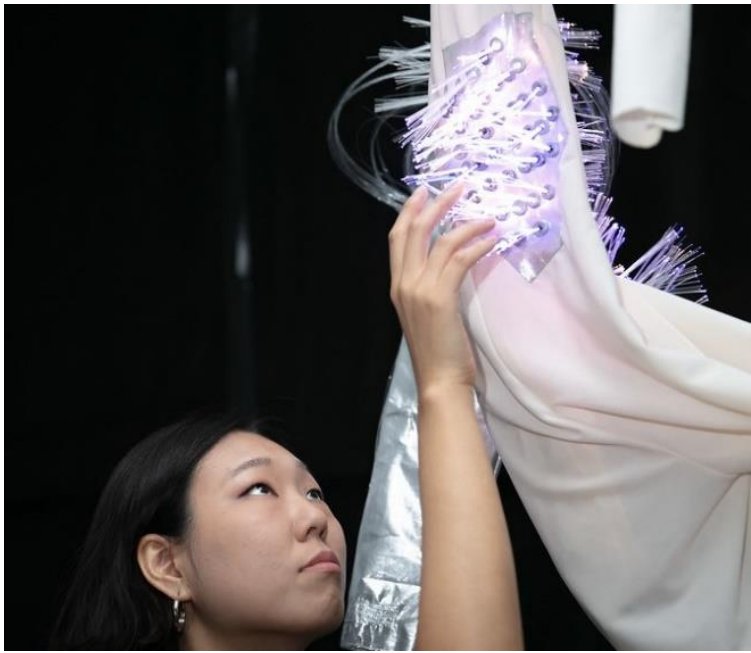

Figure 253 Aesun Kim, A Spiritual Space. Wearable.

\subsubsection{Programmea Mentoras/Mentorship Programme}

Continuing with the abovementioned awareness recently shown by international institutions and organisations such as UNESCO, ATENEA has widened its formats audience to young girls and people with disabilities. In a Report published by the European Parliament in 2016 named Gender Equality and Empowering Women in the Digital Age $(2015 / 2007 \text { (INI) })^{247}$ we find in the following points:

\footnotetext{
${ }^{247}$ Available at <http://www.europarl.europa.eu/doceo/document/A-8-2016-0048_EN.html>
} 
34. Emphasizes the value of ICTs, and more specifically online training courses, for girls and women, but also people with special needs, such as those with disabilities, and the inhabitants of rural areas and remote areas, as well as the possibilities for teleworking, in order to improve education among these groups and increase their chances of financial independence.

35. Notes the important role and enormous potential that arts and design education, formal, informal and non-formal, the creative industries, and the cultural sector have in empowering women and girls and propelling them into the digital sector; emphasizes therefore the importance of connecting STEM and the economic sectors constituted by education and the arts, transforming STEM into STEAM;

Aiming to bring innovative proposals to face the lack of interest by young girls in STEM fields in our society, in Atenea we have designed a starting programme called "Programmea Mentoras" ([female] mentorship programme) based on workshops leaded by Spanish digital and electronic female artists addressing girls and boys as well from eight to eighteen years old and people with disabilities. We have received a national public grant from the Fundación Española para la Ciencia y la Tecnología (FECYT) from the Ministerio de Ciencia, Innovación y Universidades, to be able to develop this programme in three cities from November 2019 to April 2020. Atenea proposal was rated in the $8^{\text {th }}$ position in the national ranking of proposals. The programme will be divided in five sessions in different cultural centers, three in Valencia, one in Madrid and one in Barcelona, each session formed by two workshops. One of the workshops in Valencia will be especially addressed to people with disabilities.

The main objectives of this programme are:

- To make visible the work of national professional women as examples of inspiration and guidance in STEM careers and Arts. 
- To improve education and increase interest in scientific culture and technology in the youngest and through contemporary artistic practices, having in groups with risk of social exclusion and functional diversity.

- Transmit values of equality, diversity and social inclusion through methodologies based on participation, collaboration and free education.

\section{Context}

Studies such as the abovementioned report from UNESCO or the recent Microsoft 2017 in Europe, show that the interest of girls in mathematics or computing worldwide and in Europe at the age of eight to eleven years is comparable, if not higher than boys (Huyer, 2016). However, from eight

to eleven years of age, children's success in science and mathematics increases from $13 \%$ to $43 \%$ of the world average. Contrary to the general conception, the gender gap in the choice of STEM careers exists in countries where gender equality is more related to social conceptions. Between all the reasons that these studies show to argue the radical lack of interest in entering puberty in the educational, family and social environment, the main emphasis is on: gender stereotypes in relation to technology and science, the absence of motivation for lack of female figures, the lack of obvious relationship with the practicality or social action of the STEM areas, the lack of connection with the real work that these studies will entail in the future, and especially the self-perception and self-demand that girls have of themselves (UNESCO, 2016, Microsoft, 2018). Most girls at the age of fifteen prefer careers with social vocations such as health sciences, social sciences, or creative ones such as arts and humanities: globally, $2 \%$ of girls imagine ICT careers. These and other studies promote the creation of associations and networks for collaboration and support (networking) for women in STEM, as well as promoting free workshops, tutorial programmes and guidance for women as reference cases (UNESCO, 2016; Microsoft 2018). At the national level, associations such as Girls in Tech, Women in Mobile, AMIT, Dones en Xarxa, are doing an immeasurable job to encourage girls and young women in STEM careers, 
promoting the figures of successful women scientists and technologists and fighting through of reports and research the gender gap and the 'glass ceiling' existing in the workplace and academia. However, from Atenea we propose to go a step further in the methodology of teaching science and technology to attract interest and increase the motivation of girls towards STEM careers, especially those related to ICT. As we have seen, the interest in humanities and social studies is high in female students. The lack of interest in STEM careers lies essentially in how these professions and studies are shown to the youngest. At UPV for example, the initiative $U p !$ Steam $^{248}$ founded in 2018 has designed a programme for girls to encourage them towards choosing STEM carries for their future through alternative educational programmes (UPV, 2018). At Atenea we want to take advantage of this evident interest of girls and young people for artistic careers to demonstrate how science, art and technology are closely linked $^{249}$. Within Visual Arts, the flow of digital arts and new media is an example of this interdisciplinarity and passion for technology from a gender and artistic perspective. Artists working from feminisms have recovered the female figures of computer history and communication sciences, turning them into heroines of technofeminism and cyberfeminism. Women artists who work with code, programmeming and communication technologies are a unique example for girls and young women, showing them that technology is not only passive and consumer use (as in the case girls using video games who share same interest as male users, but are only $22 \%$ of video game developers (Taylor, 2019), but that they themselves can be creators and programmemers of the product. The figure of the digital and electronic artist woman teaches children that whoever is behind the screen of video games and computer programmes can surely be a woman, thus transmitting values of equality and breaking cultural and gender stereotypes from the earliest youth

\footnotetext{
${ }^{248}$ See < https://www.upv.es/entidades/CS/infoweb/cs/info/1054056normalc.html>

${ }^{249}$ As happened in the Italian Renaissance, and in the Reinassence teams we have studies in chapter 2.4.2
} 
Finally, recent studies show that artistic methodologies to teach robotics, programmeming and scientific and physical elements help to stimulate the creative capacity of children and young people, developing their problem-solving skills. Teaching technology and science through art renews the methodology of work, self-perception, levels of stress and competitiveness, the enjoyment of activities and the perception of the material transmits social and ethical values based on equality and inclusiveness, transforming the conception of technology as a closed consumer product to an artistic material of creation, innovation and social transformation.

\section{Description}

The guest mentors will be selected by the core team of Atenea under previous requirements and suitability of the profiles for the workshops. The mentor's profile will be interdisciplinary, with a combination of STEM and Art skills. The mentors will illustrate the students with the creative possibilities of science and technology through techniques and methods of the contemporary practices of Bio Art, Eco Art, Digital Art and New Media, transmitting technical scientific knowledge in an alternative and original way to awaken your attention and curiosity, with a view to a future vocational choice. The work and role of mentors in This programme will encourage the figure of women as an entrepreneur, technologist, intellectual and creative, being able to strengthen the inspiration of the youngest towards STEM careers and breaking with the archaic stereotypes of scientist and technologist: tech boy, geek, etc.

\section{Workshops content:}

Workshop Sound Art and Performance with Lucia Peiró, Workshop on forst fires and environment with Clara Molinicos, Workshop on Little Bits and Music composition with Alayna Hughe and workshop on Soundcool for groups with motor disabilities (art therapy) in Valencia. 
In Málaga workshop on Mathematics and Art with Mercedes Siles, analyzing two scultptoric pieces by Picasso and Berrocal In Barcelona workshop on Drawing with Code with Alba G. Corral, workshop on Creating a floating Robot with Monica Rikic. In Madrid workshops on soft interfaces and soft circuits with María Castellanos.

\subsubsection{Next activities}

In Atenea we are designing several activities to develop in the current year 2020. Such activities are based on the following directions the project aims to adopt, however the implementation of such depends on the financial support the project will receive from the funding programmes we have applied for:

- Work on alliances and partnership with other projects in Spain and Europe.

- Repeat the curatorial and organisational event reshaping the structure and involving primary and secondary schools' students and teachers.

- Create a programme of female mentorship addressed to girls and collectives with functional diversity and motor disabilities.

Currently, we have started to design the third edition of the conference and exhibition together with the organisational team of Las Naves. We have also applied for the FECYT call for Research Groups for this year 2020, to continue the Mentorship Programme in primary and secondary schools in the Comunitat Valenciana. We have been granted by the Decanato de Cultura at the UPV to organize a STEM+Art symposium the day before the III Conference, for the female students in the different faculties in the campus. We are coordinating at the moment the workshops of the mentorship programme with art museums in Valencia (IVAM), Málaga (Museo Picasso and Museo de Málaga en el Palacio de la Aduana), Barcelona (CCCB) and Madrid (Media Lab Prado). 
[This page intentionally left blank] 


\section{V.}

\section{DISCUSSION}




\subsection{Discussion}

Main results I have obtained with this research work are the historical and archival research through the mapping process, the visualization map as a result and from the practice side, and the curatorial and organisational project: Atenea.

Along this dissertation I have studied in-depth a socio-technical and artistic phenomenon related to women's segregation, activism and associationism that has appeared at the intersection of art and technology.

I have mapped a series of all-women initiatives which have emerged in different periods and locations worldwide, comprised by a wide range of formats. In total, I have identified ninety-two different initiatives in a total of twenty countries, existing along three decades and half, located in all continents but Africa and Antarctica.

My research work adopted its focus of interest on those initiatives that have appeared in the grassroots of a general panorama, generally in new media arts, which follow self-organised methods, and which are generally artist-run. From the total number above-mentioned, sixty-six are selforganised initiatives located in eighteen countries. Both institutional or self-organised, I have identified the earliest practices in the year 1986 in the United States of America, in East and West Coast respectively (New York and California). Within the number of initiatives mapped, I have described in detail within this dissertation fifty-nine self-organised initiatives, and two organised within an institutional framework in the earliest practices in the late 1980s early 1990s. To have a better understanding of the topic, I have interviewed founding and relevant members of twenty-two of them, collecting a rich and notable qualitative material on the topic. Regarding ICT, despite the increasing formats of communication that ICTs enable, emerging initiatives studied in this dissertation state and 
manifest that analog formats of real encounter are still the dominant form for community building and network establishment.

After the mapping process, I can summarize in general terms the aims of my case studies in three points:

1. To establish networks of support between women in new media arts while promoting their work.

2. To create alternative spaces to learn technology, offering mentorship and self-learning environments, specially addressed to women and girls, but not only.

3. To build spaces and formats for alternative discourses and perspectives on technology and society, for the own members of the network or for others.

Each initiative can have one, two or all three of these aims at the same time. While feminism has become an ideological identity and discourse composed by different brunches and approaches, not all the initiatives' members define the project as feminist neither relate themselves to feminist politics directly, and from those who do, there are a wide range of positions and considerations, terminologies and approaches depending on the member.

Through the mapping I have visualised a retrospective of this techno-social and artistic phenomenon, thus I can conclude that the first practices happened in United States of America, Western Europe and Australia in the middle 1980s and early 1990s, while for the last five years there have appeared beyond Western countries, like Latino American countries and Asia. However, these remain still a minority. The mapping I have developed helps to visualise the specific context of each initiative within a global panorama, general objectives, patterns of formats and nodes of connectivity and influence in the translocal and transnational network they all form. 
Regarding the context that may give rise to these initiatives, firstly they have generally appeared in countries where there is a scene of new media art practices, generally male-dominated or lack in diversity. Other factors are related to the emerging initiatives in non-Western countries are influenced by feminist ideology which spreads through media, becoming sources of inspiration for formats and discourses. Additionally, only and all-women organisations formats are increasing in numbers in the last years due to the international programmes to promote women in STEM fields. Organisations such as Girls in Tech, Women Who Code, The Ada Project, etc, have nodes in countries all around the world and might inspire in formats and strategies of segregation and mentorship to young girls. However, regarding my cases, the purposes of some initiatives are diverse and not always centered to women only, as I have noted an increasing awareness for "underrepresented folks", principally LGTB community and women and people of color also, belonging to different feminist discourses. Therefore, I can outline three factors that might shape the context that gives rise my case studies, in terms of barriers or in terms of nodes of influence, which can coexist individually or simultaneously:

1. The existence of a new media arts scene.

2. A cultural influence of feminist theories and methodologies regarding activism, segregation and space appropriation.

3. The establishment of a node within the network by a third element (i.e.MzBaltaz,/etc,...)

Regarding the first point, it is comprehensible that without the existence of a specific artistic and technical field at a professional and academic level, one community or project based on it could possibly emerge. It is important to take into consideration not only the technological development of each of the countries where the case studies have emerged but also the situation of women in it. For example, post-communist countries in Europe have a different percentage of women involved in STEM fields, compared to Western Europe due a different socio-political framework, as it happens in Middle 
East countries, India and Indonesia, where women are in equal numbers to men in STEM fields (Galpin, 2002; Lagesen, 2008; UNESCO, 2017; Seager, 2018). Therefore, the campaigns that seek to involve women in tech or initiatives to support women as a minority in tech fields are less necessary in those other locations.

However, and regarding the second point, the spread in global media and academic press of theories on gender and technology from Western sources mainly is also a notable motivator. Although I argue that feminist politics are not the solely source for self-organised women's segregation as strategy, yet it would not be far from reality to claim that since feminism became a global concern involving institutional parties from each continent (see UN Decade of Women) nowadays local activism is influenced by foreign methodologies and ideologies. In places where media promotes global Western feminist discourses, its formats are adopted, such as segregated groups, specific ideological approaches, terminologies, etc. Massive information through the internet also promotes ideologies to spread globally and reach locally. This leads to the establishment of feminist initiatives based on an external and implemented ideology rather than as a reaction of a critical situation of gender inequity in art and technology.

Regarding the third point, there are three factors that enable the emergence of new initiatives within the existing network. The first is the performance of a concrete event by a collective or project in a new country, fact that may inspire and encourage attendants to do something similar on their own (i.e. XXLab with Mz.Baltazar's Lab). The second possibility is that local artists and activists decide to start a project based on other that they have get to know while traveling abroad, remaining impressed and inspired (i.e. Electric Women). The third possibility is that a member of a network starts a project on her own in a new country based on her background and original location context (i.e. extantation).

In addition to all three points, cultural movements related to technology such as hackerculture and DIY movement have spread through the Internet networks. Therefore, alternative formats for 
technology building and learning are being adopted in new places, for example hackerspaces in Brazil. In this regard, the techno-cultural context of each location may differ from general trends. Another example, while cyberfeminism seems to be over in Europe and North America since early 2000s, in Latino American countries there is a contemporary emerging movement regarding cyberfeminism, which has by the way emerged due to linguistic flows.

In relation to this last point, I want to discuss some invisible barriers that I have noticed to be influents on the emergence of such initiatives, in addition to the three points above mentioned. First are economical resources, as per accessing new media programmes in most of the countries of my case studies you need to be able provide a notable economic support, therefore not anyone can afford to be a new media artist, the implications of ethnicity and social class that it obviously carries. Second is language. Language has been a barrier that I have been aware of from the beginning of this work in terms of the accessibility to all the existing initiatives, but also in terms of Western supremacy over other possible cultural approaches to new technologies and access to general bibliography on the topic, specially pointing the dominance of English language in academic discourses. As explained in the chapter on all-women art groups, the construction of history and narratives shapes the perception of the contemporary practices. Anglo-American culture and language supremacy in the general economic, technological and socio-cultural panorama, including academia, is probably the most notable factor to comprehend the contemporary discourses and contents in women's groups in new media arts. Localizing language zones helps to understand why new initiatives may emerge or not in other countries. For instance, while Anglo-American countries consider cyberfeminism a topic already expired, working from a further theoretical position, Latino American countries have just started to develop their own cyberfeminist proposals, by influence of Spanish cyberfeminist authors, while for other countries seemed to be a topic over. Postcolonial studies attempt to understand the current 
situation of non-Western countries; however, they may follow the previous formats leaving behind proposals out of mainstream Anglophone and Western Europe.

With the whole retrospective done through the mapping, I can state that despite the selforganize forms that all these initiatives follow, most of them work on collaboration with small cultural centers, university departments, art galleries, or bodies of that sort. Like Rasa Smite (2012) states on creative networks, the initiatives studies in this work have permanent or punctual collaborations with other centers, which provide them of space, tools, communication support, etc. Happening mostly in the margins, these initiatives attempt to survive constantly looking for funding, collaboration crossinstitutions and voluntary work. And there is where the clue to last over the time is. As I have described along the analysis of the initiatives in the second block, a notable number of them were projects with a strong potential and commitment that unfortunately couldn't last much. For example, M-Artech, Fem.Elek, etc. After studying the context of all of them, I can presume that the reason behind the success for an initiative to perdure over the time is the financial support. Therefore, the socio-political context is essential for the perdurability of the project. While in countries like Canada, Austria or United States the few initiatives that exist can provide excellent conditions to the artists involved, that is not the case in other countries like Spain. In the Spanish cases, for example, due to the lack of public and private funding dedicated to the nature of these projects and the complex and dense bureaucracy behind it. Although most of them are artist-run and self-organised, most of the work done voluntarily, when working and dealing with artists the members expect to provide a fear economical compensation, that most of the times was not possible (see Fem Elek in point 3.4.5.3.).

Another factor that I have noticed behind the disappearance of a network is the lack of involvement of the members due to personal reasons, such as family, kids, job, etc. Some initiatives have adopted a political position and have redacted manifestos, objectives, while others not. The case that exemplifies how a network can last over the years with no commitment, founding, manifesto or established 
programme is Faces mailing list. Founded in 1997 with the only purpose to remain in contact and provide alternative space of communication for women in the emerging net art, Faces is still an active mailing list through which women in new media art organizes encounters, share information and events, promote their work, etc. With more than 450 members, the list has witnessed more than two decades of women in new media arts.

As further findings of my research, I have found earlier all-women self-organised curatorial practices in computer arts earlier to cyberfeminism, which were unpublished in academic format. These findings have also shown that women of color were present in the early computer art practices, who contributed to the first computer and network arts, in contrast to a while dominance in the first years of cyberfeminism. This also relates us to the fact that technology companies such as Apple and IBM used to promote interdisciplinary teams of artists and engineers that do not exist today.

I have also discussed that when feminism and computer arts finally collided along the early 1990s, collective activist practices by feminist artists were named cyberfeminism, opening a new style active until today that performs with a strong ideology in its discourse. However, I consider important to notice that women artists in early network arts developed works with a strong social content, which aims seek connectivity cross-borders and cross-cultures. Women in telecollaborative and network arts exploded the possibilities of pioneer technology to create new forms of communication through a nonelitist art. Through the history of women in network arts I have found precedents of the first all-women mailing lists which show cross-borders women alliances through analog and electronic networks. The early projects on html by women also showed a strong feminist concern in social issues while exploding the electronic networks possibilities through interactive and participative pieces, which have not been consider within the feminist historiography of cyberfeminism. Therefore, I can presume that although cyberfeminism is considered the start of women's collective activism on the Net with a strong feminist position, yet women in computer and networked arts were previously developing collective 
works with a very notable social content but with less emphasis in exposing their ideology. Here is where I see a main difference.

In the fourth block, I have presented the gathered qualitative data retrieved by a survey to women involved in new media arts or fields in arts and technology. Within that chapter I have discussed the results and exposed the conclusions in referring to the dissertation topic. In the second part of this block I have addressed the contemporary impact that the situation of women in new media arts has in institutional entities. From those all-women initiatives that have been conceived within an institutional framework, the first format I have come across was a panel dedicated to women in computer arts in 1986 called The Future of Today ${ }^{250}$, with Women of SIGGRAPH 1985 was already identify as an allwomen group within, and other women artists took part. This means that the early manifestations happened within an institutional framework, which was different to the European Net Art scene ten years later, which some point to the culture of women-only groups that has happening in USA along the 1970s and 1980s. Over the years, both in Europe and North America and later beyond, institutional bodies, mainly academic, have demonstrated interest in the topic. However, the last years international organisations such as the European Commission and UNESCO have designed programmes specifically addressed to women in new media arts and creative industries. The popular awareness of women in STEM has reached the creative panorama, and today such institutions work on the promotion of women in creative industries, facing the problems that this lack of diversity may bring. UNESCO acknowledges too, that the possibilities for women of the "Global South". I have noted a symbolic parallelism when SIGGRGRAPH L.A organised Women in Technology ${ }^{251}$. and hosted Matrix: Women Networking ${ }^{252}$ in 1993 and since 2014 to 2018 SIGGRAPH organised five conferences on Women in Computer graphics in United States and Asia.

\footnotetext{
${ }^{250}$ See chapter 3.1 .1

${ }^{251}$ See chapter 3.1 .3

252 See chapter 3.1.4.
} 
Lastly, in the last part of the fourth block I have presented Atenea and its three main channels, as an own practice that joins the listing of the mapping. Moreover, Atenea is an ongoing project based on providing a space for networking for women in STEM and Arts, believing in collaboration and interdisciplinarity as tools for innovation and creativity to shape the future. It is also based on the idea of mentoring in STEM through new media arts. Atenea is the only active project or platform in Spain dedicated to women in STEM and Arts, and one of the few at an international level. The experience building Atenea as a combination of formats has provided me of a rich experience in cultural management, curating new media arts and organizing mentoring formats. The most notable experience, however, has been facing the difficulties to create an initiative and establish networks from the starting point, with no founding and with a lack of collaboration and support by the closest institutions to the project.

\subsection{Conclusions}

I started this research aiming to deeply investigate all types of existing associationism and networks of women in arts and technology at an international level from its earliest practices.

In order to achieve this, my first objective was to develop a theory and practice research through a combination of qualitative and quantitative ethnographic methods. Besides the historical and archival research, I would like to note the elaboration of the in-depth interviews with members of the initiatives here presented, and the survey as well. Thanks to this I have achieved a profound understanding of this techno-social and artistic phenomenon by hand of the same women who form part of it since the middle 1980s, while I have also collected and published noteworthy qualitative data. I can conclude that I have been able to draw a general panorama of the wide range of all-women initiatives at the intersection of art and technology, providing documentation of the earliest practices which has been never published 
in an academic work before. Indeed, this dissertation can be considered a unique source of information and archive on women's associationism and networks in new media arts or art and technology fields.

Moreover, regarding my second objective, this dissertation innovatively presents the linkage of this phenomenon with the history of all-women spaces and art groups, widening the contemporary feminist historiography on gender, art and technology and DIY culture. It also presents the linkage to the history of women in computer and networked arts and a retrospective analysis of the past and contemporary institutional awareness on women in new media arts. This research work exposes clears origins of all-women's cultural resistance in arts through associationism, space appropriation and activism and the wide range of formats that have been adopted in the last three decades in the field of new media arts and related. This historical retrospective provides a wider understanding of all the cases of study as a single techno-social and artistic phenomenon, while contributes to the current feminist historiography and the scarce bibliography on women in new media arts. The visualization of its results in the visualization map are expected to become a useful tool for students and researchers on new media arts history, fine arts, IT, women studies, sociology and for general audience as well. It is the first and unique source of references on all-women initiatives in arts and technology projected at a global scale and sorted by categories.

Finally, one of my initial objectives was to understand: why these initiatives keep appearing after three decades. If all-women and feminist initiatives are necessary in new media arts is still a topic of discussion. While some point the lack of diversity or the mere wish to establish networks of support through women, others point the necessity to perform alternative ways to develop different discourses through art and technology beyond the mainstream one. The variety of positions towards the situation of women in arts and technology and new media arts is as wide and diverse as the positions within feminism. While theoretical works on the topic generally point discussions on poststructuralist concepts such as gender identity, agency, gender representation, etc., after my experience through the 
qualitative methods performed in this dissertation I have ended up with the presumption that women gather together for different reasons, between which I would outline: a way of cultural resistance to make things in a different way to the commercial or mainstream one, a way to create a space on their own, a way to gather together and support each other. And these ways can occur without declared feminist positions. So, answering the initial question, one could presume from a pessimistic point that not much has changed, or that within this socio-technical and artistic panorama, women will still appear in the grassroots to collectively resist aiming to make a difference.

Regarding my third objective, the project Atenea, I can outline that after three years we have achieved the managing and organising of: two international conferences with two international exhibitions, one programme of mentorship funded by FECYT (Fundación Española para la Ciencia y la Tecnología from the Minsiterio de Ciencia, Innovación y Universidades) and a recognised impact on academic journals, conferences and general national press. Atenea nowadays counts on the collaboration of outstanding national and international art and science institutions and with acclaimed female new media artists, educators and researchers.

\subsection{Future Research}

I acknowledge that the scope of my research has exceeded the limits of this doctoral research period and extension. For example, within the discussion on gender equity in new media arts that embraces also race equity, it is necessary to develop a further and deeper investigation that gathers quantitative and qualitative data from a high number of new media arts institutions, centers, departments and artists to be able to stablish concrete conclusions.

For the next phase I plan to continue developing the mapping focused on the network visualization aspects, considering factors of time and collaboration. Another scope is to bring the current results to Atenea's platform as an open archival available for different audiences and to adapt the current dissertation to a non-informal format to be published as a book. 


\section{REFERENCES}

A

Abbate, J. (2010). The Pleasure Paradox: Bridging the Gap Between Popular Images of Computing and Women's Historical Perspective. Gender codes: why women are leaving computing, pp.213-228.

The Ada Project. (n.d.). [official website]. Retrieved from https://www.women.cs.cmu.edu/ada

Addison, R. (2018) Lauren Valley’s Electric Women Project Provides a Space for Women of Color, Pittsburgh City Paper. Retrieved from https://bit.ly/2zK1Ayw. Consulted on the 02.12.2018

The Aerospace Corporation (1986). Invitation letter for Lucia Grossberger from Meet the Challenge, Shape the Future, $11^{\text {th }}$ Annual Women's Week Celebration organised by The Aerospace Corporation. Unpublished document.

Aguiar y Wedge, C., Tankal, E. \& Clark, A. (2019). On bringin the future into the present through radical collaboration, interview by Willa Köerner for The Creative Independent. Retrieved from <https://bit.ly/2wkReGN>

Ajuntament de Barcelona. [Barcelona.cat] (2014, 6th March) El llegat de Bonnemaison, encara vigent. [video file]. Retrieved from <https://bit.ly/2lovPqO >

A.I.R, (2017) A.I.R. Gallery [official website]. Retrieved from https://www.airgallery.org Almerini K, (2018) Women's Art Spaces: Two Mediterranean Cases Studies in Jakubowska, A., \& Deepwell, K. (Ed.) All-women art spaces in Europe in the long 1970s. Liverpool University Press. ISBN: 97817869540582 
Altmann, (2018) 'And-I Have not taken him'. The Erfurt Women Artists' Group in Jakubowska, A., \& Deepwell, K. (Ed.) All-women art spaces in Europe in the long 1970s. Liverpool University Press. ISBN: 97817869540582.

The American Women's Group (AWG) (2019). American Women's Group in Paris. Retrieved from <www.awgparis.es>

Angerer, M. L. (2004). The Making of... Desire, Digital. Medien Kunst Netz/Media Art Net, pp.46-53. Retrieved from <https://bit.ly/2lECcWT> on the 28.12.2017

Angliss, S., McDonald, S. \& Northmore, S., [MAT_OPEN] (5 ${ }^{\text {th }}$ Feb. 2010) MzTEK: women artists, techies and tinkerers [video interview]. Retrieved from https://vimeo.com/9226266 on the 01.12 .2018

Appleby, J., Chang, E., Goodwin, N. (2015). Encyclopedia of Women in American History. Routledge. ISBN 9781317471622.

Artz, L., Meer, T., Galgut, H., \& Müller, A. (2017). Participation in practice: a case study of a collaborative project on sexual offences in South Africa. Feminist Review, 115(1): pp.79-96. https://doi.org/10.1057/s41305-017-0040-4

Ascott, R. (1984). Art and Telematics: towards a network consciousness. Art Telecommunication. Vancouver: The Western Front, pp.25-67.

Ascott, R. (2003). Telematic embrace: Visionary theories of art, technology, and consciousness. University of California Press: Berklee and Los Angeles, California. ISBN: 0-520-21803-5

Athens Digital Arts Festival [ADAF] (2019) Women in Media Technology, Open Air Screenings, 1 \& 2 of June. Retrieved from <https://bit.ly/2ScGhxT> 
AWARE (2017). Symposium: WAS - Women Artists Shows, Salons, Societies: Group Exhibitions of Women Artists 1876-1976. Retrieved from <https://bit.ly/2NIA91S>

\section{B}

Barrat, V. (2015). The Artists. Retrieved from www.vnsmatrix.net/the-artists

Basu, A. (2000). Globalization of the local/localization of the global: Mapping transnational women's movements. Meridians, 1(1): pp.68-84.

Basu, A. (2003). Globalizing Local Women's Movements in Mirsepassi, A. (Ed.). Localizing knowledge in a globalizing world: Recasting the area studies debate, pp.82-100. Syracuse University Press.

Bazzichelli, T. (2008) The Net as Artwork, Digital Aesthetics Research Center, Arhus University. Retrieved from <www.digital-aestetik.dk>

Beauvoir, S. D. (1949). Le deuxième sexe I: Les faits et les mythes. Paris: Éditions Gallimard.

Benson, K., \& Nagar, R. (2006). Collaboration as resistance? Reconsidering the processes, products, and possibilities of feminist oral history and ethnography. Gender, Place \& Culture, 13(5): pp.581-592.

Berghaus, G. (2015). Futurist Performance, 1910-1916. In Back to the Futurists. Manchester University Press.

Bertomeu, A. (2004) Fundación del Portal E-leusis.net, e-mujeres [website article]. Retrieved from <https://e-mujeres.net/fundacion-del-portal-e-leusis-net> on the 03.02.2019

Bertomeu, A., (2006) Arte Electronico, e-mujeres [website article]. Retrieved from <https://emujeres.net/fundacion-del-portal-e-leusis-net> on the 03.02.2019 
Bhattacharya, (2018) WITCiH, The Barge House. Retrieved from <http://www.bargehouse.co.uk/witcih> on the 12.11 .2018

Bhattacherjee, A. (2012). Social science research: Principles, methods, and practices. Textbooks Collection. 3. Retrieved from <http://scholarcommons.usf.edu/oa_textbooks/3>

Birnbaum, P. J. (2019). The Exhibitions of the Femmes Artistes Modernes (FAM), Paris, 193138.Artl@s Bulletin, 8(1), 10. Retrieved from <https://bit.ly/2kk9LNK>.

Blair, K. J. (1994). The torchbearers: Women and their amateur arts associations in America, 18901930. Indiana University Press.

Bloch, N. (2012). Cultural resistance: The art of protest. Retrieved from <https://bit.ly/2UKDKhJ>

Boix, M. (2001). La Comunicación como Aliada: Tejiendo Redes de Mujeres, en Boix, M., Fraga, C., \& Sedón, V. (2001). El viaje de las internautas: una mirada de genero a las nuevas tecnologías. Madrid. AMECO. Retrieved from <www.mujeresenred.net > on the 12.03.2017

Boix, M. (2006). Hackeando el patriarcado en la lucha contra la violencia hacia las mujeres. Filosofía y práctica de mujeres en red desde el ciberfeminismo social. Perspectivas feministas en la España del siglo XXI en Labrys, Études féministes junio/diciembre. Retrieved from < shorturl.at/cgnPV>

Boix, M. (2002). Feminismos, comunicación y tecnologías de la información. Aportes Andinos, (4). Retrieved from <shorturl.at/ijU13> on the 12.01.2018

Boix, M. \& Nomada (2003) Hacklabs, de lo digital a lo analógico. En Mujeres en Red. Retrieved from <www.mujeresenred.net $\geq$ on the 06.10.2017

Borrego, M., Newswander, L., \& McNair, L. D. (2007, October). Special session-Applying theories of interdisciplinary collaboration in research and teaching practice. In 2007 37th Annual 
Frontiers In Education Conference-Global Engineering: Knowledge Without Borders, Opportunities Without Passports (pp. S2F-1). IEEE. Retrieved from <https://bit.ly/2loSLpU> on the 05.03.2018

Bosco, R., \& Caldana, S. (2006). La Universidad Bocconi convierte la economía en un juego. El Pais.

Bosna, J. (2005). Constructing media spaces> The novelty of net(worked) art was and is all about access and engagement, in: Frieling, Rudolf and Dieter Daniels (eds): Medien Kunst Netz. Thematische Schwerpunkte. Vol.2. Retrieved from <https://bit.ly/38PG0IO>

Bourdieu, P. (1990). In other words: Essays towards a reflexive sociology. Stanford University Press. ISBN 0804717257

Boussahba-Bravard, M., \& Rogers, R. (Eds.). (2018). Women in International and Universal Exhibitions, 1876-1937. New York: Routledge. ISBN 9781315196534

Bowie, M.B. (2019) United Nations NGO Programme of Women's Caucus for Art, Retrieved from <https://bit.ly/2ljEP0a>. Consulted on the 23.01.2019.

Bozhinov, T. (2015). Behind the Silicon Curtain: Computer Art in the Eastern Bloc [Master thesis], University of the Arts Bremen. Retrieved from < https://go.aws/37uijnG>

Brandt, J., \& Kizer, S. (2015). From street to tweet: Popular culture and feminist activism. In Feminist theory and pop culture. A. Trier-Bieniek (ed.): pp. 115-127. Brill Sense Publishers. E-book ISBN: 9789463000604

Braidotti, R. (2014). Punk women and riot grrls. Retrieved from <https://bit.ly/2lWIOLI > on the 15.03.2019

Briggs, B. N. (1932). The national association of women painters and sculptors. Parnassus, 4(4): pp.33-33. Retrieved from <https://bit.ly/2STFVge>. DOI: 10.1080/15436314.1932.11467299 
Burke, S. (2015), West Oakland's New All-Female Art Collective, East Bay Express. Retrieved from <https://bit.ly/2lk7nqe>. Consulted 11.11.2018

C

Caramés Sales, Á. (2016). Las prácticas curatoriales feministas en el Estado Español (1993-2013). La gestión cultural como productora del discurso de las identidades de género [Doctoral dissertation], Universitat Politècnica de València. Retrieved from <https://riunet.upv.es/handle/10251/62863>

Carpenter, E. (2010). Activist tendencies in craft. Concept Store\# 3 Art, Activism and Recuperation., 3. Retrieved from <http://research.gold.ac.uk/3109>.

Casacuberta, D. (2003). Creación colectiva: en Internet el creador es el público. Editorial Gedisa: Barcelona.

Castells, M. (2001). The Internet galaxy: Reflections on the Internet, business, and society. Oxford University Press on Demand. ISBN: 0-19-924153-8

Cech, E. A., \& Blair-Loy, M. (2019). The changing career trajectories of new parents in STEM. Proceedings of the National Academy of Sciences: pp:4182-4187. Retrieved from <https://www.pnas.org/content/116/10/4182.short>. https://doi.org/10.1073/pnas.1810862116

Chevalier, J.M. and Buckles, D.J. (2013) Participatory Action Research: Theory and Methods for Engaged Inquiry, Routledge UK. ISBN 978-0415540315

Chidgey, R. (2009). DIY Feminist Networks in Europe: Personal and Collective Acts of Resistance in Transform!europe. Retrieved from <https://bit.ly/31NTYYH> 
Chidgey, R. (2012) Hand-Made Memories: Remediating Cultural Memory in DIY Feminist Networks Feminist Media: Participatory Spaces, Networks and Cultural Citizenship, Zobl, E. \& Drüeke, R. (Eds). Retrieved from < https://bit.ly/37BTS7X>. PDF-ISBN 978-3-8394-2157-4

Chidgey, R. (2013) Reassess Your Weapons: the making of feminist memory in young women's zines, Women's History Review, 22(4): pp.658-672, DOI: 10.1080/09612025.2012.751773

CIMUAT (2010). Presentación CIMUAT [official website]. Retrieved from <https://bit.ly/2UL5aUA>

ČIPke, (2013, 2016). [Official website]. Retrieved from $<$ https://cipkeen.wordpress.com $\geq$

Cilleruelo, L. (2006). Arte y comunidades virtuales: el aspecto creativo de la comunicación in Cilleruelo, L. \& Baigorri, L. Net Art. Prácticas estéticas y políticas en la red: pp.29-39. Madrid: Brumaria. Retrieved from <https://bit.ly/37yXA24>

Chandler, A., \& Neumark, N. (Eds.). (2005). At a distance: precursors to art and activism on the Internet. MIT Press. ISBN: 0-262-03328-3

Cheryan S, Master A \& Meltzoff AN (2015) Cultural Stereotypes as gatekeepers: increasing girls' interest in computer science and engineering by diversifying stereotypes. Front. Psychol. 6(49).

DOI: $10.3389 /$ fpsyg.2015.00049

Conn, C. (1992). Women and Technology, [Conference Catalogue] from L.A. ACM Siggraph.

Costantino, T. (2018). STEAM by another name: Transdisciplinary practice in art and design education. Arts education policy review, 119(2): pp.100-106.

Couey, A. (1991). Cyber Art: The Art of communication systems. Retrieved from <https://bit.ly/31Nkxxj> 
Couey, A. (1993) Matrix: Women Networking, in Visual Proceedings, Computer Graphics Annual Conference Series [Exhibition Catalogue], edited by Thomas E. Linehan. ACM SIGGRAPH

Couey, A. (2003). Restructuring power: telecommunication works produced by women. Women, Art, and Technology, The MIT Press. ISBN 0-262-13424-1

Couey, A. (2016), Cultures in cyberspace: Communications system design as social sculpture in Malloy, J. (ed) Social Media Archeology and Poetics. DOI:10.7551/mitpress/9780262034654.003.0021

Couey A. \& Grossberger, L. (1993). Matrix: Women Networking in Visual Proceedings [catalogue] Computer Graphics Annual Conference Series, ACM SIGGRAPH, Edited by Thomas E. Linehan

Cox, D. J. (1989). The Tao of postmodernism: computer art, scientific visualization and other paradoxes. Leonardo, 22(5): pp.7-12. The MIT Press. Retrieved from <muse.jhu.edu/article/609415>

Cox, D.J., Sandor, E., \& Fron, J. (Eds.). (2018). New media futures: The rise of women in the digital arts. University of Illinois Press. ISBN: 9780252041549

Collins, P. H. (2000). Gender, black feminism, and black political economy. The Annals of the American Academy of Political and Social Science,568(1), 41-53. Retrieved from <https://bit.ly/2lkpT1K> on the 12.01.2010

Costamoling, F. (2017). Women in Media Arts (Interview by Martin Hieslmair for Ars Electronica. Retrieved from <https://ars.electronica.art/aeblog/en/2017/02/20/women-in-media-arts>

Crack, A. (2008). Global communication and transnational public spheres. Springer. ISBN: 978-1$349-53584-2$ 
Crichton, S., \& Kinash, S. (2003). Virtual ethnography: Interactive interviewing online as method. Canadian Journal of Learning and Technology/La revue canadienne de l'apprentissage et de la technologie,29(2). Retrieved from <https://www.learntechlib.org/p/43044>. e-ISSN 1499-6677

Critical Art Ensemble [CAE]. (2001). Digital resistance: Explorations in tactical media. Autonomedia. ISBN-10: 1570271194

Ctrl+Shft, (2019). [Official website]. Retrieved from <http://ctrlshftcollective.com>

Current, (2019). Current: Feminist electronic art symposium [Facebook official page]. Retrieved from <https://www.facebook.com/currentsymposium>

D

Dahle, R., Jockers, L., Scott, A., \& Wilson, K. (2017). Major in engineering, minor in art: A new approach to retaining females in engineering. In 2017 IEEE Women in Engineering (WIE) Forum USA East: pp. 1-3). IEEE. Retrieved from <https://bit.ly/2jUQpi6> on the 04.06.2019 doi:10.1177/000271620056800105

Dear, M. J., \& Wolch, J. R. (Eds.). (1989). The Power of geography: how territory shapes social life. Unwin Hyman.

Deepwell, K. (2015). Narratives of Women Artists in/out of Vorticism, in Gunter Berghaus (Ed.). International Yearbook of Futurism Studies, vol.5. ISBN: 3110334100

Deepwell, K. (2018) Feminist Collaborative Projects in the UL in Jakubowska, A., \& Deepwell, K. (Ed.) All-women art spaces in Europe in the long 1970s. Liverpool University Press. ISBN: 97817869540582 
Deleuze, G., \& Guattari, F. (1987). A Thousand Plateaus: Capitalism and Schizophrenia. Brian Massumi (trans). Minneapolis: University of Minnesota Press. (Originally published in 1980). ISBN: 9780816614028

Derieg, A. (2007). Things Can Break: Tech Women Crashing Computer and Preconceptions, eipcp. Retrieved from <http://eipcp.net/transversal/0707/derieg/en.html $\geq$ on 08.05.2018

Dewey-Harborg, H. \& Santos, D., [macfound] (2018) Refiguring the Future, A NetGain Event [video of the conference]. Retrieved from <https://bit.ly/21RY1CA $>$

Diaz Ramos, L. (2016). Feminist curatorial interventions in museums and organisational change: Transforming the museum from a feminist perspective (Doctoral dissertation, School of Museum Studies). Retrieved from <http://hdl.handle.net/2381/39450>

DigitalES, (2018). Mujeres en la economía digital en España 2018. [report] Elaborated by Qanticae for DigitalES. Retrieved from <https://bit.ly/2VpNvCb>.

Dubber, C. (2017). Current in Discorder. Retrieved from <https://bit.ly/2OMRrZu>

Dumitriu A., Novakovic, G. \& Papadimitriou, I., (2016) Technology is not neutral [exhibition catalogue]. London: The Blurb. Retrieved from < https://bit.ly/37pUcq9>

Duncombe, S. (2007). (From) Cultural resistance to community development. Community Development Journal,42(4): pp.490-500. Retrieved from <https://bit.ly/2lKj1el $\geq$ https://doi.org/10.1093/cdj/bsm039

Donestech, (2009), Lelacoders [online entry]. Retrieved from <www.donestech.cat $>$

Downey J. (2007) Participation and/or Deliberation? The Internet as a Tool for Achieving Radical Democratic Aims. In: Dahlberg L., Siapera E. (eds) Radical Democracy and the Internet. Palgrave Macmillan, London. https://doi.org/10.1057/9780230592469_7 
Dumont, F. (2018) Women Artist's Collectives in France: a Multiplicity of Positions in a Turbulent Context, in Jakubowska, A., \& Deepwell, K. (Ed.) All-women art spaces in Europe in the long 1970s. Liverpool University Press. ISBN: 97817869540582

$\mathbf{E}$

Eclectic Tech Carnival [ETC], (2009), Eclectic Tech Carnival (/ETC) in Umeå 8-12 June 2009, Humlab Blog, created on the 3th April 2009, Retrieved from <www.blog.humlab.umu.se $\geq$

Electric Women, (2019). [official website]. Retrieved from <www.electric-women.com $\geq$

Electronnes (2017). [Facebook official page]. Retrieved from <https://www.facebook.com/electronnes>

e-leusis, (1999, 2001). Historia e-leusis [online entry] in e-mujeres official website. Retrieved from <www.e-mujeres.net>

Elliot, M.H. et al. (Ed.) (1893). Art and Handicraft in the Woman's Building of the World's Columbian Exposition [exhibition catalogue], Elliot, M.H. (Ed.). Chicago. Retrieved from <https://bit.ly/2lQWa0P> on the 25.09.2018

Ember, C. R., \& Ember, M. (Eds.). (2003). Encyclopedia of Sex and Gender: Men and Women in the World's Cultures Topics and Cultures AK-Volume 1; Cultures LZ(Vol. 2). Springer Science \& Business Media.

enrREDadas (2014). EnREDadas por el arte y la tecnología. [online source]. Retrieved from < https://enredadas.org/category/uncategorised/page/9>

enrREDadas (2017). FemHack: ¿Qué es un FEMHACK? Retrieved from <https://enredadas.org/femhack> 
enrREDadas (2018). No estamos por estar, estamos para hacer el cambio. [online entry]. Retrieved from <https://enredadas.org/2017/12/15/no-estamos-por-estar-estamos-para-hacer-elcambio>

Ensmenger, N.L. (2010). Making programmeming masculine. Gender codes: Why women are leaving computing, 115-141. Retrieved from <https://bit.ly/2k8Cx3X>

Ensmenger, N.L. (2012). The computer boys take over: Computers, programmemers, and the politics of technical expertise. Cambridge, Massachusetts; London, England: The MIT Press. doi:10.2307/j.ctt5hhjdh

Escobar, M.M. (2013) Talleres, enREDadads por el Arte y la Tecnologia. Retrieved from $<$ https://enredadas.org/tag/talleres $\geq$ on the 19.10 .2018

Eurostat, (2018) Distribution of Scientists and engineers by gender in Employed HRST by category, sex, age and NACE Rev. 2 activity (from 2008 onwards), European Commission. Retrieved from <https://bit.ly/2lpPkPM>

Evans, C. L. (2018). Broad band: the untold story of the women who made the Internet. U.S.A., Penguin.

ISBN 9780735211766

Extantation (2016). [official website]. Retrieved from <www.extantation.wordpress.com>

F

Faces (2006). Faces Story in Faces: Gender, Technology, Art [old website]. Retrieved from <http://archive.faces-1.net/en/content/faces-storyhtml.html>

Faces (2017). FACES@ARS ELECTRONICA 2017. Retrieved from <https://bit.ly/37kk5Ys> 
FEMeeting (2018). Retrieved from <www.femeeting.com>

Femmebit (2019). About. Retrieved from <www.femmebit.com>

FemTek (2018). Retrieved from <www.femtekbilbao.net>

Fernandez, M., Aristarkhova, I. \& Fusco, C. (2002). Undercurrents: a dialogue. Fine Art Forum, 16(8). Retrieved from <https://bit.ly/2lhn1Tr $>$

Fernandez, M., \& Wilding, F. (2002). Situating cyberfeminisms in Domain errors! Cyberfeminist practices: pp.17-28. Retrieved from <shorturl.at/fstyD>

Fernandez, M., \& Wilding, F. (2003). Cyberfeminism, racism, embodiment. Domain errors! Cyberfeminist practices: pp.29-44. Retrieved from <https://bit.ly/2jUOv0X>

Ferranto, M. (n.d.). (Mis)reading m@ilart, Anna Banana and Guy Bleus: Studies in Networking. Retrieved from <http://www.spareroom.org/mailart/mis_3.html $\geq$ on the 17.11 .2018

Fidler, L. (2018) Between the body and the touchscreen: A Review of 'Murmurs and Palpitations: Her Environment \#7 at TCC Gallery, New City Art. Retrieved from <https://bit.ly/2km6Sfd> on the 09.01.2019

Föllmer, G., \& Badenoch, A. W. (2018). Transnationalizing Radio Research: New Approaches to an Old Medium (Vol. 42). Transcript Retrieved from <www.oapen.org>.

Fotopoulou, A. (2016). Digital and networked by default? Women's organisations and the social imaginary of networked feminism. New Media \& Society, 18(6): pp.989-1005. https://doi.org/10.1177/1461444814552264

Fredrickson, L. (2009). Trap: Kate Millett, Japan, Fluxus and Feminism. Women \& Performance: a journal of feminist theory, 19(3): pp.337-367. https://doi.org/10.1080/07407700903399516 
Freelands Foundation, (2019). [official website]. Retrieved from <www.freelandsfoundation.co.uk>

Friedman, K. (1995). The early days of Mail Art: A historical overview. In Welch, C. (Ed). Eternal network: A mail art anthology: pp.3-16. Univ of Calgary Pr. Canada. ISBN: 1-895176-27-1

Frieze, C., Quesenberry, J. L., Kemp, E., \& Velázquez, A. (2012). Diversity or difference? New research supports the case for a cultural perspective on women in computing. Journal of Science Education and Technology, 21(4): pp.423-439. https://doi.org/10.1007/s10956-0119335-y

Frieze, C., \& Quesenberry, J. (2015). Kicking butt in computer science: Women in computing at Carnegie Mellon University. Dog Ear Publishing. ISBN-13: 978-1457539275

Fritz, D. (2016). International Networks of Early Digital Art. In Christiane Paul (ed.) A Companion to Digital Art: pp.46-68. John Wiley \& Sons. ISBN 9781118475188

$\mathbf{G}$

Galán, M. P. (2000). La enseñanza en la Segunda República. Revista de Educación, $n^{\circ}$ extraordinario, 317-citation_lastpage. Retrieved from <https://bit.ly/2jUYVO6>. Consulted 10.01.2019

Galasso, B. (2011, March). A Virtual Ethnography as a Methodological Approach in Digital Spaces. In S. Barton, J. Hedberg \& K. Suzuki (Eds.), Proceedings of Global Learn Asia Pacific 2011-Global Conference on Learning and Technology: pp.394-399. Melbourne, Australia: Association for the Advancement of Computing in Education (AACE). Retrieved from <https://www.learntechlib.org/primary/p/37202>

The Gallery@CALIT2, (2011) Synthesis: Processing and Collaboration [exhibition catalogue]. No.11 University of California, San Diego. Published by The Gallery@CALIT2. Retrieved from <https://bit.ly/2UTvagB>. ISBN 978-0-578-07737-6 
Galloway, K. \& Rabinowitz, S. (n.d.) Tellecollaborative art projects of Electronic Café International founders [website entry]. Retrieved from <www.ecafe.com>

Galpin, V. (2002). Women in computing around the world. ACM SIGCSE Bulletin, 34(2): pp.94-100. Retrieved from <https://bit.ly/2uPKURe>

Gender Changers Academy [GCA]. (2015). Sleight Mirror Party - networked performance installation and workshop [official website entry]. Retrieved from < https://genderchangers.org>

Giannetti, C. (1998). Ars telemática. Telecomunicacion, Internet y Ciberespacio. Barcelona, $L$ ' Angelot (Ed.). Retrieved from <https://bit.ly/2IOjSiS >

Giannetti, C. (2002). Estética digital: Sintopía del arte, la ciencia y la tecnología. L'Angelot. ISBN: 8492226560

Giannetti, C. (2005). Aesthetics of the digital in Medienkunstnetz. Dieter Daniels, Rudolf Frieling, Heike Helfert (Eds), Tom Morrison (trans). Retrieved from < https://bit.ly/38yQWue>

Giles, E. [TeDx Talks] (31 ${ }^{\text {st }}$ Dec. 2012) MzTEK: Emile Giles at TEDxUWestminster [video of the conference presentation]. Retrieved from <https://bit.ly/2lFQ6Ii >

Gill, R. (2005) Technofeminism, in Science as Culture, 14(1): pp.97-101, DOI:10.1080/09505430500042130. Retrieved from < https://bit.ly/3bJPQh9>.

Gonda, P. (2017) Against Techno Patriarchy in Norilent. Retrieved from $<$ https://norient.com/stories/constanza-pina> on the 17.12.2018

Gonnard, C., \& Lebovici, E. (2007). Femmes artistes, artistes femmes: Paris, de 1880 à nos jours. Hazan. ISBN 9782754102063

Goshinski, L. (2019). GirlFx [website entry], Retrieved from <www.laurengoshinski.com>. 
González, María José (2011). El Lyceum Club de Barcelona, Institut Català de les Dones. Retrieved from $<$ shorturl.at/BFS05>.

Graf, V. (2018). Featured Artist: Elisabeth Schimana in Ars Electronica Blog. Retrieved from <https://bit.ly/3bvZ801>

Graham, J. (1980). American Women Artists' Groups: 1867-1930. In Woman's Art Journal, 1(1): pp.712. DOI: $10.2307 / 1358011$.

Grewal, I., \& Kaplan, C. (Eds.). (1994). Scattered hegemonies: Postmodernity and transnational feminist practices. University of Minnesota Press. ISBN: 0816621381

Grier, D. A. (2007). When computers were human. Princeton University Press. ISBN: 0-691-09157-9

Grossberger-Morales, L. (1991). Dressing Images [catalogue exhibition] Grossberger-Morales, L. \& Thoma, M. (eds.) South Bay Women's Caucus for the Art, San Jose, California, United States of America.

The Guardian (2016) Why women are asking a major art and technology festival to \#KissMyArs. The Guardian. Retrieved from <https://bit.ly/2kbGq8k> on the 07.05.2018

Guerrilla Girls (2016). Is It Even Worse in Europe, [text from exhibition catalogue]. Retrieved from <https://www.guerrillagirls.com/exhibitions $\geq$ on the 13.11.2018

a Gueye, O. (2019) A propos, Afrocyberfeminismes. Retrieved from <www.afrocyberfeminismes.org>

$\mathbf{H}$

HackerMoms (2019). [official website]. Retrieved from <www.hackermoms.org> 
Hackers of Resistance (2018). h0rd14r13z in Ada: A Journal of Gender, New Media, and Technology, No. 13. Retrieved from: <https://adanewmedia.org/2018/05/issue13-hors>, doi: 10.5399/uo/ada.2018.13.6.

Hackers of Resistance [HORs], (2018). [Official website]. Retrieved from <http://wearehors.xyz>

Hajek, A. (2018). A Room of One's Own. Feminist Intersections between Space, Women's Writing and Radical Bookselling in Milan (1968-1986). Italian Studies, 73(1): pp.81-97. https://doi.org/10.1080/00751634.2018.1414376

Haraway, D. (1985). A manifesto for cyborgs: science, technology, and socialist feminism in the 1980s. Socialist review, 15(2): pp.65-107.

Haraway, D. (1991). Simians, cyborgs and women: the reinvention of nature. London: Free Association Books. ISBN: 1853431397

Haraway, D. (1989). Introduction: The persistence of vision. V: Primate Visions. Gender, Race, and Nature in the World of Modern Science: pp.1-15. New York in London: Routledge.

Harren, Natilee. (2015) The Crux of Fluxus: Intermedia, Rear-guard in Art Expanded, 1958-1978, edited by Eric Crosby with Liz Glass. Vol. 2 of Living Collections Catalogue. Minneapolis: Walker Art Center. Retrieved <from http://walkerart.org/collections/pub>

Hawthorne, S., \& Klein, R. (Eds.). (1999). Cyberfeminism: Connectivity, critique and creativity. Spinifex Press. ISBN: 187555968X

Held, J. (1995). New directions: Into the nineties in Chuck Welch (ed.). Eternal network, University of Calgary Press, Canada. ISBN: 1-895176-27-1

Henn, S. (2014). When Women Stopped Coding, in NPR. Retrieved from <https://n.pr/2xEWz99> on the 05.03.2018 
Henry, A. (2004). Not my mother's sister: Generational conflict and third-wave feminism. Indiana University Press. ISBN: 025321713X

Her Environment, (2018). [Official website]. Retrieved from <www.herenvironment.com>

Hess, A. (2019). 29 years old Katie Bouman ‘didn’t know anything about black holes' -then she helped capture the first photo of one, in $C N B C$ online. Retrieved from <https://cnb.cx/2GerPzM?> on the 01.06 .2019

Hesse-Biber, S. N. (Ed.). (2013). Feminist research practice: A primer. Sage Publications. ISBN: 9781412994972

Hicks, M. (2017). Programmemed inequality: How Britain discarded women technologists and lost its edge in computing. MIT Press.

Hiršenfelder, I. \& Spačal, S. (2015). ČIPke: Ženske s čutom za tehnologijo, znanost in umetnost, (interview by Ana Eterovic for Netokracija). Retrieved from <https://bit.ly/2lKs3bf> on the 11.02.2019. Translated from Slovenian to English by Google Translator App.

Hodges, J. (2008). She Was a Computer When Computers Wore Skirts. NASA. Retrieved from <https://go.nasa.gov/2jXF2pE> on the 15.04.2018

Hogan, K. (2016). The Feminist Bookstore Movement: Lesbian Antiracism and Feminist Accountability. Duke University Press. ISBN: 9780822361107

Holt, N. (2016). Rise of the rocket girls: The women who propelled us, from missiles to the moon to Mars. Little, Brown. ISBN: 0316338907

Hooks, B. (1989). Choosing the Margin as Space for Radical Openness. The Journal of Cinema and Media, No. 36: pp. 15-23. Drake Stutesman; Wayne State University Press. Retrieved from at <http://www.jstor.org/stable/44111660> on the 10.03.2019 
Huffman, K.R. (2003). Face Settings: An international co-cooking and communication project by Eva Wohlgemuth and Kathy Rae Huffman in Women, Art and Technology, Judy Malloy (ed.). Massachusetts. The MIT Press. pp. 398-411. ISBN 0-262-13424-1

Huffman, K.R. (2009). Electronic brides, machine divas and robotic visionistas, in Institute für Medienarchäologie [online article]. Retrieved from <https://bit.ly/2P2IPOK>.

Huffman, K.R. \& Djordjevic, V. (2017). Where are the women? Interview with Kathy Rae Huffman and Valie Djordjevic (interviewer Anna Gorchakovskaya for Digicult). Retrieved from <https://bit.ly/323Qodd>

Huffman, K.R. \& Wohlgemuth, E. (1998) Face Settings. In Sollfrank, C. \& Old Boys Network (Ed.), First cyberfeminist international [exhibition programme]: pp.78-9. Hamburg. Retrieved from: 〈https://www.obn.org/obn_pro/downloads/reader1.pdf>

Huhtamo, E. (2016). Art in the Rear-View Mirror: The Media-Archaeological Tradition in Christiane Paul (ed.) A Companion to Digital Art: pp. 69-110. John Wiley \& Sons. ISBN 9781118475188

Huyer, S. (2015). Is the gender gap narrowing in science and engineering? In UNESCO science report: towards, 2030: pp.85-103. Retrieved from <https://bit.ly/2wM4qVn>.ISBN: 978-92-3100129-1

\section{I}

Institute for Media Archeology [IMA], (n.d.). About: digging |women, art and technology [official website]. Retrieved from <https://ima.or.at/en/ueber>.

Institute for Media Archeology [IMA], (2019). IMAfiction [official website]. Retrieved from $<$ https://ima.or.at/en/imafiction> 
Instituto Nacional de Estadística [INE], (2017). Mujeres y Hombres en España, Instituto Nacional de Estadística. Retrieved from <https://bit.ly/OxYBPx> on the 05.04.2018

Irigaray, L. (1977). Ce sexe qui n'en est pas un. Editions de Minuit: Paris

\section{J}

Jacobs, J. A. (2014). In defense of disciplines: Interdisciplinarity and specialization in the research university. University of Chicago Press. E-book ISBN-13: 978-0-226-06946-3

Jakubowska, A. (2018). No groups but friendship: All-women initiatives in Poland at the turn of the 1980s, in Jakubowska, A., \& Deepwell, K. (Eds.) All-women art spaces in Europe in the long 1970s. Liverpool University Press. ISBN: 97817869540582

Jakubowska, A., \& Deepwell, K. (2018). All-women art spaces in Europe in the long 1970s. Liverpool University Press. ISBN: 97817869540582

Jamieson, H.V. (2004). Eclectic Tech Carnival (/etc) 2004 [website entry] in Furtherfield. Retrieved from < https://bit.ly/322uAi4>.

Jepsen, T. C. (2000). My sisters telegraphic: Women in the telegraph office, 1846-1950. Ohio University Press. ISBN: 0-8214-1343-0

Jia, O. (2017). Making/Breaking the Binary, Women, Art and Technology in Rosenwald-Wolf Gallery, The Artblog. Retrieved from <https://bit.ly/2klD824> on the 13.12.2017

Johnson, K.H. (2017). Jean. E. Sammet, [blog entry] in Women, Art \& Technology. Retrieved from https://bit.ly/21SXY9C on the 06.11.2018 CURATOR OF WOMEN ART AND TECHNOLOGY 
Johnson, K.H. (2018). Women, Art and Technology: Kelsey Halliday Johnson and Amy Beste in conversation, interview in The Pew Center for Arts \& Heritage [online article]. Retrieved from <https://bit.ly/2lunnGc> on the 13.12.2017

$\mathbf{K}$

Kapor Center/ASU CGEST (2018). Women and Girls of Color in Computing. Kapor Center/ASU CGEST. Retrieved from <https://bit.ly/2n2U8rC> on the 11.04.2019

Katz, Richard (2010) About Margaret Hamilton. NASA Office of Logic Design. Retrieved from <http://klabs.org/home_page/hamilton.htm> on the 10.01.2018

Kemp, T.; Powel, C.\& Link, B. (2018). Accounting for Women: Collaborators, Networks and Alliances in the arts [programme description]. ATW Conference June 2018. Retrieved from <https://bit.ly/2jZeTqw>.

Kraiser, M. (2018). The International Exhibition Kvindeudstillingen XX på Charlottenborg in Copenhagen and the Idea of Feminist Art Space in Jakubowska, A., \& Deepwell, K. (Ed.) Allwomen art spaces in Europe in the long 1970s. Liverpool University Press. ISBN: 97817869540582

Krasny, E. (2018). For Us, Art is Work': In + Akt - International Action Community of Women Artists, in Jakubowska, A., \& Deepwell, K. (Ed.) All-women art spaces in Europe in the long 1970s. Liverpool University Press. ISBN: 97817869540582

Kroll, Z. et al. (1995). UTOPIA/DYSTOPIA: Third Annual Conference of Feminism Activism and Art [Catalogue Festival], The LAB, San Francisco. 
Krolokke, C., \& Sorensen, A. S. (2006). Gender communication theories and analyses: From silence to performance, N. 50. Sage. ISBN: 0-7619-2918-5.

Kuni, V. (1998). The Art of performing cyberfeminism, in Sollfrank, C. \& Old Boys Network (Ed.), First cyberfeminist international [exhibition programme]: pp.69-72. Hamburg. Retrieved from: <https://www.obn.org/obn_pro/downloads/reader1.pdf>

$\mathbf{L}$

Lagesen, V. A. (2008). A cyberfeminist utopia? Perceptions of gender and computer science among Malaysian women computer science students and faculty, in Science, Technology, \& Human Values, 33(1): pp.5-27. https://doi.org/10.1177/0162243907306192

Land, M. H. (2013). Full STEAM ahead: The benefits of integrating the arts into STEM. Procedia Computer Science, 20: pp.547-552. https://doi.org/10.1016/j.procs.2013.09.317

Latour, B. (2005). Reassembling the social: An introduction to Actor-Network-Theory, OUP Oxford. ISBN 0199256047

Lenz, M. (2014). Cataloguing change: Women, art and technology, in V\&A [online], n.6, Summer 2014. ISSN 2046-667X. Retrieved from < https://bit.ly/2HJ05o1>.

Leonard, M. (1998). PAPER PLANES: travelling the new grrrl geographies in Skelton, T. \&Valentine, G.(eds.) Cool Places: Geographies of Youth Culture, Routledge: London. ISBN 0-203-97559-6

Levine, C. \& Glhan, P. (2016). Interrogating invention: Electronic Café and the politics of technology in Panorama. Summer 2016 (2.1). Retrieved from <https://bit.ly/2UTbVDT> on the 21.01.2019 https://doi.org/10.24926/24716839.1536 
Liao, C. (2016). From interdisciplinary to transdisciplinary: An arts-integrated approach to STEAM education. Art Education, 69(6), 44-49. https://doi.org/10.1080/00043125.2016.1224873

Light, J. S. (1999). When computers were women. Technology and Culture 40(3), pp.455-483. John Hopkins University Press. Retrieved from Project MUSE database <https://bit.ly/327VkxX> on the 02.09.2019

Lillemose, J. \& Kryger, M. (2015). The (Re)invention of cyberspace, in Kinstkritikk: Nordic Art Review. Retrieved from <https://kunstkritikk.com/the-reinvention-of-cyberspace> on the 06.03.2019

Lippard, L. R. (1973). Six years; the Dematerialization of the art object from 1966 to 1972 . Berkeley and Los Angeles, CA: University of California Press, 2001, originally published in New York: Praeger, 1973. Retrieved from <https://bit.ly/2OTIKN1>.

Lippard, L. R. (1995). The Pink glass swan: Selected Essays on Feminist Art. New Press. ISBN-10: 1565842138

Lippard, L. (2002). Biting the hand: Artists and museums in New York since 1969 in Ault, J. (Ed.). (2002). Alternative art, New York, 1965-1985: a cultural politics book for the Social Text Collective. p.79. University of Minnesota Press. ISBN: 0-8166-3793

Llinàs Carmona, C. (2008). Feminismes de la transició a catalunya: Textes i materials. Horsori (Ed), Barcelona. ISBN: 978-84-96108-50-9

Lovelace, C. (2008). Making it Together: Women's Collaborative Art + Community [preface exhibition catalogue]. Retrieved from < https://bit.ly/3c7O2P3> on the 11.12 .2018

Lorde, A. (1984) The Master's tools will never dismantle the master's house, in Sister Outsider: Essays and Speeches, pp.110-14. California, The Crossing Press. ISBN: 0-89594-142-2 
López Castilla, M.T. (2015) Música electrónica y cultura de club: un estudio postfeminista de la escena española [doctoral dissertation] Universidad de la Rioja. Retrieved from <https://dialnet.unirioja.es/servlet/tesis?codigo=46122>

Lovink, G. \& Rositter, N. (2018). Organisation after social media. Autonomedia. ISBN: 1570273383

Lykke, N. (2010). Feminist studies: A guide to intersectional theory, methodology and writing. Routledge. ISBN: 1136978992

M

M-Artech (2012), Open Call [blog entry]. Retrieved from <https://bit.ly/31XmcAo>

Magenta, M., (1995) The World's Women On-Line! Official Website. Retrieved from <wwol.inre.asu.edu/artists.html > on the 09.12.2018

Magenta, M., (2012). Momentum: Women/Art/Technology, official website. Retrieved from <https://www.momentum-women-art-technology.com> on the 01.10.2018

Malloy, J. (1991). Uncle Roger: An online narrabase. Leonardo 24, n.2: pp.195-202. Retrieved from <https://www.jstor.org/stable/1575298>. DOI: 10.2307/1575298

Malloy, J. (2003) Women, Art and Technology. Massachusetts. The MIT Press. ISBN 0-262-13424-1

Malloy, J. (Ed.). (2016). Social media archeology and poetics. Massachusetts. The MIT Press. ISBN: 9780262034654

Malloy, J. (2019). The women who shaped Art and Technology studies, in ats@50 Art and Technology Studies 1969-2019 [catalogue], Kac, E. \& Bass, D. (ed), published by the School of the Art Institute of Chicago: pp.48-55. ISBN: 978-0-578-51202-0 
Marsh, A. (1981), Hypatia Cluster: A Space Group for Women in Weber, J. (ed) (1982), Weberwoman's Wrevenge Fanzine, vol 1 number 5: pp. 5-7. Australia. Online copy retrieved from <http://pdf.textfiles.com/efanzines/Wrevenge/wrevenge05.pdf>

Martínez-Collado, A. (2011). Prácticas artísticas y activistas feministas en el escenario electrónico: Transformaciones de género en el futuro digital. Asparkía: investigació feminista, (22): pp. 99-114. ISSN 1132-8231

Marvin, C. (1988). When old technologies were new: Thinking about electric communication in the late nineteenth century. Oxford University Press, USA. ISBN: 0-19-504468-1

Marx, G., \& Virnoche, M. (1997). Only connect. EM Forster in an age of electronic communication: Computer-mediated association and community networks. Sociological Inquiry, 67: pp.645650.

Masegosa, J. \& Márquez, I. (2016). Barreras para la Igualdad entre mujeres y hombres. La importancia de las redes de mujeres in Revista Yo Dona de El Mundo. Retrieved from <https://bit.ly/2IV5alD> on the 28.11.2018

Matalone, S. \& Smith, S. (2012). Mothership HackerMoms: Where Hackerspace Meets Motherhood, interview by GeekMom for WIRED. Retrieved from <https://bit.ly/37Cuwqm> on the 08.07.2019.

Massey, D., \& Allen, J. (1984). Geography Matters. Cambridge University Press. ISBN: 0-521268877

Mayayo, P. (2007) Otras miradas: Mujeres artistas, nuevas tecnologías y capitalismo transnacional, in POLIS, n.17 [online]. Published on the 25th July 2012. Retrieved from <http://journals.openedition.org/polis/4367>. 
Merck, M., \& Sandford, S. (2010). Further adventures of the dialectic of sex: critical essays on Shulamith Firestone. Springer. ISBN: 978-0-230-10999-5

Mereu, F. [Medialab-Prado] (28 ${ }^{\text {th }}$ March 2012). Presentación de M-Artech, mujeres en artes $y$ tecnología. [video] Medialab Prado, Madrid. Retrieved from < https://bit.ly/2V2W2L9> on the 10.07.2018

Mereu, F. (2013) M-Artech [official website]. Retrieved from <https://martechplatform.wordpress.com>

Metzlar, D. (2008) Faces Community [blog post]. Retrieved from $<$ https://bit.ly/2ko1wAg $>$ on the 06.12 .2017

Meyer, L., \& Wilding, F. (2010). Collaboration and conflict in the Fresno Feminist Art Programme: An experiment in feminist pedagogy. N. Paradoxa: International Feminist Art Journal, 26: pp. 40-51. Retrieved from <https://bit.ly/2Vtej4J>

Michaud, (1986). Reaching for the High Frontier, chapter 8. National Space Society. Retrieved from <https://space.nss.org/reaching-for-the-high-frontier-chapter-8> on the 03.11.2018

Microsoft (2013). Girls in STEM and ICT Careers: The path towards gender equality. Available at <www.download.microsoft.com/downaload/E/6/5/E6523A39-82DF-4330-A216AA520EB4FEB7/Girls In Stem and ICT Carreers_WP_FINAL.pdf>

Ministerio de Educación y Formación Profesional [MEFP] (2019). Igualdad en cifras. Secretaría General Técnica (Ed). Retrieved from <https://bit.ly/37ol1ew>. NIPO: 847-19-020-1

Microsoft, (2018), Inspire Girls in STEM. Retrieved from <https://www.microsoft.com/en-us/digitalskills/girls-stem-cs> on the 01.06.2019 
De Miguel, A., \& Boix, M. (2005). Los géneros de la red: los ciberfeminismos. El feminismo social in Mujeres en Red. Retrieved from <http://www.mujeresenred.net/spip.php?article297>

Mir, S. (2017). Women Artists Working with Technology, Hyperallergic. Retrieved from <https://bit.ly/2ymICuA> on the 11.11.2018

Misa, T. J. (Ed.). (2011). Gender Codes.: Why Women Are Leaving Computing. John Wiley \& Sons. IEEE Computer Society. ISBN: 978-0470-59719-4

MIT, (2013). Leonardo Journal [online archive]. The MIT Press. Retrieved from <https://www.leonardo.info/leonardo $\geq$ on the 14.11.2018

Mitchell, C. (1998) Women's (community) radio as a feminist public sphere, Javnost - The Public, 5(2): pp.73-85. Retrieved from <www.tandfonline.com> DOI: $10.1080 / 13183222.1998 .11008676$

Mitchell, C. (2000). Women and radio: Airing differences. Routledge. ISBN: 0-415-22071-8

Mitchell, C. (2016). Women and Radio - airing differences: On the Importance of Community Radio as a space for women's representation, participation and resistance. [Doctoral dissertation] University of Sunderland. Retrieved from <http://sure.sunderland.ac.uk/id/eprint/6858> on the 10.12.2018

McLuhan, M. (1994). The Medium is the message, in Understanding media: The extensions of man. MIT press. Originally published in 1964.

Moghadam, V. M. (1996). Feminist networks north and south: DAWN, WIDE and WLUML. Journal of International Communication, $3(1): \quad$ pp.111-26. https://doi.org/10.1080/13216597.1996.9751827 
Molina, M. [intermedia0], (15th February 2011). Radio-Arte de las vanguardias [video]. Retrieved from <https://www.youtube.com/watch?v=_fxRP3TBvQ8 $\geq$

MoMA (2010). Women in Flux [exhibition text]. New York. Retrieved from <https://mo.ma/2kn8xRR> on the 11.11.2018

MoMA (2018). Shigeko Kubota [website entry]. Retrieved from <https://www.moma.org/artists/3277?>

Monleon, P. [Nonsite] (2010) Mau Monleon - Congreso [video interview] CIMUAT Conference at Universitat Politecnica de Valencia November 2010. Retrieved from <https://vimeo.com/85437895 $\geq$ on the 03.12.2018

Morbey, M. L. (1992). From canvas to computer: Harold Cohen's artificial intelligence paradigm for art making [Doctoral dissertation] The Ohio State University. Available at $<$ https://bit.ly/2jTIzoL>

Morbey, M. L. (2000). Academic computing and beyond: New opportunities for women, minority populations, and the new media arts. Convergence, 6(4): pp.54-77. https://doi.org/10.1177/135485650000600405

Moravec, M. (2017). Network Analysis and Feminist Artists. Artl@ s Bulletin, 6(3), art 5. I S S N : $2264-2668$

MPavilion (2019) Q\&A: Global Collective Hypen-Labs on the Future of Women in Design in MPavilion Magazine. Retrieved from <https://bit.ly/2ka8n0g> on the 02.08.2018

Munroe, A. (2013). All the Landscapes: Gutai’s World. In Gutai: Splendid Playground, Alexandra Munroe and Ming Tiampo (Ed.). New York: Guggenheim Museum Publications. 
Muller, N. (1999). Suggestions for good cyberfem (house)-keeping: or how to party with the hyperlink. In Sollfrank, C. \& Old Boys Network (Ed.), Next cyberfeminist international [exhibition programme]: pp.73-76. Hamburg. Retrieved from: 〈https://bit.ly/2SB4GPj>.

Müller, U. (2009). Bauhaus women: Art, handicraft, design. Flammarion.

Mujeres en las Artes Visuales [MAV] (2015). Informe MAV \#15: Discriminación Sexual en el Profesorado de Masters Universitarios Oficiales en España [Report]. Retrieved from <www.mav.org./informes> on the 10.05.2018

Mujeres en las Artes Visuales [MAV] (2019). Informe MAV Ferias 2019 [Report]. Retrieved from <www.mav.org./informes> on the 20.05.2019

$\mathbf{N}$

National Association of Women Artists, [NAWA]. (2019). NAWA History. Retrieved from <https://www.thenawa.org/nawa-history> on the 15.11.2018

Navarreta, C. (1982). The Guide to Women's Art Organisations and Directory for the Arts. Midmarch Associates: New York City (originally published in 1979). ISBN: 0-9602476-3-7

Núñez Puente, S. (2008). Una exploración de la praxis feminista en España: nuevas tecnologías y nuevos espacios de relación desde el ciberfeminismo. In Feminismo/s. No. 11 (jun. 2008): pp. 109-123. Retrieved from <http://hdl.handle.net/10045/9001> ISSN 1696-8166

$\mathbf{O}$

Öhrner, A. (2018) Making Space for Feminism. All-Women Art Exhibitions in Sweden in the 1970s in Jakubowska, A., \& Deepwell, K. (Ed.) All-women art spaces in Europe in the long 1970s. Liverpool University Press. ISBN: 97817869540582 
Oldenziel, R. (1999). Making technology masculine: men, women and modern machines in America, 1870-1945. Amsterdam University Press. ProQuest Ebook Central Retrieved from, $<\mathrm{http}: / /$ ebookcentral.proquest.com/lib/cm/detail.action?docID=437599> on the 29.10.2018

Oliveira, M. (2018). Portuguese Women Artists at the National Society of Fine Arts: Why Was This Not a Feminist Exhibition? in Jakubowska, A., \& Deepwell, K. (Ed.) All-women art spaces in Europe in the long 1970s. Liverpool University Press. ISBN: 97817869540582

Onosaka, J. (2006). Feminist Revolution in Literacy: Women's Bookstores in the United States. Routledge. https://doi.org/10.4324/9780203959565

$\mathbf{P}$

Paasonen, S. (2005). Figures of fantasy: Internet, women and cyberdiscourse. New York: Peter Lang

Paasonen, S. (2011). Revisiting cyberfeminism. Communications, 36(3): pp.335-352. Retrieved from <https://bit.ly/2HWtL1b>. DOI: 10.1515/comm.2011.017

Padmanabhan, S. (2019). Young artists integrate into Chicago art scene by opening DIY gallery space. Retrieved from <https://bit.ly/2lxZ9Lg > on the 08.10.2018

Paterson, N. (1991). Cyberfeminism. Retrieved from <www.people.well.com> originally published in <www.echonyc.com>. Currently available at <gopher://echonyc.com/00/Cul/Cyber/paterson>

Paterson, N. [Kleurnet Interviews English] ( $9^{\text {th }}$ December 1997). Ict Nancy Paterson cyberfeminism 1997 [video interview], for Kleurnet Television Amsterdam. Retrieved from < https://bit.ly/2vUa0nY>

Paterson, N. (2014). [Interview Transcript], Interviewers Ann Dean, Luis Jacob \& Maurice Carroll on the $16^{\text {th }}$ February 2014. Retrieved from <https://bit.ly/2jTs0cL > on the 04.10 .2018 
Paul, C. (2016). A Companion to Digital Art. Christiane Paul (ed.) John Wiley \& Sons. ISBN 9781118475188

Paul, C. (Presenter) (20 ${ }^{\text {th }}$ May 2019). Women in Technology (WiT) Pioneering Digital Artists, [Podcast]. In Technycal: Silicon Alley meets Silicon Valey. Retrieved from $\langle$ https://bit.ly/21Gs12N>

Pérez-Hernández, M. [Ptqk] (2006). Programmea EnRE/Dades, in PTQK_BLOGZINE. Retrieved from <https://ptqkblogzine.blogia.com/2006/022701-programmea-enre-dades.php>

Pérez-Hernández, M. [Ptqk] (2014). SOFT POWER. Exposición y programmea de actividades sobre ciencias naturales y biotecnología, in Maria Ptqk web. Retrieved from <http://www.mariaptqk.net/soft-power>

Pérez-Hernández, M., [Ptqk] (2017) Tecnociencia, Feminismos y Biopolítica Táctica: contextos y prácticas del colectivo subRosa [doctoratal dissertation]. Universidad del País Vasco

Pérez-Martínez, J. E. (2015). Airing the Differences: An Approach to the Role of Women in the Spanish Free Radio Movement (1976-2014). In Connecting Women (pp. 47-60). Springer, Cham.

Pierce, J. (1998). Info heavy cyber babe. In Sollfrank, C. \& Old Boys Network (Ed.), First cyberfeminist international [exhibition programme]: p.10. Hamburg. Retrieved from $<$ https://bit.ly/38wYXzE $>$.

Piña, C. (2017). Entrevista a Constanza Piña sobre CyborGrrrls: Encuentro Tecnofeminista, interview by Radio Zapote. Retrieved from <https://bit.ly/2kod1rq>. 
Plana, M., \& Vergés, M. (2015). La socialización de los saberes femeninos: El "Instituto de Cultura y Biblioteca Popular para la Mujer”, Barcelona (1900-1936). In Historia Social, 82: pp.133-147. Retrieved February 7, 2019, from <www.jstor.org/stable/43867465>.

Plant, S. (1995). The future looms: weaving women and cybernetics. Body \& Society, 1(3-4): pp.4564. Retrieved from https://bit.ly/2kbJeST. Consulted 19.05.2018

Plant, S. (1997). Zeros and Ones. Digital Women and the New Technologies. Fourth State, London. Retrieved from <https://bit.ly/2jVpByg $>$. Consulted 19.05.2018

Pohlad, M. [PBS] (10 ${ }^{\text {th }}$ May 2018). Lorado Taft and The White Rabbits, [video] Art \& Design in Chicago. Retrieved from <https://www.pbs.org/video/lorado-taft-and-white-rabbits-eumkmz>

Pollock, Griselda (2013). Introduction, in Parker, R., \& Pollock, G. Old mistresses: Women, art and ideology. IB Tauris. ISBN: 0857722263

Praba, P, Siembieda, D. \& La Rocca, I. (2018). *feminist tECnOart* [exhibition curatorial statement]. Retrieved from <https://www.weadartists.org/curatorialstatement>

PRS Foundation, (2019). [Official Website]. Retrieved from <https://prsfoundation.com>

Puchades Pla, R., Cerdá Hernández, M., Sanz Montrull, L., \& García, L. M. (2019). Personas Trans: identidad, libertad y respeto. Guía de buenas prácticas. Editorial Universitat Politécnica de València. ISBN: 978-84-9048-795-2.

Q

Q-Space, (2018). [official Facebook page]. Retrieved from <https://www.facebook.com/qspacebeijing>. 
Q-Space (2019). A Queer feminist maker space Beijing. Here are our stories [official website]. Retrieved from <https://qspaceblog.wordpress.com>.

Quinn, D. (2017). Because We Had To: Open Hardware at the Intersection of art and Innovation. Open Source Stories in Red Hat. Retrieved from <https://red.ht/2lW23dd> on the 05.12.2017

$\mathbf{R}$

Rackham, M. (2013) WWWO - Wollongong World's Women Online. Retrieved from <www.subtle.net/curatorial>

Rahmani, A. (2014). Communities of resistance: How ecological artists and scientists might help resist the environmental wars. Retrieved from <https://bit.ly/2Tkx4EO>.

Re, L. (1989). Futurism and feminism, in Annali d'italianistica, No.7: pp.253-272. Retrieved from <www.jstor.org/stable/24003870>

Re, L. (2009). Futurism and the Feminine: New Perspectives. European Legacy, 14(7): pp.877-880.

Rendell. J (1999). Introduction in Borden, I., Penner, B., \& Rendell, J. (Eds.). (2002). Gender space architecture: an interdisciplinary introduction. Routledge. ISBN 0-203-75736-X

REFRESH (2019). [Official website]. Retrieved from <www.refreshart.tech>.

Reiche, C., \& Kuni, V. (Eds.). (2004). Cyberfeminism. Next Protocols. Autonomedia. ISBN: 1570271496

Reilly, M. (2015). Taking the measure of sexism: Facts, figures and fixes in ARTnews. June 2015. Retrieved from <maurareilly.com/pdf/essays/Reilly_ArtNews.pdf>

Reitsamer, R. (2012) Female Pressure: A translocal feminist youth-oriented cultural network, Continuum, 26(3): pp.399-408. DOI: 10.1080/10304312.2012.665837 
Reynolds, S. I. Â. N. (2000). Running away to Paris: expatriate women artists of the 1900 generation, from Scotland and points south. Women's History Review, 9(2): pp.327-344.

Rheingold, H. (1993). The virtual community: Finding connection in a computerized world. AddisonWesley Longman Publishing Co., Inc.

Ribeaux, T. \& Fleetwood, F. (2017). Vital Hybrids [Press Release, exhibition text]. B4BEL4B Gallery, Bay Area, San Francisco, United States of America.

Ritchie, J., Lewis, J., Nicholls, C. M., \& Ormston, R. (2013). Qualitative research practice: A guide for social science students and researchers. London: Sage.

Root-Bernstein, R. (2015). Arts and crafts as adjuncts to STEM education to foster creativity in gifted and talented students. Asia Pacific Education Review, 16(2): pp.203-212.

Rossiter, N. (2006). Organised Networks, Transdisciplinarity and New Institutional Forms. In Intelligent Agent (Vol. 6, No. 2). Retrieved from <https://bit.ly/2w1NxWg>

Rupp, L. J. (1997). Worlds of women: The making of an international women's movement. Princeton University Press. ISBN: 0-691-01675-5

Rutgers, (2019). Momentum Technology Videos in Rutgers: Center for women in the arts [online]. Retrieved from <https://sites.rutgers.edu/cwah/event/mtv-momentum-technology-videos/>

\section{$\mathbf{S}$}

Sánchez Hernández, María F. (2011). De la identidad a la identidad virtual de género: nuevas aproximaciones desde el ciberfeminismo, in Asparkia, n.22: pp.131-146. Retrieved from <https://dialnet.unirioja.es/servlet/articulo?codigo=3824424> ISSN 1132-8231 
Sandoval, C. (1994). Re-entering cyberspace: sciences of resistance. Dispositio, 19(46): pp.75-93. Retrieved from <https://www.jstor.org/stable/41491506>.

Schmidt-Burkhardt, A., (2003). Maciunas' Learning Machines: From Art History to a Chronology of Fluxus. Retrieved from <https://link.springer.com/book/10.1007/978-3-7091-0480-4> Springer. DOI: 10.1007/978-3-319-20837-4

Schafer, V., \& Thierry, B. G. (Eds.). (2015). Connecting women: women, gender and ICT in Europe in the nineteenth and twentieth century. Springer. ISBN: 3319208365

School of the Art Institute (2019), ats@50 Art and Technology Studies 1969-2019 [catalogue], Kac, E. \& Bass, D. (ed), published by the School of the Art Institute of Chicago, pp.48-55. ISBN: 978-0-578-51202-0

Scott, A. F. (1993). Natural allies: Women's associations in American history (Vol. 132). University of Illinois Press.

Seager, S. (2018). The Women's Atlas. Penguin Books. New York. ISBN: 9780143132349

SisterSMATR, (2018). [Official website]. Retrieved from <www.sistersmatr.org>

Shanken, E. A. (2002). Cybernetics and art: Cultural convergence in the 1960s. From energy to information, pp.155-177.

Shanken, E. A. (2003). From Cybernetics to Telematics: the art, pedagogy, and theory of Roy Ascott. Preface. Ascott, R. Telematic embrace: Visionary theories of art, technology, and consciousness. University of California Press: Berklee and Los Angeles, California. ISBN: 0$520-21803-5$

Shetterly, M. L. (2016). Hidden figures. HarperCollins Nordic. ISBN: 978-0-06-236360-2. 
Smite, R. (2012). Creative Networks. Institute of Network Cultures. ISBN: 978-90-818575-0-5

Smith, F. M. (1997). Between east and west. Cool Places: Geographies of Youth Cultures, pp.290305.

Las Sinsombrero, [RTVE] (23th July 2018) Especials TVE Catalunya - Las sinsombrero. [video documentary]. Available at $\langle$ https://bit.ly/37BFXyP $>$.

Sollfrank, C. (1998). Women hackers, in Sollfrank, C. \& Old Boys Network (Ed.), First cyberfeminist international [exhibition programme]: pp.78-9. Hamburg. Retrieved from: <https://www.obn.org/obn_pro/downloads/reader1.pdf>

Sollfrank, C. (2002). The truth about cyberfeminism. Old Boys Network. Accessible at <https://www.obn.org/reading_room/writings/html/truth.html>

Sollfrank, C. (2018) Preface. Die schönen Kriegerinnen. Technofeministische Praxis im 21. Jahrhundert, Vienna, transversal texts. Sollfrank, C. (trans). Retrieved from <https://bit.ly/3a8cxdo>

Sochacka, N. W., Guyotte, K. W., \& Walther, J. (2016). Learning together: a collaborative autoethnographic exploration of STEAM (STEM+ the Arts) education. Journal of Engineering Education, 105(1): pp.15-42. https://doi.org/10.1002/jee.20112

Sørensen, K. H., Faulkner, W., \& Rommes, E. (2011). Technologies of Inclusion: Gender in the information society. Trondheim: Tapir Academic Press.

Spain, D. (1992). Gendered spaces. Univ of North Carolina Press. ISBN: 0-8078-4357-1

Spain, D. (2016). Constructive Feminism: Women's Spaces and Women's Rights in the American City. Cornell University Press. ISBN 9780801453199 
Standage, T. (1999). The Victorian Internet. Phoenix Books. ISBN 0753807033

Studio XX (n.d.). [Official website]. Retrieved from <www.studioxx.org>

subRosa (2010) Bodies Unlimited: Strategies and Tactics for Becoming Feminist Scientists. Soft Power. Sala Amarika, Bilbao

subRosa (2011). Bodies Unlimited: A Decade of subRosa's Art Practice. n. paradoxa n.28: pp.16-25.

Superrr (2019). [Official website]. Retrieved from <www.superrr.net>

$\mathbf{T}$

Taylor, G.D. (2013). Up for Grabs: Agency, Praxis, and the Politics of Early Digital Art, Lateral 2. https://doi.org/10.25158/L2.1.5

Taylor, G. D. (2014). When the Machine Made Art: The Troubled History of Computer Art, Bloomsbury Academic, ISBN: 978-1-6235-6561-9

Taylor, L. (2019). Girls got game: Young women hope to level up video game coding skills for Reuters Available at https://reut.rs/3bH6DBw

Terpenkas, A. (2017). Fluxus, Feminism, and the 1960's. Western Tributaries, 4. Retrieved from <https://bit.ly/2jTRab3>.

Terranova, T. (2004). Network Culture: Cultural Politics for the Information Age. Pluto Press. ISBN 0-7453-1748-0

Thoma, M. (1991). Foreword in Dressing Images [catalogue exhibition] Grossberger-Morales, L. \& Thoma, M. (eds.) South Bay Women's Caucus for the Art, San Jose, California, United States of America. 
Tornero, P. (2012). Tecnologías de la creatividad: conexiones entre arte y ciencia en la contemporaneidad (Doctoral dissertation, Universidad Complutense de Madrid).

Topaz CM, Klingenberg B, Turek D, Heggeseth B, Harris PE, Blackwood JC, et al. (2019) Diversity of artists in major U.S. museums. PLoS ONE 14(3): e0212852. https://doi.org/10.1371/journal.pone.0212852

Transitory, T. (2016), in Extantation [Official website]. Retrieved from <www.extantation.com>

Tuer, D. (2005). Mining the media archive: Essays on art, technology and cultural resistance. Toronto: YYZ Books. Retrieved from < https://bit.ly/2VkOofj>.

$\mathbf{U}$

UNESCO (2017). Cracking the Code: Girls' and Women's Education In Science, Technology. ISBN 978-92-3-100233-5

UNESCO (2018). UNESCO's Create|2030 Talks, called You Are Next: Empowering Women in the Digital Arts. Retrieved from <https://bit.ly/2WZihUD> on the 15.04.2019

UN Women (1995). Beijing declaration and Platform for Action, for the Fourth World Conference on Women, United Nations. Retrieved from <https://bit.ly/2vOJpZD>

University of Wollongong, (1995), World's Women Online, Women's art on the Net, The University of Wollongong Magazine, p.15. Retrieved from <www.subtled.net> on the 13.03.2018

Universitat Politecnica de Valencia [UPV] (2018), Up!Steam [online resource] Retrieved from <https://bit.ly/2kmJUEU> on the 16.02.2019

$\mathbf{V}$ 
Valentine, G., Skelton, T., \& Chambers, D. (1998). Cool places: Geographies of Youth Culture. London: Routledge. ISBN 0-203-97559-6

Ventepakamchatka, (2015) Las 16 librerías feministas más bellas del mundo, in Algo pasa en Kamchatka [online]. Retrieved from <https://bit.ly/2HQHt5L>

VeNuS (1994). Bitch Mutant Manifesto [online]. Retrieved from <www.vnsmatrix.net>

VeNus (2005). VNS MATRIX: Curriculum Vitae. Retrieved from <https://bit.ly/2PnPVNU>

VeNuS (2019). [Official website]. Retrieved from <www.vnsmatrix.net>

Vergés Bosch, N. (2012). De la exclusión a la autoinclusión de las mujeres en las TIC. Motivaciones, posibilitadores y mecanismos de autoinclusión. Athenea digital, 12(3): pp.129-150.ISSN: 1578-8946. Retrieved from <shorturl.at/moxKP>

Vergés Bosch, N., Cruells López, E., \& Hache, A. (2009a). Descrifrando el código Lela. [PowerPoint presentation] for X0y1. Retrieved from <https://donestech.net/files/x0y1_prep_cast1.pdf>

Vergés Bosch, N., Cruells López, E., \& Hache, A. (2009b). Retos y potencialidades para las mujeres en la participación del desarrollo de la sociedad de la información. Feminismo/s, 2009, vol. 2009, n. 14, pp.163-182. DOI: 10.14198/fem.2009.14.10. Retrieved from <https://bit.ly/32jNa5p>.

Vesna, V. (1997). From Fe-Mail to f-e-mail \& Beyond: Cyberfeminist Networks on the Web. Retrieved from <http://vv.arts.ucla.edu/projects/95-97/f-e-mail> on the 12.04.2018

Void Lab, (2016). [Official website]. Retrieved from <http://projects.dma.ucla.edu/voidlab>

Vose Frey, E. (2012). Beyond a Woman's Place: Pioneers in American Art. [exhibition catalogue] Vose Galleries. Boston. Retrieved from in from 〈https://bit.ly/2lqfd1L〉. 
W

Wagenknecht, A. (2015). Deep lab [artist website]. Retrieved from <https://bit.ly/2ThACY2>

Wagenknecht, A. et al. (2015) in Deep Lab Retrieved from www.deeplab.net

Wajcman, J. (1991). Feminism confronts technology. Penn State Press. ISBN: 0271008024

Wajcman, J. (2000). Reflections on gender and technology studies: in what state is the art? Social studies of science, 30(3): pp.447-464. https://doi.org/10.1177/030631200030003005

Wajcman, J. (2004). Technofeminism. Cambridge: Polity. ISBN: 0745630448.

Wajcman, J. (2006). TechnoCapitalism Meets TechnoFeminism: Women and Technology in a Wireless World, Labour \& Industry: a journal of the social and economic relations of work, 16(3): pp.7-20. DOI: 10.1080/10301763.2006.10669327

Wajcman, J. (2009). Feminist Theories of Technology. Cambridge Journal of Economics 2009, 1 of 10 doi:10.1093/cje/ben057

Wajcman, J. (2010). Feminist theories of technology. Cambridge journal of economics, 34(1): pp.143152. https://doi.org/10.1093/cje/ben057

Way, J. (2016) Digital Art at the Interface of Technology and Feminism, in Christiane Paul (ed.) A Companion to Digital Art, pp.181-202. John Wiley \& Sons. ISBN: 9781118475188

Wentrack, K. (2018) Heterotopian Spaces of Feminist Art Practice: The Schule für kreativen Feminismus and the Stichting Vrouwen in de Beeldende Kunst in Jakubowska, A., \& Deepwell, K. (Ed.) All-women art spaces in Europe in the long 1970s. Liverpool University Press. ISBN: 97817869540582 
Wentrack, K. (2019). Women's art collectives: Framing the future, In The Brooklyn Rail, March 2019. Retrieved from <https://bit.ly/392CWJa>

The WELL (1992). Cultures in Cyberspace [online announcement]. Retrieved from <https://people.well.com/user/couey/cultures/cultures1.html>

Wiener, N. (1948). Cybernetics or Control and Communication in the Animal and the Machine. Technology Press.

Wilding, F. (1994). The Feminist art programmes at Fresno and Calarts, 1970-75. The power of feminist art: The American movement of the 1970s, history and impact, pp.32-47.

Wilding, F. (1998). Where is feminism in cyberfeminism? In OBN online archive. Retrieved from <https://www.obn.org/cfundef/faith_def.html>

Wilding, F., \& Critical Art Ensemble (CAE). (1998). Notes on the political condition of cyberfeminism. Art Journal, 57(2), pp.47-60.

Wilding, F., \& Willis, H. (2016). SmartMom Rebooted: A Cyberfeminist Art Collective Reflects on its Earliest Work of Internet Art. Studies in the Maternal, 8(2).

Wilson, K. (2017). Women Power up in the Current with electronic arts and music festival, Straight. Retrieved from <https://bit.ly/2lzzQsf> on the 10.09.2018

Wolf, N. (2013). Do we still need women-only spaces? The Guardian. Retrieved from <https://bit.ly/21Pq9pL on the 01.10.2018>

Wolverton, T. (2002) The Woman's Building, L.A. 1973-1991. Retrieved from <www.thewomansbuilding.org/woveltonessay.html> on the 09.12.2018 
The Woman's Building, (2019). [Official website]. Retrieved from <www.thewomansbuilding.org>

WOMARTS, (2018). [Official website]. Retrieved from <www.womarts.eu>

Women Beyond Borders [WBB] (2019). [Official website]. Retrieved from <www.womenbeyondborders.com>

Woolf, V. (1935). A Room of One's Own. London: Hogarth Press (originally published in 1927).

Wosk, J. (2003). Women and the machine: representations from the spinning wheel to the electronic age. JHU Press. ISBN: 0-8018-6607-3

Wuschitz, S. (2014) Feminist Hackerspaces: A Research on Feminist Space Collectives in Open Culture. [Doctoral Dissertation]. Vienna University of Technology.

Wuschitz, S. (2019). Background, in Mz. Baltazar's Laboratory website. Retrieved from <https://bit.ly/2lVpdQU> on the 01.05.2019

Wuschitz, S. \& Reis, P. (2016). Dear Arduina: An Interview with Miss Baltazar's Laboratory (interview by Rachelle Beaudoin for The Journal of Peer Production, 8. Retrieved from <https://bit.ly/2lHk2DW>. Consulted 05.01.2018

Wuschitz, S.\& Savic, S. (2019). Feminist hackerspace as a place for infrastructure production, in Ada: A journal of gender, new media and technology (online), No13. Retrieved from <https://bit.ly/2uUaZVq>

$\mathbf{Y}$

Yoshimoto, M., Knowles, F. A., Schneemann, C., Seagull, S., Moore, B., Shiovitz, B. W., Yoshimoto, M., \& Pittman, A. (2009). An evening with Fluxus women: a roundtable discussion. Women \& Performance: a journal of feminist theory, 19(3): pp.369-389. 
Yu, E. (2017). West Oakland Collective CTRL+SHFT Carves Out Space for Underrepresented Artists, in KQED. Retrieved from <https://bit.ly/2keSN3t> on the 12.01.2019

$\mathbf{Z}$

Zafra, R. (2009, 2014) X0y1

Zafra, R. (2010). Un cuarto propio conectado:(Ciber) espacio y (auto) gestión del yo (Vol. 5). Fórcola Ediciones.

Zafra, R. (2016). (H) adas: mujeres que crean, programmean, prosumen, teclean. Editorial Páginas de Espuma.

Zafra, R. (2017). El entusiasmo. Precariedad y trabajo creativo en la época digital. Anagrama: Barcelona. 


\section{APPENDICES}

\section{Appendix 1. Table of Interviews}

Table 3 List of interviews with founders and main members of the initiatives

\begin{tabular}{|c|c|c|c|c|c|}
\hline Name & $\begin{array}{l}\text { Network } \\
\text { /Initiative }\end{array}$ & Role & $\begin{array}{l}\text { Nature of } \\
\text { Interview }\end{array}$ & $\begin{array}{c}\text { Interview } \\
\text { Data }\end{array}$ & $\begin{array}{l}\text { Interview } \\
\text { Language }\end{array}$ \\
\hline $\begin{array}{c}\text { Veronika Liebl } \\
\text { Florina Costamoling } \\
\text { Cristina Radner }\end{array}$ & $\begin{array}{c}\text { Women in New } \\
\text { Media Arts }\end{array}$ & $\begin{array}{l}\text { Founders } \\
\text { and admins }\end{array}$ & Face-to-face & March 2018 & English \\
\hline Anja Westerfrölke & $\begin{array}{l}\text { Faces } \\
\text { Xxero }\end{array}$ & $\begin{array}{l}\text { Relevant } \\
\text { member }\end{array}$ & $\begin{array}{c}\text { Face-to-face } \\
\text { email }\end{array}$ & $\begin{array}{l}\text { May. } 2018 \\
\text { 23 June } .19\end{array}$ & $\begin{array}{l}\text { English } \\
\text { English }\end{array}$ \\
\hline Ushi Reiter & $\begin{array}{l}\text { Faces } \\
/ \text { ETC } \\
\text { Xxero }\end{array}$ & $\begin{array}{l}\text { Relevasnt } \\
\text { member }\end{array}$ & Face-to-face & May 2018 & English \\
\hline Aileen Derieg & $\begin{array}{c}\text { Faces } \\
\text { genderchangers, } \\
\text { /ETC }\end{array}$ & $\begin{array}{l}\text { Relevant } \\
\text { member }\end{array}$ & Face-to-face & Sept. 2018 & English \\
\hline Muriel Magenta & Momentum & Founder & Telephone & 4 Oct. 2018 & English \\
\hline Amanda Stojanov & Void Lab & $\begin{array}{l}\text { Relevant } \\
\text { member }\end{array}$ & Skype & 27 Nov. 2018 & English \\
\hline Kathy Rae Huffman & Faces & Co-Founder & $\begin{array}{c}\text { Face-to-face } \\
\text { emails }\end{array}$ & $\begin{array}{l}17 \text { Nov. } 2018 \\
\text { along year } \\
2019\end{array}$ & English \\
\hline Soledad Muñoz & Current & Co-Founder & Face-to-face & 5 Dec. 2018 & English \\
\hline Lauren Goshinski & GrlFx & Co-Founder & Face-to-face & 7 Dec. 2018 & English \\
\hline Erin Gatz & Prototype & Co-Founder & Face-to-face & 19 Dec. 2018 & English \\
\hline
\end{tabular}




\begin{tabular}{|c|c|c|c|c|c|}
\hline Shusha Niederberger et al. & Electronnes & Members & email/chat & 26 Mar.2019 & English \\
\hline Lauren Valley & Electric Women & Founder & Skype & 19 Mar.2019 & English \\
\hline Angustias Bertomeu & e-mujeres & Founder & Telephone & 22 Jan.2019 & Spanish \\
\hline Francesca Mereu & M-Artech & Founder & Telephone & 29 Jan.2019 & Spanish \\
\hline Marise Cardoso & Fem.elek & Founder & Skype & 12 Mar.2019 & Spanish \\
\hline Lena Matthew & AWMAS & Founder & Skype & 8 Apr.2019 & English \\
\hline Blanca Ortiga & FemTek Bilbao & Founder & Telephone & 17 April2019 & Spanish \\
\hline Veronica Paredes & FemTechNet & $\begin{array}{l}\text { Relevant } \\
\text { member }\end{array}$ & Skype & 04.Feb 2019 & English \\
\hline Q-Space & Q-Space & Co-Founder & Messenger & May 2019 & English \\
\hline \multicolumn{6}{|l|}{$(\mathrm{Ptqk})$} \\
\hline Queer magazine & Gendertech & Founder & Messenger & June 2019 & Spanish \\
\hline \multicolumn{5}{|l|}{ Spačal } & English \\
\hline Anna Couey & Matrix: Women & Founders & Zoom & 25 June 2019 & English \\
\hline Lucia Grossberger & Networking & & email & JuneJuly & English \\
\hline & Addressing Images & Curator & & 2019 & \\
\hline
\end{tabular}

Note. All Interviews but those in text format (email and chat) have been transcript from audio. Interviews in languages other than English were personally translated to English. 


\section{Appendix 2. List of Figures}

Figure 1 Picture: Dans l'atelier (1881); Marie Bashkirtseff. Piece currently exhibited in the Dnipropetrovsk State Art Museum

Figure 2 Anonyme-1889-Madame Léon Bertaux (1825-1909)

Figure 3 Image of the students of Biblioteca Popular de la Dona circa 1914. Source: Beteve.cat

Figure 4 Carmen Baroja in Revista Pergola (Bilbao) VII: "Art and Science are authentic religions for me".

Retrieved from www.kachumbambeteatro.com

Figure 5 Group portrat of the "Lyceum Club de Barcelona" 7th January 1933. Credit: Pérez de Rozas, Carlos 38

Figure 6 An early studio session of The Women's Art Association of Canada, circa 1887.

Figure 7 Picture Madeleine Lemaire's poster for poster for The Art \& Handicraft in the Woman's Building 43 Figure 8 The Woman's Building. World's Columbian Exposition, Chicago, 1893. Retrieved from Navarreta, 1982.

Figure 9 Lorado Taft and several of his female students at work, known as The White Rabbits, circa 1899

Figure 10 Old Wives' Tales in Valencia 16 Calle San Francisco founder Carol Seajav's. Opened from 1976 to 1995.

Source: $w w w$. foundsf.org

Figure 11 Librairie Des femmes founded in 1974 in Paris. Source: www.librairie-des-femmes.fr

Figure 12 Librerie delle Done in Milan, active with platform, providing resources, creating meetings, social networks, blog, art. Left: circa 1974, Right: photo from 2017. Source: www.libreriadelledonne.it

Figure 13 A.I.R's first gallery on 97 Wooster Street, 1974. Pictured from left to right: Rachel bas-Cohain, Joan Snitzer, Kazuko Miyamoto, Blythe Bohnen, unidentified, Daria Dorosh, Laurace James, unidentified, Dotty

Attie, Anne Healy. Retrieved from www.airgallery.com

Figure 14 SOHO20 members in 1976, photo credit: John Waggaman / SOHO2O archive

Figure 15 Photo Credit: Detail from Members of the Fresno Feminist Art Programme at work in the feminist studio, 1970. Photograph by Dori Atlantis.

Figure 16 Womanhouse catalogue, Feminist Art Programme at CalArts, 1972. Designed by Sheila Levrant de Bretteville. The Getty Research

Figure 17 Woman House students 1972, available at http://home.refugia.net/portfolio/womanhouse

Figure 19 Feminist Studio Workshop in 1973, from “!Women Art Revolution”. Credit: Sheila Levrant de

Bretteville / Zeitgeist Films

Figure 20 Judy Chicago's 39th birthday dinner in The Dinner Party Studio. Source:

https://judychicagocollaboration.org

Figure 21 Initial logo Image of San Francisco Womens Center. The Womens Building of the Bay Area. Retrieved from Navarreta, 1982

Figure 22 laSal was a women's space for art, Reading circles, meetings, and founded a press editorial itself. Photos circa 1976. Retrieved from http://tiny.cc/eb64iz

Figure 23 Members from the Cooperativa Beato Angelico opening party at Eva Menzio;s place. Aprile 1976. Retrieved from www.herstory.it

Figure 24 Image of InAkt [Internationale Aktionsgemeinschaft Bildender Künstlerinnen] Vienna, 1983.

Figure 25 Las Comadres, New York. Photo by Nydza Bajandas. Retrieved from Navarreta, 1982.

Figure 26 Marylin Wescoff and Ruth Lichterman, two of the programmemers in the switchboard of ENIAC 72

Figure 27 Right: composition by Roma Vaquero Diaz, author of Mujeres tejedoras de tecnologia, $2017 \quad 72$

Figure 28 Groups of computers at NACA (in 1958 NASA), circa 1935, in charge of satellite trajectory calculation and others.

Figure 29 "Women computer scientists working with colleagues". (Courtesy of Charles Babbage Institute.) in Misa, 2011. 
Figure 30 "What happened to Women in Computer Science in United States?" Source: National Science

Foundation, American Bar Association, American Association of Medical Colleges. Credit: Quoctrung Bui/NPR. Data United States of America

Figure 31 The computer artist Lillian Schwartz's Analysis of Mona Lisa “MonaLeo" 1984

Figure 321966 The Evenings: Theatre and Engineering $\quad 82$

Figure 33 Art and Technology Poster, 1971, LACMA, Los Angeles. 82

Figure 34 Frame of Pixillation a four-minute film by Lillian Schwarz 1970 commissioned by AT\&T Bell

Laboratories.

84

Figure 35. Interruptions (1969) by Vera Molnar is a plotter drawing. The image was made by a pen attached to a computer-controlled drawing machine - in this instance an IBM 370 with an IBM 2250 cathode ray tube (CRT) monitor and plotter.

Figure 36 Invitation to Cybernetic Serendipity. 1968

Figure 37 Jasia Reichardt presenting Cybernetic Serendipity, 1968, London. Fragment of the video, retrieved from www.youtube.com/watch?v=n8TJx8n9UsA

Figure 38 Sonia Sheridan manipulating the Cromemco Z-2D system with EASEL software, 1982. Courtesy The Daniel Langlois Foundation for Art, Science, and Technology, Sonia Landy Sheridan fonds.

Figure 39 Barbara Sykes jamming and performing on the image processor during "Environmental Symmetry," 1977, a day-long multimonitor, interactive performance environment that included audience participation, dancers, and musicians. Courtesy of Barbara Sykes

Figure 40 Steve Waldeck teaching electronics and kinetics to his female and male students at the School of Art Institute of Chicago, late 1970s, in ats@50, 2019

Figure 41 Dick Higgins, Intermedia Chart, 1995, offset lithograph on paper. Dick Higgins Papers Collection, Charles Deering McCormick Library of Special Collections, Northwestern University Library. OEstate of Dick Higgins

Figure 43 From left: Shigeko Kubota, Alison Knowles, Mieko Shiomi, Yoko Ono, Carolee Schneemann, and Sara Seagull, at the Fluxus exhibition "Ubi Fluxus, Ibi Motus"

Figure 44 Freya Zabitsky, Men Make Manifestos, U.S.A., 1987(?). Handcarved Rubber Stamp. Retrieved from Friedman, 1995.

Figure 45 Pat Larter, rubberstamps. Letter to Lomholt 1978-11-19. Envelope. Pat and Richard Larter, Australia 96 Figure 46 Anna Banana, front image, VILE vol. 6, no 3. The Yellow Book 1978-00-00., Canada. 96 Figure 47 Beth Jacobson, Girlilla Post, USA, 1994, Handcanceled Artists' Stamp. 97 Figure 48 Vera Frenkel, String Games: Improvisations for Inter-City Video (Montreal-Toronto, 1974) 99 Figure 49 Mobile Image, Electronic Café, 1984. Photograph of live event in Los Angeles. Courtesy of Kit Galloway, retrieved from Levine \& Glahn, $2016 . \quad 100$

Figure 50 Images of Electronic Café Network, Galloway \& Rabinowitz 1984. Retrieved from www.ecafe.com 101 Figure 51 Figure 45 Logo Electronic Café International, 1888. Retrieved from www.ecafe.com 102 Figure 52 Tele/PoetryNet, Galloway \& Rabinowitz. Retrieved from www.ecafe.com 102 Figure 53 Figure 12. Kathy Ernst, Networking, U.S.A., 1991. Computer generated visual poem 103 Figure 54 Carol Stetser, Page from Currents, U.S.A., 1992, Artists' Book. 103 Figure 55 NSFNET 1991 visualization by Donna Cox and Robert Patterson, National Center for Supercomputing Applications, University of Illinois at Urbana-Champaign $\quad 105$ Figure 56 Echo NYC announcement, in Evans, 2018. Figure 57 Screenshot of the main page of www.thing.net, 2019 Figure 58 Screenshot of the website "Conversations with Artists*Art Works" The Interactive Art Conference on

Arts Wire. http://www.artswire.org 112

Figure 59 Uncle Roger by Judy Malloy, 1986-1988 retrieved from The WELL 115 Figure 60 Women and Technology, silkscreen print, Barbara Nessim, 1986. Museum no. E.62-2013 @ Victoria and Albert Museum, London/ Barbara Nessim. Retrieved from Lenz, 2014. 
Figure 61 Addressing Images. Exhibition poster designed by Beth Regardz and Lucia Grossberger, 1991.

Courtesy: Lucia Grossberger.

Figure 62 Catalog/invitation letter page from 'Women and Technology' Symposium, L.A. SIGGRAPH, 1991.

Courtesy: Lucia Grossberger.

Figure 63 Susanne Ussing, Cyberspace, 1968-70, collages, dry transfers and photolithography. Retrieved from Lillemose \& Kryger, 2015

Figure 64 UTOPIA/DYSTOPIA poster, designed by Rex Ray. San Francisco, April 1995. Courtesy of Lucia Grossberger

Figure 65 UTOPIA/DYSTOPIA poster, 1995. Courtesy of The LAB

Figure 66 VIRTUAL FEMALE, in UTOPIA/DYSTOPIA poster, designed by Rex Ray. San Francisco, April 1995.132

Figure 67 Three of VNS members posing in front of a billboard based on the Cyberfeminist Manifesto, shown on

the side of Tin Sheds Gallery, Sydney, in 1992. Source: www.rhizome.org

Figure 68 VNS Matrix postcard, 1994. Left to Right Francesca Da Rimini, Virginia Barratt, Julianne Pierce, Josephine Starrs. Image courtesy of Virgina Barratt via Motherboard

Figure 69 Wollongong's World's Women Online (WWWO) curators Melinda Rackham (left) and Louise Manner, with the Home Page of WWWO displayed on screen. Louis. Source: www.ouw.edu

Figure 70 Wired F-e-mail, Victoria Vesna, 1995. In the body of the piece we read: "Women of the World, Get

Wired f-e-mail to f-e-mail".

Figure 71 Face Settings, September 1996, dinner in Rotterdam, the Netherlands. Courtesy: Kathy Rae Huffman

Figure 72 Face Settings, October 1996, in St. Petersburg, Russia. Courtesy: Kathy Rae Huffman

Figure 73 Kathy Rae Huffman (backfront) and Margarete Jahrman on Pop TARTS, 1997. Source: www.heise.de

Figure 74 Face Settings image. Courtesy: Kathy Rae Huffman

Figure 76 Kathy Rae Huffman and Eva Wohlgemuth, in the soup point at Ars Electronica 1997. Courtesy: Kathy

Rae Huffman

Figure 77 Poster Face2Face in Graz, July 1998. Courtesy: Kahty Rae Huffman

Figure 78 Founders. Left to right: Kathy Rae Huffman, Diana McCarty, Valie Djordjevic, circa 1997. Austria.

Source: Digicult

Figure 79 Members of the collective Frauen und Technik, 1992. Courtesy: Cornelia Sollfrank 159

Figure 80 pictures of -innen collective. From 1994 to 1996.

Figure 81 pictures of -innen collective From 1994 to 1996.

Figure 83 Advert/Logo for IC by Verena Kuni, in documenta x, Kassel 1997. Source: www.obn.org 161

Figure 84 Women artists at Hybrid Workspace in documenta X, Kassel, 1997. Courtesy: Kathy Rae Huffman. 161

Figure 85 Participants in the First Cyberfeminist International after the dinner at Hybrid WorkSpace at

Documenta X, 1997. Courtesy: Kathy Rae Huffman

Figure 86 Photograph from the First Cyberfeminist International, part of the Hybrid WorkSpace programme at

documenta X. Source: www.rhizome.org

Figure 87 first logo of OBN, retrieved from First IC

Figure 88 screenshot OBN platform in 1998. Source: rhizome.org

Figure 89 Participants in the First Cyberfeminist International socializing during the dinner at Hybrid WorkSpace

at Documenta X, 1997. Source (left): www.rhizome.org; (middle and right) www.Faces-I.net

Figure 90 screenshots of the splash page, original site of Faces in 1998. Source: http://archive.FacesI.net/en/Faceshtml.html

Figure 91 Figure 83 Images from FACES in Paris, cyberfemmes sur le mode de la démo party. organised by Kathy Rae Huffman, l'Ecole nationale superieure des beaux arts de Paris and Nathalie Magnan, 8th Decembre 2000. Source: : http://n4314.free.fr 
Figure 92 Faces meeting at Ars Electronica in 2000. Courtesy: Kathy Rae Huffman.

Figure 93 Faces informal lunch at Transmediale Festival in Berlin, encounter in the edge. Courtesy of Kathy Rae Huffman

Figure 95 From C to X: networked feminisms. Left to right: Alla Mitrofanova, Virginia Barratt, and Annie Goh and Diana McCarty

Figure 98 Visualization Map All-Women Initiatives since 1986, self-organised and institutionalized since 1986.

Retrieved from <http://tiny.cc/rlmw9y>

Figure 99 Visualization Map All-Women Self-organised Initiatives since 1986. Retrieved from <http://tiny.cc/rlmw9y>

Figure 100 Visualization Map All-Women Initiatives since 1986 to 2020 conceived within an institutional framework or by art institution members. Retrieved from <http://tiny.cc/rlmw9y>

Figure 101 Image of female:pressure encounter. From left to right: pandora, lighta, dork, shroombab, indigo @ U4 in vienna,

Figure 102 Image of female:pressure encounter. From left to right: empty taxi, angie balata, agf, annie goh, leyla boran, ipek Ipekçioglu, leyla ahmed @ ctm \#rojava panel in berlin, 2016

Figure 103 Collectives (orange) and Creative Networks (black/place of founding) mapping by its place of founding since 1991. Screenshot taken 18th July 2019

Figure 104 A 10-day subRosa residency in Zagreb June 2008, Courtesy of Faith Wilding

Figure 105 Left: subRosa U-Gen/ Why are Women Like Chickens, and Chickens, Like Women? In City of Women Festival, Ljubljana, Slovenia, 13 oct 2008. Right: subRosa Biopower Unlimited! 23rd Annual New Media \& Art Festival, Bowling Green State University, Ohio, Oct2002

Figure 108 Figure 8 Left to right: Tankal y Wedge, and Baccus and Aguilar posing on her own installation work. Titled 'joining @mssngpeces Pushing immersive experiences through Design, Virtual Reality and Emerging Technology. Source: Twitter @hypen_labs

Figure 109 NeuroSpeculative AfroFeminism Installation, 2017. Tribeca, New York City. Source: Hypen-Labs 205 Figure 110 View of Deep Lab members working at STUDIO for Creative Inquiry at CMU, 2014. Figure 111 Left to right: Allison Cosby, Lauren Goshinski, Sydney Lytle, Ariel Norris, Julie Mallis, Evelyn Pandos, December 2018

Figure 112 Refiguring The Future Exhibition, New York City, 2019. Exhibition organised by Eyebeam and REFRESH in collaboration with Hunter College Art Gallerie

Figure 113 Heather Dewey-Hagborg and Dorothy Santos presenting REFRESH at Refiguring the Future in New York June 2018. Video available at <http://tiny.cc/6ckojz>

Figure 114 HORhouse, installation at Vital Hybrids exhibition: visitors are free to roam the HORs' makeshift hacker den where environmental storytelling provides a cyberfeminist take on cybersecurity, community resources, and DIY-DIWO experiments. Image credit: HORs

Figure 115 All-Women Self-organised Curatorial Projects Worldwide since 1986 (Star-icon: online exhibition location of the server, list in the following chapter). Screenshot taken 18th August 2019

Figure 116 Compilation of images of the first e-leusis meetings in the early 2000s. Courtesy of Angustias Bertomeu

Figure 117 Screenshots of Bertomeu using different parts of the installation in 2001 
Figure 120 Artwork at Cyberfem by Diane Ludin, Francesca da Rimini, Agnese Trocchi: "ID_Runners". Available at https://ibiology.info/ursula/idrunner/index.html $\quad 220$

Figure 121 Images of subRosa performance at Ciberfem. 2006. Source: www.cyberfeminism.net 221

Figure 122 Iryne Roh, Body Lensing, view of the opening Dream Machines, 2016, TCC Gallery Chicago, Photo Credit: Carolina Poveda $\quad 223$

Figure 123 Comfort Film \&Her Environment: Homonyms, 2016, Comfort Station Logan Square. Photo credit: Cory Malnarick.

223

Figure 124 Anna Dumitriu on new genomic technologies explaining her artwork and introducing the technology

to her hands-on workshop. Source: TINN $2016 \quad 225$

Figure 125 Laura Dekker presenting her work on robotics developed with Arduino. Source: TINN $2016 \quad 225$

Figure 126 Making/Breaking the Binary: Women, Art, \& Technology, installation view 226

Figure 127 Jeep Jeep a video game art experience by Anna Luyisa Petrisko, Tonia B, Bela Messex, David Lyons. photo by Tonia B $\quad 229$

Figure 128 Visuel Inner Fire - Pimp my Brain de Tabita Rezaire (2016-2017) 230

Figure 129 Elas Fan tech opening, 2013. Francesca Mereu and Angela, third and fourth starting from right side.

Photo Credit: Oscar Gorriz

Figure 130 Screenshot of the main page (left) and search engine (right) of the website

<http://wwol.inre.asu.edu/artists.html> 233

Figure 131 Lauren Valley CP Photo by Sarah Huny Young 235

Figure 132 screenshot website wwww.electric-women.com 235

Figure 133 Kite, aka Suzanne Kite, is an Oglala Lakota artist who works with computational media, audio, and performance. 2017 work Everything I Say Is True $\quad 238$

Figure 134 Maria Paz Gutierrez, Reclaiming Plant-Waste. Chilean artists that brings cultural aesthetic and resilient design together.

Figure 135 Suzanne Anker, bioartist combines new technologies and science with contemporary art, concerning bio-terrorism. 238

Figure 136 All-Women Self-organised Festivals, Conferences, Symposiums and Encounters at the intersection of Arts and Technology since 1991 (purple Eclectic Tech Carnival editions, in 3.4.5.1.). Screenshot taken 18th July 2019

Figure 137 ETC 2007 in Linz

Figure 138Material for workshop Things can break, ETC 2018. Bologna

Figure 139 Speakers left to right: Cornelia Solfrank, Valje, Remedios Zafra. Photo Courtesy: Maria PérezHernández

Figure 140 Beth Pibernat and Marise Cardoso, 2011, photo by Eduardo Miera 246

Figure 141 STENDHAL SYNDROME + ALBA G. CORRAL (visuales) @ Les Basses $2010 \quad 246$

Figure 142 Compilation of images of X0Y1 activities, retrieved from www.x0y1.net/proyectos $\quad 248$

Figure 143 Logo X0y1 248

Figure 144 Panel on 2016 with Rebecca Allen, Shelley Holcomb, Holly Willis, Candace Reckinger and JJ Stratford

Figure 145 Compilation of highlights images of FEMMEBIT Fest 2016

Figure 146 Arduino workshop CURRENT $2017 \quad 254$

Figure 147 Shanique Kelly giving a workshop on electronic live composition, CURRENT edition $2017 \quad 254$

Figure 148 Workshop for kids on mathematics, art and electronics, September $2010 \quad 258$

Figure 149 Experimental megaphone workshop by Anna Cholinska with some participants 258

Figure 150 Open Software Workshop Photo: Constanza Pina $2018 \quad 260$

Figure 151 Workshop Fuck the Soundcheck women against violence in the soundchecks 260

Figure 152 AWMAS Opening 7th February 2019. Organisation team and artists. 263

Figure 153 Image of the first FEMeeting in 2018, retrieved from the official website: www.femeeting.org 265

Figure 154 Composition of different talks from FEMeeting 2019 video, by Marta de Menezes. 265 
Figure 155 All-Women Self-organised Projects and Organisations at the intersection of Arts and Technology worldwide

Figure 156 Screenshot from the website hosted by Servus server in Linz. Available at <www.xxero.servus.at $>267$

Figure 157 List of the ten portraits of IMAfictions. 2018. Retrieved from <www.ima.or.at>

Figure 158 Screenshots of Electronics Introduction Workshops in 2009. Available at https://vimeo.com/9226266

273

Figure 159 Mereu presenting M-Artech in Elas Fan Tech photo by Anxela Caramés, 2013

Figure 160 Left to Right: Beatrix Garcia, Francesca Mereu, Elizabeth Ross and Luisiana Rodriguez at the

presentation of M-Artech in Medialab Prado Madrid, March 2012. Photo Credit: Elizabeth Ross

Figure 161 Cybferminism introduction Workshop 2017

Figure 162 Workshop Cortos Creativos, 2017

Figure 163 Screenshot main page Momentum website at https://bit.ly/31TurwS

Figure 164 Screenshot of the video excerpt from the Momentum: Women/Art/Technology special event on the theme of "Art Practice," held at the Whitney Museum of American Art, Film and Video Gallery, June 13, 2013. Left Muriel Magenta, Right artists presented Adrianne Wortzel, Janet Echelman, Ferris Olin and Karolina Sobecka

Figure 165 Collaborated with K-12 students and the Lab School with littleBits to integrate electronics into art installations with the intention of exploring sound and light. Photo credit: Janelle Castillo.

Figure 166 SisterSMATR, Group in The Fab Lab, working course 6th October 2018. Photo Credit: Nona Hendryx.

Figure 167 Chagall performing on 26th September 2018. Chagall is part of PRSF Keychange. www.keychange.eu

Figure 168 Miri Kat, Live Code performance 26th September 2018

Figure 169 Feminist Tech Night hosted by Superrr in Berlin on May 2019. Retrieved from official twitter Superrr account.

Figure 170 Announce Maria Castellanos and Rachel_Runner and Jana Jan performances 2018291

Figure 171 Jara Rocha, Saioa Olmo and Femke Snelting talk in November 2018

Figure 172 All-Women and Feminist Self-organised Spaces at the intersection of Arts and Technology since 1998 worldwide. Screenshot taken 18th July 2019

Figure 173 Studio XX. Networked Art Forms and Tactical Magick Faerie Circuits. 2013. Photo: Aaron Horsley

Figure 174 Workshop Built your Prototype with the Toolkit, 2019. Retrieved from Studio XX Official Facebook Page.

Figure 175 CIPke Images of Workshop by Robertina Šebjanič Underwater Lounge about underwater acoustics and sound spectrum in May 2016

Figure 176 CIPke members meeting. Screenshot of CIPke::: Flow Documentary (Trailer) 2014. Available at https://vimeo.com/84292161

Figure 177 Lab in Sechshauserstraße . Source: @ MzBaltazarsLaboratory Facebook 301

Figure 178 Current Mz*Baltazar Lab members, photo retrieved from Quinn, 2018

Figure 179The Inanna project in Damascus, 2010. Wuschitz at the left presenting. Source: Karin Kosina 302 Figure 180 Barbie Wiring. Arduina workshop material, in Aalborg, 2011. Photo Credit: Stefanie Wuschitz

Figure 181 Picture of HackerMoms and their kids. Source: www.hackermoms.org 304 Figure 182 XX Lab XXLab space. Photo Credit:Yudhistira Purwa Anugrah 305 Figure $183 \mathrm{Ctrl}+$ Shft members at the door's space. Source: www.ctrlshftcollective.com 306 Figure 184 Images from extantation events and open calls. Retrieved from <www.extantation.wordpress.com>

Figure 185 Q-Space Maker Space Photo by: Elna Van Dyk. October, 2016

Figure 186 Prototype Femnist Makerspace, 2017. Source: www.prototype.pgh.com 312 
Figure 187 : Images from video interview on WQED Pittsburgh. Retrieved from <https://www.youtube.com/watch?v=RuQ3rOu1j7l>

Figure 188 Visualization chart to the question Do you know feminist projects in art and tech outside western countries?

Figure 189 Visualization chart of the question Do you think there are other minority folks also unrepresented?

Figure 190 Differences with first wave of cyberfeminism. Answers visualization with Advanced Summary by Awesome Table

Figure 191 Visualization chart of: Have you felt any kind of unequal treatment in your professional experience based on your gender?

Figure 192 What means gender equality to you at your workplace? Answers cloud visualization with Advanced Summary by Awesome Table

Figure 193 \#KissMyArs campaign design, retrieved from The Guardian <https://bit.ly/2cpdovk>

Figure 194 Four new projects awarded, UNESCO-Sabrina Ho, You are Next, 2018. Retrieved from <https://bit.ly/2Zz7rRW>

Figure 195 Atenea's Logo.

Figure 196 Share of female and male students enrolled in higher education, by field of study, global average.

Data Source: UIS 2014-2016 on 115 countries (UNESCO, 2017)

Figure 197 Percentage by gender of artists exhibited by gender of gallery director in ARCO 2019. \#MAV2019 341

Figure 198 Percentage of artists by gender exhibited in Spanish Galleries in ARCO 2019. \#MAV2019 341

Figure 199 Percentage of artists by gender exhibited in European Galleries in ARCO 2019. \#MAV2019 341

Figure 200 Percentage by gender during all grades of education in public universities, data from 2014-2015. INE, 2017

Figure 201 Proportion of women and men in higher education and research, world average. Source: UNESCO, data from 2008-2014, on 226 countries. (UNESCO, 2017)

Figure 202 Distribution by gender in decision-making positions in public and private universities in Spain, data from 2015 (INE, 2017)

Figure 203 Screenshot website ATENEA www.atenea.in.

Figure 204 Atenea at MWW 2019 on Women and Digital Technologies, Madrid, 2019. Left to right: Narce Guzman, Nuria Lloret, Ofelia Santiago as moderator and Elena Robles. Photo Credit: Narce Guzman

Figure 205 Atenea's Panel at CICFEM 2019, Valencia. Left to Right: Luisa Tolosa, Elena robles, Narce Guzman, moderator and Nuria Lloret. Photo Credit: Narce Guzman

Figure 206 speakers from the Panel on Spanish all-women associations in Spain, representants of MAV, Girls in Tech Spain, AMIT, Madrid Woman's Week, Plataforma de Genero UC3M

Figure 207 faculty and students from Berklee School of Music Valencia at Music and Technology panel. Photo

Credit: Laura Tabares

Figure 208 Images of the opening. Photo Credit Laura Tabares

Figure 211 Ana Marti and Adolfo Munoz, The Battle of the Pictures, 2017 generative artwork, time-based search engine. Photo: Laura Tabares

Figure 212 Susana Sánchez Las ausencias son las evidencias, 2018. QR code printed on female silhouete to read online news on female femicide Photo: Sandra Estrada

Figure 213 Selene Sanchez and Roser Domingo, Interactive Piano, developed with Max/MSP. Photo Credit: Laura Tabares

Figure 214 Sara \& Sarah , "SARA'S WORLD”. Cassette, auto-edición. 2018. Unusual and experimental way to use technology with low-cost objects, experimenting with the limits of sound though synthesizers. Photo credit: Laura Tabares 
Figure 215 Sara \& Sarah , "SARA'S WORLD". Cassette, auto-edición. 2018. Unusual and experimental way to use technology with low-cost objects, experimenting with the limits of sound though synthesizers. Photo credit: Laura Tabares

Figure 216 Marta P.Campos, "Anxiume", 2017 acronym from anxiety and perfum, technological wearable combined with parfume essential oils testing, the piece works on the human reaction to certain social situations with perfums, dealing with psycological emotions. Photo Stefano Scarani

Figure 217 Julia Chiner and Stefano Scarani, "Il velo", interactive installation produced by Tangatamanu on Max/MSP, 2018. Photo Credit: Laura Tabares

Figure 218 Marta P.Campos,"Anxiume", 2017. Photo Credit Stefano Scarani

358

Figure 219 Sandra López Estrada, "Erritmia Neuronal", 2018. Experimental installation on body, sound and light.

Photo Credit: Laura Tabares

Figure 220 Images of Julia del Río during her sound performance. 2018. Photo Credit: Laura Tabares

Figure 221 Sara Rasines during her sound performance. 2018. Photo Credit: Laura Tabares

Figure 222 Laptop Orchestra Composition Workshop by Nela Brown. Photo credit: Cristina Santos, Video available at https://bit.ly/2Xj92xN

Figure 223 Laptop Orchestra Composition Workshop by Nela Brown. Photo credit: Cristina Santos 360 Figure 224 VR and Music by Alayna Hughes 2018 (W5). Photo credit left Elena Pelejero; Photo credit right: Pep

Sales

Figure 225 María José Martínez de Pisón workshop on programmeming with Gamuza, (W6)2018. Photo credit Raquel Brelt

Figure 226 Atenea interviewed in the radio programme "Si no puedo bailar..." from RNE3, RTVE studio in Valencia, October, 2019. From left to right: Lucia Peiro, Elena Robles and Nuria Lloret.

Figure 227 Atenea interviewed in the Cultural Section of Radio Comunidad Valenciana, October 2019. Left to right: Elena Robles and Nuria Lloret

Figure 228 Opening with Atenea's Director Nuria Lloret and the Concejal de Innovación from the Excmo. Ajuntamnt de València

Figure 229 Panel on Electronic and Digital Arts with Alba G. Prado, Raquel Meyers and Ramona Rodríguez. Rosa

Sánchez de Kónic Theatre joined in streaming.

Figure 230 Panel on Mentorship in STEM Mercedes Siles, Catedrática de álgebra en la Universidad de Málaga y Vicepresidenta de la Real Sociedad Matemática Española, María José Valero, Talent Growth Management, desde la RSC es la Embajadora Regional de la Comunidad del Technovation Girls y Victoria Majadas, Gerente Editorial Prensa Valenciana y Presidenta asociación Big Ban Angels (Valencia). Photo Credit: Laura Simó

Figure 231 Panel on Bio Art. Speakers from left to right: María Castellanos, Clara Boj, Clara Molinicos. Photo Credit: Laura Simó

Figure 232 Panel on software and performing arts. From left to right: Pablo Palacio, Aesun Kim, Carmen Giménez Morte (moderator). Photo credit: Laura Simó

Figure 233 Panel on Audiovisual Ecosystems. Left to right: Marga Cabrera, Kim-Marlène Le, Sandra Mora

Figure 237 Panel on Women in Graphic Edition con Merche Medina (MAKMA y Sindokma), Carmen G. Palacios y Manuela Martínez Romero (LALATA Revista Ensamblada) and Andrea Familiar.

Figure 238 Panel on Women in Animation with María Manero, Rocío Benavent Méndez, Sofía Herrero,

Moderadora: Beatriz Herraiz (Valencia). Photo Credit: Laura Simó

Figure 239 Panel on Art and Design: Mujeres en la construcción de lo visual. Photo Credit: Laura Simó 
Figure 243 Alayna Hughes: Mixed Reality and Music 365

Figure 244 María Castellanos Workshop "Experimentación audiovisual con interfaces blandas" 366

Figure 245 Lucia Peiró Lloret Workshop: "Les Portadores, feminismo y textiles" 366

Figure 246 Captions of the exhibition route. Photo credit Laura Simó 366

Figure 247 Captions of the exhibition route II. Photo credit Laura Simó 366

Figure 248 Captions of the exhibition route III. Photo credit: Laura Simó 367

Figure 249 Catering at the end of the opening 367

Figure 250 Clara González García (Valencia). Reset the Forest: Interactive Reforestation Device (2019) 368

Figure 251 Marina García Jiménez, Stefano Scarani y Magda Meseguer. Madre (2019).Instalción Multimedia 368

Figure 252 Ramona Rodríguez. Panel \#6-30. Linz soundscapes 368

Figure 253 Aesun Kim, A Spiritual Space. Wearable. 368

\section{Appendix 3. List of Tables}

Table 1 All-Women Self-organised initiatives in Art and Technology since 1986 worldwide.......... 180

Table 2 All-Women Initiatives conceived within an institutional framework 1986-2020 ...............190

Table 3 List of interviews with founders and main members of the initiatives .............................430

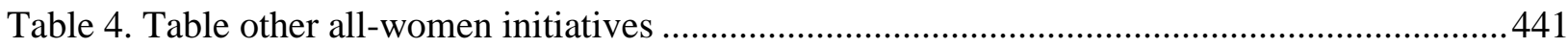




\section{Appendix 4. Partial list of other all-women initiatives in technology and arts}

Table 4. Table other all-women initiatives

\begin{tabular}{|c|c|c|c|c|c|}
\hline NAME & TYPE & $\begin{array}{c}\text { FOUNDER } \\
\text { ORGANIZER }\end{array}$ & YEAR & LOCATION & WEBSITE \\
\hline $\begin{array}{l}\text { The Ada Project } \\
\text { (TAP) }\end{array}$ & $\begin{array}{c}\text { Online resources } \\
\text { women in } \\
\text { computing }\end{array}$ & $\begin{array}{l}\text { The Yale University and } \\
\text { Women@SCS (CMU) }\end{array}$ & 1994 & $\begin{array}{l}\text { United States } \\
\text { (online) }\end{array}$ & https://www.women.cs.cmu.edu \\
\hline Les Penelopes & $\begin{array}{l}\text { Press Organisation } \\
\text { Feminism, politic } \\
\text { and free culture }\end{array}$ & $\begin{array}{c}\text { Dominique Foufelle and } \\
\text { Joelle Palmieri }\end{array}$ & $\begin{array}{c}1996 \\
- \\
2004\end{array}$ & $\begin{array}{l}\text { Paris, France } \\
\text { (online) }\end{array}$ & \\
\hline The Orlando Project & $\begin{array}{l}\text { Digital tools and } \\
\text { methods to advance } \\
\text { feminist literacy } \\
\text { scholarship }\end{array}$ & & 1998 & $\begin{array}{l}\text { Edmonton, } \\
\text { Canada }\end{array}$ & www.artsrn.ualberta.ca \\
\hline Linux Chix & $\begin{array}{c}\text { Digital Platform, } \\
\text { Courses }\end{array}$ & & 1999 & Transnational & www.linuxchix.org \\
\hline cyberfeminismes & Digital platform & Nathan Magnan & 1999 & Paris, France & www.cyberfeminismes.org \\
\hline GawLab collective & $\begin{array}{l}\text { Digital art, public } \\
\text { spaces }\end{array}$ & $\begin{array}{l}\text { N'Goné Fall, Sylviane } \\
\text { Diop aka PralineB }\end{array}$ & 2004 & $\begin{array}{l}\text { Dakar, } \\
\text { Senegal }\end{array}$ & www.gawlab.net \\
\hline $\begin{array}{c}\text { AbTeC } \\
\text { Aboriginal } \\
\text { Territories in } \\
\text { Cyberspace }\end{array}$ & $\begin{array}{l}\text { Indigenous presence } \\
\text { in the web pages, } \\
\text { online } \\
\text { environments, video } \\
\text { games, and virtual } \\
\text { worlds that } \\
\text { comprise } \\
\text { cyberspace. }\end{array}$ & $\begin{array}{c}\text { Jason Edward } \\
\text { Lewis and Skawennati, }\end{array}$ & 2005 & $\begin{array}{c}\text { Montreal, } \\
\text { Canada }\end{array}$ & www.abtec.org \\
\hline
\end{tabular}




\begin{tabular}{|c|c|c|c|c|c|}
\hline GenderIT & $\begin{array}{c}\text { Project of the } \\
\text { Women's Rights } \\
\text { Programmeme of } \\
\text { the Association for } \\
\text { Progressive } \\
\text { Communication }\end{array}$ & $\begin{array}{c}\text { Namita Aavriti, Kateruna } \\
\text { Fialova, Dafne Sabanes } \\
\text { Plou }\end{array}$ & 2006 & South Africa & www.genderit.org \\
\hline PyLadies & $\begin{array}{l}\text { Mentorship group, } \\
\text { Python open-source } \\
\text { community }\end{array}$ & & 2007 & International & www.pyladies.com \\
\hline $\begin{array}{l}\text { Feminist Tech } \\
\text { eXchange (FTX) }\end{array}$ & $\begin{array}{l}\text { (Feminist Principles } \\
\text { of the Internet) }\end{array}$ & $\begin{array}{c}\text { Erika Smith, Jac sm Kee, } \\
\text { Kennifer Radloff }\end{array}$ & 2008 & $\begin{array}{l}\text { Transnational } \\
\text { (Mexico, } \\
\text { Malaysia, } \\
\text { South Africa) }\end{array}$ & https://bit.ly/2JK2vmU \\
\hline HACKfemEAST & & & 2008 & $\begin{array}{l}\text { Berlin, } \\
\text { Germany }\end{array}$ & \\
\hline Pechblenda LAB & $\begin{array}{l}\text { Experimental Lab } \\
\text { on Open Hardware }\end{array}$ & & 2011 & $\begin{array}{l}\text { Barcelona } \\
\text { Spain }\end{array}$ & www.pechblenda.hotglue.me \\
\hline FemHack & $\begin{array}{l}\text { Feminist hacker } \\
\text { collective }\end{array}$ & Sophie Toupin et al. & 2011 & Montreal & www.femhack.noblogs.org \\
\hline G.Hack & $\begin{array}{c}\text { Collective } \\
\text { Engineers, feminist } \\
\text { hacker project }\end{array}$ & Nela Brown et al. & 2012 & $\begin{array}{c}\text { London, } \\
\text { United } \\
\text { Kingdom }\end{array}$ & http://ghack.eecs.qmul.ac.uk/ \\
\hline $\begin{array}{l}\text { Women Arts Media } \\
\text { Coalition }\end{array}$ & $\begin{array}{c}\text { Organisation: } \\
\text { Women in Media } \\
\text { and Theater }\end{array}$ & & 2012 & New York & www.womenartsmediacoalition.org \\
\hline Fem Tech Net & Academic network & Anne Balsamo et al. & 2012 & United States & www.femtechnet.org \\
\hline $\begin{array}{c}\text { Feminist } \\
\text { Infraestructures }\end{array}$ & & $\begin{array}{c}\text { UC FemTechNet } \\
\text { University San Diego CA }\end{array}$ & 2013 & United states & https://bit.ly/2Jwr73N \\
\hline $\begin{array}{c}\text { TransHackFeminist! } \\
\text { (THF!) }\end{array}$ & Encounter & letc + Calafou & 2013 & Translocal & https://transhackfeminist.noblogs.org \\
\hline Wikid Grrls & $\begin{array}{l}\text { Online courses for } \\
\text { girls }\end{array}$ & Stine Eckert & 2013 & Detroit, USA & www.wikidgrrls.wordpress.com \\
\hline
\end{tabular}




\begin{tabular}{|c|c|c|c|c|c|}
\hline MariaLab & $\begin{array}{l}\text { Feminist Hacker } \\
\text { Collective }\end{array}$ & & 2014 & Brazil & www.marialab.org \\
\hline Feminism in India & $\begin{array}{l}\text { Digital Platform, } \\
\text { women's rights and } \\
\text { marginalized } \\
\text { communities }\end{array}$ & Japleen Pasricha et al & 2016 & India & www.feminisminindia.com \\
\hline Double Union & $\begin{array}{l}\text { Feminsit Hacker } \\
\text { and Makerspace }\end{array}$ & $\begin{array}{c}\text { Carmen Jackson, } \\
\text { Stephanie Andrews, Nora } \\
\text { Trapp }\end{array}$ & 2013 & $\begin{array}{c}\text { San } \\
\text { Francisco, } \\
\text { United States }\end{array}$ & www.doubleunion.org \\
\hline Art+Feminism & $\begin{array}{c}\text { Wikipedia } \\
\text { Campaign Kit } \\
\text { Workshops }\end{array}$ & $\begin{array}{c}\text { Siân Evans } \\
\text { Jacqueline Mabey } \\
\text { Michael Mandiberg } \\
\text { Laurel Ptak }\end{array}$ & 2013 & transnational & www.artandfeminism.org \\
\hline Women Shift Digital & $\begin{array}{l}\text { Plaftorm for women } \\
\text { in digital carreers }\end{array}$ & $\begin{array}{c}\text { Ghislaine Boddington and } \\
\text { Marie Proffit }\end{array}$ & 2013 & & https://www.womenshiftdigital.com/ \\
\hline $\begin{array}{c}\text { Lab de } \\
\text { Interconectividades }\end{array}$ & $\begin{array}{l}\text { Cyberfeminism, } \\
\text { hacktivism, free } \\
\text { software, open } \\
\text { source, surveillance, } \\
\text { cyber security, } \\
\text { hackfemnism }\end{array}$ & $\begin{array}{c}\text { Liana Zaragoza Cano } \\
\text { (Lili Anaz) }\end{array}$ & 2014 & Mexico & www.lab-interconectividades.net \\
\hline $\begin{array}{c}\text { Feminist Internet } \\
\text { (Imagine a Feminist } \\
\text { Internet) }\end{array}$ & $\begin{array}{c}\text { International } \\
\text { encounters, } \\
\text { Feminist Principles } \\
\text { of the Internet, } \\
\text { gender, Internet }\end{array}$ & & 2014 & $\begin{array}{l}\text { Malaysia, } \\
\text { transnational }\end{array}$ & www.feministinternet.org \\
\hline TEKLA Festival & Girls in technology & Robyn & 2015 & Sweeden & www.teklafestival.se \\
\hline Rosa Digitale & $\begin{array}{c}\text { National non-profit } \\
\text { movement }\end{array}$ & $\begin{array}{l}\text { Sara Broi, Liliana de los } \\
\text { Rios, Matteo Enna }\end{array}$ & 2016 & Milano, Italy & www.rosadigitale.it \\
\hline
\end{tabular}




\begin{tabular}{|c|c|c|c|c|c|}
\hline & $\begin{array}{l}\text { women and } \\
\text { Technology }\end{array}$ & & & & \\
\hline D’EST & Festival Video Art & $\begin{array}{l}\text { erhar erhardt, xandra } \\
\text { popescu, vlad anghel }\end{array}$ & 2016 & Berlin & www.d-est.com \\
\hline $\begin{array}{c}\text { Women of } \\
\text { Wereables (WoW) }\end{array}$ & $\begin{array}{c}\text { Global organisation, } \\
\text { network }\end{array}$ & & 2016 & $\begin{array}{l}\text { London, UK, } \\
\text { transnational }\end{array}$ & www.womenofwereables.com \\
\hline $\begin{array}{l}\text { IGDA women in } \\
\text { games }\end{array}$ & & & 2016 & $\begin{array}{l}\text { UNITED } \\
\text { STATES }\end{array}$ & \\
\hline $\begin{array}{c}\text { [Declaration] } \\
\text { Decolonizing the } \\
\text { Internet: Second } \\
\text { International } \\
\text { cyberfeminist }\end{array}$ & $\begin{array}{l}\text { Women, ICT, } \\
\text { cyberfeminism }\end{array}$ & $\begin{array}{l}\text { Plataforma } 9 \text { and Forum } \\
\text { Social Mundial }\end{array}$ & 2018 & $\begin{array}{l}\text { Salvador } \\
\text { Brazil }\end{array}$ & https://bit.ly/2Sep33h \\
\hline XENOFEMINISM & Book + Manifesto & $\begin{array}{c}\text { Helen Hester (Laura } \\
\text { Cuboniks) }\end{array}$ & 2018 & & http://www.laboriacuboniks.net \\
\hline SonicWilderness & $\begin{array}{c}\text { Collaborative } \\
\text { practice }\end{array}$ & $\begin{array}{c}\text { SAGF Nonasonic } \\
\text { Poemproducer }\end{array}$ & 2018 & $\begin{array}{c}\text { Yogyakarta, } \\
\text { Indonesia }\end{array}$ & http://nusasonic.poemproducer.com \\
\hline WikiFemia & $\begin{array}{c}\text { Interactive } \\
\text { Visualization }\end{array}$ & Roberte la Rousse & 2019 & France & http://wikifemia.org/wikifemia/computer_grrrls \\
\hline \multicolumn{6}{|c|}{ Unknown data of founding } \\
\hline p-node & $\begin{array}{c}\text { Resources about } \pi- \\
\text { Boxes, Radio Art }\end{array}$ & & & & www.p-node.org \\
\hline Kefir & $\begin{array}{l}\text { Cooperative, free } \\
\text { software, } \\
\text { community } \\
\text { building, human } \\
\text { rights, collaborative } \\
\text { creation }\end{array}$ & & & Mexico & Kefir.red \\
\hline Freakabolic & Gender lab & Calafou & & Calafou & www.freakabolic.hotglue.me \\
\hline
\end{tabular}




\begin{tabular}{|c|c|c|c|c|c|}
\hline Heart of Code & $\begin{array}{c}\text { Feminist } \\
\text { hackerspace and } \\
\text { network }\end{array}$ & & & Berlin & www.heartofcode.org \\
\hline Cl4ndestina & $\begin{array}{l}\text { Feminist and } \\
\text { activist server }\end{array}$ & & & $\begin{array}{c}\text { Brazil / } \\
\text { Latino } \\
\text { America }\end{array}$ & www.clandestina.io \\
\hline Vedetas & Feminsit Server & & & Brazil & www.vedetas.org \\
\hline $\begin{array}{c}\text { Anarchafeminist } \\
\text { Hackerhive }\end{array}$ & $\begin{array}{c}\text { Feminist Hacker } \\
\text { Collective with } \\
\text { mailing list }\end{array}$ & & $\begin{array}{c}\text { Before } \\
2012\end{array}$ & San Francisco & https://bit.ly/2XMGyc1 \\
\hline $\begin{array}{c}\text { Fembot collective } \\
\text { (adajournal) }\end{array}$ & $\begin{array}{c}\text { Collective, gender } \\
\text { new media and } \\
\text { technology } \\
\text { community }\end{array}$ & $\begin{array}{l}\text { Group within Center fir } \\
\text { the Study of Women in } \\
\text { Society (CSWS) } \\
\text { University of Oregon }\end{array}$ & & $\begin{array}{c}\text { Oregon, } \\
\text { United States }\end{array}$ & www.fembot.adanewmedia.org/ \\
\hline POWRPLNT & $\begin{array}{c}\text { Free digital art } \\
\text { projects and } \\
\text { educational } \\
\text { programmes for } \\
\text { teenagers }\end{array}$ & & & $\begin{array}{l}\text { New York } \\
\text { City }\end{array}$ & https://www.powrplnt.org/ \\
\hline
\end{tabular}


[This page intentionally left blank] 


\begin{abstract}
This dissertation explores a series of all-women self-organised initiatives that have emerged at the intersection of art and technology internationally. These grassroot initiatives have continued to appear in places where there is a new media arts scene, generally male-dominated and low in diversity. This research work is a mapping of this techno-social and artistic phenomenon, attempting to identify its earliest practices. Through interviews, surveys and ethnographic research, this thesis seeks to comprehend the context that has given rise to such initiatives over three decades and half, examining the different typologies by formats, extension, space and structure that they have adopted to address the situation of women in these fields.
\end{abstract}

There is a void of references on all-women curatorial and organisational forms in art and technology. Moreover, general literature points at digital subcultures of the 1990s such as cyberfeminism and DIY movement as first referents for women's alliance and translocal activism in the digital age. However, collaboration and segregation strategies in new media arts have not been discussed in feminist scholarship from a deeper historical perspective. Therefore, this dissertation elaborates the linkage of such initiatives to early history of all-women art groups and alternative art spaces, history of women in new media arts and to network cultures. New information and communication technologies have enabled new forms of communication and connectivity cross-borders; however, this work investigates in which measure these initiatives are dependent upon ICT for the establishment of a community, compared to analog formats. With the results, this dissertation aims to become a source of references that enriches the scarce bibliography on the topic, providing a list of curatorial and organisational forms with the earliest and unpublished practices that altogether contribute to current women's historiography. 
Lastly, while discussing the current situation of women in art and technology fields, this works presents Atenea, a mentoring and networking platform for women in Arts and STEM careers. Atenea is comprised of a programme having different organizational, curatorial and networking activities. Additionally, the platform has a project focused on teaching STEM skills to girls through new media arts with female artists as mentors.

Keywords: All-women, self-organised, initiatives, new media arts, digital arts, electronic arts, art, technology, activism, mapping, alternative art spaces, collaboration, segregation, ICT, digital age, virtual, community, network cultures, feminism, cyberfeminism, Atenea, STEM, STEAM, girls, organisational, curatorial, networking platform, mentoring, 


\section{RESUMEN}

La presente tesis doctoral es una exploración sobre las iniciativas autoorganizadas de mujeres que han surgido en la intersección del arte y la tecnología a nivel internacional. Estas iniciativas comunitarias han ido apareciendo en lugares donde existe una escena de arte y nuevos medios, la cual es generalmente de dominación masculina y baja en diversidad. Este trabajo de investigación es un mapeo de este fenómeno tecno-social y artístico, tratando de identificar las primeras prácticas. A través de entrevistas, encuestas y métodos de investigación etnográfica, esta tesis aspira a comprender el contexto que ha dado lugar a semejantes iniciativas a lo largo de tres décadas y media, examinando las diferentes tipologías por los formatos, extensión, espacio y estructura que éstas han adoptado para afrontar la situación de las mujeres en estas áreas.

Existe un vació de referencias sobre formas organizativas y de comisariado en las áreas de arte y tecnología. Además, la literatura general señala las subculturas digitales de los noventa, tales como el ciberfeminismo y el movimiento DIY, como los primeros y principales referentes para las alianzas de mujeres y el activismo translocal en la era digital. Sin embargo, las estrategias de colaboración y segregación en áreas de arte y tecnología no han sido analizadas desde los estudios feministas desde una perspectiva histórica en profundidad. Por lo tanto, esta tesis establece la relación entre dichas iniciativas con la historia de los grupos de mujeres artistas y espacios de arte alternativos, la historia de las mujeres en el arte de nuevos medios y la cultura de redes. Las nuevas tecnologías de la información y comunicación han permitido nuevas formas de comunicación y conectividad transfronterizas; sin embargo, este trabajo investiga en qué medida estas iniciativas dependen de las TIC para el establecimiento de su comunidad, comparado con los formatos analógicos. Con los resultados, esta tesis aspira a convertirse en una fuente de referencias que enriquezca la escasa bibliografía de la temática, proporcionando una lista de formas organizativas y de comisariado, así 
como las practicas más tempranas nunca publicadas, y en conjunto contribuir a la historiografía actual sobre mujeres.

Por último, a la vez que se comenta la situación actual de las mujeres en las áreas de arte y tecnología, este trabajo presenta Atenea, una plataforma de mentorización y networking para mujeres en las artes y carreras STEM. Atenea está compuesto de un programa con diferentes actividades organizativas y de comisariado, así como una plataforma de networking. Adicionalmente, el proyecto tiene un programa enfocado en transmitir conocimientos C.T.I.M. a niñas a través de prácticas artísticas con tecnología de la mano de mujeres artistas nacionales como mentoras.

Palabras clave: mujeres, autogestión, iniciativas, arte y nuevos medios, digital; arte electrónico ; arte, tecnología, mapeo, espacios de arte alternativos, colaboración, segregación, TIC, era digital, comunidad virtual, cultura de redes, feminismo, ciberfeminismo, Atenea, CTIM, CTIAM, niñas, organizativo, comisariado, networking, plataforma, mentorización 


\section{RESUM}

La present tesi doctoral és una exploració sobre les iniciatives autoorganitzades de dones que han sorgit en la intersecció de l'art i la tecnologia a nivell internacional. Aquestes iniciatives comunitàries han anat apareixent en llocs on hi ha una escena d'art i nous mitjans, la qual és generalment de dominació masculina i baixa en diversitat. Aquest treball de recerca és un mapeig d'aquest fenomen tecno-social i artístic, tractant d'identificar les primeres pràctiques. A través d'entrevistes, enquestes i mètodes d'investigació etnogràfica, aquesta tesi aspira a comprendre el context que ha donat lloc a semblants iniciatives al llarg de tres dècades i mig, examinant les diferents tipologies pels formats, extensió, espai i estructura que aquestes han adoptat per afrontar la situació de les dones en aquestes àrees.

Hi ha un buit de referències sobre formes organitzatives i de comissariat en les àrees d'art i tecnologia. A més, la literatura general assenyala les subcultures digitals dels noranta, com ara el ciberfeminisme i el moviment DIY, com els primers i principals referents per a les aliances de dones i l'activisme translocal en l'era digital. No obstant això, les estratègies de col·laboració i segregació en àrees d'art i tecnologia no han estat analitzades des dels estudis feministes des d'una perspectiva històrica en profunditat. Per tant, aquesta tesi estableix la relació entre aquestes iniciatives amb la història dels grups de dones artistes i espais d'art alternatius, la història de les dones en l'art de nous mitjans i la cultura de xarxes. Les noves tecnologies de la informació i comunicació han permès noves formes de comunicació i connectivitat transfrontereres; però, aquest treball investiga en quina mesura aquestes iniciatives depenen de les TIC per a l'establiment de la seva comunitat, comparat amb els formats analògics. Amb els resultats, aquesta tesi aspira a convertir-se en una font de referències que enriqueixi l'escassa bibliografia de la temàtica, proporcionant una llista de formes organitzatives i de comissariat, així com les pràctiques més primerenques mai publicades, i en conjunt contribuir a la historiografia actual sobre dones. 
Finalment, alhora que es comenta la situació actual de les dones en les àrees d'art i tecnologia, aquest treball presenta Atenea, una plataforma de mentorització i networking per a dones en les arts i carreres STEM. Atenea està compost d'un programa amb diferents activitats organitzatives i de comissariat, així com una plataforma de networking. Addicionalment, el projecte té un programmea enfocat a transmetre coneixements STEM a nenes a través de pràctiques artístiques amb tecnologia de la mà de dones artistes nacionals com mentores.

Paraules clau: dones, autoorganització, iniciatives, art i nous mitjans, art digital, art electrònic, tecnologia, activisme, mapatge, espais d'art alternatius, col·laboració, segregació, TIC, era digital, comunitat virtual, cultura de xarxes, feminisme, ciberfeminisme, Atenea, STEM, STEAM, nenes, organitzatiu, comissariat, networking, plataforma, mentorització 
[This page intentionally left blank] 